\title{
REPORT ON HIGH ENERGY ARCING FAULT EXPERIMENTS
}

\section{Experimental Results from Medium Voltage Electrical Enclosures}

Date Published: November 2021

Prepared by:

G. Taylor

Office of Nuclear Regulatory Research

A.D. Putorti Jr.

National Institute of Standards and Technology

C. LaFleur

Sandia National Laboratories

Mark Henry Salley, NRC Project Manager 
This report was published as National Institute of Standards and Technology (NIST) Technical Note 2188 as part of a series of experiments funded by the U.S. Nuclear Regulatory Commission's Office of Nuclear Regulatory Research. The report has been re-published as an NRC Research Information Letter (RIL).

Sandia National Laboratories is a multimission laboratory managed and operated by National Technology \& Engineering Solutions of Sandia, LLC, a wholly owned subsidiary of Honeywell International Inc., for the U.S. Department of Energy's National Nuclear Security Administration under contract DE-NA0003525.

\section{Disclaimer}

Legally binding regulatory requirements are stated only in laws, NRC regulations, licenses, including technical specifications, or orders; not in Research Information Letters (RILs). A RIL is not regulatory guidance, although NRC's regulatory offices may consider the information in a RIL to determine whether any regulatory actions are warranted.

Certain commercial equipment, instruments, or materials are identified in this paper in order to specify the experimental procedure adequately. Such identification is not intended to imply recommendation or endorsement by the US Nuclear Regulatory Commission, or the National Institute of Standards and Technology, or Sandia National Laboratories, nor is it intended to imply that the materials or equipment identified are necessarily the best available for the purpose. 
NIST Technical Note 2188

\section{Report on High Energy Arcing Fault Experiments}

\section{Experimental Results from Medium Voltage Electrical Enclosures}

\author{
Anthony D. Putorti Jr. \\ Scott Bareham \\ Edward Hnetkovsky \\ Christopher Brown \\ Wai Cheong Tam \\ Eric Link \\ Michael Selepak \\ Philip Deardorff \\ National Institute of \\ Standards and Technology
}

\author{
Kenneth Hamburger \\ Nicholas Melly \\ Kenneth Miller \\ Gabriel Taylor \\ U.S. Nuclear Regulatory \\ Commission
}

Paul Clem

Byron Demosthenous

Austin Glover

Chris LaFleur

Raymond Martinez

Anthony Tanbakuchi

Sandia National

Laboratories

This publication is available free of charge from:

https://doi.org/10.6028/NIST.TN.2188

November 2021
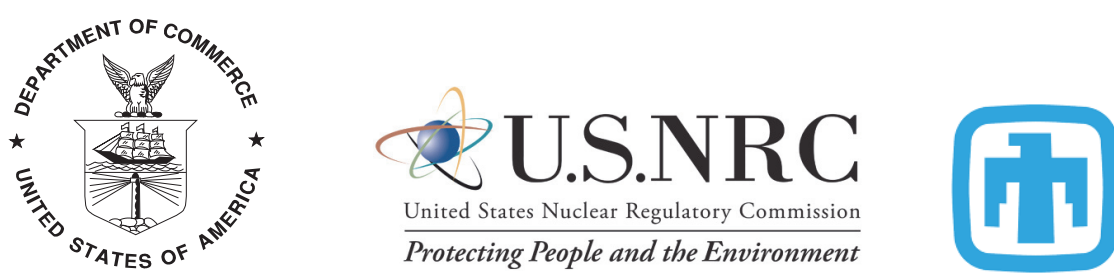

Sandia

National

Laboratories

\section{U.S. Department of Commerce} Gina M. Raimondo, Secretary

National Institute of Standards and Technology James K. Olthoff, Performing the Non-Exclusive Functions and Duties of the Under Secretary of Commerce for Standards and Technology \& Director, National Institute of Standards and Technology 
Certain commercial entities, equipment, or materials may be identified in this document in order to describe an experimental procedure or concept adequately. Such identification is not intended to imply recommendation or endorsement by the National Institute of Standards and Technology, nor is it intended to imply that the entities, materials, or equipment are necessarily the best available for the purpose.

National Institute of Standards and Technology Technical Note 2188 Natl. Inst. Stand. Technol. Tech. Note 2188, 286 pages (November 2021) CODEN: NTNOEF

This publication is available free of charge from: https://doi.org/10.6028/NIST.TN.2188 


\begin{abstract}
This report documents an experimental program designed to investigate High Energy Arcing Fault (HEAF) phenomena for medium voltage electrical switchgear containing aluminum conductors. This report covers full-scale laboratory experiments using representative nuclear power plant (NPP) three-phase electrical equipment. Electrical, thermal, and pressure data were recorded for each experiment and documented in this report. This report covers four of the fourteen planned medium voltage electrical enclosure experiments. Subsequent reports will document the additional experiments performed in the future.

The experiments were performed at KEMA Labs located in Chalfont, Pennsylvania. The experimental design, setup, and execution were completed by staff from the United States Nuclear Regulatory Commission (NRC), the National Institute of Standards and Technology (NIST), Sandia National Laboratories (SNL) and KEMA. In addition, representatives from the Electric Power Research Institute (EPRI) observed some of the experimental setups and execution.

The HEAF experiments were performed on four near-identical units of General Electric metal-clad medium voltage switchgear. The three-phase arcing fault was initiated on the primary cable connection bus. All four experiments used the same system voltage $(6.9 \mathrm{kV})$ but varied the current and duration. Real-time electrical operating conditions, including voltage, current and frequency, were measured during the experiments. Heat fluxes and incident energies were measured with plate thermometers and slug calorimeters at various locations around the electrical enclosures. Internal enclosure pressures were measured during the experiments. The experiments were documented with normal and high-speed videography, infrared imaging, and photography.

Insights from the experimental series included timing information related to enclosure breach, event progression, mass loss measurements for electrodes and steel enclosures, peak pressure rise, particle analysis, along with visual and thermal imaging data to better understand and characterize the hazard. These results will be used in subsequent efforts to advance the state of knowledge related to HEAF.
\end{abstract}

\title{
Key words
}

High Energy Arcing Fault, Arc Flash, Electrical Enclosure, Electric Arc, Fire Probabilistic Risk Assessment 


\section{Table of Contents}

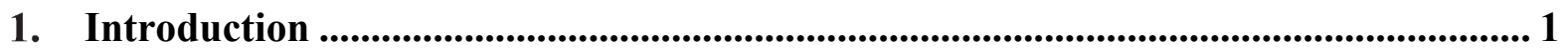

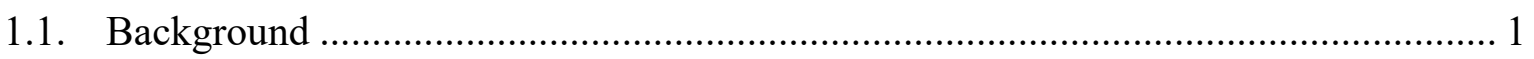

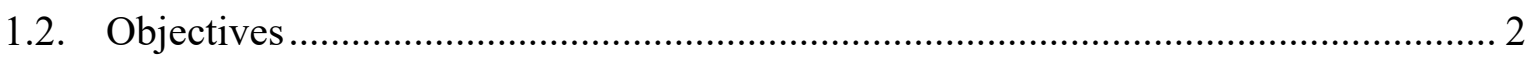

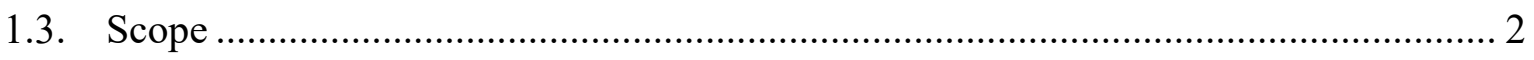

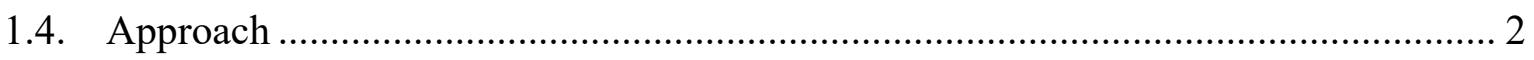

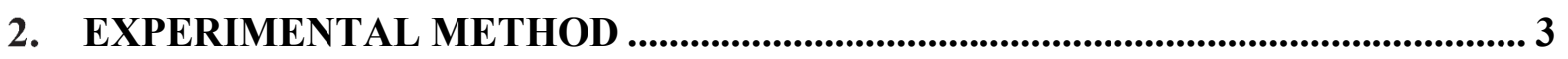

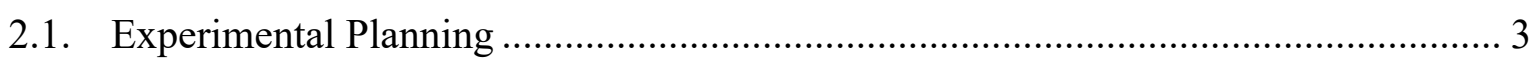

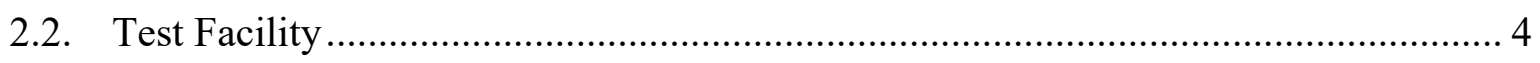

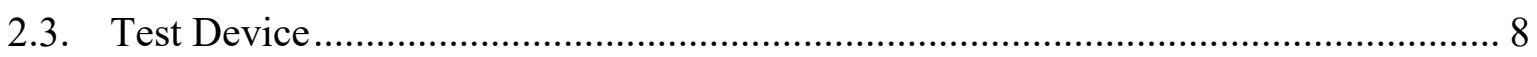

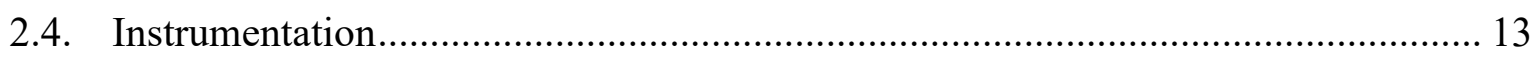

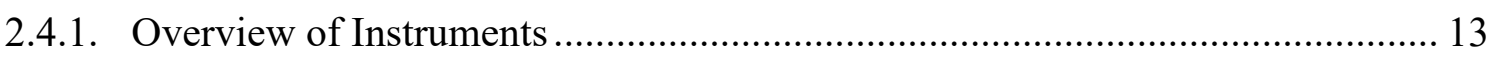

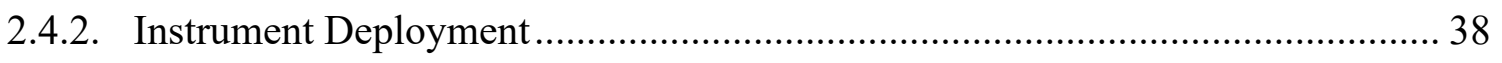

3. Experimental Results ....................................................................................................5 50

3.1. Test 2-19- $6.9 \mathrm{kV}, 25 \mathrm{kA}, 2 \mathrm{~s}$ duration, aluminum bus ......................................... 51

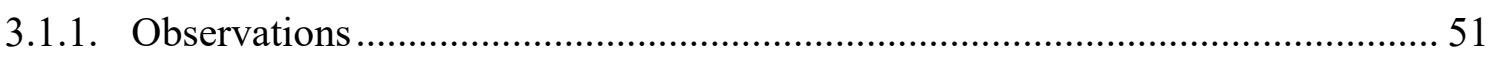

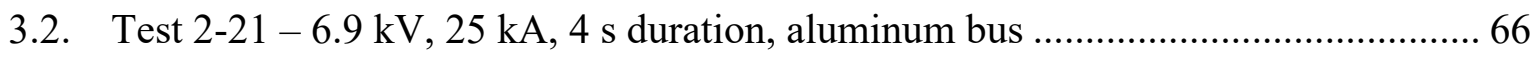

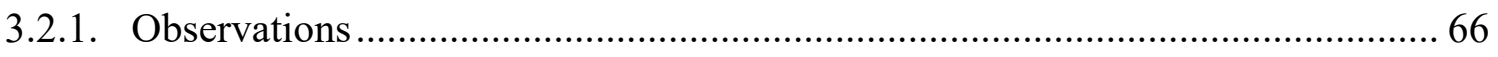

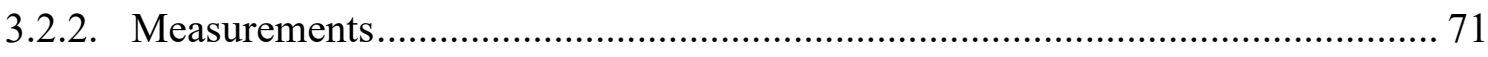

3.3. Test $2-22-6.9 \mathrm{kV}, 32 \mathrm{kA}, 2 \mathrm{~s}$ duration, aluminum bus ……………………....... 90

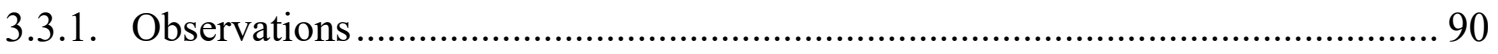

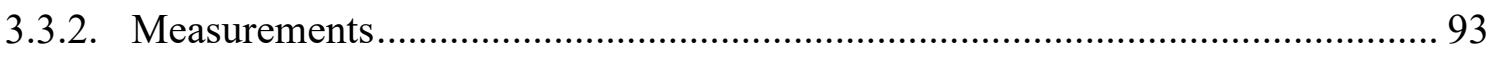

3.4. Test 2-24-6.9 kV, $32 \mathrm{kA}, 4 \mathrm{~s}$ duration, aluminum bus ………………………... 103

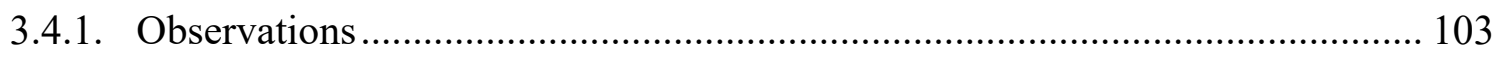

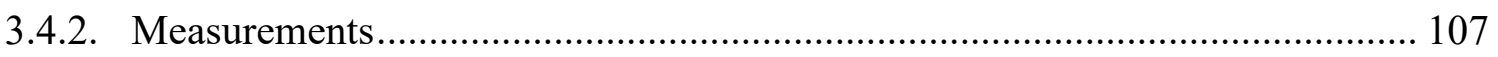

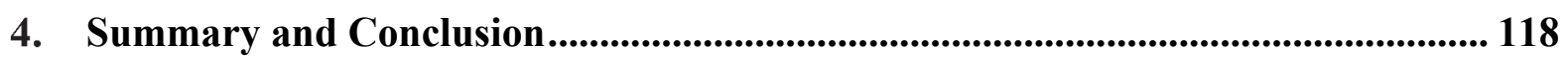

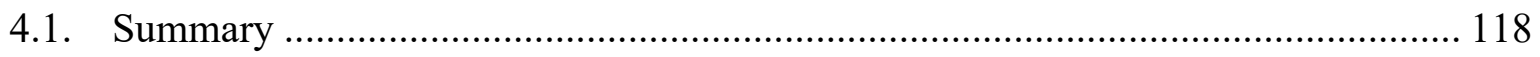

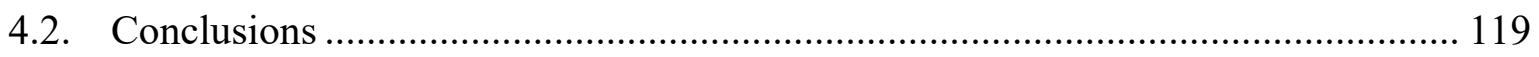

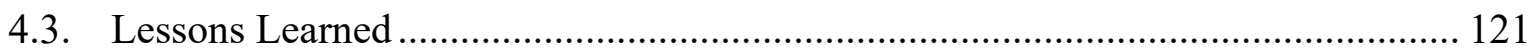

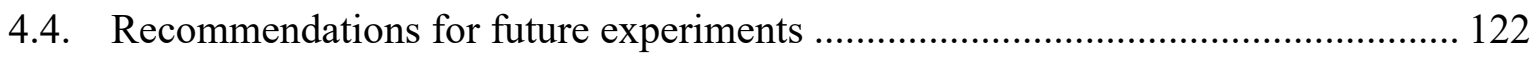

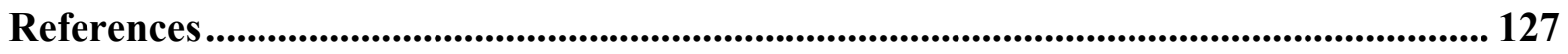

Appendix A: Electrical Enclosure Configuration................................................................... 131

A.1 Variations between relay instrumentation and control as delivered......................... 131

A.2 Primary Cable Connection Compartment Modifications ........................................ 133 
Appendix B: Engineering Drawings ................................................................................... 136

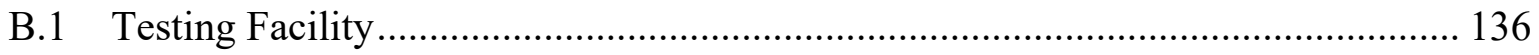

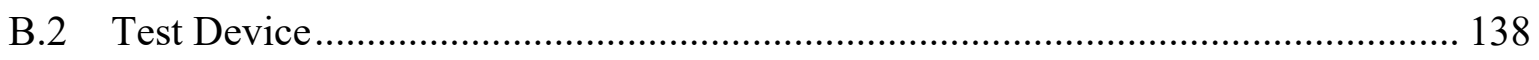

Appendix C: Weights and Measurements ..................................................................... 150

C.1 Electrical Enclosure and Conductors ……………........................................... 150

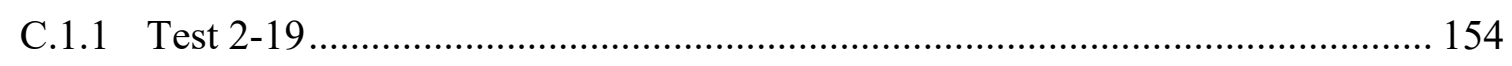

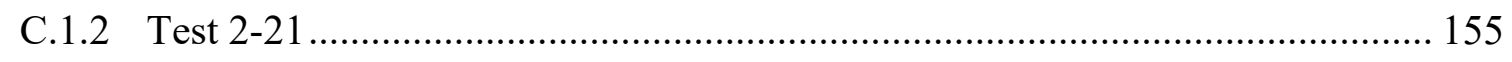

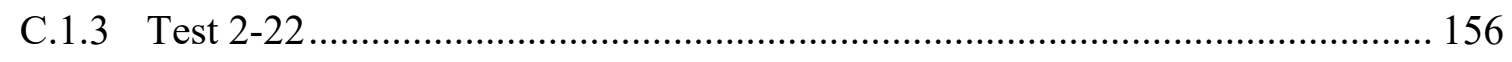

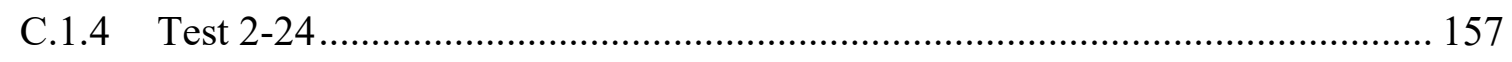

Appendix D: Photographs ..................................................................................................... 159

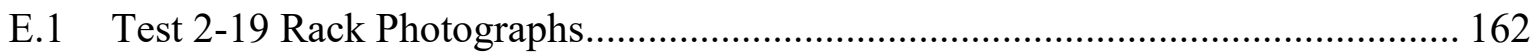

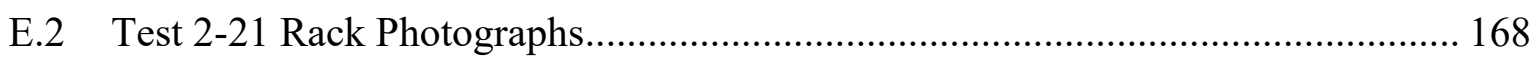

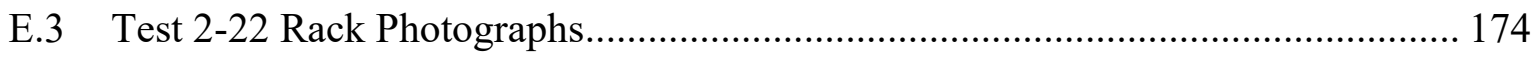

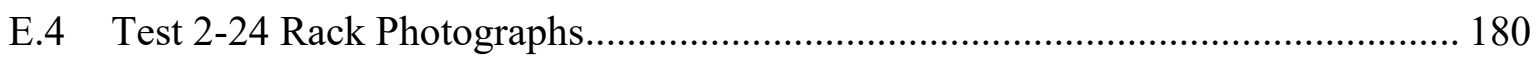

Appendix E: Data Pre-Processing ............................................................................. 187

Appendix F: Tcap Heat Transfer Analysis........................................................................... 191

Appendix G: Plate Thermometer Heat Transfer Analysis ................................................. 196

Appendix H: KEMA Test Report............................................................................................. 199 



\section{List of Tables}

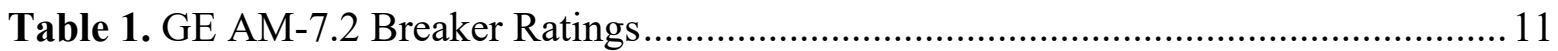

Table 2. Experimental Measurement Instrumentation and Techniques............................. 14

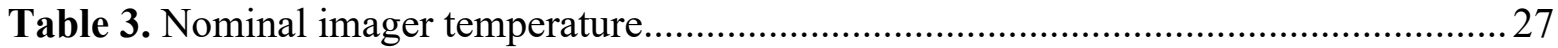

Table 4. Uncertainty components used to determine expanded uncertainty .....................29

Table 5. Expanded uncertainty for IR imager temperatures ..........................................29

Table 6. Manufacturers' descriptions of the cables used in the experiments. ...................... 35

Table 7. Nominal cable properties. ........................................................................... 35

Table 8. Experimental Parameters, measured values are \pm 3 percent. ................................50

Table 9. Summary of Peak Asymmetrical Fault experimental data to IEEE standard C37.010-1999. Measured values are \pm 3 percent.......................................... 51

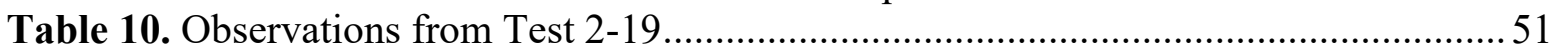

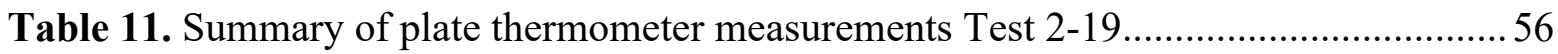

Table 12. Summary of ASTM slug calorimeter measurements, Test 2-19 _.....................57

Table 13. Summary of $T_{\text {cap }}$ slug measurement, Test $2-19$............................................ 58

Table 14. Key measurements for Test 2-19. Measurement uncertainty \pm 3 percent...........63

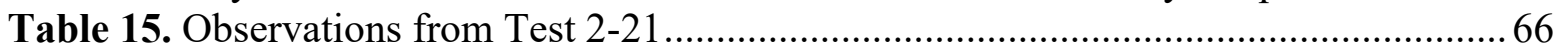

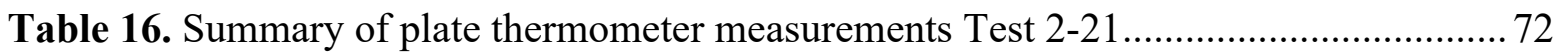

Table 17. Summary of ASTM slug calorimeter measurements, Test 2-21 ...................... 73

Table 18. Summary of $T_{\text {cap }}$ Slug Measurement, Test 2-21 …......................................... 74

Table 19. Key measurements for Test 2-21. Measurement uncertainty \pm 3 percent............88

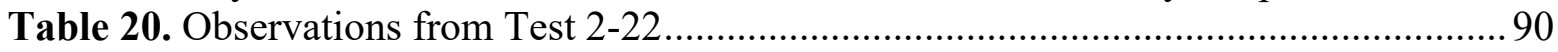

Table 21. Summary of plate thermometer measurements Test 2-22 ...............................94

Table 22. Summary of ASTM slug calorimeter measurements, Test 2-22 ...................... 95

Table 23. Summary of $T_{\text {cap }}$ slug measurements, Test $2-22$........................................... 96

Table 24. Key measurements for Test 2-22. Measurement uncertainty \pm 3 percent.......... 101

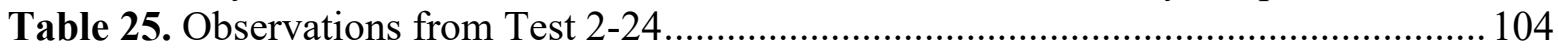

Table 26. Summary of plate thermometer measurements Test 2-24............................. 109

Table 27. Summary of $T_{\text {cap }}$ slug Measurement, Test 2-24 ............................................ 110

Table 28. Key measurements for Test 2-24. Measurement uncertainty \pm 3 percent.......... 115

Table 29. Experimental Parameter Summary ............................................................ 118

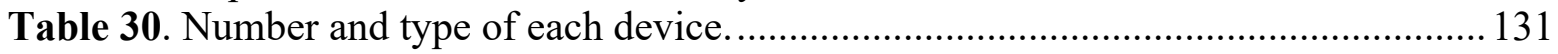

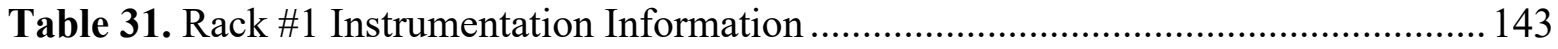

Table 32. Rack \#2 Instrumentation Information ........................................................ 144

Table 33. Rack \#3 Instrumentation Information ........................................................... 145

Table 34. Rack \#4 Instrumentation Information ......................................................... 146

Table 35. Rack \#5 Instrumentation Information ......................................................... 147

Table 36. Test Device Mass Measurements from Test 2-19 - Enclosure Metal-

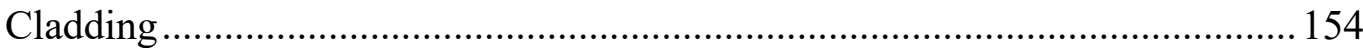

Table 37. Test Device Mass Measurements from Test 2-19 - Electrical Conductors [made using Scale 2 with uncertainty of $\pm 1 \mathrm{~g}$ ] ........................................... 155

Table 38. Test Device Mass Measurements from Test 2-21 - Enclosure Metal-

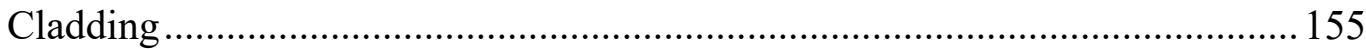

Table 39. Test Device Mass Measurements from Test 2-21 - Electrical Conductors

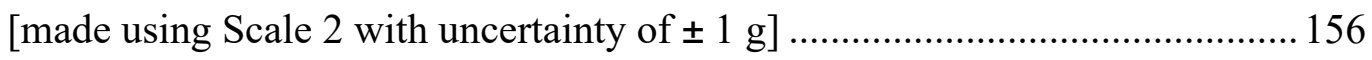


Table 40. Test Device Mass Measurements from Test 2-22 - Enclosure Metal-

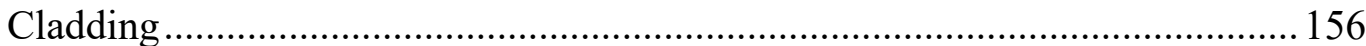

Table 41. Test Device Mass Measurements from Test 2-22 - Electrical Conductors [made using Scale 2 with uncertainty of $\pm 1 \mathrm{~g}$ ] ............................................... 157

Table 42. Test Device Mass Measurements from Test 2-24 - Enclosure MetalCladding

Table 43. Test Device Mass Measurements from Test 2-24 - Electrical Conductors [made using Scale 2 with uncertainty of $\pm 1 \mathrm{~g}$ ] ............................................... 158

Table 44. Manufacturers' Descriptions of cables included in experiments.........................159

Table 45. Nominal Cable Properties 159 


\section{List of Figures}

Fig. 1. Graphical Phase II Experimental Matrix for Electrical Enclosure........................... 3

Fig. 2. Plan view of KEMA test cell \#9 ..................................................................... 5

Fig. 3. Elevation view of KEMA test cell \#9 (note 'breaker' shown is make-break breaker and not the test device under evaluation.)......................................... 6

Fig. 4. Isometric drawing of Test Cell \# 9 - Left and Location of Test Cell \#9 with respect to KEMA facility

Fig. 5. Type M-36 Metal Clad Enclosure, metal cladding removed to show internal structure and bus bars in primary enclosure (left), secondary enclosure with breaker in un-racked position.

Fig. 6. Drawing of Medium Voltage Electrical Enclosure - Test device ........................... 9

Fig. 7. Photo of AM-7.2-500 GE Magne-blast breaker.................................................... 11

Fig. 8. Photograph of tinned copper wire used to create the short ................................. 12

Fig. 9. Photo of combustible component loading in the secondary enclosure .................... 13

Fig. 10. Exploded view of modified plate thermometer (left); Cross-sectional view of modified plate thermometer placed on cone calorimeter sample holder (right)

Fig. 11. Cross-section of ASTM Slug (top) nominal dimensions in millimeters, photo of device being prepared in the field (bottom). Note that the two bolts on each side of the device are used for mounting to the DIN rail of the instrumentation rack.

Fig. 12. Thermal capacitance style slug, illustration (top left), photo of device being prepared in the field (top right), dimensional drawings showing internal construction (bottom left and right). All dimensions in $\mathrm{mm}$. 20

Fig. 13. Pressure Measurement Device Locations (drawing left, photo right) .................... 23

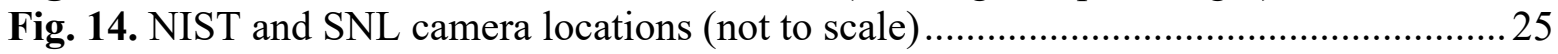

Fig. 15. Spectral response of imager. ....................................................................... 27

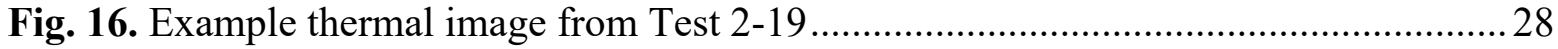

Fig. 17. Camera array located in courtyard. Front tented cameras fielded by SNL. Back shelter camera fielded by NIST. .................................................... 30

Fig. 18. Camera locations within cell identified with triangles ..................................... 31

Fig. 19. Photo of carbon tape (left), and aerogel (right) particle collection apparatus .......... 32

Fig. 20. Energy Dispersive Spectroscopy of commercial CoorsTek aluminum oxide. The peak ratio of fully oxidized aluminum was approximately $\mathrm{Al}: \mathrm{O}=1.04$ $: 1$.

Fig. 21. SEM images of bimodal particle sizes observed from aluminum bus bar HEAF particle collection: $2 \mu \mathrm{m}$ to $20 \mu \mathrm{m}$ scale aluminum particles (top) and $10 \mathrm{~nm}$ to $50 \mathrm{~nm}$ scale aluminum oxide particles (bottom)

Fig. 22. Cable coupon constructed of seven conductor PE / PVC control cable (Cable 900). Front view.

Fig. 23. Cable coupon constructed of seven conductor PE / PVC control cable (Cable 900). Side view

Fig. 24. Data Acquisition System Configuration with EMI rejection ................................ 37

Fig. 25. Elevation view of instrument rack configuration around electrical enclosure.........39 
Fig. 26. Plan view of instrument rack configuration around electrical enclosure. The enclosure is approximately $0.927 \mathrm{~m}$ (36.5 in) wide, $2.019 \mathrm{~m}$ (79.5 in) deep, and $2.286 \mathrm{~m}$ (90.0 in) tall.

Fig. 27. Illustration of Vertical Instrumentation Rack 1 with data acquisition channels. Dimensions in $\mathrm{mm} \pm 5 \mathrm{~mm}$.

Fig. 28. Detailed Horizontal Locations of Instruments on Instrument Racks 1, 2, and

4. Dimensions in $\mathrm{mm} \pm 5 \mathrm{~mm}$

Fig. 29. Illustration of Vertical Instrumentation Rack 2 with data acquisition channels. Dimensions in $\mathrm{mm} \pm 5 \mathrm{~mm}$.

Fig. 30. Illustration of Vertical Instrumentation Rack 3 with data acquisition channels. Dimensions in $\mathrm{mm} \pm 5 \mathrm{~mm}$.

Fig. 31. Detailed Horizontal Locations of Instruments on Instrument Rack 3. Dimensions in $\mathrm{mm} \pm 5 \mathrm{~mm}$.

Fig. 32. Illustration of vertical Instrumentation Rack 4 with data acquisition channels. Dimensions in $\mathrm{mm} \pm 5 \mathrm{~mm}$.

Fig. 33. Illustration of horizontal Instrumentation Rack 5 with data acquisition channels. Electrical enclosure outline shown in red on left. Dimensions in $\mathrm{mm} \pm 5 \mathrm{~mm}$.

Fig. 34. Detailed locations of instruments on Instrument Rack 5. Dimensions in $\mathrm{mm} \pm 5 \mathrm{~mm}$.

Fig. 35. Photo of Instrumentation Racks during experimental setup.

Fig. 36. Sequence of Images from Test 2-19 (image time stamp in seconds)

Fig. 37. Sequence of Thermal Images from Test 2-19 (image time stamp in seconds) .......53

Fig. 38. Enclosure Post-Test 2-19. (Top: back of enclosure; Bottom: remaining bus bar material. Bottom left as viewed from rear of enclosure, bottom right as viewed from the side at the rear of the enclosure with the side panel removed.)

Fig. 39. Pressure measurements from Test 2-19 (breaker compartment - left; arcing compartment - right). Measurement uncertainty \pm 3 percent.

Fig. 40. Photo showing approximate breach opening areas on the upper back panel for Test 2-19. Software used to estimate opening area.

Fig. 41. KEMA Test Circuit S01 used in Test 2-19

Fig. 42. Voltage and Current profile during Test 2-19. Measurement uncertainty \pm 3 percent.

Fig. 43. Transient current profiles for Test 2-19. Measurement uncertainty \pm 3 percent.

Fig. 44. Power and Energy for Test 2-19. Measurement uncertainty \pm 3 percent.

Fig. 45. Rack 3 particle SEM (upper left) with intensity plot for iron (upper right), aluminum (lower right) and oxygen (lower left). The elemental composition included primarily separate particles composites of partially oxidize aluminum and iron, iron only or aluminum only. Compared to Fig. 76 , a low density of background aluminum oxide was observed. 65

Fig. 46. Sequence of images for Test 2-21 (image time stamp in seconds)

Fig. 47. Sequence of Thermal Images from Test 2-21 (image time stamp in seconds)

Fig. 48. Enclosure Post-Test 2-21. (Top: back of enclosure; Bottom: remaining bus bar material. Bottom left as viewed from rear of enclosure, bottom right as 
viewed from the side at the rear of the enclosure with the side panel removed.)

Fig. 49. Photo of damage to central instruments (Rack \#2 - $0.91 \mathrm{~m}$ rear)

Fig. 50. Pressure Measurements from Test 2-21 (breaker compartment - left; arcing compartment - right). Measurement uncertainty \pm 3 percent.

Fig. 51. Photo showing breach opening on far side rear panel (left), upper rear panel (center), and the primary cable compartment bus side upper panel (right). Software used to estimate opening area.

Fig. 52. Scanning electron micrograph showing a roughly $30 \mu \mathrm{m}$ size particles of partial oxidation, estimated at 73 percent, as well as a nanoscale layer displaying higher oxidation estimated at 100 percent. The carbon tape contains both carbon (C) and oxygen background.

Fig. 53. Scanning electron micrograph showing a $20 \mu \mathrm{m}$ particle displaying approximately 45 percent oxidation, and a composition including both aluminum and iron.

Fig. 54. Scanning electron micrograph showing a roughly $20 \mu \mathrm{m}$ particle displaying approximately 45 percent oxidation, and both aluminum and iron rich regions.

Fig. 55. Rack 1 particle compositions

Fig. 56. Rack 3 particle SEM (upper left) with intensity plot for iron (upper right), aluminum (lower right) and oxygen (lower left). Composition included composites of aluminum and iron, iron only, or aluminum only, with oxygen:metal ratios of 32 percent to 70 percent.

Fig. 57. Rack 3 micrometer size particle compositions were primarily iron only, aluminum only, or composites of aluminum and iron, with oxygen:metal ratios of 32 percent to 73 percent. The background shows a higher density of nanosized aluminum oxide vs. Rack 1, suggestive of evaporated $\mathrm{Al}_{2} \mathrm{O}_{3}$.

Fig. 58. Conductive white powder residue after previous aluminum bus bar switchgear experiments, which may have consisted of melted $\mathrm{Al}$ and evaporated $\mathrm{Al}_{2} \mathrm{O}_{3}$. (Photo from Phase 1 experiments [6])

Fig. 59. Back wall particulates consisted of nanoscale $\mathrm{Al}_{2} \mathrm{O}_{3}$ (large background $\mathrm{Al}$ and $\mathrm{O}$ signal) and partially oxidized particles of aluminum (red) and iron (green).

Fig. 60. Back wall deposits included nanoscale $\mathrm{Al}_{2} \mathrm{O}_{3}$ (upper left, $\mathrm{O}: \mathrm{Al}$ ratio 0.65), oxidized Al microparticles (upper right), and individual Fe particles (green).

Fig. 61. Rack 4 micrometer size particle compositions were a mixture of iron only, aluminum only, and mixed iron/aluminum, with oxygen:metal ratios of approximately 90 percent. The background shows a relatively low level of nanosized aluminum oxide, similar to Rack 1.

Fig. 62. Rack 5 micrometer size particle compositions were mixed iron/aluminum, iron only and aluminum only with oxygen:metal ratios of approximately 75 percent. The background shows a relatively low level of nanosized aluminum oxide, similar to Rack 1.

Fig. 63. KEMA Test Circuit S01 used in Test 2-21. 
Fig. 64. Voltage and Current Profile during Test 2-21. Measurement uncertainty \pm 3

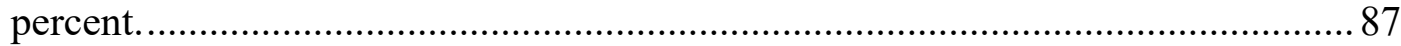

Fig. 65. Transient current profiles for Test 2-21. Measurement uncertainty \pm 3

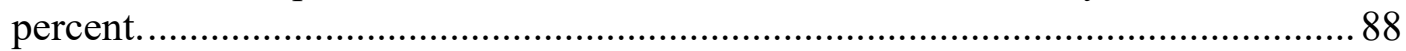

Fig. 66. Power and Energy for Test 2-21. Measurement uncertainty \pm 3 percent...............89

Fig. 67. Sequence of Images from Test 2-22 (image time stamp in seconds) .................... 91

Fig. 68. Sequence of Thermal Images from Test 2-22 (image time stamp in seconds) ........92

Fig. 69. Enclosure Post-Test 2-22. (Top: back of enclosure; Bottom: remaining bus bar material. Bottom left as viewed from rear of enclosure, bottom right as viewed from the side at the rear of the enclosure with the rear and side panels removed.)

Fig. 70. Pressure measurements from Test 2-22 (breaker compartment - left; arcing compartment - right). Measurement uncertainty \pm 3 percent.

Fig. 71. Photos showing breach opening on far side rear panel (left), rear upper panel (center) and the primary cable compartment bus side upper panel (right).

Software used to estimate opening area.

Fig. 72. KEMA Test Circuit S01 used in Test 2-22

Fig. 73. Voltage and Current profile for Test 2-22. Measurement uncertainty \pm 3 percent.

Fig. 74. Transient current profiles for Test 2-22. Measurement uncertainty \pm 3 percent.

Fig. 75. Power and Energy for Test 2-22. Measurement uncertainty \pm 3 percent. 102

Fig. 76. Rack 3 particle SEM (upper left) with intensity plot for iron (upper right), aluminum (lower right) and oxygen (lower left). The elemental composition included primarily separate particles composites of partially oxidize aluminum and iron.

Fig. 77. Sequence of Images of Test 2-24 (image time stamp in seconds)

Fig. 78. Sequence of Thermal Images from Test 2-24 (image time stamp in seconds) ...... 106

Fig. 79. Enclosure Post-Test 2-24. (Top: back of enclosure; Bottom: remaining bus bar material. Bottom left as viewed from rear of enclosure, bottom right as viewed from the side at the rear of the enclosure with the side panel removed.)

Fig. 80. Pressure measurements from Test 2-24 (breaker compartment - left; arcing compartment - right). Measurement uncertainty \pm 3 percent.

Fig. 81. Photos showing breach openings or remaining cladding

Fig. 82. KEMA Test Circuit S01 used in Test 2-24

Fig. 83. Voltage and Current Profile for Test 2-24. Measurement uncertainty \pm 3 percent.

Fig. 84. Transient current profiles for Test 2-24. Measurement uncertainty \pm 3 percent.

Fig. 85. Power and Energy for Test 2-24. Measurement uncertainty \pm 3 percent. 116

Fig. 86. Rack \#3 particle SEM (upper left) with intensity plot for iron (upper right), aluminum (lower right) and oxygen (lower left). The elemental composition included primarily separate particles composites of partially oxidize aluminum and iron, iron only or aluminum only.

Fig. 87. Energy Profile by experiment (at generator) 
Fig. 88. Electrical energy (at generator) versus bus bar mass loss

Fig. 89. Electrical enclosure steel mass loss versus electrical generator energy during the experiments.

Fig. 90. Photographs of front door of test device

Fig. 91. Photographs of enclosure door internals

Fig. 92. Photographs of location of removed current transformers (CTs). The CTs were removed by the equipment vendor.

Fig. 93. Photograph of Primary Cable Connection Compartment prior to experiment....... 135

Fig. 94. Plan view of test cell \#9 showing test device, instrument stands, and primary connections to circuit make switch (breaker).

Fig. 95. Elevation view of test cell \#9 showing test device, instrument stands, and primary connections to circuit make switch (breaker).

Fig. 96. Drawing B01-113317-M1, Electrical Equipment Cabinet Bus Bar and Structure

Fig. 97. Drawing B01-113317-M2, Electrical Equipment Cabinet Door Configuration

Fig. 98. Drawing B01-113317-M3, Electrical Equipment Breaker.

Fig. 99. Drawing B01-113317-M4, Typical Pressure Transducer Location on Cabinet

Fig. 100. Drawing KPT-MB-4657, ASTM Calorimeter Assembly ....

Fig. 101. Drawing KPT-MA-4599, ASTM Calorimeter Cup

Fig. 102. Exterior Isometric. Dimensions in inches \pm 0.25 inches.

Fig. 103. Interior Front. Dimensions in inches \pm 0.25 inches.

Fig. 104. Exterior Top. Dimensions in inches \pm 0.25 inches.

Fig. 105. Side Left. Dimensions in inches. Overall dimensions \pm 0.25 inches, interior dimensions \pm 0.13 inches.

Fig. 106. Interior Rear. Dimensions in inches \pm 0.25 inches.

Fig. 107. Exterior Rear. Dimensions in inches \pm 0.25 inches.

Fig. 108. Cable coupon constructed of seven conductor PE / PVC control cable (Cable 900). Front view.

Fig. 109. Cable coupon constructed of seven conductor PE / PVC control cable (Cable 900). Side view.

Fig. 110 Cable coupon constructed of three conductor PE / PVC control cable (Cable 902). Front view.

Fig. 111. Cable coupon constructed of three conductor PE / PVC control cable (Cable 902). Side view.

Fig. 112. Test 2-19, Rack \#1

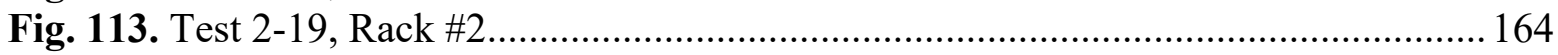

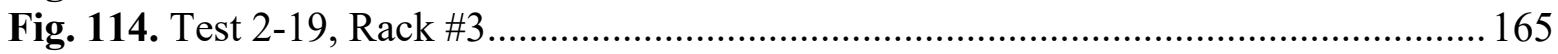

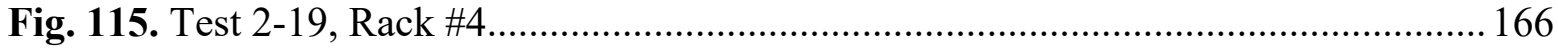

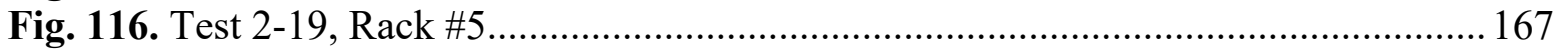

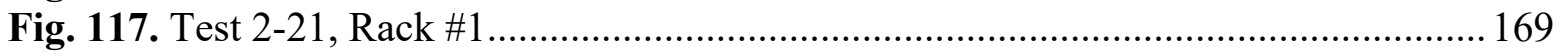

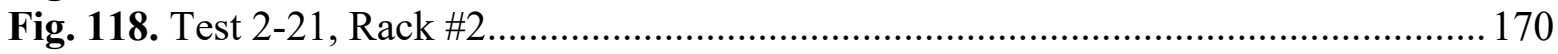

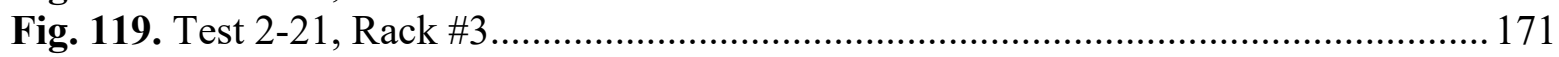

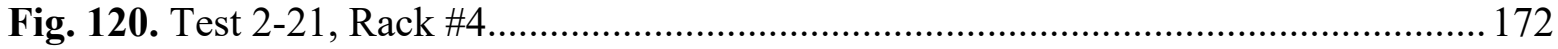

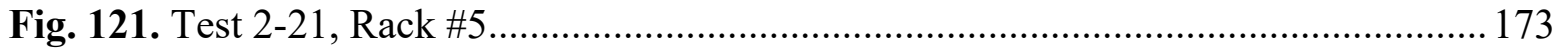




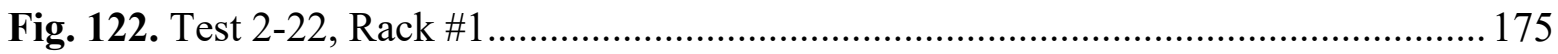

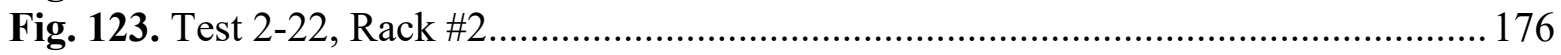

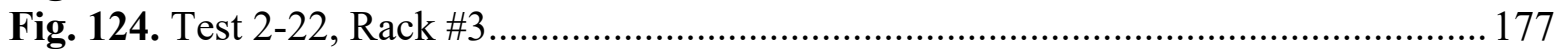

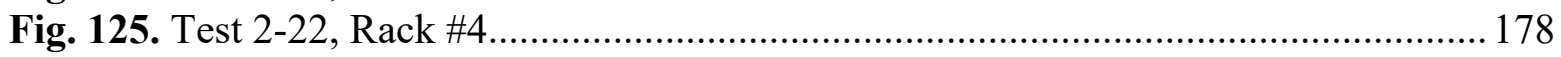

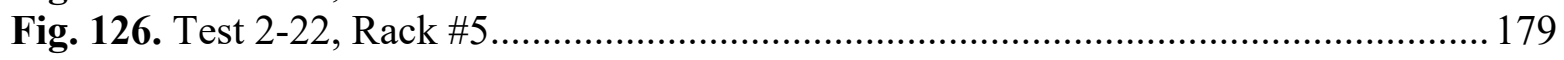

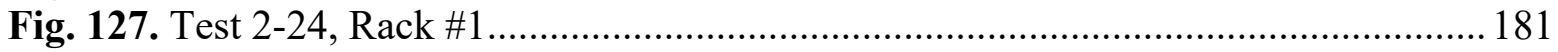

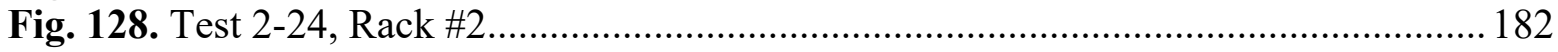

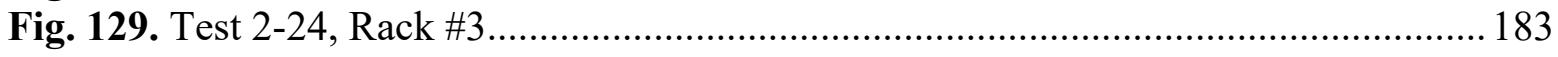

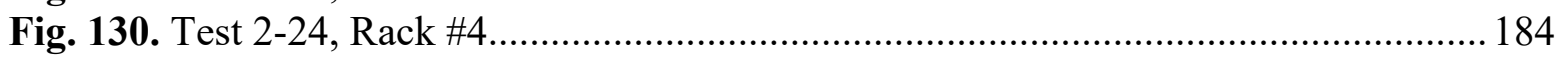

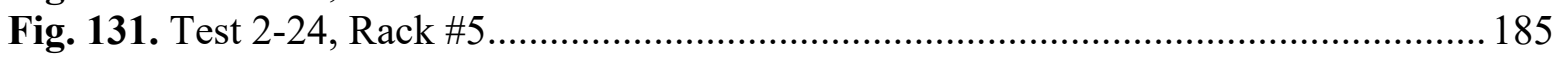

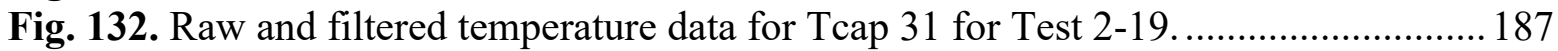

Fig. 133. Voltage vs time plot for Test 2-19........................................................... 188

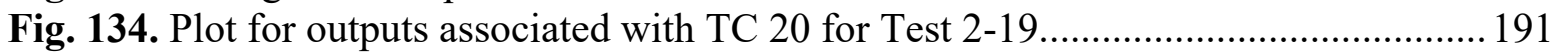

Fig. 135. Raw data, linear regression, and 95\% confidence interval for a) Tcap 2 and

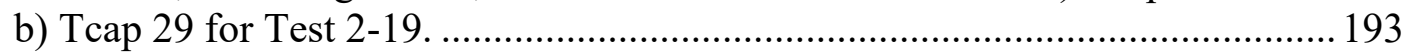

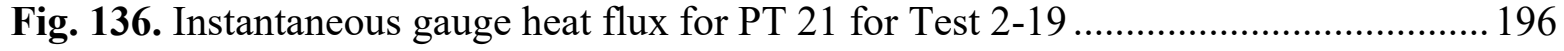




\section{EXECUTIVE SUMMARY}

PRIMARY AUDIENCE: Fire protection, electrical, and probabilistic risk assessment engineers conducting or reviewing fire risk assessments related to high energy arcing faults.

SECONDARY AUDIENCE: Engineers, reviewers, utility managers, and other stakeholders who conduct, review, or manage fire protection programs and need to understand the underlying technical basis for the hazards associated with high energy arcing faults.

KEY RESEARCH QUESTION: How do aluminum components involved in a high energy arcing fault event influence the hazard to external targets?

\section{RESEARCH OVERVIEW}

Operating experience has shown that high energy arcing faults pose a hazard to the safe operation of nuclear facilities. Current regulations and probabilistic risk assessment methods were developed using limited information, and these uncertainties required the use of safety margins to bound the hazard. Experimentation performed by an international community of regulators to improve the state-of-knowledge identified a potential concern with the involvement of aluminum in a HEAF causing a potentially larger hazard. In response to this new information, the NRC issued Information Notice (IN 2017-04) [1] and entered the concern as a potential generic issue. Limited operational experience with insufficient details and available data resulted in the NRC to decide to perform additional experimentation. The experimental results presented in this report are aimed at providing additional data to improve realism.

A series of high energy arcing fault experiments were performed on medium voltage metalclad switchgear. Each experiment consisted of an arcing fault initiated and sustained on an aluminum bus within the switchgear. The magnitude of the arc current and duration was varied between experiments, while all experiments used a nominal system voltage per the equipment rating. Numerous measurements were taken to characterize the environment within and surrounding the switchgear, including internal pressure, external heat flux, external incident energy, external particulate composition, and mass loss. Photometric equipment and techniques were deployed to capture the event using a combination of devices to characterize the thermal environment, particulate trajectory and velocity, and event timing.

This report documents the experiments performed, including the experimental methods, test facility, test device, instrumentation, experimental observations, and results. Videos and photometric data files are provided by laboratories contracted to the $\mathrm{NRC}$ and information on accessing that information is identified. Information gained from this experimental series will be used by the NRC and collaborative research partners to advance the state-of-the-art methods for characterizing the hazard and associated risks. This report does not provide detailed evaluation of the results or comparisons of the results to other methods or data. Those efforts will be documented in subsequent reports. 


\section{KEY FINDINGS}

This experimental series consisted for four (4) individual high energy arcing fault trials on near identical medium voltage switchgear. Key experimental parameters and measurements are summarized in the table below.

\begin{tabular}{|c|c|c|c|c|c|c|}
\hline \multirow[b]{2}{*}{ No. } & \multirow[b]{2}{*}{$\begin{array}{c}\text { Voltage } \\
\text { (V) } \\
\pm \mathbf{3 \%}\end{array}$} & \multirow[b]{2}{*}{$\begin{array}{l}\text { Current } \\
\text { (kA) } \\
\pm \mathbf{3 \%}\end{array}$} & \multicolumn{4}{|c|}{$\begin{array}{c}\text { Max. Total Incident } \\
\text { Energy }\left(\mathrm{MJ} / \mathrm{m}^{2}\right), \pm \mathbf{5 \%}\end{array}$} \\
\hline & & & $\begin{array}{c}\text { Duration } \\
\text { (s) } \\
\pm 3 \%\end{array}$ & $\begin{array}{c}0.91 \mathrm{~m} \\
(3.00 \mathrm{ft}) \\
\pm 13 \mathrm{~mm}\end{array}$ & $\begin{array}{c}1.83 \mathrm{~m} \\
(6.00 \mathrm{ft}) \\
\pm 13 \mathrm{~mm}\end{array}$ & $\begin{array}{c}\text { Peak } \\
\text { Pressure rise } \\
(\mathrm{kPA}) \pm \mathbf{3 \%}\end{array}$ \\
\hline $2-19$ & 6900 & 25.8 & 2.0 & 1.35 & 0.33 & 28.0 \\
\hline $2-21$ & 6900 & 26.6 & 4.1 & 7.79 & 3.35 & 28.3 \\
\hline $2-22$ & 6900 & 32.0 & 2.1 & 2.13 & 0.68 & 28.3 \\
\hline $2-24$ & 6900 & 29.8 & 4.2 & $\begin{array}{l}\text { Devices } \\
\text { Damaged }\end{array}$ & 4.70 & 30.3 \\
\hline
\end{tabular}

This research yields a significant data set of information to characterize the hazard associated with high energy arcing faults in medium voltage electrical equipment with aluminum buses. The results from this research include:

- Each medium voltage aluminum experiment breached the enclosure walls and directed significant amounts of energy toward instrumentation stands and test cell walls.

- The mass loss of electrode material and electrical enclosure cladding correlates linearly with electrical energy.

- Significant amounts of energy (incident energy $\left[\mathrm{MJ} / \mathrm{m}^{2}\right]$ ) were transferred to the thermal transducers surrounding the switchgear during the post-arcing phase of the HEAF. In locations not directly impacted by a HEAF arc jet, the incident energy measured during the post-arcing phase could be multiple times greater than the incident energy measured during the arcing phase.

- Internal overpressure profiles for all experiments were consistent with a peak pressure between approximately $27.6 \mathrm{kPa}$ and $30.3 \mathrm{kPa}$ (4.0 psi and $4.4 \mathrm{psi}$ ) above ambient for the compartment where the arc was initiated and sustained.

- The composition of the ejected material in components containing aluminum is substantially different than those containing copper, as is readily observed from its color.

- Particle analysis indicated the oxidation characteristics from this series of experiments were similar to the results from bench-scale experiments [2]. 
- The density of aluminum oxide nanoparticles correlates linearly with the duration of the arc (higher density for longer duration arc experiments).

- The arc migration direction and cabinet breach location were successfully predicted when the arc was sustained.

- Each experiment experienced cabinet breach and energy release in the same location, corresponding to the location of fault initiation and magnetic flux.

\section{WHY THIS MATTERS}

This report provides empirical evidence to assist U.S. NRC staff and stakeholders in evaluating the adequacy of current methods. The information provided will support advances in state-of-the-art methods and tools to assess the high energy arcing fault hazard in nuclear facilities. This information may also be applicable to fossil fuel and alternative energy facilities and other buildings with low and medium voltage electrical distribution equipment such as switchgear and bus duct.

\section{HOW TO APPLY RESULTS}

Engineers and scientists advancing hazard and fire probabilistic risk assessment methods should focus on Section 3 of this report.

\section{LEARNING AND ENGAGEMENT OPPORTUNITIES}

Users of this report may be interested in the following opportunities:

Nuclear Energy Institute (NEA) HEAF Project to conduct experiments in order to explore the basic configurations, failure modes and effects of HEAF events. Primary objectives include (1) development of a peer-reviewed guidance document that could be readily used to assist regulators of participants, and (2) joint nuclear safety project report covering all testing and data captured. More information on the project and opportunities to participate in the program can be found online at https://www.oecd-nea.org/. 


\section{CITATIONS}

The following organizations contributed to this research:

National Institute of Standards and Technology (NIST)

Engineering Laboratory; Fire Research Division

Gaithersburg, Maryland 20899

Anthony D. Putorti Jr.

Scott Bareham

Edward Hnetkovsky

Christopher Brown

Wai Cheong Tam

Eric Link

Michael Selepak

Phil Deardorff

Sandia National Laboratories (SNL)

Albuquerque, New Mexico 87185

Paul Clem

Byron Demosthenous

Austin Glover

Chris LaFleur

Raymond Martinez

Anthony Tanbakuchi

U.S. Nuclear Regulatory Commission

Washington, DC 20555-0001

Kenneth Hamburger

Nicholas Melly

Kenneth Miller

Gabriel Taylor 


$\begin{array}{ll}\text { ABBREVIATIONS AND ACRONYMS } \\ \text { ASTM } & \text { ASTM International } \\ \text { AWG } & \text { American Wire Gauge } \\ \text { CSNI } & \text { Committee on the Safety of Nuclear Installations } \\ \text { CT } & \text { current transformer } \\ \text { CY } & \text { calendar year } \\ \text { DAQ } & \text { data acquisition } \\ \text { DIN } & \text { Deutsches Institut für Normung } \\ \text { EDS } & \text { energy dispersive spectroscopy } \\ \text { EDT } & \text { eastern daylight time } \\ \text { EMI } & \text { electro-magnetic interference } \\ \text { EPRI } & \text { Electric Power Research Institute } \\ \text { FDS } & \text { Fire Dynamics Simulator } \\ \text { GE } & \text { General Electric } \\ \text { GI } & \text { generic issue } \\ \text { GIRP } & \text { Generic Issue Review Panel } \\ \text { HEAF } & \text { high energy arcing fault } \\ \text { IEEE } & \text { Institute of Electrical and Electronic Engineers } \\ \text { IN } & \text { information notice } \\ \text { IR } & \text { infra-red } \\ \text { ISO } & \text { International Organization for Standardization } \\ \text { LW } & \text { long wave } \\ \text { MD } & \text { management directive } \\ \text { NEA } & \text { Nuclear Energy Agency } \\ \text { NIST } & \text { National Institute of Standards and Technology } \\ \text { NRC } & \text { Nuclear Regulatory Commission } \\ \text { OECD } & \text { Organisation for Economic Co-operation and Development } \\ \text { PIRT } & \text { Phenomena Identification and Ranking Table } \\ \text { PRA } & \text { probabilistic risk assessment } \\ \text { PT } & \text { plate thermometer } \\ \text { RES } & \text { Office of Nuclear Regulatory Research } \\ \text { RIL } & \text { research information letter } \\ \text { SEM } & \text { scanning electron microscopy } \\ \text { SIS } & \text { switchboard or panelboard wire } \\ \text { SNL } & \text { Sandia National Laboratories } \\ \text { Tcap } & \text { tungsten slug calorimeter } \\ \text { U.S. } & \text { United States of America } \\ & \end{array}$




\section{Introduction}

Infrequent events such as fires at a nuclear power plant can pose a significant risk to safe plant operations. Licensees combat this risk by having robust fire protection programs designed to minimize the likelihood and consequences of fire. These programs provide reasonable assurance of adequate protection from known fire hazards. However, several hazards remain subject to a large degree of uncertainty, requiring significant safety margins in plant analyses.

One such hazard comprises an electrical arcing fault involving electrical distribution equipment and components comprised of aluminum. While the electrical faults and subsequent fires are considered in existing fire protection programs, recent research [1] has indicated that the presence of aluminum during the electrical fault can exacerbate the damage potential of the event. The extended damage capacity could exceed the protection provided by existing fire protection features for specific fire scenarios and increase plant risk estimated in fire probabilistic risk assessments (PRAs).

The U.S. Nuclear Regulatory Commission (NRC) Office of Nuclear Regulatory Research (RES) studies fire and explosion hazards to the safe operation of nuclear facilities. This includes developing data, tools, and methodologies to support risk and safety assessments. Through recent research efforts and collaboration with international partners, a nonnegligible number of reportable high energy arcing fault (HEAF) events have been identified as occurring in nuclear facilities [3]. HEAF events pose a unique hazard in nuclear facilities and additional research in this area is needed to ensure that the hazard is accurately characterized and assessed for its impact on nuclear safety.

\subsection{Background}

In June 2013, an OECD/NEA report [3] on international operating experience documented 48 HEAF events, accounting for approximately 10 percent of the total fire events reported. These HEAF events are often accompanied by loss of essential power and complicated shutdowns. Existing PRA methodology for HEAF analysis is prescribed in NUREG/CR-6850 "EPRI/NRC-RES Fire PRA Methodology for Nuclear Power Facilities Vol. 2 [4]," and its Supplement 1 [5]. To confirm these methods, the NRC led an international experimental campaign from 2014 to 2016. This experimental campaign is referred to as "Phase 1 testing." The results of these experiments [6] uncovered a potential increase in hazard posed by aluminum components in or near electrical equipment, as well as unanalyzed equipment failure mechanisms.

In response to this new information, the NRC performed a thorough review of U.S. operating experience with a focus on instances where HEAF-like events have occurred in the presence of aluminum. This review uncovered six events where aluminum effects like those observed in the experimental program were present. Information Notice 2017-004, "High Energy Arcing Faults in Electrical Equipment Containing Aluminum Components (IN 2017-04)" details the relevant aspects of the licensee event reports and Phase 1 experiments published in August of 2017 [1].

Additionally, staff in the Office of Nuclear Regulatory Research (RES) proposed a potential safety concern as a generic issue (GI) in a letter dated May 6, 2016 [7]. The Generic Issue 
Review Panel (GIRP) completed its screening evaluation [8] for proposed Generic Issue (GI) PRE-GI-018, "High-Energy Arc Faults (HEAFs) Involving Aluminum," and concluded that the proposed issue met all seven screening criteria outlined in Management Directive (MD) 6.4, "Generic Issues Program." Therefore, the GIRP recommended that this issue continue into the Assessment Stage of the GI program. The GIRP has completed an assessment plan, issued August 23, 2018 [9]. The assessment plan identifies the need for additional experimental data to support better characterization of the HEAF zone of influence. Though the HEAF research project will result in updated fire PRA guidance for all arcing faults, much of the HEAF research program exists to resolve PRE-GI-018 in accordance with the assessment plan.

These actions resulted in the identification of a need for more data to better understand the hazard. The NRC developed an experimental plan in collaboration with its international collaborative partners under the OECD/NEA program and based on information from a Phenomena Identification and Ranking Table (PIRT) exercise performed in 2017 [10].

On August 31, 2021, the NRC closed the proposed generic issue PRE-GI-018, "High Energy Arc Faults involving Aluminum," [11] based on fact that the proposed GI did not meet one of the seven screening criteria. The GIRP concluded that the risk and safety significance of HEAFs involving aluminum cannot be adequately determined without performing additional, long-term research to develop the methodology for such a determination. As such, Criterion 5 of the screening criteria in NRC Management Directive 6.4 is no longer being met and the proposed GI exited the program.

\subsection{Objectives}

The research objectives for this experimental series include: 1) quantitatively characterize the thermal conditions, pressure conditions, and byproduct deposits on surfaces created by HEAFs occurring in electrical enclosures, 2) evaluate imaging technologies capabilities for data acquisition and 3 ) document the experiments and results.

\subsection{Scope}

The scope of this research includes evaluating the HEAF hazard on medium voltage electrical equipment containing aluminum components. This characterization involves measurement and documentation of electrical and thermal parameters, along with physical evidence. Detailed data analysis for specific applications is beyond the scope of this report.

\subsection{Approach}

The approach taken for this work follows practices from past efforts. Specifically, the test device (medium voltage switchgear) was faulted between three phases. The testing laboratory provided electrical energy to the test device at the specified experimental parameters (voltage, current, duration). Measurements internal and external to the switchgear were made using robust measurement devices. Measurements were recorded, scaled, and reported. Feedback received during the developmental stage of this project was incorporated into the experimental approach. This included arc location, fault current magnitude, and experiment duration. 


\section{EXPERIMENTAL METHOD}

This section provides information on methods used to perform the experiments ${ }^{1}$, including experiment planning, overview of the test facility, the test device, and the various instrumentation that were used.

\subsection{Experimental Planning}

The experimental plan was developed over an extended period with input provided by numerous stakeholders. Lessons learned from the Phase 1 experiments, results from the Phenomena Identification and Ranking Table (PIRT) exercise, and the literature were used to develop the initial experimental plan. The experimental plan is a living document and has undergone several revisions over time as new information is brought to light. Subsequent review and feedback by the OECD/NEA and other stakeholders resulted in changes to the plan. Support from stakeholders and collaborative research partners such as the Electric Power Research Institute (EPRI) greatly enhanced the experimental plan. The central key component of the experimental plan is the experimental matrix which specifies the key parameters for each experiment. A graphical experimental matrix for electrical enclosures is presented in Fig. 1. The experiments shown in blue are sponsored jointly between the NRC and $\mathrm{OECD} / \mathrm{NEA}$ member countries, while the experiments highlighted in orange are sponsored solely by the NRC to support resolution of the Pre-GI. This report covers experiment number 2-19, 2-21, 2-22 and 2-24.

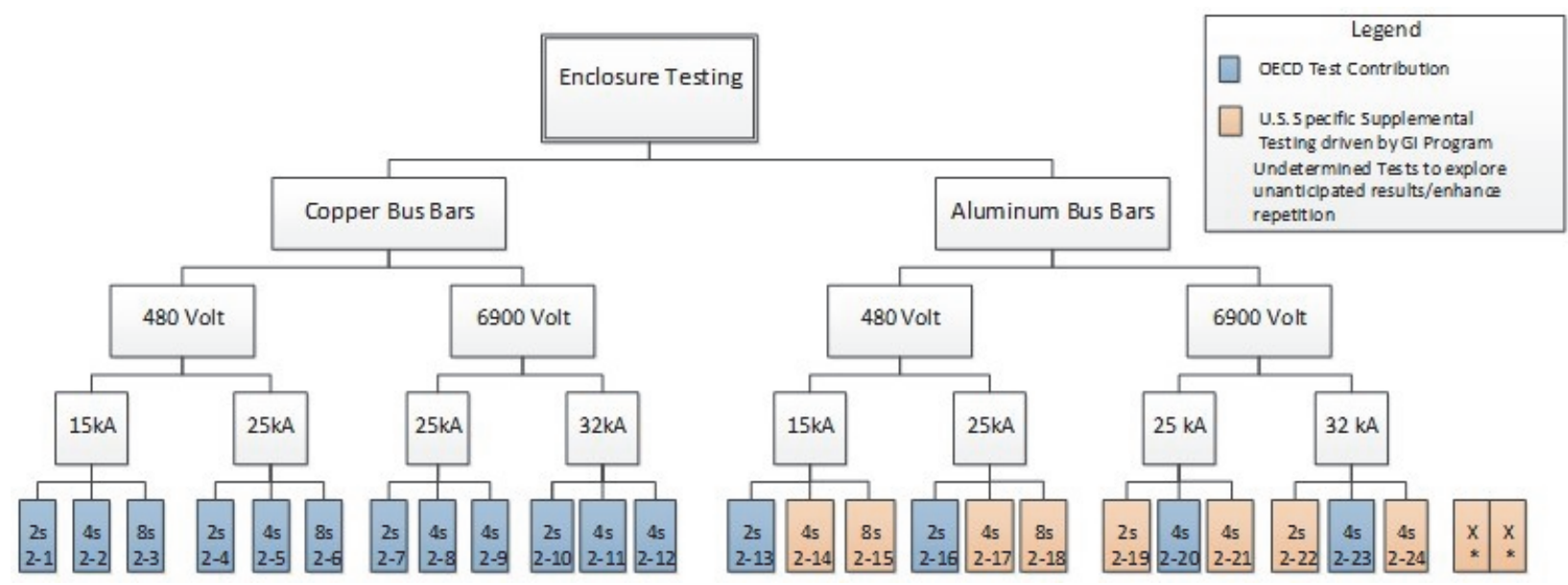

Fig. 1. Graphical Phase II Experimental Matrix for Electrical Enclosure

The key parameters that the experimental plan evaluates include;

- Material - copper vs. aluminum

\footnotetext{
${ }^{1}$ The term 'test' implies the use of a standardized test method promulgated by a standards development organization such as the International Organization for Standardization (ISO), ASTM International, Institute of Electrical and Electronics Engineers (IEEE), etc. The experiments described in this report are not standardized tests and were specifically developed to examine HEAF phenomena. The term 'test' is used in some contexts to preserve continuity with previous programs or to describe facilities where standard tests are frequently performed. Standard test methods, where they exist, are used for some measurements.
} 
○ Voltage - low vs medium

- Current - select credible arcing current

○ Duration - multiples of HEAF duration

\subsection{Test Facility}

The full-scale experiments were performed at KEMA Labs (referred to in the remainder of this report as "KEMA"), located in Chalfont, Pennsylvania. A single round of experiments was performed in September of 2018. The test facility was chosen for its ability to meet the requirements of the program, specifically the electrical voltages, currents, and energies needed for sustained arcing within the subject enclosures, and ability to permit fire conditions for a period after completion of the HEAF experiment. KEMA provided the electrical measurements required to quantify the characteristics of the power supplied to the enclosures during the arcing experiments. KEMA also provided incident energy and pressure measurements.

The experimental test cell was composed of a roughly cubical space with one open side. The open side was equipped with a roll-up door for security and weather protection when not in use. A rolling chain-link fence was available for protection from the shrapnel that may be generated during the experiments. The open side of the test cell faces the operator control room, with a courtyard area between. The control room is equipped with impact resistant glazing so that the operators, clients, and guests can observe the experiments. A door in the rear of the test cell leads to a protected space where SNL data acquisition equipment was located and operated. NIST data acquisition equipment was located and operated in a climate-controlled instrumentation van located outside the test cell.

The test cell is shown in Fig. 2, Fig. 3 and Fig. 4. Detailed drawings of the facility are provided in Appendix B. Drawings of the test cell are courtesy of KEMA. 


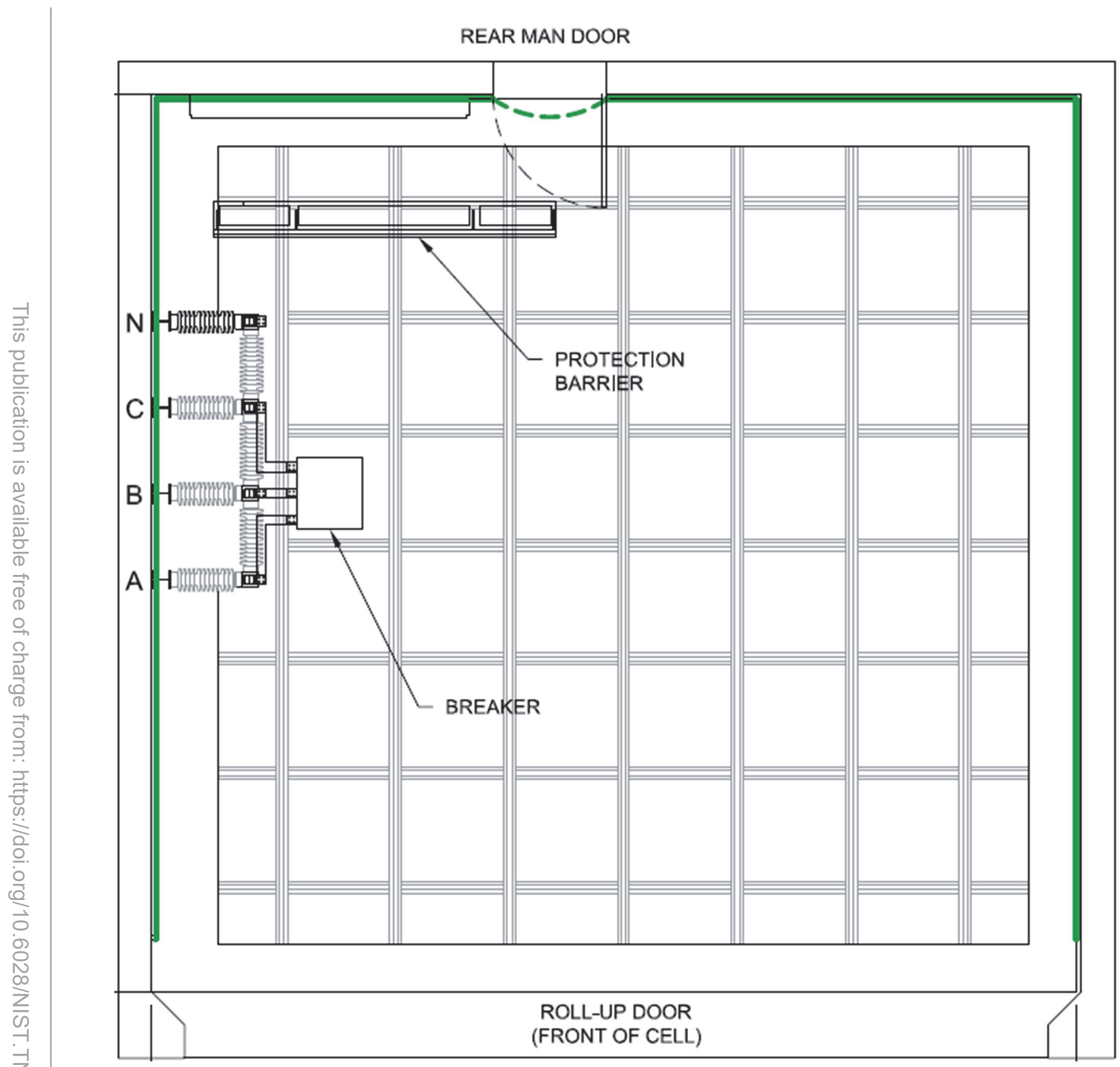

Fig. 2. Plan view of KEMA test cell \#9 


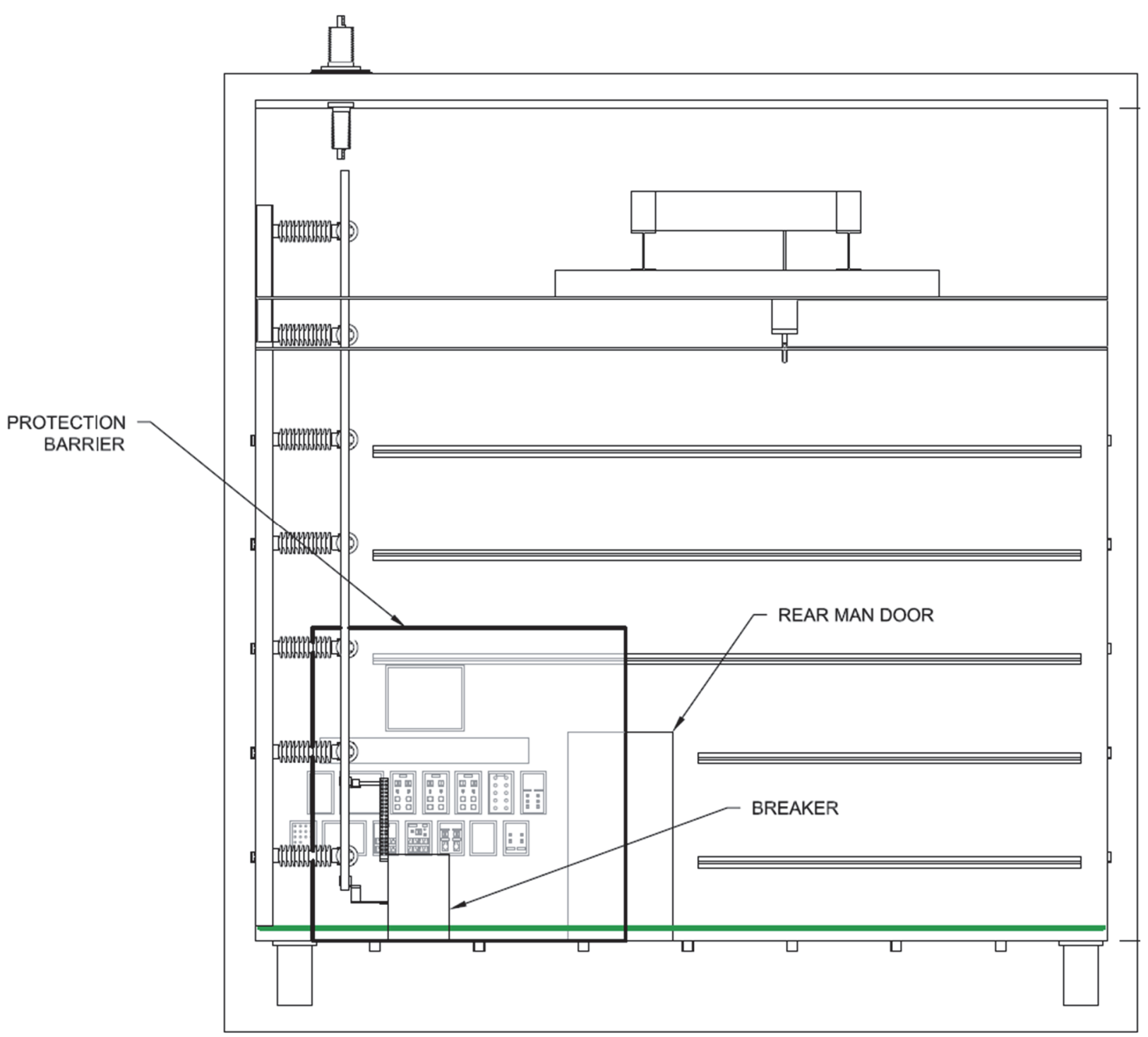

Fig. 3. Elevation view of KEMA test cell \#9 (note 'breaker' shown is make-break breaker and not the test device under evaluation.) 


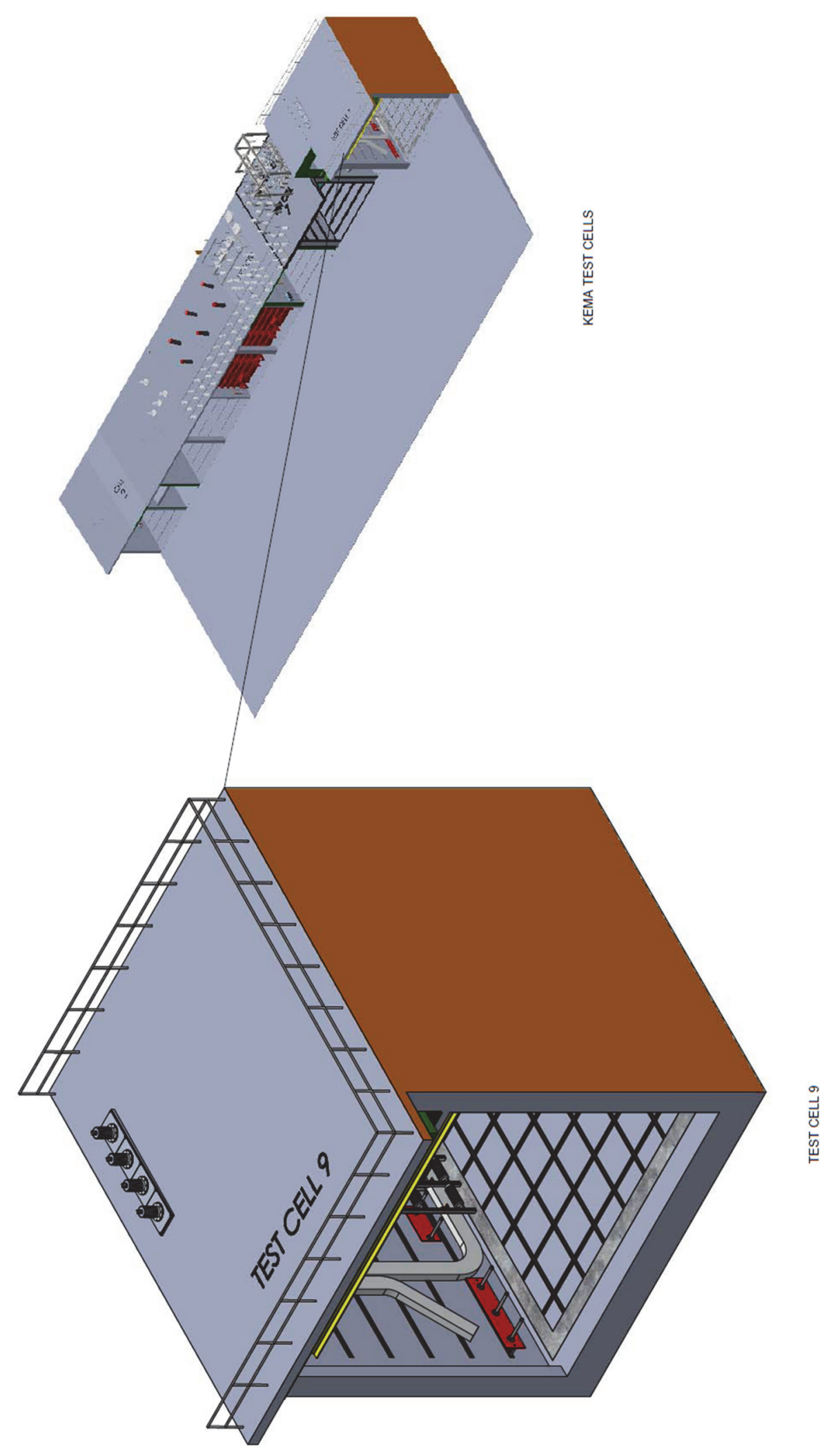

Fig. 4. Isometric drawing of Test Cell \# 9 - Left and Location of Test Cell \#9 with respect to KEMA facility 


\subsection{Test Device}

The four metal-clad switchgear units were General Electric ${ }^{2}$ Type M-36, used and refurbished from an ISO 9001 certified low and medium voltage circuit breaker and electrical power distribution supplier. The units were approximately $92 \mathrm{~cm}(36$ in) wide by $202 \mathrm{~cm}$ (79.5 in) long and $229 \mathrm{~cm}$ (90 in) high. Main buses were extended outside of the enclosure approximately $46 \mathrm{~cm}$ (18 in) to allow for connection to the test laboratory's power supply. A shorter grounding stab also extended outside the enclosure. Fig. 5 presents photographs of one of the units. The photo on the left has the side, top, and internal panels removed, revealing the "Primary cable compartment" bus conductors internal to the enclosure. The left photo also shows the "main bus bars" in the upper right, as annotated. The photo on the right shows the secondary enclosure section, with the breaker in the cubicle, but not racked into the bus. The only difference between the four (4) enclosures were the protective relaying and internal control wiring configuration located on the front door and secondary enclosure. These differences are noted in Appendix A. Fig. 6 provides a drawing and isometric view of the enclosure used in Experiment 2-19.

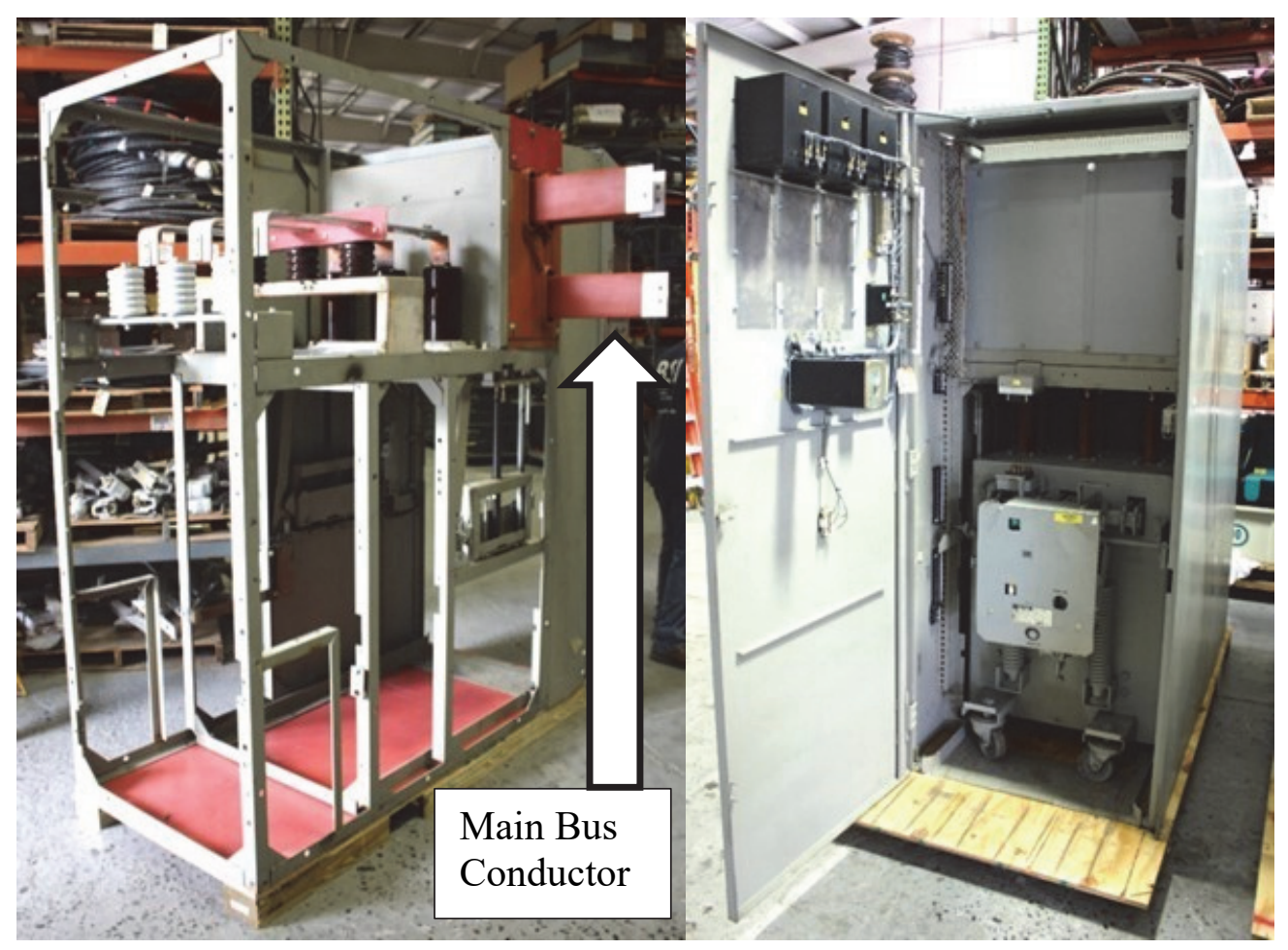

Fig. 5. Type M-36 Metal Clad Enclosure, metal cladding removed to show internal structure and bus bars in primary enclosure (left), secondary enclosure with breaker in un-racked position

\footnotetext{
${ }^{2}$ Certain commercial equipment, instruments, or materials are identified in this paper in order to specify the experimental procedure adequately. Such identification is not intended to imply recommendation or endorsement by the US Nuclear Regulatory Commission or the National Institute of Standards and Technology, nor is it intended to imply that the materials or equipment identified are necessarily the best available for the purpose.
} 


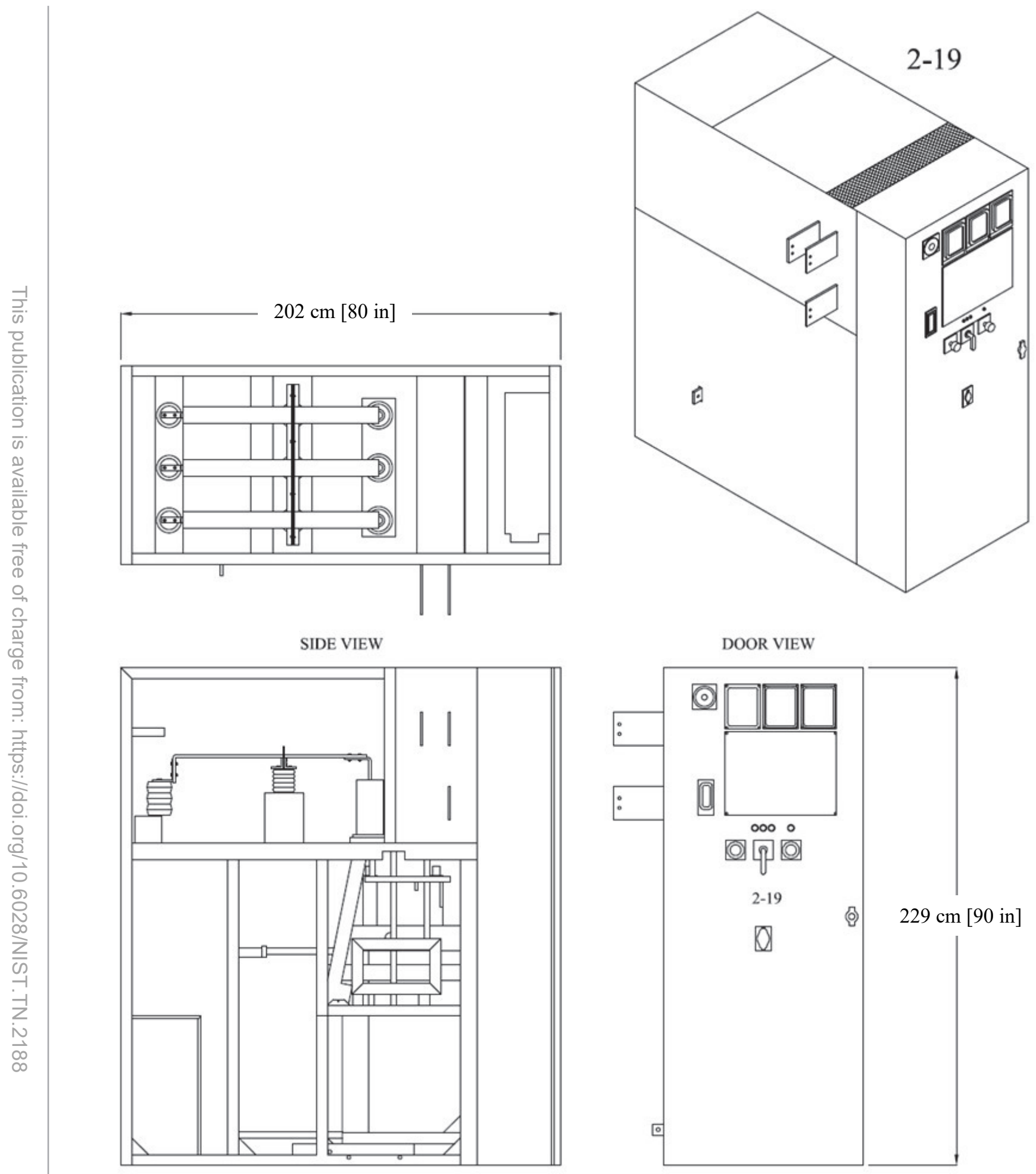

Fig. 6. Drawing of Medium Voltage Electrical Enclosure - Test device 
Aluminum bus bars were used on the main bus conductors and primary cable compartment buses. The breaker socket/tube conductors were copper. The original equipment contained copper conductors in the primary cable compartment but were replaced with uninsulated aluminum bus bars consistent with vendor designs and US plant configurations. In the US, equipment can be found with and without insulation on the bus bars. After consultation with subject matter experts, it was decided to use uninsulated bus bars since 1) uninsulated configurations exist in the field and 2) including insulation would require failure mode(s) that may not be representative of actual plant failures and result in non-typical event progression during the experiments. The primary cable compartment buses differed from typical field configurations in that they did not contain current transformers (CTs) or field bus cable connections. The CTs were not needed and removed to eliminate the potential for secondary high voltage conditions that could be created if the $\mathrm{CT}$ circuit were to become open circuited during fault conditions. Removing the CTs reduced the combustible fuel load within the enclosure and removed bus support provided by the CT assembly. Comments received on the experimental plan also recommended not including CTs. The CTs were removed by the equipment supplier. Field-installed cable potheads or cable clamp terminations were not included. The absence of bus cabling also reduced the amount of combustible load. With the removal of the CTs and absence of mock field connections, the bus required mechanical support to simulate field configurations. This was achieved by adding $15 \mathrm{kV}$ insulators at the bus termination point and $7.2 \mathrm{kV}$ insulators combined with insulative glass reinforced polyester board ("red board") at the location where the CTs would have been installed. Vendor manuals and images of similar class equipment were reviewed and used to support the representative modifications to the bus support. All modifications to the primary cable compartment bus were made by the electrical contractor. Additional details on the modifications to these enclosures can be found in Appendix B.

Each unit contained one medium voltage circuit breaker. All breakers were GE Magne-blast Type AM-7.2-500 circuit breakers. The breaker ratings are shown in Table 1 and a photo of a breaker removed from the enclosure is shown in Fig. 7. After receipt of the equipment, the breakers were tested by the electrical contractor to ensure functionality. The breaker in the test enclosure was closed prior to, and remained closed during, the arc experiment. Prior to the experiments, Megger testing was performed with and without the breaker closed. A Megger test consists of applying a DC voltage across an insulator and measuring the resulting current. Ohms law allows for the measurement of the insulation resistance, typically in the megaohm range for a good insulator. This ensured the equipment and breaker were functional prior to each experiment. 
Table 1. GE AM-7.2 Breaker Ratings

\begin{tabular}{|l|l|}
\hline Parameter & \multicolumn{2}{l|}{ Value } \\
\hline Rated Max Voltage & $8.25 \mathrm{kV}$ \\
\hline Rated Amps & $1.2 \mathrm{kA}$ \\
\hline Frequency & $60 \mathrm{~Hz}$ \\
\hline $\begin{array}{l}\text { Rated Short Circuit } \\
\text { Amps }\end{array}$ & $33 \mathrm{kA}$ \\
\hline Weight & $680 \mathrm{~kg}(1500 \mathrm{lb})$ \\
\hline
\end{tabular}

\begin{tabular}{|l|l|}
\hline Parameter & Value \\
\hline Breaker Type & AM-7.2-500 \\
\hline Rated voltage range factor & 1.25 \\
\hline Impulse Withstand & $95 \mathrm{kV}$ \\
\hline Close / Latch Capability & $66 \mathrm{kA}$ \\
\hline Date Manufactured & February 1976 \\
\hline
\end{tabular}
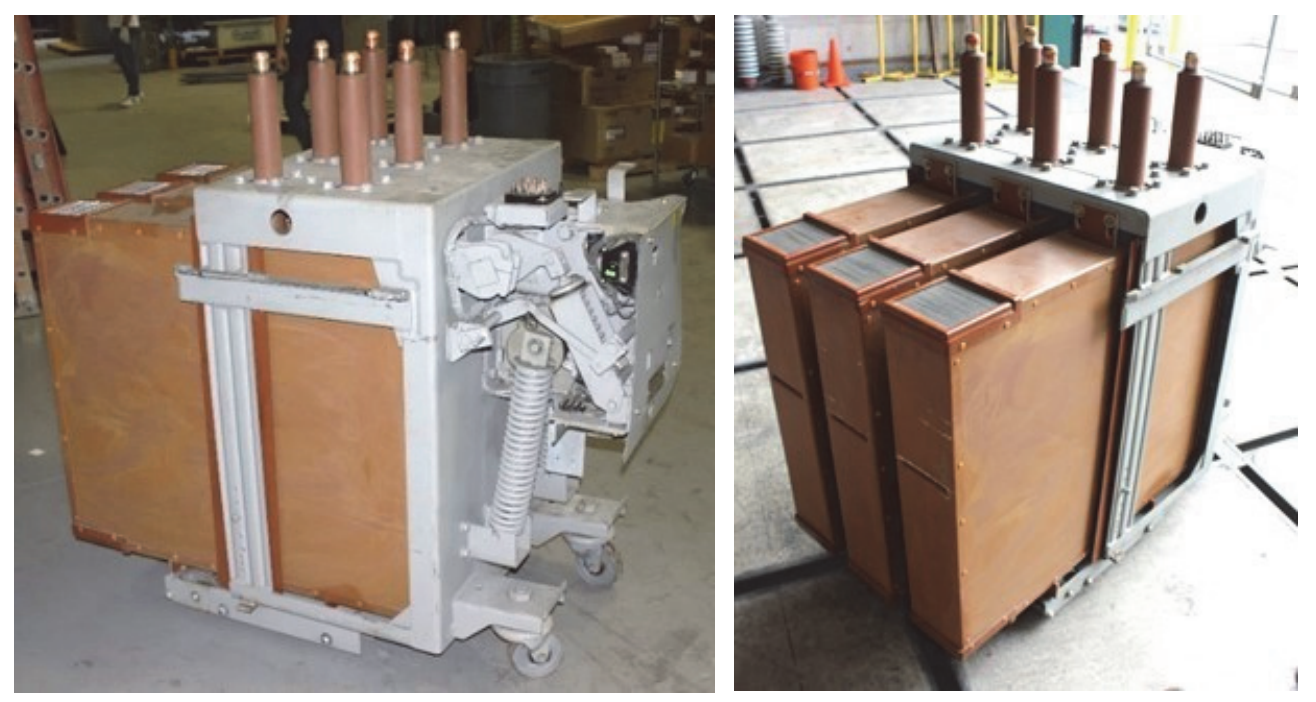

Fig. 7. Photo of AM-7.2-500 GE Magne-blast breaker

Initiation of the arc followed the process outlined in Annex E.4 of IEEE C.37.20.7, "IEEE Guide for Testing Switchgear Rated Up to $52 \mathrm{kV}$ for Internal Arcing Faults [12].” A nominally $0.511 \mathrm{~mm}$ diameter (24 American Wire Gauge [AWG]) tinned copper wire was placed at the cable termination points on the primary cable compartment aluminum bus bars at the 90-degree bend from the horizontal to vertical change in orientation. This configuration is shown in Fig. 8. The shorting wire was placed on the bus conductors prior to securing the back panel of the electrical enclosure. The air gap spacing between each phase bus bar in the primary cable compartment was approximately $14.6 \mathrm{~cm}$ [5.75 in] and the bus bar centerline to centerline spacing was approximately $24.8 \mathrm{~cm}$ [9.75 in]. These aluminum bus bars were approximately $1.3 \mathrm{~cm}$ [0.5 in] thick and $10.2 \mathrm{~cm}$ [4.0 in] wide. This configuration resulted in the switchgear configured in a bus-tie or load circuit breaker configuration. 


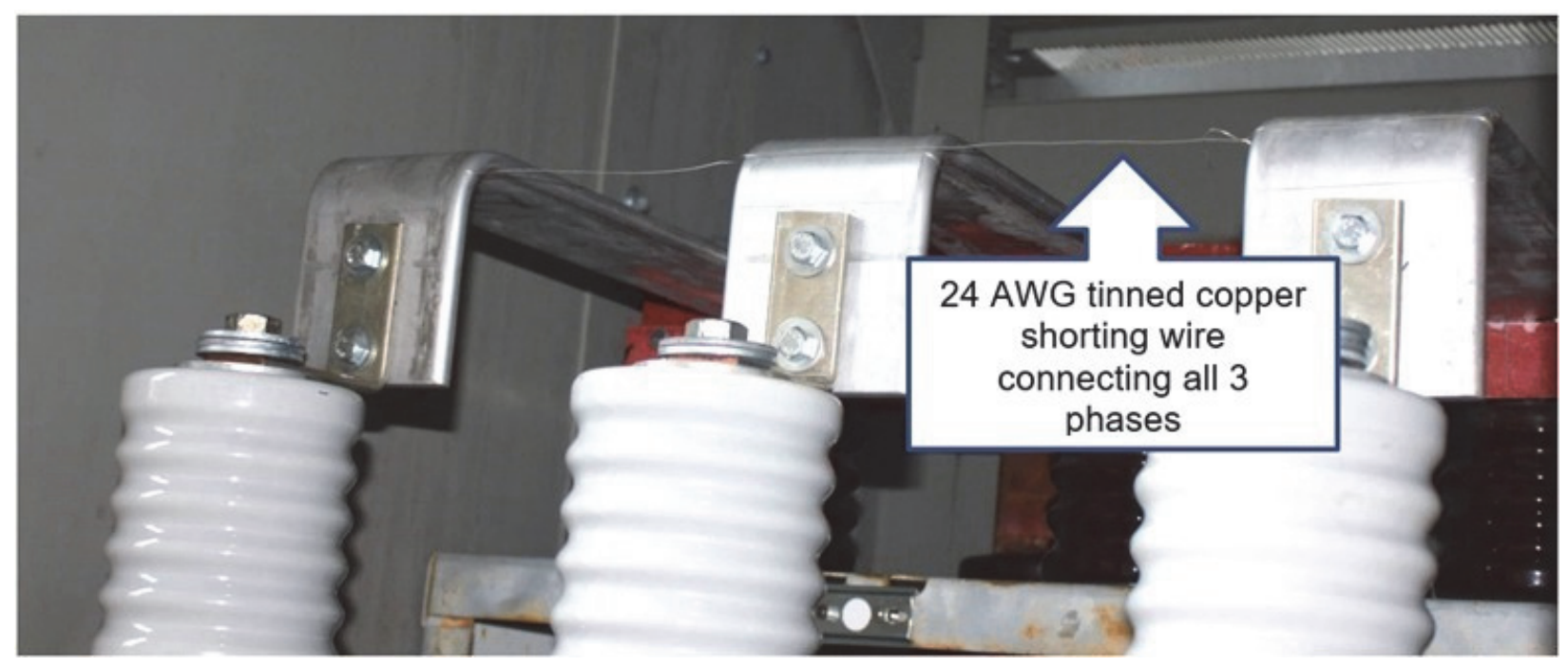

Fig. 8. Photograph of tinned copper wire used to create the short

The combustible loading within the enclosure was minimal. The primary enclosure contained polyolefin heat shrink tubing on the bus bars. However, the location where this material was located was separated from the primary cable compartment buses by metal cladding. The material was not on the primary cable compartment buses as discussed previously. The secondary enclosure contained protective relays, fuse holders, control switches, meters, resistors, and associated insulated conductors. The insulation on the SISinsulated conductors represented most of the combustible loading in the secondary enclosure. Some of the wiring had been cut and removed prior to receipt of the equipment. It was unclear if the equipment supplier removed it, or if it was removed by the previous owner. Although the conductor insulation was most of the loading, the amount varied between enclosures, was limited in total combustible component weight, and separated from the arc location by metal cladding. Fig. 9 shows this loading. 

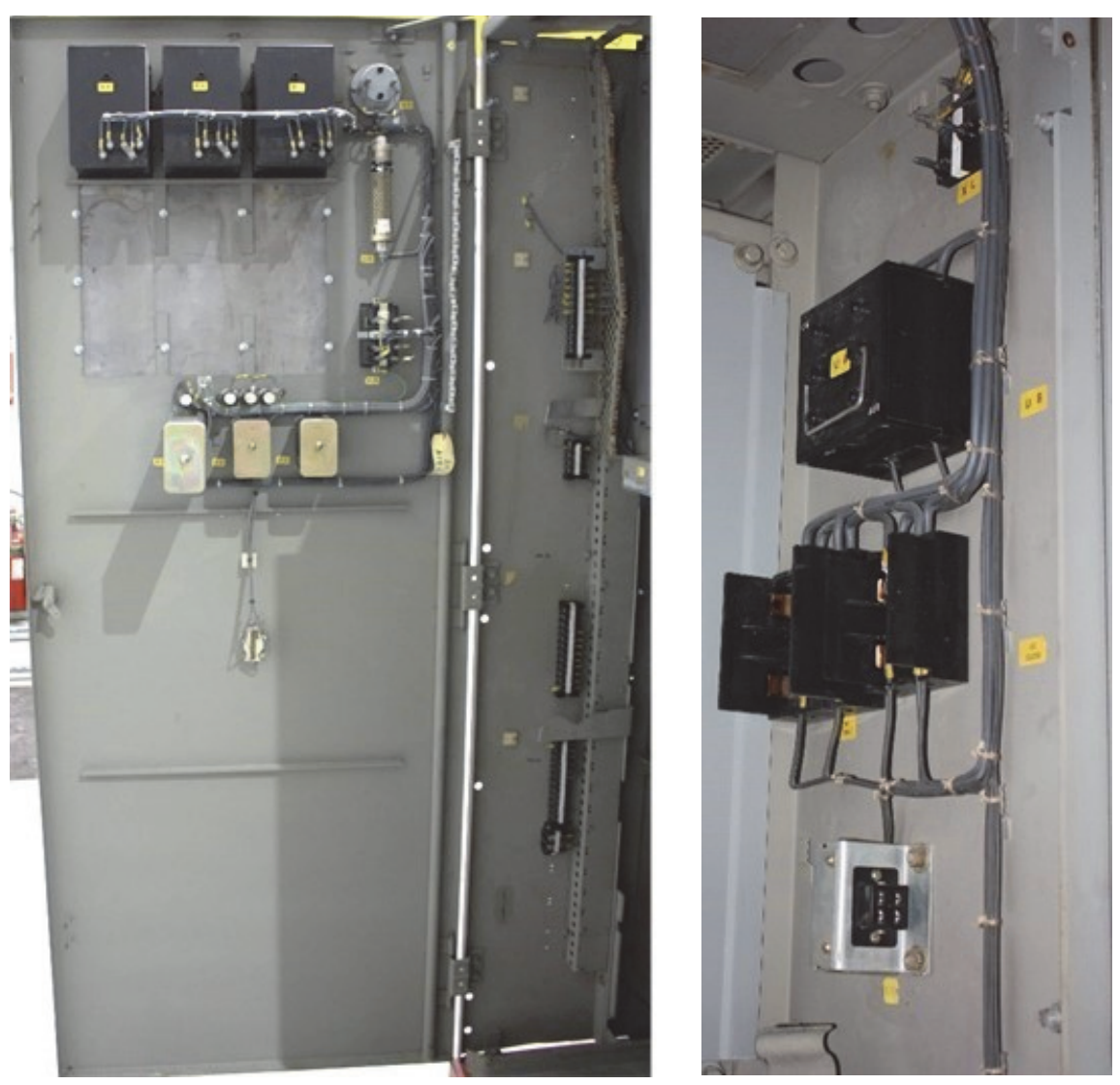

Fig. 9. Photo of combustible component loading in the secondary enclosure

\subsection{Instrumentation}

Thermal, pressure, and HEAF byproduct measurements were made using a variety of instruments and techniques. This section provides an overview of each, along with the methods and location of measurement.

\subsubsection{Overview of Instruments}

Measurements and instrumentation / techniques used are identified in Table 2. The thermal environment around the enclosure during the HEAF experiments was characterized by measurements of temperature, time-varying and average heat flux, and incident energy. The time-varying and maximum pressure inside of the enclosure was also measured during the experiments. HEAF-generated deposits were collected on vertical coupons and analyzed for composition and conductivity after the experiments. 
Table 2. Experimental Measurement Instrumentation and Techniques.

\begin{tabular}{|c|c|}
\hline Measurements & Instrument / Technique \\
\hline Temperature & Infrared (IR) Imaging, Plate Thermometer (PT) \\
\hline Heat flux (time-varying) & Plate Thermometer (PT) \\
\hline Heat flux (average) & $\begin{array}{l}\text { Plate Thermometer (PT), Thermal Capacitance Slug } \\
\text { ( } T_{\text {cap }} \text { slug) }\end{array}$ \\
\hline Incident Energy & $\begin{array}{l}\text { ASTM F1959 Slug calorimeter (slug), Thermal } \\
\text { Capacitance Slug ( } T_{\text {cap }} \text { slug) }\end{array}$ \\
\hline Pressure & Piezoelectric pressure transducer \\
\hline $\begin{array}{l}\text { Arc plasma / } \\
\text { fire dimensions }\end{array}$ & Videography, IR Imaging \\
\hline Surface deposit analysis & $\begin{array}{l}\text { Sample collection (carbon tape / aerogels), post- } \\
\text { experiment laboratory analysis (energy dispersive } \\
\text { spectroscopy) }\end{array}$ \\
\hline Qualitative damage & Cable samples \\
\hline
\end{tabular}

\subsubsection{Plate Thermometer (PT)}

Plate thermometers (PTs) are robust thermal sensors that can survive in hostile HEAF environments $[6,13]$. They were chosen for heat flux measurements in the HEAF experiments due to their rugged construction, low cost, lack of cooling water, and known emissivity and convective heat flux coefficients. The design of the typical PT described in the literature for use in fire experiments $[14,15,16]$ was modified for faster response and simpler manufacture. The modified PT has been in use since the first OECD HEAF Phase 1 experiments began in 2014 [13]. While the construction of the modified PTs used in the HEAF experiments differ from those described in the fire literature $[14,15,16]$, a similar analysis method is applied to calculate heat flux. A PT style device modified for faster response has also been developed by others since and reported in the literature [17].

In order to decrease the response time of the typical PT, the specified sheathed thermocouple was replaced by $0.51 \mathrm{~mm}$ (0.02 in) nominal diameter (24 AWG) Type-K thermocouple wires welded directly to the rear of an $0.787 \mathrm{~mm} \pm 0.051 \mathrm{~mm}(0.031 \mathrm{in} \pm 0.002 \mathrm{in}, 99$ percent confidence interval per manufacturer specifications) thick Inconel 600 plate. The thickness of the mineral fiber blanket was increased to approximately $25.4 \mathrm{~mm}(1.0 \mathrm{in})$ to decrease heat loss. A square plate of Inconel, approximately $100 \mathrm{~mm}$ (3.94 in) by $100 \mathrm{~mm}$ (3.94 in) in size, replaces the bent plate to reduce heat losses / gains from the sides and simplify electrical isolation. Machine screws with ceramic washers allow for legs to be attached at the rear of the plate thermometer in order to simplify installation onto instrumentation racks. The 
modified plate thermometer used in the OECD HEAF Phase 1 experiments and the experiments discussed in this report is shown in Fig. 10.
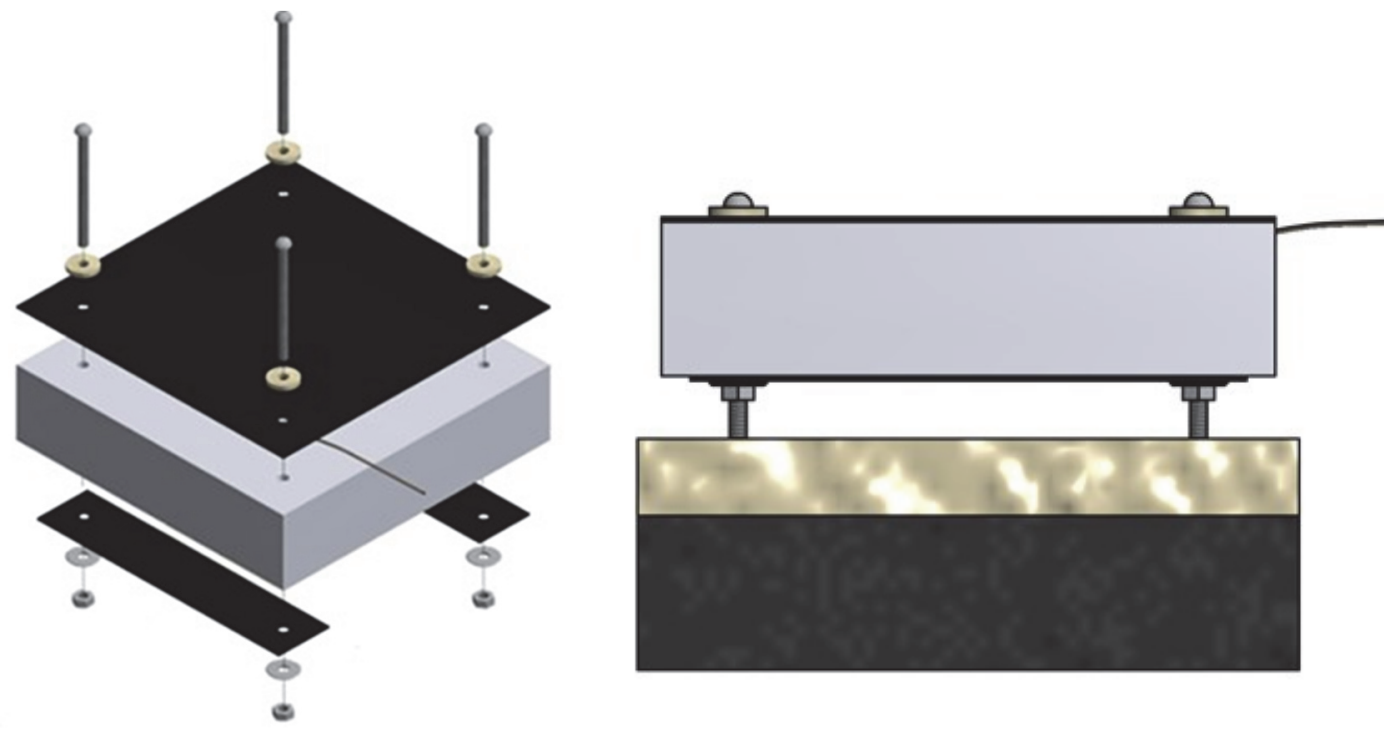

Fig. 10. Exploded view of modified plate thermometer (left); Cross-sectional view of modified plate thermometer placed on cone calorimeter sample holder (right)

The incident heat flux on a plate thermometer can be calculated from a heat balance using the following relation, a rearrangement of Equation 18 from Ingason and Wickstrom [15]:

$$
\dot{\mathrm{q}}_{\text {inc }}^{\prime \prime}=\sigma \cdot \mathrm{T}_{\mathrm{PT}}^{4}+\frac{\left(\mathrm{h}_{\mathrm{PT}}+\mathrm{K}_{\text {cond }}\right)\left(\mathrm{T}_{\mathrm{PT}}-\mathrm{T}_{\infty}\right)}{\varepsilon_{\mathrm{PT}}}+\frac{\rho_{\mathrm{ST}} \cdot \mathrm{C}_{\mathrm{ST}} \cdot \delta \cdot\left(\frac{\Delta \mathrm{T}_{\mathrm{PT}}}{\Delta \mathrm{t}}\right)}{\varepsilon_{\mathrm{PT}}}
$$

Here $\dot{\mathrm{q}}_{\mathrm{inc}}^{\prime \prime}$ is the incident heat flux $\left(\mathrm{W} / \mathrm{m}^{2}\right), \sigma$ is the Stefan-Boltzmann Constant, $5.670 \times 10^{-8} \mathrm{~W} /\left(\mathrm{m}^{2} \cdot \mathrm{K}^{4}\right)$, T $\mathrm{PT}$ is the temperature of the plate $(\mathrm{K})$, hPT is the convection heat transfer coefficient, $10 \mathrm{~W} /\left(\mathrm{m}^{2} \cdot \mathrm{K}\right), \mathrm{K}_{\text {cond }}$ is the conduction correction factor determined from NIST cone calorimeter data, $4 \mathrm{~W} /\left(\mathrm{m}^{2} \cdot \mathrm{K}\right), \mathrm{T}_{\infty}$ is the ambient temperature $(\mathrm{K}), \varepsilon_{\mathrm{PT}}$ is the plate emissivity, 0.85 at $480{ }^{\circ} \mathrm{C}$ as rolled and oxidized and specified by the alloy manufacturer, $\rho$ PT is the alloy plate density, $8470 \mathrm{~kg} / \mathrm{m}^{3}$ from the alloy manufacturer, CsT is the alloy plate heat capacity, $502 \mathrm{~J} /(\mathrm{kg} \cdot \mathrm{K})$ at $300{ }^{\circ} \mathrm{C}$ from the alloy manufacturer, $\delta$ is the alloy plate thickness, $0.79 \mathrm{~mm}(0.03 \mathrm{in})$, and $\Delta \mathrm{t}$ is the data acquisition time step of $0.1 \mathrm{~s}$.

The gauge heat flux can also be calculated and is the heat flux listed in the tables of this report. The gauge heat flux is the heat flux that would be reported by an ideal water-cooled transducer such as a Schmidt-Boelter or Gardon gauge operating at a constant temperature of $\mathrm{T}_{\text {gauge. }}$ The gauge heat flux, $\dot{\mathrm{q}}_{\text {gauge }}^{\prime \prime}$, is calculated from [15]:

$$
\dot{\mathrm{q}}_{\text {gauge }}^{\prime \prime}=\sigma \cdot \mathrm{T}_{\mathrm{PT}}^{4}+\frac{\left(\mathrm{h}_{\mathrm{PT}}+\mathrm{K}_{\text {cond }}\right)\left(\mathrm{T}_{\mathrm{PT}}-\mathrm{T}_{\infty}\right)}{\varepsilon_{\mathrm{PT}}}+\frac{\rho_{\mathrm{ST}} \cdot \mathrm{C}_{\mathrm{ST}} \cdot \delta \cdot\left(\frac{\Delta \mathrm{T}_{\mathrm{PT}}}{\Delta \mathrm{t}}\right)}{\varepsilon_{\mathrm{PT}}}-\sigma \cdot \mathrm{T}_{\text {gauge }}^{4}
$$


The modified PTs were heated in the cone calorimeter [18] to verify their performance and the fit of the simple thermal model in Equation (2). The plates were tested from $5 \mathrm{~kW} / \mathrm{m}^{2}$ to $75 \mathrm{~kW} / \mathrm{m}^{2}$ by heating from ambient temperature to steady state and then allowing them to cool. At a steady state flux of $75 \mathrm{~kW} / \mathrm{m}^{2}$ the calculated heat flux reached 63 percent of the incident heat flux in approximately $0.7 \mathrm{~s}$. The combined standard uncertainty in steady state heat flux measured by the plate thermometers, composed of Type A and Type B

uncertainties, is 2.5 percent at $75 \mathrm{~kW} / \mathrm{m}^{2}$. The expanded uncertainty in the steady state heat flux measurement is 5 percent at $75 \mathrm{~kW} / \mathrm{m}^{2}$, with a coverage factor of 2 which corresponds to a confidence interval of 95 percent [19].

Type A evaluation of uncertainty is performed by the statistical analysis of a series of measurements. Type B evaluation of uncertainty is based on scientific judgement using relevant available information such as manufacturer specifications, calibration data, handbook data, previous experiments, and knowledge of the behaviors of materials and measurement equipment $[19,20,21]$.

The heating of plate TCs described here in the cone calorimeter was modeled in one dimension with the Fire Dynamics Simulator (FDS) [22] to verify the assumptions and property data. Agreement to within 1 percent was found between the temperatures measured during exposure in the cone calorimeter and the FDS predicted temperatures. Data from heating the plate thermometer at $75 \mathrm{~kW} / \mathrm{m}^{2}$ in the cone calorimeter is included in the FDS validation library.

The plate thermometer temperature increase, $\Delta \mathrm{T}_{\mathrm{PT}}$, during the arcing phase of the HEAF is reported along with heat flux later in this report. The uncertainty in the temperature of the Type- $\mathrm{K}$ thermocouple wire is given by the manufacturer as $\pm 1.1^{\circ} \mathrm{C}$ or 0.4 percent with a 99 percent confidence interval [23]. The uncertainty can be viewed as the potential systematic difference between the response of the thermocouple and the ASTM standardized thermocouple tables [23, 24]. For large temperature changes, it is assumed that the initial temperature and the final temperature of the PT are each known to within $\pm 1.1^{\circ} \mathrm{C}$ or 0.4 percent, whichever is greater. The expanded uncertainty in a PT temperature change of $0{ }^{\circ} \mathrm{C}$ to $1250{ }^{\circ} \mathrm{C}$ is 0.3 percent, with a coverage factor of 2 , which corresponds to a confidence interval of 95 percent [25]. For small temperature changes, this approach is expected to overestimate the uncertainty since the systematic differences between the thermocouple response and the ASTM thermocouple table should nearly cancel out when calculating the PT temperature change. Comparisons of thermocouple performance found in the literature [26] show differences in thermocouple deviation from the thermocouple tables of approximately $1{ }^{\circ} \mathrm{C}$ over the temperature range of $100^{\circ} \mathrm{C}$ to $200^{\circ} \mathrm{C}$. This difference, which was found to be approximately linear over the $100^{\circ} \mathrm{C}$ temperature range, was an extreme example of the data reported. Based on this data, the expanded uncertainty of small temperature changes on the order of $100^{\circ} \mathrm{C}$ is less than \pm 1 percent, with a confidence interval of 95 percent. Systematic differences would be proportionally smaller for smaller PT temperature changes. The population standard deviations in the PT temperatures during the $100 \mathrm{~s}$ time periods before the experiments are approximately $0.025^{\circ} \mathrm{C}$, which results in an expanded uncertainty of temperature change of $\pm 0.05^{\circ} \mathrm{C}$ with a confidence interval of 95 percent. In order to be conservative in the reporting of the temperature change data in this report, the values are rounded to the nearest $1{ }^{\circ} \mathrm{C}$, and the expanded uncertainty reported as 
$\pm 0.5{ }^{\circ} \mathrm{C}$ or \pm 1 percent with a confidence interval of 95 percent. Appendix $\mathrm{G}$ provides additional detail on the plate thermometer heat transfer analysis.

\subsubsection{ASTM Slug Calorimeter (Slug)}

Incident energy was measured using slug calorimeters described in ASTM F1959 [27] and shown in Fig. 11. These instruments are customarily used to measure radiant energy and determine the arc flash hazard to personnel in the area of electrical enclosures. Due to the characteristics of the HEAF phenomena, which can result in convective arc jets, the calorimeters are reacting to convective heat transfer in addition to radiant heat transfer. ASTM slug calorimeters consist of a copper disc with an approximate thickness of $1.6 \mathrm{~mm}$ (0.063 in) and diameter of $40 \mathrm{~mm}$ (1.6 in). An iron-constantan thermocouple (Type J), composed of two $0.255 \mathrm{~mm}$ (0.01 in) nominal diameter (30 AWG) wires, is soldered to the back of the copper disc using silver solder. The ASTM standard specifies that the copper disc be installed in an insulation board. The KEMA slug calorimeters were installed in a G-11 fiberglass epoxy phenolic cup, which was then placed in a calcium silicate board holder nominally $100 \mathrm{~mm}$ by $100 \mathrm{~mm}$ by $32 \mathrm{~mm}$ thick (4 in by 4 in by 1.25 in nominal thickness) for mounting on instrument rack. The use of calcium silicate board is a change made for this series of experiments. In past experiments, KEMA supplied the ASTM slugs with the copper disk and phenolic cup assembled into a plywood substrate. High heat fluxes sometimes caused ignition of the plywood, resulting in erroneously high readings. The use of calcium silicate board substrate instead of the plywood eliminates this error. The instruments were provided by KEMA. The slug temperatures were reported by the KEMA data acquisition system at a rate of $20 \mathrm{~Hz}$.

The incident energy absorbed by the slug calorimeter during the HEAF experiments is calculated according to the methodology in ASTM F1959 [27]. The method reports the net heat absorbed over the arc duration and assumes that there are no losses from the disc due to re-radiation, convection, or conduction to the disc holder. The absorptivity of the disc is assumed to be one.

The total energy per unit area, $\mathrm{Q}^{\prime \prime}\left(\mathrm{J} / \mathrm{m}^{2}\right)$, is calculated by:

$$
Q^{\prime \prime}=\frac{m \cdot \overline{C_{p}} \cdot\left(T_{f}-T_{i}\right)}{A}
$$

where $\mathrm{m}$ is the mass of the copper disc $(\mathrm{g}), \mathrm{C}_{\mathrm{p}}$ is the average heat capacity of the copper disc $\left(\mathrm{J} / \mathrm{g}{ }^{\circ} \mathrm{C}\right), \mathrm{T}_{\mathrm{f}}$ is the temperature of the disc at the end of the $\operatorname{arc}\left({ }^{\circ} \mathrm{C}\right), \mathrm{T}_{\mathrm{i}}$ is the temperature of the disc before the arc $\left({ }^{\circ} \mathrm{C}\right)$, and $\mathrm{A}$ is the front surface area of the disc $\left(\mathrm{m}^{2}\right)$. The total energy per unit area resulting from the arc is reported in a summary table for each sensor location in each experiment. The ASTM F1959 standard also refers to the total energy per unit area as incident energy $\left(\mathrm{cal} / \mathrm{cm}^{2}\right.$ or $\left.\mathrm{kJ} / \mathrm{m}^{2}\right)$. 

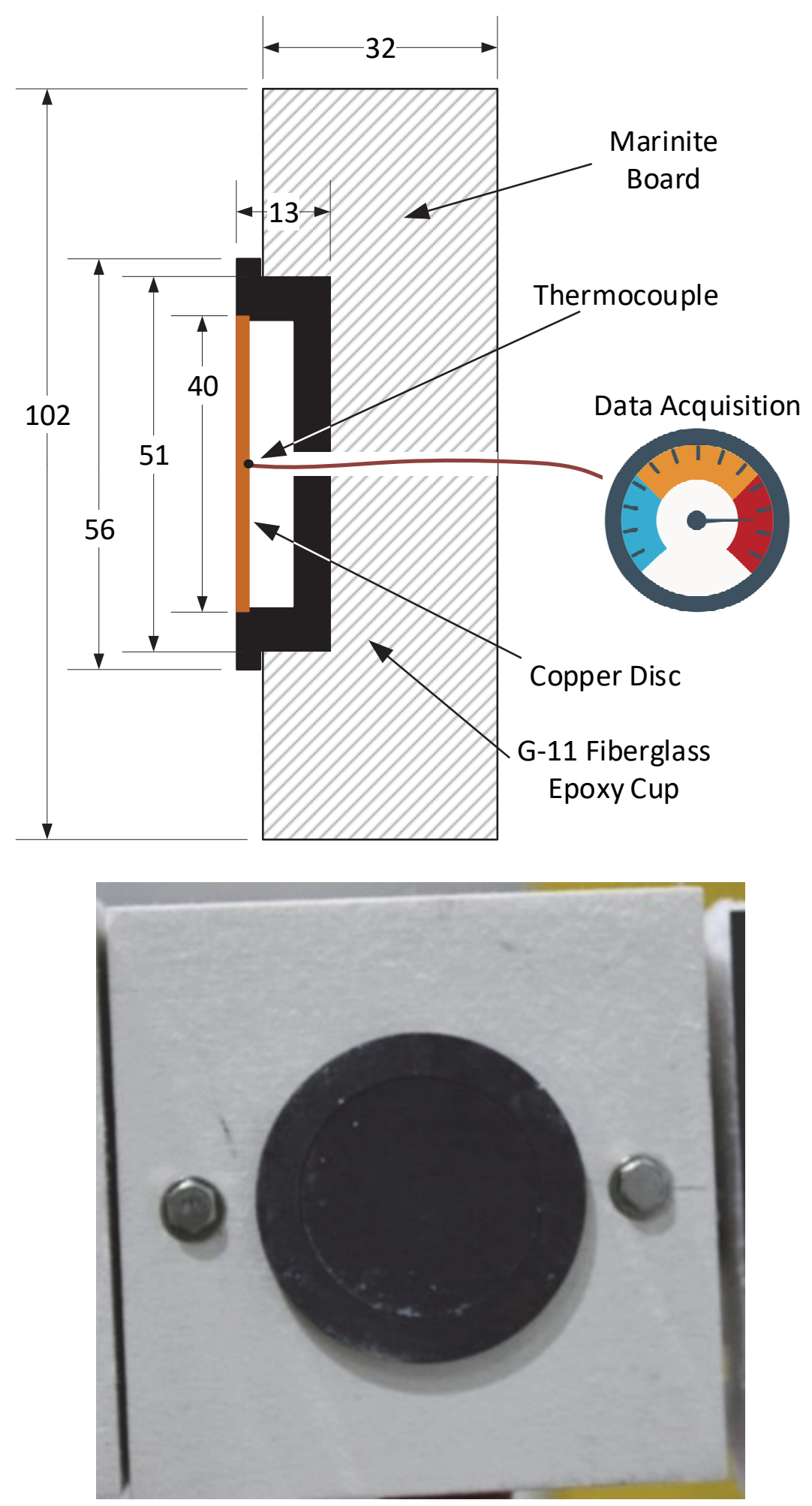
Fig. 11. Cross-section of ASTM Slug (top) nominal dimensions in millimeters, photo of device being prepared in the field (bottom). Note that the two bolts on each side of the device are used for mounting to the DIN rail of the instrumentation rack.

The Type B standard uncertainty in the thermocouple measurement, derived from typical thermocouple manufacturer data, with a coverage factor of 2 , is $2.2^{\circ} \mathrm{C}$ or 0.75 percent. The ASTM calculation method assumes that the absorptivity of the disc is 1.0 , however inspection of the discs over the course of the experiments suggests that the emissivity may vary from approximately 0.9 to 1.0 , in a rectangular probability distribution. It was found that the uncertainty in the thermocouple wire drives the uncertainty at low energies, while the uncertainty in the absorptivity drives the uncertainty at high energies [25]. The combined standard uncertainty in the absorbed energy, composed of Type A and Type B uncertainties, is 17 percent at $50 \mathrm{~kJ} / \mathrm{m}^{2}$ and 4 percent at $500 \mathrm{~kJ} / \mathrm{m}^{2}$. The expanded uncertainty in the steadystate absorbed energy measurement is 35 percent at $50 \mathrm{~kJ} / \mathrm{m}^{2}$ and 8 percent at $500 \mathrm{~kJ} / \mathrm{m}^{2}$, with a coverage factor of 2 , which corresponds to a confidence interval of 95 percent [19].

\subsubsection{Thermal Capacitance Slug ( $T_{\text {cap }}$ slug)}

Tungsten thermal capacitance slugs ( $\mathrm{T}_{\text {cap }} \mathrm{slug}$ ) were used to measure the heat flux and incident energy during the HEAF experiment. These sensors were developed as a result of experience gained in Phase 1, where the thermal conditions during some experiments exceeded the measurement capabilities and caused destruction of the ASTM slug calorimeters and modified plate thermometers. A cross section of a $\mathrm{T}_{\text {cap }}$ slug is shown in Fig. 12, which is a modified example of the thermal capacitance slug described in ASTM E45708 [28]. The slug is composed of a tungsten cylinder approximately $15 \mathrm{~mm}(0.59 \mathrm{in})$ long mounted in calcium silicate board. A type- $\mathrm{K}$ thermocouple is attached to the rear of the tungsten to measure the temperature during heating. Tungsten has a higher melting point (approximately $3422^{\circ} \mathrm{C}\left[6192^{\circ} \mathrm{F}\right]$ ) than copper (approximately $1085^{\circ} \mathrm{C}\left[1985^{\circ} \mathrm{F}\right]$ ) or Inconel (approximately $1400^{\circ} \mathrm{C}\left[2552^{\circ} \mathrm{F}\right]$ ), while having similar thermal inertia and an order of magnitude higher thermal conductivity than Inconel. These properties increase the survivability of the slug in the harsh HEAF thermal environment while providing good thermal performance. The addition of the $\mathrm{T}_{\text {cap }}$ slug to the instrument matrix improves measurement capabilities in severe environments, such as the HEAF and aluminum combustion previously seen in Test 23 of the Phase 1 experimental program [6]. 

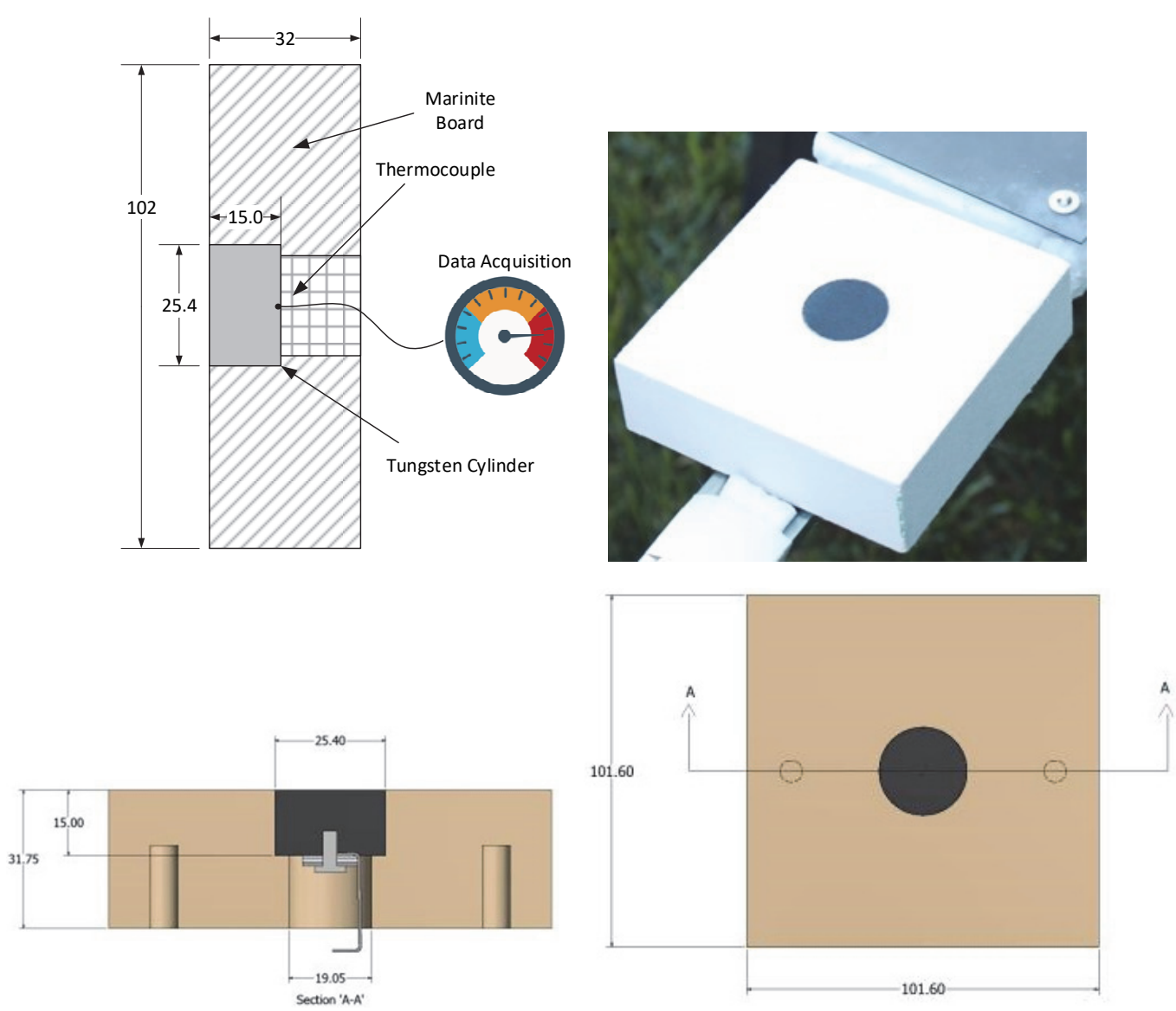

Fig. 12. Thermal capacitance style slug, illustration (top left), photo of device being prepared in the field (top right), dimensional drawings showing internal construction (bottom left and right). All dimensions in $\mathrm{mm}$.

The length of the slug was designed based on direct exposure to the HEAF arc jet for the entire expected arc duration. The Phase 1 experiments resulted in a plate thermometer measured heat flux exceeding $3.2 \mathrm{MW} / \mathrm{m}^{2}$. To provide additional dynamic range for the Phase 2 experiments, the $T_{\text {cap }}$ slug was designed to have the capability to measure heat fluxes greater than $5 \mathrm{MW} / \mathrm{m}^{2}$ for $8 \mathrm{~s}$. This design allows for greater thermal exposure over the duration of the experiment for a reasonable level of measurement uncertainty while not overranging the device. The $\mathrm{T}_{\text {cap }}$ slug was modeled with the Fire Dynamics Simulator (FDS) [22] to determine the optimal length of the metal cylinder. This effort resulted in a $15 \mathrm{~mm}$ (0.59 in) long cylinder and a predicted peak temperature of approximately $865^{\circ} \mathrm{C}$ at the thermocouple during an $8 \mathrm{~s}$ exposure to $5 \mathrm{MW} / \mathrm{m}^{2}$ of external heat flux. Since type-K thermocouples have good performance and are within their specified uncertainty bounds up to approximately $1260^{\circ} \mathrm{C}\left(2300^{\circ} \mathrm{F}\right)$, there is additional dynamic range available for more extreme conditions. Further FDS simulations indicated that the maximum useful exposure for the $\mathrm{T}_{\text {cap }}$ transducer is a heat flux of $8 \mathrm{MW} / \mathrm{m}^{2}$ for $8 \mathrm{~s}$, which results in a predicted maximum TC temperature of approximately $1295^{\circ} \mathrm{C}\left(2363^{\circ} \mathrm{F}\right)$, slightly over-ranging the thermocouple. If the exposure time or arc duration are shorter, larger heat fluxes can be measured. During the experiments described in this report, the $\mathrm{T}_{\text {cap }}$ transducers all survived 
direct exposure to HEAF arc jets. The only failures that occurred during the experiments related to the $\mathrm{T}_{\text {cap }}$ transducers were due to thermal failure of the thermocouple wires in the instrument racks.

The $\mathrm{T}_{\text {cap }}$ slugs were heated in the cone calorimeter $[18,29]$ to verify their performance and the fit of the simple thermal model in Equation (4). The $T_{\text {cap }}$ slugs were tested at $25 \mathrm{~kW} / \mathrm{m}^{2}$, $50 \mathrm{~kW} / \mathrm{m}^{2}$, and $75 \mathrm{~kW} / \mathrm{m}^{2}$ by heating from ambient temperature to an asymptotic temperature approaching steady state and then allowing them to cool. The maximum heat flux was determined from Equation (4), where $\left(\dot{q}^{\prime \prime}\right)$ is the heat flux into the surface of the tungsten slug $\left(\mathrm{kW} / \mathrm{m}^{2}\right), \rho$ is the density of the tungsten slug $\left(\mathrm{kg} / \mathrm{m}^{3}\right),\left(\overline{C_{p}}\right)$ is the average heat capacity of the tungsten slug $(\mathrm{kJ} /[\mathrm{kg} \cdot \mathrm{K}]), l$ is the thickness of the slug $(\mathrm{m}), \Delta \mathrm{T}$ is the change in temperature of the tungsten slug $\left({ }^{\circ} \mathrm{C}\right)$, and $\Delta \mathrm{t}$ is the corresponding change in time (s). The combined standard uncertainty in steady state heat flux measured by the $\mathrm{T}_{\text {cap }}$ slugs, composed of Type A uncertainties, is 2.4 percent at $50 \mathrm{~kW} / \mathrm{m}^{2}$. The expanded uncertainty in the maximum heat flux measurement is 4.8 percent at $50 \mathrm{~kW} / \mathrm{m}^{2}$, with a coverage factor of 2 , that corresponds to a confidence interval of 95 percent [19]. These uncertainties were determined by calculating the sample standard deviation of the calculated maximum heat flux values from the cone calorimeter experiments.

$$
\dot{q}^{\prime \prime}=\rho \cdot \overline{C_{P}} \cdot l \cdot\left(\frac{\Delta T}{\Delta t}\right)
$$

In addition to the uncertainty bounds, a systemic error of approximately -9 percent was present in the $75 \mathrm{~kW} / \mathrm{m}^{2}$ experiments. This was likely caused by the observed partial failure of the optical coating applied to the transducers. The coating remained intact during the $25 \mathrm{~kW} / \mathrm{m}^{2}$ and $50 \mathrm{~kW} / \mathrm{m}^{2}$ experiments but degraded over time during the $75 \mathrm{~kW} / \mathrm{m}^{2}$ experiments. Due to the reduced radiative absorptivity as the coating failed, the measured heat flux decreased over the series of $75 \mathrm{~kW} / \mathrm{m}^{2}$ experiments. This effect is not expected to affect the full-scale experimental results. Coating failures were not observed during the fullscale experiments, and the high heat fluxes measured in the full-scale experiments were convective dominated (arc jet) and would not be appreciably affected by the change in radiative absorptivity. Even with the radiative absorptivity decreasing over the series of $75 \mathrm{~kW} / \mathrm{m}^{2}$ experiments, the calculated expanded uncertainty in the heat flux measurement is 5.9 percent at $75 \mathrm{~kW} / \mathrm{m}^{2}$, with a coverage factor of 2 , that corresponds to a confidence interval of 95 percent.

The heating of $\mathrm{T}_{\text {cap }}$ slugs in the cone calorimeter was modeled with the Fire Dynamics Simulator (FDS) [22] to verify the assumptions and property data and to extrapolate the results to higher heat fluxes than are possible in the cone calorimeter. The heat fluxes of $50 \mathrm{~kW} / \mathrm{m}^{2}$ and $5 \mathrm{MW} / \mathrm{m}^{2}$ were examined. During the simulations, the simulated temperature of a thermocouple device at the end of the tungsten slug was recorded during radiant heating. The FDS simulation included both the tungsten slug and the calcium silicate board configured as shown in Fig. 12 without the mounting bores. It also included the temperature dependent values of heat conduction and heat capacity for both tungsten and calcium silicate board. The simulated temperature versus time data was analyzed for maximum heat flux according to the same method as the $\mathrm{T}_{\text {cap }}$ slugs in the cone calorimeter and full-scale experiments. The results were compared to the radiant heat flux imposed on the $\mathrm{T}_{\text {cap }}$ slug in 
FDS. It was determined that the calculation of maximum heat flux according to the ASTM E457-08 [28] method is sensitive to the temperature varying heat capacity.

An uncertainty analysis using Type A and Type B components was performed on the $\mathrm{T}_{\text {cap }}$ slug at $50 \mathrm{~kW} / \mathrm{m}^{2}$ and $5 \mathrm{MW} / \mathrm{m}^{2}$ using the NIST Uncertainty Machine [25]. At a simulated heat flux of $50 \mathrm{~kW} / \mathrm{m}^{2}$ the expanded uncertainty was found to be 2.9 percent, with a coverage factor of 2, corresponding to a 95 percent confidence interval. The uncertainty at low heat flux was found to be dominated by the uncertainty in the thermocouple measurement of temperature. At a simulated heat flux of $5 \mathrm{MW} / \mathrm{m}^{2}$ the expanded uncertainty was found to be 2.0 percent, with a coverage factor 1.9 , corresponding to a 95 percent confidence interval. The uncertainty at high heat flux was found to be dominated by the uncertainty in the heat capacity of tungsten, which is a function of temperature. In addition to the uncertainty, the high heat flux analysis using FDS simulations showed a systematic error of - 8.5 percent, indicating that the heat flux calculated using equation (4) and the ASTM E457-08 approach is 8.5 percent lower than the heat flux absorbed by the surface of the sensor. The $\mathrm{T}_{\text {cap }}$ measurement results reported in the tables of this report have not been corrected for this systematic error.

The experimental uncertainty of incident energy measurements was calculated using simulated data and the NIST Uncertainty Machine, including Type A and Type B components, with a 95 percent confidence interval. The uncertainty ranges from 1.2 percent at $200 \mathrm{~kJ} / \mathrm{m}^{2}\left(50 \mathrm{~kW} / \mathrm{m}^{2}\right.$ for $\left.4 \mathrm{~s}\right)$ to 0.8 percent at $18.1 \mathrm{MJ} / \mathrm{m}^{2}\left(5 \mathrm{MW} / \mathrm{m}^{2}\right.$ for $\left.4 \mathrm{~s}\right)$. The maximum incident energy seen in the experiments was approximately $7.2 \mathrm{MJ} / \mathrm{m}^{2}\left(2 \mathrm{MW} / \mathrm{m}^{2}\right.$ for $4 \mathrm{~s}$ ), which is calculated to have an uncertainty of 0.9 percent. In addition to the aforementioned uncertainty, estimates of the heat losses to the calcium silicate portion of the $\mathrm{T}_{\text {cap }}$ sensor during simulated exposures resulted in an error of +2.1 percent at $200 \mathrm{~kJ} / \mathrm{m}^{2}$ $\left(50 \mathrm{~kW} / \mathrm{m}^{2}\right.$ for $\left.4 \mathrm{~s}\right)$ to -4.2 percent at $18.1 \mathrm{MJ} / \mathrm{m}^{2}\left(5 \mathrm{MW} / \mathrm{m}^{2}\right.$ for $\left.4 \mathrm{~s}\right)$, with -2.8 percent at $7.2 \mathrm{MJ} / \mathrm{m}^{2}\left(2 \mathrm{MW} / \mathrm{m}^{2}\right.$ for $\left.4 \mathrm{~s}\right)$. The expanded uncertainty of the incident energy over the measurement range is estimated at \pm 5 percent, with a 95 percent confidence interval, which includes the estimated error due to conduction effects. Appendix F provides additional details on the $\mathrm{T}_{\text {cap }}$ heat transfer analysis.

\subsubsection{Pressure Transducer}

Pressure measurement methods were improved from the Phase 1 experiments. First, the test laboratory changed the data link cable between the data acquisition cart (located in the test cell) and the data logging station (located in the control room) to a fiber optic cable. This greatly improved the signal to noise ratio and resistance to EMI. Secondly, a magnetic shielding alloy (Mu-metal) was used to shield the sensor. This material is a ferromagnetic alloy with a very high magnetic permeability. The material was installed around the pressure sensor between the sensor and the PVC enclosure. Lastly, piezoelectric-style pressure transducers were used instead of the strain gauge-type in Phase 1. The combination of these three changes greatly improved the electro-magnetic interference (EMI) rejection.

The assembly for measuring pressure consisted of a through-bolt that was installed in a hole drilled in the metal cladding of the electrical switchgear enclosure. A 90-degree fitting was connected to the through-bolt on one end and a pressure hose was connected to the other. The opposite end of the pressure hose was connected to the pressure transducer, which was 
housed within a white PVC tube for mechanical protection. Within the PVC tube, the Mumetal was installed. The electrical connection from the transducer exited the PVC tube and was routed to the data collection cart. Prior to the experiments, additional thermal protection was added to the electrical cable by surrounding it with ceramic fiber thermal insulation and secured with fiberglass tape. The configuration is shown in Fig. 13. Two general locations were selected. At each location, transducers of different nominal ranges were used. One ranged from $0 \mathrm{kPa}(0 \mathrm{psia})$ to $207 \mathrm{kPa}(30 \mathrm{psia})$, while the other ranged from $0 \mathrm{kPa}(0 \mathrm{psia})$ to $345 \mathrm{kPa}(50 \mathrm{psia})$. The location with pressure transducers labeled PT1 and PT2 measured pressure in the breaker cubicle, while the other location consisting of PT3 and PT4 measured the primary cable connection compartment pressure, the latter being the compartment where the arc was initiated and sustained.
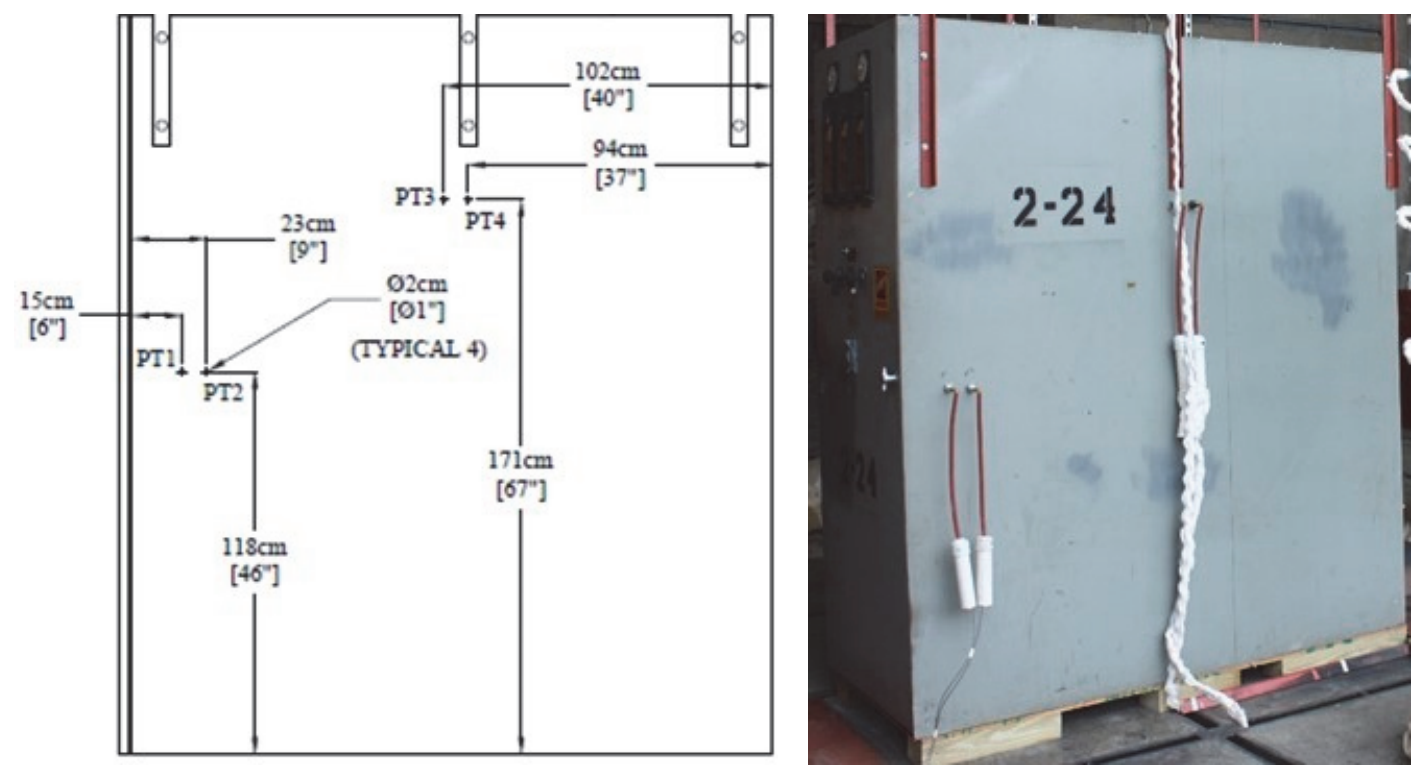

Fig. 13. Pressure Measurement Device Locations (drawing left, photo right)

\subsubsection{Photometrics}

NIST and SNL fielded numerous imaging technologies during this experimental series to provide high-speed qualitative and quantitative imaging of the HEAF experiments. The measurement methods included visible high-speed and high-definition imaging, high-speed high dynamic range visible imaging, and high-speed thermal imaging. The equipment fielded by NIST is like that used in the HEAF Phase 1 experiments [6] to capture high definition visible and high-speed thermal images. Equipment fielded by SNL was new to the program and provided photometric data that may help in defining the zone of influence and characterizing particle speed and trajectories. For this series, SNL was directed to use as many instruments as practical, and a post-experiment evaluation of the results would then determine the most useful data and allow for the scaling down of deployed technologies in subsequent experiments. Conclusions on the use of these technologies are presented in Section 4.2. 


\subsection{SNL Imaging}

SNL cameras were placed in two general locations within the test cell near the wall opposite the test device (unit) and outside the test cell approximately $21 \mathrm{~m} \mathrm{(70} \mathrm{ft),} \mathrm{as} \mathrm{shown} \mathrm{in} \mathrm{Fig.} 14$. Within the test cell, a high-speed color imager was used to capture enclosure breach evolution. Because of its location in the test cell, this camera required physical and thermal protection. A concrete block was placed between the camera and the test device, and an optical mirror was used to provide a view of the test device to the camera. Image distortion was corrected with software processing. Additionally, up to two GoPro cameras were used in the cell to provide wide-angle footage of the event. The locations of these cameras were changed between experiments, determined based on judgement and lessons learned from previous experiments. These cameras were enclosed within a protective case. 


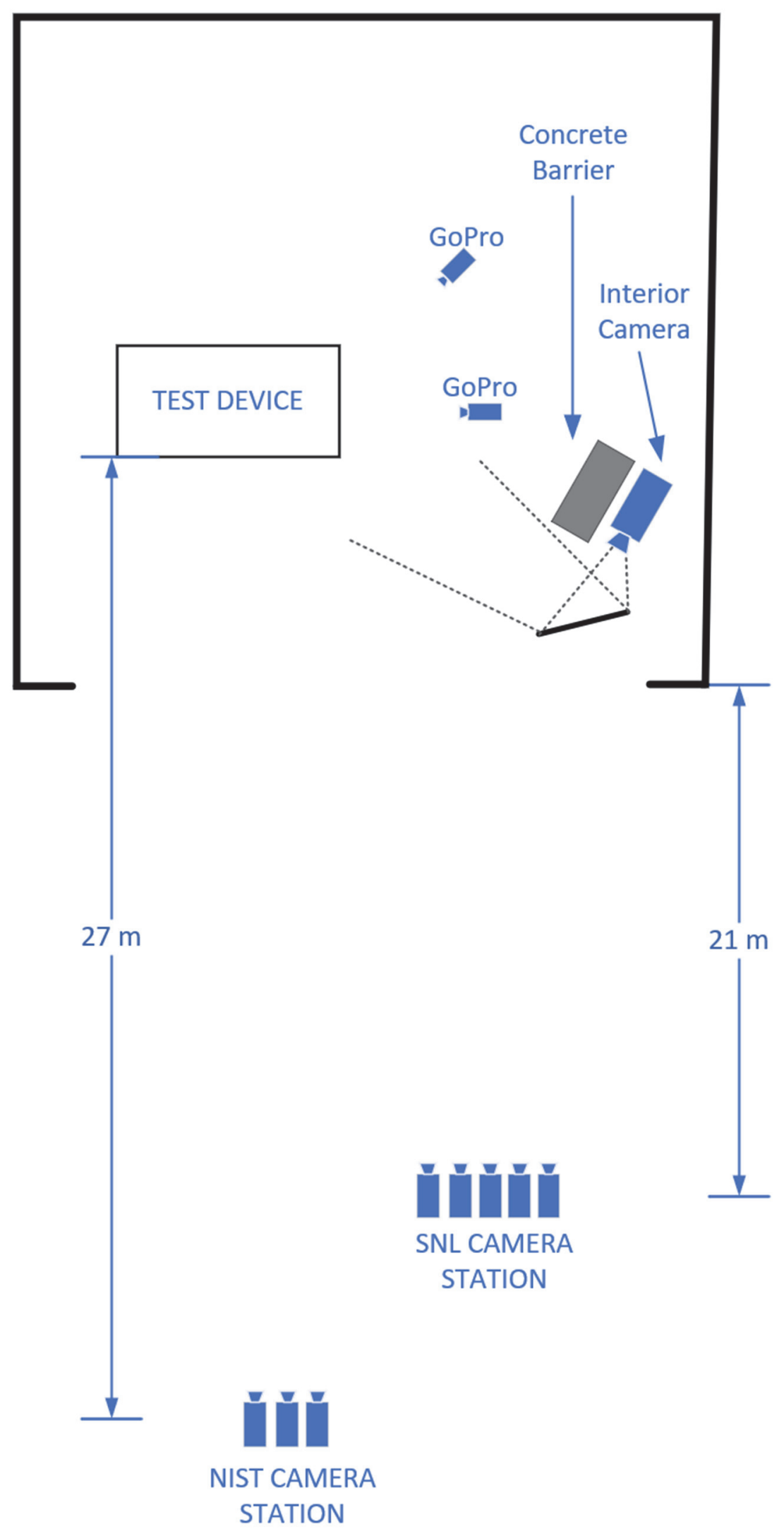

Fig. 14. NIST and SNL camera locations (not to scale) 
Five different imaging systems were used at the SNL camera station.

High-speed high dynamic range color imaging system used an array of color high-speed cameras with offset exposures to render output imagery with approximately three times the dynamic range of a traditional high-speed camera system.

High-speed 4k resolution system was used to capture the event and use the data to evaluate particle speed analysis. However, this technique experienced expanded uncertainties due to the events flashing behavior and presence of protective chain link fence.

High-speed black and white imager used high-speed imaging with a detailed view of the electrical enclosure to capture early arcing dynamics.

Short-wave high-speed thermal imaging is a temperature imaging system capable of measuring up to 1000 frames/s.

High-definition real-time Imager provided an overall view with audio.

Data collected from the fielded imagers was processed and combined to provide composite information. Examples include optical flow measurements of particle speed and thermal/visible data fusion to provide improved geometrical detail and thermal data. SNL fielded a series of imagers to evaluate existing capabilities to capture qualitative and quantitative information. SNL reports document the approach, uncertainties, and results in greater detail [30].

The processed images can be accessed from the NRC RIL website ${ }^{3}$ : https://www.nrc.gov/reading-rm/doc-collections/research-info-letters/index.html

\subsection{NIST Thermal Imaging}

For this study, the thermal imaging was performed with two main goals. The first goal was to obtain qualitative information about the development and movement of the arc, the development of plumes of hot gases and HEAF products issuing from the enclosure, the impingement of the arc jets on the targets and thermal transducers, and the penetrations formed in the enclosure. The second goal was to provide quantitative measurements of enclosure surface temperatures during and after the HEAF event.

The NIST thermal imaging video was captured with a FLIR Systems model SC6701 SLS thermal imager and $50 \mathrm{~mm}$ lens, with an F/2.5 aperture, at a rate of approximately 126 images per second $(\mathrm{Hz})$. The video capture was performed using a super-framing and dynamic range extension technique, where the imager alternates image capture between two temperature ranges (see Table 3), and software combines each pair of images into one image with an expanded temperature range. After dynamic range extension is applied, the video images are $640 \times 512$ pixels in size, covering from $-20{ }^{\circ} \mathrm{C}$ to $650{ }^{\circ} \mathrm{C}\left(-4{ }^{\circ} \mathrm{F}\right.$ to $\left.1202^{\circ} \mathrm{F}\right)$, with an effective video frame rate of approximately $63 \mathrm{~Hz}$. The spectral response of the long

${ }^{3}$ The RIL website can be accessed by visiting http://www.NRC.gov, selecting the "NRC Library" >> "Document Collections" >> "Research Information Letters". 
wave (LW) thermal imaging camera is specified as approximately $7.5 \mu \mathrm{m}$ to $9.5 \mu \mathrm{m}$. The spectral response as provided by the manufacturer is shown in Fig. 15.

Table 3. Nominal imager temperature

\begin{tabular}{|c|c|c|}
\hline Temperature Range $\left({ }^{\circ} \mathbf{C}\right)$ & Frame Rate $(\mathbf{H z})$ & Integration Time (ms) \\
\hline $\mathbf{- 2 0}$ to $\mathbf{1 5 0}$ & 125.6 & 0.1973 \\
\hline $\mathbf{1 5 0}$ to $\mathbf{6 5 0}$ & 125.6 & 0.0181 \\
\hline
\end{tabular}

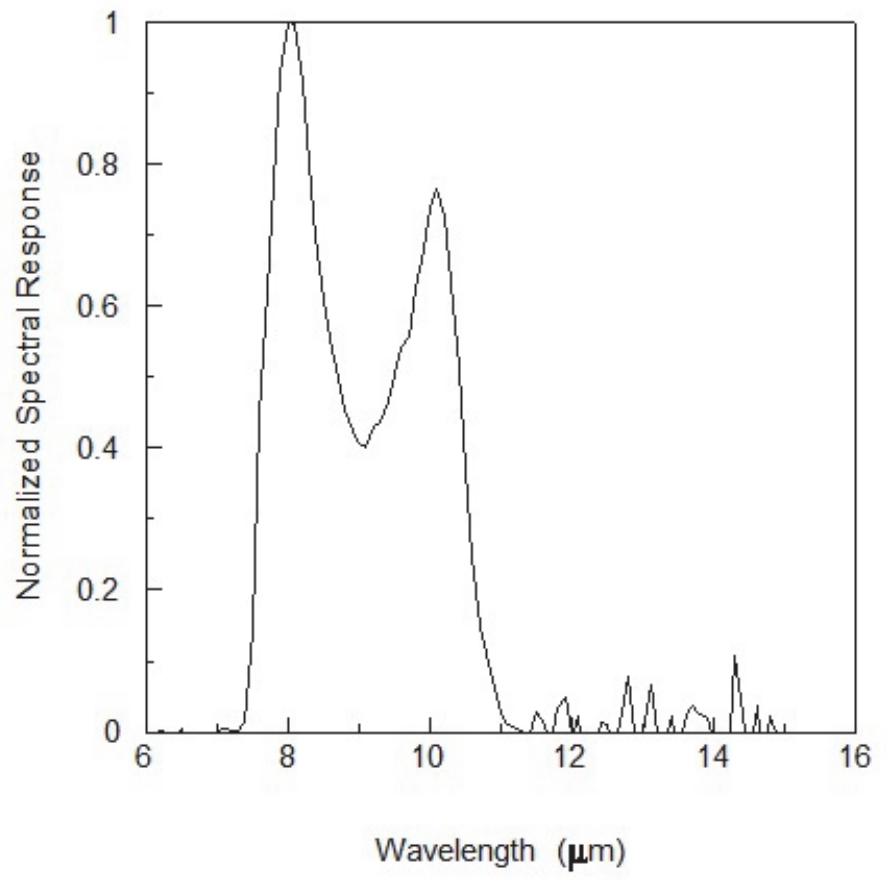

Fig. 15. Spectral response of imager.

Post-HEAF photos show that the steel enclosure areas of interest were primarily covered with paint or oxidized paint. Small regions of oxidized steel were present surrounding the penetrations formed by melting of the exterior cladding of the enclosure. Data from the thermal imager manufacturer and the literature [31,32], report the total emissivity of oxidized iron and steel between $25^{\circ} \mathrm{C}$ and $600{ }^{\circ} \mathrm{C}\left(77^{\circ} \mathrm{F}\right.$ to $\left.1112^{\circ} \mathrm{F}\right)$ as approximately 0.80 . The same sources report the total emissivity and LW emissivity of green, grey, and various colored painted surfaces from approximately $0{ }^{\circ} \mathrm{C}$ to $100{ }^{\circ} \mathrm{C}\left(32^{\circ} \mathrm{F}\right.$ to $\left.212^{\circ} \mathrm{F}\right)$ as approximately 0.94 . It is assumed that blackened and charred paint has an emissivity in the same range.

The thermal images were captured assuming a target emissivity of 1.0, then post-processed at an emissivity of 0.94 to better represent the painted surfaces of the enclosure. The thermal images and video include a temperature legend to correlate image color with temperature. Linear scaling is used so that temperatures values can be interpolated between the labeled temperature divisions. The image coloration rescales during the experiment as the minimum and maximum temperatures in the field of view change. Objects with temperatures greater than the upper calibration limit of $650{ }^{\circ} \mathrm{C}\left(1202^{\circ} \mathrm{F}\right)$ are shown as salmon-colored areas in the 
legend and the image. Imposing the upper limit decreases qualitative image quality but is necessary for identification of the out-of-range areas of the images. An example image is presented in Fig. 16. The NIST thermal images and video can be accessed from the NRC website ${ }^{4}$ : https://www.nrc.gov/reading-rm/doc-collections/research-info-letters/index.html

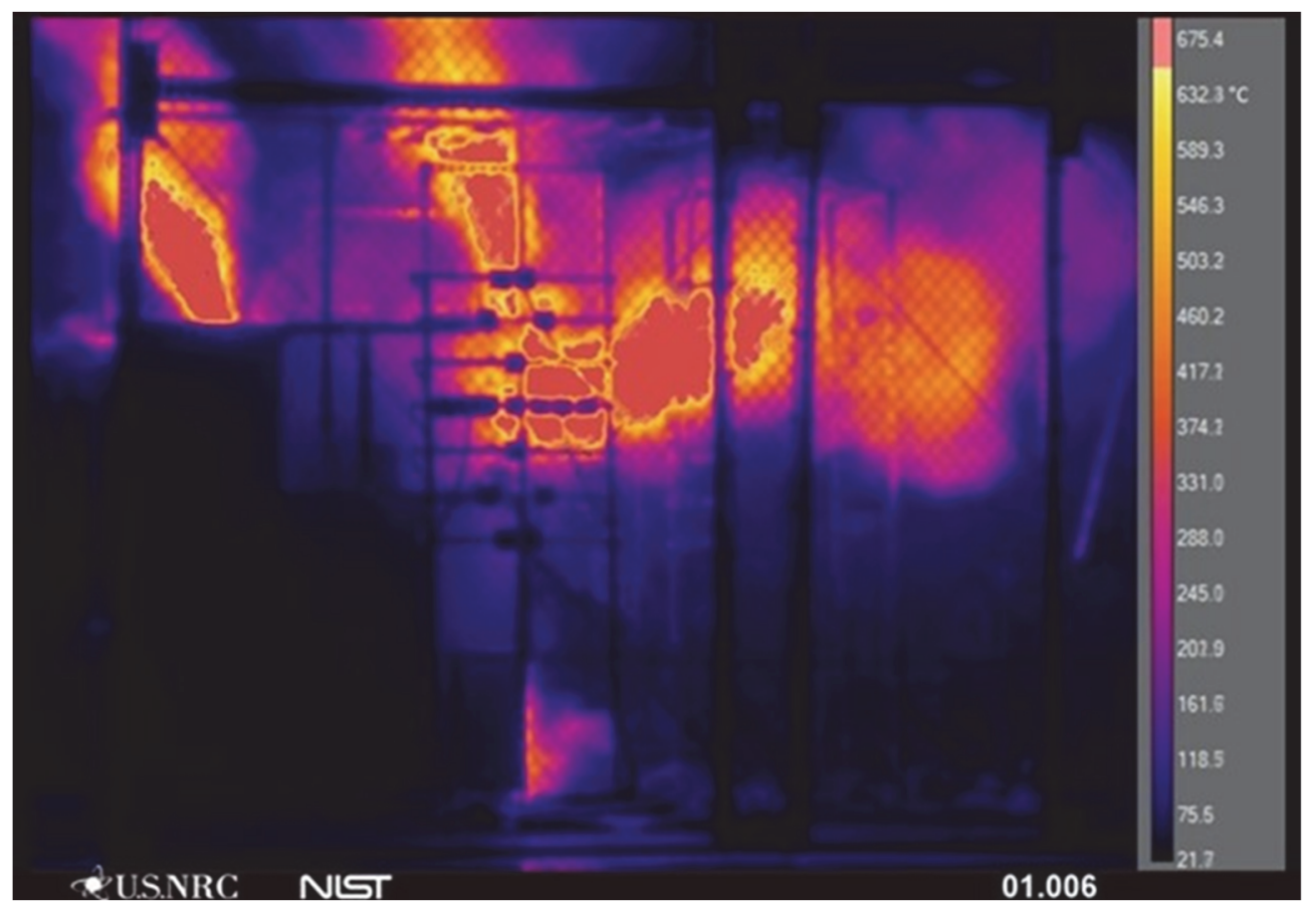

Fig. 16. Example thermal image from Test 2-19

The uncertainty of the thermal imager temperature measurements was determined assuming that the radiation incident on the detector was emitted from the painted surfaces and oxidized steel, and free of reflections from surrounding sources such as the sun, flames, HEAF jets, etc. and approximates a thermally gray surface. The greatest contributors to the uncertainty are expected to be the capabilities of the imager and the variation in the reported values of emissivity. These uncertainties are summarized in Table 4 . The expanded uncertainty is determined from Type B methods [19, 20, 21], including thermal imager manufacturer data and target emissivity values, and calculated using the NIST Uncertainty Machine [25].

\footnotetext{
${ }^{4}$ The RIL website can be accessed by visiting http://www.NRC.gov, selecting the "NRC Library" >> "Document Collections" >> "Research Information Letters".
} 
Table 4. Uncertainty components used to determine expanded uncertainty

\begin{tabular}{|l|ll|l|l|}
\hline $\begin{array}{l}\text { Uncertainty } \\
\text { source }\end{array}$ & $\begin{array}{l}\text { Temperature } \\
\text { Range }\left({ }^{\circ} \mathbf{C}\right)\end{array}$ & $\begin{array}{l}\text { Standard } \\
\text { Deviation (SD) } \\
\text { or range }\end{array}$ & $\begin{array}{l}\text { Uncertainty } \\
\text { Distribution }\end{array}$ & Notes \\
\hline IR Imager & -20 to 650 & $\begin{array}{l}\text { SD greater of } \\
\pm 0.67^{\circ} \mathrm{C} \text { or } \\
\pm 0.67 \%\end{array}$ & Gaussian & $\begin{array}{l}\text { Manufacturer } \\
\text { calibration data }\end{array}$ \\
\hline $\begin{array}{l}\text { Emissivity of } \\
\text { Oxidized } \\
\text { Steel }\end{array}$ & 25 to 600 & $\begin{array}{l}\text { Mean: } 0.80 \\
\text { Range: } 0.78 \text { to } \\
0.82\end{array}$ & Rectangular & Total emissivity \\
\hline $\begin{array}{l}\text { Emissivity of } \\
\text { Paint }\end{array}$ & 0 to 100 & $\begin{array}{l}\text { Mean: } 0.94 \\
\text { Range: } 0.92 \text { to } \\
0.96\end{array}$ & Rectangular & $\begin{array}{l}\text { Total and long } \\
\text { wave emissivity }\end{array}$ \\
\hline
\end{tabular}

The thermal video was post-processed assuming an overall emissivity of 0.94 , and the expanded uncertainty in the temperature of the painted steel surfaces is $\pm 2.6{ }^{\circ} \mathrm{C}$ at $100{ }^{\circ} \mathrm{C}( \pm$ $4.7^{\circ} \mathrm{F}$ at $\left.212^{\circ} \mathrm{F}\right)$ and $\pm 10.5^{\circ} \mathrm{C}$ at $650{ }^{\circ} \mathrm{C}\left( \pm 18.9^{\circ} \mathrm{F}\right.$ at $\left.1202^{\circ} \mathrm{F}\right)$. The uncertainty analysis also provides the approximate relative contributions of the uncertainty components on the expanded uncertainty in the temperature measurement. The expanded uncertainty is shown in Table 5.

Table 5. Expanded uncertainty for IR imager temperatures

\begin{tabular}{|l|l|l|l|l|l|l|}
\hline Surface & $\begin{array}{l}\text { Mean } \\
\text { Emissivity }\end{array}$ & $\begin{array}{l}\text { Temperature Uncertainty Confidence } \\
\left({ }^{\circ} \mathbf{C}\right)\end{array}$ & $\begin{array}{l}\text { Coverage } \\
\text { Factor }\end{array}$ & $\begin{array}{l}\text { Approximate } \\
\text { Uncertainty } \\
\text { Contribution }\end{array}$ \\
\hline Paint & 0.94 & 100 & \pm 2.6 & $95 \%$ & 1.7 & $\begin{array}{l}\text { Imager: } 30 \% \\
\text { Emissivity: } 70 \%\end{array}$ \\
\hline Paint & 0.94 & 650 & \pm 10.5 & $95 \%$ & 1.9 & $\begin{array}{l}\text { Imager: } 70 \% \\
\text { Emissivity: } 30 \%\end{array}$ \\
\hline $\begin{array}{l}\text { Oxidized } \\
\text { Steel }\end{array}$ & 0.80 & 100 & \pm 3.0 & $95 \%$ & 1.8 & $\begin{array}{l}\text { Imager: } 20 \% \\
\text { Emissivity: } 80 \%\end{array}$ \\
\hline $\begin{array}{l}\text { Oxidized } \\
\text { Steel }\end{array}$ & 0.80 & 650 & \pm 11.1 & $95 \%$ & 1.9 & $\begin{array}{l}\text { Imager: } 65 \% \\
\text { Emissivity: } 35 \%\end{array}$ \\
\hline
\end{tabular}

The thermal video and video snapshot images shown in this report are based on a global emissivity of 0.94 , which is a good match for the painted areas of the image. For the areas with an emissivity of approximately 0.80 , such as the oxidized areas of the steel electrical enclosure after the HEAF event, there will be a systematic error in the measurement that under-report the temperatures of the oxidized steel surfaces. 


\subsubsection{Videography}

The evolution of each experiment was documented with stationary high-definition video cameras. Cameras from SNL and NIST were deployed at numerous locations (as shown in Fig. 17 and Fig. 18). Not every camera view was provided in every experiment due to the limited viewing angles available within the test cell. The NIST high-definition video and images can be accessed from the NRC website ${ }^{5}$ : https://www.nrc.gov/reading-rm/doccollections/research-info-letters/index.html

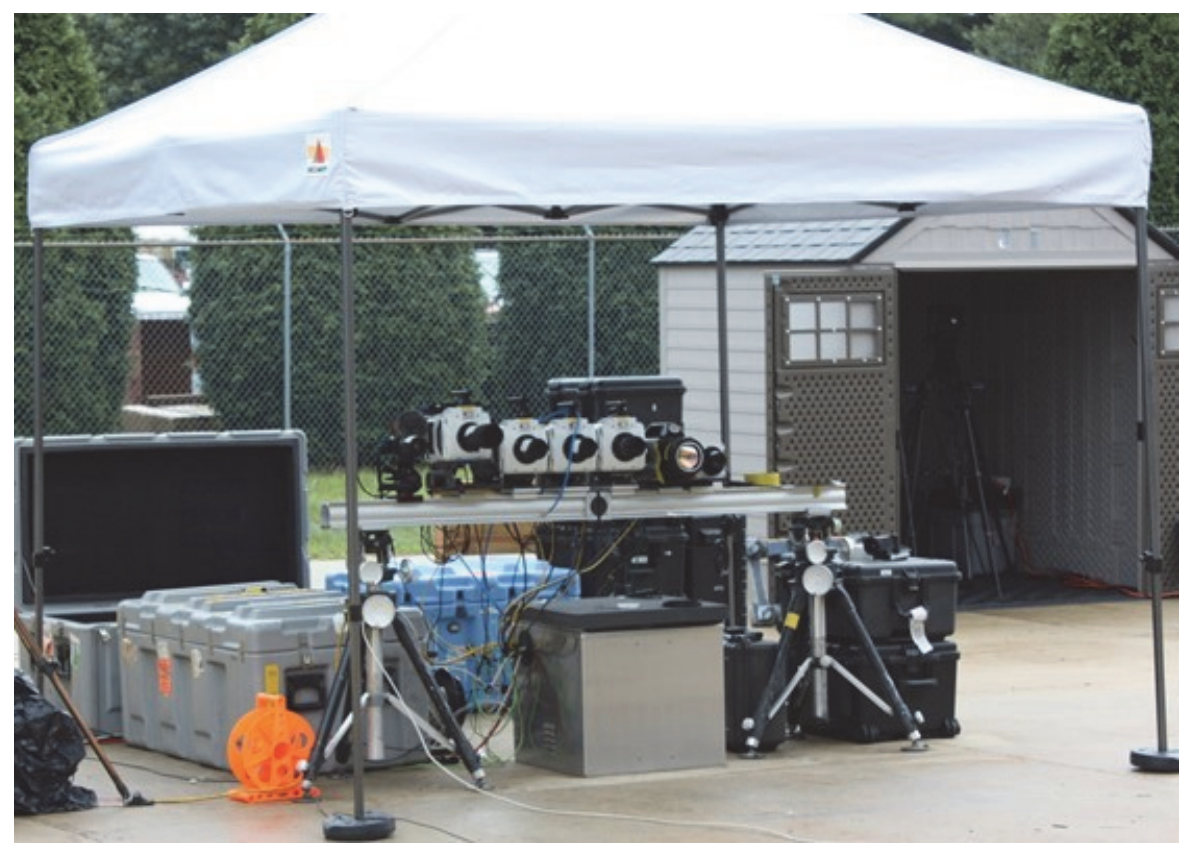

Fig. 17. Camera array located in courtyard. Front tented cameras fielded by SNL. Back shelter camera fielded by NIST.

${ }^{5}$ The RIL website can be accessed by visiting http://www.NRC.gov, selecting "NRC Library" >>

"Document Collections" >> "Research Information Letters". 


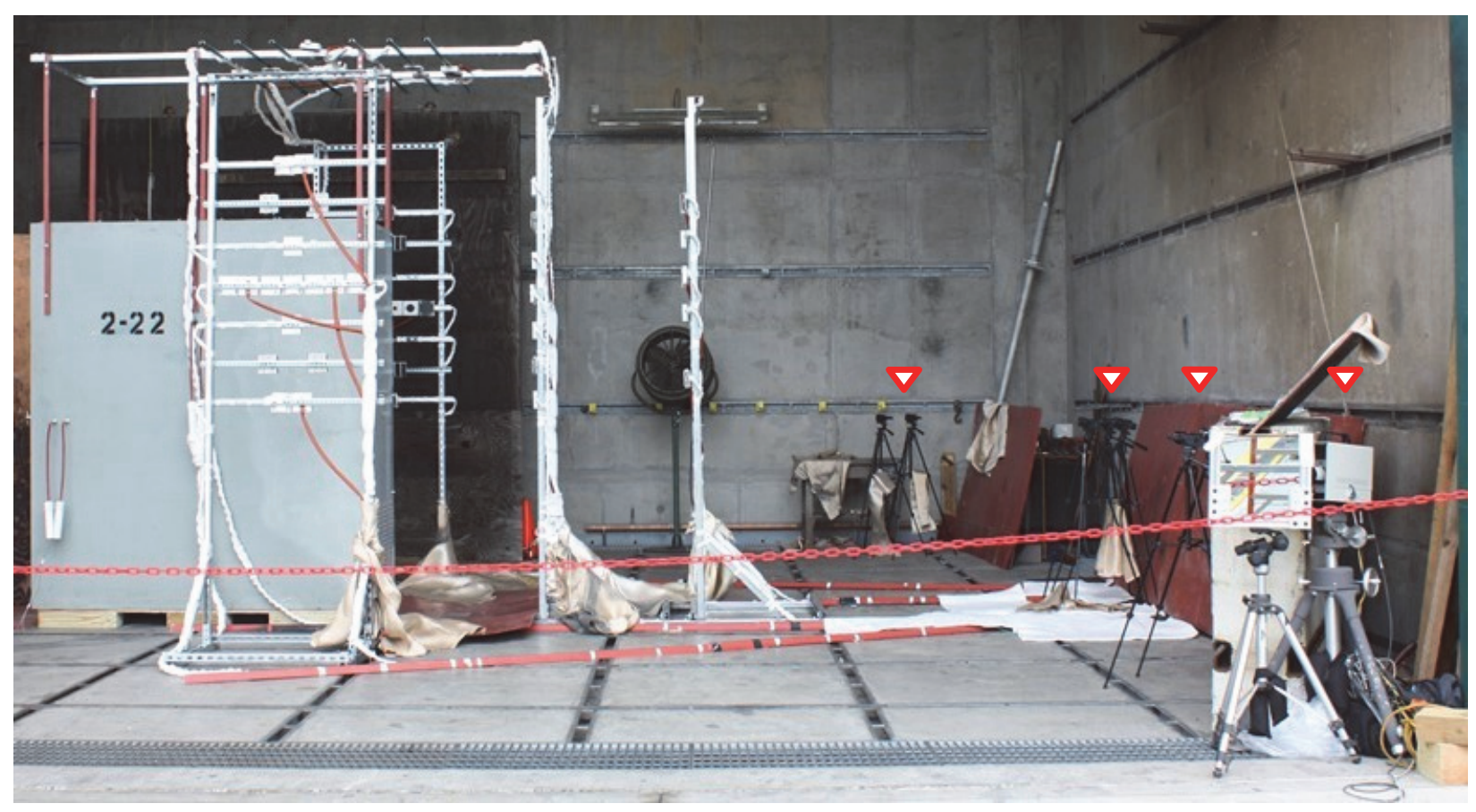

Fig. 18. Camera locations within cell identified with triangles

\subsubsection{Particulate characteristic measurements}

Two types of particle collection devices were deployed during this experimental series to provide redundant and diverse means to collect the particles and preserve the particle characteristics for subsequent analysis. Particles were collected on carbon tape and aerogel collectors for all experiments documented in this report. Photos of each device collection apparatus are shown in Fig. 19. The black carbon tape is a double-sided tape that allows for its placement on a short section (approximately $5 \mathrm{~cm}$ [2 in.]) of DIN rail. The short DIN rail is attached to a horizontal DIN rail on an instrumentation rack. During the experimental setup in the test cell, the protective covering on one side of the tape is removed and the tape is adhered to the short DIN rail. Just prior to performing the HEAF experiment, the front protective cover is removed from the tape, exposing the black carbon surface. After the experiment, the short DIN rail section is removed from the horizontal rail with the tape remaining attached and placed into a storage device. The aerogel was placed in a specimen holder constructed of two short sections of DIN rail that were aligned opposing each other. Two slots were used for mounting this assembly to the horizontal DIN rail on an instrumentation rack. On one side of the assembly, a circular hole was drilled. The aerogel is sandwiched between the two DIN rail sections and the hole allows for direct particle transport, impingement, and collection in the aerogel. After the experiment, the aerogel is removed from the holder and placed in a storage container, protecting the sample for subsequent analysis. 

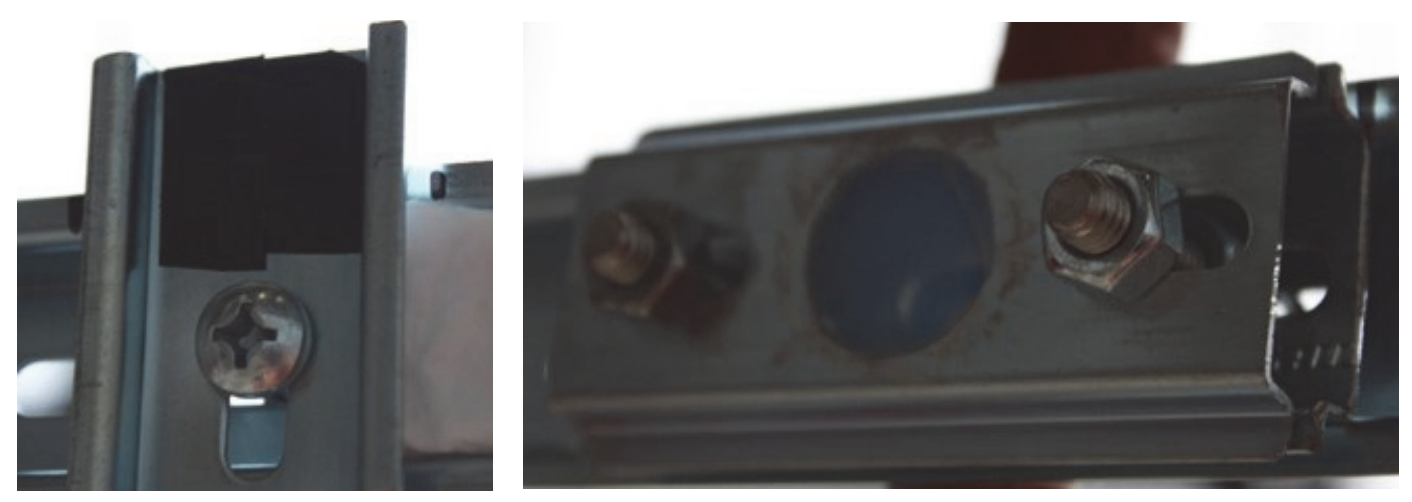

Fig. 19. Photo of carbon tape (left), and aerogel (right) particle collection apparatus

Particles were collected to quantify evolved particle sizes and chemical composition. The rack geometry is described below in Section 2.4.2. Racks 1,2, 4 and 5 were located approximately $92 \mathrm{~cm}$ [36 in] from the enclosure surface surrounding the test device. Rack 3 was behind Rack 2 and located approximately $183 \mathrm{~cm}$ [72 in] from the surface of the test device. The choice of location for sampling was based on several factors. There was a desire to ensure particle characterization at the same radial location as the active measurement devices (heat flux and incident energy gauges). The number of sample locations was relatively high due to the low cost of these devices and uncertainty about the arc progression and areas where particle data would be of interest. Most racks contained four black carbon tape devices, and two to four aerogel collection devices. On each rack there were locations where the black carbon tape and the aerogel samples were located adjacent to each other to allow for direct comparison between the two sampling methods. Postexperiment analysis indicated that both samples provided clean and consistent particle capture. Due to its relative ease, black carbon tape is the recommended method of particle capture for future experiments.

Following the experiments, scanning electron microscopy (SEM) and energy dispersive spectroscopy (EDS) were used to characterize evolved particle sizes collected and EDS spectra, including peak intensities of metal species (i.e., aluminum, iron, lead) and oxygen. Standard samples of unoxidized bus bar alloys and commercial polycrystalline aluminum oxide ceramic were also collected as baselines for unoxidized aluminum and fully oxidized aluminum, respectively. As shown in Fig. 20, fully oxidized aluminum oxide ceramic displayed an aluminum-to-oxygen peak ratio of approximately 1.04:1, which was utilized to estimate relative degree of evolved aluminum particle oxidation. 


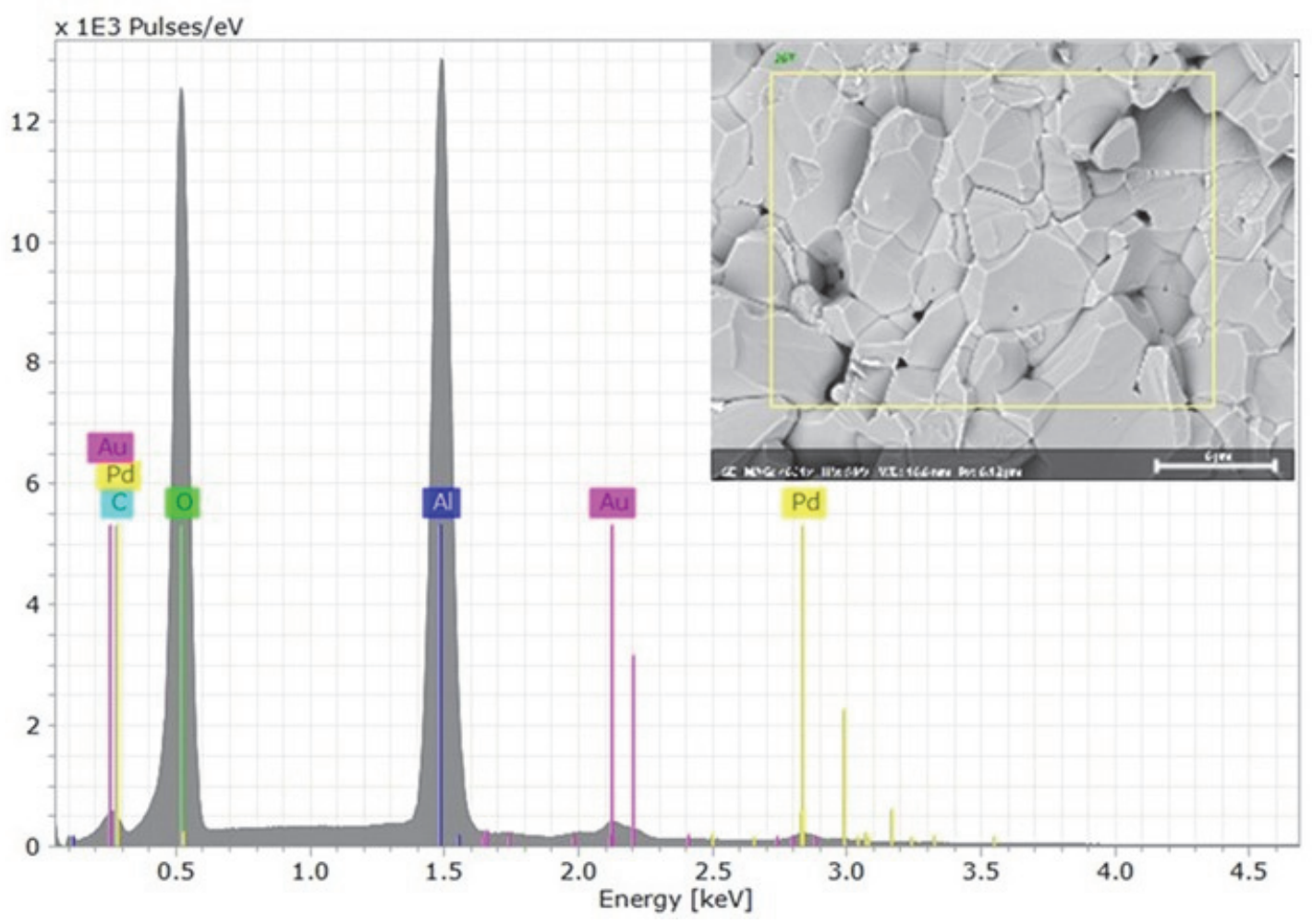

Fig. 20. Energy Dispersive Spectroscopy of commercial CoorsTek aluminum oxide. The peak ratio of fully oxidized aluminum was approximately $\mathrm{Al}: \mathrm{O}=1.04: 1$.

Collection of particles on carbon tape enabled imaging and quantification of particles without conductive overcoating, whereas samples collected on silica aerogels would require carbon, gold-palladium or other conductive overcoating to minimize sample charging for accurate imaging. As mentioned previously, the experiments were over sampled due to the uncertainty on the progression of the experiment with respect to the arc jet external to the enclosure. Processing all the collected samples is not reasonable due to the level of effort required. As such, the samples were analyzed to understand any variations among the sampling locations within an experiment and variations between experiments. For this approach, Test 2-21 (4 s arc, $25 \mathrm{kA}$ ) was selected as the experiment where samples from each instrument rack were analyzed. For the other three experiments, only samples from Rack 3 $(1.83 \mathrm{~m}[6 \mathrm{ft}])$ from the rear of the enclosure were analyzed.

In prior lab scale arc experiments conducted at a nominal $6.9 \mathrm{kV}$, particle characterization was discussed in detail [2]. Two particle types were identified: small size particles (10 $\mathrm{nm}$ to $50 \mathrm{~nm}$ particle size) which appeared to be fully oxidized (Al:O ratio near 1:1) and larger $2 \mu \mathrm{m}$ to $25 \mu \mathrm{m}$ particle size aluminum spheres, which appeared to be 10 percent to 70 percent oxidized (Fig. 21). The latter particles appeared consistent with melted aluminum droplets, viewed by high-speed videography and particle tracking, which were entrained in an arc jet, ejected from the arc, and solidified before collection. Surface features of these large particles displayed dendritic microstructures consistent with a history of melting (Fig. 21 , top row). The finer, nanoscale aluminum oxide particles collected appeared be consistent with aluminum that had been heated to evaporation and condensed as aluminum oxide nanoparticles. Similar analysis techniques were applied to the full-scale HEAF experiments, 
and discussion of particle sizes and relative degrees of oxidation that were collected for Test 2-24 are described in more detail in Section 3.2.2.4.

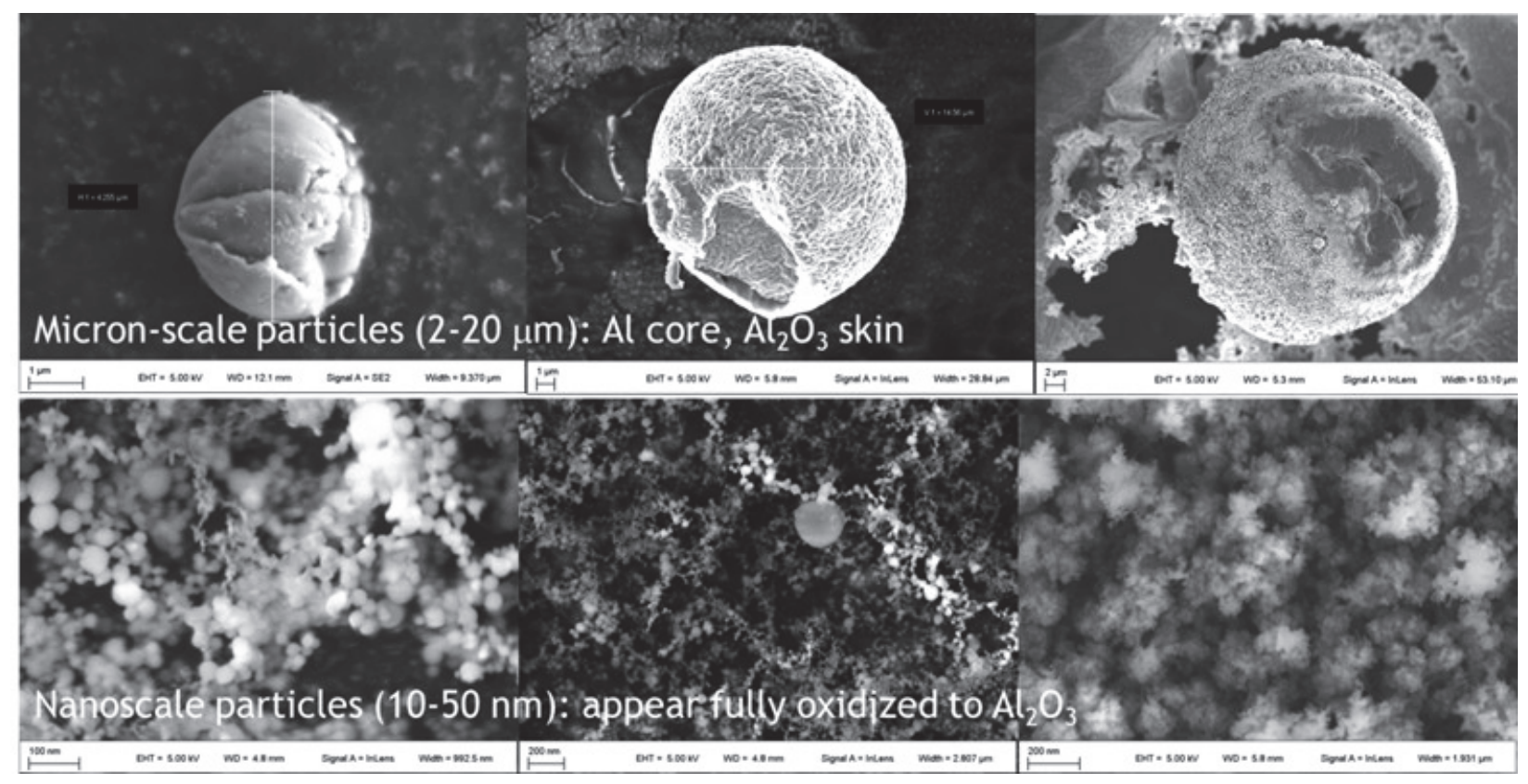

Fig. 21. SEM images of bimodal particle sizes observed from aluminum bus bar HEAF particle collection: $2 \mu \mathrm{m}$ to $20 \mu \mathrm{m}$ scale aluminum particles (top) and $10 \mathrm{~nm}$ to $50 \mathrm{~nm}$ scale aluminum oxide particles (bottom).

\subsubsection{Cable Samples}

Cable samples (coupons) were provided in every experiment as a passive indication of thermal damage. The inclusion of cable samples was highly recommended by stakeholders during the April 2018 public workshop [35].

The cable coupons were constructed using six or eight segments of cable, approximately $100 \mathrm{~mm}$ (4 in) long. The cables were affixed to a square piece of fiberglass reinforced cement board ("Durock ${ }^{\mathrm{TM}}$ "), measuring approximately $100 \mathrm{~mm}$ (4 in) square and nominally $13 \mathrm{~mm}(0.5 \mathrm{in})$ thick, using steel wire protected with a glass braid sheath. The wire was also used to connect the cable coupon to the horizontal steel DIN rail. Descriptions and specifications of the cables are listed in Table 6 and Table 7. Face and side views of a typical cable coupon are presented in Fig. 22 and Fig. 23. Photographs of the cable coupons were taken before and after every experiment, and are shown in Appendix D. 
Table 6. Manufacturers' descriptions of the cables used in the experiments.

\begin{tabular}{|c|c|c|c|c|}
\hline $\begin{array}{l}\text { Cable } \\
\text { No. }\end{array}$ & Source & Manufacturer & Date & Cable Markings \\
\hline 900 & Purchased & Lake Cable & 2015 & $\begin{array}{l}\text { \#2582 FT. TPT127 LAKE CABLE 12AWG 7C } \\
\text { PE/PVC2010 CONTROL CABLE 600V } 75^{\circ} \text { C } 2015 \\
\text { "ROHS } 11 \text { " REACH MADE IN USA } 280547\end{array}$ \\
\hline 902 & TVA & $\begin{array}{l}\text { Cyprus Wire \& } \\
\text { Cable }\end{array}$ & 1975 & $\begin{array}{l}3460 \text { FEET CYPRUS WIRE \& CABLE 75K/-8615U-1 } \\
\text { PJJ-600 3/C \#14 } 1975\end{array}$ \\
\hline \multicolumn{5}{|c|}{$\begin{array}{l}\text { \#ote that the CAROLFIRE \# refers to the number assigned to that particular cable during the } \\
\text { CAROLFIRE program [36] }\end{array}$} \\
\hline
\end{tabular}

Table 7. Nominal cable properties.

\begin{tabular}{|c|c|c|c|c|c|c|c|c|c|c|c|c|}
\hline $\begin{array}{l}\dot{z} \\
\frac{0}{0} \\
\frac{\tilde{J}}{\tilde{J}}\end{array}$ & 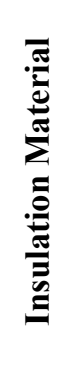 & 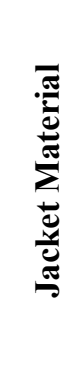 & $\begin{array}{l}\dot{\dot{v}} \\
\frac{\hat{\sigma}}{U}\end{array}$ & 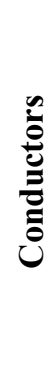 & 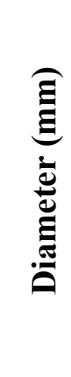 & 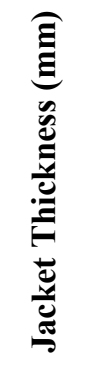 & 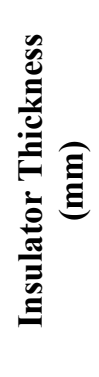 & 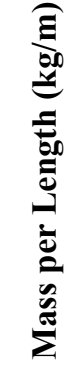 & 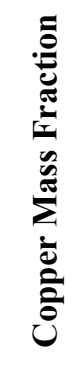 & 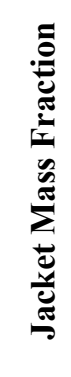 & 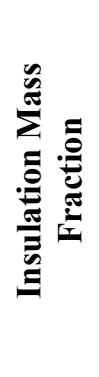 & 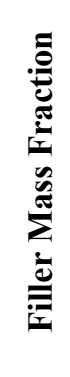 \\
\hline 900 & $\mathrm{PE}$ & PVC & $\mathrm{TP}$ & 7 & 15.9 & 1.85 & 1.07 & 0.38 & 0.55 & 0.27 & 0.10 & 0.08 \\
\hline 902 & $\mathrm{PE}$ & PVC & $\mathrm{TP}$ & 3 & 10.0 & 1.32 & 1.09 & 0.13 & 0.42 & 0.36 & 0.10 & 0.12 \\
\hline
\end{tabular}




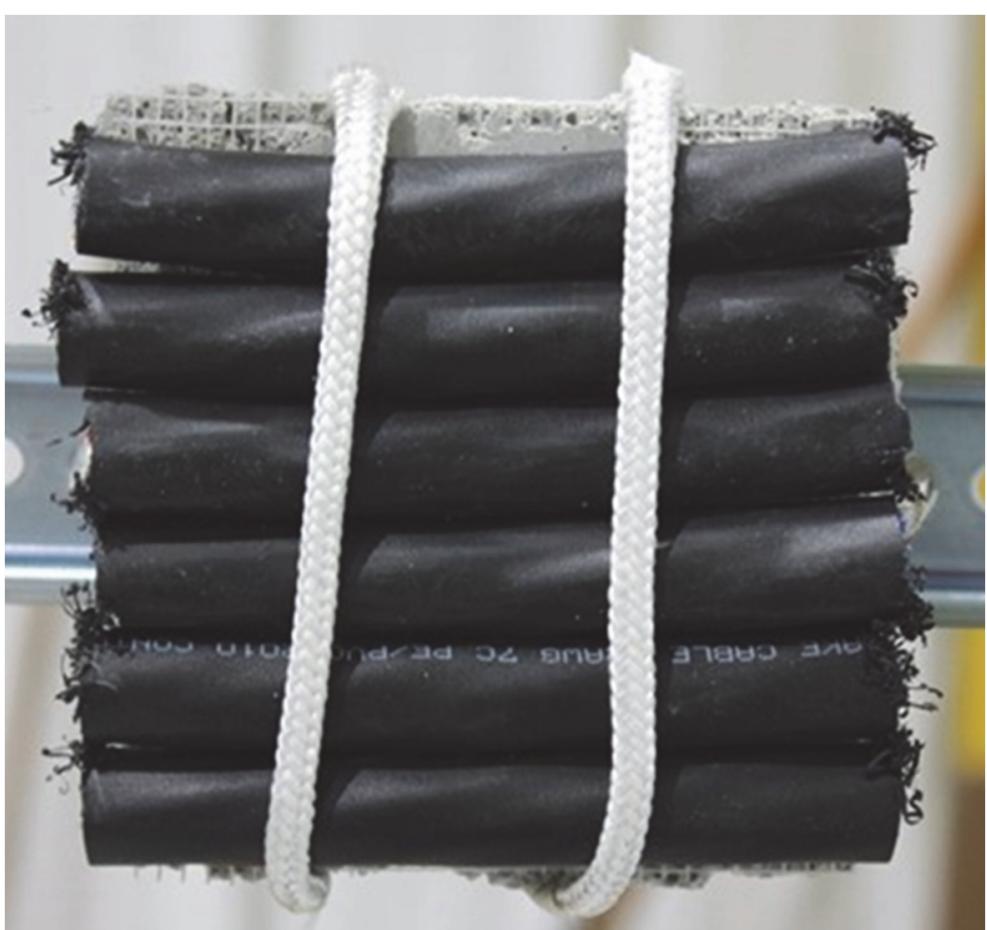

Fig. 22. Cable coupon constructed of seven conductor PE / PVC control cable (Cable 900). Front view.

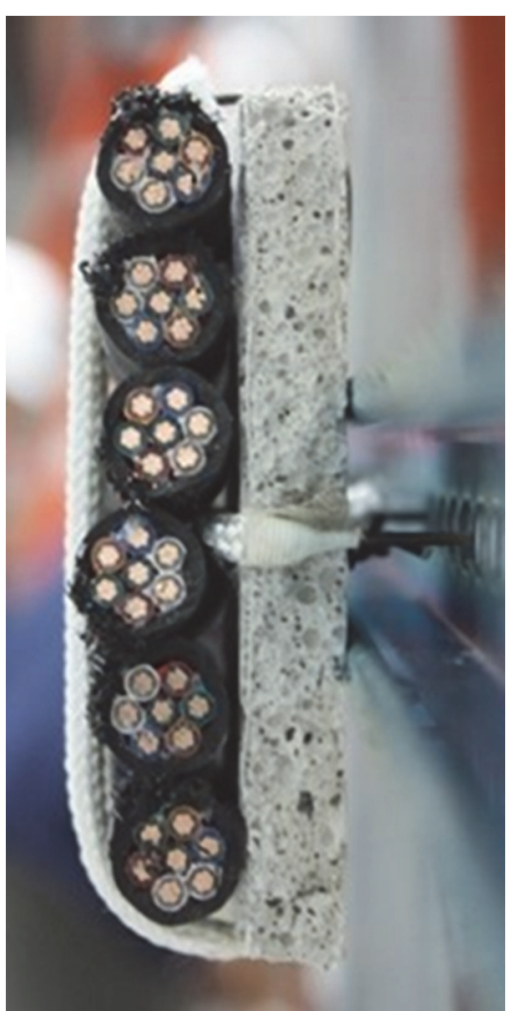

Fig. 23. Cable coupon constructed of seven conductor PE / PVC control cable (Cable 900). Side view. 


\subsubsection{Data Acquisition System}

The NIST data acquisition system used a combination of shielding, grounding, isolation, and system configuration that reduced the impact of electromagnetic interference (EMI), as shown in Fig. 24. This data acquisition system was used for the NIST plate thermometer and $\mathrm{T}_{\text {cap }}$ instruments and is described in the literature $[6,13]$. Data acquisition systems for use in arc flash measurements have also been described in the literature by others [34]. The NIST data acquisition system was improved for Phase 2 by incorporating non-multiplexed data acquisition, so that each data channel has a dedicated analog to digital converter in addition to a dedicated isolation transformer. This approach was found to reduce measurement errors when an adjacent data channel over-ranged or became an open circuit due to extreme thermal conditions. The isolation module components were housed in two audio equipment rack mount shipping cases along with power supplies and uninterruptable power supplies, one for each half of the data channels. The data acquisition system components were also housed in two audio equipment rack mount shipping cases along with power supplies and uninterruptable power supplies, one for each half of the data channels. All the equipment, including the power supply isolation transformers and data recording PC, was operated in an air-conditioned van parked next to the test cell.

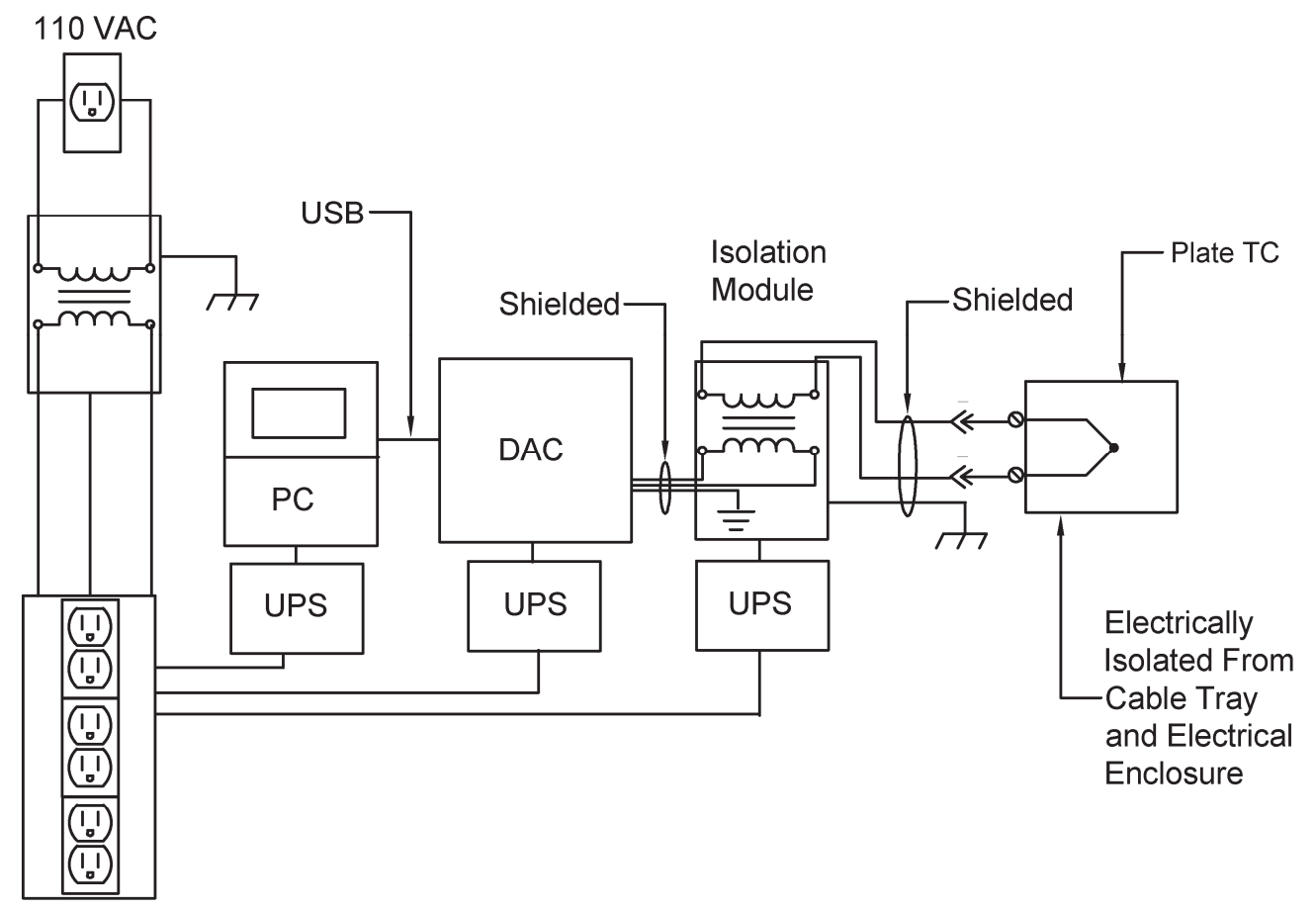

Fig. 24. Data Acquisition System Configuration with EMI rejection

The data acquisition process involved starting the data recording prior to the experiment and stopping after the experiment. Due to the system being located outside of the main control room, the acquisition was manually started, and the operator traveled to the control room for safety. After the experiment was complete and deemed safe for travel back to the data acquisition location, the operator would travel back to the system and stop the recording. Due to the safety procedures, there is significant pre-experiment and post-experiment data 
recorded. Since the KEMA trigger signal was acquired via the DAQ system, the actual start of the experiment was post processed and the time was adjusted to set the experiment time zero to the actual start of the experiment. For transparency, the DAQ time and experiment time have been reported for each experiment. The difference between these two-time stamps is the time delay between starting the DAQ recording and the start of the experiment. This time delay will be different for each experiment. In addition, the pre- and post-experiment data has been preserved in the data files for purity.

\subsubsection{Other reported test information}

Atmospheric conditions are reported for each experiment, including temperature and humidity.

The equipment test samples were weighed before and after each experiment to obtain mass loss information associated with the vaporization of the bus bars through arcing. A summary of this information is provided for each experiment and complete details are provided in Appendix C.

\subsubsection{Instrument Deployment}

The majority of the thermal instrumentation devices were located on instrument racks with the face of the instrument located approximately $0.91 \mathrm{~m}(3.00 \mathrm{ft})$ from the exterior of the metal clad enclosure. One additional instrument rack (Rack 3 ) was located approximately $1.83 \mathrm{~m}(6.00 \mathrm{ft})$ from the expected arc breach side of the electrical enclosure. Rack 3 had a different physical distribution of sensors to prevent shadowing from the sensors located on the instrument rack located between it and the electrical enclosure. Thus, Rack 3 has a slightly different sensor layout than Racks 1, 2, and 4. An instrumentation rack was also located above the electrical enclosure. This instrumentation rack (Rack 5) was secured to the electrical enclosure with 90-degree angle red GPO-3 board (glass reinforced thermoset polyester) and nominal $1 / 4$ in-20 fasteners. The sensors on Rack 5 are located approximately $0.91 \mathrm{~m}(3.00 \mathrm{ft})$ from the top of the enclosure metal cladding. This instrumentation rack configuration is shown in Fig. 25. Details of the instrument location are shown in Fig. 27 through Fig. 34, with a photograph showing the instrumentation racks around the test device during setup in Fig. 35. The expanded uncertainty in the measurement of the distances from the instrumentation racks to the electrical enclosure is $\pm 13 \mathrm{~mm}(0.5 \mathrm{in})$ with a coverage factor of 2 and an estimated confidence interval of 95 percent. 


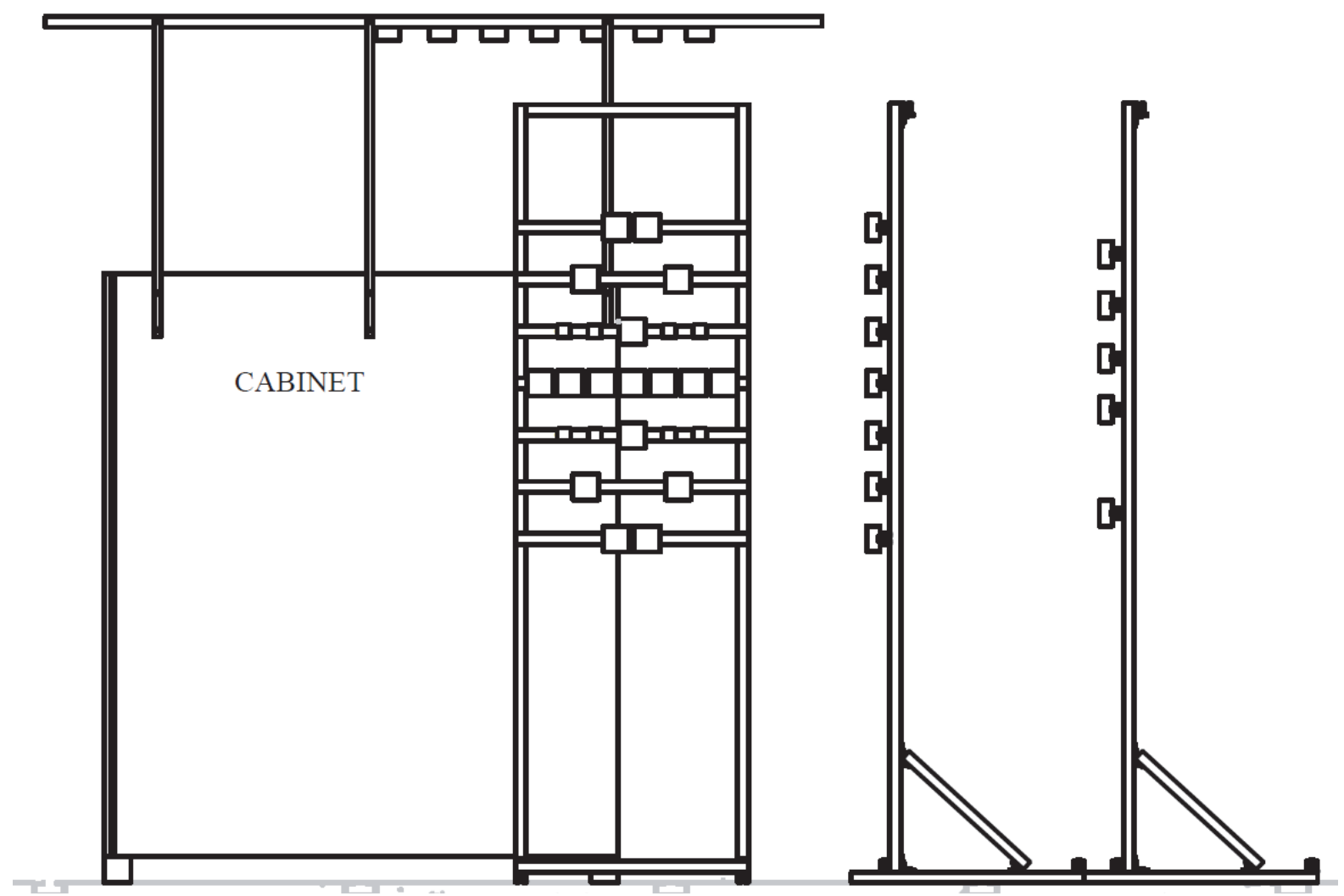

Fig. 25. Elevation view of instrument rack configuration around electrical enclosure. 


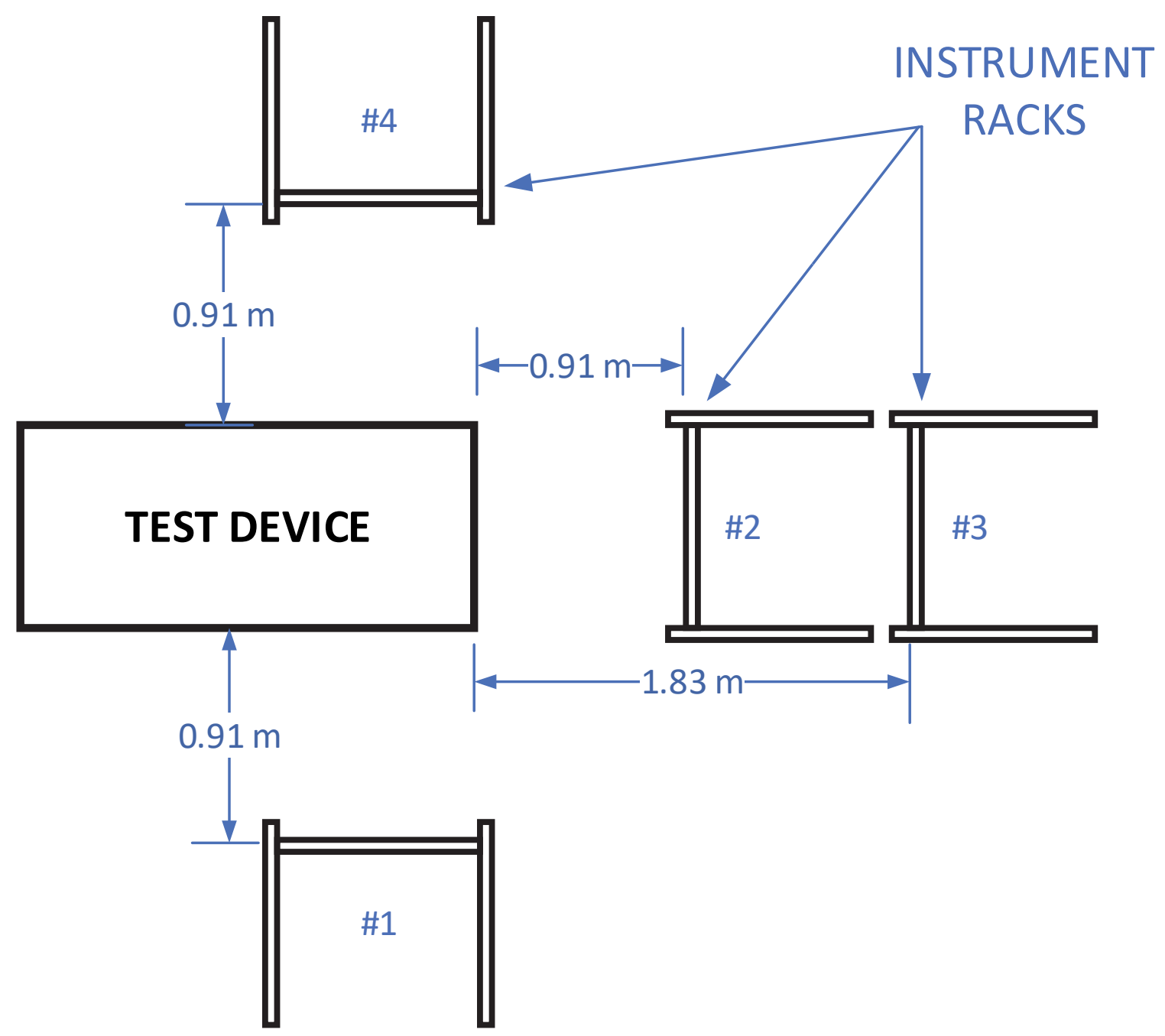

Fig. 26. Plan view of instrument rack configuration around electrical enclosure. The enclosure is approximately $0.927 \mathrm{~m}$ (36.5 in) wide, $2.019 \mathrm{~m}$ (79.5 in) deep, and $2.286 \mathrm{~m}$ (90.0 in) tall. 

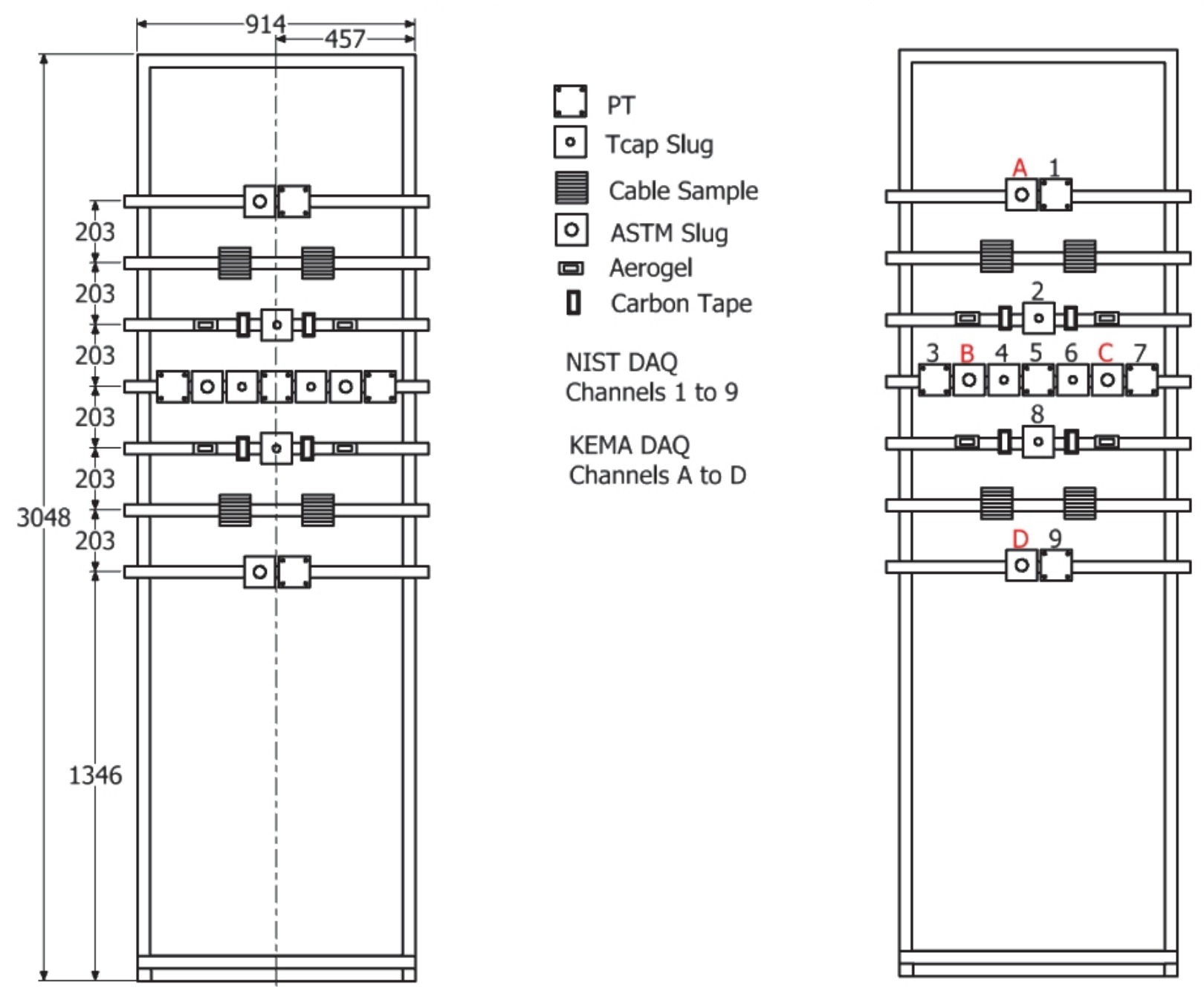

Fig. 27. Illustration of Vertical Instrumentation Rack 1 with data acquisition channels. Dimensions in $\mathrm{mm} \pm 5 \mathrm{~mm}$. 

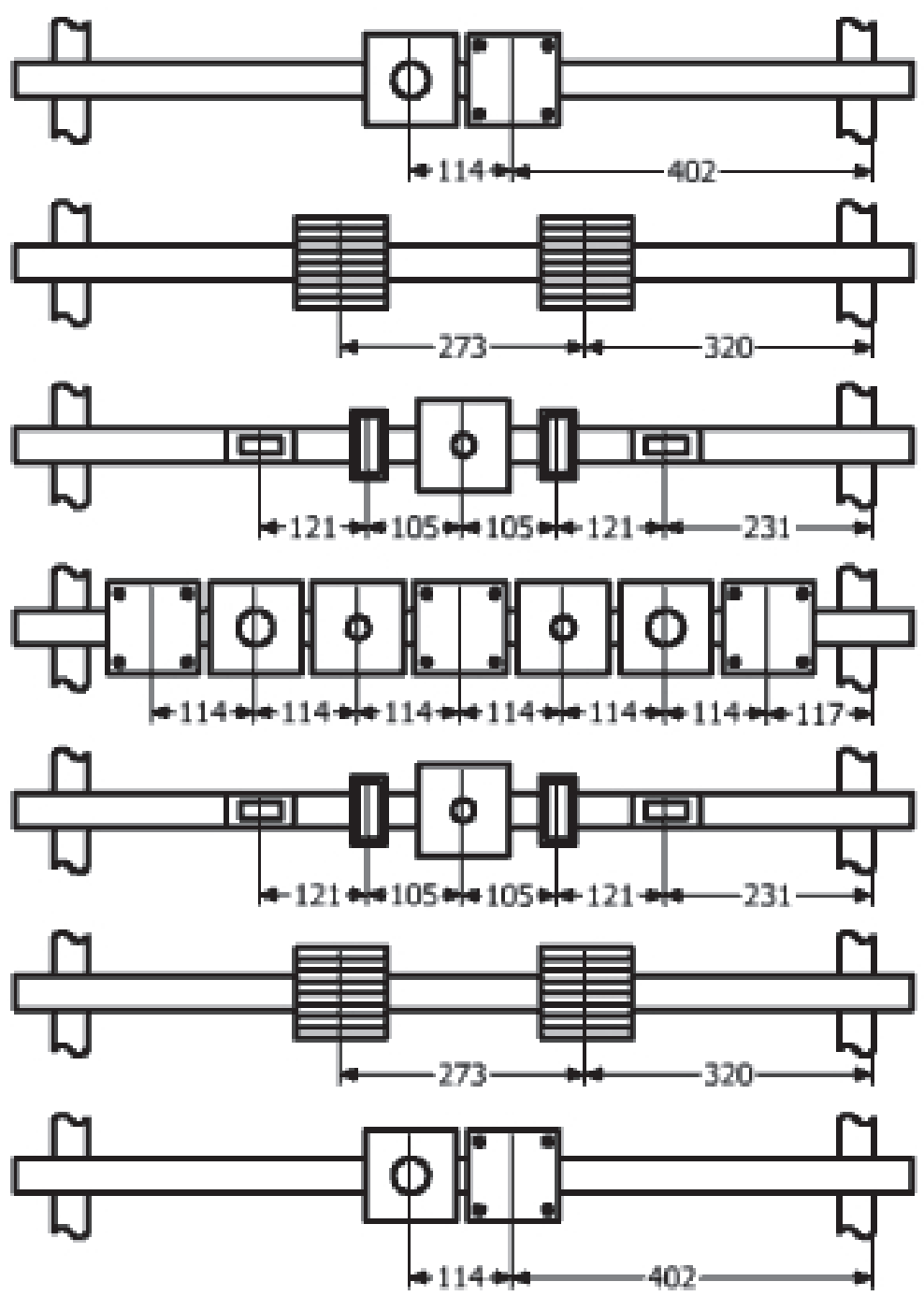

Fig. 28. Detailed Horizontal Locations of Instruments on Instrument Racks 1, 2, and 4. Dimensions in $\mathrm{mm} \pm 5 \mathrm{~mm}$ 


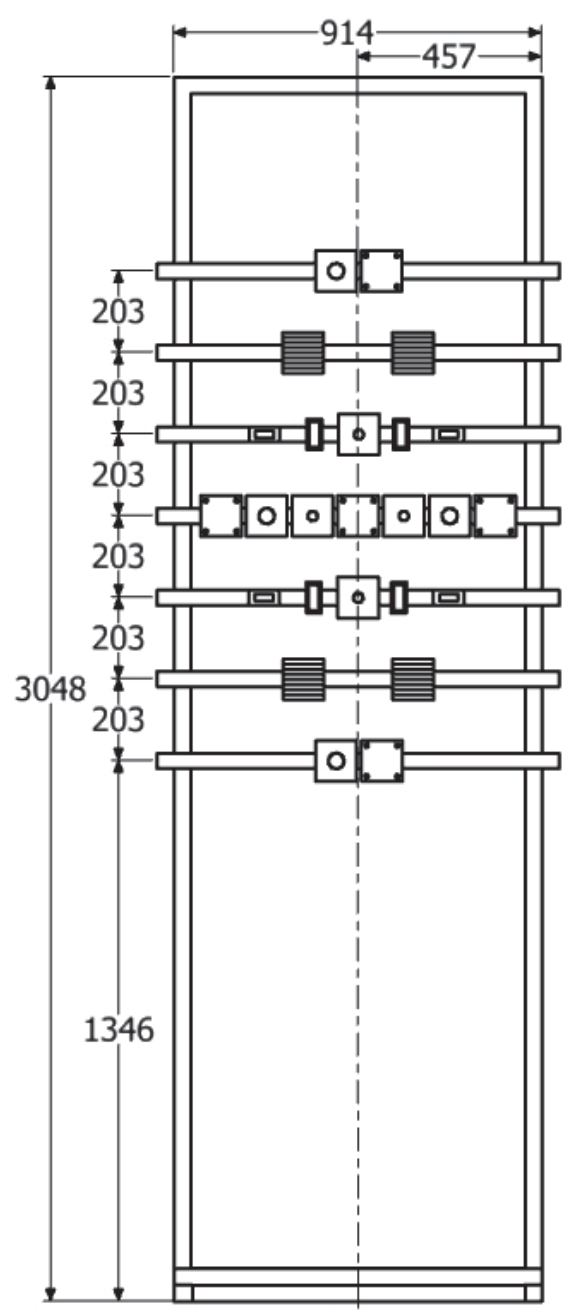

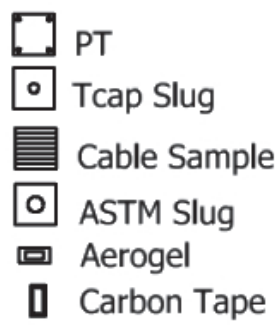

NIST DAQ

Channels 10 to 18

KEMA DAQ

Channels $\mathrm{E}$ to $\mathrm{H}$

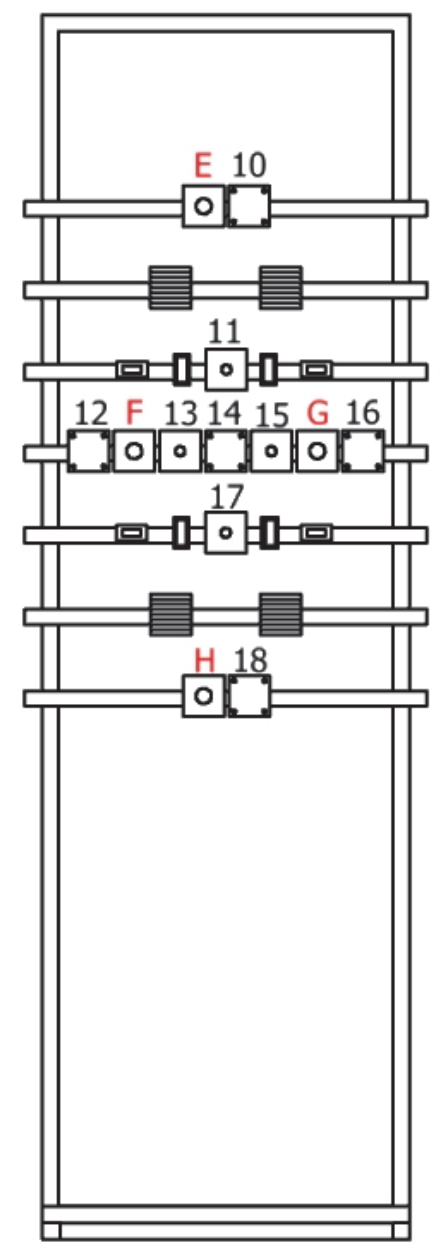

Fig. 29. Illustration of Vertical Instrumentation Rack 2 with data acquisition channels. Dimensions in $\mathrm{mm} \pm 5 \mathrm{~mm}$. 

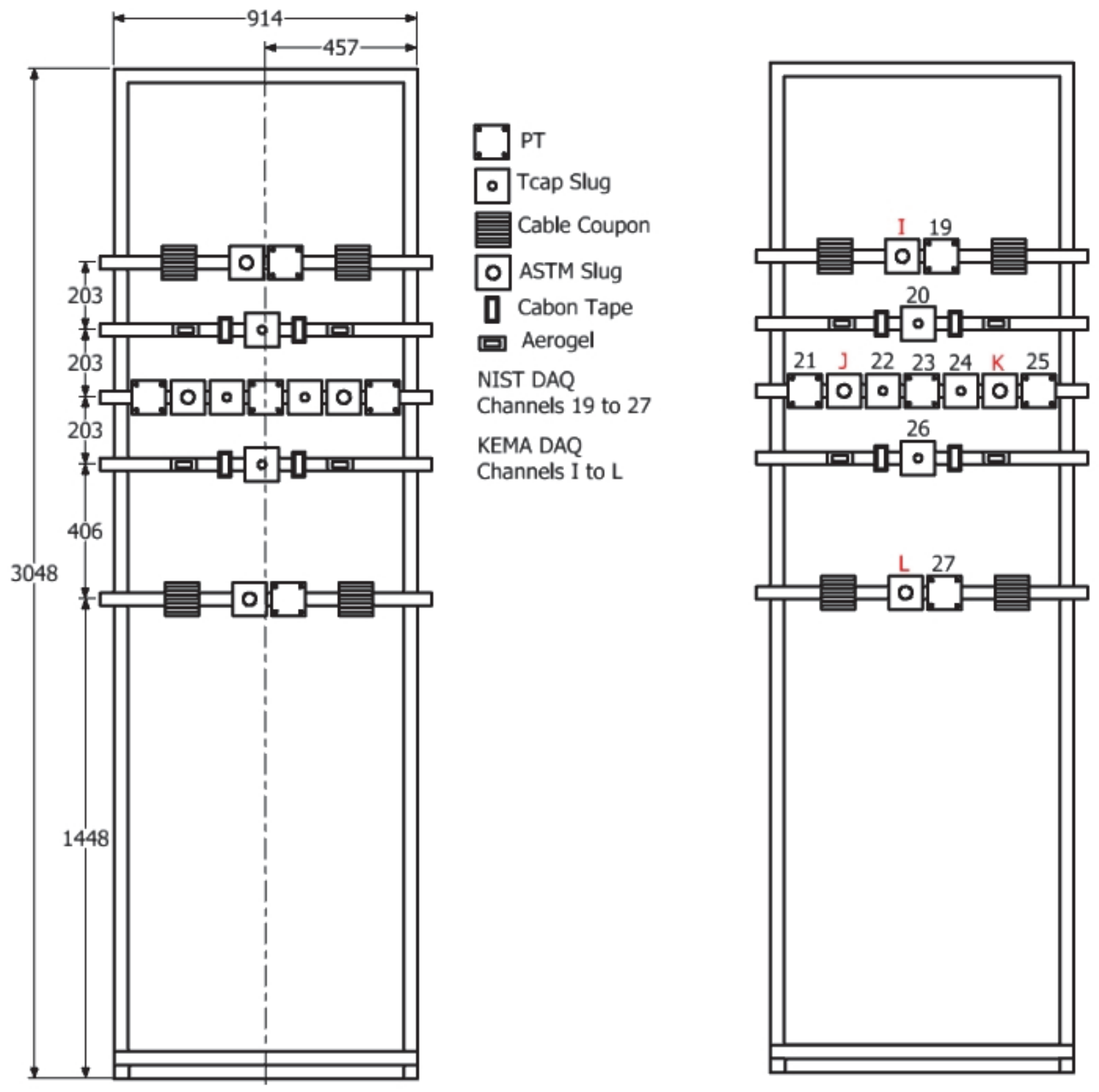

Fig. 30. Illustration of Vertical Instrumentation Rack 3 with data acquisition channels. Dimensions in $\mathrm{mm} \pm 5 \mathrm{~mm}$. 

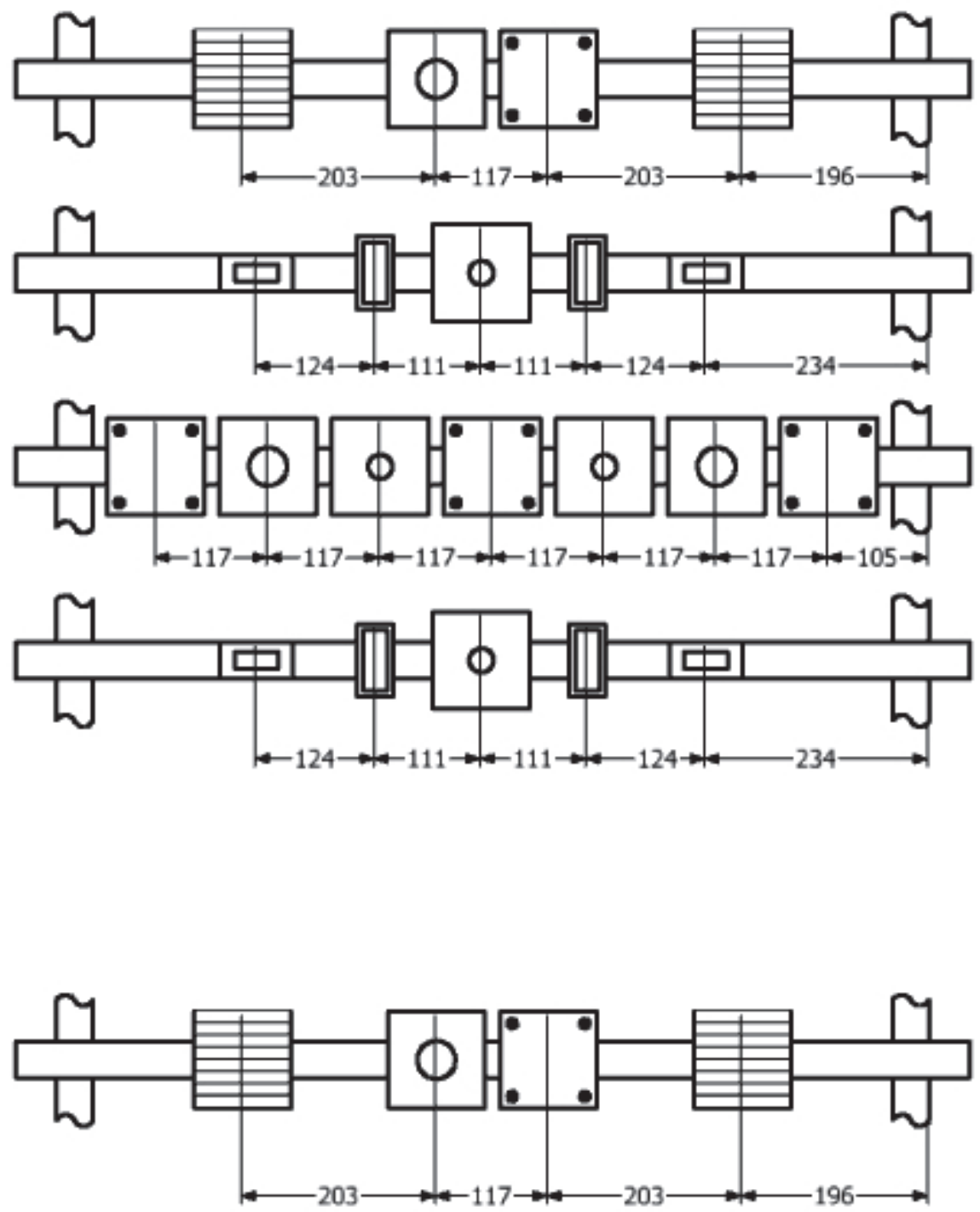

Fig. 31. Detailed Horizontal Locations of Instruments on Instrument Rack 3. Dimensions in $\mathrm{mm} \pm 5 \mathrm{~mm}$ 

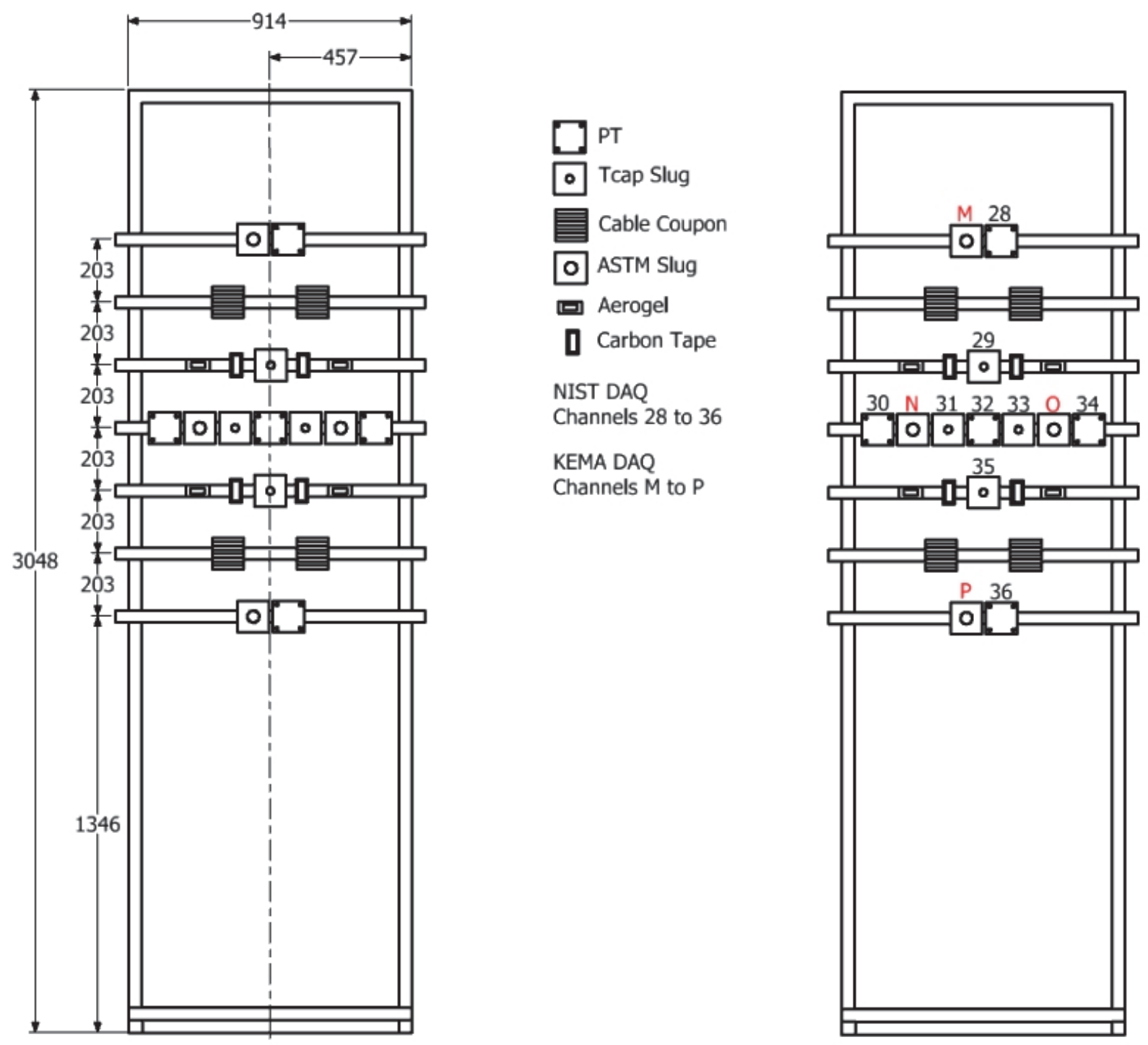

Fig. 32. Illustration of vertical Instrumentation Rack 4 with data acquisition channels. Dimensions in $\mathrm{mm} \pm 5 \mathrm{~mm}$. 

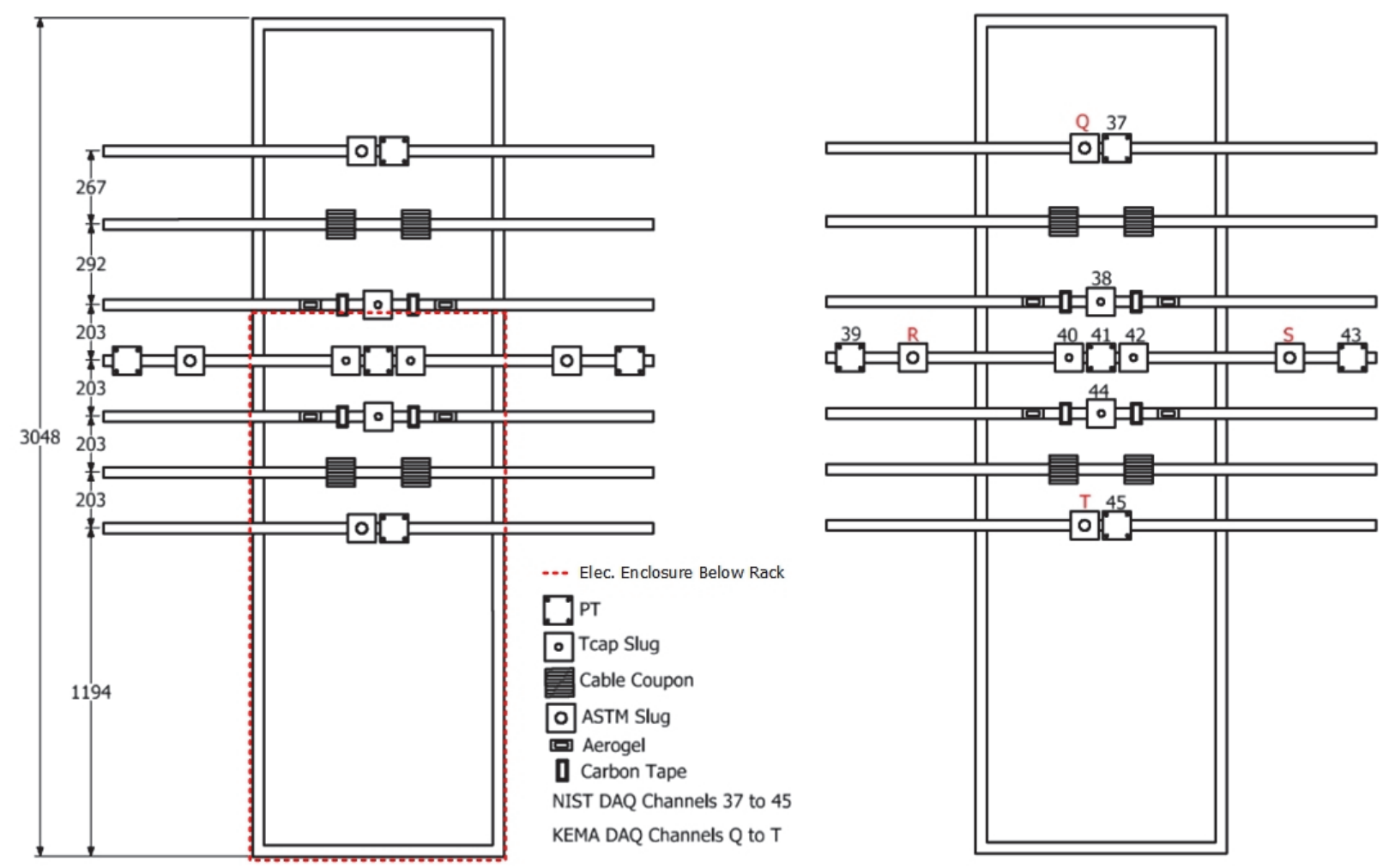

Fig. 33. Illustration of horizontal Instrumentation Rack 5 with data acquisition channels. Electrical enclosure outline shown in red on left. Dimensions in $\mathrm{mm} \pm 5 \mathrm{~mm}$. 

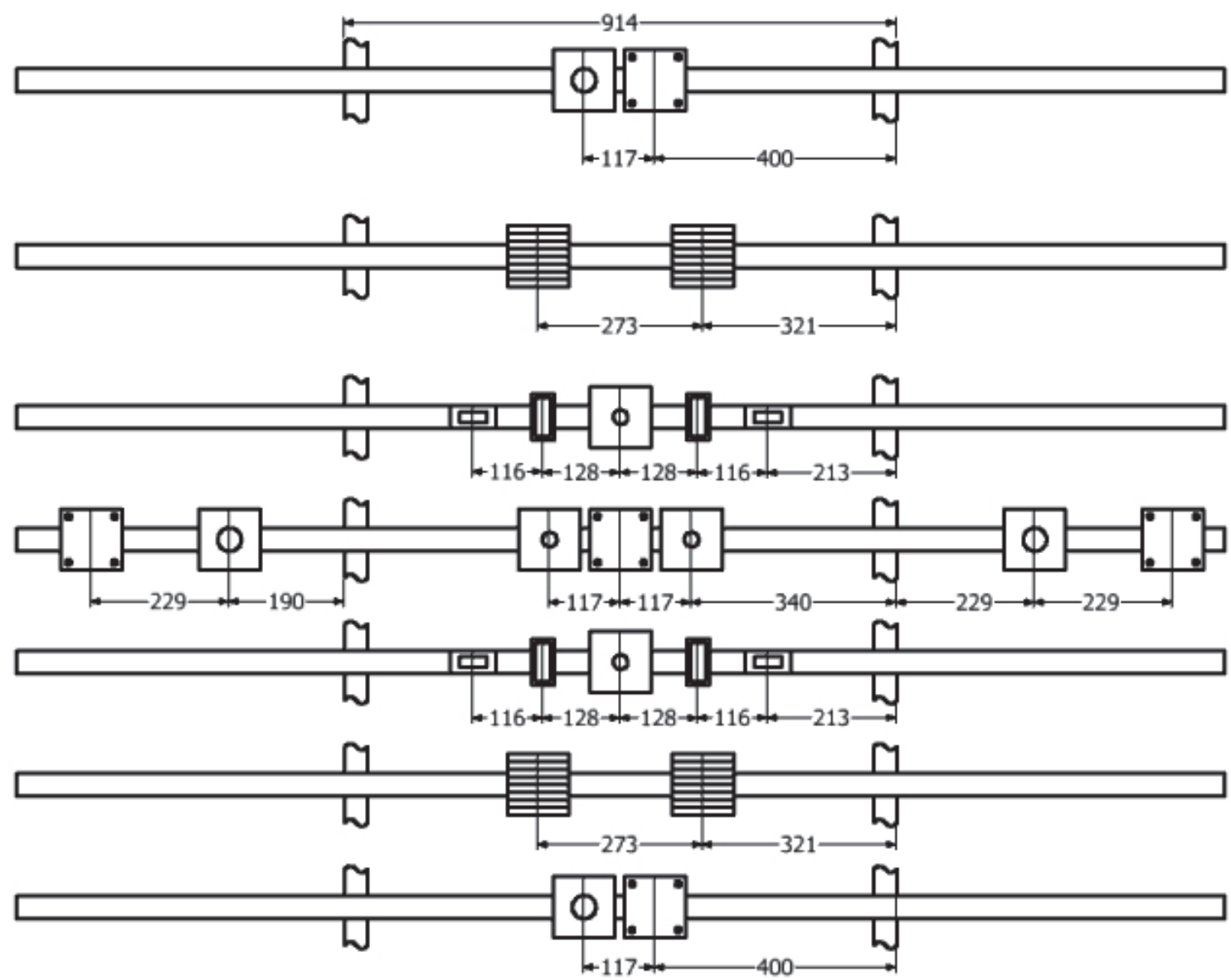

Fig. 34. Detailed locations of instruments on Instrument Rack 5.

Dimensions in $\mathrm{mm} \pm 5 \mathrm{~mm}$. 


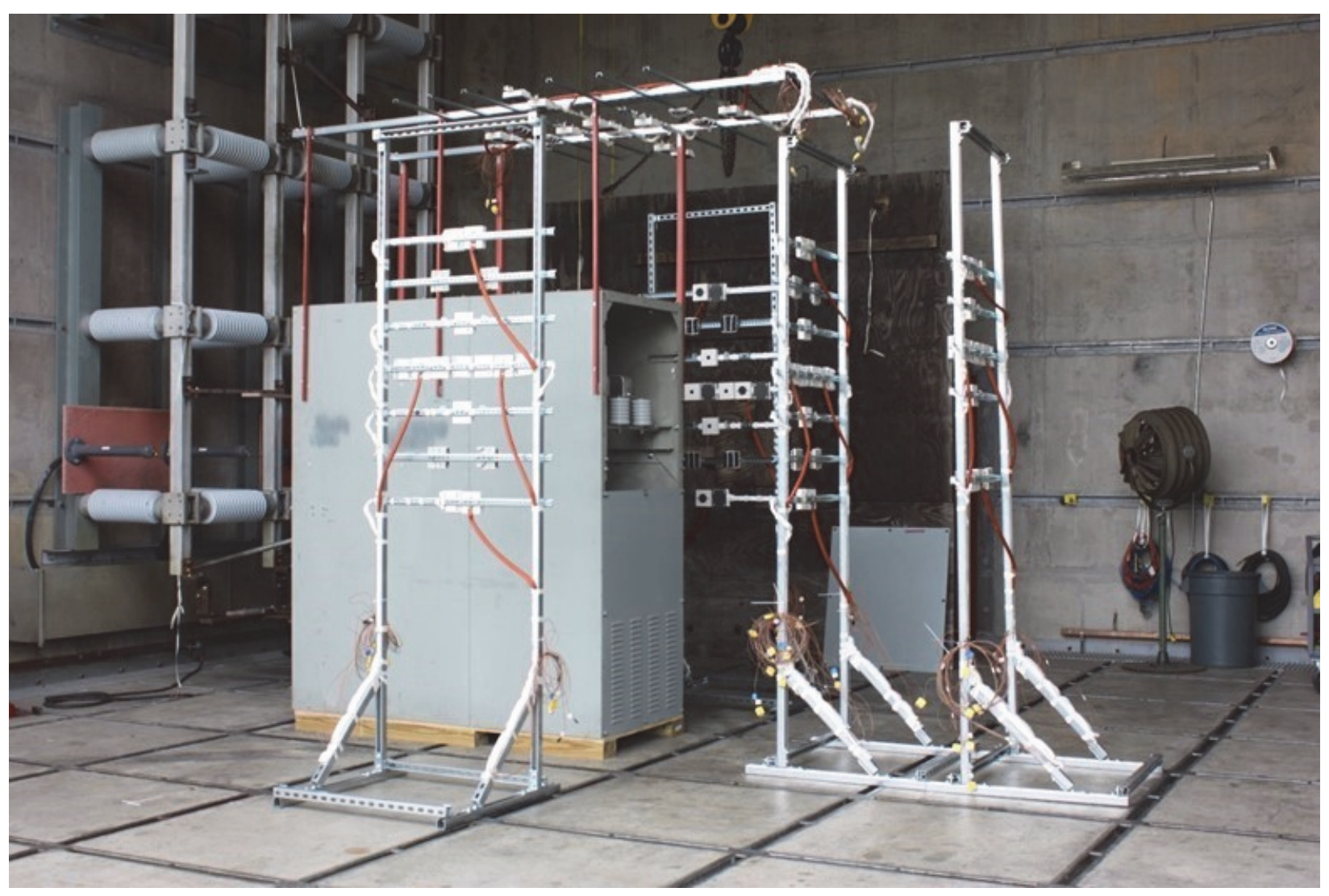

Fig. 35. Photo of Instrumentation Racks during experimental setup. 


\section{Experimental Results}

The testing laboratory performed calibration runs to ensure that the power circuits selected met the experimental program needs. The calibrations are measured at a shorting bus within the laboratory's facility and the actual experimental conditions will be slightly different because of the additional circuit length to the test equipment and that of the test equipment. For the $25 \mathrm{kA}$ experiment, calibrations were run, with final calibration values of $6.89 \mathrm{kV}$ and $29.2 \mathrm{kA}$. The uncertainty of the testing laboratory reported values, considering the total measuring system, is less than 3 percent. For the $32 \mathrm{kA}$ experiment, the final calibration values were $7.0 \mathrm{kV}$ and $33.0 \mathrm{kA}$. Target and actual experimental parameters are shown in Table 8. As is shown, the actual arc current is less than that of the calibration. The added circuit length, arc impedance and finite power circuit configuration places some constrains on achieving the exact specified parameters. The nominal target experiment durations were either $2 \mathrm{~s}$ or $4 \mathrm{~s}$. The duration of the arc is controlled by the ability to maintain the arc within the enclosure and the breaking of the circuit by the test laboratory protective device(s). Provided that the arc does not prematurely extinguish prior to the desired arc time, the testing laboratory ensures that the arc duration parameter is met by automatically triggering their protectives devices to open at the specified duration. Because there is a delay in the opening of the circuit (breaker opening time), the actual durations are longer than the desired durations. For these experiments, the maximum durations were no more than 3.75 percent longer than the planned durations ( $2 \mathrm{~s}$ or $4 \mathrm{~s}$ ). The frequency of the power source was selected consistent with the US power grid (i.e., $60 \mathrm{~Hz}$ ). Because the electrical power source is the generator's inertia, the frequency decreases during the experiment. The actual electrical measurements recorded by the testing laboratory during each experiment are provided in a report included in Appendix $\mathrm{H}$. The uncertainty of the testing laboratory reported values, considering the total measuring system, is less than 3 percent. The actual experimental parameters (system voltage, current, and arc time) were close to the targets, with the maximum differences being no more than 7 percent.

Table 8. Experimental Parameters, measured values are \pm 3 percent.

\begin{tabular}{|c|c|c|c|c|c|c|c|c|c|c|}
\hline \multirow[t]{2}{*}{$\begin{array}{l}\text { Test } \\
\text { No. }\end{array}$} & \multicolumn{3}{|c|}{$\begin{array}{l}\text { System Voltage } \\
\left(k^{L-L}\right)\end{array}$} & \multicolumn{2}{|c|}{ Current (kA) } & \multicolumn{3}{|c|}{ Frequency $(\mathrm{Hz})$} & \multicolumn{2}{|c|}{$\begin{array}{l}\text { Arc Duration } \\
\text { (sec) }\end{array}$} \\
\hline & Target & Actual & Arc & Target & Actual & Target & Start & End & Target & Actual \\
\hline $2-19$ & 6.9 & 6.9 & 0.772 & 25 & 25.76 & 60.0 & 60.0 & 55.6 & 2.0 & 2.05 \\
\hline $2-21$ & 6.9 & 6.9 & 0.826 & 25 & 26.57 & 60.0 & 60.3 & 46.2 & 4.0 & 4.11 \\
\hline 2-22 & 6.9 & 7.0 & 0.873 & 32 & 31.97 & 60.0 & 60.3 & 52.6 & 2.0 & 2.07 \\
\hline $2-24$ & 6.9 & 7.0 & 0.937 & 32 & 29.84 & 60.0 & 60.0 & 42.3 & 4.0 & 4.15 \\
\hline
\end{tabular}

During the experimental plan public comment period, one potential concern was related to the test facility's ability to ensure the "peak" asymmetrical fault current (typically first $1 / 2$ cycle) not exceed the rating for the cabinet. Based on the experimental data reported in subsequent sections (see Table 14, Table 19, Table 24, and Table 28), the asymmetrical current during the experiments did not exceed the cabinet rating per IEEE C37.010-1999, Section 6.1.3 [12]. Experimental conditions and comparisons of experimental current ratios to the standard ratio are presented in Table 9 . 
Table 9. Summary of Peak Asymmetrical Fault experimental data to IEEE standard C37.010-1999. Measured values are \pm 3 percent.

\begin{tabular}{|l|l|l|c|c|c|}
\hline $\begin{array}{l}\text { Test } \\
\text { No. }\end{array}$ & $\begin{array}{l}\text { Test } \\
\text { Voltage } \\
\text { (kV) }\end{array}$ & $\begin{array}{l}\text { Test } \\
\text { Current } \\
\text { (kA rms) }\end{array}$ & $\begin{array}{l}\text { Target Arc } \\
\text { Duration (s) }\end{array}$ & $\begin{array}{l}\text { Asymmetrical 1/2 } \\
\text { cycle current } \\
\text { (kA Peak, absolute) }\end{array}$ & $\begin{array}{l}\text { IEEE C37.010-1999 } \\
\text { ratio ( } \mathbf{2 . 6 0 )}\end{array}$ \\
\hline $\mathbf{2 - 1 9}$ & 6.9 & 25.8 & 2 & 63.0 & 2.44 \\
\hline $\mathbf{2 - 2 1}$ & 6.9 & 26.6 & 4 & 62.9 & 2.38 \\
\hline $\mathbf{2 - 2 2}$ & 7.0 & 32.0 & 2 & 75.9 & 2.42 \\
\hline $\mathbf{2 - 2 4}$ & 7.0 & 30.2 & 4 & 75.0 & 2.48 \\
\hline
\end{tabular}

\subsection{Test $2-19-6.9 \mathrm{kV}, 25 \mathrm{kA}, 2$ s duration, aluminum bus}

Test 2-19 was performed on September 10, 2018 at 1:50 PM eastern daylight time (EDT). The temperature was approximately $18^{\circ} \mathrm{C}\left(65^{\circ} \mathrm{F}\right)$, approximately 97 percent relative humidity and approximately $102.1 \mathrm{kPa}$ of pressure. The weather was overcast with light rain and an east-north east wind at approximately $13 \mathrm{~km} / \mathrm{h}(8 \mathrm{mi} / \mathrm{h})$.

\subsubsection{Observations}

Observations documented below are based on review of video and thermal imaging that was taken during the experiment. The observations provided in Table 10 include an approximate time reference. Corresponding images are provided in Fig. 36. Thermal images are presented in Fig. 35.

Table 10. Observations from Test 2-19

\begin{tabular}{|c|l|}
\hline Time (ms) & Observation \\
\hline $\mathbf{4 0}$ & Bottom of front door begins to open \\
\hline $\mathbf{4 9}$ & Particle ejecta reaches top rack $(0.91 \mathrm{~m}[3.00 \mathrm{ft}]$ above enclosure) \\
\hline $\mathbf{4 9}$ & Particle ejecta passes rear rack (rack \#2 at $0.91 \mathrm{~m}[3.00 \mathrm{ft}]$ behind enclosure) \\
\hline $\mathbf{9 3}$ & Front door no longer secured by latch (continues to open) \\
\hline $\mathbf{1 6 0}$ & Particle ejecta passes $1.83 \mathrm{~m}[6.00 \mathrm{ft}]$ above enclosure \\
\hline $\mathbf{2 1 2}$ & $\begin{array}{l}\text { Particle ejecta passes } 2^{\text {nd }} \text { rear rack (rack \#3 at } 1.83 \mathrm{~m}[6.00 \mathrm{ft}] \text { behind } \\
\text { enclosure) }\end{array}$ \\
\hline $\mathbf{5 3 4}$ & Initial arc breach of rear panel \\
\hline $\mathbf{8 1 9}$ & $\begin{array}{l}\text { Particle ejecta impacts test facility cell wall }(5.18 \mathrm{~m}[17.00 \mathrm{ft}] \text { behind } \\
\text { enclosure) }\end{array}$ \\
\hline $\mathbf{1 0 7 7}$ & Top front vent stops emitting hot gas and particle ejecta \\
\hline $\mathbf{1 2 0 0}$ & $\begin{array}{l}\text { Significant quantity of particle ejecta impacting test facility cell wall behind } \\
\text { enclosure }\end{array}$ \\
\hline $\mathbf{2 0 5 7}$ & Decrease in cell illumination consistent with experiment termination \\
\hline $\mathbf{2 7 6 0 0 0}$ & Test cell pedestal ventilation fan turned on \\
\hline $\mathbf{6 1 3 0 1 8}$ & NIST data acquisition ends \\
\hline
\end{tabular}



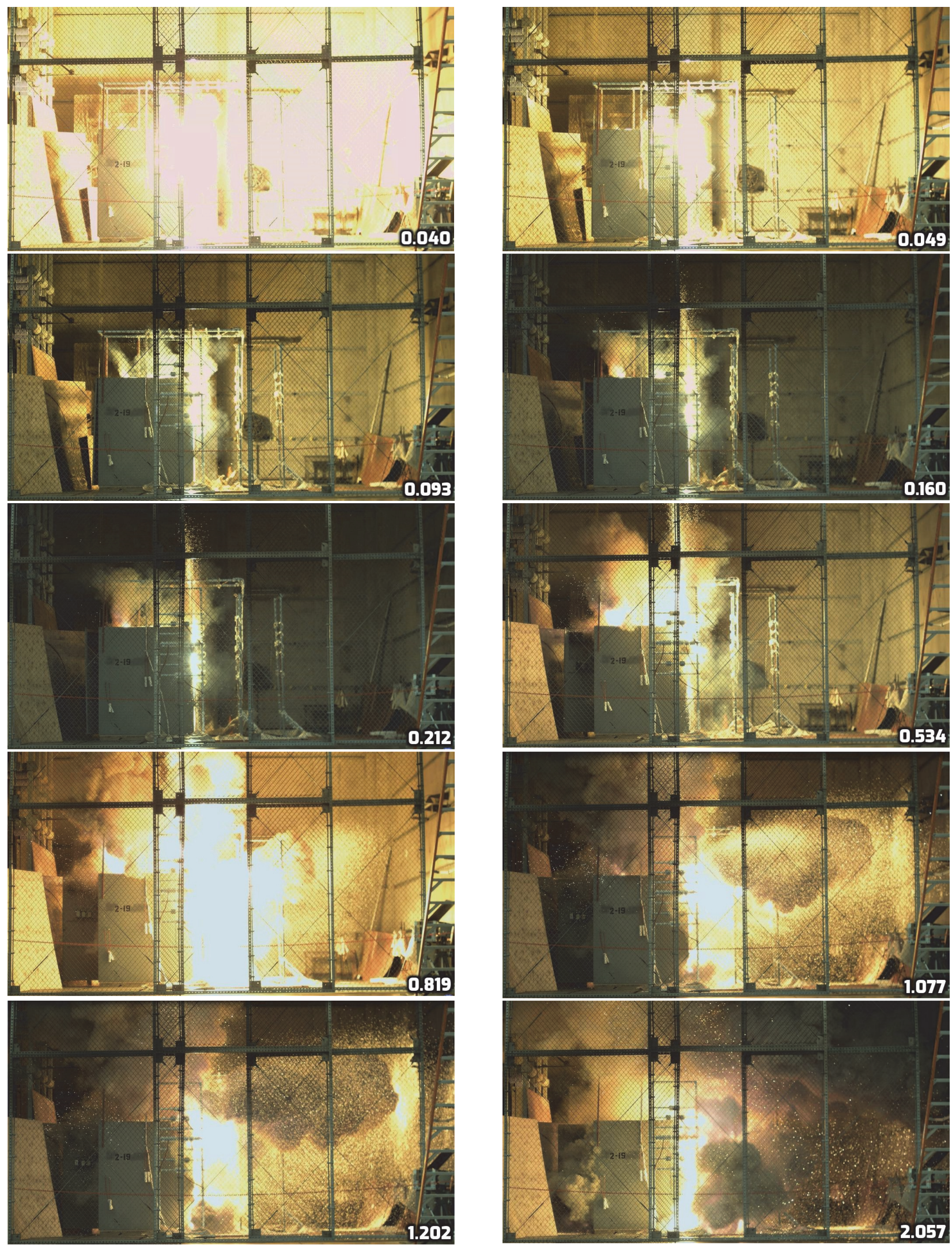

Fig. 36. Sequence of Images from Test 2-19 (image time stamp in seconds) 


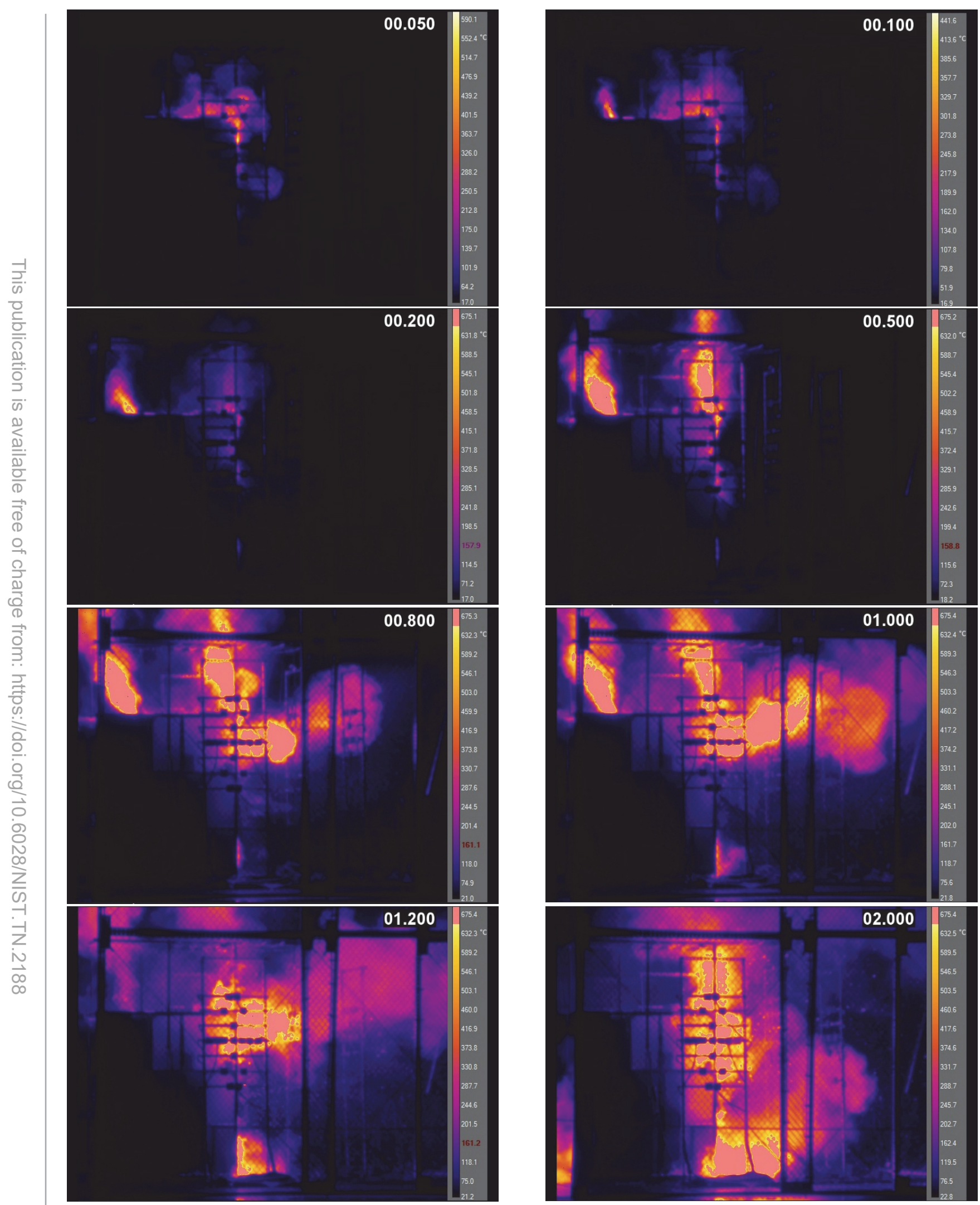

Fig. 37. Sequence of Thermal Images from Test 2-19 (image time stamp in seconds) 

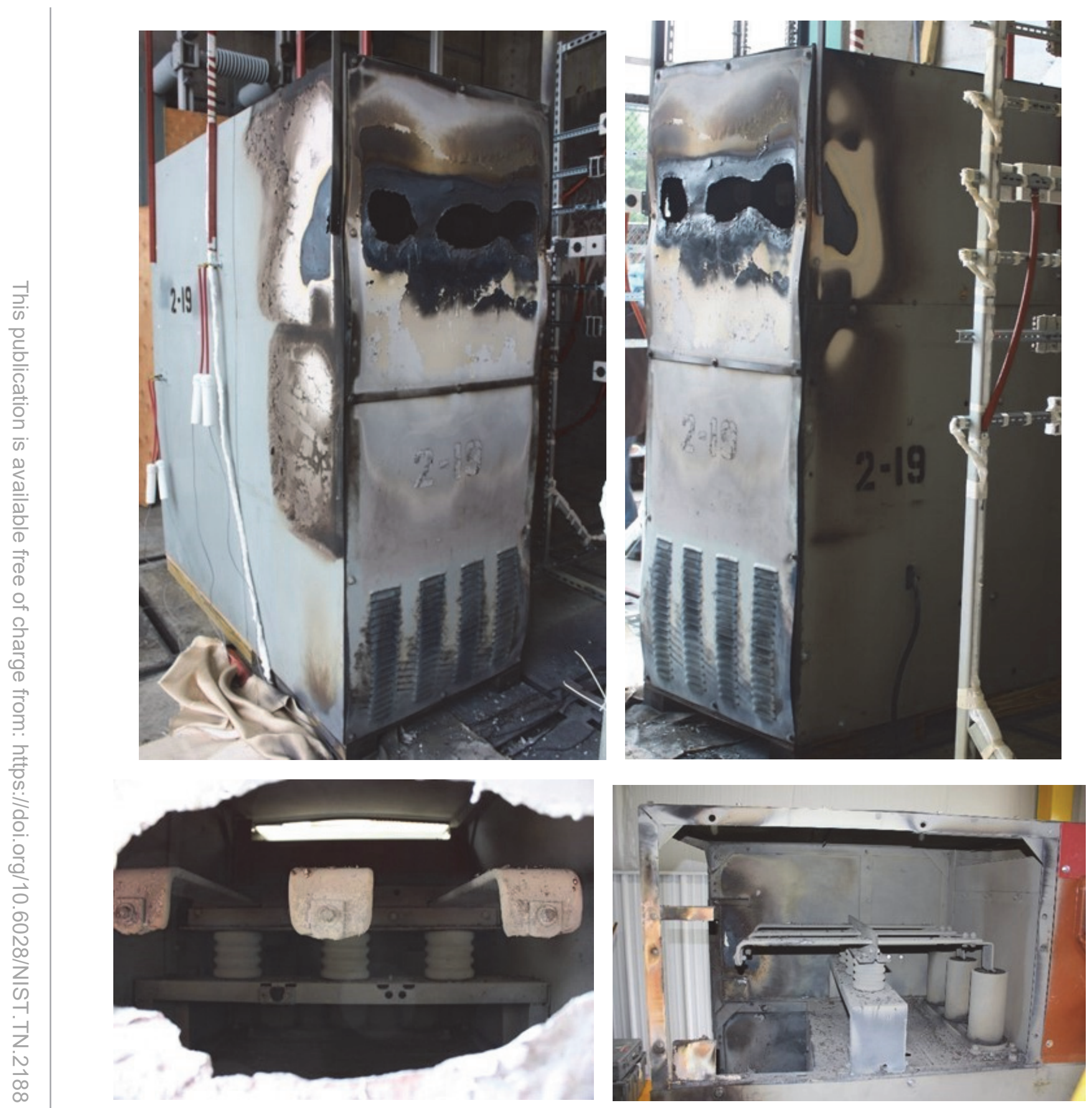

Fig. 38. Enclosure Post-Test 2-19. (Top: back of enclosure; Bottom: remaining bus bar material. Bottom left as viewed from rear of enclosure, bottom right as viewed from the side at the rear of the enclosure with the side panel removed.) 
Photographs of damage to the electrical enclosure are shown in Fig. 38. The enclosure experienced a breach of the upper rear panel and one small breach on each of the side rear panels of the primary cable connection compartment. These were the only panels to exhibit openings caused by the arc. However, there was evidence of excessive heating of the busside upper panel. The door on the front of the enclosure with a single quarter-turn latch did open. It was observed that internal pressure caused the bottom of the door to push out and post-experiment inspection indicated that the side of the panel was bowed. The combination of these two effects allowed the latch mechanism to slip and the door to open. Following the experiment, no apparent evidence of aluminum oxide coating was observed on the test cell walls. Post-experiment photographs of the electrical enclosure are shown in Fig. 38.

\subsubsection{Measurements}

Measurements made during Test 2-19 are presented below. These measurements include;

- Thermal

○ Heat flux - Plate Thermometers

○ Incident energy - ASTM Slug Calorimeter

- Heat flux, incident energy - Tcap Slug Calorimeter

- Pressure

- Internal pressure

- Mass Loss

○ Pre- / Post-experiment measurements

- Electrical

○ Voltage profiles

- Current profiles

○ Power / Energy profiles

\subsubsection{Thermal Measurements}

Thermal measurements from the active instruments are reported below for Test 2-19. These include PT measurements in Table 11, ASTM Slug Calorimeter measurements in Table 12,

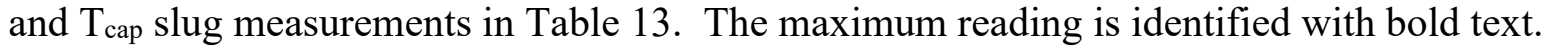
Significant amounts of incident energy $\left(\mathrm{kJ} / \mathrm{m}^{2}\right)$ were transferred to areas surrounding the switch gear during the post-arcing phase of the HEAF. This is especially evident for the $\mathrm{T}_{\text {cap }}$ slugs $(13,16,18)$ located approximately $0.91 \mathrm{~m}(3.00 \mathrm{ft})$ from the switchgear on the right side of the test cell where the arc penetrated the rear panel of the switchgear. The post-arcing phase incident energy contribution was multiple times greater than the incident energy contribution from the arcing phase.

Several failures of the ASTM calorimeters were noted. The calorimeters connected to the data acquisition system channels A2-A8 (Instruments A-D, M, N and P) did not capture any temperature data during the experiment due to a system error. The error reporting log identified that a connection error occurred between the start of the experiment and the end. Calorimeters connected to Instruments $\mathrm{G}$ and $\mathrm{Q}$ show normal ambient temperatures, however, immediately after the arc begins, the temperature readings go negative. The 
ambient temperatures on laboratory channels $\mathrm{C}, \mathrm{N}, \mathrm{H}$, and $\mathrm{S}$ are higher than other temperatures, the reason is unknown.

Table 11. Summary of plate thermometer measurements Test 2-19

\begin{tabular}{|c|c|c|c|c|c|}
\hline $\begin{array}{c}\text { Rack } \\
\text { No. }\end{array}$ & $\begin{array}{l}\text { Plate } \\
\text { No. }\end{array}$ & Location & $\begin{array}{c}\text { Max Heat } \\
\text { Flux } \\
\left(\mathbf{k W} / \mathbf{m}^{2}\right) \\
\pm 1 \mathbf{k W} / \mathbf{m}^{2} \\
\text { or } \pm 5 \%\end{array}$ & $\begin{array}{c}\text { Average Heat } \\
\text { Flux During } \\
\text { Arc }\left(\mathbf{k W} / \mathrm{m}^{2}\right) \\
\pm 1 \mathrm{~kW} / \mathrm{m}^{2} \text { or } \\
\pm 5 \%\end{array}$ & Notes \\
\hline 1 & 1 & Top & 47.1 & 34.5 & \\
\hline 1 & 3 & Mid-Right & 91.5 & 56.0 & \\
\hline 1 & 5 & Mid-Center & -- & -- & $\begin{array}{c}\text { Plate inoperable prior to } \\
\text { experiment }\end{array}$ \\
\hline 1 & 7 & Mid-Left & 30.8 & 22.2 & \\
\hline 1 & 9 & Bottom & 50.3 & 27.8 & \\
\hline 2 & 10 & Top & 134.0 & 93.1 & \\
\hline 2 & 12 & Mid-Right & 377.1 & 179.3 & \\
\hline 2 & 14 & Mid-Center & -- & 349.6 & $\begin{array}{c}\text { Possible EMI spike at } \\
\text { arc start }\end{array}$ \\
\hline 2 & 16 & Mid-Left & 419.6 & 134.5 & \\
\hline 2 & 18 & Bottom & 81.5 & 72.2 & \\
\hline 3 & 19 & Top & 55.6 & 34.4 & \\
\hline 3 & 21 & Mid-Right & 234.4 & 45.0 & \\
\hline 3 & 23 & Mid-Center & 4.4 & 1.0 & \\
\hline 3 & 25 & Mid-Left & 79.9 & 30.5 & \\
\hline 3 & 27 & Bottom & 48.0 & 32.8 & \\
\hline 4 & 28 & Top & 171.4 & 69.7 & \\
\hline 4 & 30 & Mid-Right & 59.3 & 25.4 & \\
\hline 4 & 32 & Mid-Center & 140.5 & 80.1 & \\
\hline 4 & 34 & Mid-Left & 158.5 & 90.4 & \\
\hline 4 & 36 & Bottom & 449.5 & --- & $\begin{array}{c}\text { Plate damaged during } \\
\text { test }\end{array}$ \\
\hline 5 & 37 & Front & 110.4 & 76.3 & \\
\hline 5 & 39 & Center-Right & 40.3 & 26.7 & \\
\hline 5 & 41 & Center-Mid & 274.5 & 110.6 & \\
\hline 5 & 43 & Center-Left & 65.8 & 30.1 & \\
\hline 5 & 45 & Back & 50.2 & 26.6 & \\
\hline
\end{tabular}


Table 12. Summary of ASTM slug calorimeter measurements, Test 2-19

\begin{tabular}{|c|c|c|c|c|c|}
\hline $\begin{array}{c}\text { Rack } \\
\text { No. }\end{array}$ & $\begin{array}{c}\text { ASTM } \\
\text { No. }\end{array}$ & Location & $\begin{array}{c}\text { Incident } \\
\text { Energy }\left(\mathrm{kJ} / \mathrm{m}^{2}\right) \\
\pm 18 \mathrm{~kJ} / \mathrm{m}^{2} \text { or } \\
\pm 4 \%\end{array}$ & $\begin{array}{c}\text { Time to Max } \\
\text { Temperature } \\
\text { (s) } \\
\pm \mathbf{3} \%\end{array}$ & Comment \\
\hline 1 & A & Top & - - - & - - - & DAQ Error \\
\hline 1 & B & Mid-Right & - - - & - - - & DAQ Error \\
\hline 1 & $\mathrm{C}$ & Mid-Left & - - - & - - - & DAQ Error \\
\hline 1 & $\mathrm{D}$ & Bottom & $\ldots$ & $-\ldots$ & DAQ Error \\
\hline 2 & $\mathrm{E}$ & Top & 308.2 & 48.4 & \\
\hline 2 & $\mathrm{~F}$ & Mid-Right & 561.5 & 49.2 & \\
\hline 2 & G & Mid-Left & $-\ldots$ & $-\ldots$ & Temp. measurement error \\
\hline 2 & $\mathrm{H}$ & Bottom & 399.0 & 75.9 & \\
\hline 3 & I & Top & 140.0 & 49.3 & \\
\hline 3 & $\mathrm{~J}$ & Mid-Right & 134.1 & 48 & \\
\hline 3 & $\mathrm{~K}$ & Mid-Left & 131.6 & 49.3 & \\
\hline 3 & $\mathrm{~L}$ & Bottom & 139.3 & 48.9 & \\
\hline 4 & M & Top & $-\cdots$ & $-\cdots$ & DAQ Error \\
\hline 4 & $\mathrm{~N}$ & Mid-Right & $\ldots$ & $\ldots$ & DAQ Error \\
\hline 4 & $\mathrm{O}$ & Mid-Left & 221.6 & 79.4 & \\
\hline 4 & $\mathrm{P}$ & Bottom & $-\ldots$ & $-\ldots$ & DAQ Error \\
\hline 5 & $\bar{Q}$ & Front & $\overline{---}$ & $-{ }_{-1}$ & Temp. measurement error \\
\hline 5 & $\mathrm{R}$ & Center-Right & 94.3 & 103.8 & \\
\hline 5 & $\mathrm{~S}$ & Center-Left & 86.9 & 22.0 & \\
\hline 5 & $\mathrm{~T}$ & Back & 91.4 & 189.1 & \\
\hline
\end{tabular}


Table 13. Summary of $\mathrm{T}_{\text {cap }}$ slug measurement, Test 2-19

\begin{tabular}{|c|c|c|c|c|c|}
\hline $\begin{array}{c}\text { Rack } \\
\text { No. }\end{array}$ & $\mathbf{T}_{\text {cap }} \mathbf{N o .}$ & Location & $\begin{array}{l}\text { Heat Flux } \\
\text { During Arc } \\
\left(\mathbf{k W} / \mathrm{m}^{2}\right) \\
\pm 2.9 \%\end{array}$ & $\begin{array}{c}\text { Incident } \\
\text { Energy } \\
\text { During Arc } \\
\text { Phase }\left(\mathrm{kJ} / \mathrm{m}^{2}\right) \\
\pm 5 \%\end{array}$ & $\begin{array}{c}\text { Total Incident } \\
\text { Energy } \\
\left(\mathbf{k J} / \mathbf{m}^{2}\right) \\
\pm 5 \%\end{array}$ \\
\hline 1 & 2 & Top & 41.3 & 93.8 & 459.8 \\
\hline 1 & 4 & Mid-Right & 43.5 & 101.0 & 540.1 \\
\hline 1 & 6 & Mid-Left & 33.3 & 80.5 & 511.1 \\
\hline 1 & 8 & Bottom & 35.4 & 73.5 & 532.7 \\
\hline 2 & 11 & Top & 115.3 & 260.3 & 1132.1 \\
\hline 2 & 13 & Mid-Right & 131.3 & 297.1 & 1353.4 \\
\hline 2 & 15 & Mid-Left & 144.1 & 309.5 & 1270.0 \\
\hline 2 & 17 & Bottom & 136.3 & 298.9 & 1257.0 \\
\hline 3 & 20 & Top & 39.8 & 90.2 & 309.4 \\
\hline 3 & 22 & Mid-Right & 38.8 & 79.1 & 326.1 \\
\hline 3 & 24 & Mid-Left & 42.3 & 88.9 & 312.8 \\
\hline 3 & 26 & Bottom & 22.2 & 50.1 & 307.0 \\
\hline 4 & 29 & Top & 59.0 & 116.0 & 506.7 \\
\hline 4 & 31 & Mid-Right & 39.0 & 66.1 & 534.7 \\
\hline 4 & 33 & Mid-Left & 76.5 & 145.1 & 634.7 \\
\hline 4 & 35 & Bottom & 28.8 & 56.0 & 556.6 \\
\hline 5 & 38 & Front & 101.2 & 188.6 & 524.5 \\
\hline 5 & 40 & Center-Right & 140.7 & 232.0 & 533.2 \\
\hline 5 & 42 & Center-Left & 83.9 & 151.5 & 515.7 \\
\hline 5 & 44 & Back & 75.6 & 105.1 & 427.0 \\
\hline
\end{tabular}

\subsubsection{Internal Pressure}

The pressure profiles for the first two tenths of a second are shown in Fig. 39. After the initial pressure spike, the pressure rapidly decays to a relative steady state. The peak pressure is higher in the primary cable connection compartment as would be expected since this is the compartment where the arc is initiated. The maximum change in pressure in the primary cable connection compartment is approximately $28 \mathrm{kPa}(4.0 \mathrm{psi})$ above ambient at its peak. The maximum change in pressure in the breaker compartment is approximately $4 \mathrm{kPa}$ (0.6 psi) above ambient. The $0 \mathrm{kPa}$ to $207 \mathrm{kPa}(0$ psia to $30 \mathrm{psia})$ and $0 \mathrm{kPa}$ to $345 \mathrm{kPa}$ (0 psia to 50 psia) transducer recordings at a specific location were consistent. 

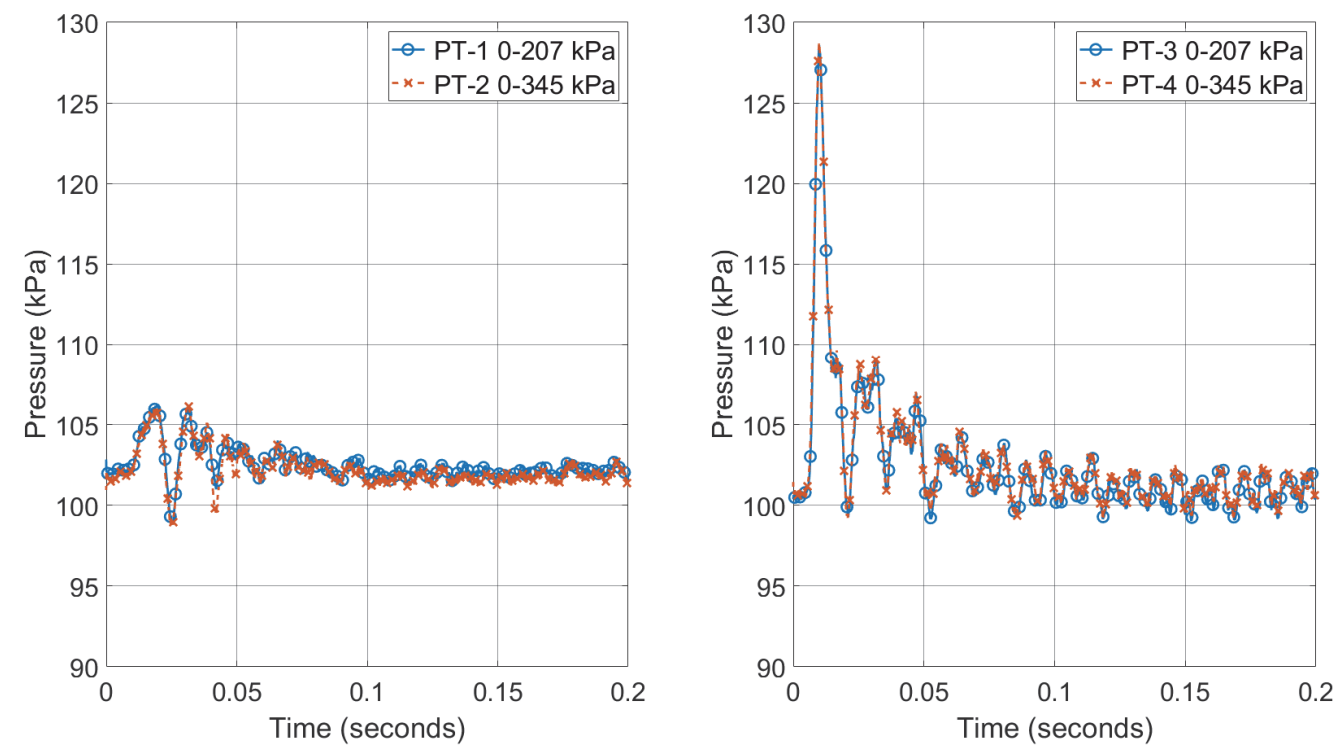

Fig. 39. Pressure measurements from Test 2-19 (breaker compartment - left; arcing compartment - right). Measurement uncertainty \pm 3 percent.

\subsubsection{Mass measurements}

Mass loss measurements were made for the enclosure metal cladding and the bus conductors. All measurements are reported in Appendix C. One observation that was made in all experiments was that for many of the steel cladding panels, the post-experiment measurements were larger than the pre-experiment measurements. This is likely caused by the plating of the electrical conductors onto the metal cladding. As such, for the panels that experienced breach, the actual mass loss is likely greater than what is reported below. For this experiment, only the upper rear panel experienced a significant breach. The initial mass was approximately $16.38 \mathrm{~kg}$ and a final mass of approximately $14.86 \mathrm{~kg}$ was observed for a total mass loss of approximately $1.52 \mathrm{~kg}$ for the enclosure. The bus bars lost a total of $458 \mathrm{~g}$ (152 g Phase A, $149 \mathrm{~g}$ Phase B, and $157 \mathrm{~g}$ Phase C). These mass measurements were made using an electronic mass balance (NIST Scale 2) with an expanded uncertainty, derived from manufacturer specifications, of $\pm 1 \mathrm{~g}$, with a 95 percent confidence interval.

Since the measured mass loss for the enclosure cladding is likely under-represented due to the plating of the electrodes and other materials onto the surface of the panels, an alternative mass loss estimation technique was developed. Using software and photos with measurement references, the missing area can be calculated. Given the known thickness of the panel and density, a comparable mass loss estimate is provided. For this experiment, the breach area estimates are shown in Fig. 40. Using this technique, the mass loss estimate is approximately $1.64 \mathrm{~kg}$, representing approximately 8 percent difference between the two methods. 


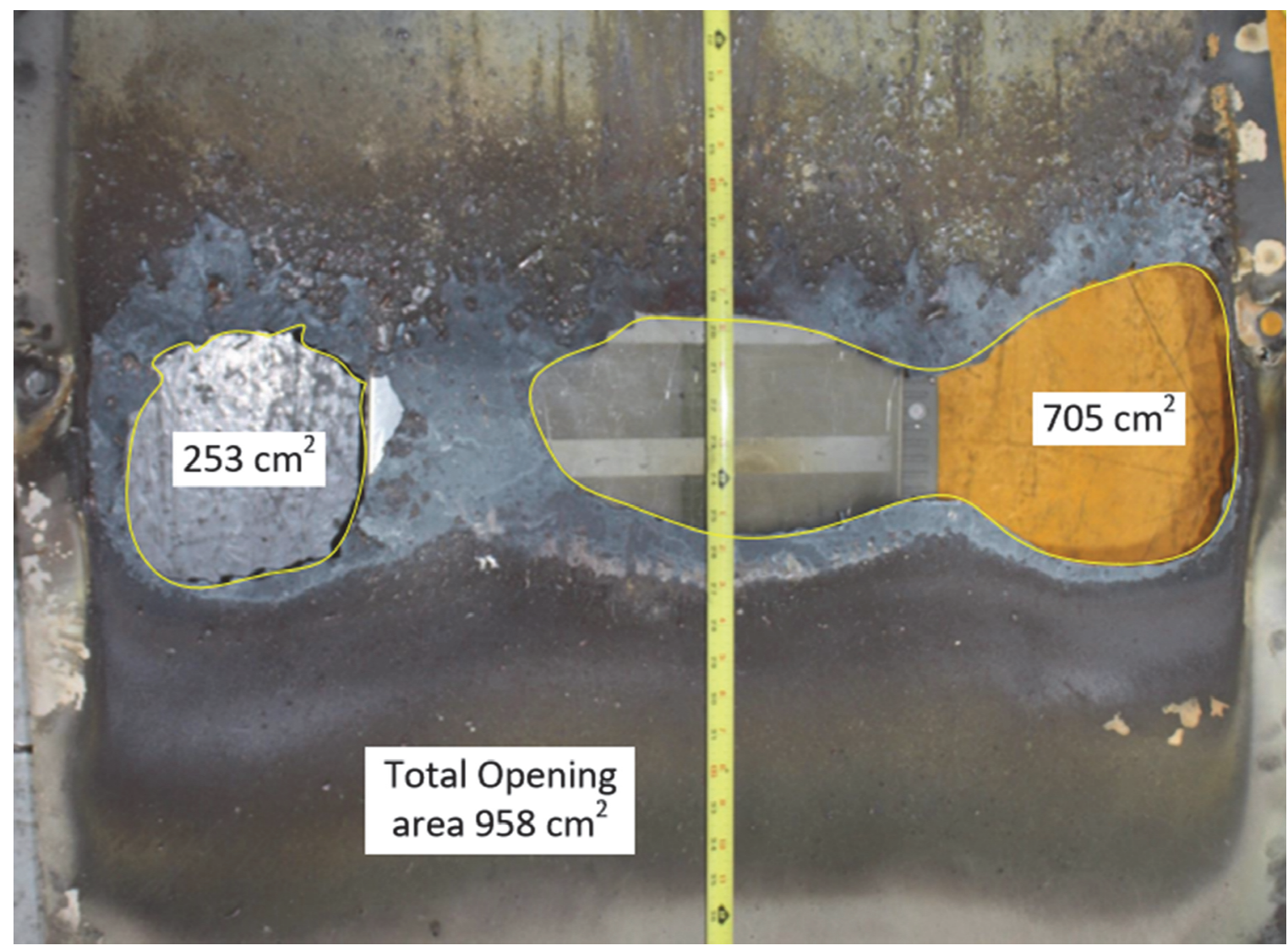

Fig. 40. Photo showing approximate breach opening areas on the upper back panel for Test 2-19. Software used to estimate opening area.

\subsubsection{Electrical Circuit and Measurements}

Test 2-19 used KEMA test circuit S01 shown in Fig. 41. Full-level circuit checks (calibration tests) were performed prior to the experiment to verify experimental parameters were acceptable. For this experiment the calibration tests configured the power system to $6.9 \mathrm{kV}, 25.6 \mathrm{kA}$ symmetrical, and $70.2 \mathrm{kA}$ peak. The KEMA Test report identifies this experiment as 180910-9005. 


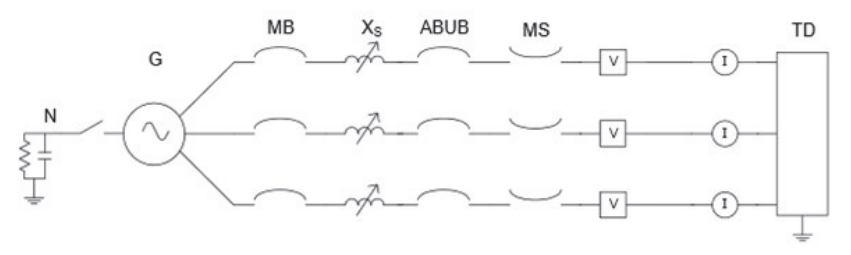

\begin{tabular}{|c|c|c|c|c|r|}
\hline \multicolumn{2}{|c|}{ Supply } & \multicolumn{4}{c|}{ Nomenclature } \\
\hline Power & $306 \mathrm{MVA}$ & $\mathrm{G}$ & Generator & $\mathrm{R}$ & Resistance \\
\hline Frequency & $60 \mathrm{~Hz}$ & $\mathrm{~N}$ & Neutral & $\mathrm{C}$ & Capacitance \\
\hline Phase(s) & 3 & $\mathrm{MB}$ & Main Breaker & $\mathrm{U}$ & Voltage Measurement \\
\hline Voltage & $6.9 \mathrm{kV}$ & $\mathrm{MS}$ & Make Switch & $\mathrm{I}$ & Current Measurement \\
\hline Current & $25.6 \mathrm{kA}$ & $\mathrm{ABUB}$ & Aux. Breaker & & \\
\hline Impedance & $0.1556 \Omega$ & XFMR & Transformer & & \\
\hline Peak Current & $70.2 \mathrm{kA}$ & $\mathrm{TD}$ & Test Device & & \\
\hline Neutral & Not Earthed & $\mathrm{X}$ & Inductance & & \\
\hline
\end{tabular}

Fig. 41. KEMA Test Circuit S01 used in Test 2-19

The voltage and current profile for the entire duration of the experiment is shown in Fig. 42. Key experimental measurements are presented in Table 14. The transient region for current phases is presented in Fig. 43. Energy and power profiles are presented in Fig. 44. 


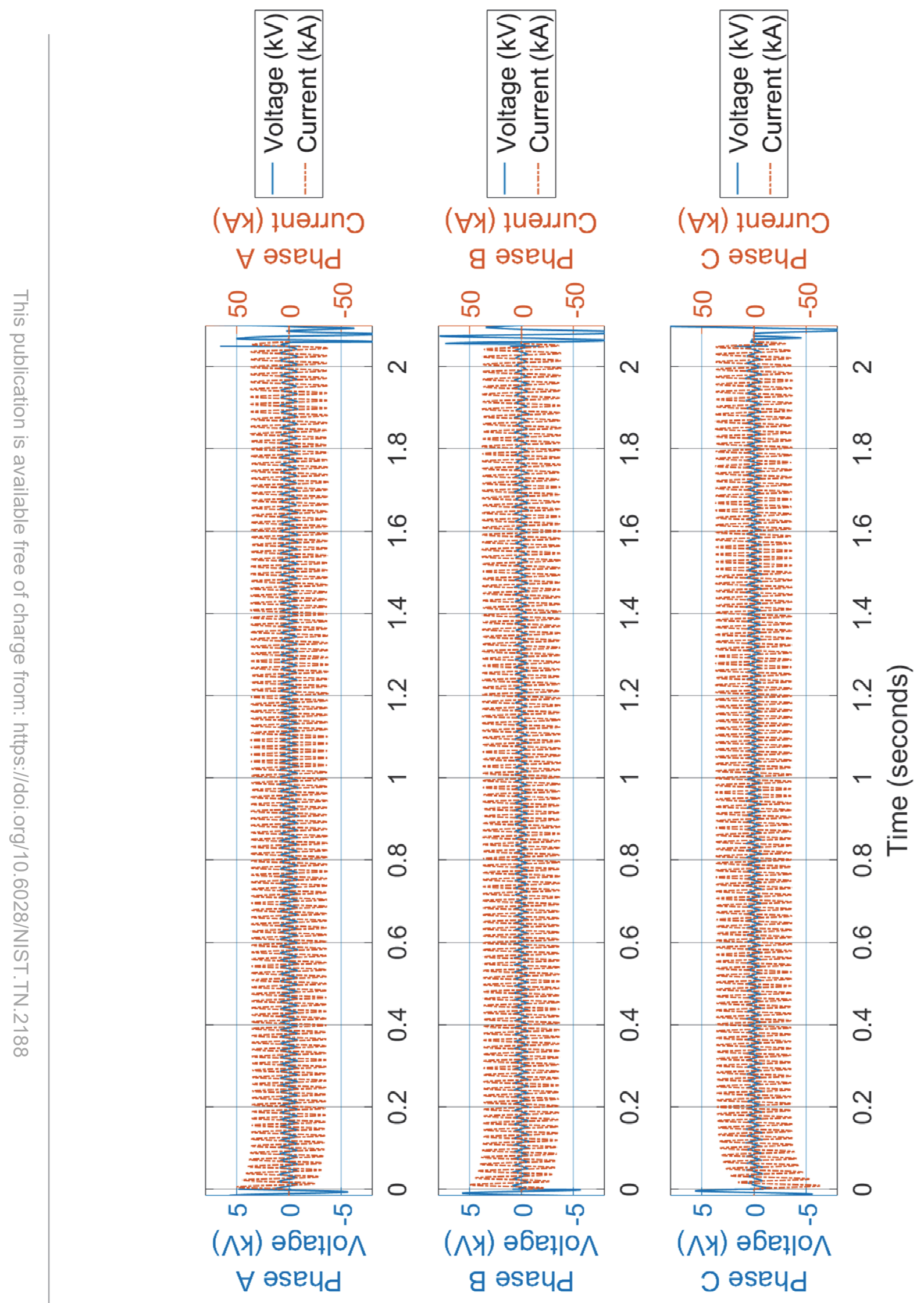

Fig. 42. Voltage and Current profile during Test 2-19. Measurement uncertainty \pm 3 percent. 
Table 14. Key measurements for Test 2-19. Measurement uncertainty \pm 3 percent.

\begin{tabular}{|l|l|c|c|c|}
\hline Phase & Units & A & B \\
\hline Applied voltage, phase-to-ground & $\mathrm{kV} R M S$ & 4.00 & 4.02 & 3.97 \\
\hline Applied voltage, phase-to-phase & $\mathrm{kV}$ RMS & \multicolumn{4}{|c|}{6.92} \\
\hline Making current & $\mathrm{kA}$ peak & 50.2 & 49.3 & -63.0 \\
\hline Current, a.c. component, beginning & kARMS & 25.5 & 25.9 & 25.8 \\
\hline Current, a.c. component, middle & kARMS & 25.8 & 26.5 & 25.7 \\
\hline Current, a.c. component, end & kARMS & 25.8 & 26.6 & 25.5 \\
\hline Current, a.c. component, average & kARMS & 25.6 & 26.1 & 25.6 \\
\hline Current, a.c. component, three-phase average & kARMS & \multicolumn{4}{|c|}{25.8} \\
\hline Duration & S & 2.05 & 2.05 & 2.05 \\
\hline Generator Energy & MJ & \multicolumn{4}{|c|}{46.5} \\
\hline
\end{tabular}
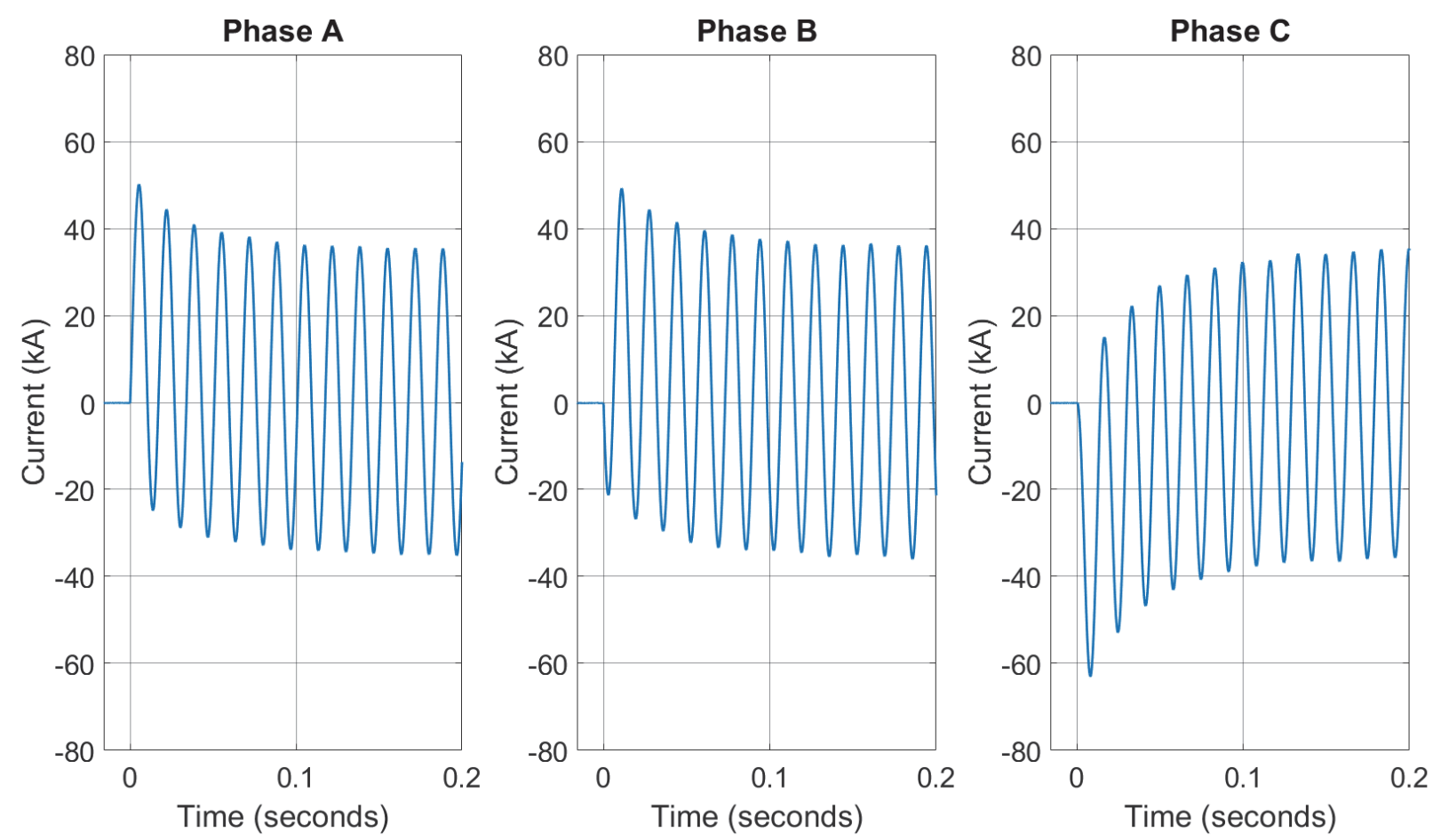

Fig. 43. Transient current profiles for Test 2-19. Measurement uncertainty \pm 3 percent. 


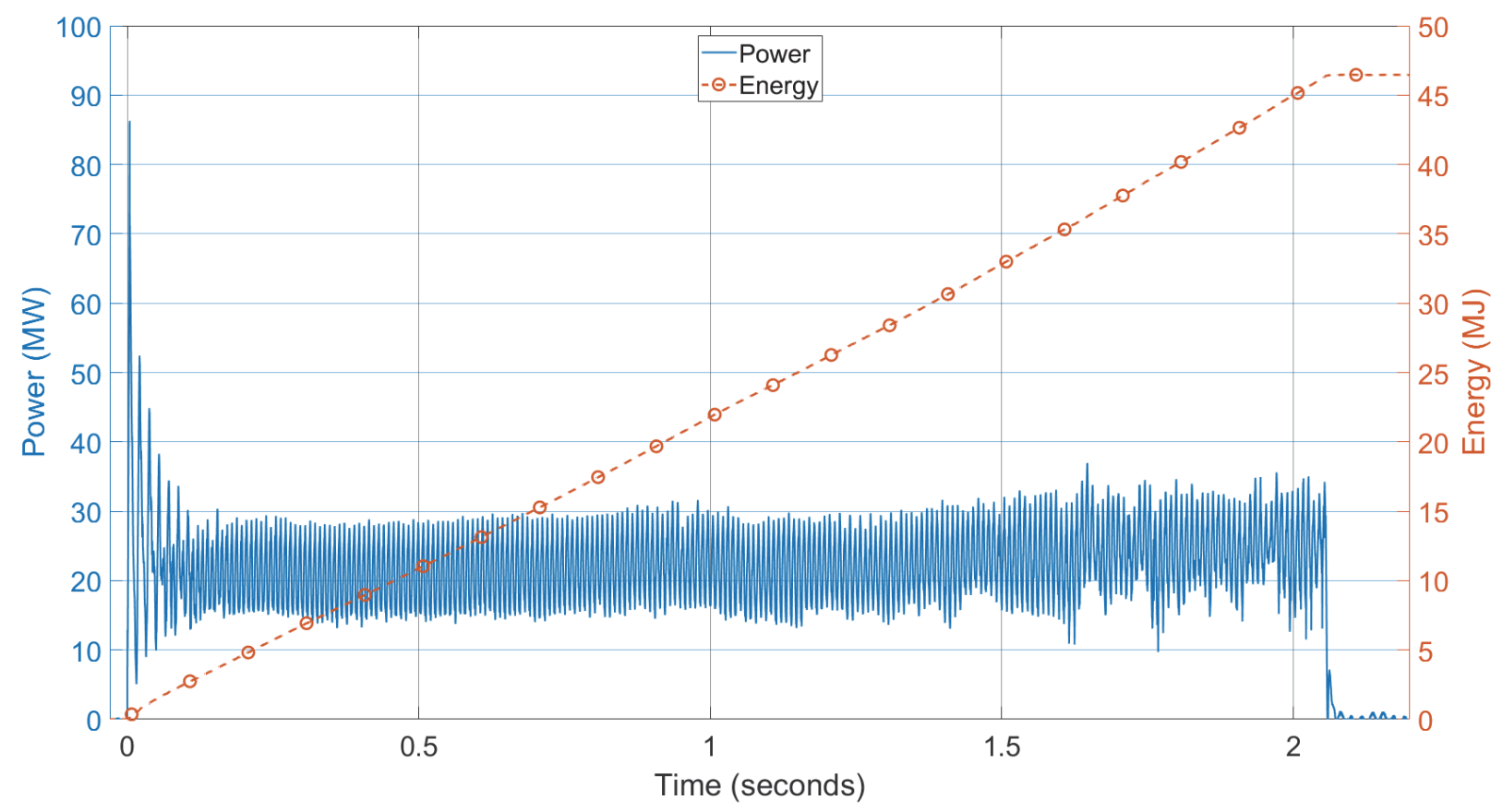

Fig. 44. Power and Energy for Test 2-19. Measurement uncertainty \pm 3 percent.

\subsubsection{Rack 3 particle collection}

Particles were collected on carbon tape for the five equipment rack locations described in Section 2.4.1.7; scanning electron microscopy was used to analyze characteristic particle size and metal composition for samples on the conductive carbon tape from Rack 3 for all four experiments, and for Racks 1 to 5 on Test 2-21, described in Section 3.2.2.4.

Carbon tape collectors on Rack 3 of Test 2-19 displayed a low density of micrometer-scale particles, primarily mixed oxidized aluminum and oxidized iron particles. An area scan showing the density and mixtures of these oxidized aluminum, and iron particles is shown in Fig. 45 More detailed analysis of particle types and degrees of oxidation is discussed in Section 3.2.2.4. 


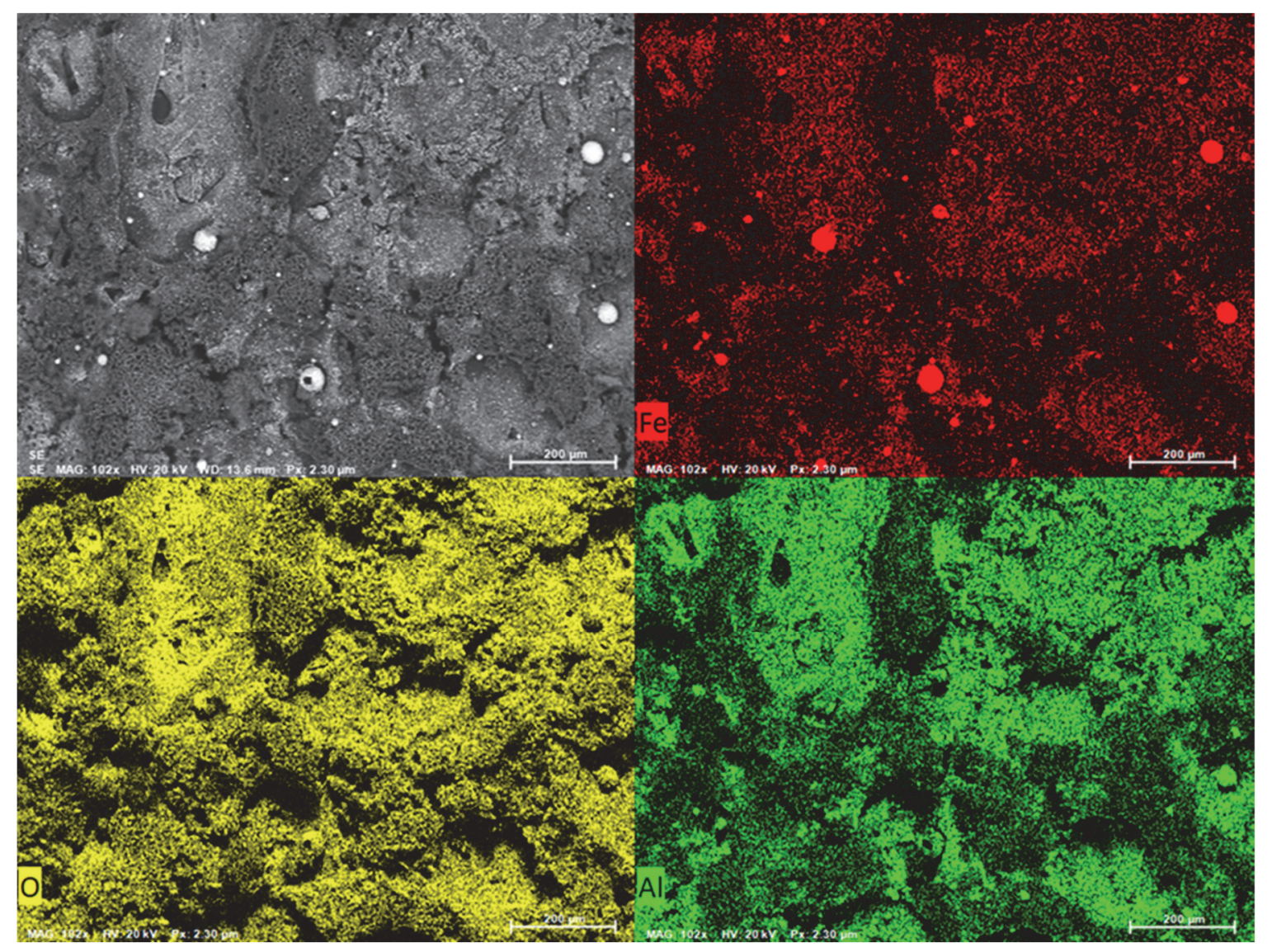

Fig. 45. Rack 3 particle SEM (upper left) with intensity plot for iron (upper right), aluminum (lower right) and oxygen (lower left). The elemental composition included primarily separate particles composites of partially oxidize aluminum and iron, iron only or aluminum only. Compared to Fig. 76, a low density of background aluminum oxide was observed. 


\subsection{Test $2-21-6.9 \mathrm{kV}, 25 \mathrm{kA}, 4 \mathrm{~s}$ duration, aluminum bus}

Test 2-21 was performed on September 13, 2018 at 3:56 PM eastern daylight time (EDT). The temperature was approximately $24^{\circ} \mathrm{C}\left(75^{\circ} \mathrm{F}\right)$, approximately 85 percent relative humidity and approximately $102.5 \mathrm{kPa}$ of pressure. The weather was overcast with zero precipitation and an east wind at approximately $11 \mathrm{~km} / \mathrm{h}(7 \mathrm{mi} / \mathrm{h})$.

\subsubsection{Observations}

Observations documented below are based on review of video and thermal imaging that was taken during the experiment. The observations provided in Table 15 include an approximate time reference. Corresponding images are provided in Fig. 46. Thermal images are presented in Fig. 47.

Table 15. Observations from Test 2-21

\begin{tabular}{|c|l|}
\hline Time (ms) & Observation \\
\hline $\mathbf{2 5}$ & Bottom of front door begins to open \\
\hline $\mathbf{4 9}$ & Particle eject reaches top rack $(0.91 \mathrm{~m}[3.00 \mathrm{ft}]$ above enclosure) \\
\hline $\mathbf{8 1}$ & Particle ejecta passes rear rack $($ rack $\# 2$ at $0.91 \mathrm{~m}[3.00 \mathrm{ft}]$ behind enclosure) \\
\hline $\mathbf{1 0 1}$ & Front door no longer secured by latch (continues to open) \\
\hline $\mathbf{1 0 1}$ & Particle eject passes $1.83 \mathrm{~m}[6.00 \mathrm{ft}]$ above enclosure \\
\hline $\mathbf{3 2 5}$ & $\begin{array}{l}\text { Particle ejecta passes } 2^{\text {nd }} \text { rear rack (rack \#3 at } 1.83 \mathrm{~m}[6.00 \mathrm{ft}] \text { behind } \\
\text { enclosure) }\end{array}$ \\
\hline $\mathbf{6 4 5}$ & Initial arc breach of rear panel \\
\hline $\mathbf{8 9 7}$ & $\begin{array}{l}\text { Particle ejecta impacts test facility cell wall }(5.18 \mathrm{~m}[17.00 \mathrm{ft}] \text { behind } \\
\text { enclosure) }\end{array}$ \\
\hline $\mathbf{9 0 5}$ & Top front vent stops emitting hot gas and particle ejecta \\
\hline $\mathbf{1 1 8 1}$ & $\begin{array}{l}\text { Significant quantity of particle ejecta impacting test facility cell wall behind } \\
\text { enclosure }\end{array}$ \\
\hline $\mathbf{4 1 2 1}$ & Decrease in cell illumination consistent with experiment termination \\
\hline $\mathbf{1 5 1 0 0 0}$ & Test cell pedestal ventilation fan turned on \\
\hline $\mathbf{8 0 3 0 7 7}$ & NIST data acquisition ends \\
\hline
\end{tabular}

Photographs of damage to the electrical enclosure are shown in Fig. 48. The enclosure breached at the upper rear panel of the primary cable connection compartment. There were also breaches on both sides of the enclosure adjacent to the breach on the upper rear panel. The door on the front of the enclosure with a single quarter turn latch opened during the experiment. As in Test 2-19, internal pressure caused the bottom of the door to push out and the post-experiment inspection indicated that the side of the panel was bowed outward. The combination of these two effects allowed the latch mechanism to slip and the door to open.

The instrumentation Rack \#2 located approximately $0.91 \mathrm{~m}(3.00 \mathrm{ft})$ from the rear of the enclosure sustained damage to one of the horizontal DIN rails. One DIN rail on Rack \#2 was severed. Aluminum and steel byproducts were observed on all instrumentation racks and the cameras located near the cell wall. The amount was less than that observed in Test 2-24. Due to Test 2-24 being performed sequentially before this Test 2-21, the amount of aluminum oxide on the test cell surfaces is difficult to characterize from observation. Within 
the electrical enclosure, there were puddles of solidified aluminum on the enclosure floor. This was later determined to be the aluminum from the rear electrical insulators supporting the bus bars directly below the location of the shorting wire. These insulators are shown in Fig. 8 prior to the experiment. 

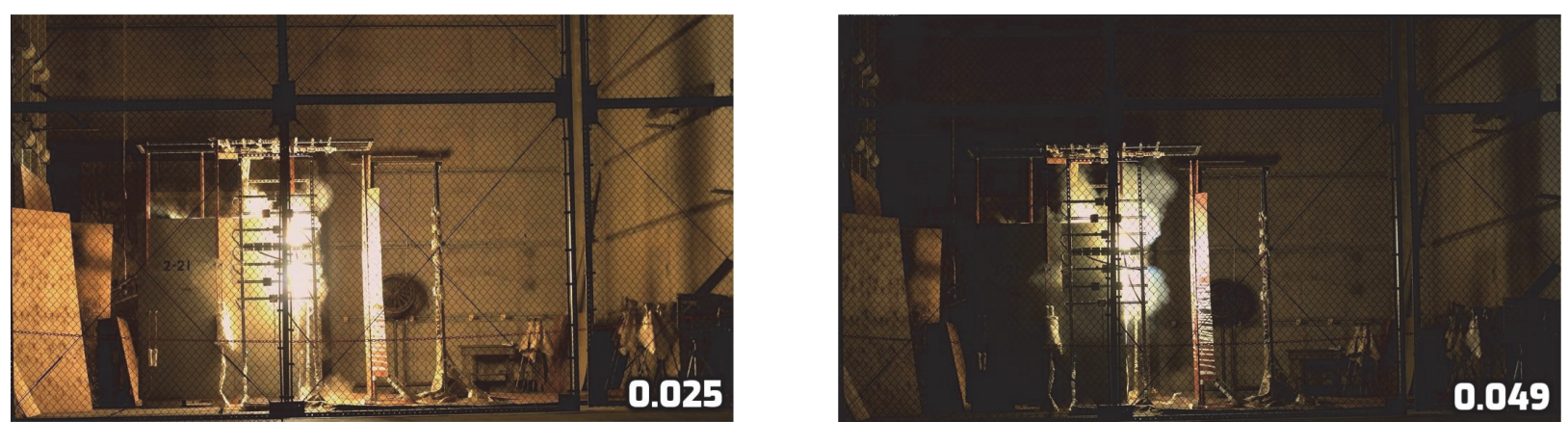

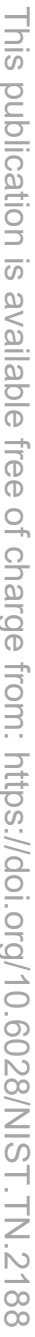
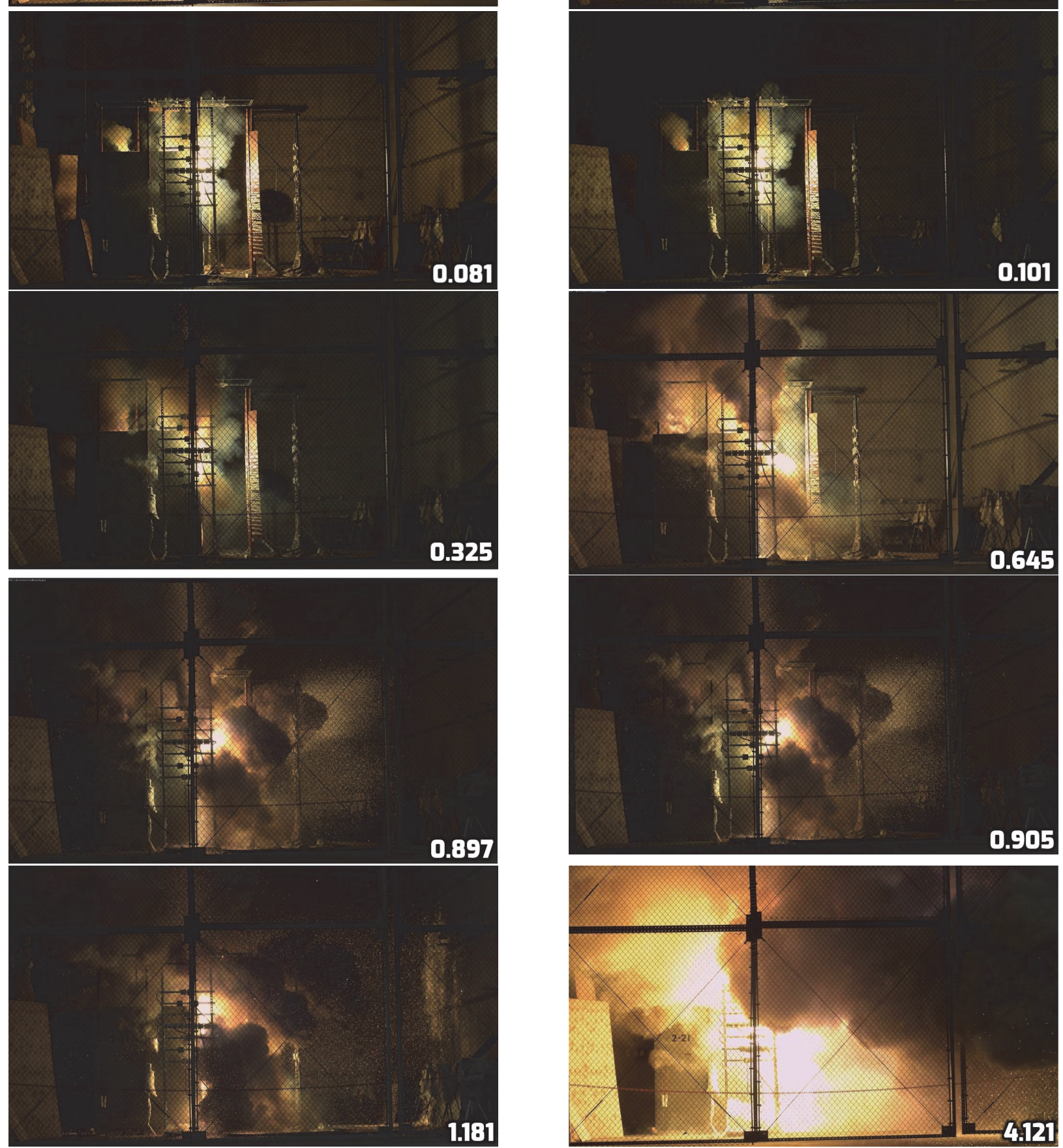

Fig. 46. Sequence of images for Test 2-21 (image time stamp in seconds) 


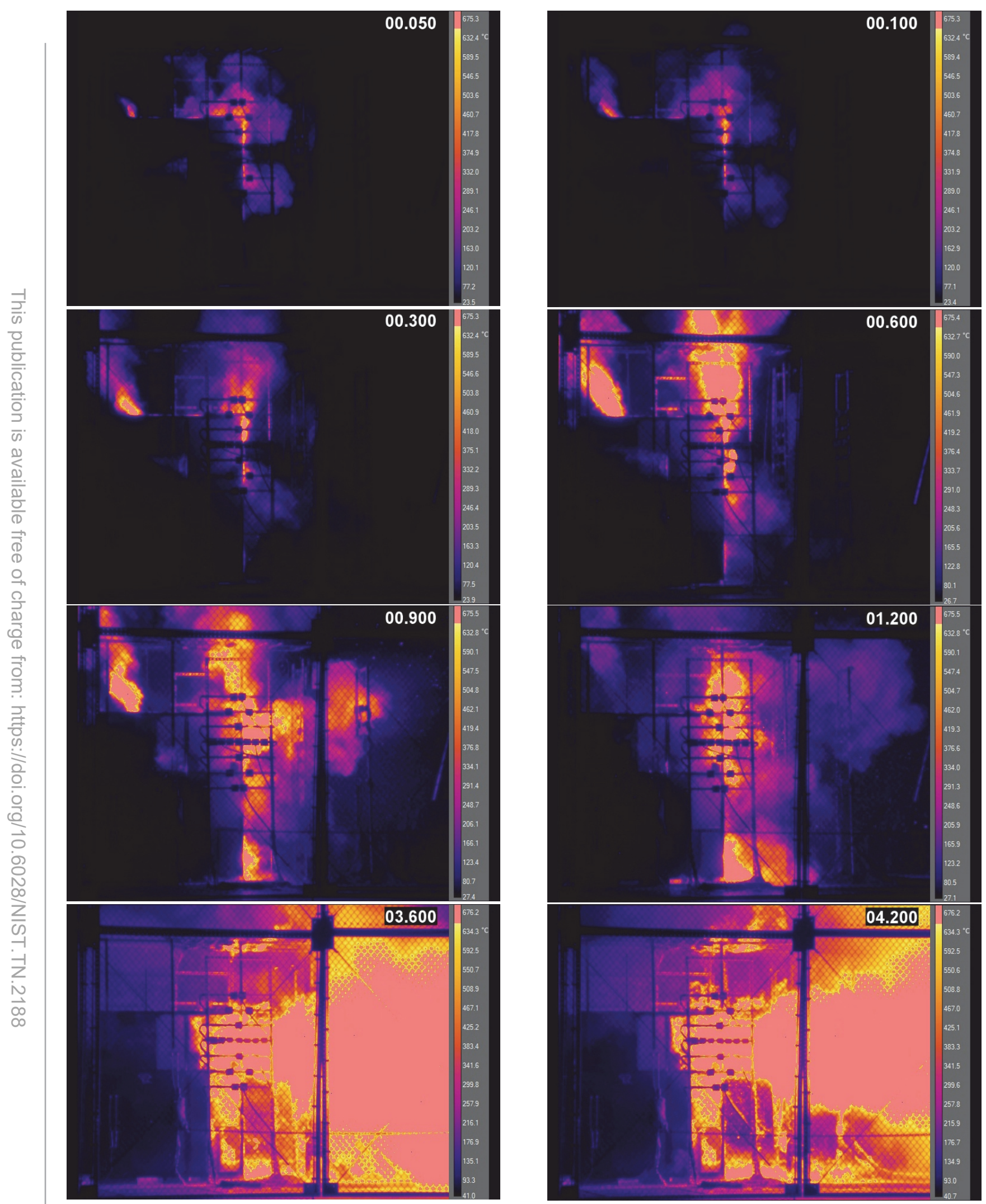

Fig. 47. Sequence of Thermal Images from Test 2-21 (image time stamp in seconds) 

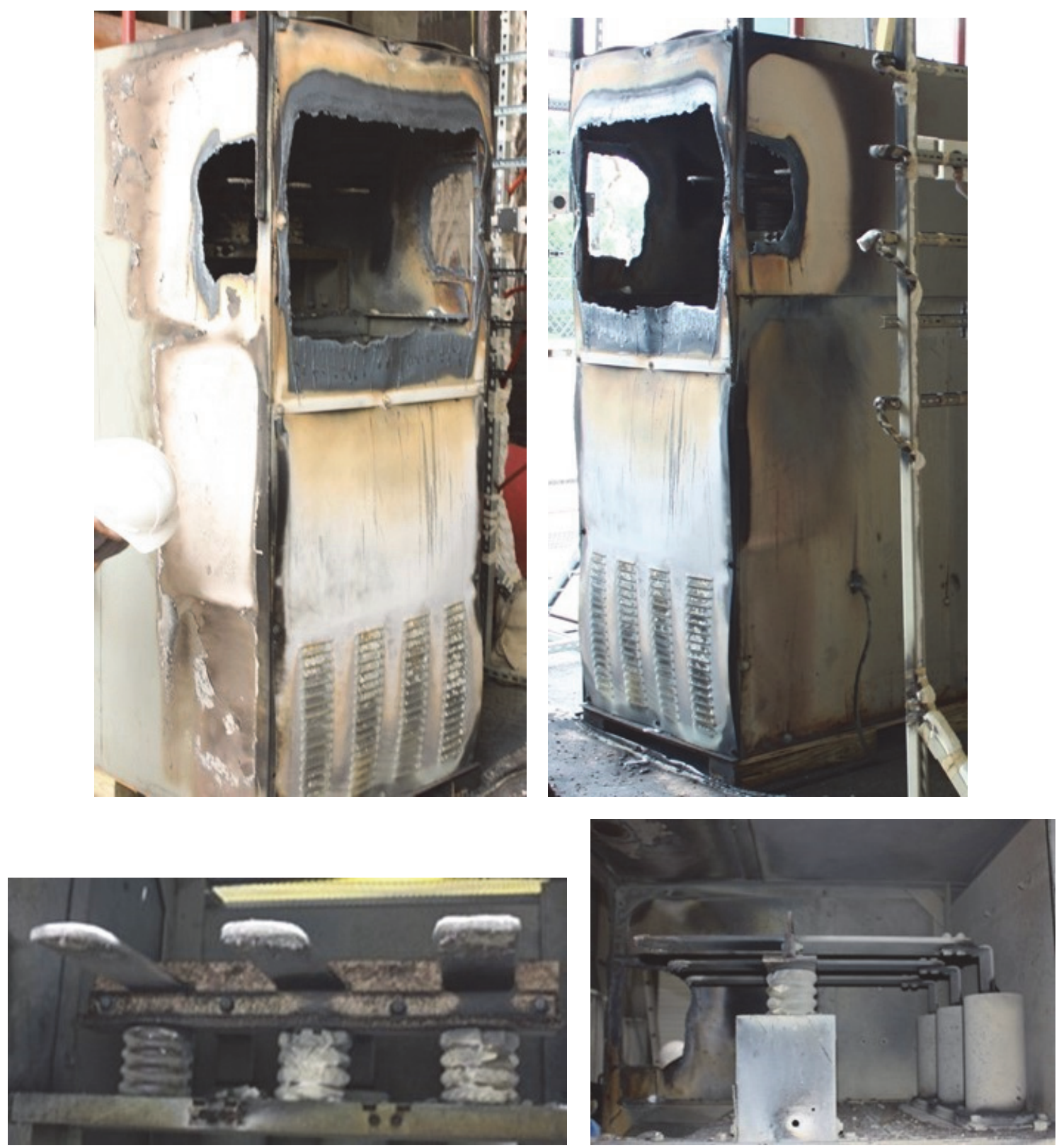

Fig. 48. Enclosure Post-Test 2-21. (Top: back of enclosure; Bottom: remaining bus bar material. Bottom left as viewed from rear of enclosure, bottom right as viewed from the side at the rear of the enclosure with the side panel removed.) 


\subsubsection{Measurements}

Measurements made during Test 2-21 are the same as made in Test 2-19. Measurements are reported below.

\subsubsection{Thermal Measurements}

This experiment resulted in physical damage to several thermal instruments located directly behind the test device. Fig. 49 shows the damage to Rack \#2 which is located approximately $0.91 \mathrm{~m}(3.00 \mathrm{ft})$ from the back of the enclosure. The central rail (middle in photo) showed damage to four instruments. The Inconel on the center plate TC is completely gone, and the outer plate TCs show partial destruction of the Inconel. The right (in photo) ASTM slug calorimeter was damaged, and the copper slug was not present after the experiment.

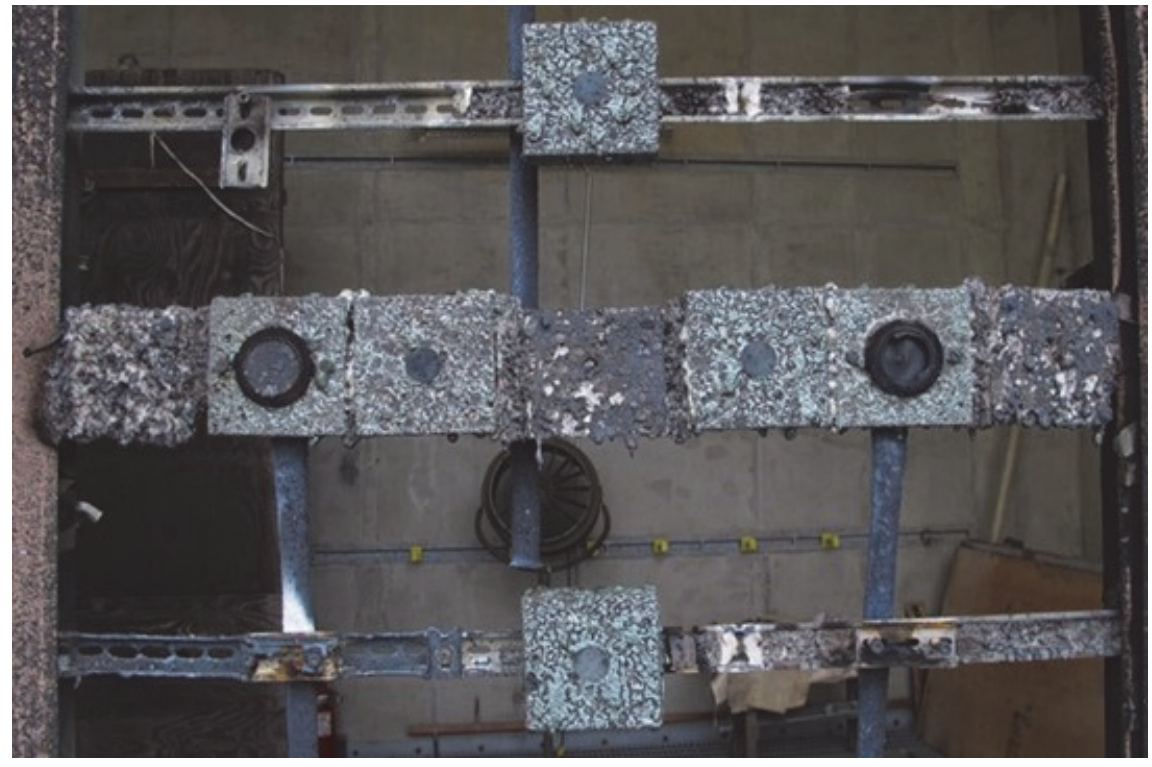

Fig. 49. Photo of damage to central instruments (Rack \#2-0.91 m rear)

Thermal measurements from the active instruments are reported below for Test 2-21. These include PT measurements in Table 16, ASTM Slug Calorimeter measurements in Table 17, and $\mathrm{T}_{\text {cap }}$ slug measurements in Table 18. The maximum reading is identified with bold text. Two ASTM slug calorimeters were non-functional during this experiment. Instrument E and F show normal ambient temperatures prior to the experiment; however, immediately after the arc begins, the measurements provide abnormal readings.

Significant amounts of incident energy $\left(\mathrm{kJ} / \mathrm{m}^{2}\right)$, as measured by the $\mathrm{T}_{\text {cap }}$ slugs, were transferred to areas surrounding the switchgear during the post-arcing phase of the HEAF. For this experiment, the effect is most evident in areas on the top and sides of the switchgear rather than near the rear of the switchgear where the arc jet penetrated the rear panel. In the area where the arc jet penetrated the rear panel ( $\mathrm{T}_{\text {cap }} 11$ through $\left.\mathrm{T}_{\text {cap }} 26\right)$, most of the incident energy contribution occurred during the arcing phase of the HEAF. 
Table 16. Summary of plate thermometer measurements Test 2-21

\begin{tabular}{|c|c|c|c|c|c|}
\hline $\begin{array}{c}\text { Rack } \\
\text { No. }\end{array}$ & $\begin{array}{c}\text { Plate } \\
\text { No. }\end{array}$ & Location & $\begin{array}{c}\text { Max Heat } \\
\text { Flux } \\
\left(\mathbf{k W} / \mathbf{m}^{2}\right) \\
\pm 1 \mathbf{k W} / \mathbf{m}^{2} \\
\text { or } \pm 5 \%\end{array}$ & $\begin{array}{c}\text { Average } \\
\text { Heat Flux } \\
\text { During Arc } \\
\left(\mathbf{k W} / \mathbf{m}^{2}\right) \\
\pm 1 \mathrm{~kW} / \mathbf{m}^{2} \\
\text { or } \pm 5 \%\end{array}$ & Comment \\
\hline 1 & 1 & Top & 424.3 & 190.4 & \\
\hline 1 & 3 & Mid-Right & 795.9 & 344.8 & \\
\hline 1 & 5 & Mid-Center & 567.1 & 257.9 & \\
\hline 1 & 7 & Mid-Left & 415.6 & 183.1 & \\
\hline 1 & 9 & Bottom & 779.3 & 236.1 & \\
\hline 2 & 10 & Top & 835.2 & 415.0 & \\
\hline 2 & 12 & Mid-Right & --- & --- & Possible EMI \\
\hline 2 & 14 & Mid-Center & 4296.5 & 1659.4 & \\
\hline 2 & 16 & Mid-Left & --- & --- & \\
\hline 2 & 18 & Bottom & 5381.7 & 1146.9 & \\
\hline 3 & 19 & Top & 2677.0 & 470.9 & \\
\hline 3 & 21 & Mid-Right & 1732.5 & 643.0 & \\
\hline 3 & 23 & Mid-Center & --- & --- & Possible EMI \\
\hline 3 & 25 & Mid-Left & 1552.0 & 583.9 & \\
\hline 3 & 27 & Bottom & 2481.9 & 891.9 & \\
\hline 4 & 28 & Top & 1135.1 & 181.1 & \\
\hline 4 & 30 & Mid-Right & 294.4 & 113.3 & \\
\hline 4 & 32 & Mid-Center & 596.0 & 117.7 & \\
\hline 4 & 34 & Mid-Left & 548.5 & 263.9 & \\
\hline 4 & 36 & Bottom & 1515.4 & 318.1 & \\
\hline 5 & 37 & Front & 644.8 & 268.2 & \\
\hline 5 & 39 & Center-Right & 445.5 & 169.1 & \\
\hline 5 & 41 & Center-Mid & 452.3 & 187.6 & \\
\hline 5 & 43 & Center-Left & 372.1 & 125.4 & \\
\hline 5 & 45 & Back & 130.1 & 60.7 & \\
\hline
\end{tabular}


Table 17. Summary of ASTM slug calorimeter measurements, Test 2-21

\begin{tabular}{|c|c|c|c|c|c|}
\hline $\begin{array}{c}\text { Rack } \\
\text { No. }\end{array}$ & $\begin{array}{c}\text { ASTM } \\
\text { No. }\end{array}$ & Location & $\begin{array}{c}\text { Incident } \\
\text { Energy } \\
\left(\mathbf{k J} / \mathrm{m}^{2}\right) \\
\pm 18 \mathrm{KJ} / \mathrm{m}^{2} \text { or } \\
\pm 4 \%\end{array}$ & $\begin{array}{c}\text { Time to Max } \\
\text { Temperature } \\
\text { (s) } \\
\pm \mathbf{3} \%\end{array}$ & Comment \\
\hline 1 & A & Top & 735.7 & 6.5 & \\
\hline 1 & B & Mid-Right & 1106.3 & 7.3 & \\
\hline 1 & $\mathrm{C}$ & Mid-Left & 808.7 & 7.7 & \\
\hline 1 & D & Bottom & 799.1 & 7.8 & \\
\hline 2 & $\mathrm{E}$ & Top & - - - & - - - & Device Failure \\
\hline 2 & $\mathrm{~F}$ & Mid-Right & $-\ldots$ & $-\ldots$ & Device Failure \\
\hline 2 & G & Mid-Left & 3642.2 & 11.2 & \\
\hline 2 & $\mathrm{H}$ & Bottom & 2014.2 & 16.6 & \\
\hline 3 & I & Top & 1334.9 & 5.3 & \\
\hline 3 & $\mathrm{~J}$ & Mid-Right & 1684.0 & 10.5 & \\
\hline 3 & $\mathrm{~K}$ & Mid-Left & 2223.8 & 5.7 & \\
\hline 3 & $\mathrm{~L}$ & Bottom & 2876.7 & 6.4 & \\
\hline 4 & M & Top & -- & -- & Device Failure \\
\hline 4 & $\mathrm{~N}$ & Mid-Right & 539.7 & 10.3 & \\
\hline 4 & $\mathrm{O}$ & Mid-Left & 1009.7 & 9.0 & \\
\hline 4 & $\mathrm{P}$ & Bottom & 589.8 & 16.5 & \\
\hline 5 & Q & Front & 1098.4 & 5.7 & \\
\hline 5 & $\mathrm{R}$ & Center-Right & 590.6 & 4.8 & \\
\hline 5 & $\mathrm{~S}$ & Center-Left & 544.7 & 5.8 & \\
\hline 5 & $\mathrm{~T}$ & Back & 257.9 & 5.3 & \\
\hline
\end{tabular}


Table 18. Summary of $T_{\text {cap }}$ Slug Measurement, Test 2-21

\begin{tabular}{|c|c|c|c|c|c|}
\hline $\begin{array}{c}\text { Rack } \\
\text { No. } \\
\end{array}$ & $T_{\text {cap }}$ No. & Location & $\begin{array}{c}\text { Heat Flux } \\
\text { During Arc } \\
\left(\mathbf{k W / m ^ { 2 } )}\right. \\
\pm 2.9 \%\end{array}$ & $\begin{array}{c}\text { Incident } \\
\text { Energy } \\
\text { During Arc } \\
\text { Phase }\left(\mathrm{kJ} / \mathrm{m}^{2}\right) \\
\pm 5 \%\end{array}$ & $\begin{array}{c}\text { Total } \\
\text { Incident } \\
\text { Energy } \\
\left(\mathbf{k J} / \mathbf{m}^{2}\right) \\
\pm 5 \%\end{array}$ \\
\hline 1 & 2 & Top & 550.7 & 1156.9 & 1397.1 \\
\hline 1 & 4 & Mid-Right & 521.9 & 1112.4 & 1635.9 \\
\hline 1 & 6 & Mid-Left & 446.6 & 972.0 & 1296.3 \\
\hline 1 & 8 & Bottom & 461.2 & 986.0 & 1455.4 \\
\hline 2 & 11 & Top & 3318.4 & 5610.8 & 5901.6 \\
\hline 2 & 13 & Mid-Right & 6741.4 & 6219.9 & 6987.5 \\
\hline 2 & 15 & Mid-Left & 3422.0 & 6567.6 & 6861.0 \\
\hline 2 & 17 & Bottom & 3509.2 & 7162.8 & 7790.5 \\
\hline 3 & 20 & Top & 1034.0 & 1974.1 & 2270.6 \\
\hline 3 & 22 & Mid-Right & 1090.7 & 2200.3 & 2703.2 \\
\hline 3 & 24 & Mid-Left & 1133.3 & 2181.9 & 2638.1 \\
\hline 3 & 26 & Bottom & 1557.5 & 2995.1 & 3346.5 \\
\hline 4 & 29 & Top & 284.8 & 652.5 & 1192.4 \\
\hline 4 & 31 & Mid-Right & 299.3 & 696.0 & 1142.2 \\
\hline 4 & 33 & Mid-Left & 355.1 & 882.6 & 1491.2 \\
\hline 4 & 35 & Bottom & 322.7 & 779.4 & 1282.2 \\
\hline 5 & 38 & Front & 492.2 & 983.9 & 1292.6 \\
\hline 5 & 40 & Center-Right & 343.2 & 818.3 & 1084.9 \\
\hline 5 & 42 & Center-Left & 304.3 & 678.1 & 1082.7 \\
\hline 5 & 44 & Back & 203.0 & 446.1 & 845.1 \\
\hline
\end{tabular}

\subsubsection{Internal Pressure}

The pressure profiles for the first two tenths of a second are shown in Fig. 50. After the initial pressure spike, the pressure rapidly decays to a relative steady state. The peak pressure is higher in the primary cable connection compartment as would be expected since this is the compartment where the arc is initiated. The maximum change in pressure in the primary cable connection compartment is approximately $28.3 \mathrm{kPa}(4.1 \mathrm{psi})$ above ambient at its peak. The maximum change in pressure in the breaker compartment is approximately $4.8 \mathrm{kPa}(0.7 \mathrm{psi})$ above ambient. The $0 \mathrm{kPa}$ to $207 \mathrm{kPa}(0 \mathrm{psia}$ to $30 \mathrm{psia})$ and $0 \mathrm{kPa}$ to $345 \mathrm{kPa}(0 \mathrm{psia}$ to $50 \mathrm{psia})$ transducer recordings at a specific location were consistent. 

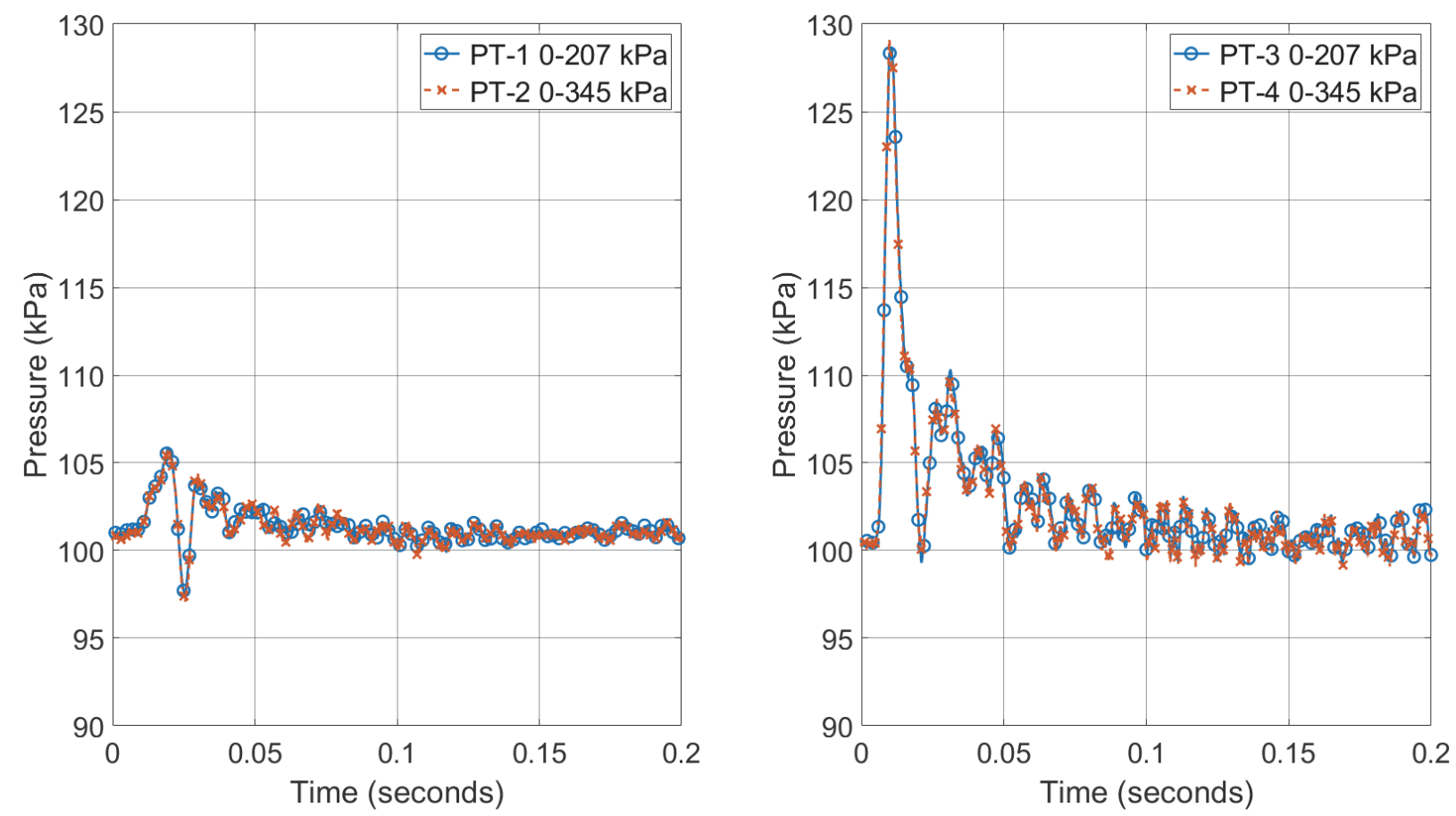

Fig. 50. Pressure Measurements from Test 2-21 (breaker compartment - left; arcing compartment - right). Measurement uncertainty \pm 3 percent.

\subsubsection{Mass Measurements}

Mass loss measurements were made for the enclosure metal cladding and the bus conductors. All measurements made are reported in Appendix C. One observation that was made in all experiments was that for many of the steel cladding panels, the post-experiment measurements were larger than the pre-experiment measurements. This is likely caused by the plating of the electrical conductors on to the metal cladding. As such, for the panels that experienced breach, the actual mass loss is likely greater than what is reported below. For this experiment, the upper rear panel experienced breach as did the two adjacent side panels (far side rear panel and primary cable compartment bus upper panel). The total mass loss measured using an electronic balance (NIST Scale 2) was approximately $1.15 \mathrm{~kg}$ for the primary cable compartment bus side upper panel and approximately $8.09 \mathrm{~kg}$ for the rear upper panel. The mass loss for the far side rear panel was not made due to the mass exceeding the range of the balance. Using the photographic method, the estimated mass loss for the far side rear panel was approximately $1.85 \mathrm{~kg}$. The bus bars lost a total of $1.966 \mathrm{~kg}$ (658 g Phase A, $641 \mathrm{~g}$ Phase B, $667 \mathrm{~g}$ Phase C). These mass measurements were made using an electronic mass balance (NIST Scale 2) with an expanded uncertainty, derived from manufacturer specifications, of $\pm 1 \mathrm{~g}$, with a $95 \%$ confidence interval.

Given the known thickness of the panel and density comparable mass loss estimate could be provided using the graphical approximation approach. For this experiment the breach area estimates are shown in Fig. 51. Using this technique, the mass loss estimate is approximately $11.24 \mathrm{~kg}$. Therefore, the total mass loss from the electrical enclosure is estimated via graphical analysis at approximately $10.63 \mathrm{~kg}$ to $11.24 \mathrm{~kg}$. 

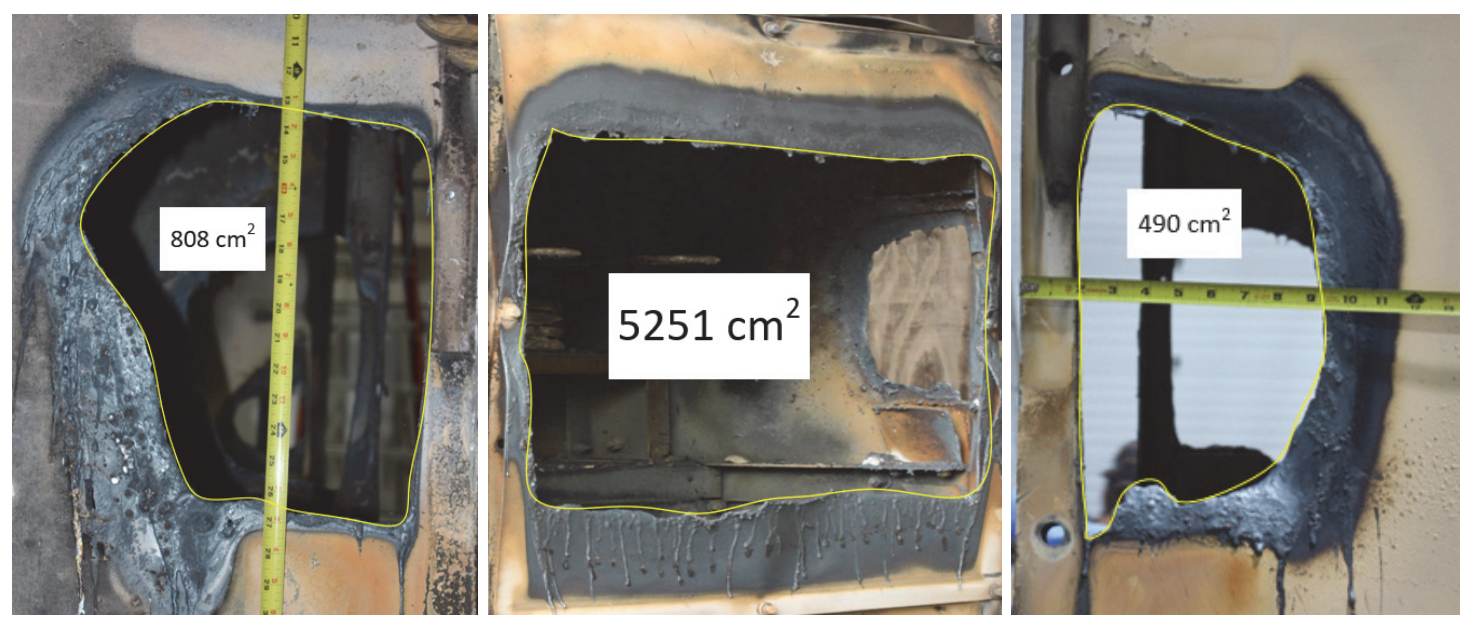

Fig. 51. Photo showing breach opening on far side rear panel (left), upper rear panel (center), and the primary cable compartment bus side upper panel (right). Software used to estimate opening area.

\subsubsection{Particle Characterization}

Particles were collected on carbon tape and aerogel blocks from the five equipment rack locations described in Section 2.4.1.7. Scanning electron microscopy was used to analyze characteristic particle size, metal composition and degree of oxidation of particles from samples on the conductive carbon tape from racks 1, 3, 4, and 5. Samples from rack 2, located approximately $0.91 \mathrm{~m}(3.00 \mathrm{ft})$ from the rear of the switchgear, were damaged or combusted due to high temperatures and/or exposure to the arc jet.

Degree of oxidation in collected particles was quantified by energy dispersive spectroscopy $\mathrm{x}$-ray analysis (EDS). Like prior small-scale $(6.9 \mathrm{kV}, 10 \mathrm{kA}, 4 \mathrm{~ms}$ [2]) arc fault experiments, a bimodal particle size distribution was observed including nanoscale particles displaying full oxidation (O:Al ratios near 1:1) and micrometer-scale particles displaying partial oxidation (O:Al ratios of 0.24-0.74:1). An example of this bimodal distribution is shown in Fig. 52; (a) $10 \mu \mathrm{m}$ particles displayed an oxidized surface skin and metal core (attributed to melted, then solidified Al microparticles) and (b) $<100 \mathrm{~nm}$ particles which displayed full oxidation (attributed to melted, then vaporized and oxidized $\mathrm{Al}$ ). 


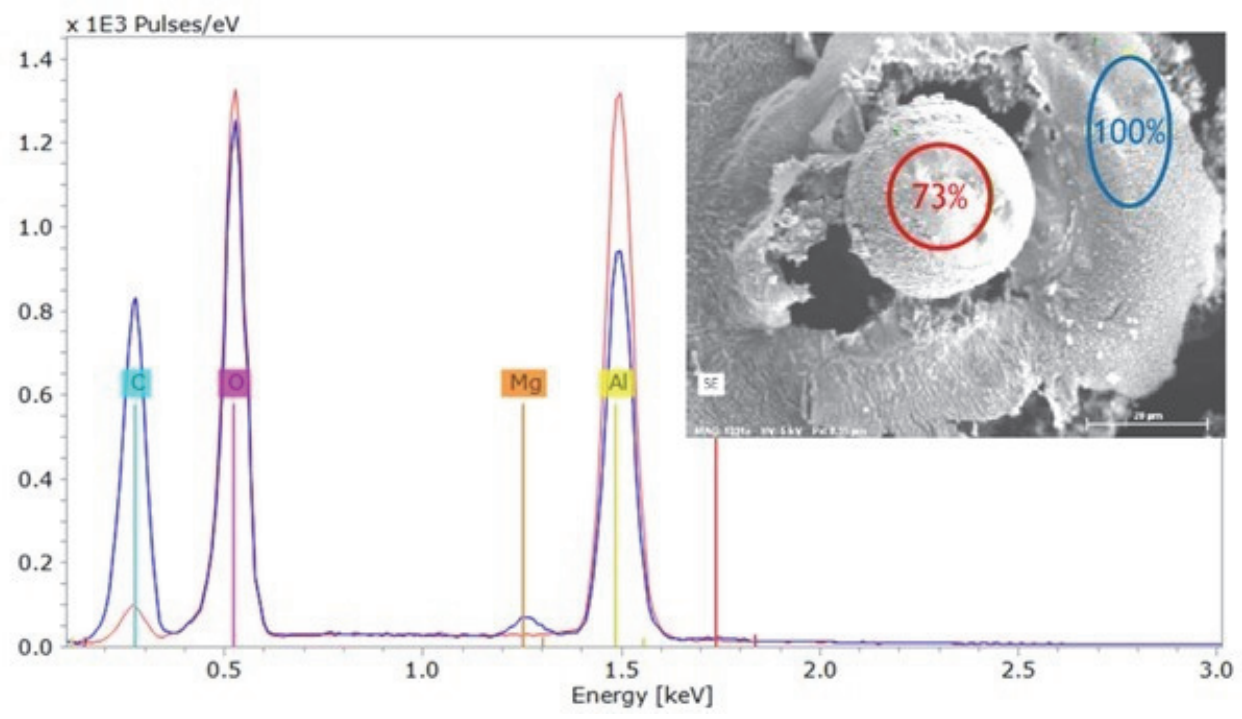

Fig. 52. Scanning electron micrograph showing a roughly $30 \mu \mathrm{m}$ size particles of partial oxidation, estimated at 73 percent, as well as a nanoscale layer displaying higher oxidation estimated at 100 percent. The carbon tape contains both carbon (C) and oxygen background.

\subsection{Rack 1 particle collection}

Rack 1 (approximately $0.91 \mathrm{~m}$ from the switchgear) primarily displayed micrometer sized metal particles with degrees of oxidation of 25 percent to 75 percent. Micrometer sized particles were identified of three types: aluminum/oxygen, iron/oxygen, and aluminum/iron/oxygen. An example of an aluminum, oxygen and iron particle is shown in Fig. 53 and Fig. 54.

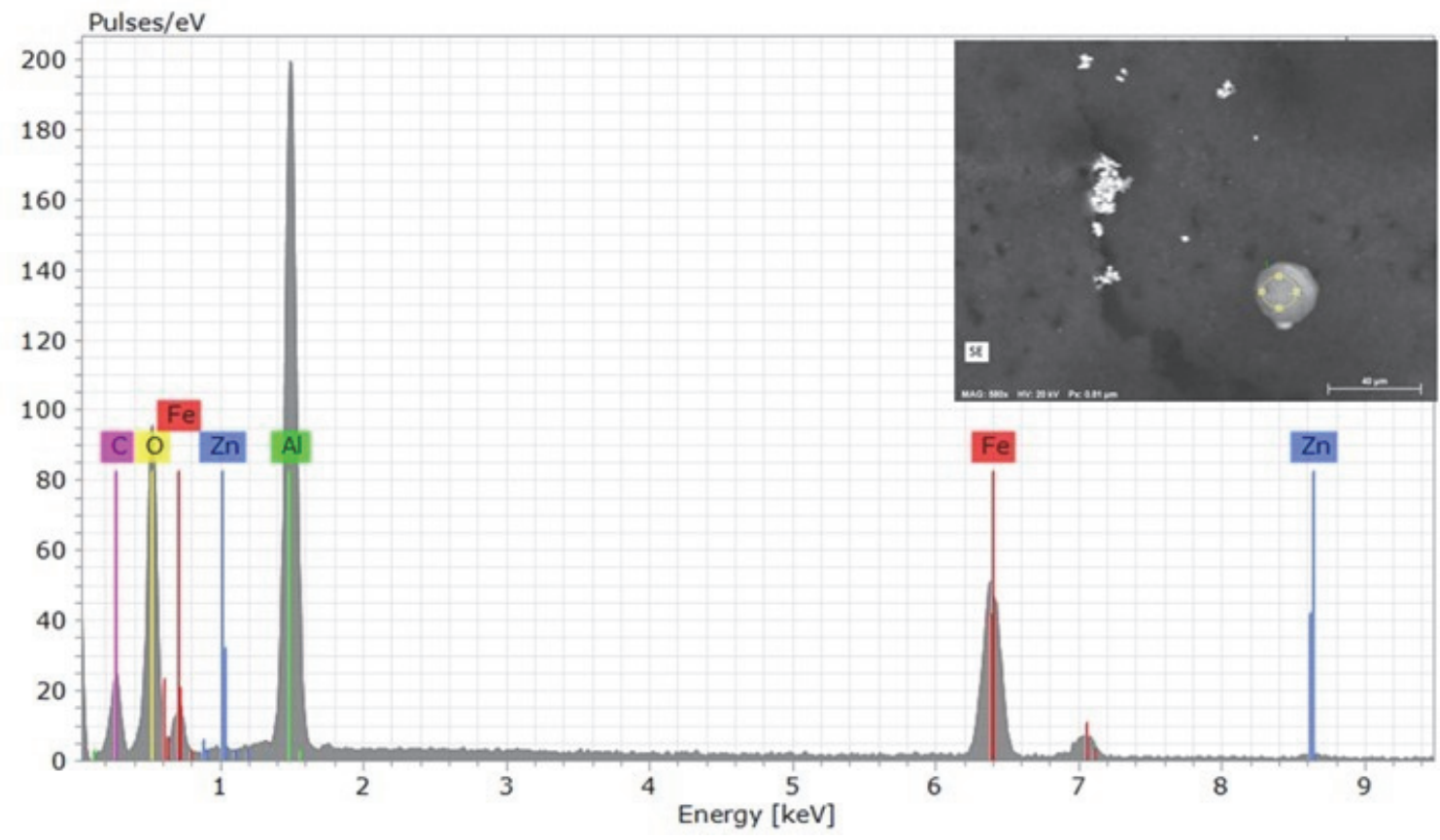

Fig. 53. Scanning electron micrograph showing a $20 \mu \mathrm{m}$ particle displaying approximately 45 percent oxidation, and a composition including both aluminum and iron. 


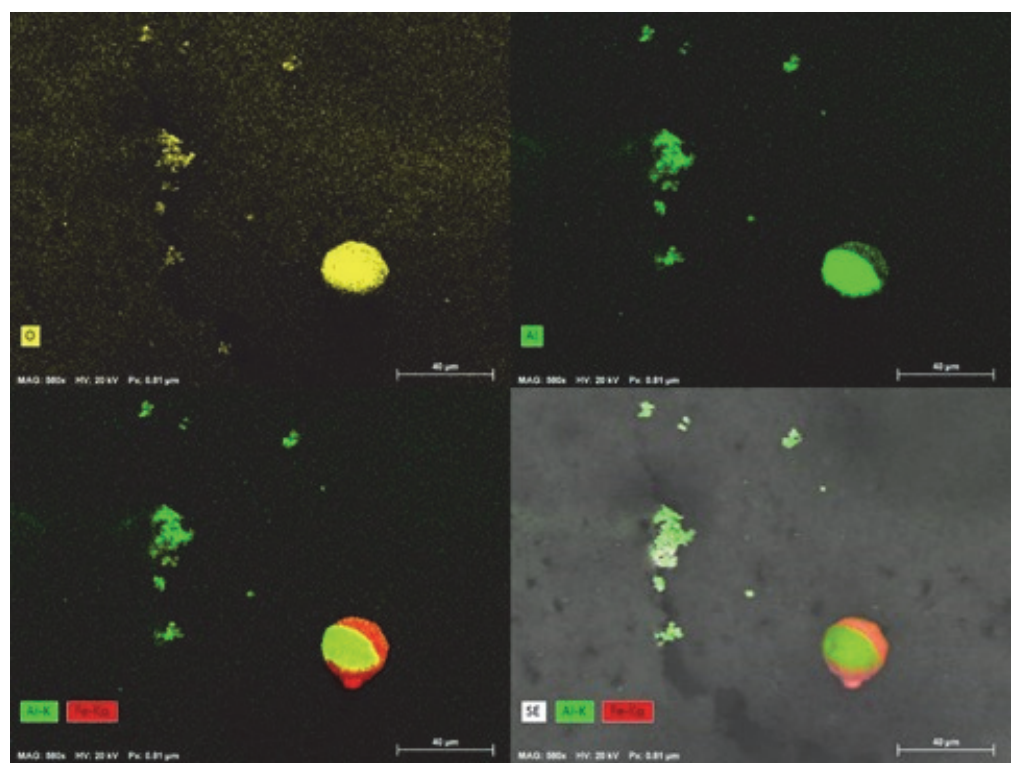

Fig. 54. Scanning electron micrograph showing a roughly $20 \mu \mathrm{m}$ particle displaying approximately 45 percent oxidation, and both aluminum and iron rich regions.

This region was further analyzed to spatially separate the signals for aluminum, iron, and oxygen to display the particle composition and spatial oxidation more clearly, and results are shown in Fig. 54. The spherical particle appears composed of separate regions of aluminum or iron with a higher degree of oxidation apparent for the aluminum portion of the particle. The aluminum droplet would appear to be consistent with bus bar composition, while the molten iron may be consistent with the steel switchgear enclosure, which melted during breach, as shown in Fig. 51 (left). In addition, a sparse concentration of aluminum oxide nanoparticles was observed, as shown in Fig. 54. As described below, much higher concentrations of aluminum oxide particles were observed on Rack 3 and the wall associated with the direction of the arc jet, which emerged from the cable connection compartment of the enclosure.

Individual particles collected on Rack 1 were analyzed by energy dispersive x-ray analysis to determine ratios of elements including aluminum, iron, and oxygen. These particles were analyzed at the location of the yellow crosshairs shown in Fig. 55, and analysis indicated particles were partially oxidized and composed of iron only, aluminum only, or composites of aluminum and iron, with observed oxygen: metal ratios of 38 percent to 73 percent. 

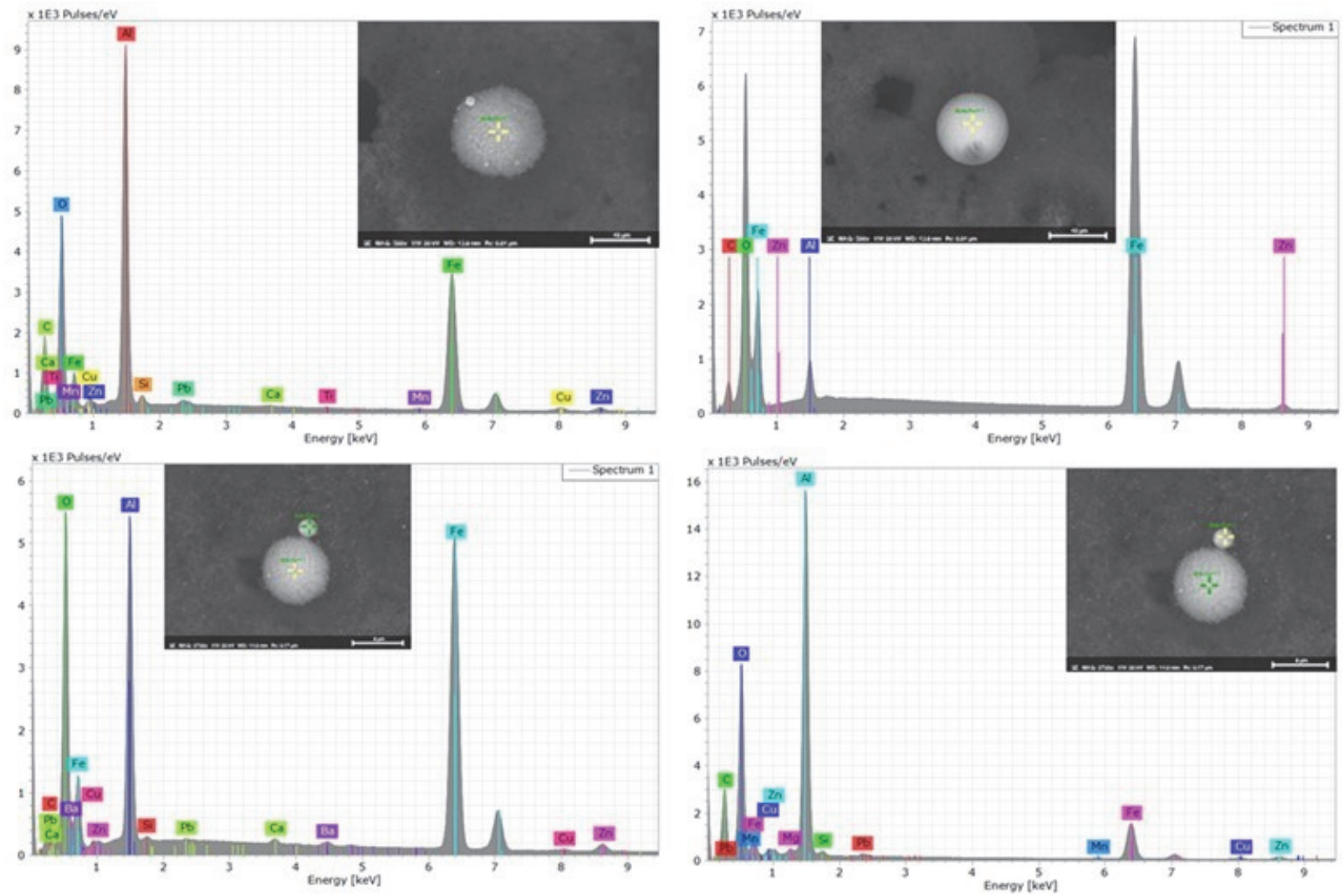

Fig. 55. Rack 1 particle compositions

\subsection{Rack 3 particle collection}

Rack 3 (approximately $1.83 \mathrm{~m}$ from the rear of the switchgear) displayed a much higher density of background nanoscale aluminum oxide particles, as well as a distribution of mixed oxidized aluminum and oxidized iron particles. Oxidation ratios of 32 percent to 73 percent were measured. An area scan showing the increased density and mixtures of these oxidized aluminum, and iron particles is shown in Fig. 56. 


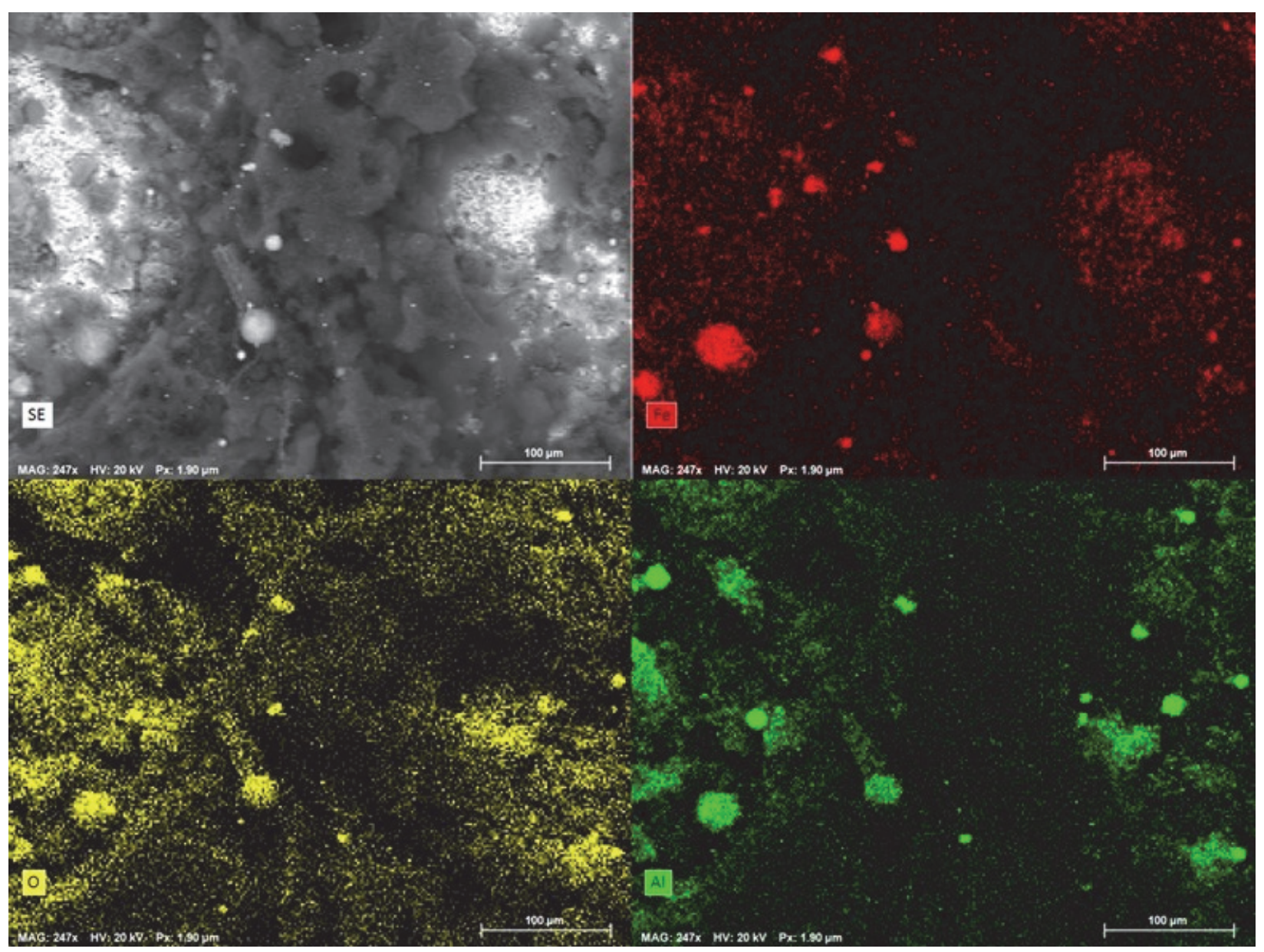

Fig. 56. Rack 3 particle SEM (upper left) with intensity plot for iron (upper right), aluminum (lower right) and oxygen (lower left). Composition included composites of aluminum and iron, iron only, or aluminum only, with oxygen:metal ratios of 32 percent to 70 percent.

Individual micrometer size particles and the nanoparticle background collected on Rack 3 were analyzed by energy dispersive $x$-ray analysis at the location of the yellow crosshairs shown in Fig. 57, and analysis indicated particles were partially oxidized and composed of iron only, aluminum only, or composites of aluminum and iron, with observed oxygen:metal ratios of 38 percent to 73 percent. The background of Rack 3 contained a higher density of nanosized aluminum oxide than other rack locations, which may be consistent with evaporation of aluminum electrodes, followed by oxidation and condensation. 

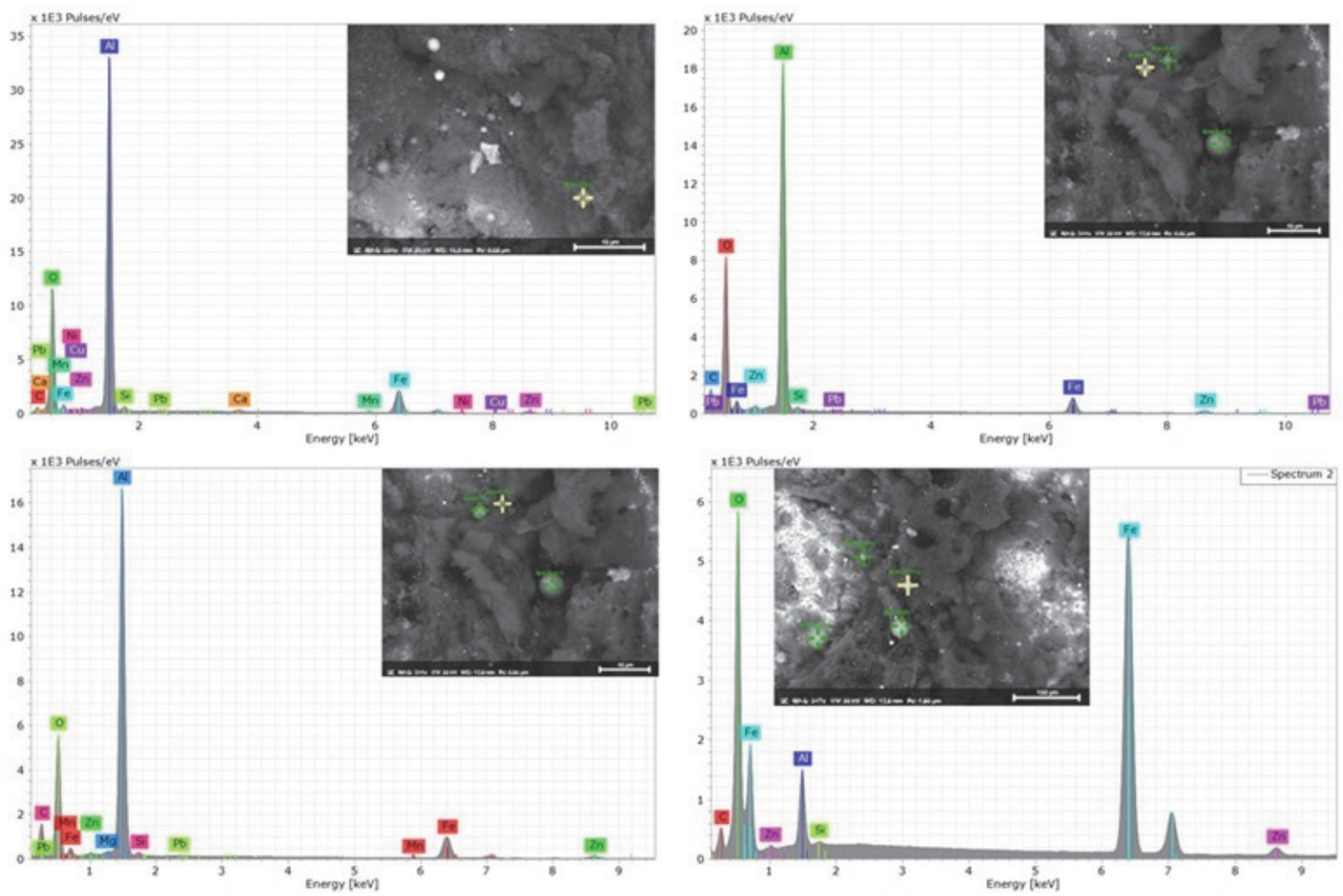

Fig. 57. Rack 3 micrometer size particle compositions were primarily iron only, aluminum only, or composites of aluminum and iron, with oxygen:metal ratios of 32 percent to 73 percent. The background shows a higher density of nanosized aluminum oxide vs. Rack 1 , suggestive of evaporated $\mathrm{Al}_{2} \mathrm{O}_{3}$.

\subsection{Back wall particle collection}

In prior aluminum bus bar experiments [6], the post-experiment presence of aluminum residue on chamber walls and electrical supplies was noted. The residue was sufficiently conductive to short the three phases of power shown in Fig. 58, motivating interest in confirming the occurrence of the phenomena and determining composition of wall deposits. In Test 2-21, carbon tape was used to collect post-HEAF particle deposits on the back wall of the chamber at approximately $5.18 \mathrm{~m}(17.00 \mathrm{ft})$ from the rear of the switchgear.

Individual micrometer size particles and the nanoparticle background collected on the back wall were analyzed by energy dispersive x-ray analysis as shown in Fig. 59 and Fig. 60. Individual micrometer-scale particles shown in Fig. 59 again consisted of iron only, aluminum only, or composites of aluminum and iron, atop a dense background of deposited aluminum oxide nanoparticles. For the micrometer sized particles, oxygen:metal ratios of approximately 40 percent to 75 percent were observed as shown in Fig. 60. This type of analysis could not conclusively conclude the conductive characteristics of the particles. Given that the phenomena were observed in several of the experiments, future experiments should focus on developing apparatus to evaluate the conductive nature of this phenomena. 


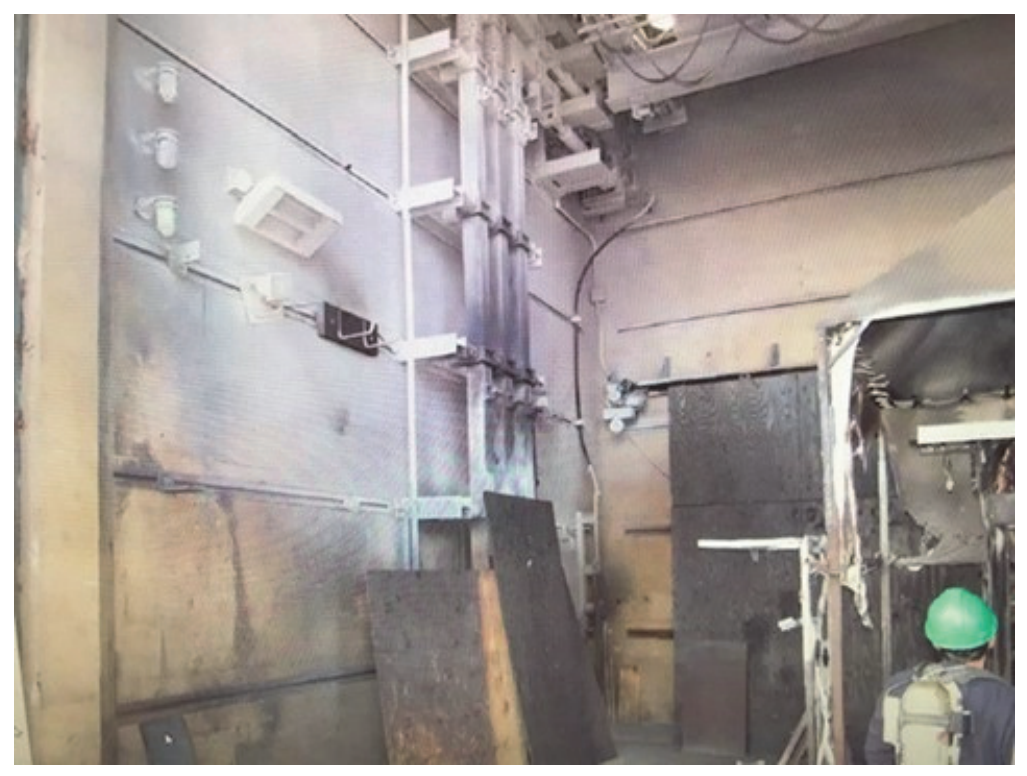

Fig. 58. Conductive white powder residue after previous aluminum bus bar switchgear experiments, which may have consisted of melted $\mathrm{Al}$ and evaporated $\mathrm{Al}_{2} \mathrm{O}_{3}$. (Photo from Phase 1 experiments [6])

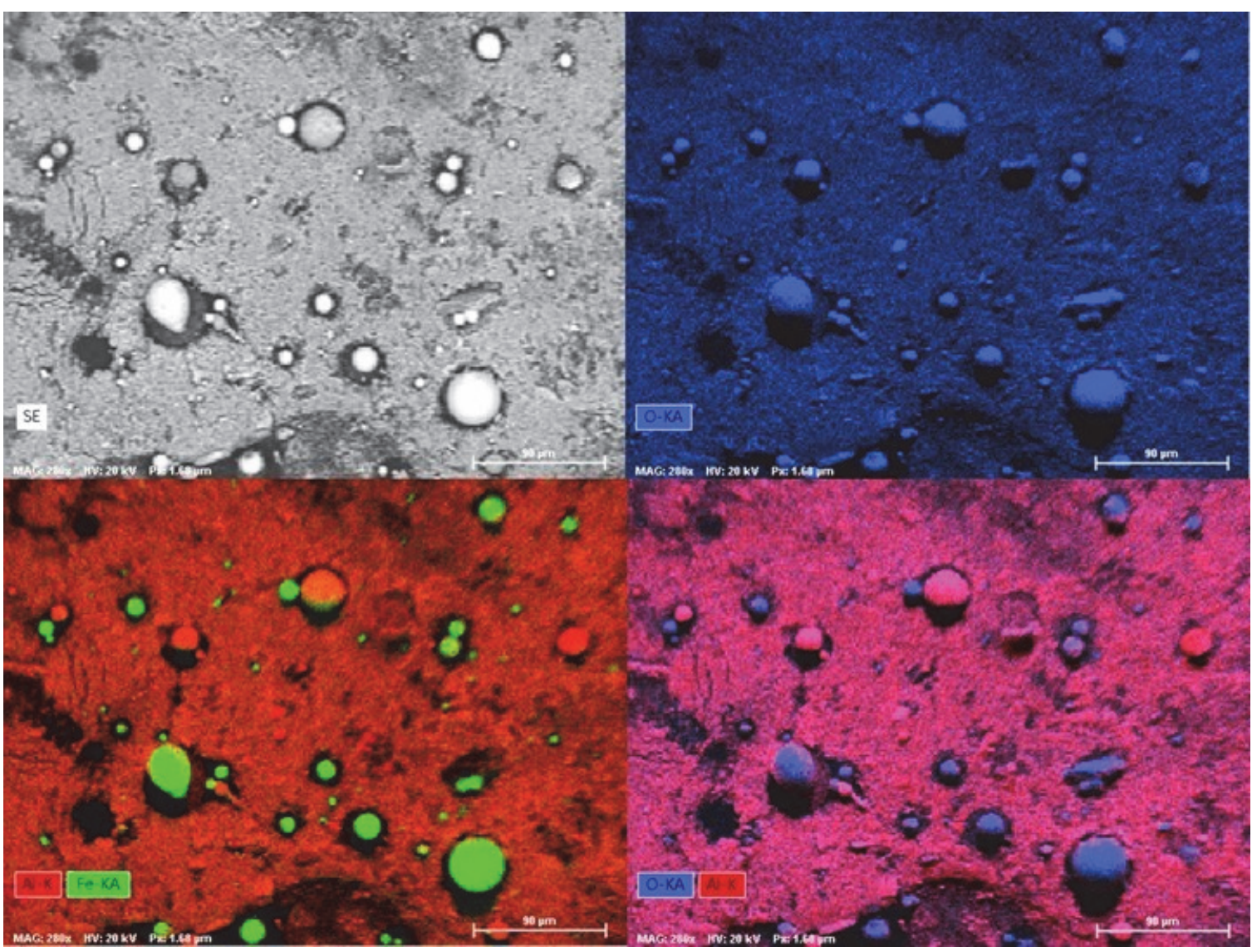

Fig. 59. Back wall particulates consisted of nanoscale $\mathrm{Al}_{2} \mathrm{O}_{3}$ (large background $\mathrm{Al}$ and $\mathrm{O}$ signal) and partially oxidized particles of aluminum (red) and iron (green). 

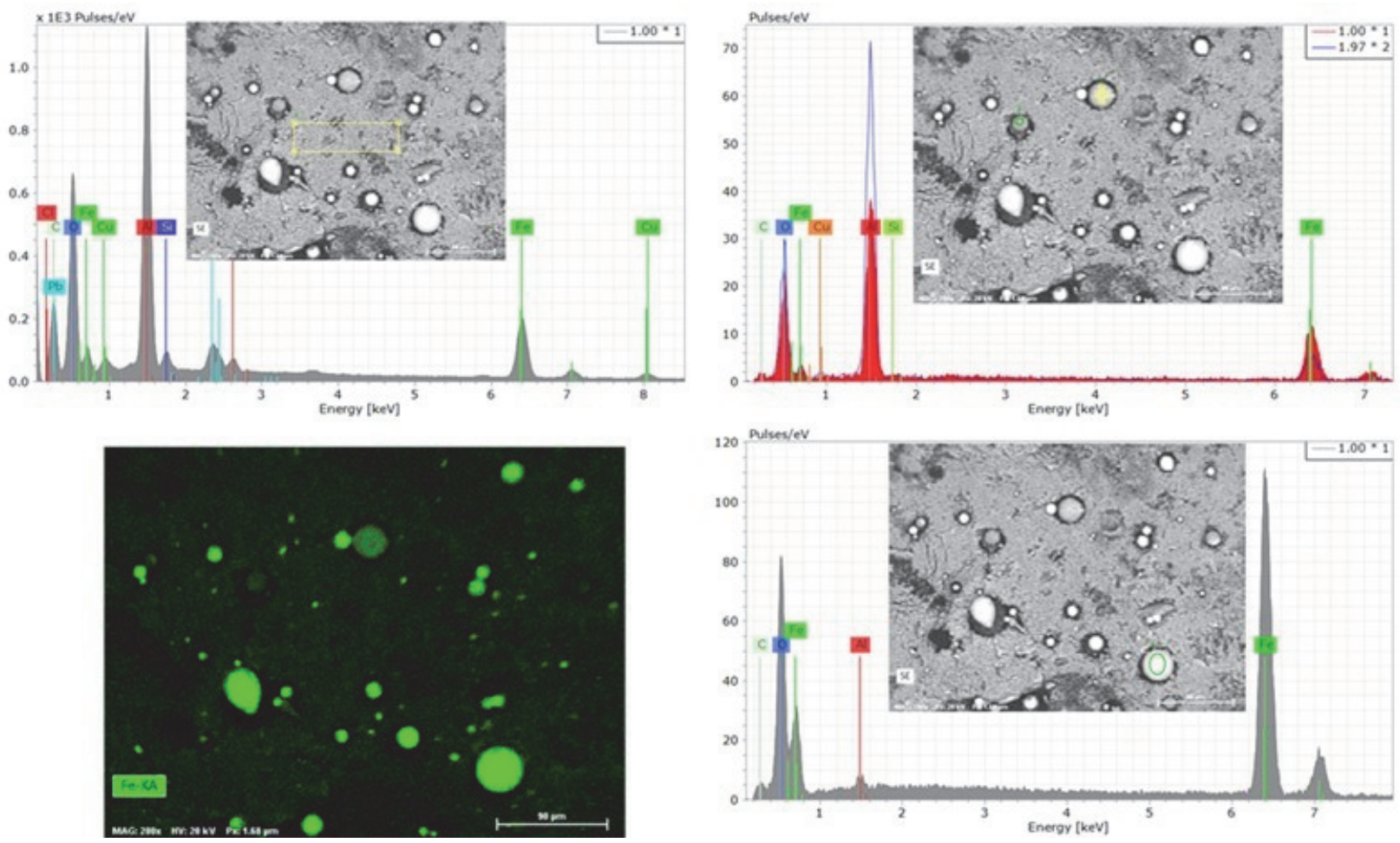

Fig. 60. Back wall deposits included nanoscale $\mathrm{Al}_{2} \mathrm{O}_{3}$ (upper left, $\mathrm{O}: \mathrm{Al}$ ratio $~ 0.65$ ), oxidized Al microparticles (upper right), and individual Fe particles (green).

\subsection{Rack 4 particle collection}

Rack 4 (approximately $0.91 \mathrm{~m}$ to the side of the switchgear) displayed a low density of background nanoscale aluminum oxide particles, and separate oxidized iron and oxidized aluminum micrometer-scale particles, as shown in Fig. 61. Due to analysis equipment issues, relative oxygen:metal ratios were not calculated for individual particles. Global oxygen:metal ratios of approximately 90 percent were observed for large area scans, similar to Racks 1 through 3. 


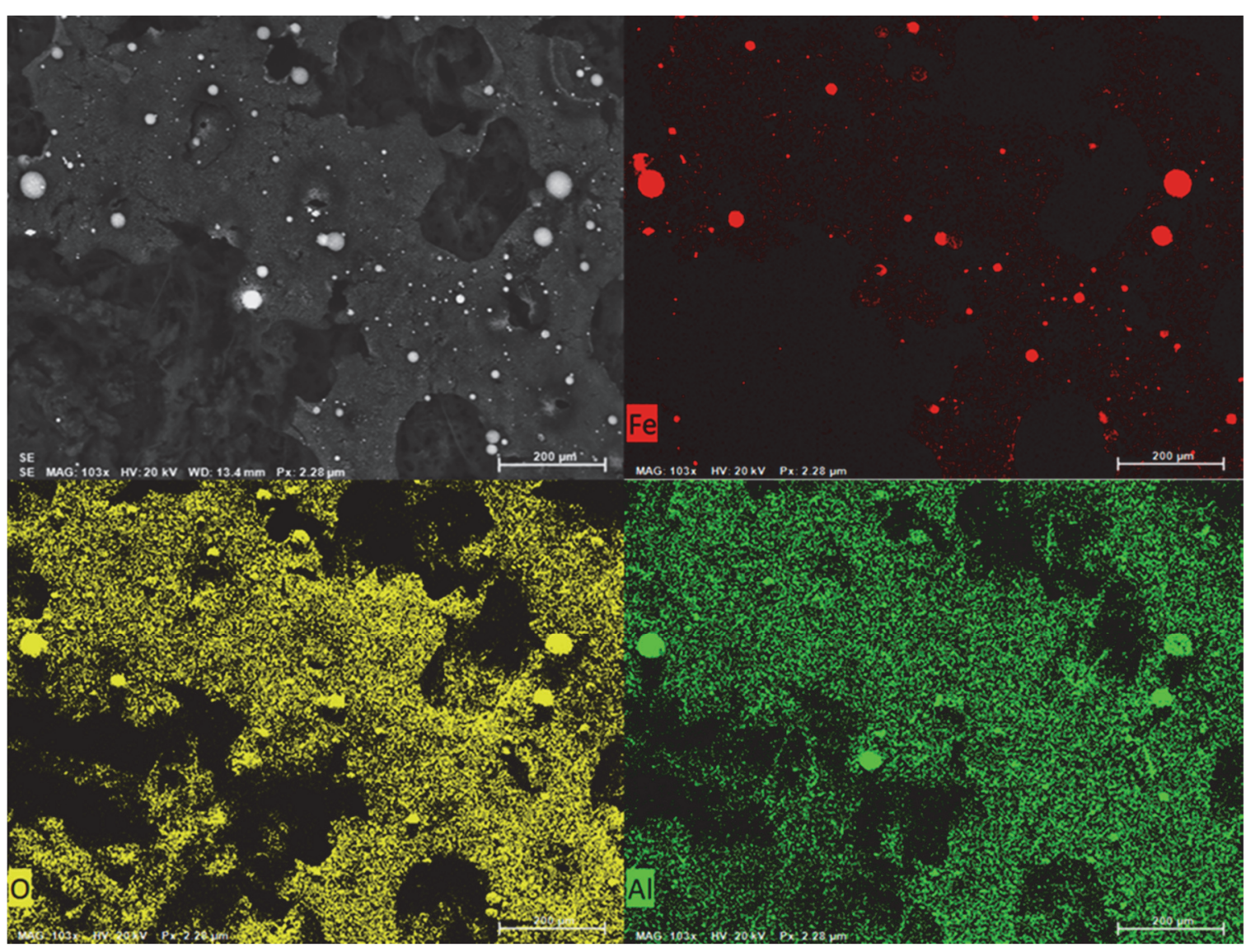

Fig. 61. Rack 4 micrometer size particle compositions were a mixture of iron only, aluminum only, and mixed iron/aluminum, with oxygen:metal ratios of approximately 90 percent. The background shows a relatively low level of nanosized aluminum oxide, similar to Rack 1.

\subsection{Rack 5 particle collection}

Rack 5 (approximately $0.91 \mathrm{~m}$ above the switchgear) displayed a low density of background nanoscale aluminum oxide particles, and separate oxidized iron and oxidized aluminum micrometer-scale particles, as shown in Fig. 62. Due to analysis equipment issues, relative oxygen:metal ratios were not calculated for these particles. Global oxygen:metal ratios of approximately 75 percent were observed for large area scans, similar to Racks 1 through 3. 


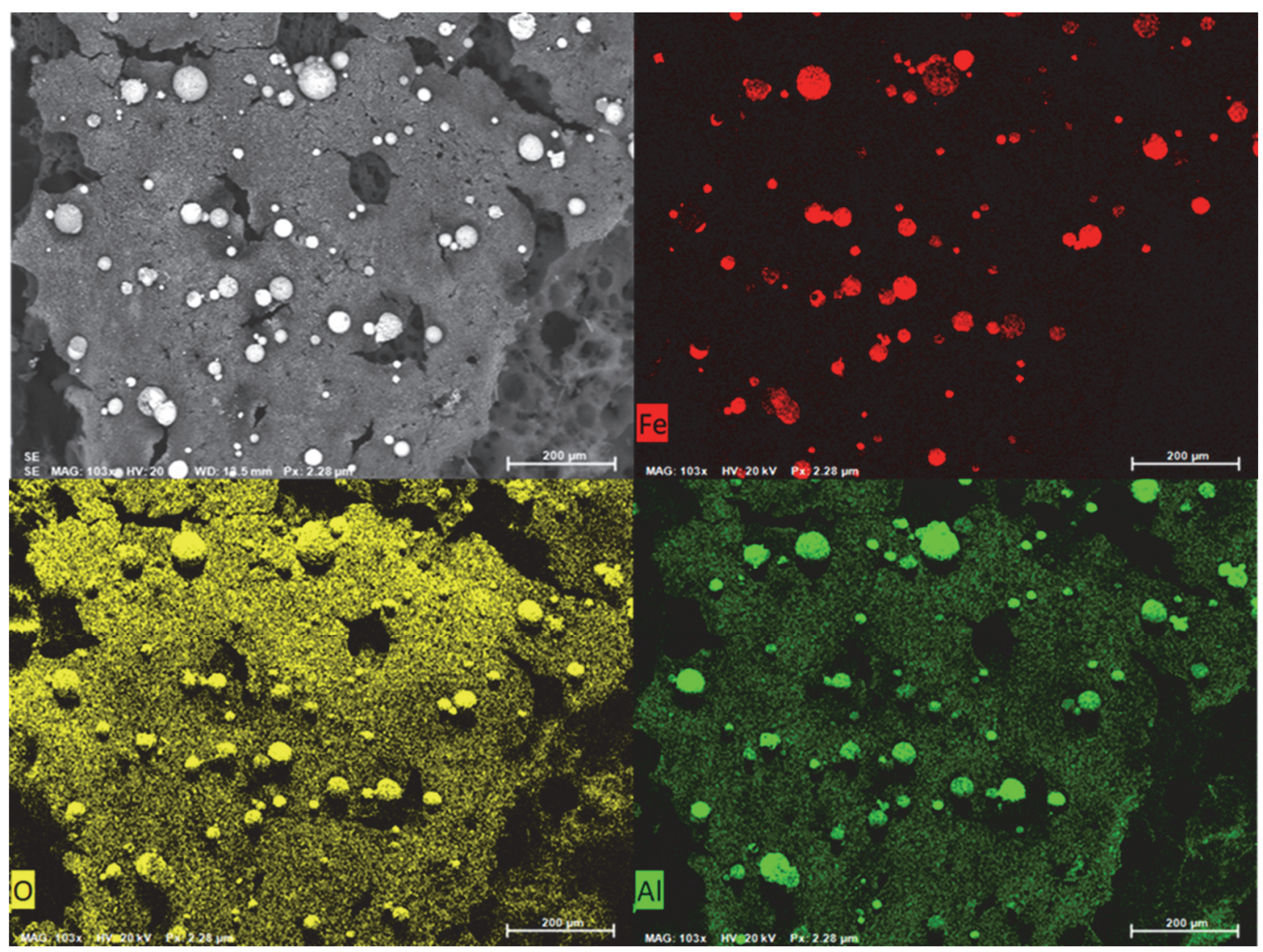

Fig. 62. Rack 5 micrometer size particle compositions were mixed iron/aluminum, iron only and aluminum only with oxygen:metal ratios of approximately 75 percent. The background shows a relatively low level of nanosized aluminum oxide, similar to Rack 1.

In summary, particles collected from the rear-facing regions (Rack 3 and the back wall) appear to display higher nanoparticle concentrations, including high areal densities of $\mathrm{Al}_{2} \mathrm{O}_{3}$, Al microparticles, and Fe microparticles. Particles collected from side (Racks 1 and 4) and top rack (Rack 5) appeared to display much lower particle nanoscale $\mathrm{Al}_{2} \mathrm{O}_{3}$ particle concentrations, and sparse micrometer-scale particles of partially oxidized $\mathrm{Al}$ and $\mathrm{Fe}$. 


\subsubsection{Electrical Circuit and Measurements}

Test 2-21 used KEMA test circuit S01 shown in Fig. 63. Full-level circuit checks (calibration tests) were performed prior to the experiment to verify experimental parameters were acceptable. For this experiment the calibration tests configured the power system to $6.9 \mathrm{kV}, 25.6 \mathrm{kA}$ symmetrical, and $70.2 \mathrm{kA}$ peak. The KEMA test report identifies this experiment as 180913-9003.

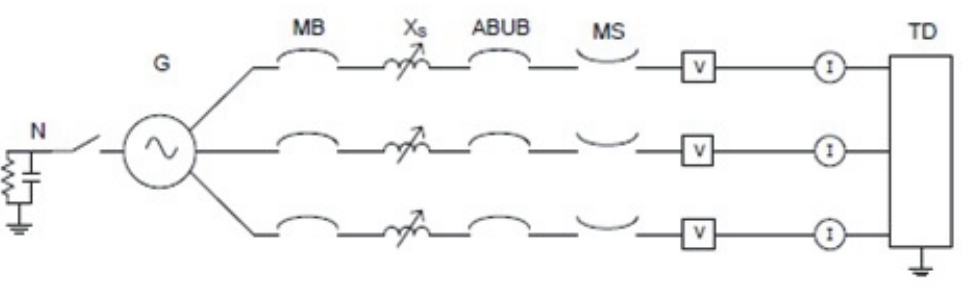

\begin{tabular}{|c|c|c|c|c|c|}
\hline \multicolumn{2}{|c|}{ Supply } & \multicolumn{5}{c|}{ Nomenclature } \\
\hline Power & $306 \mathrm{MVA}$ & $\mathrm{G}$ & Generator & $\mathrm{R}$ & Resistance \\
\hline Frequency & $60 \mathrm{~Hz}$ & $\mathrm{~N}$ & Neutral & $\mathrm{C}$ & Capacitance \\
\hline Phase(s) & 3 & $\mathrm{MB}$ & Main Breaker & $\mathrm{U}$ & Voltage Measurement \\
\hline Voltage & $6.9 \mathrm{kV}$ & $\mathrm{MS}$ & Make Switch & $\mathrm{I}$ & Current Measurement \\
\hline Current & $25.6 \mathrm{kA}$ & $\mathrm{ABUB}$ & Aux. Breaker & & \\
\hline Impedance & $0.1556 \Omega$ & XFMR & Transformer & & \\
\hline Peak Current & $70.2 \mathrm{kA}$ & $\mathrm{TD}$ & Test Device & & \\
\hline Neutral & Not Earthed & $\mathrm{X}$ & Inductance & & \\
\hline
\end{tabular}

Fig. 63. KEMA Test Circuit S01 used in Test 2-21.

The voltage and current profile for the entire duration of the experiment is shown in Fig. 64 . Key experimental measurements are presented in Table 19. The transient region for current phases is presented in Fig. 65. Energy and power profiles are presented in Fig. 66. 


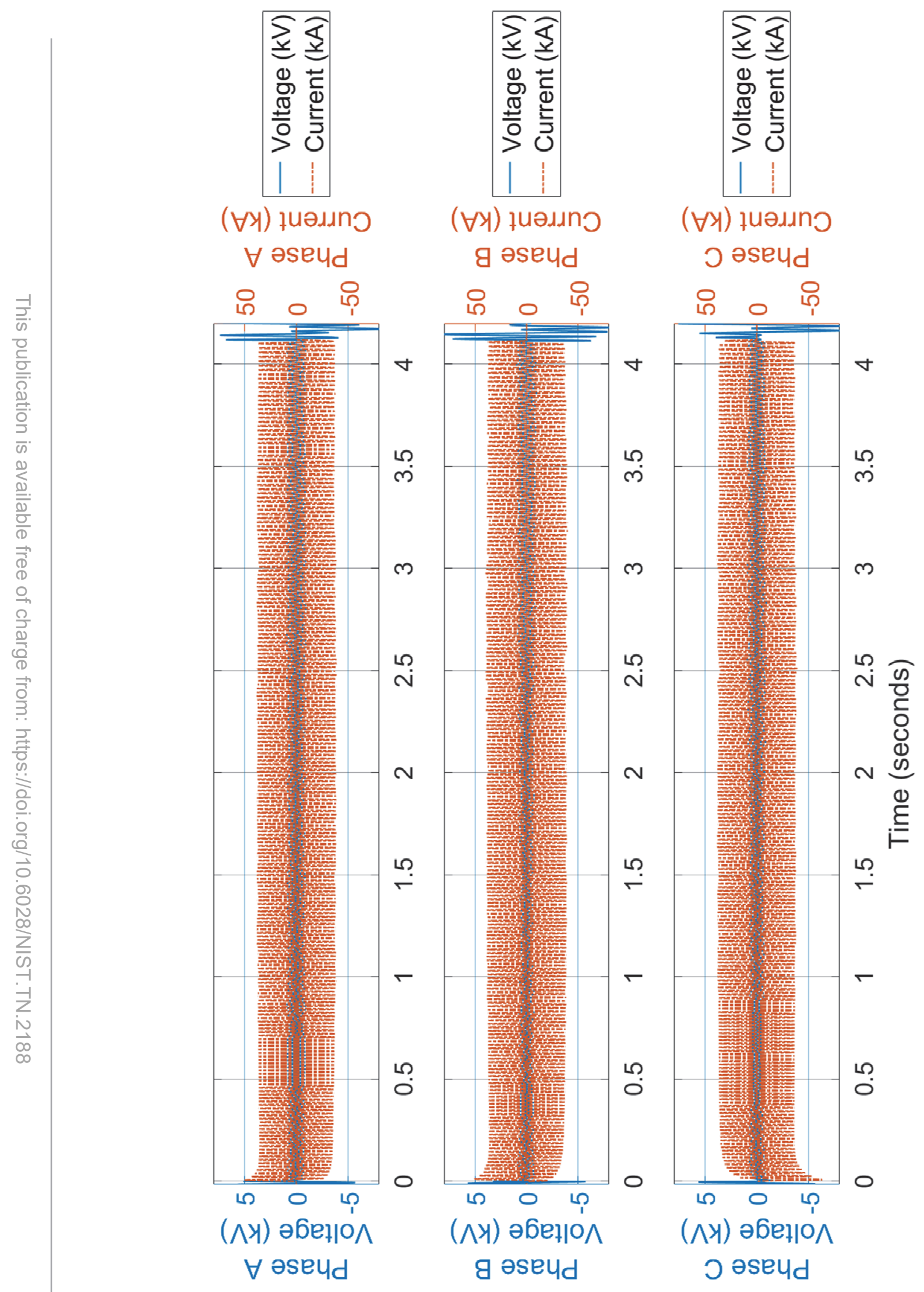

Fig. 64. Voltage and Current Profile during Test 2-21. Measurement uncertainty \pm 3 percent. 
Table 19. Key measurements for Test 2-21. Measurement uncertainty \pm 3 percent.

\begin{tabular}{|l|l|l|c|c|}
\hline Phase & Units & A & B \\
\hline Applied voltage, phase-to-ground & $\mathrm{kV}$ RMS & 3.00 & 4.00 & 4.02 \\
\hline Applied voltage, phase-to-phase & $\mathrm{kV}$ RMS & \multicolumn{4}{|c|}{6.91} \\
\hline Making current & $\mathrm{kA}$ peak & 49.9 & 50.5 & -62.9 \\
\hline Current, a.c. component, beginning & $\mathrm{kARMS}$ & 25.7 & 26.1 & 26.1 \\
\hline Current, a.c. component, middle & $\mathrm{kARMS}$ & 26.5 & 27.2 & 26.4 \\
\hline Current, a.c. component, end & $\mathrm{kARMS}$ & 26.0 & 26.1 & 25.5 \\
\hline Current, a.c. component, average & $\mathrm{kARMS}$ & 26.2 & 26.8 & 26.2 \\
\hline Current, a.c. component, three-phase average & $\mathrm{kARMS}$ & \multicolumn{4}{|c|}{26.4} \\
\hline Duration & $\mathrm{s}$ & 4.11 & 4.11 & 4.11 \\
\hline Generator Energy & $\mathrm{MJ}$ & \multicolumn{4}{|c|}{119.8} \\
\hline
\end{tabular}
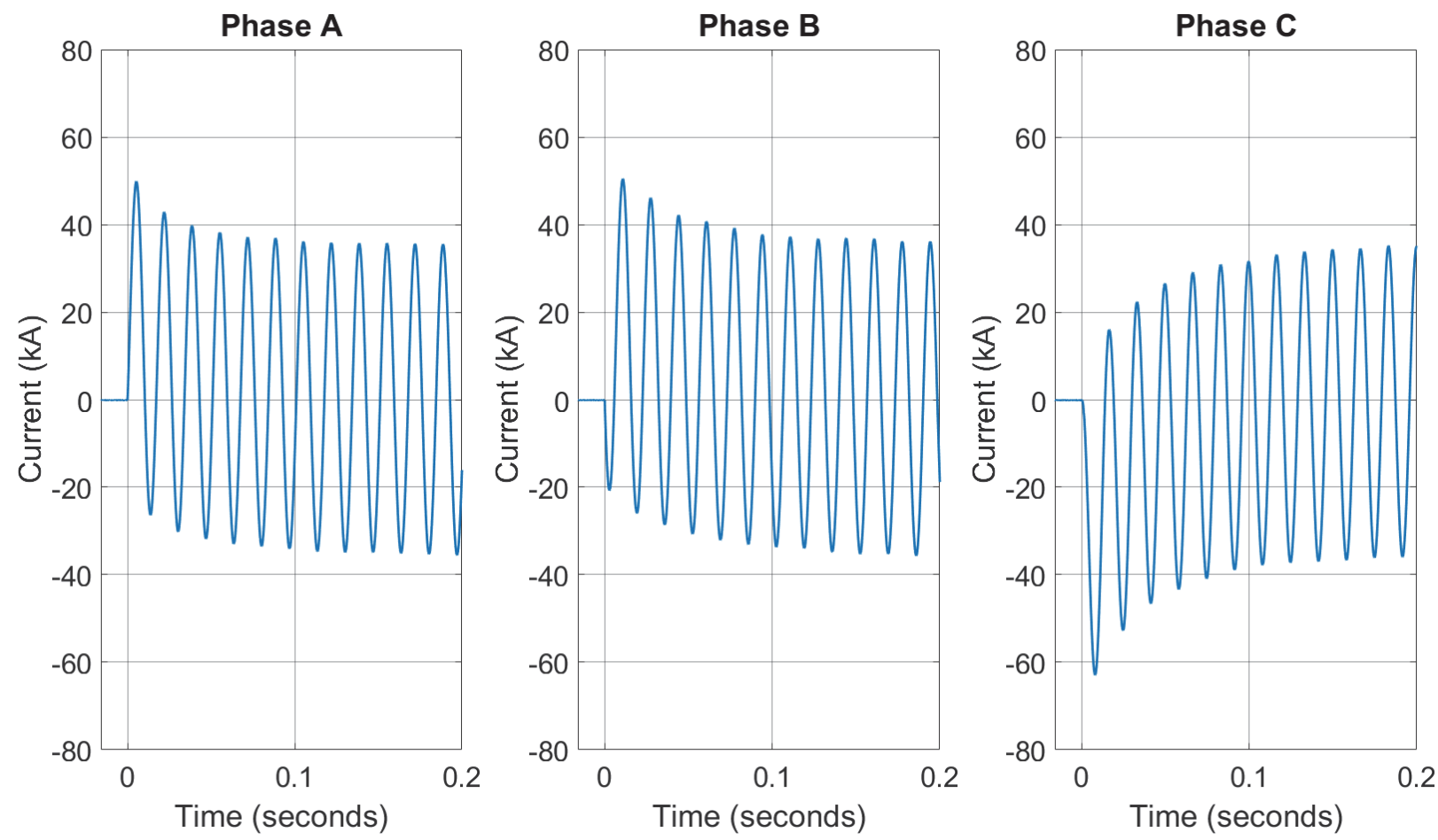

Fig. 65. Transient current profiles for Test 2-21. Measurement uncertainty \pm 3 percent. 


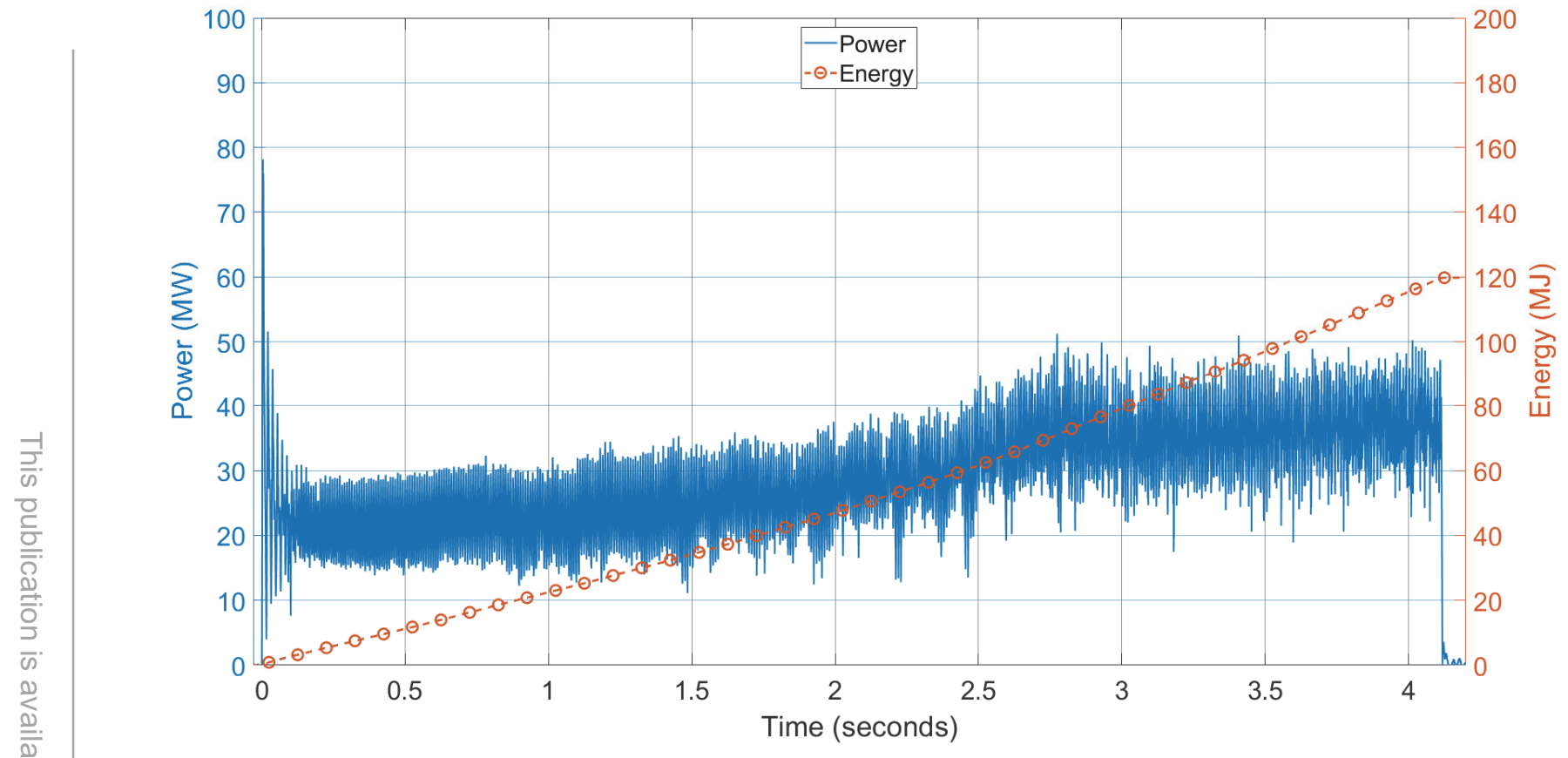

Fig. 66. Power and Energy for Test 2-21. Measurement uncertainty \pm 3 percent. 


\subsection{Test $2-22-6.9 \mathrm{kV}, 32 \mathrm{kA}, 2 \mathrm{~s}$ duration, aluminum bus}

Test 2-22 was performed on September 11, 2018 at 1:53 PM eastern daylight time (EDT). The temperature was approximately $20^{\circ} \mathrm{C}\left(68^{\circ} \mathrm{F}\right)$, approximately 90 percent relative humidity and approximately $101.9 \mathrm{kPa}$ of pressure. The weather was overcast with a northeast wind at approximately $16 \mathrm{~km} / \mathrm{h}(10 \mathrm{mi} / \mathrm{h})$.

\subsubsection{Observations}

Observations documented below are based on review of video and thermal imaging that was taken during the experiment. The observations provided in Table 20 include an approximate time reference. Corresponding images are provided in Fig. 67.

Table 20. Observations from Test 2-22

\begin{tabular}{|c|l|}
\hline Time (ms) & Observation \\
\hline $\mathbf{2 1}$ & Bottom of front door begins to open \\
\hline $\mathbf{3 0}$ & Particle eject reaches top Rack $(0.91 \mathrm{~m}[3.00 \mathrm{ft}]$ above enclosure) \\
\hline $\mathbf{3 6}$ & Particle ejecta passes rear rack (Rack \#2 at $0.91 \mathrm{~m}[3.00 \mathrm{ft}]$ behind enclosure) \\
\hline $\mathbf{7 2}$ & Front door no longer secured by latch (continues to open) \\
\hline $\mathbf{1 0 0}$ & $\begin{array}{l}\text { Particle ejecta passes } 2^{\text {nd }} \text { rear rack (Rack \#3 at } 1.83 \mathrm{~m}[6.00 \mathrm{ft}] \text { behind } \\
\text { enclosure) }\end{array}$ \\
\hline $\mathbf{1 0 0}$ & Particle eject passes $1.83 \mathrm{~m}[6.00 \mathrm{ft}]$ above enclosure \\
\hline $\mathbf{6 0 0}$ & Initial arc breach of rear panel \\
\hline $\mathbf{8 6 7}$ & Top front vent stops emitting hot gas and particle ejecta \\
\hline $\mathbf{1 1 2 8}$ & $\begin{array}{l}\text { Particle ejecta impacts test facility cell wall }(5.18 \mathrm{~m}[17.00 \mathrm{ft}] \text { behind } \\
\text { enclosure) }\end{array}$ \\
\hline $\mathbf{2 0 7 5}$ & Decrease in cell illumination consistent with experiment termination \\
\hline $\mathbf{2 1 2 8}$ & $\begin{array}{l}\text { Significant quantity of particle ejecta impacting test facility cell wall behind } \\
\text { enclosure }\end{array}$ \\
\hline $\mathbf{1 4 5 0 0 0}$ & Test cell pedestal ventilation fan turned on \\
\hline $\mathbf{5 0 1 1 1 8}$ & NIST data acquisition ends \\
\hline
\end{tabular}

Photographs of damage to the electrical enclosure are shown in Fig. 69. The enclosure breached at the upper rear panel of the primary cable connection compartment. There were additional breaches on both sides of the enclosure adjacent to the breach on the upper rear panel. The door on the front of the enclosure with a single quarter turn latch did open. Just as in Test 2-19 and 2-21, internal pressure caused the bottom of the door to push out and post-experiment inspection indicated that the side of the panel was bowed outward. The combination of these two effects allowed the latch mechanism to slip and the door to open. Following the experiment, no apparent aluminum oxide residue was observed on the test cell wall. Molten splatter beads were present on various instrumentation rack coupons. Passive cable samples experienced thermal stress, but the cable jacket was intact and not breached. 

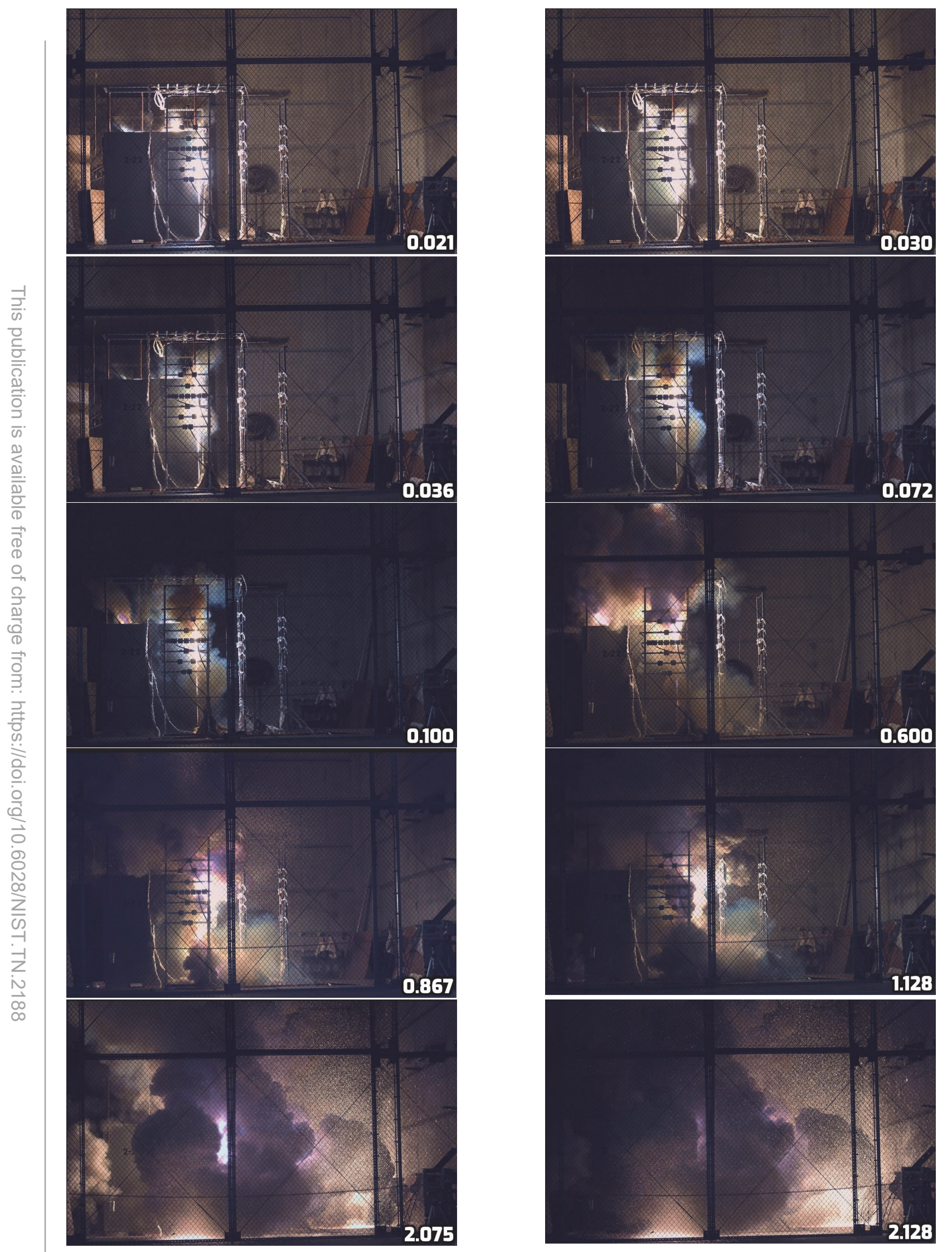

Fig. 67. Sequence of Images from Test 2-22 (image time stamp in seconds) 


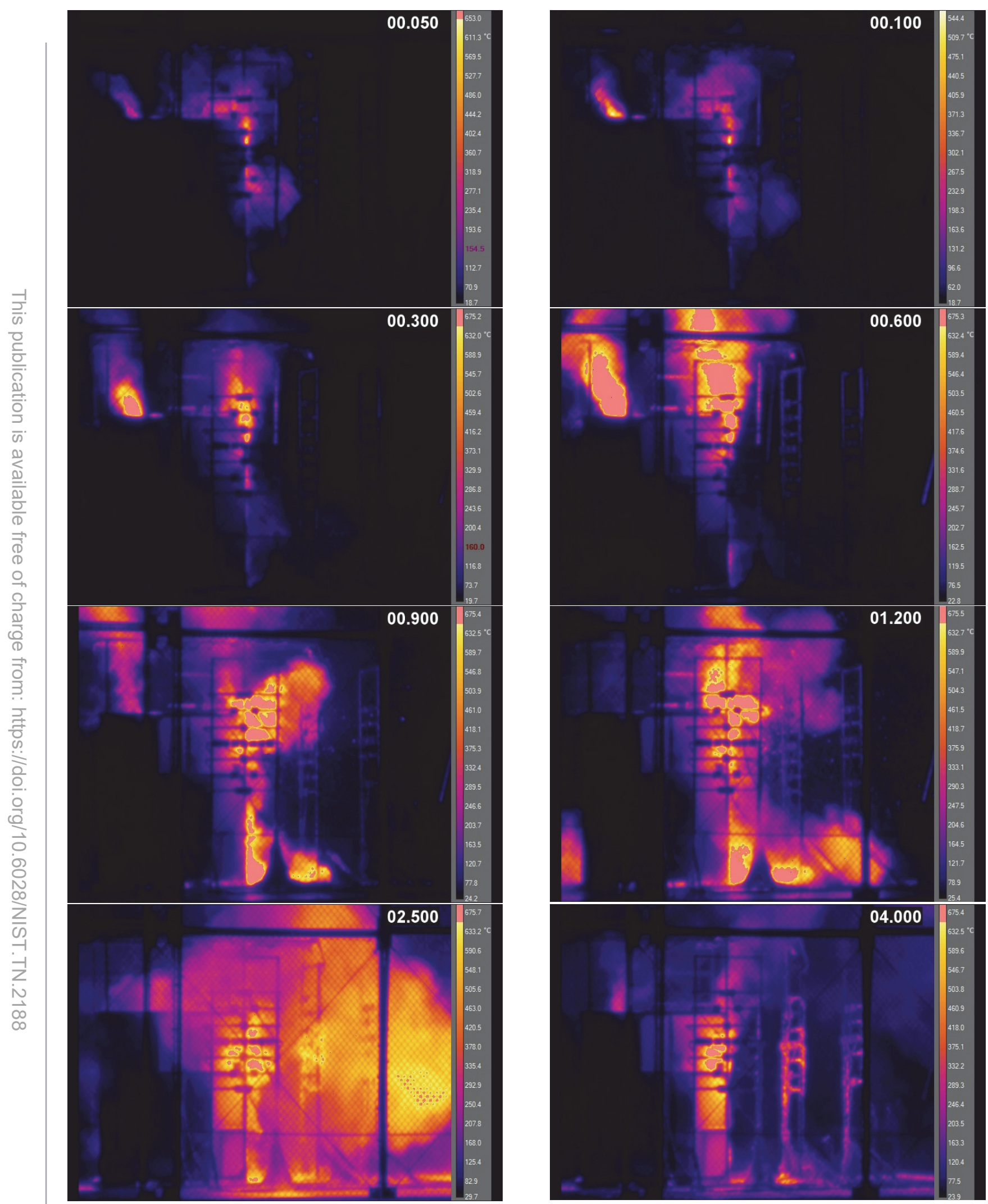

Fig. 68. Sequence of Thermal Images from Test 2-22 (image time stamp in seconds) 

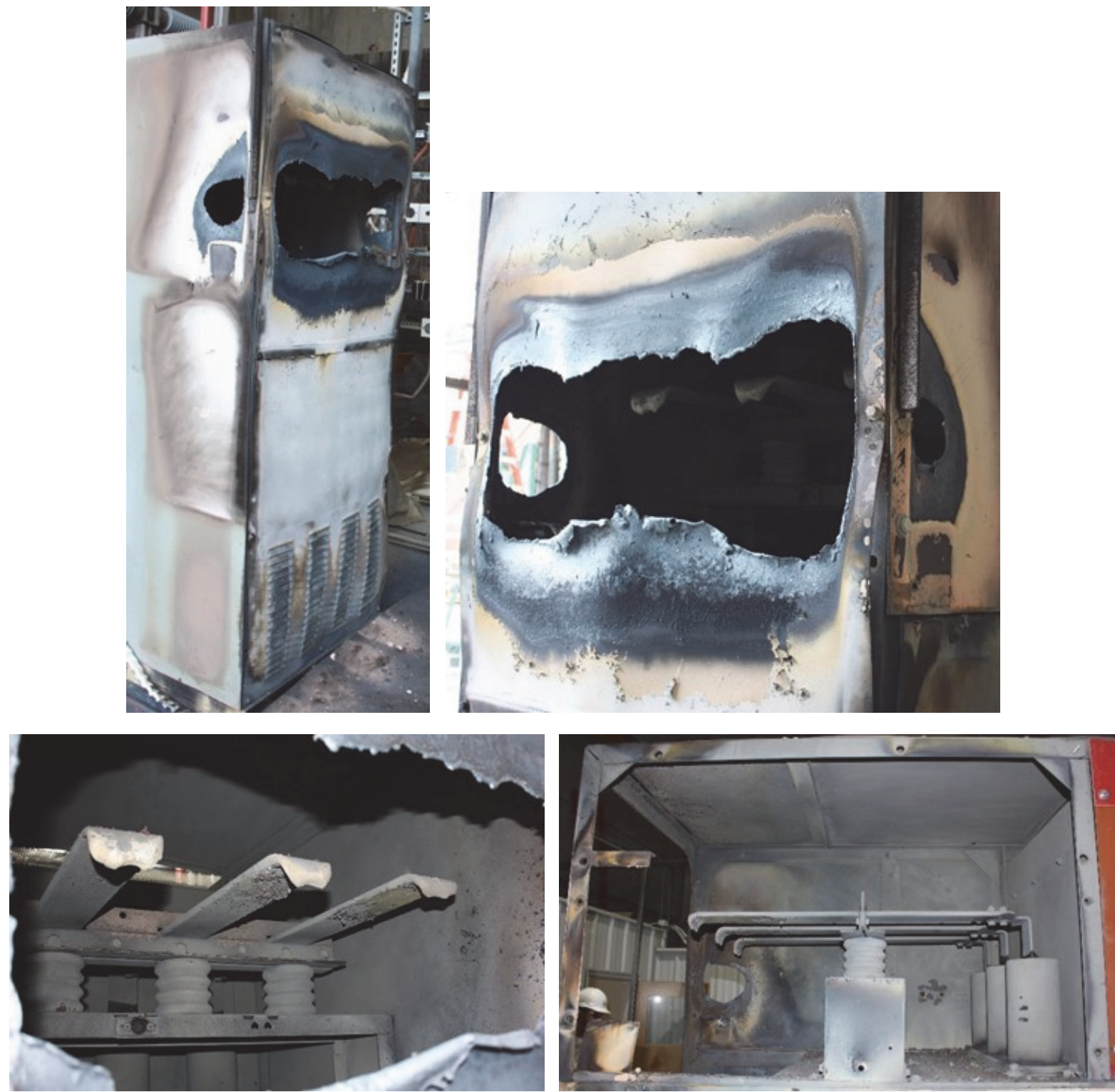

Fig. 69. Enclosure Post-Test 2-22. (Top: back of enclosure; Bottom: remaining bus bar material. Bottom left as viewed from rear of enclosure, bottom right as viewed from the side at the rear of the enclosure with the rear and side panels removed.)

\subsubsection{Measurements}

Measurements made during Test 2-22 are the same as made in Test 2-19 and Test 2-21. Measurements are reported below.

\subsubsection{Thermal Measurements}

Thermal measurements from the active instruments are reported below for Test 2-22. These include PT measurements in Table 21, ASTM Slug Calorimeter measurements in Table 22 and $\mathrm{T}_{\text {cap }}$ slug measurements in Table 23. The maximum reading is identified with bold text. 
Significant amounts of incident energy $\left(\mathrm{kJ} / \mathrm{m}^{2}\right)$ were transferred to areas surrounding the switch gear during the post-arcing phase of the HEAF. The post-arcing phase incident energy contribution, as measured by the $\mathrm{T}_{\text {cap }}$ slugs, was one or more times greater than the incident energy contribution from the arcing phase for nearly all measurement locations.

Table 21. Summary of plate thermometer measurements Test 2-22

\begin{tabular}{|c|c|c|c|c|c|}
\hline $\begin{array}{c}\text { Rack } \\
\text { No. }\end{array}$ & Plate No. & Location & $\begin{array}{c}\text { Max Heat } \\
\text { Flux }\left(\mathrm{kW} / \mathrm{m}^{2}\right) \\
\pm 1 \mathrm{~kW} / \mathrm{m}^{2} \text { or } \\
\pm 5 \%\end{array}$ & $\begin{array}{c}\text { Average Heat } \\
\text { Flux During } \\
\text { Arc }\left(\mathbf{k W} / \mathrm{m}^{2}\right) \\
\pm 1 \mathbf{k W} / \mathrm{m}^{2} \text { or } \\
\pm 5 \%\end{array}$ & Comment \\
\hline 1 & 1 & Top & 164.1 & 86.5 & \\
\hline 1 & 3 & Mid-Right & 354.3 & 143.9 & \\
\hline 1 & 5 & Mid-Center & 224.0 & 94.5 & \\
\hline 1 & 7 & Mid-Left & 116.5 & 52.5 & \\
\hline 1 & 9 & Bottom & 303.0 & 101.3 & \\
\hline 2 & 10 & Top & 665.4 & 222.2 & \\
\hline 2 & 12 & Mid-Right & 2153.7 & 677.1 & \\
\hline 2 & 14 & Mid-Center & 3128.6 & 754.5 & \\
\hline 2 & 16 & Mid-Left & 1845.8 & 447.5 & \\
\hline 2 & 18 & Bottom & -- & 321.8 & $\begin{array}{l}\text { Possible EMI } \\
\text { spike }\end{array}$ \\
\hline 3 & 19 & Top & 425.7 & 177.5 & \\
\hline 3 & 21 & Mid-Right & 798.7 & 185.6 & \\
\hline 3 & 23 & Mid-Center & 909.8 & 204.6 & \\
\hline 3 & 25 & Mid-Left & 688.0 & 207.1 & \\
\hline 3 & 27 & Bottom & 1996.9 & 402.0 & \\
\hline 4 & 28 & Top & 317.8 & 110.5 & \\
\hline 4 & 30 & Mid-Right & 109.7 & 58.8 & \\
\hline 4 & 32 & Mid-Center & 15.3 & 5.1 & \\
\hline 4 & 34 & Mid-Left & -- & -- & $\begin{array}{l}\text { Inoperable } \\
\text { prior to } \\
\text { experiment }\end{array}$ \\
\hline 4 & 36 & Bottom & 579.6 & 189.2 & \\
\hline 5 & 37 & Front & 268.0 & 122.6 & \\
\hline 5 & 39 & Center-Right & 116.6 & 62.1 & \\
\hline 5 & 41 & Center-Mid & 220.4 & 135.5 & \\
\hline 5 & 43 & Center-Left & 137.3 & 60.9 & \\
\hline 5 & 45 & Back & 74.7 & 37.0 & \\
\hline
\end{tabular}


Table 22. Summary of ASTM slug calorimeter measurements, Test 2-22

\begin{tabular}{|c|c|c|c|c|c|}
\hline $\begin{array}{c}\text { Rack } \\
\text { No. }\end{array}$ & $\begin{array}{c}\text { ASTM } \\
\text { No. } \\
\end{array}$ & Location & $\begin{array}{c}\text { Incident } \\
\text { Energy }\left(\mathrm{kJ} / \mathrm{m}^{2}\right) \\
\pm 18 \mathrm{KJ} / \mathrm{m}^{2} \text { or } \\
\pm 4 \% \\
\end{array}$ & $\begin{array}{c}\text { Time to } \\
\operatorname{Max}(\mathrm{s}) \\
\pm 3 \%\end{array}$ & Comment \\
\hline 1 & A & Top & 202.6 & 7.7 & \\
\hline 1 & B & Mid-Right & 308.2 & 23.8 & \\
\hline 1 & $\mathrm{C}$ & Mid-Left & 202.1 & 85 & \\
\hline 1 & $\mathrm{D}$ & Bottom & 292.1 & 14.3 & \\
\hline 2 & E & Top & 507.0 & 12.1 & \\
\hline 2 & F & Mid-Right & 1107.8 & 12.5 & \\
\hline 2 & G & Mid-Left & 973.4 & 14 & \\
\hline 2 & $\mathrm{H}$ & Bottom & 787.8 & 22.7 & \\
\hline 3 & I & Top & 286.5 & 12.4 & \\
\hline 3 & $\mathrm{~J}$ & Mid-Right & 414.0 & 5.3 & \\
\hline 3 & K & Mid-Left & 374.2 & 10.5 & \\
\hline 3 & $\mathrm{~L}$ & Bottom & 500.6 & 2 & \\
\hline 4 & M & Top & 171.8 & 57.7 & \\
\hline 4 & $\mathrm{~N}$ & Mid-Right & 232.8 & 92.2 & \\
\hline 4 & $\mathrm{O}$ & Mid-Left & 350.7 & 21.3 & \\
\hline 4 & $\mathrm{P}$ & Bottom & 287.7 & 72.3 & \\
\hline 5 & Q & Front & 273.0 & 12.9 & \\
\hline 5 & $\mathrm{R}$ & Center-Right & 149.0 & 4.6 & \\
\hline 5 & $\mathrm{~S}$ & Center-Left & 158.9 & 5.4 & \\
\hline 5 & $\mathrm{~T}$ & Back & 105.9 & 170.2 & \\
\hline
\end{tabular}


Table 23. Summary of $\mathrm{T}_{\text {cap }}$ slug measurements, Test 2-22

\begin{tabular}{|c|c|c|c|c|c|}
\hline $\begin{array}{c}\text { Rack } \\
\text { No. }\end{array}$ & $\mathbf{T}_{\text {cap }}$ No. & Location & $\begin{array}{c}\text { Heat Flux } \\
\text { During Arc } \\
\left(\mathbf{k W} / \mathbf{m}^{2}\right) \\
\pm 2.9 \%\end{array}$ & $\begin{array}{c}\text { Incident } \\
\text { Energy } \\
\text { During Arc } \\
\text { Phase }\left(\mathbf{k J} / \mathbf{m}^{2}\right) \\
\pm \mathbf{5} \%\end{array}$ & $\begin{array}{c}\text { Total Incident } \\
\text { Energy } \\
\left(\mathbf{k J} / \mathbf{m}^{2}\right) \\
\pm 5 \%\end{array}$ \\
\hline 1 & 2 & Top & 109.1 & 138.9 & 578.1 \\
\hline 1 & 4 & Mid-Right & 166.6 & 207.4 & 687.7 \\
\hline 1 & 6 & Mid-Left & 73.1 & 145.8 & 636.4 \\
\hline 1 & 8 & Bottom & 256.0 & 235.6 & 732.1 \\
\hline 2 & 11 & Top & 671.5 & 836.9 & 1562.9 \\
\hline 2 & 13 & Mid-Right & 873.0 & 1068.6 & 1933.1 \\
\hline 2 & 15 & Mid-Left & 781.0 & 883.9 & 1836.7 \\
\hline 2 & 17 & Bottom & 721.5 & 945.4 & 2125.3 \\
\hline 3 & 20 & Top & 131.7 & 203.4 & 493.9 \\
\hline 3 & 22 & Mid-Right & 387.7 & 424.1 & 645.8 \\
\hline 3 & 24 & Mid-Left & 252.4 & 355.9 & 611.2 \\
\hline 3 & 26 & Bottom & 299.9 & 420.1 & 678.2 \\
\hline 4 & 29 & Top & 86.1 & 163.0 & 668.8 \\
\hline 4 & 31 & Mid-Right & 94.2 & 162.2 & 730.3 \\
\hline 4 & 33 & Mid-Left & 198.1 & 289.1 & 804.9 \\
\hline 4 & 35 & Bottom & 149.7 & 217.5 & 815.8 \\
\hline 5 & 38 & Front & 139.4 & 268.8 & 636.1 \\
\hline 5 & 40 & Center-Right & 166.3 & 315.3 & 630.9 \\
\hline 5 & 42 & Center-Left & 138.0 & 265.8 & 649.6 \\
\hline 5 & 44 & Back & 74.1 & 159.4 & 507.2 \\
\hline
\end{tabular}

\subsubsection{Internal Pressure}

The pressure profiles for the first two tenths of a second are shown in Fig. 70. After the initial pressure spike, the pressure rapidly decays to a relative steady state. The peak pressure is higher in the primary cable connection compartment as would be expected since this is the compartment where the arc is initiated. The maximum change in pressure in the primary cable connection compartment is approximately $28.3 \mathrm{kPa}(4.1 \mathrm{psi})$ above ambient at its peak. The maximum change in pressure in the breaker compartment is approximately $5.4 \mathrm{kPa}(0.78 \mathrm{psi})$ above ambient. The $0 \mathrm{kPa}$ to $207 \mathrm{kPa}(0$ psia to $30 \mathrm{psia})$ and $0 \mathrm{kPa}$ to $345 \mathrm{kPa}$ (0 psia to $50 \mathrm{psia})$ transducer recordings at a specific location were consistent. 

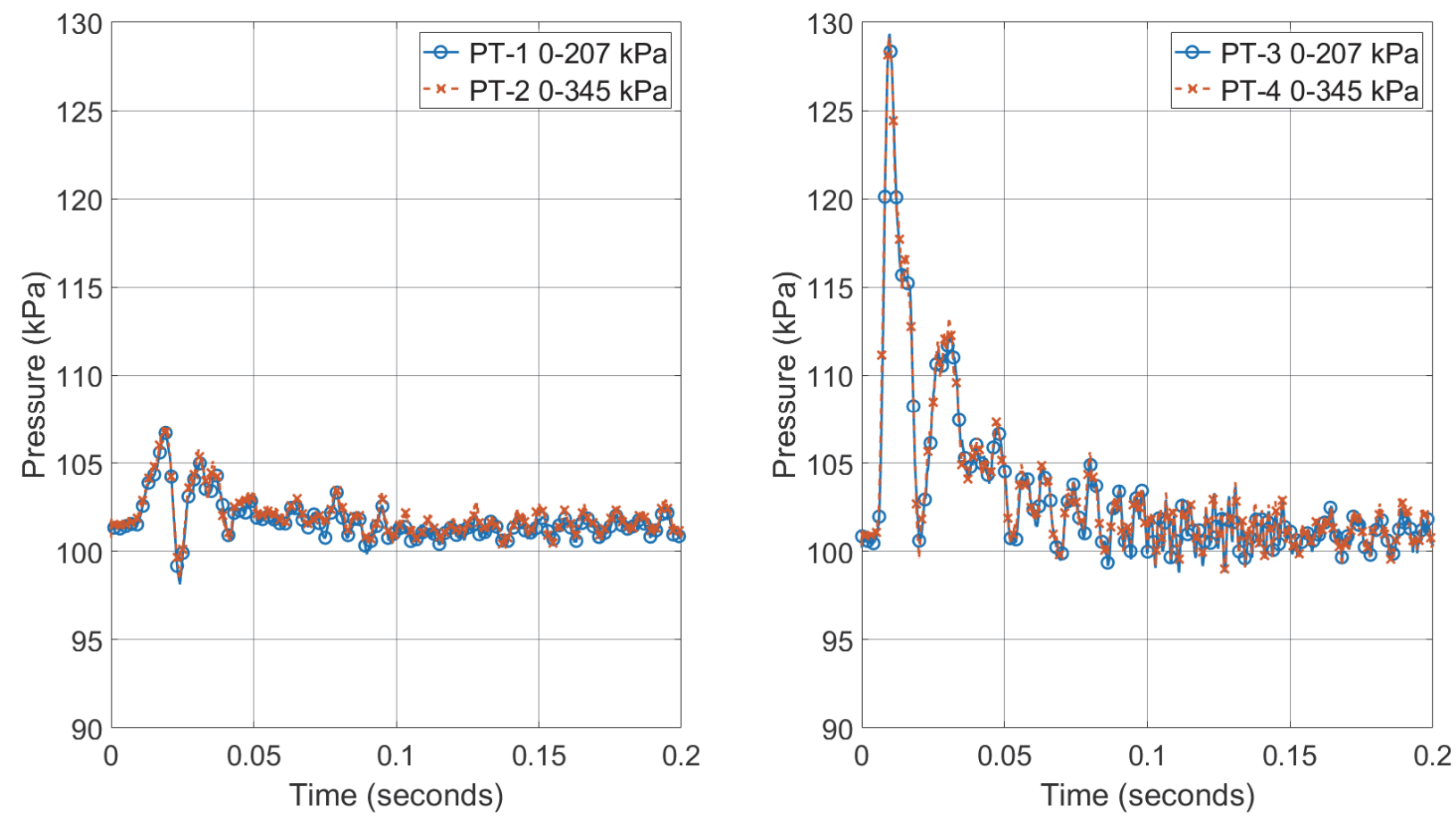

Fig. 70. Pressure measurements from Test 2-22 (breaker compartment - left; arcing compartment - right). Measurement uncertainty \pm 3 percent.

\subsubsection{Mass Measurements}

Mass loss measurements were made for the enclosure metal cladding and the bus conductors. All measurements made are reported in Appendix C. One observation that was made in all experiments was that for many of the steel cladding panels, the post-experiment measurements were larger than the pre-experiment measurements. This is likely caused by the plating of the electrical conductors on to the metal cladding. As such, for the panels that experienced breach, the actual mass loss is likely greater than what is reported below. For this experiment, the upper rear panel experienced breach as did the two adjacent side panels (far side rear panel and primary cable compartment bus side upper panel). The total mass loss measured using an electronic balance (NIST Scale 2) was approximately $1.29 \mathrm{~kg}$ for the primary cable compartment bus side upper panel and approximately $3.85 \mathrm{~kg}$ for the rear upper panel. The mass loss for the far side rear panel was not made due to the mass exceeding the range of the balance. The bus bars lost a total of $896 \mathrm{~g}$ (313 g Phase A, $308 \mathrm{~g}$ Phase B, $275 \mathrm{~g}$ Phase $\mathrm{C}$ ). These mass measurements were made using an electronic mass balance (NIST Scale 2) with an expanded uncertainty, derived from manufacturer specifications, of $\pm 1 \mathrm{~g}$, with a 95 percent confidence interval.

Given the known thickness of the panel and density, comparable mass loss estimates could be calculated. For this experiment, the breach area estimates are shown in Fig. 71. Using this graphical technique, the mass loss estimate for the upper rear panel was $4.20 \mathrm{~kg}$, representing approximately 9 percent difference between this method and the mass balance measurement. For the side panel with mass loss data, the graphical technique significantly underestimated the mass loss by approximately 100 percent. That approach did show that the openings were of relatively the same size $230 \mathrm{~cm}^{2}$ compared to $226 \mathrm{~cm}^{2}$. As such, the 
measured mass loss for the primary cable compartment bus side upper panel could be a reasonable estimate for the mass loss on the far side rear panel.
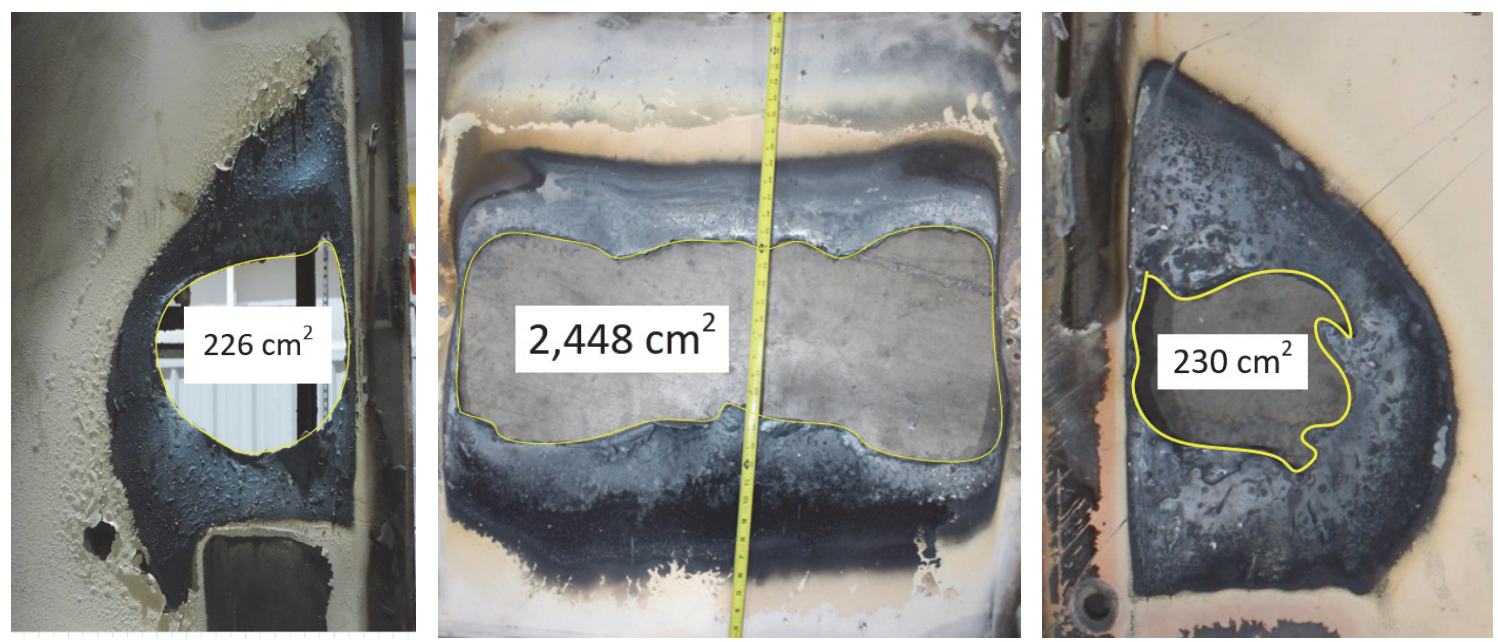

Fig. 71. Photos showing breach opening on far side rear panel (left), rear upper panel (center) and the primary cable compartment bus side upper panel (right). Software used to estimate opening area.

\subsubsection{Electrical Circuit and Measurements}

Test 2-22 used KEMA test circuit S02 shown in Fig. 72. Full-level circuit checks (calibration tests) were performed prior to the experiment to verify experimental parameters were acceptable. For this experiment the calibration tests configured the power system to $7 \mathrm{kV}, 32.0 \mathrm{kA}$ symmetrical, and $86.4 \mathrm{kA}$ peak. The KEMA Test report identifies this experiment as 180911-9001. 


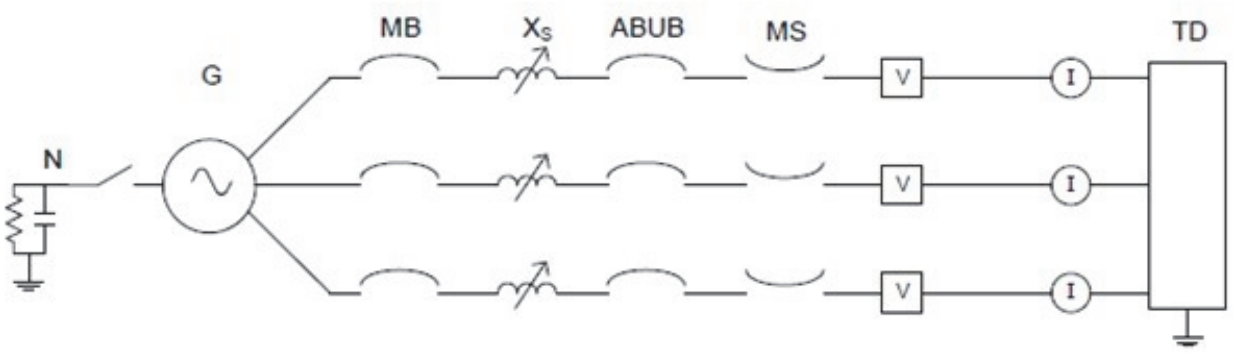

\begin{tabular}{|c|c|c|c|c|c|}
\hline \multicolumn{2}{c}{ Supply } & \multicolumn{4}{c|}{ Nomenclature } \\
\hline Power & $388 \mathrm{MVA}$ & $\mathrm{G}$ & Generator & $\mathrm{R}$ & Resistance \\
\hline Frequency & $60 \mathrm{~Hz}$ & $\mathrm{~N}$ & Neutral & $\mathrm{C}$ & Capacitance \\
\hline Phase(s) & 3 & $\mathrm{MB}$ & Main Breaker & $\mathrm{U}$ & Voltage Measurement \\
\hline Voltage & $7.0 \mathrm{kV}$ & $\mathrm{MS}$ & Make Switch & $\mathrm{I}$ & Current Measurement \\
\hline Current & $32.0 \mathrm{kA}$ & $\mathrm{ABUB}$ & Aux. Breaker & & \\
\hline Impedance & $0.1263 \Omega$ & XFMR & Transformer & & \\
\hline Peak Current & $86.4 \mathrm{kA}$ & $\mathrm{TD}$ & Test Device & & \\
\hline Neutral & Not Earthed & $\mathrm{X}$ & Inductance & & \\
\hline
\end{tabular}

Fig. 72. KEMA Test Circuit S01 used in Test 2-22

The voltage and current profile for the entire experiment duration is shown in Fig. 73. It should be noted that the current for phase $\mathrm{C}$ was not recorded. C-phase current (I3TO) was patched to the data system improperly. However, it was re-created using the negative sum of Phases A and B. Key experimental measurements are presented in Table 24. The transient region for current phases is presented in Fig. 74. Energy and power profiles are presented in Fig. 75. 


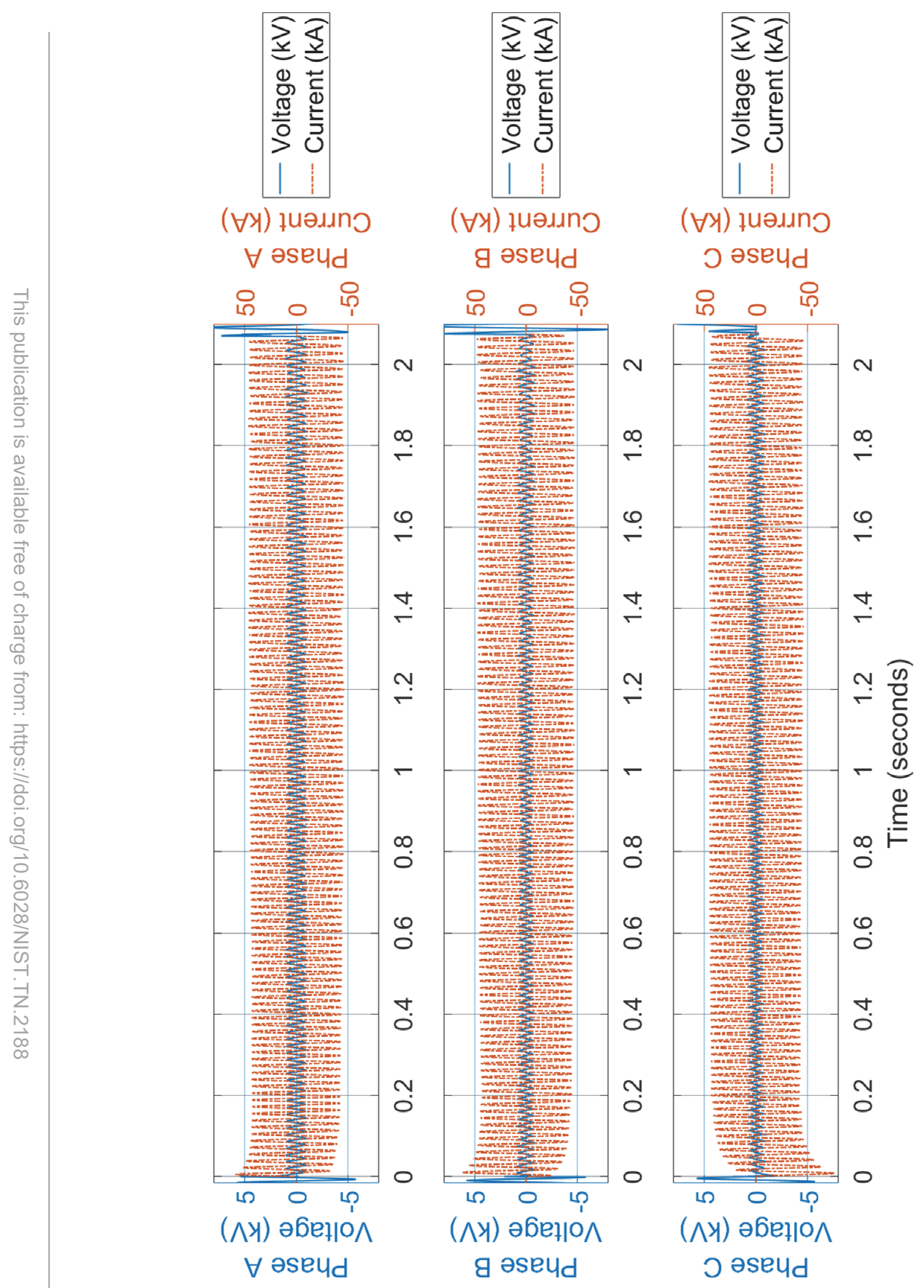

Fig. 73. Voltage and Current profile for Test $2-22$. Measurement uncertainty \pm 3 percent. 
Table 24. Key measurements for Test 2-22. Measurement uncertainty \pm 3 percent.

\begin{tabular}{|l|l|c|c|c|}
\hline Phase & Units & A & B \\
\hline Applied voltage, phase-to-ground & $\mathrm{kV}$ RMS & 4.06 & 4.09 & 4.03 \\
\hline Applied voltage, phase-to-phase & $\mathrm{kV}$ RMS & \multicolumn{4}{|c|}{7.03} \\
\hline Making current & $\mathrm{kA}$ peak & 58.9 & 61.6 & -75.9 \\
\hline Current, a.c. component, beginning & $\mathrm{kARMS}$ & 31.0 & 31.5 & 31.4 \\
\hline Current, a.c. component, middle & $\mathrm{kARMS}$ & 32.0 & 32.6 & 31.8 \\
\hline Current, a.c. component, end & $\mathrm{kARMS}$ & 31.9 & 33.4 & 31.3 \\
\hline Current, a.c. component, average & $\mathrm{kARMS}$ & 31.4 & 32.2 & 30.6 \\
\hline Current, a.c. component, three-phase average & kARMS & \multicolumn{4}{|c|}{31.4} \\
\hline Duration & $\mathrm{s}$ & 2.07 & 2.07 & 2.07 \\
\hline Generator Energy & $\mathrm{MJ}$ & \multicolumn{4}{|c|}{63 est. } \\
\hline
\end{tabular}
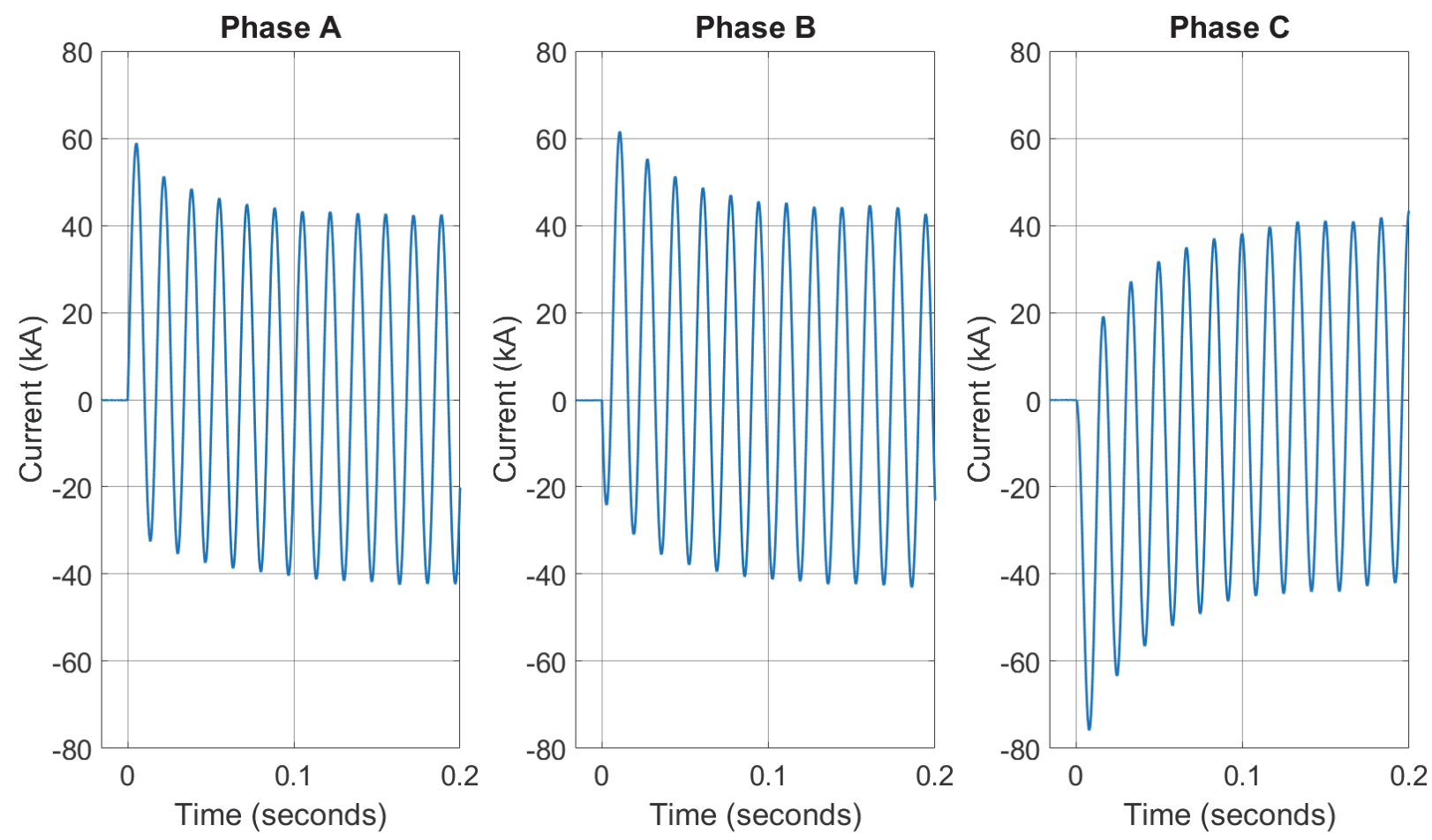

Fig. 74. Transient current profiles for Test 2-22. Measurement uncertainty \pm 3 percent. 


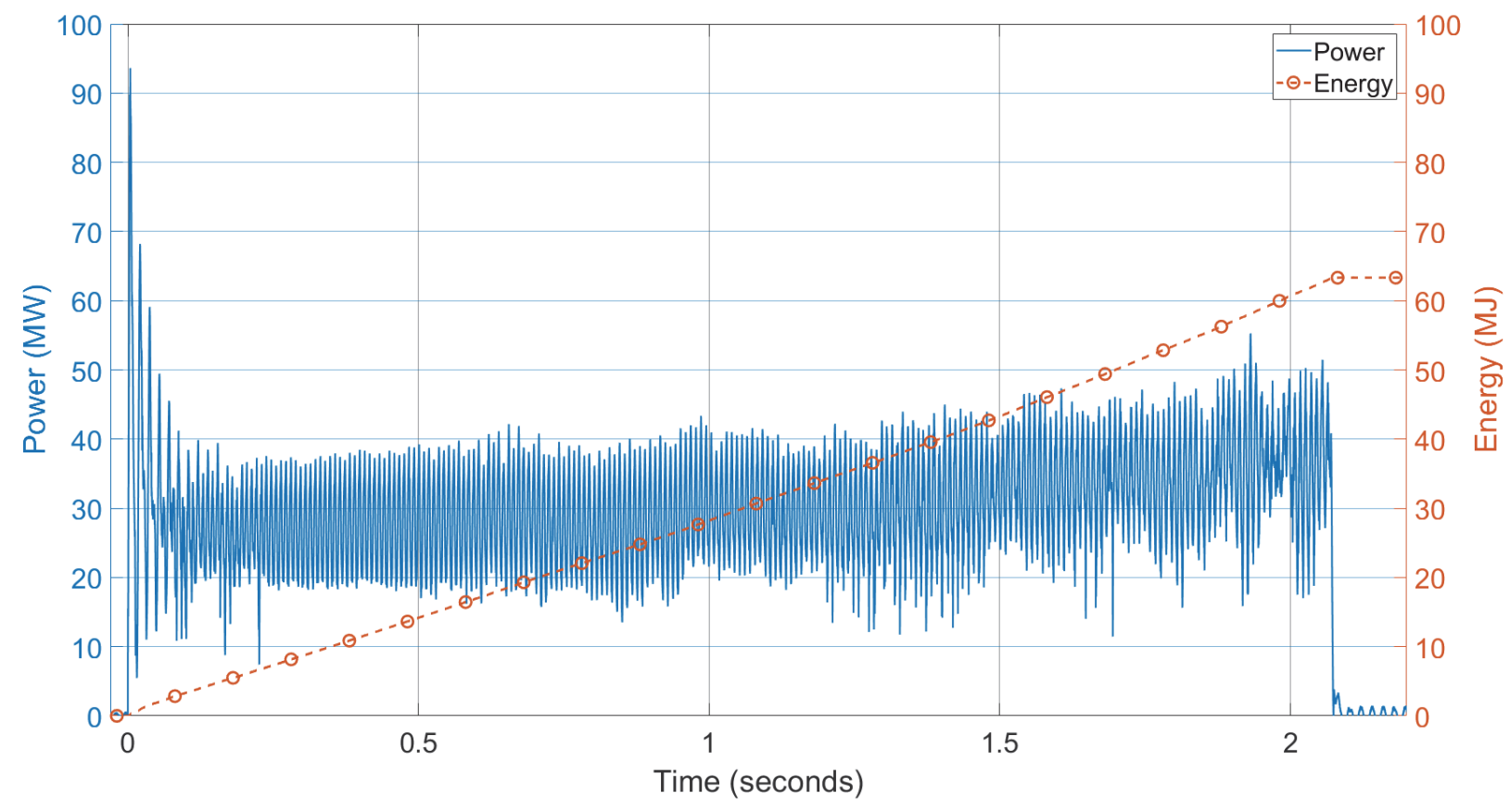

Fig. 75. Power and Energy for Test 2-22. Measurement uncertainty \pm 3 percent.

\subsubsection{Rack 3 particle collection}

For comparison to other experiments, collected particles were analyzed for Test 2-22, Rack 3 (1.83 $\mathrm{m}$ from the switchgear rear). The collected particles displayed a low density of background nanoscale aluminum oxide particles, as well as a distribution of mixed oxidized aluminum and oxidized iron particles. Oxidation ratios of approximately 32 percent to 70 percent were measured. An area scan showing the increased density and mixtures of these oxidized aluminum, and iron particles is shown in Fig. 76. 


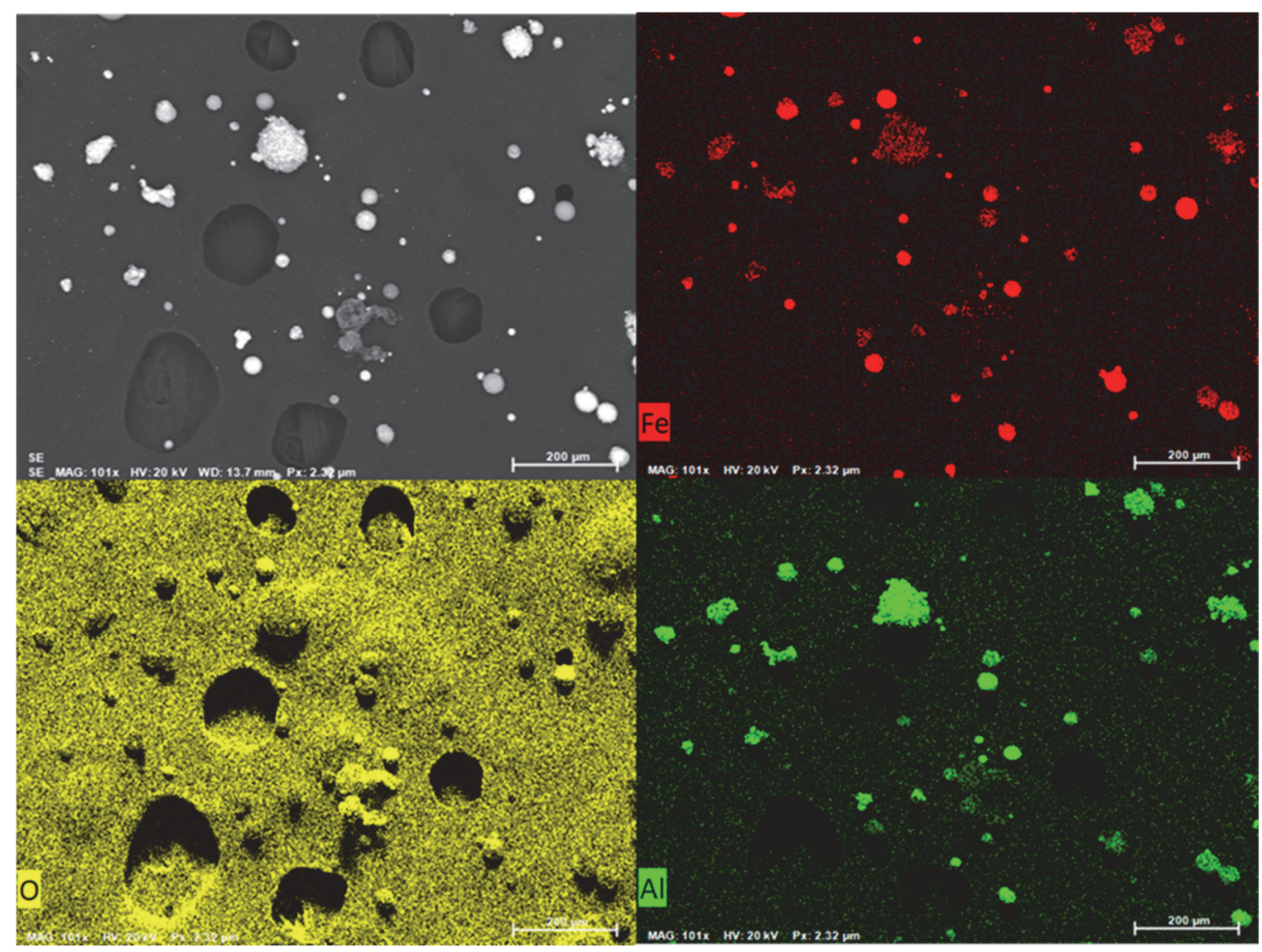

Fig. 76. Rack 3 particle SEM (upper left) with intensity plot for iron (upper right), aluminum (lower right) and oxygen (lower left). The elemental composition included primarily separate particles composites of partially oxidize aluminum and iron.

\subsection{Test $2-24-6.9 \mathrm{kV}, 32 \mathrm{kA}, 4 \mathrm{~s}$ duration, aluminum bus}

Test 2-24 was performed on September 12, 2018 at 1:50 PM eastern daylight time (EDT). The temperature was approximately $24^{\circ} \mathrm{C}\left(76^{\circ} \mathrm{F}\right)$, approximately 81 percent relative humidity and approximately $102.4 \mathrm{kPa}$ of pressure. The weather was overcast with zero precipitation and a north wind at approximately $3 \mathrm{~km} / \mathrm{h}(2 \mathrm{mi} / \mathrm{h})$.

\subsubsection{Observations}

Observations documented below are based on review of video and thermal imaging that was taken during the experiment. The observations provided in Table 25 include an approximate time reference. Corresponding images are provided in Fig. 77. Thermal images are shown in Fig. 78. 
Table 25. Observations from Test 2-24

\begin{tabular}{|c|l|}
\hline Time (ms) & Observation \\
\hline $\mathbf{2 8}$ & Bottom of front door begins to open \\
\hline $\mathbf{3 6}$ & Particle ejecta reaches top rack $(0.91 \mathrm{~m}[3.00 \mathrm{ft}]$ above enclosure) \\
\hline $\mathbf{3 6}$ & Particle ejecta passes rear rack (Rack $\# 2$ at $0.91 \mathrm{~m}[3.00 \mathrm{ft}]$ behind enclosure) \\
\hline $\mathbf{4 4}$ & Front door no longer secured by latch $($ continues to open) \\
\hline $\mathbf{8 4}$ & Particle ejecta passes $1.83 \mathrm{~m}[6.00 \mathrm{ft}]$ above enclosure \\
\hline $\mathbf{8 4}$ & $\begin{array}{l}\text { Particle ejecta passes } 2^{\text {nd }} \text { rear rack (Rack \#3 at } 1.83 \mathrm{~m}[6.00 \mathrm{ft}] \text { behind } \\
\text { enclosure) }\end{array}$ \\
\hline $\mathbf{6 0 7}$ & Initial arc breach of rear panel \\
\hline $\mathbf{8 4 8}$ & Top front vent stops emitting hot gas and particle ejecta \\
\hline $\mathbf{9 8 4}$ & $\begin{array}{l}\text { Particle ejecta impacts test facility cell wall }(5.18 \mathrm{~m}[17.00 \mathrm{ft}] \text { behind } \\
\text { enclosure) }\end{array}$ \\
\hline $\mathbf{2 1 5 6}$ & $\begin{array}{l}\text { Significant quantity of particle ejecta impacting test facility cell wall behind } \\
\text { enclosure }\end{array}$ \\
\hline $\mathbf{4 1 5 6}$ & Decrease in cell illumination consistent with experiment termination \\
\hline $\mathbf{1 3 7 0 0 0}$ & Test cell pedestal ventilation fan turned on \\
\hline $\mathbf{1 7 9 0 0 0}$ & CO 2 extinguisher applied to rear of switchgear \\
\hline $\mathbf{1 9 5 0 0 0}$ & CO 2 extinguisher applied inside rear of switchgear \\
\hline $\mathbf{4 8 8 6 4 2}$ & NIST data acquisition ends \\
\hline
\end{tabular}

Photographs of damage to the electrical enclosure are shown in Fig. 79. The enclosure breached at the upper rear panel of the primary cable connection compartment. There were also breaches on both sides of the enclosure adjacent to the breach on the upper rear panel. The electrical enclosure in this experiment experienced the most material loss from the enclosure metal cladding. The door on the front of the enclosure with a single quarter turn latch did open. Just as observed on all three previous experiments, internal pressure caused the bottom of the door to push out and post-experiment inspection indicated that the side of the panel was bowed outward. The combination of these two effects allowed the latch mechanism to slip and the door to open.

HEAF particulate was clearly observed on the test cell wall. The distance between the wall and the rear panel of the electrical enclosure is approximately $5.18 \mathrm{~m}(17.00 \mathrm{ft})$. A fine, white powder was observed on the test cell walls opposite the HEAF blast. The powder was also found on the cameras located along the cell wall. The aluminum bus rear supports were missing, and the mid-span supports showed signs of heat damage. Much of the instrumentation on Rack \#2 (0.91 m [3.00 ft] to the rear) sustained significant damage and melting. The instrumentation cables routed along Rack \#2 were damaged (severed) during the experiment. 

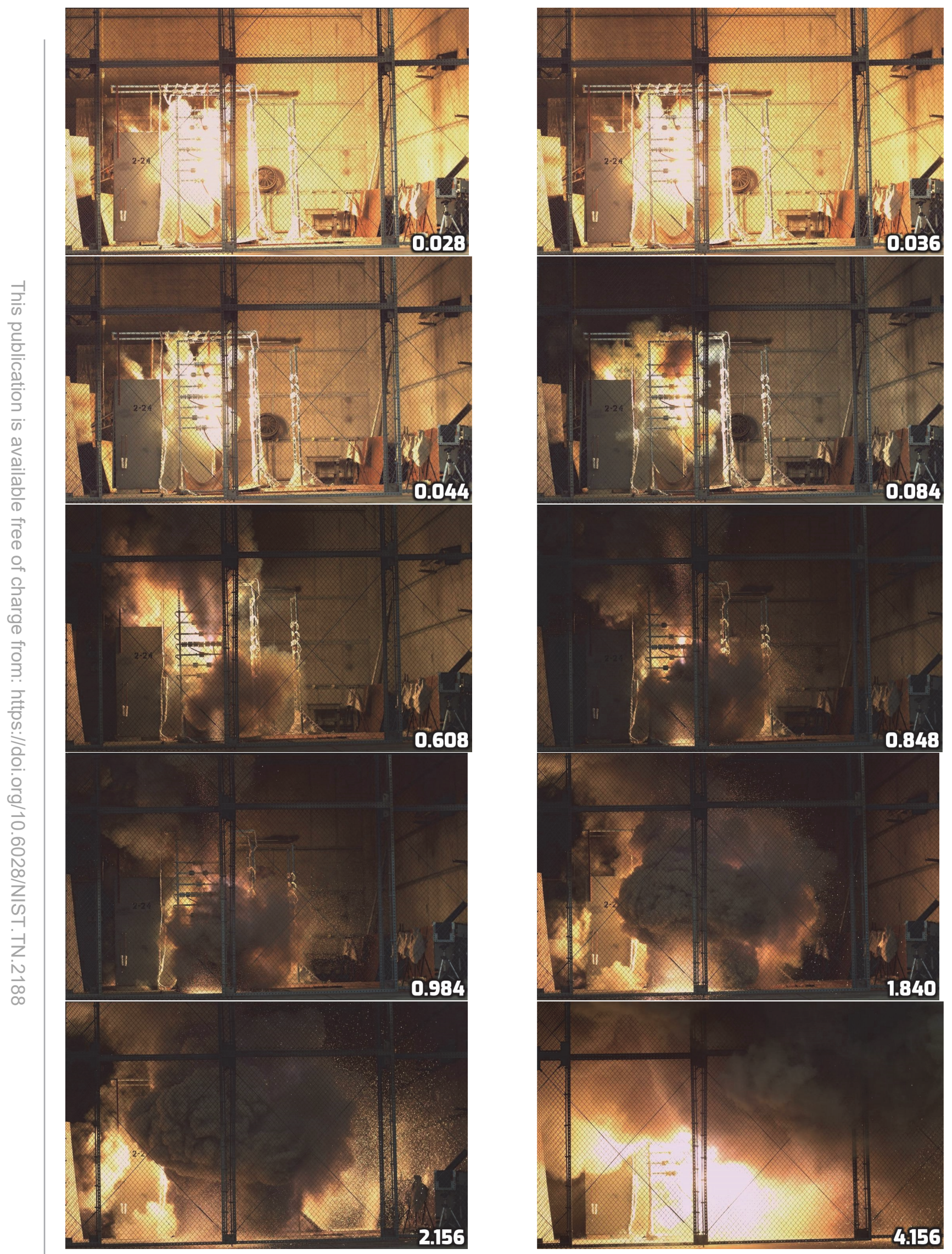

Fig. 77. Sequence of Images of Test 2-24 (image time stamp in seconds) 


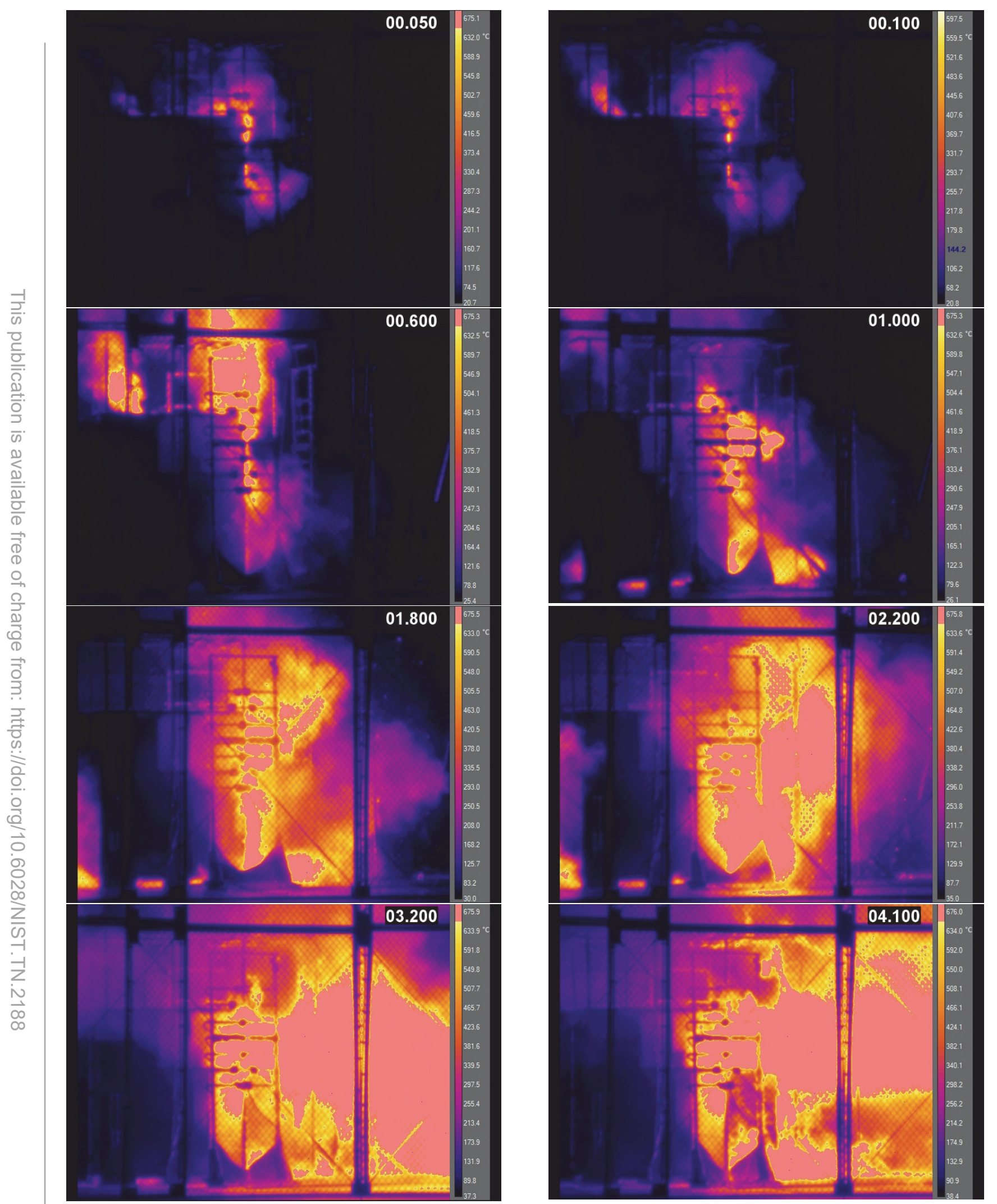

Fig. 78. Sequence of Thermal Images from Test 2-24 (image time stamp in seconds) 

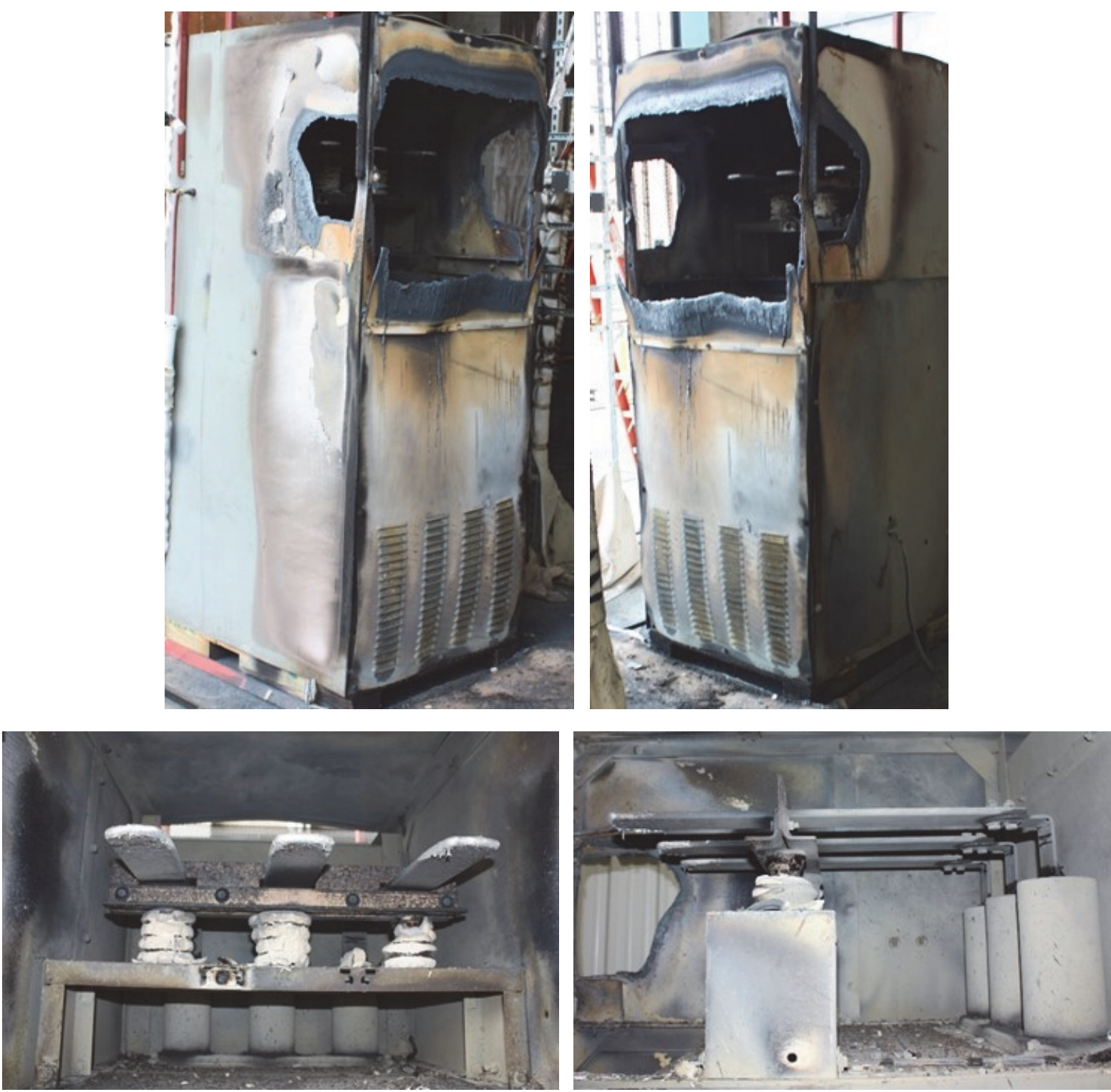

Fig. 79. Enclosure Post-Test 2-24. (Top: back of enclosure; Bottom: remaining bus bar material. Bottom left as viewed from rear of enclosure, bottom right as viewed from the side at the rear of the enclosure with the side panel removed.)

\subsubsection{Measurements}

Measurements made during Test 2-24 are the same as made in other experiments previously reported in this document. Measurements are reported below. 


\subsubsection{Thermal Measurements}

Thermal measurements from the active instruments are reported below for Test 2-24. These include PT measurements in Table 26, and Tcap slug measurements in Table 27. The maximum reading is identified with bold text.

The ASTM Slug calorimeter data was not recorded due to a human error. The KEMA data acquisition system involves several actions to activate and arm the system. During the preexperiment evolution, the arming of the data acquisition system was performed in error. This resulted in the data not being recorded by the DAQ system. The laboratory has corrected the procedure by providing indication in the control room to allow for verification of the system status.

Numerous sensors failed during the experiments due to the HEAF arc jet destroying the thermocouple wiring in the instrument stand. This issue was corrected in later experiments by further protecting the wiring in the instrument stand with glass reinforced epoxy board in addition to ceramic fiber insulating blanket. It is notable that all instruments on Rack \#2 (located $0.91 \mathrm{~m}[3.00 \mathrm{ft}]$ from the enclosure) were damaged, a few instruments on Rack \#3 (located $1.83 \mathrm{~m}[6.00 \mathrm{ft}]$ from the enclosure) survived and recorded a Max Heat Flux of $4.8 \mathrm{MW} / \mathrm{m}^{2}$.

Significant amounts of incident energy $\left(\mathrm{MJ} / \mathrm{m}^{2}\right)$ were transferred to areas surrounding the switch gear during the post-arcing phase of the HEAF. The post-arcing phase incident energy contribution, as measured by the Tcap slugs, varied greatly depending on the measurement location. 
Table 26. Summary of plate thermometer measurements Test 2-24

\begin{tabular}{|c|c|c|c|c|c|}
\hline $\begin{array}{c}\text { Rack } \\
\text { No. }\end{array}$ & Plate No. & Location & $\begin{array}{c}\text { Max Heat } \\
\text { Flux }\left(\mathbf{k W} / \mathbf{m}^{2}\right) \\
\pm 1 \mathrm{~kW} / \mathrm{m}^{2} \text { or } \\
\pm 5 \%\end{array}$ & $\begin{array}{c}\text { Average Heat } \\
\text { Flux During } \\
\text { Arc }\left(\mathbf{k W} / \mathbf{m}^{2}\right) \\
\pm 1 \mathbf{k W} / \mathbf{m}^{2} \text { or } \\
\pm 5 \%\end{array}$ & Comment \\
\hline 1 & 1 & Top & 431.2 & 202.1 & \\
\hline 1 & 3 & Mid-Right & 764.5 & 414.2 & \\
\hline 1 & 5 & Mid-Center & 23.8 & 7.3 & \\
\hline 1 & 7 & Mid-Left & 419.2 & 185.7 & \\
\hline 1 & 9 & Bottom & 410.3 & 223.1 & \\
\hline 2 & 10 & Top & -- & -- & $\begin{array}{c}\text { Device } \\
\text { destroyed }\end{array}$ \\
\hline 2 & 12 & Mid-Right & --- & --- & $\begin{array}{c}\text { Device } \\
\text { destroyed }\end{array}$ \\
\hline 2 & 14 & Mid-Center & --- & --- & $\begin{array}{c}\text { Device } \\
\text { destroyed }\end{array}$ \\
\hline 2 & 16 & Mid-Left & --- & --- & $\begin{array}{c}\text { Device } \\
\text { destroyed }\end{array}$ \\
\hline 2 & 18 & Bottom & --- & -- & $\begin{array}{c}\text { Device } \\
\text { destroyed }\end{array}$ \\
\hline 3 & 19 & Top & 1565.6 & 620.5 & \\
\hline 3 & 21 & Mid-Right & --- & -- & $\begin{array}{c}\text { Device } \\
\text { destroyed }\end{array}$ \\
\hline 3 & 23 & Mid-Center & --- & --- & $\begin{array}{c}\text { Device } \\
\text { destroyed }\end{array}$ \\
\hline 3 & 25 & Mid-Left & 4811.9 & 1437.6 & \\
\hline 3 & 27 & Bottom & 3620.3 & 1088.9 & \\
\hline 4 & 28 & Top & 739.6 & 200.5 & \\
\hline 4 & 30 & Mid-Right & 279.8 & 131.4 & \\
\hline 4 & 32 & Mid-Center & 1225.4 & 273.2 & \\
\hline 4 & 34 & Mid-Left & 760.8 & 391.2 & \\
\hline 4 & 36 & Bottom & 2448.7 & 411.0 & \\
\hline 5 & 37 & Front & -- & -- & $\begin{array}{c}\text { Device } \\
\text { destroyed }\end{array}$ \\
\hline 5 & 39 & Center-Right & -- & -- & $\begin{array}{c}\text { Device } \\
\text { destroyed }\end{array}$ \\
\hline 5 & 41 & Center-Mid & -- & --- & $\begin{array}{c}\text { Device } \\
\text { destroyed }\end{array}$ \\
\hline 5 & 43 & Center-Left & -- & --- & $\begin{array}{c}\text { Device } \\
\text { destroyed }\end{array}$ \\
\hline 5 & 45 & Back & $-\ldots$ & -- & $\begin{array}{c}\text { Device } \\
\text { destroyed }\end{array}$ \\
\hline
\end{tabular}


Table 27. Summary of $\mathrm{T}_{\text {cap }}$ slug Measurement, Test 2-24

\begin{tabular}{|c|c|c|c|c|c|c|}
\hline $\begin{array}{c}\text { Rack } \\
\text { No. }\end{array}$ & $\begin{array}{l}\mathbf{T}_{\text {cap }} \\
\text { No. }\end{array}$ & Location & $\begin{array}{c}\text { Heat Flux } \\
\text { During Arc } \\
\left(\mathbf{k W / m ^ { 2 } )}\right. \\
\pm 2.9 \%\end{array}$ & $\begin{array}{c}\text { Incident } \\
\text { Energy } \\
\text { During Arc } \\
\text { Phase } \\
\left(\mathbf{k J} / \mathbf{m}^{2}\right) \\
\pm 5 \%\end{array}$ & $\begin{array}{c}\text { Total } \\
\text { Incident } \\
\text { Energy } \\
\left(\mathbf{k J} / \mathbf{m}^{2}\right) \\
\pm 5 \%\end{array}$ & Comments \\
\hline 1 & 2 & Top & 500.7 & 1168.0 & 1530.7 & \\
\hline 1 & 4 & Mid-Right & 559.3 & 1467.4 & 1928.8 & \\
\hline 1 & 6 & Mid-Left & 578.6 & 1162.8 & 1498.4 & \\
\hline 1 & 8 & Bottom & 475.8 & 1193.5 & 1666.8 & \\
\hline 2 & 11 & Top & --- & -- & -- & Device Failure \\
\hline 2 & 13 & Mid-Right & --- & -- & --- & Device Failure \\
\hline 2 & 15 & Mid-Left & -- & -- & -- & Device Failure \\
\hline 2 & 17 & Bottom & --- & --- & --- & Device Failure \\
\hline 3 & 20 & Top & 2018.0 & 3343.6 & 3488.5 & \\
\hline 3 & 22 & Mid-Right & --- & --- & --- & Device Failure \\
\hline 3 & 24 & Mid-Left & 3140.1 & 3819.8 & 4164.9 & \\
\hline 3 & 26 & Bottom & 2400.4 & 4574.0 & 4695.7 & \\
\hline 4 & 29 & Top & 405.8 & 945.8 & 1375.2 & \\
\hline 4 & 31 & Mid-Right & 420.0 & 848.1 & 1304.2 & \\
\hline 4 & 33 & Mid-Left & 461.1 & 1237.6 & 1745.6 & \\
\hline 4 & 35 & Bottom & 447.2 & 1102.9 & 1535.7 & \\
\hline 5 & 38 & Front & --- & --- & --- & Device Failure \\
\hline 5 & 40 & $\begin{array}{c}\text { Center- } \\
\text { Right }\end{array}$ & -- & & --- & Device Failure \\
\hline 5 & 42 & Center-Left & --- & --- & -- & Device Failure \\
\hline 5 & 44 & Back & 226.5 & 569.4 & 975.9 & \\
\hline
\end{tabular}

\subsubsection{Internal Pressure}

The pressure profiles for the first two tenths of a second are shown in Fig. 80. After the initial pressure spike, the pressure rapidly decays to a relative steady state. The peak pressure is higher in the primary cable connection compartment as would be expected since this is the compartment where the arc is initiated. The maximum change in pressure in the primary cable connection compartment is approximately $30.3 \mathrm{kPa}$ (4.4 psi) above ambient at its peak. The maximum change in pressure in the breaker compartment is approximately $5.5 \mathrm{kPa}(0.8 \mathrm{psi})$ above ambient. The $0 \mathrm{kPa}$ to $207 \mathrm{kPa}(0$ psia to $30 \mathrm{psia})$ and $0 \mathrm{kPA}$ to $245 \mathrm{kPa}$ ( 0 psia to $50 \mathrm{psia})$ gauge recordings at a specific location were consistent. 

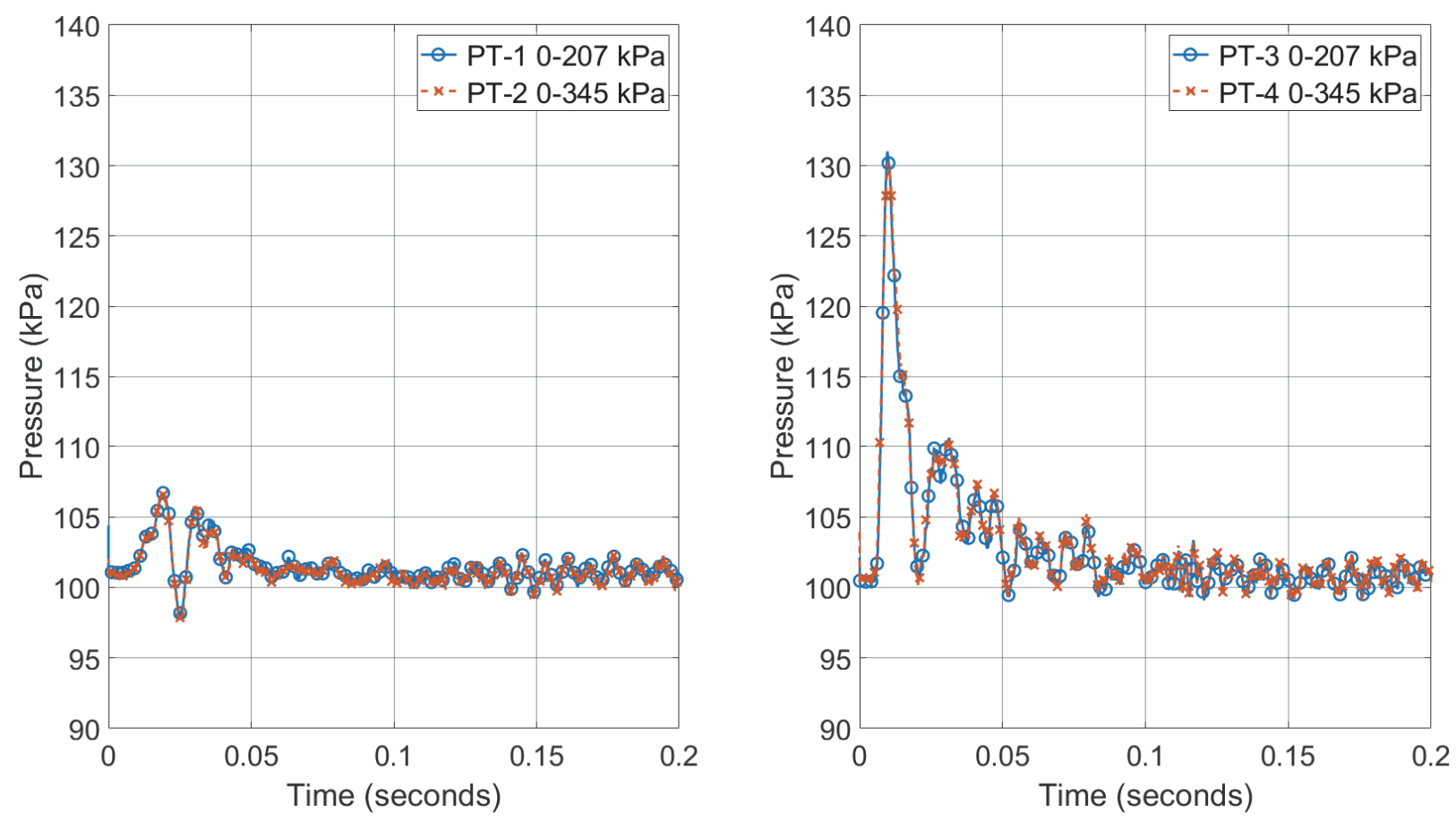

Fig. 80. Pressure measurements from Test 2-24 (breaker compartment - left; arcing compartment - right). Measurement uncertainty \pm 3 percent.

\subsubsection{Mass measurements}

Mass loss measurements were made for the enclosure metal cladding and the bus conductors. All measurements made are reported in Appendix C. One observation that was made in all experiments was that for many of the steel cladding panels, the post-experiment measurements were larger than the pre-experiment measurements. This is likely caused by the plating of the electrical conductors on to the metal cladding. As such, for the panels that experienced breach, the actual mass loss is likely greater than what is reported below. For this experiment, the upper rear panel experienced breach as did the two adjacent side panels (far side rear panel and primary cable compartment bus side upper panel). The total mass loss measured using an electronic balance (NIST Scale 2) was approximately $2.70 \mathrm{~kg}$ for the primary cable compartment bus side upper panel and approximately $9.37 \mathrm{~kg}$ for the rear upper panel. The bus bars lost a total of $2.566 \mathrm{~kg}$ (846 g Phase A, $868 \mathrm{~g}$ Phase B, and $852 \mathrm{~g}$ Phase C). These mass measurements were made using an electronic mass balance (NIST Scale 2) with an expanded uncertainty, derived from manufacturer specifications, of $\pm 1 \mathrm{~g}$, with a 95 percent confidence interval. For this experiment the breach area estimates using the graphical approach are shown in Fig. 81. The total mass loss from the electrical enclosure is estimated using the graphical approach at approximately $14.86 \mathrm{~kg}$. Note that the upper rear panel required the measurement of the remaining steel due to the severing of the panel into two pieces. The remaining steel measurement was subtracted from the initial (preexperiment) measurement to arrive at a mass loss value for this panel. 

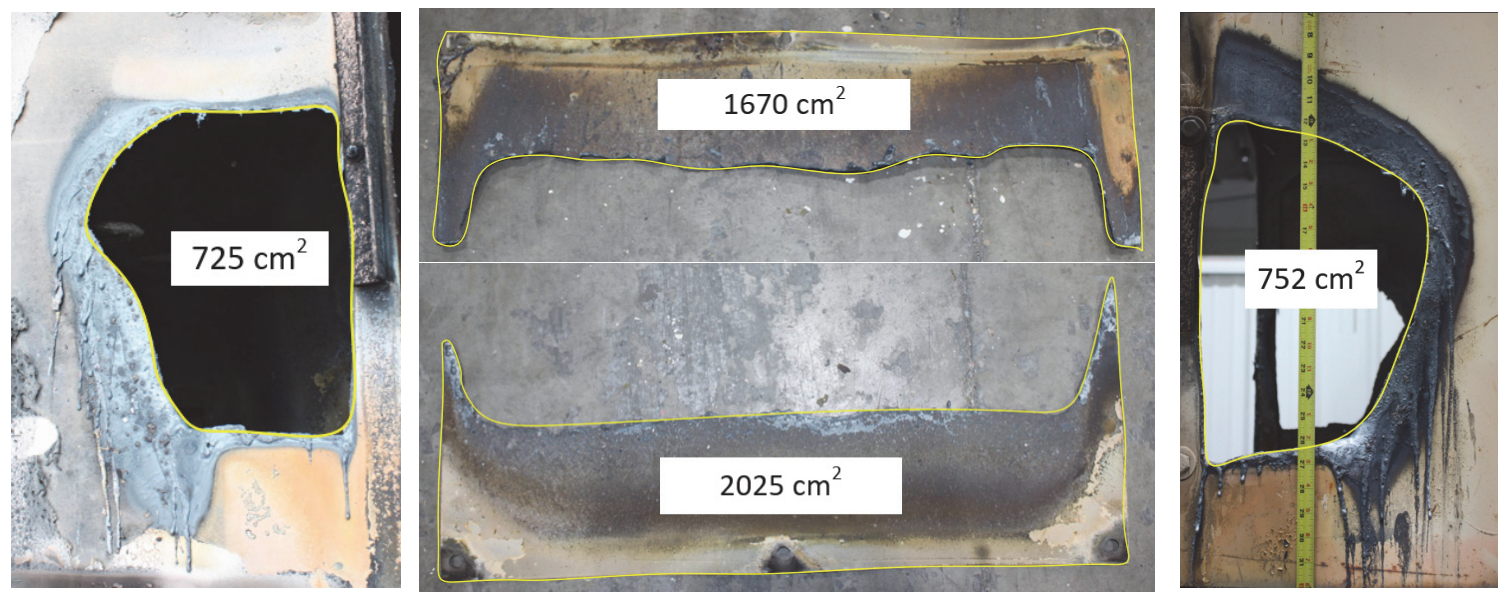

Fig. 81. Photos showing breach openings or remaining cladding

\subsubsection{Electrical Measurements}

Test 2-24 used KEMA test circuit S02 shown in Fig. 82. Full-level circuit checks (calibration tests) were performed prior to the experiment to verify experimental parameters were acceptable. For this experiment the calibration tests configured the power system to $7 \mathrm{kV}, 32.0 \mathrm{kA}$ symmetrical, and $86.4 \mathrm{kA}$ peak. The KEMA Test report identifies this experiment as 180912-9001.

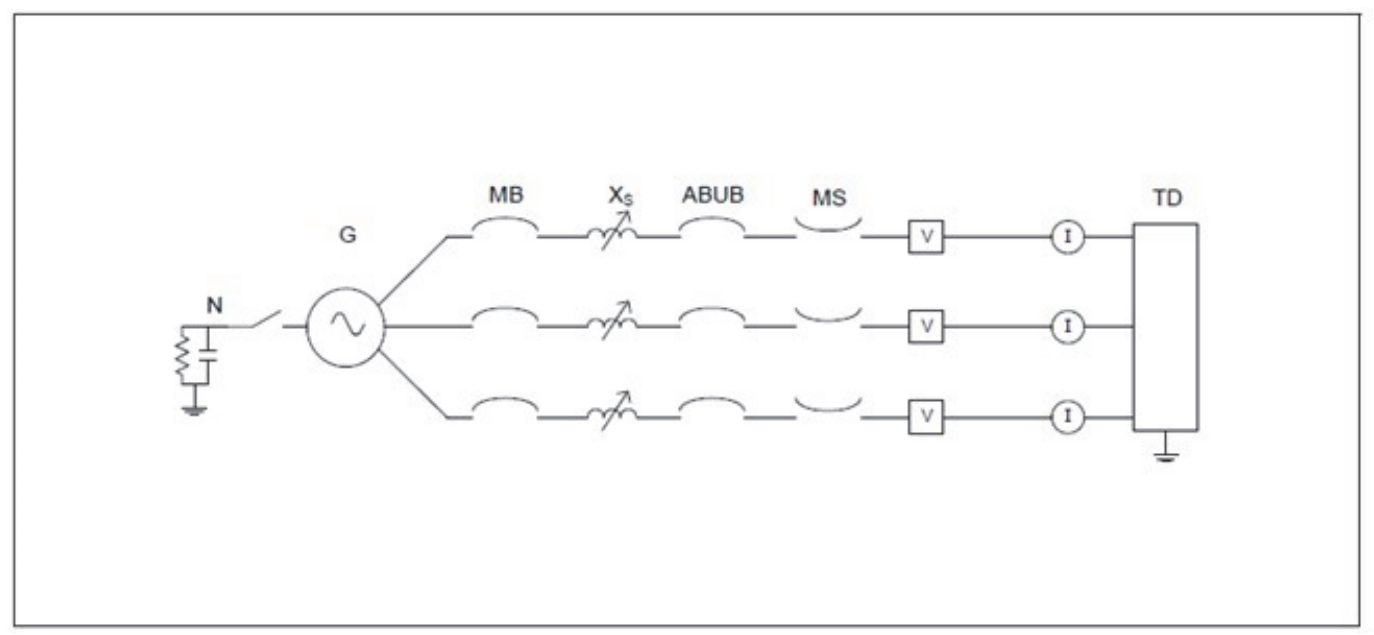

\begin{tabular}{|c|c|c|c|c|c|}
\hline \multicolumn{2}{|c|}{ Supply } & \multicolumn{4}{|c|}{ Nomenclature } \\
\hline Power & 388 MVA & G & Generator & $\mathrm{R}$ & Resistance \\
\hline Frequency & $60 \mathrm{~Hz}$ & $\mathrm{~N}$ & Neutral & $\mathrm{C}$ & Capacitance \\
\hline Phase(s) & 3 & MB & Main Breaker & $\mathrm{U}$ & Voltage Measurement \\
\hline Voltage & $7.0 \mathrm{kV}$ & MS & Make Switch & I & Current Measurement \\
\hline Current & $32.0 \mathrm{kA}$ & ABUB & Aux. Breaker & & \\
\hline Impedance & $0.1263 \Omega$ & XFMR & Transformer & & \\
\hline Peak Current & $86.4 \mathrm{kA}$ & TD & Test Device & & \\
\hline Neutral & Not Earthed & $\mathrm{X}$ & Inductance & & \\
\hline
\end{tabular}

Fig. 82. KEMA Test Circuit S01 used in Test 2-24 
The voltage and current profile for the entire duration of the experiment is shown in Fig. 83. Key experimental measurements are presented in Table 28. The transient region for current phases is presented in Fig. 84. Energy and power profiles are presented in Fig. 85. 


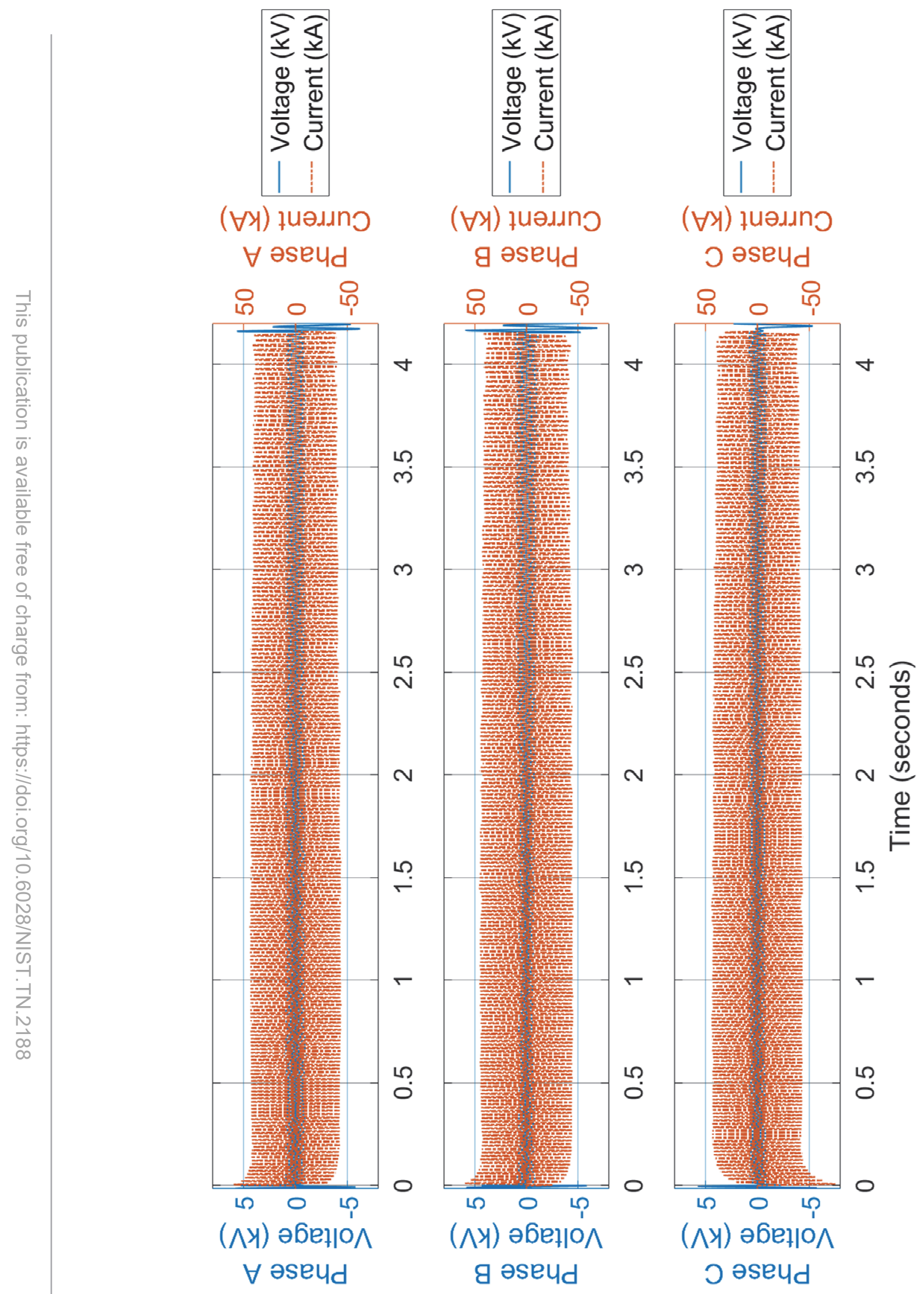

Fig. 83. Voltage and Current Profile for Test $2-24$. Measurement uncertainty \pm 3 percent. 
Table 28. Key measurements for Test 2-24. Measurement uncertainty \pm 3 percent.

\begin{tabular}{|c|c|c|c|c|}
\hline Phase & Units & $\mathbf{A}$ & B & $\mathbf{C}$ \\
\hline Applied voltage, phase-to-ground & $\mathrm{kV}$ RMS & 4.07 & 4.10 & 4.04 \\
\hline Applied voltage, phase-to-phase & $\mathrm{kVRMS}$ & \multicolumn{3}{|c|}{7.05} \\
\hline Making current & $\mathrm{kA}_{\text {peak }}$ & 59.4 & 59.3 & -75.0 \\
\hline Current, a.c. component, beginning & kARMS & 30.6 & 31.3 & 31.4 \\
\hline Current, a.c. component, middle & kARMS & 31.1 & 31.0 & 30.0 \\
\hline Current, a.c. component, end & kARMS & 27.6 & 27.7 & 27.1 \\
\hline Current, a.c. component, average & kARMS & 29.8 & 30.8 & 30.0 \\
\hline Current, a.c. component, three-phase average & kARMS & \multicolumn{3}{|c|}{30.2} \\
\hline Duration & $\mathrm{s}$ & 4.15 & 4.15 & 4.15 \\
\hline Generator Energy & MJ & \multicolumn{3}{|c|}{148.1} \\
\hline
\end{tabular}
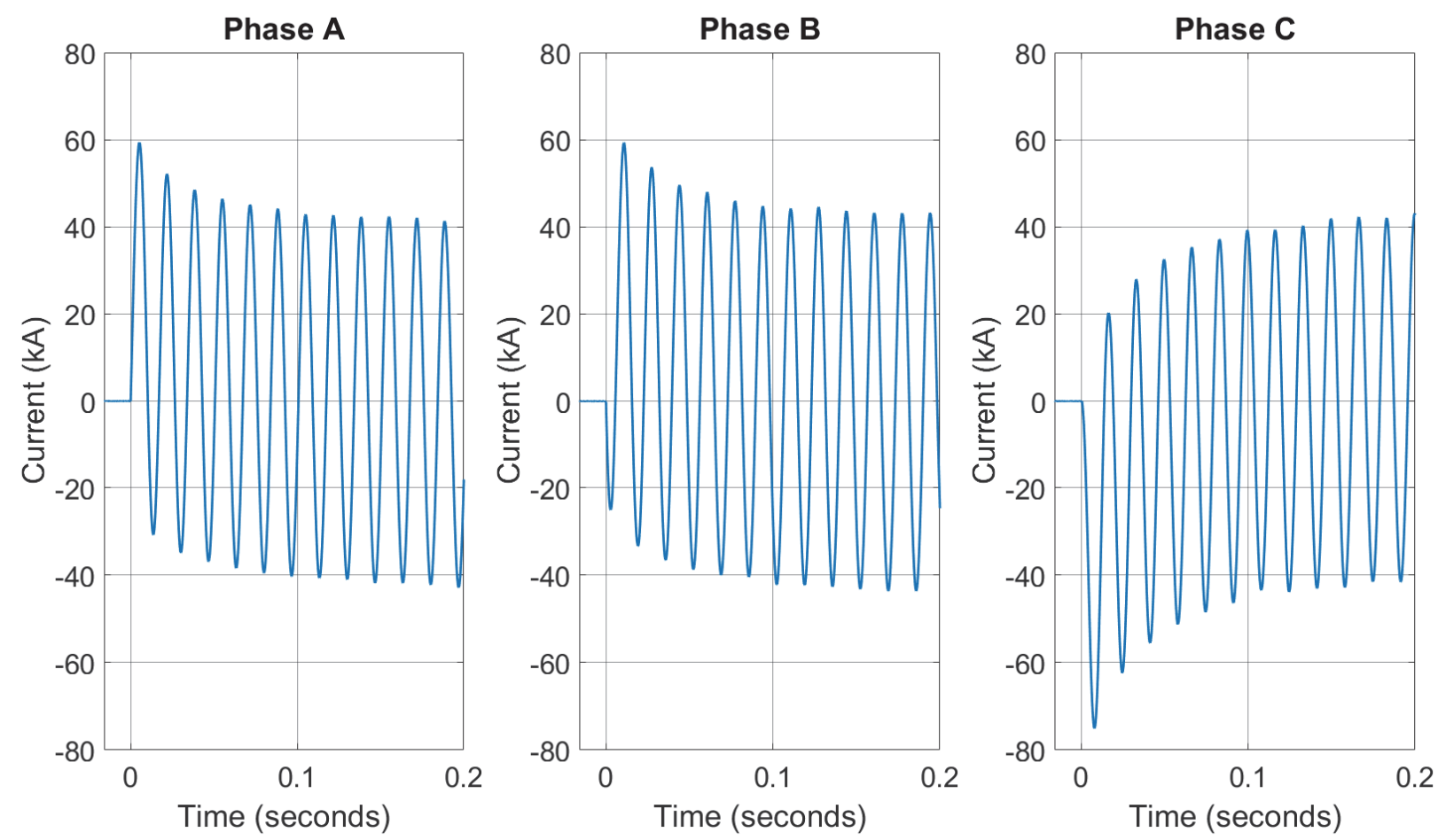

Fig. 84. Transient current profiles for Test 2-24. Measurement uncertainty \pm 3 percent. 


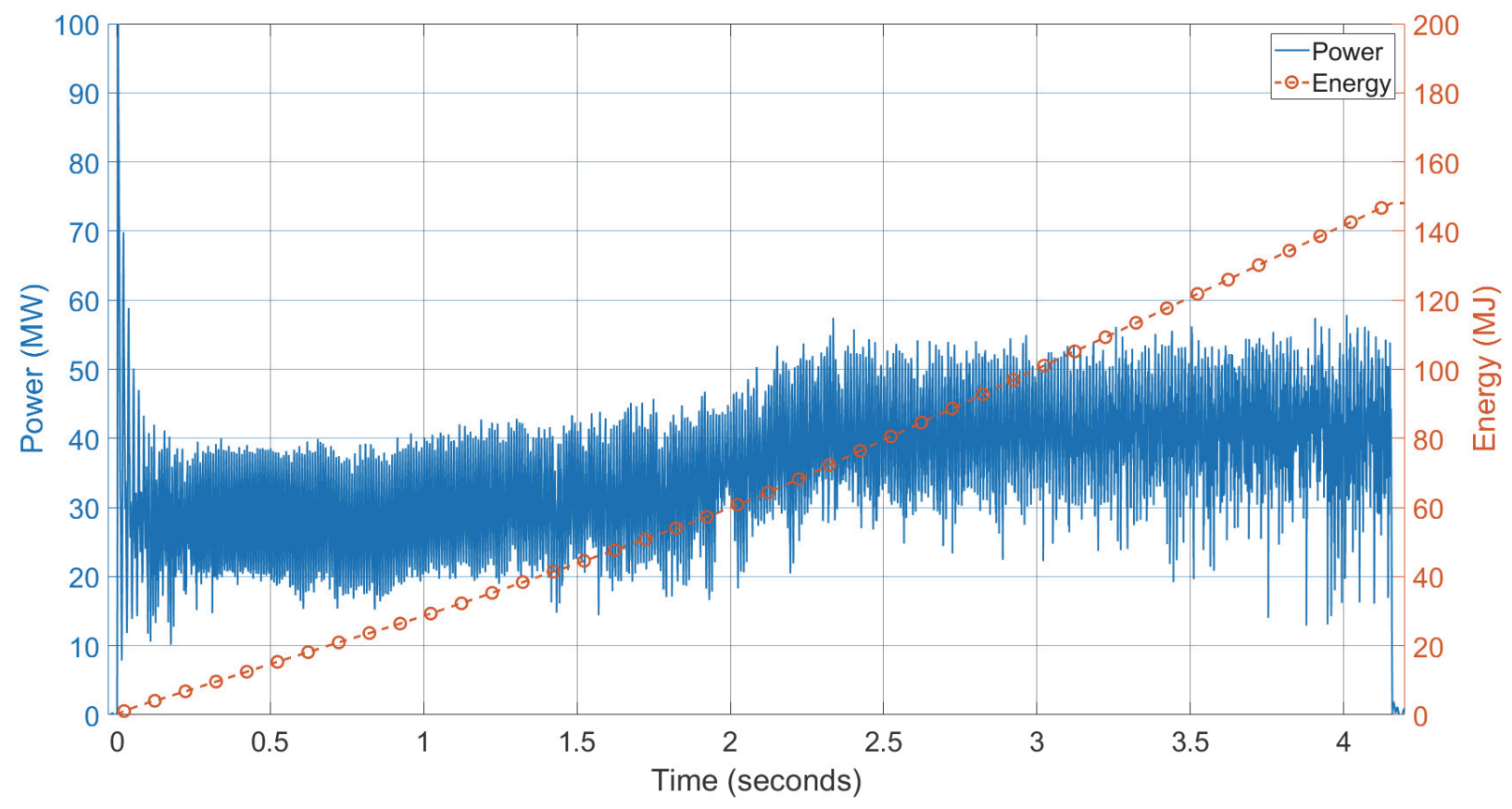

Fig. 85. Power and Energy for Test 2-24. Measurement uncertainty \pm 3 percent.

\subsubsection{Rack \#3 particle collection}

For comparison to other experiments, collected particles were analyzed for Test 2-24, Rack \#3 (1.83 m [6.00 ft] from the switchgear rear). The collected particles displayed a low density of background nanoscale aluminum oxide particles, as well as a distribution of mixed oxidized aluminum and oxidized iron particles. Oxidation ratios of approximately 32 percent to 70 percent were measured. An area scan showing the increased density and mixtures of these oxidized aluminum, and iron particles is shown in Fig. 86. 


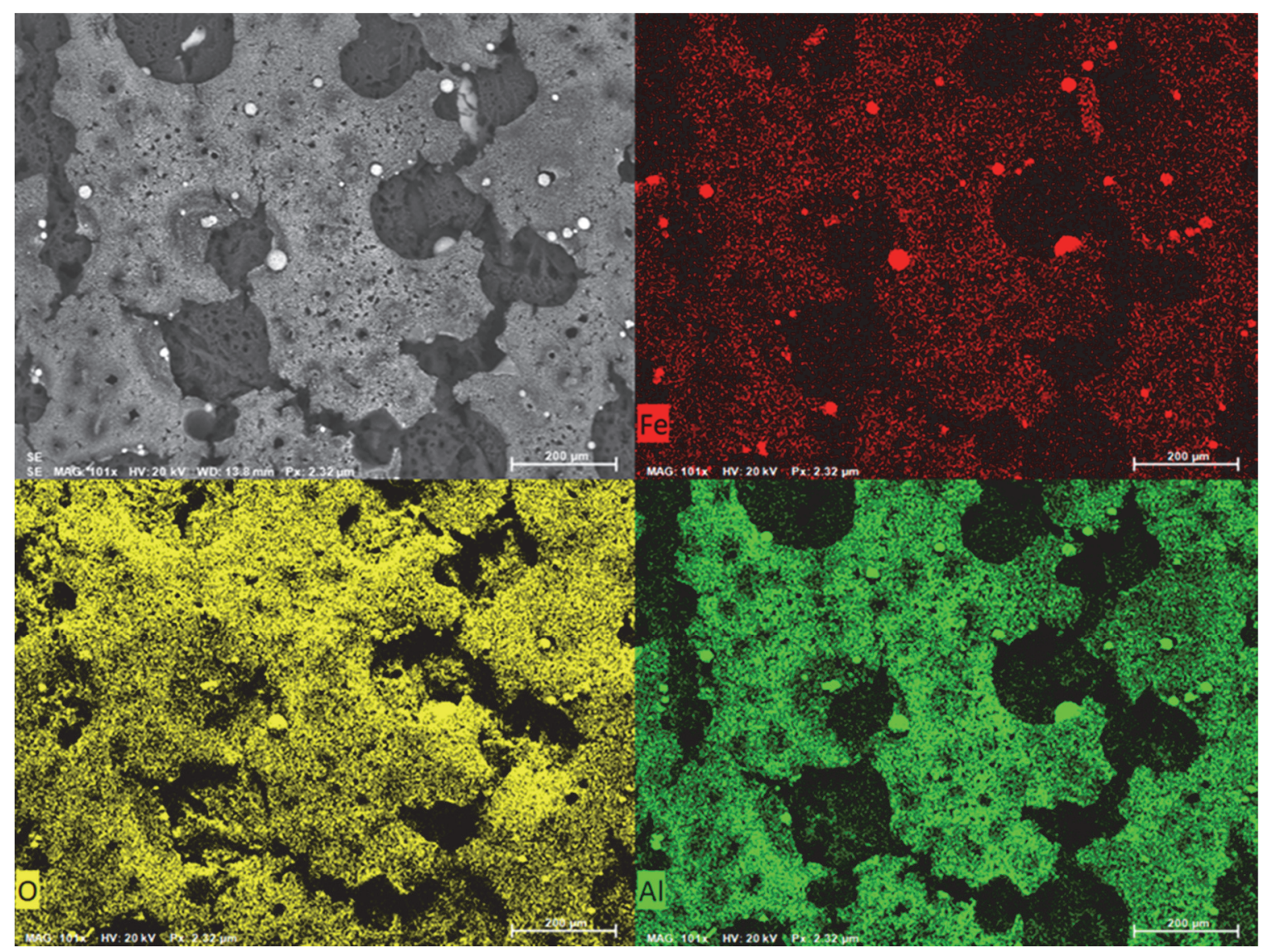

Fig. 86. Rack \#3 particle SEM (upper left) with intensity plot for iron (upper right), aluminum (lower right) and oxygen (lower left). The elemental composition included primarily separate particles composites of partially oxidize aluminum and iron, iron only or aluminum only. 


\section{Summary and Conclusion}

\subsection{Summary}

A series of four (4) high energy arcing fault experiments were performed on medium voltage metal-clad switchgear. Each experiment consisted of a three-phase arcing fault initiated and sustained on aluminum bus bars within the primary cable connection compartment of the switchgear. The magnitude of the arc current and duration was varied at a nominal system voltage per the equipment rating. Electrical parameters are summarized in Table 29 with cumulative energy profiles shown in Fig. 87. Numerous measurements were made to characterize the environment surrounding or within the switchgear, including internal pressure, external heat flux, external incident energy, external particulate composition, and mass loss. Photometric equipment was deployed to capture the event using a combination of devices to characterize the thermal environment, particulate trajectory and velocity, and event timing.

Table 29. Experimental Parameter Summary

\begin{tabular}{|c|c|c|c|c|c|c|c|c|}
\hline \multirow{2}{*}{$\begin{array}{l}\text { Test } \\
\text { No. }\end{array}$} & \multirow{2}{*}{$\begin{array}{l}\text { Voltage } \\
(\mathbf{k V})\end{array}$} & \multirow{2}{*}{$\begin{array}{l}\text { Current } \\
\text { (kA) }\end{array}$} & \multirow{2}{*}{$\begin{array}{l}\text { Arc } \\
\text { Duration } \\
\text { (sec) }\end{array}$} & \multicolumn{2}{|c|}{ Energy (MJ)* } & \multirow{2}{*}{$\begin{array}{l}\text { Breach } \\
\text { time } \\
\text { (s) }\end{array}$} & \multicolumn{2}{|c|}{ Mass loss (kg) } \\
\hline & & & & Generator & $\begin{array}{l}\text { Arc } \\
\text { (est.) }\end{array}$ & & Enclosure & Electrodes \\
\hline $2-19$ & 6.9 & 25.8 & 2.0 & 46.5 & 39 & 0.534 & 1.600 & 0.458 \\
\hline $2-21$ & 6.9 & 26.6 & 4.1 & 119.8 & 101 & 0.645 & 10.940 & 1.966 \\
\hline $2-22$ & 7.0 & 32.0 & 2.1 & 63.4 & 51 & 0.600 & 5.246 & 0.894 \\
\hline $2-24$ & 7.0 & 29.8 & 4.2 & 148.1 & 122 & 0.607 & 14.863 & 2.573 \\
\hline
\end{tabular}

* Energy at Generator (Energy at arc is lower and estimated in table)

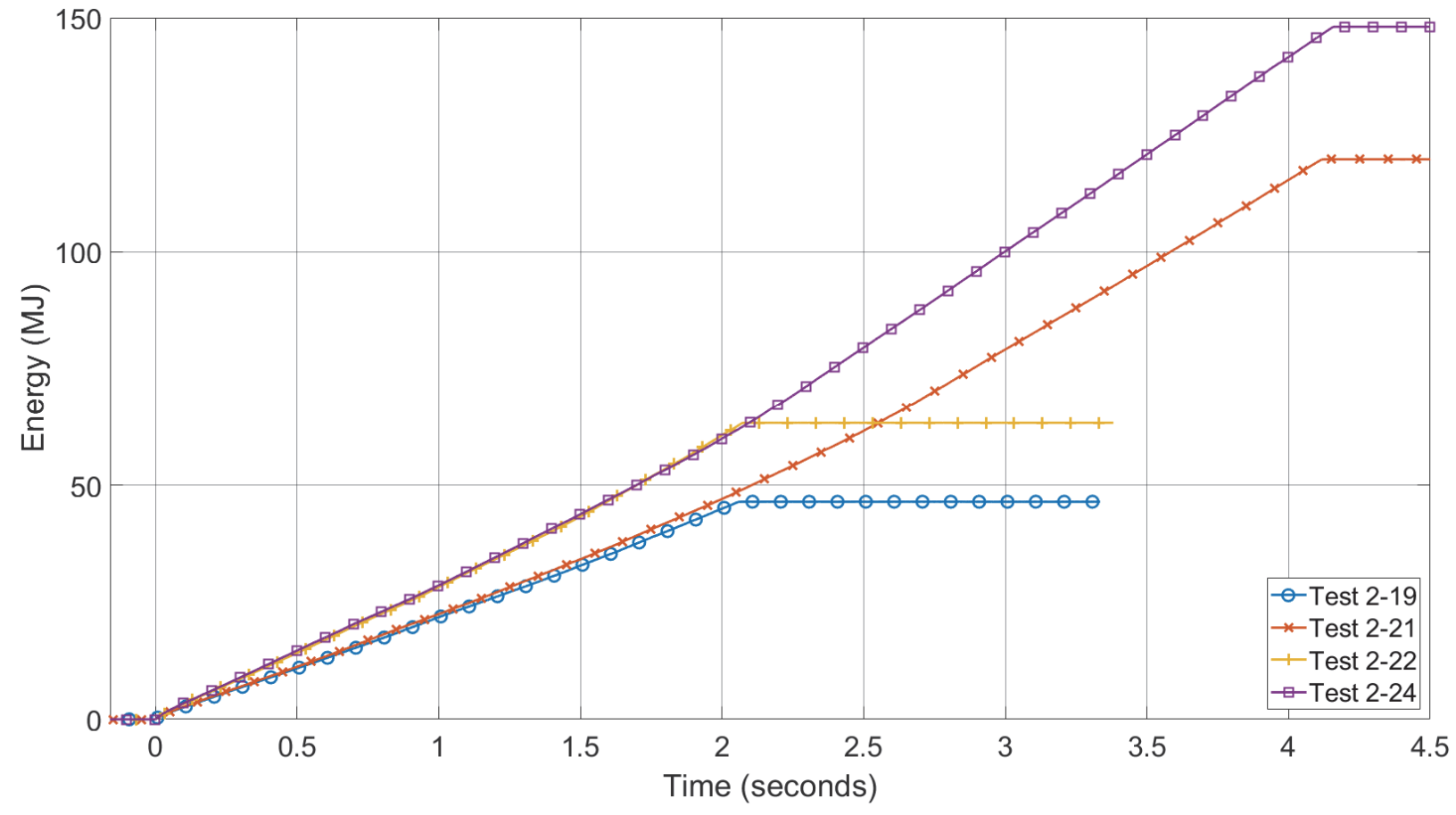

Fig. 87. Energy Profile by experiment (at generator) 


\subsection{Conclusions}

This series of experiments provide valuable information related to the hazards posed by HEAFs, including:

- Enclosure breach time was similar among the experiments ranging between $0.53 \mathrm{~s}$ and $0.64 \mathrm{~s}$ after arc initiation

- The experimental parameters that were varied in this program did not show a significant impact on the time to breach of the enclosure. Location of the arc and equipment design/configuration may have a larger influence on the time to breach of an enclosure.

- Breach time may be a useful parameter to incorporate into the hazard estimation.

- Enclosure and electrode mass loss scales linearly with electrical energy measured at the generator.

$\circ$ The mass loss of the Aluminum conductor is linearly proportional to the generator energy during experiment as shown in Fig. 88. Note that arc energy was not measured during this set of experiments.

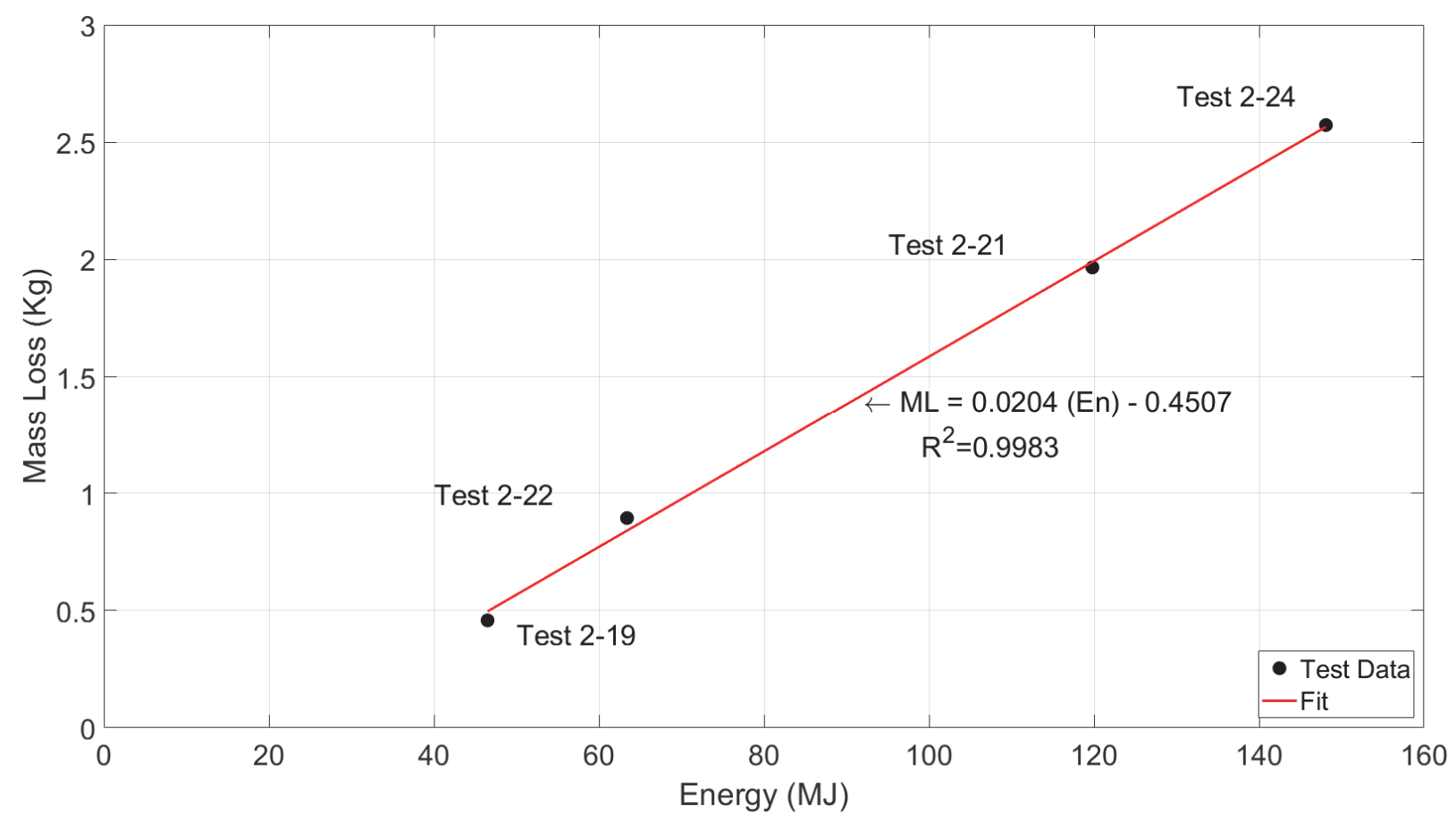

Fig. 88. Electrical energy (at generator) versus bus bar mass loss

- The mass loss of the steel enclosure is linearly proportional to the electrical generator energy during the experiments as shown in Fig. 89. 


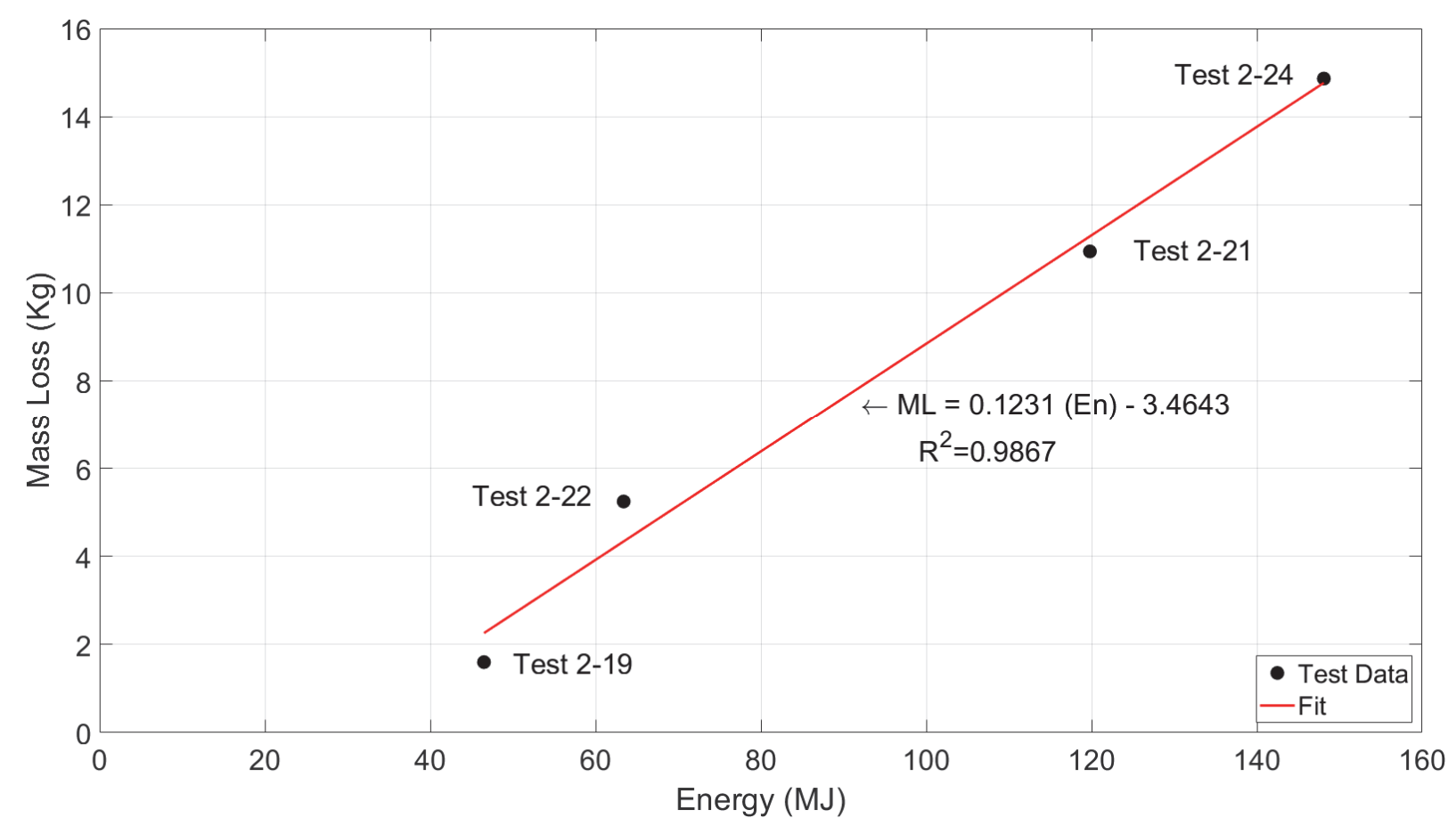

Fig. 89. Electrical enclosure steel mass loss versus electrical generator energy during the experiments.

- Significant amounts of energy (incident energy $\mathrm{MJ} / \mathrm{m}^{2}$ ) were transferred to the thermal transducers surrounding the switchgear during the post-arcing phase of the HEAF. In locations not directly impacted by a HEAF arc jet, the incident energy measured during the post-arcing phase could be multiple times greater than the incident energy measured during the arcing phase.

- Incident energy reached $7.79 \mathrm{MJ} / \mathrm{m}^{2}$ at a distance of $0.91 \mathrm{~m}(3.00 \mathrm{ft})$ from the switchgear and $3.35 \mathrm{MJ} / \mathrm{m}^{2}$ at a distance of $1.83 \mathrm{~m}(6.00 \mathrm{ft})$ from the switchgear. The incident energy at $0.91 \mathrm{~m}(3.00 \mathrm{ft})$ was likely greater than the reported $7.79 \mathrm{MJ} / \mathrm{m}^{2}$ due to the destruction of the instrument wiring serving sensors that were directly impinged on by the HEAF arc jet in Test 2-24.

- Peak pressure rise is similar among the experiments ranging from $27.6 \mathrm{kPa}$ to $30.3 \mathrm{kPa}$ ( $4.0 \mathrm{psi}$ to $4.4 \mathrm{psi}$ ) above ambient for the compartment where the arc was initiated and sustained.

- Enclosure overpressure is dependent on the arc characteristics (voltage, current, gap, material) and the enclosure characteristics (volume, venting, overpressure relief). The compartment where the arc initiated was large and the door opened quickly, which limited the peak overpressure.

- Particle analysis indicated the oxidation characteristics from this series of experiments were similar to the results from the bench-scale experiments [2]. 
- Bimodal particle size distributions were observed including nanoscale particles displaying full oxidation (O:Al ratios near 1:1) and micrometer-scale particles displaying partial oxidation (O:Al ratios of $0.24: 1$ to $0.74: 1)$.

- 10 micrometer particles displayed an oxidized surface skin and metal core (attributed to melted, then solidified Al microparticles).

$\circ<100 \mathrm{~nm}$ particles which displayed full oxidation (attributed to melted, then vaporized and oxidized $\mathrm{Al}$ ).

\subsection{Lessons Learned}

- Due to the magnitude of the incident energy from HEAF events, which is much greater than that from typical arc flash events, the ASTM slug calorimeters overranged in many locations. The newly developed $\mathrm{T}_{\text {cap }}$ slug, however, was able to measure the high incident energies from HEAF events and quantify the incident energies from the arcing and the post-arcing phases.

- Improved data acquisition methods further reduced EMI and the impact of destroyed sensors on PT and $\mathrm{T}_{\text {cap }}$ thermal sensor data quality as compared to the Phase 1 HEAF experiments. Improved data cable routing and protection improved sensor and cable survivability under direct exposure to HEAF jets.

- Replacing the ASTM slug calorimeter plywood components with calcium silicate board eliminated the thermal error contribution from burning plywood under high thermal exposures.

- Improvements to the pressure sensors and data acquisition system resulted in reduced EMI and therefore improved data quality as compared to the Phase $1 \mathrm{HEAF}$ experiments.

- High dynamic range imaging provided a good match for these experiments due to the vast range of brightness. It is likely that future experiments could use two imagers to cover the range, rather than the three fielded during these experiments.

- Thermal imaging worked well and is substantially enhanced by data fusion with synchronous visible imaging. Various temperatures ranges were fielded, and future experiments should use the highest range $\left(750^{\circ} \mathrm{C}\right.$ to $\left.3000^{\circ} \mathrm{C}\right)$ to ensure minimal saturation. Future experiments could also increase the number of sensors to capture thermal data for a wider range of temperatures. Efforts should be made to acquire thermal imaging equipment with increased dynamic range so that equipment and phenomena at temperatures from ambient up to approximately $3000^{\circ} \mathrm{C}$ can be effectively imaged.

- Particle speed measurements provide useful data for in-plane particle speed. The main limitation is the chain-link fence used at the test facility for mitigation of projectiles. Removal of this fence could improve the measurement technique and reduce uncertainties. The value of this measurement technique was impacted by the flashing of the event. Regions of substantial bright flashes caused the optical flow algorithm to fail. 
- Video recordings made from inside the test cell provided exceptional detail on the timing and location of enclosure breach. In addition to the high-speed data, the use of self-contained, low-cost, small form factor cameras provided a low-risk method to capture dynamics of the experimental evolution.

\subsection{Recommendations for future experiments}

Performance of this work has identified several key aspects of the experiments where improvements can be made. These include:

- Voltage measurement

- Issue: Voltage during the experiments was reported for the generator. Voltage at the test device will be less than reported due to losses in the laboratory's electrical distribution system. The system dynamics do not permit a simple approach for estimating voltage at the test device. This results in the energy delivered to the test device being less than that reported.

- Recommendation: Phase voltage should be measured as close to the test device as possible to ensure realistic measurement of energy delivered to the test device. Repeat experiments planned and performed in the future should include generator and test device voltage measurements using the same circuit used in these experiments.

- Incident energy

- Issue: Significant energy was transferred from the switchgear to the thermal transducers surrounding the switchgear after the arcing phase of the experiments ended and while the switchgear was still hot.

- Recommendation: Provide additional focus on the measurement of post-arcing phase heat transfer to surrounding targets and equipment.

- Instrumentation protection

- Issue: Thermal protection of active instrumentation wiring was inadequate to survive the most severe thermal exposure.

- Recommendation: Improve thermal protection while ensuring limited impact on resources needed to prepare instrumentation racks.

- Impact of aluminum byproduct on functionality of equipment

- Issue: Post-experiment observations confirmed substantial aluminum byproduct coating the test cell in some experiments. Past experiments have shown that this byproduct can impact the functionality of unprotected equipment. Knowledge of the impact this material has on the functionality of critical nuclear power plant equipment is needed. 
○ Recommendation: Plan, develop and implement instrumentation or techniques to understand the potential hazard the aluminum byproducts have on critical NPP equipment.

- Direct comparison to non-Aluminum containing equipment

- Issue: All experiments performed in this experimental series consisted of bus bars made from aluminum. There are no direct comparisons available from past experiments (Phase 1 [6]) or other literature with this arc location and energy levels. This makes qualitative and quantitative comparisons of the aluminum impact difficult.

- Recommendation: Future experiments should consist of identical switchgear units containing copper bus bars with identical experimental conditions, measurement types, and locations to allow for qualitative and quantitative comparison to the aluminum experiment results documented in this report. 



\section{Acknowledgments}

Funding for this work was provided by the U.S. Nuclear Regulatory Commission, Office of Nuclear Regulatory Research. This report was developed jointly between the National Institute of Standards and Technology (NIST), Sandia National Laboratories, and the U.S. Nuclear Regulatory Commission.

The U.S. NRC acknowledge and appreciate the organizations that supported this work, including, KEMA Labs - Chalfont and Brandon Stanton Incorporated. 



\section{References}

[1] NRC Information Notice 2017-04: High Energy Arcing Faults in Electrical Equipment Containing Aluminum Components, US NRC, Washington, DC, August 2017.

[2] K. Armijo and P. Clem, et. al., "Electrical Arc Fault Particle Size Characterization," Sandia Report SAND 2019-11145, September 2019.

[3] OECD Fire Project - Topical Report No. 1, Analysis of High Energy Arcing Faults (HEAF) Fire Events, Nuclear Energy Agency Committee on the Safety of Nuclear Installations, Organization for Economic Cooperation and Development, June 2013. http://www.oecd-nea.org/nsd/docs/2013/csni-r2013-6.pdf

[4] EPRI/NRC-RES Fire PRA Methodology for Nuclear Power Facilities, Volume 2: Detailed Methodology. Electric Power Research Institute (EPRI), Palo Alto, CA, and U.S. Nuclear Regulatory Commission, Office of Nuclear Regulatory Research (RES), Rockville, MD: 2005, EPRI TR-1011989 and NUREG/CR-6850.

[5] Fire Probabilistic Risk Assessment Methods Enhancements: Supplement 1 to NUREG/CR-6850 and EPRI 1011989, EPRI, Palo Alto, CA, and NRC, Washington, DC.: December 2009.

[6] NEA HEAF Project - TOPICAL REPORT No. 1, Experimental Results from the International High Energy Arcing Fault (HEAF) Research Program - Phase 1 Testing 2014 to 2016, Nuclear Energy Agency Committee on The Safety of Nuclear Installations, 2017

[7] Memorandum from Mark Henry Salley, to Thomas H. Boyce, Regarding submittal of possible generic issue concerning the damage caused by high energy arc faults in electrical equipment containing aluminum components, ADAMS Accession No. ML16126A096, May 2016.

[8] Memorandum from Joseph Giitter to Michael F. Weber, regarding Results of Generic Issue Review Panel Screening Evaluation for Proposed Generic Issue PRE-GI-018, 'High Energy Arcing Faults involving Aluminum,' ADAMS Accession No. ML16349A027, July 15, 2017.

[9] Memorandum from Michael Franovich and Michael Cheok to Raymond V. Furstenau, regarding Assessment Plan for Pre-GI-018, Proposed Generic Issue on High Energy Arc Faults Involving Aluminum, ADAMS Accession No. ML18172A189, August 22, 2018.

[10] An International Phenomena Identification and Ranking Table (PIRT) Expert Elicitation Exercise for High Energy Arcing Faults (HEAFs), US NRC, Washington, DC, NUREG-2218, January 2018.

[11] Memorandum from Raymond V. Fustenau to Andrea D. Veil, regarding Closure of Proposed Generic Issue Pre-GI-018, 'High-Energy Arc Faults Involving Aluminum,' ADAMS Accession No. ML21237A360, August 31, 2021.

[12] IEEE C37.010-1999, "IEEE Application Guide for AC High-Voltage Circuit Breakers Rated on a Symmetrical Current Basis," The Institute of Electrical and Electronics Engineers, Inc., New York, NY, 2000.

[13] Putorti, A., Melly, M., Bareham, S., and Praydis Jr., J., "Characterizing the Thermal Effects of High Energy Arc Faults." 23 ${ }^{\text {rd }}$ International Conference on Structural Mechanics in Reactor Technology (SMiRT 23) - $14^{\text {th }}$ International Post-Conference Seminar on "FIRE SAFETY IN NUCLEAR POWER PLANTS AND 
INSTALLATIONS," Salford, UK, August 17-18, 2015, http://www.grs.de/en/publications/grs-a-3845.

[14] Haggkvist, A., Sjostrom, J., and Wickstrom, U., "Using plate thermometer measurements to calculate incident heat radiation," Journal of Fire Sciences, Vol. 31, No. 2, 2013, pp. 166-177.

[15] Ingason, H. and Wickstrom, U., "Measuring incident radiant heat flux using the plate thermometer," Fire Safety Journal, Vol. 42, No. 2, 2007, pp. 161-166.

[16] Wickstrom, U., "The Plate Thermometer - A simple instrument for reaching harmonized resistance tests," Fire Technology, Vol. 30, No. 2, 1994, pp. 209-231.

[17] Wickstrom, U., Anderson, J., and Sjostrom, J. "Measuring incident heat flux and adiabatic surface temperature with plate thermometers in ambient and high temperatures." Fire and Materials, 2019, 43:51-56.

[18] ASTM Standard E1354-15, 2015, "Standard Test Method for Heat and Visible Smoke Release Rates for Materials and Products Using an Oxygen Consumption Calorimeter," ASTM International, West Conshohocken, PA, 2015.

[19] Taylor, B.N. and Kuyatt, C.E., "Guidelines for evaluating and expressing the uncertainty of NIST measurement results," NIST Technical Note 1297, National Institute of Standards and Technology, Gaithersburg, MD, USA, 1994.

[20] Joint Committee for Guides in Metrology. Evaluation of measurement data - Guide to the expression of uncertainty in measurement, Sèvres, France: International Bureau of Weights and Measures (BIPM), URL www.bipm.org/en/publications/guides/gum.html, BIPM, IEC, IFCC, ILAC, ISO, IUPAC, IUPAP and OIML, JCGM 100:2008, GUM 1995 with minor corrections (2008).

[21] Joint Committee for Guides in Metrology. International vocabulary of metrology Basic and general concepts and associated terms (VIM), Sèvres, France: International Bureau of Weights and Measures (BIPM), 3rd ed., URL www.bipm.org/en/publications/guides/vim.html, BIPM, IEC, IFCC, ILAC, ISO, IUPAC, IUPAP and OIML, JCGM 200:2012 (2008 version with minor corrections) (2012).

[22] McGrattan, K., Hostikka, S., McDermott, R., Floyd, J., Weinschenk, C., Overholt, K., Fire Dynamics Simulator, Technical Reference Guide. National Institute of Standards and Technology, Gaithersburg, MD, USA, and VTT Technical Research Centre of Finland, Espoo, Finland, sixth edition, September 2013. Vol. 1: Mathematical Model; Vol. 2: Verification Guide; Vol. 3: Validation Guide; Vol. 4: Configuration Management Plan.

[23] ASTM (1993), Manual on the Use of Thermocouples in Temperature Measurement, ASTM Manual Series: MNL12, Revision of Special Publication (STP) 470B, 4th ed., ASTM International, West Conshohocken, PA, 1993, United States.

[24] ASTM (2012), Standard Specification and Temperature-Electromotive Force (emf) Tables for Standardized Thermocouples, Standard E230/E230M-12, ASTM International, West Conshohocken, PA, United States.

[25] Lafarge, T. and A. Possolo, "The NIST Uncertainty Machine", NCLSI Measure J. Meas. Sci., Vol. 10, No. 3, pp. 20-27, September 2015. 
[26] Powell, L.P. et al. (1974), Thermocouple Reference Tables Based on the IPTS-68, National Bureau of Standards Monograph 125, National Bureau of Standards, Washington DC, United States.

[27] ASTM Standard F1959 / F1959M-14, 2014, "Standard Test Method for Determining the Arc Rating of Materials for Clothing," ASTM International, West Conshohocken, PA, 2014

[28] ASTM Standard E457-08, "Standard Test Method for Measuring Heat-Transfer Rate Using a Thermal Capacitance (Slug) Calorimeter," ASTM International, West Conshohocken, PA, 2008.

[29] ISO Standard 5660-1, 2015, "Reaction to fire tests - Heat release, smoke production and mass loss rate - Part 1: Heat release rate (cone calorimeter method) and smoke production rate (dynamic measurement)," International Organization for Standardization: Geneva, Switzerland, 2015.

[30] Tambakuchi, A., et. al., NRC HEAF Tests, Imaging and Measurement Methodology Report, SAND2021-12086 R, Sandia National Laboratories, September 2018.

[31] FLIR SC6700 User's Manual, Document Number 24048-000, Version 16, Issue Date March 22, 2013, FLIR Systems, Inc., 9 Townsend West, Nashua, NH 03063. Data from Bramson, M.A. Infrared Radiation, A Handbook for Applications, Plenum Press, New York.

[32] Table of Emissivity of Various Surfaces for Infrared Thermometry, Mikron Instrument Company Inc., Oakland, NJ, http://www.czlazio.com/tecnica/Tabella\%20delle\%20Emissivit\%C3\%A0.pdf, Accessed April 28, 2020.

[33] T. Lafarge and A. Possolo (2015) "The NIST Uncertainty Machine", NCSLI Measure Journal of Measurement Science, volume 10, number 3 (September), pages 20-27.

[34] Zhang, Z., Lee, W., and Dini, D. "Grounding and Isolation of Sensitive Measurement Equipment for Arc Flash Testing at High-Power Laboratory." IEEE Transactions on Industry Applications, Vol. 51, No. 6, November/December 2015, pp. 5281-5287.

[35] Taylor, G., et. al., NUREG/CP-0311, Proceedings of the Information Sharing Workshop on High Energy Arcing Fault (HEAF), U.S. Nuclear Regulatory Commission, Rockville, MD, July 2019.

[36] NUREG/CR-6931, SAND2007-600/V2, Vol. 2, Nowlen, S.P., Wyant, F.J., Cable Response to Live Fire (CAROLFIRE), Vol 2.: Cable Fire Response Data for Fire Model Improvement, U.S. Nuclear Regulatory Commission, Washington, DC, Sandia National Laboratories, Albuquerque, NM, 2008. 



\section{Appendix A: Electrical Enclosure Configuration}

This appendix provides brief description of the test objects and any modifications made for the HEAF experiments.

\section{A.1 Variations between relay instrumentation and control as delivered}

The instrumentation on the front of the vertical sections of switchgear had minor variations between switchgear samples. Table 30 identifies the number of each type of device located on the front panel of each switchgear. Photographs of the front door are provided in Fig. 90 and the internal side of the doors are provided in Fig. 91.

Table 30. Number and type of each device.

\begin{tabular}{|l|c|c|c|c|}
\hline Device & $\mathbf{2 - 1 9}$ & $\mathbf{2 - 2 1}$ & $\mathbf{2 - 2 2}$ & $\mathbf{2 - 2 4}$ \\
\hline Relays & 3 & 3 & 3 & 3 \\
\hline Relays sockets - empty & 0 & 0 & 3 & 0 \\
\hline Amp meters & 1 & 1 & 1 & 1 \\
\hline Volt meters & 0 & 0 & 0 & 1 \\
\hline Indication windows & 1 & 1 & 1 & 0 \\
\hline Switches & 3 & 3 & 3 & 3 \\
\hline Lights & 4 & 4 & 4 & 3 \\
\hline Test Connection & 1 & 1 & 1 & 1 \\
\hline
\end{tabular}




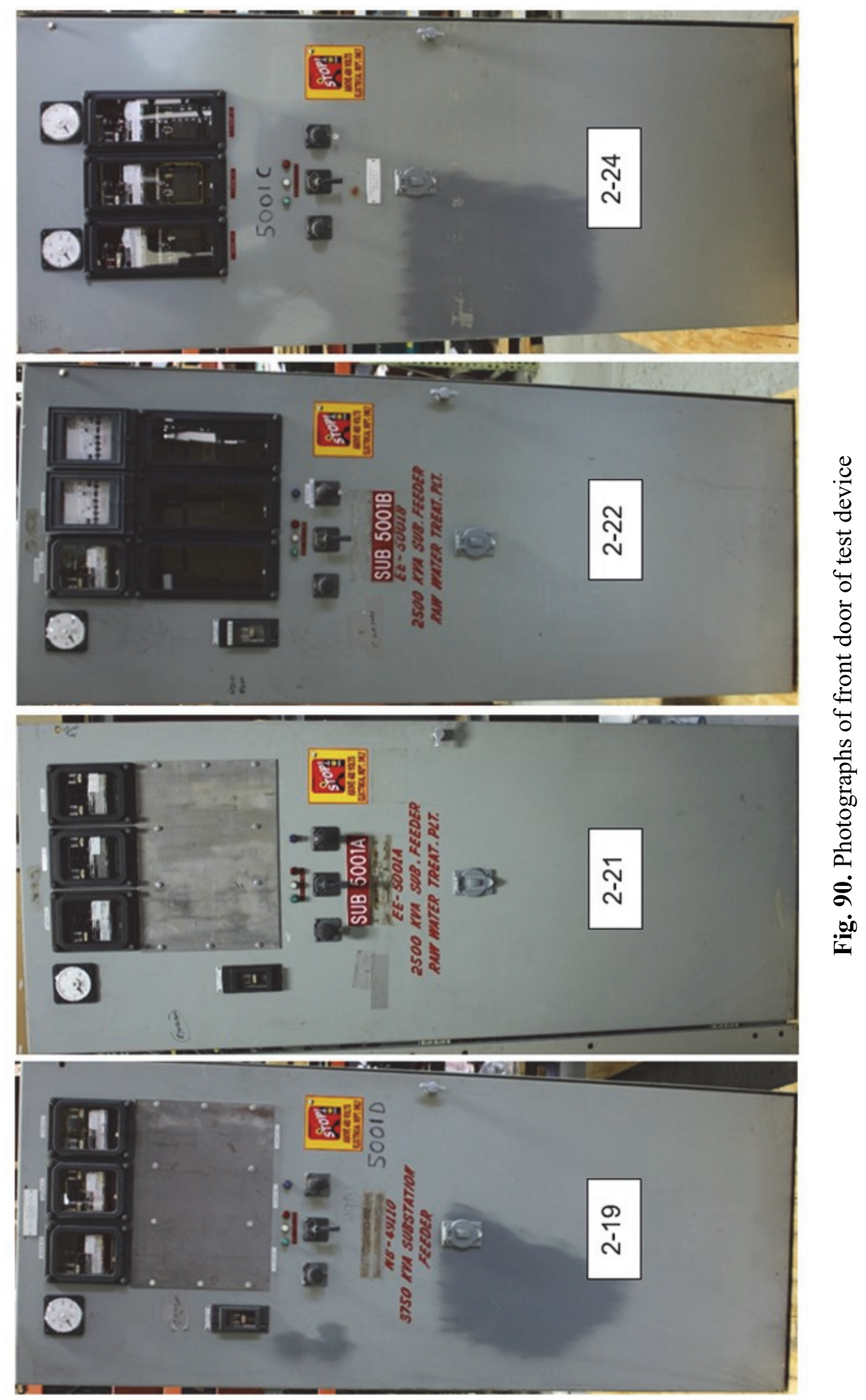



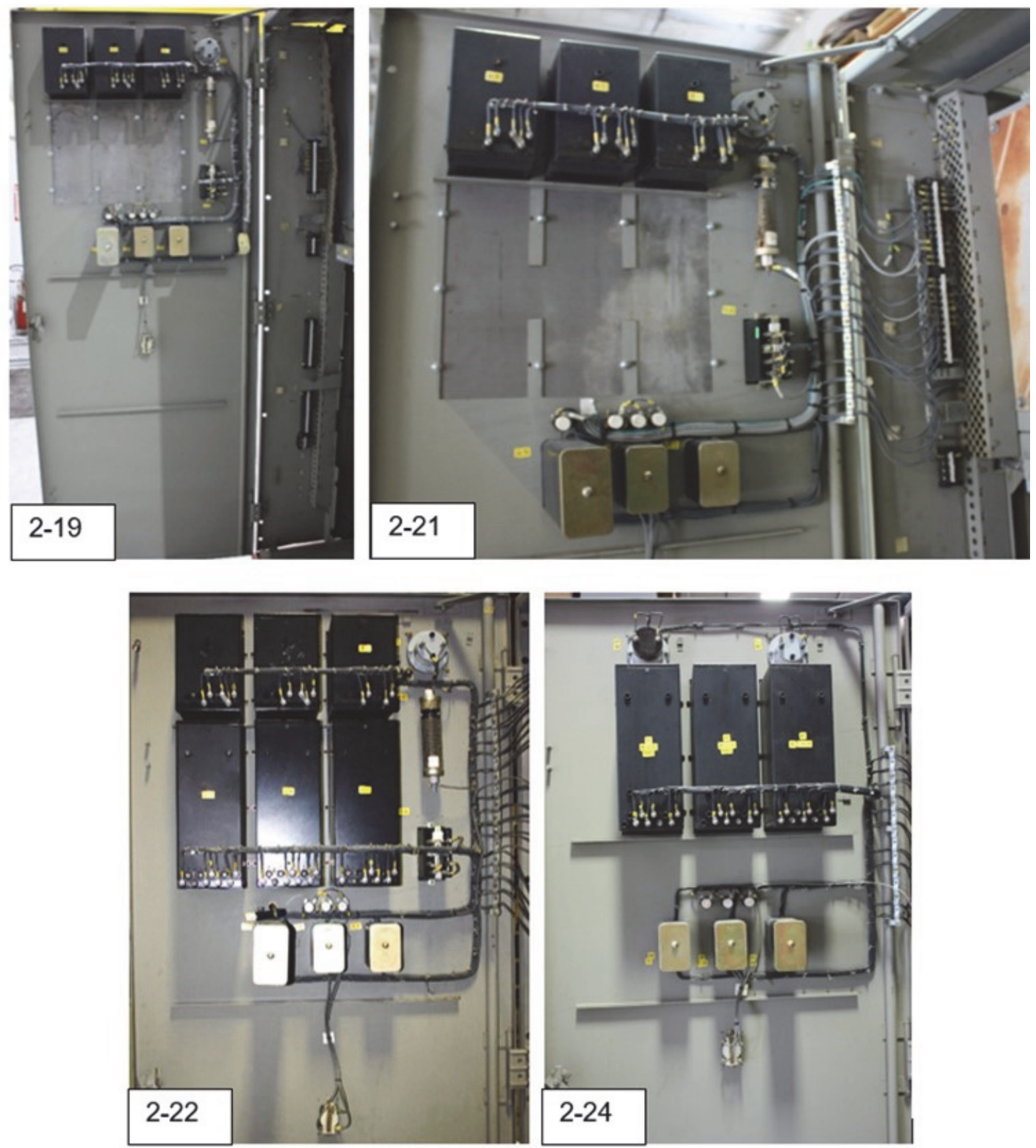

Fig. 91. Photographs of enclosure door internals

\section{A.2 Primary Cable Connection Compartment Modifications}

The used equipment vendor made modifications to the line side of the gear for use in the experiments. These included replacing the copper bus with aluminum and removing the current transformers. To show the differences, the used equipment vendor provided examples of similar equipment configurations. Fig. 92 provides these photographs and 
identifies components that were removed. Fig. 93 provides photographs of as tested equipment and includes identification of components that have been added.
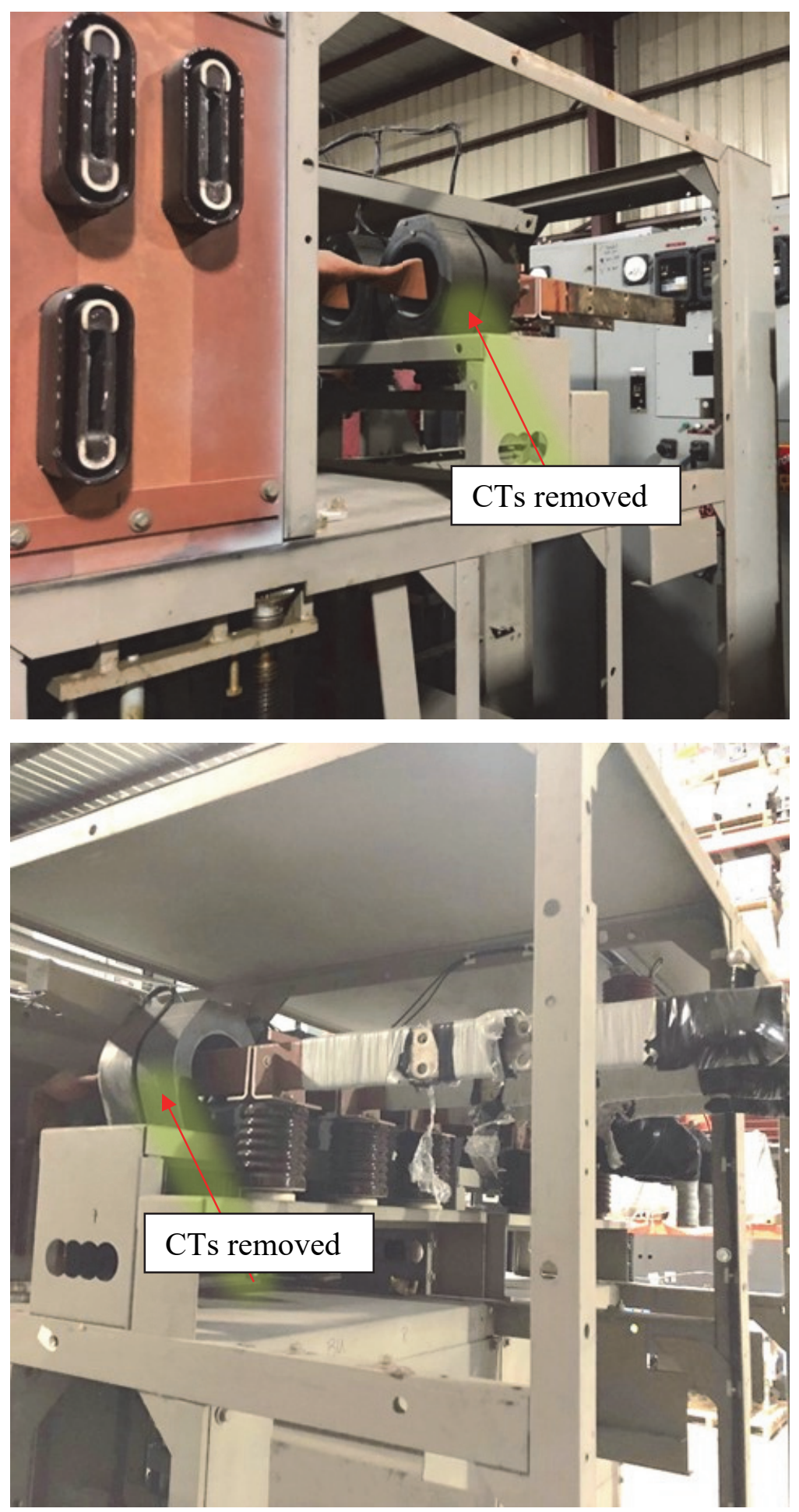

Fig. 92. Photographs of location of removed current transformers (CTs). The CTs were removed by the equipment vendor. 


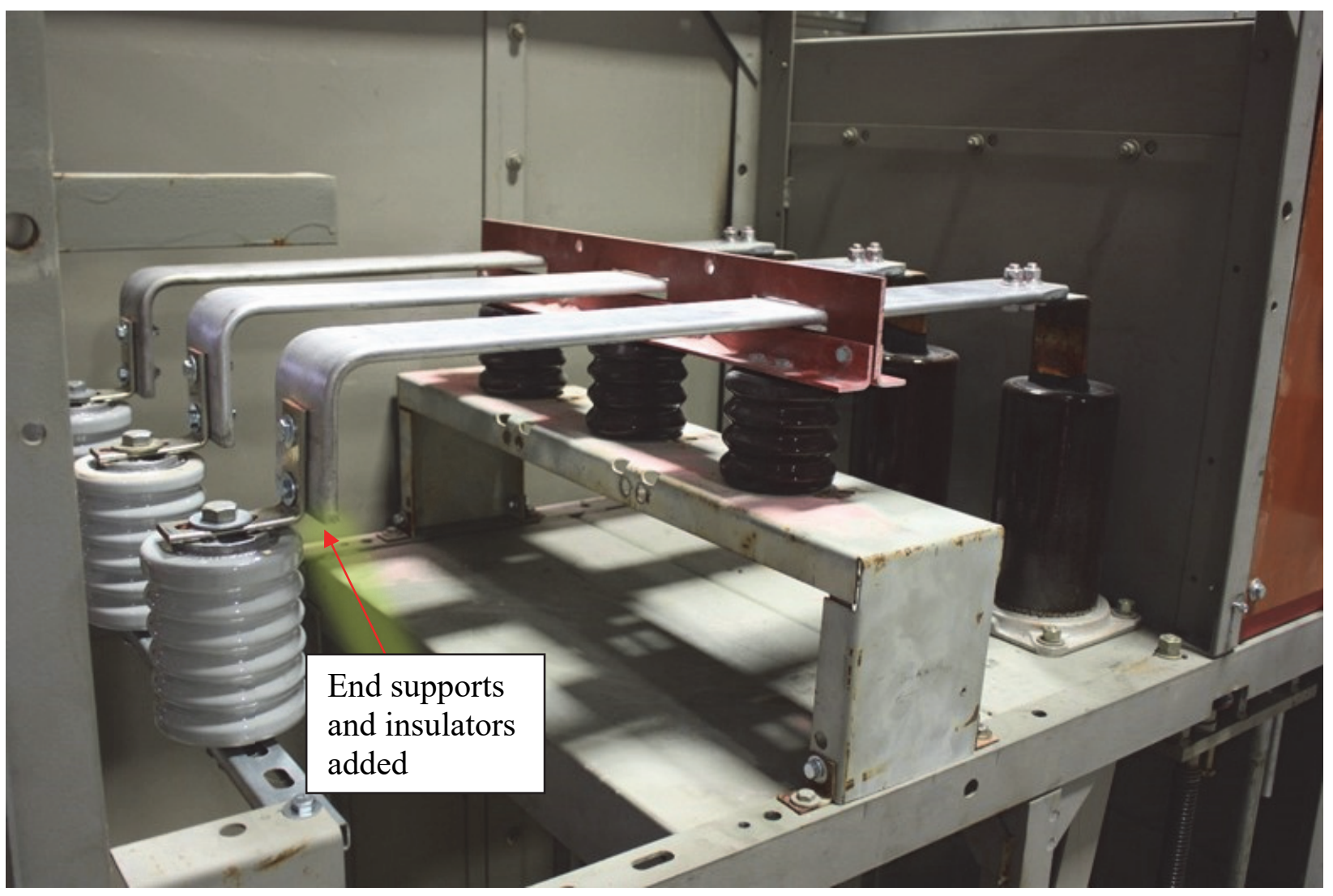

Fig. 93. Photograph of Primary Cable Connection Compartment prior to experiment 


\section{Appendix B: Engineering Drawings}

This appendix provides detailed drawings and information on the test facility, the test object, and instrumentation.

\section{B.1 Testing Facility}

Drawings of the testing facility are presented in Fig. 94 and Fig. 95.

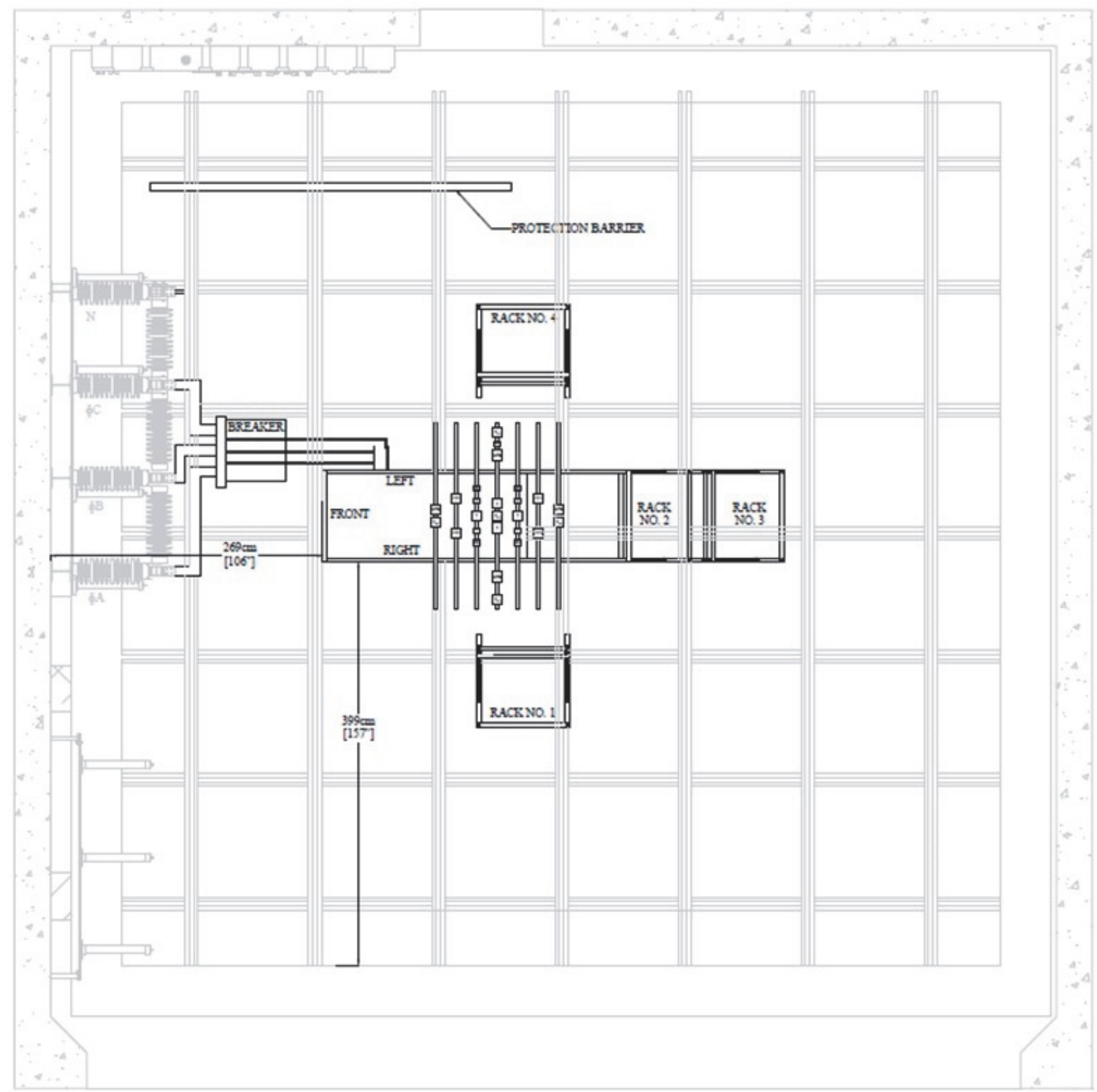

Fig. 94. Plan view of test cell \#9 showing test device, instrument stands, and primary connections to circuit make switch (breaker). 


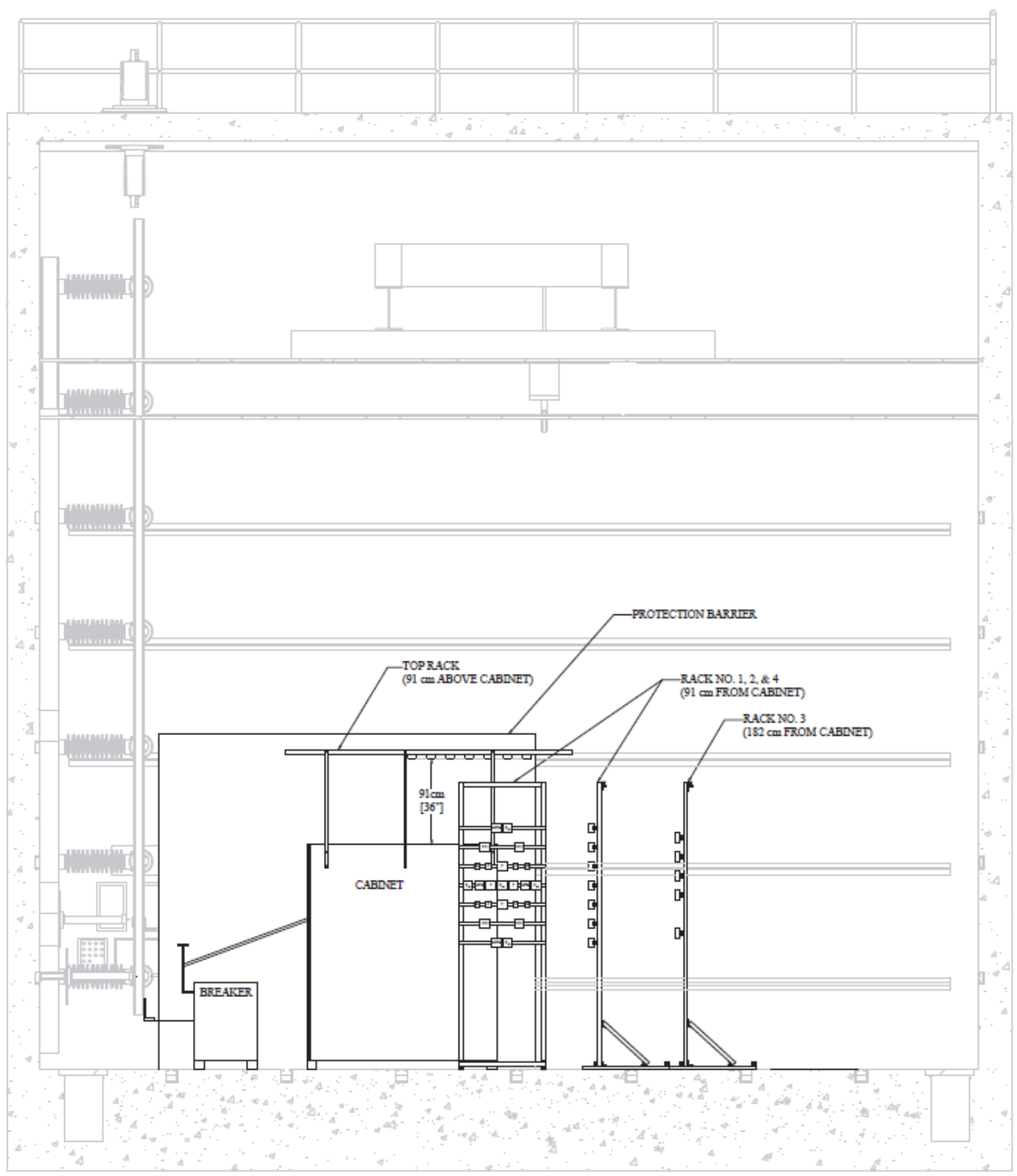

Fig. 95. Elevation view of test cell \#9 showing test device, instrument stands, and primary connections to circuit make switch (breaker). 


\section{B.2 Test Device}

Drawings of the test device are presented on the following pages and were provided by NRC contractor Brendan Stanton, Inc. Drawings are shown in Fig. 96 through Fig. 98. 

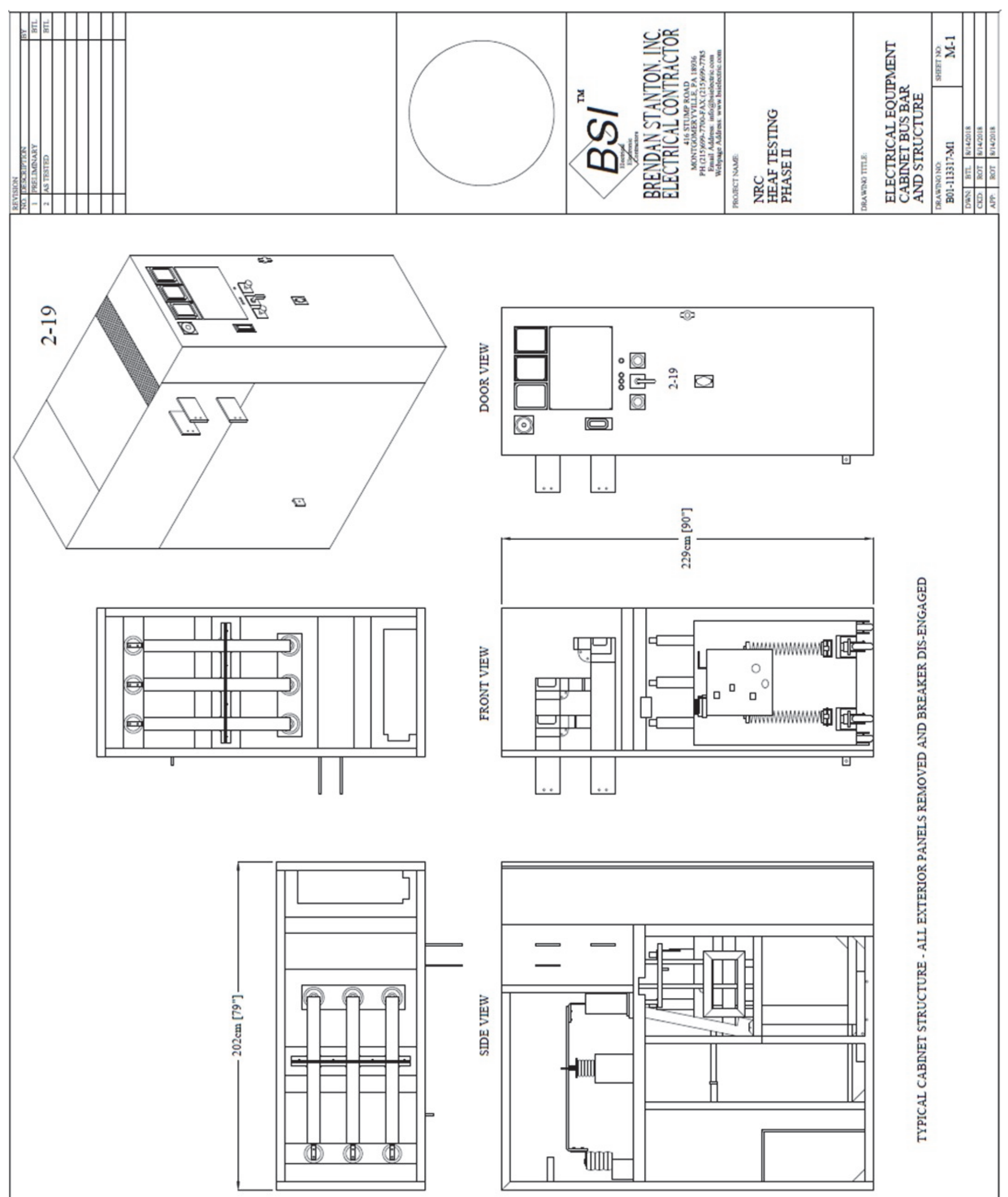

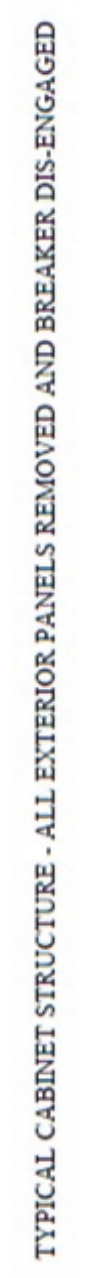

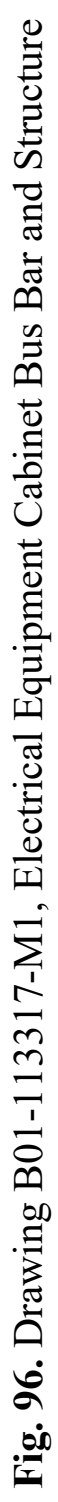
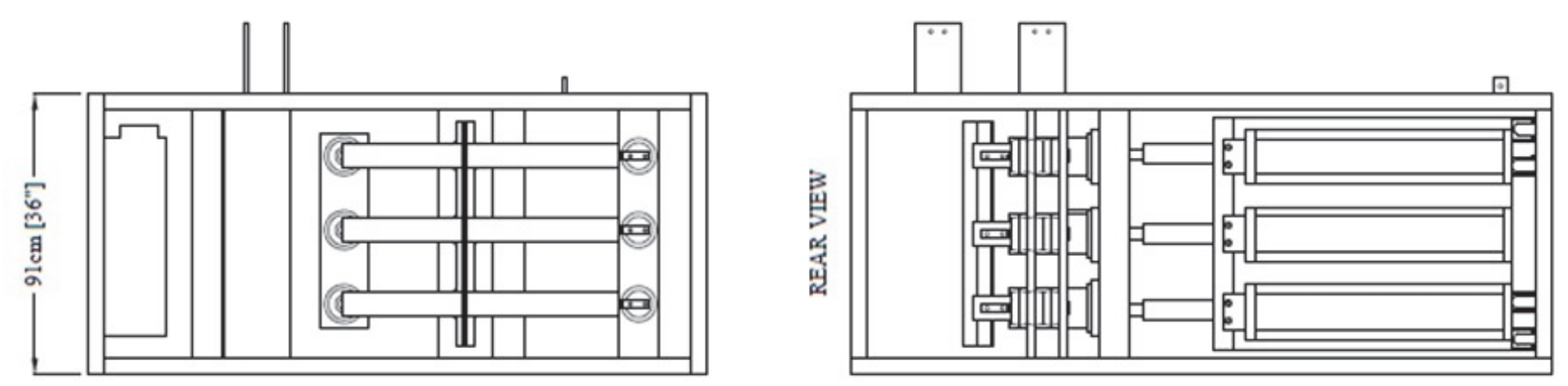

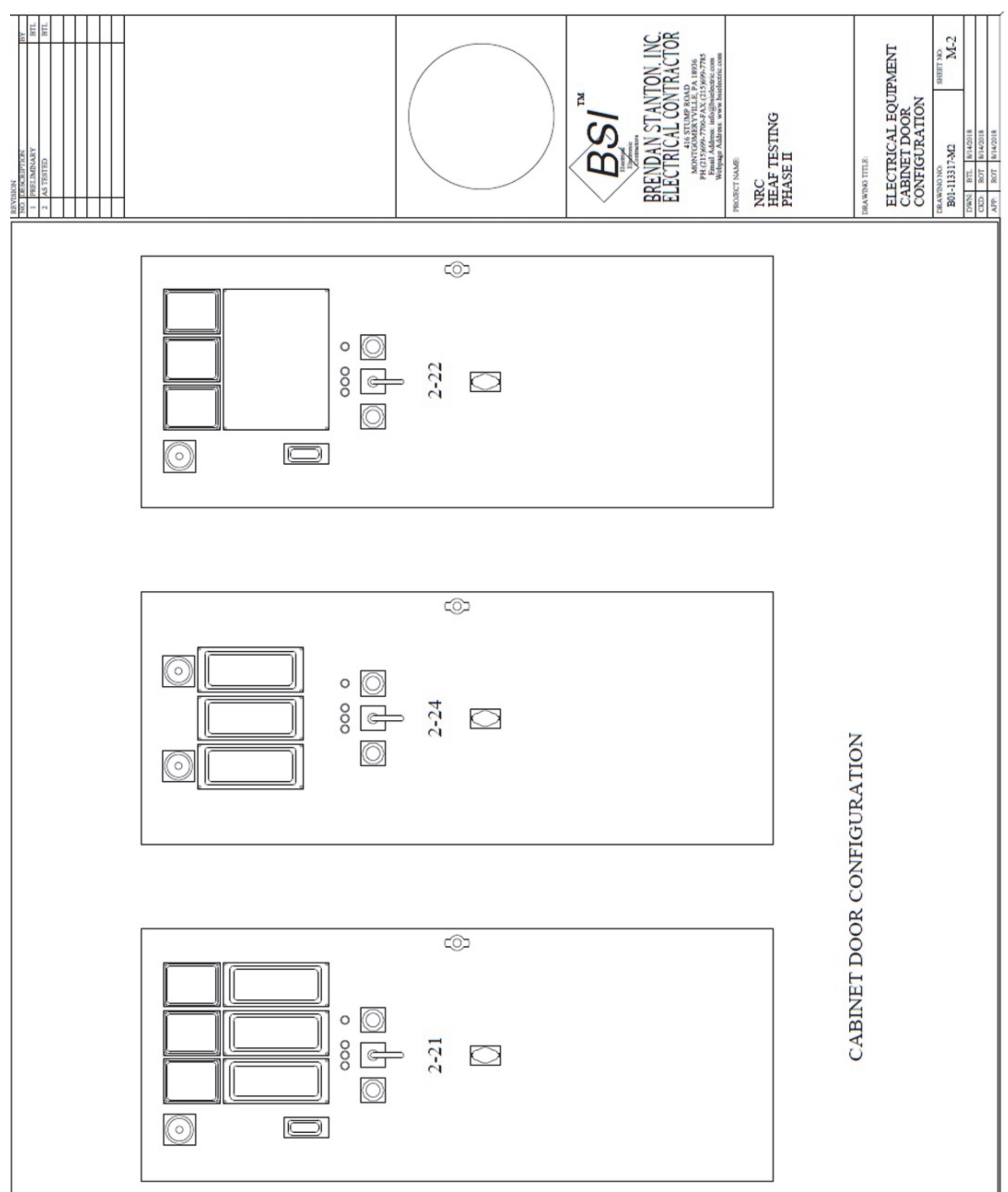

号

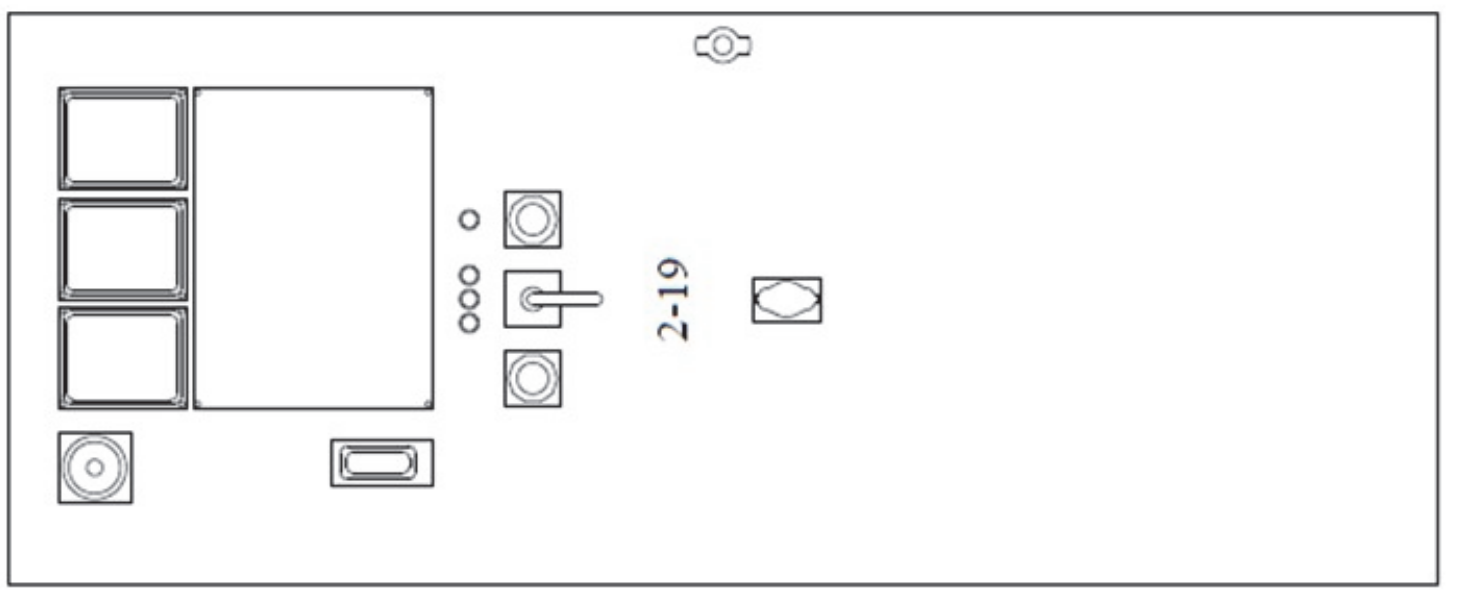




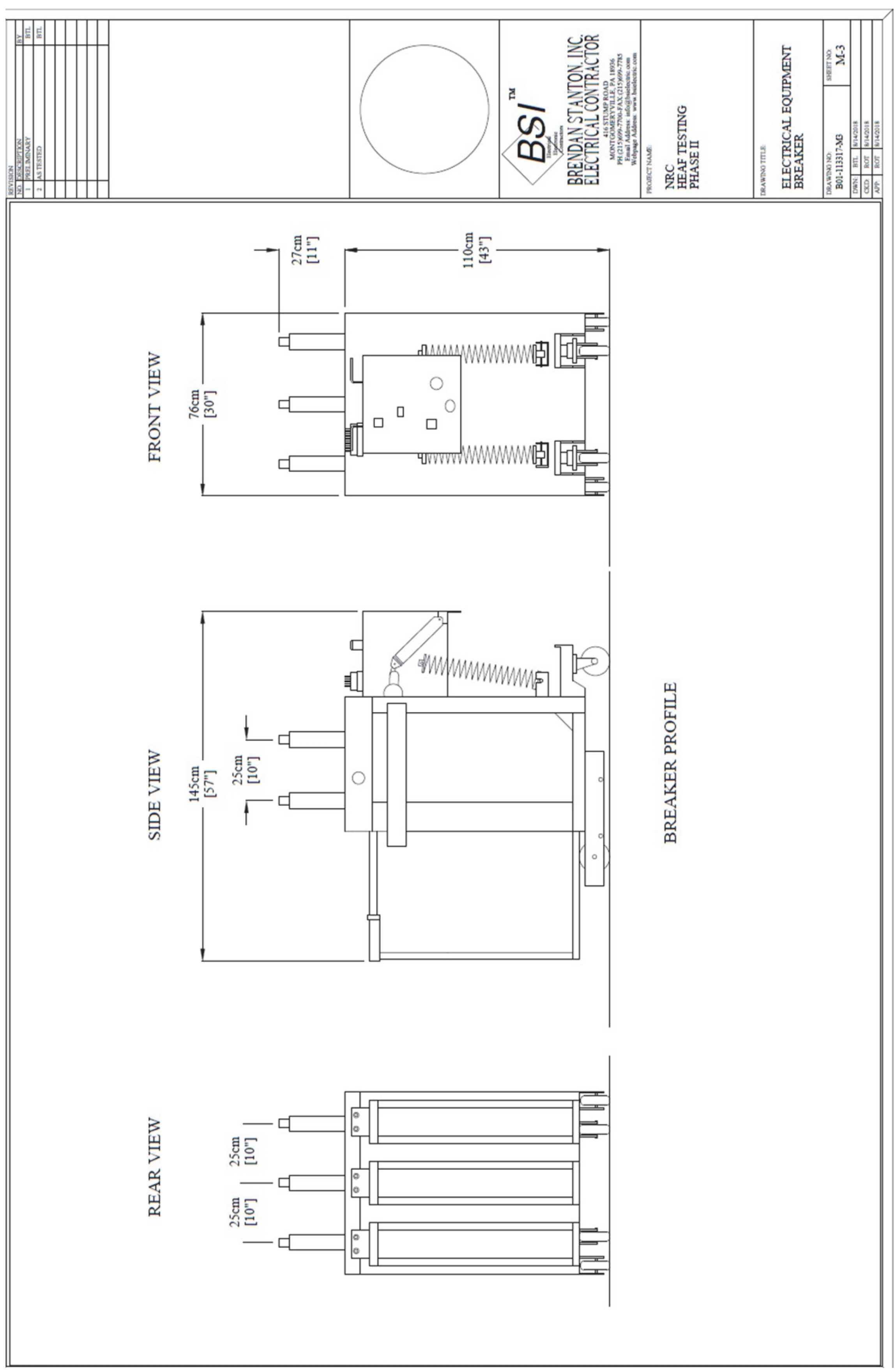

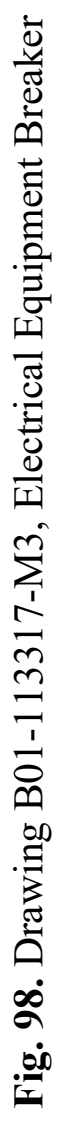



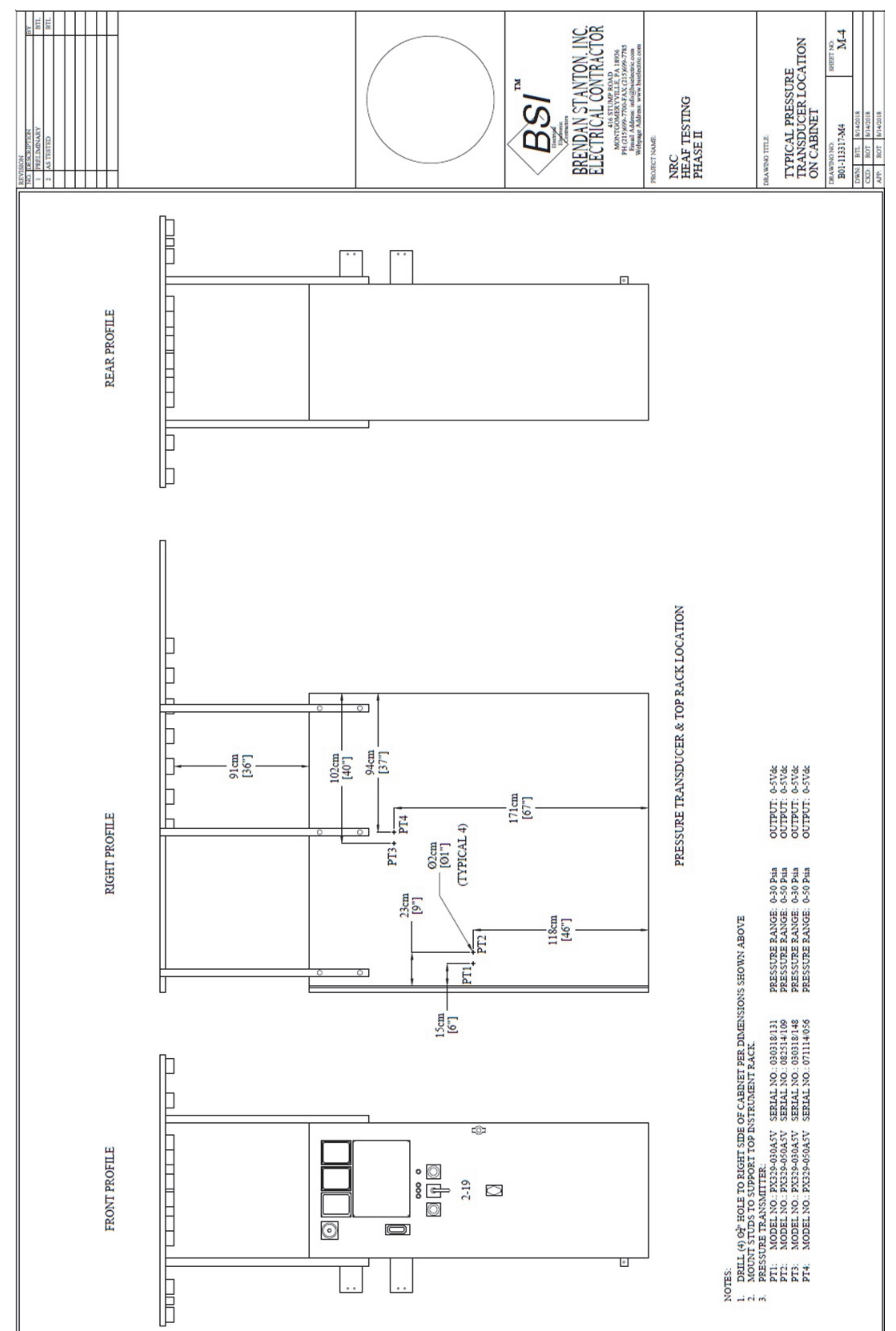
Functional checks were performed at numerous stages throughout the experimental program. At NIST the instruments were checked after fabrication. At KEMA, each instrument was checked again before and after installation on the instrument racks. Each instrument rack was checked for function with the DAQ after installation in the test cell shortly before each experiment. Assembly and thermal protection of the instrument racks and sensor wiring was a labor-intensive process. Despite careful assembly and handling, there were a few instances where individual sensors were non-functional prior to the experiments at KEMA. These failed device(s) were not replaced due to the time and resources needed, and due to the risk of damaging other circuits. The following Table 31 through Table 35 identify the functionality of the devices and identify any failed states prior to, during, or after each experiment.

Table 31. Rack \#1 Instrumentation Information

\begin{tabular}{|c|c|c|c|c|c|c|c|}
\hline \multirow{2}{*}{$\begin{array}{c}\text { Instrument } \\
\text { ID }\end{array}$} & \multirow[t]{2}{*}{ Instrument } & \multirow{2}{*}{$\begin{array}{l}\text { DAQ } \\
\text { Ch. }\end{array}$} & \multicolumn{4}{|c|}{ Condition } & \multirow{2}{*}{ Comments } \\
\hline & & & $2-19$ & $2-21$ & 2-22 & $2-24$ & \\
\hline 1 & Plate TC & 1 & Verified & Verified & Verified & Verified & \\
\hline 2 & Tcap Slug & 2 & Verified & Verified & Verified & Verified & \\
\hline 3 & Plate TC & 3 & Verified & Verified & Verified & Verified & \\
\hline 4 & Tcap Slug & 4 & Verified & Verified & Verified & Verified & \\
\hline 5 & Plate TC & 5 & Failed & Verified & Verified & Verified & $\begin{array}{c}\text { 2-19: Plate } \\
\text { TC failed } \\
\text { prior to test. }\end{array}$ \\
\hline 6 & Tcap Slug & 6 & Verified & Verified & Verified & Verified & \\
\hline 7 & Plate TC & 7 & Verified & Verified & Verified & Verified & \\
\hline 8 & Tcap Slug & 8 & Verified & Verified & Verified & Verified & \\
\hline 9 & Plate TC & 9 & Verified & Verified & Verified & Verified & \\
\hline $\mathbf{A}$ & ASTM Slug & $\mathrm{K}-3$ & $\begin{array}{l}\text { DAQ } \\
\text { Error }\end{array}$ & Verified & Verified & No Data & \\
\hline B & ASTM Slug & $\mathrm{K}-4$ & $\begin{array}{l}\text { DAQ } \\
\text { Error }\end{array}$ & Verified & Verified & No Data & \\
\hline $\mathrm{C}$ & ASTM Slug & K-5 & $\begin{array}{l}\text { DAQ } \\
\text { Error }\end{array}$ & Verified & Verified & No Data & \\
\hline D & ASTM Slug & $\mathrm{K}-2$ & $\begin{array}{l}\text { DAQ } \\
\text { Error }\end{array}$ & Verified & Verified & No Data & \\
\hline $1-1$ & $\begin{array}{c}\text { Cable } \\
\text { Coupon }\end{array}$ & - & Installed & Installed & Installed & Installed & \\
\hline $1-2$ & $\begin{array}{c}\text { Cable } \\
\text { Coupon }\end{array}$ & - & Installed & Installed & Installed & Installed & \\
\hline $1-3$ & Aerogel & - & Installed & Installed & Installed & Installed & \\
\hline $1-4$ & Carbon Tape & - & Installed & Installed & Installed & Installed & \\
\hline $1-5$ & Carbon Tape & - & Installed & Installed & Installed & Installed & \\
\hline $1-6$ & Aerogel & - & Installed & Installed & Installed & Installed & \\
\hline $1-7$ & Aerogel & - & Installed & Installed & Installed & Installed & \\
\hline $1-8$ & Carbon Tape & - & Installed & Installed & Installed & Installed & \\
\hline $1-9$ & Carbon Tape & - & Installed & Installed & Installed & Installed & \\
\hline $1-10$ & Aerogel & - & Installed & Installed & Installed & Installed & \\
\hline $1-11$ & Carbon Tape & - & Installed & Installed & Installed & Installed & \\
\hline $1-12$ & Carbon Tape & - & Installed & Installed & Installed & Installed & \\
\hline
\end{tabular}


Table 32. Rack \#2 Instrumentation Information

\begin{tabular}{|c|c|c|c|c|c|c|c|}
\hline \multirow{2}{*}{$\begin{array}{c}\text { Instrument } \\
\text { ID }\end{array}$} & \multirow[t]{2}{*}{ Instrument } & \multirow{2}{*}{$\begin{array}{l}\text { DAQ } \\
\text { Ch. }\end{array}$} & \multicolumn{4}{|c|}{ Condition } & \multirow{2}{*}{ Comments } \\
\hline & & & 2-19 & $2-21$ & $2-22$ & $2-24$ & \\
\hline 10 & Plate TC & 10 & Verified & Verified & Verified & Verified & \\
\hline 11 & Tcap Slug & 11 & Verified & Verified & Verified & Verified & \\
\hline 12 & Plate TC & 12 & Verified & Failed & Verified & Verified & $\begin{array}{l}\text { Test 2-21 PT } \\
\text { failure during } \\
\text { experiment }\end{array}$ \\
\hline 13 & Tcap Slug & 13 & Verified & Verified & Verified & Verified & \\
\hline 14 & Plate TC & 14 & Verified & Verified & Verified & Verified & \\
\hline 15 & Tcap Slug & 15 & Verified & Verified & Verified & Verified & \\
\hline 16 & Plate TC & 16 & Verified & Verified & Verified & Verified & \\
\hline 17 & Tcap Slug & 17 & Verified & Verified & Verified & Verified & \\
\hline 18 & Plate TC & 18 & Verified & Verified & Verified & Verified & \\
\hline $\mathbf{E}$ & ASTM Slug & $\mathrm{K}-15$ & Verified & Failed & Verified & No Data & \\
\hline $\mathbf{F}$ & ASTM Slug & $\mathrm{K}-21$ & Verified & Failed & Verified & No Data & \\
\hline G & ASTM Slug & $\mathrm{K}-19$ & $\begin{array}{l}\text { DAQ } \\
\text { Error }\end{array}$ & Verified & Verified & No Data & \\
\hline $\mathbf{H}$ & ASTM Slug & $\mathrm{K}-25$ & Verified & Verified & Verified & No Data & \\
\hline $1-13$ & $\begin{array}{l}\text { Cable } \\
\text { Coupon }\end{array}$ & - & Installed & Installed & Installed & Installed & \\
\hline $1-14$ & $\begin{array}{l}\text { Cable } \\
\text { Coupon }\end{array}$ & - & Installed & Installed & Installed & Installed & \\
\hline $1-15$ & Aerogel & - & Installed & Installed & Installed & Installed & \\
\hline $1-16$ & Carbon Tape & - & Installed & Installed & Installed & Installed & \\
\hline $1-17$ & Carbon Tape & - & Installed & Installed & Installed & Installed & \\
\hline $1-18$ & Aerogel & - & Installed & Installed & Installed & Installed & \\
\hline $1-19$ & Aerogel & - & Installed & Installed & Installed & Installed & \\
\hline $1-20$ & Carbon Tape & - & Installed & Installed & Installed & Installed & \\
\hline $1-21$ & Carbon Tape & - & Installed & Installed & Installed & Installed & \\
\hline $1-22$ & Aerogel & - & Installed & Installed & Installed & Installed & \\
\hline $1-23$ & Carbon Tape & - & Installed & Installed & Installed & Installed & \\
\hline $1-24$ & Carbon Tape & - & Installed & Installed & Installed & Installed & \\
\hline
\end{tabular}


Table 33. Rack \#3 Instrumentation Information

\begin{tabular}{|c|c|c|c|c|c|c|}
\hline \multirow{2}{*}{$\begin{array}{c}\text { Instrument } \\
\text { ID }\end{array}$} & \multirow[t]{2}{*}{ Instrument } & \multirow{2}{*}{$\begin{array}{c}\text { DAQ } \\
\text { Ch. }\end{array}$} & \multicolumn{4}{|c|}{ Condition } \\
\hline & & & $2-19$ & $2-21$ & 2-22 & $2-24$ \\
\hline 19 & Plate TC & 19 & Verified & Verified & Verified & Verified \\
\hline 20 & Tcap Slug & 20 & Verified & Verified & Verified & Verified \\
\hline 21 & Plate TC & 21 & Verified & Verified & Verified & Verified \\
\hline 22 & Tcap Slug & 22 & Verified & Verified & Verified & Verified \\
\hline 23 & Plate TC & 23 & Verified & Verified & Verified & Verified \\
\hline 24 & Tcap Slug & 24 & Verified & Verified & Verified & Verified \\
\hline 25 & Plate TC & 25 & Verified & Verified & Verified & Verified \\
\hline 26 & Tcap Slug & 26 & Verified & Verified & Verified & Verified \\
\hline 27 & Plate TC & 27 & Verified & Verified & Verified & Verified \\
\hline I & ASTM Slug & $\mathrm{K}-16$ & Verified & Verified & Verified & No Data \\
\hline $\mathbf{J}$ & ASTM Slug & $\mathrm{K}-22$ & Verified & Verified & Verified & No Data \\
\hline K & ASTM Slug & $\mathrm{K}-17$ & Verified & Verified & Verified & No Data \\
\hline $\mathbf{L}$ & ASTM Slug & K-14 & Verified & Verified & Verified & No Data \\
\hline $1-25$ & Cable Coupon & - & Installed & Installed & Installed & Installed \\
\hline $1-26$ & Cable Coupon & - & Installed & Installed & Installed & Installed \\
\hline $1-27$ & Aerogel & - & Installed & Installed & Installed & Installed \\
\hline $1-28$ & Carbon Tape & - & Installed & Installed & Installed & Installed \\
\hline $1-29$ & Carbon Tape & - & Installed & Installed & Installed & Installed \\
\hline $1-30$ & Aerogel & - & Installed & Installed & Installed & Installed \\
\hline $1-31$ & Aerogel & - & Installed & Installed & Installed & Installed \\
\hline 1-32 & Carbon Tape & - & Installed & Installed & Installed & Installed \\
\hline $1-33$ & Carbon Tape & - & Installed & Installed & Installed & Installed \\
\hline $1-34$ & Aerogel & - & Installed & Installed & Installed & Installed \\
\hline $1-35$ & Carbon Tape & - & Installed & Installed & Installed & Installed \\
\hline $1-36$ & Carbon Tape & - & Installed & Installed & Installed & Installed \\
\hline
\end{tabular}


Table 34. Rack \#4 Instrumentation Information

\begin{tabular}{|c|c|c|c|c|c|c|}
\hline \multirow{2}{*}{$\begin{array}{c}\text { Instrument } \\
\text { ID }\end{array}$} & \multirow[t]{2}{*}{ Instrument } & \multirow{2}{*}{$\begin{array}{l}\text { DAQ } \\
\text { Ch. }\end{array}$} & \multicolumn{4}{|c|}{ Condition } \\
\hline & & & $2-19$ & $2-21$ & $2-22$ & $2-24$ \\
\hline 28 & Plate TC & 28 & Verified & Verified & Verified & Verified \\
\hline 29 & Tcap Slug & 29 & Verified & Verified & Verified & Verified \\
\hline 30 & Plate TC & 30 & Verified & Verified & Verified & Verified \\
\hline 31 & Tcap Slug & 31 & Verified & Verified & Verified & Verified \\
\hline 32 & Plate TC & 32 & Verified & Verified & Verified & Verified \\
\hline 33 & Tcap Slug & 33 & Verified & Verified & Verified & Verified \\
\hline 34 & Plate TC & 34 & Verified & Verified & Verified & Verified \\
\hline 35 & Tcap Slug & 35 & Verified & Verified & Verified & Verified \\
\hline 36 & Plate TC & 36 & Verified & Verified & Verified & Verified \\
\hline M & ASTM Slug & K-8 & $\begin{array}{l}\text { DAQ } \\
\text { Error }\end{array}$ & Verified & Verified & No Data \\
\hline $\mathbf{N}$ & ASTM Slug & K-6 & $\begin{array}{l}\text { DAQ } \\
\text { Error }\end{array}$ & Verified & Verified & No Data \\
\hline $\mathbf{O}$ & ASTM Slug & K-10 & Verified & Verified & Verified & No Data \\
\hline $\mathbf{P}$ & ASTM Slug & $\mathrm{K}-7$ & $\begin{array}{l}\text { DAQ } \\
\text { Error }\end{array}$ & Verified & Verified & No Data \\
\hline $1-37$ & Cable Coupon & - & Installed & Installed & Installed & Installed \\
\hline 1-38 & Cable Coupon & - & Installed & Installed & Installed & Installed \\
\hline 1-39 & Aerogel & - & Installed & Installed & Installed & Installed \\
\hline $1-40$ & Carbon Tape & - & Installed & Installed & Installed & Installed \\
\hline $1-41$ & Carbon Tape & - & Installed & Installed & Installed & Installed \\
\hline $1-42$ & Aerogel & - & Installed & Installed & Installed & Installed \\
\hline $1-43$ & Aerogel & - & Installed & Installed & Installed & Installed \\
\hline $1-44$ & Carbon Tape & - & Installed & Installed & Installed & Installed \\
\hline $1-45$ & Carbon Tape & - & Installed & Installed & Installed & Installed \\
\hline $1-46$ & Aerogel & - & Installed & Installed & Installed & Installed \\
\hline $1-47$ & Carbon Tape & - & Installed & Installed & Installed & Installed \\
\hline $1-48$ & Carbon Tape & - & Installed & Installed & Installed & Installed \\
\hline
\end{tabular}


Table 35. Rack \#5 Instrumentation Information

\begin{tabular}{|c|c|c|c|c|c|c|c|}
\hline \multirow{2}{*}{$\begin{array}{c}\text { Instrument } \\
\text { ID }\end{array}$} & \multirow[t]{2}{*}{ Instrument } & \multirow{2}{*}{$\begin{array}{l}\text { DAQ } \\
\text { Ch. }\end{array}$} & \multicolumn{4}{|c|}{ Condition } & \multirow[b]{2}{*}{ Comment } \\
\hline & & & $2-19$ & $2-21$ & $2-22$ & $2-24$ & \\
\hline 37 & Plate TC & 37 & Verified & Verified & Verified & Verified & \\
\hline 38 & Tcap Slug & 38 & Verified & Verified & Verified & Verified & \\
\hline 39 & Plate TC & 39 & Verified & Verified & Verified & Failed & $\begin{array}{l}\text { Test 2-24 PT } \\
\text { failed high } \\
\text { during } \\
\text { experiment }\end{array}$ \\
\hline 40 & Tcap Slug & 40 & Verified & Verified & Verified & Verified & \\
\hline 41 & Plate TC & 41 & Verified & Verified & Verified & Verified & \\
\hline 42 & Tcap Slug & 42 & Verified & Verified & Verified & Verified & \\
\hline 43 & Plate TC & 43 & Verified & Verified & Verified & Verified & \\
\hline 44 & Tcap Slug & 44 & Verified & Verified & Verified & Verified & \\
\hline 45 & Plate TC & 45 & Verified & Verified & Verified & Verified & \\
\hline $\mathbf{Q}$ & ASTM Slug & $\mathrm{K}-18$ & $\begin{array}{l}\text { DAQ } \\
\text { Error }\end{array}$ & Verified & Verified & No Data & \\
\hline $\mathbf{R}$ & ASTM Slug & $\mathrm{K}-20$ & Verified & Verified & Verified & No Data & \\
\hline $\mathbf{S}$ & ASTM Slug & $\mathrm{K}-26$ & Verified & Verified & Verified & No Data & \\
\hline $\mathbf{T}$ & ASTM Slug & $\mathrm{K}-11$ & Verified & Verified & Verified & No Data & \\
\hline $1-49$ & Cable Coupon & - & Installed & Installed & Installed & Installed & \\
\hline $1-50$ & Cable Coupon & - & Installed & Installed & Installed & Installed & \\
\hline $1-51$ & Aerogel & - & Installed & Installed & Installed & Installed & \\
\hline $1-52$ & Carbon Tape & - & Installed & Installed & Installed & Installed & \\
\hline $1-53$ & Carbon Tape & - & Installed & Installed & Installed & Installed & \\
\hline $1-54$ & Aerogel & - & Installed & Installed & Installed & Installed & \\
\hline $1-55$ & Aerogel & - & Installed & Installed & Installed & Installed & \\
\hline $1-56$ & Carbon Tape & - & Installed & Installed & Installed & Installed & \\
\hline $1-57$ & Carbon Tape & - & Installed & Installed & Installed & Installed & \\
\hline $1-58$ & Aerogel & - & Installed & Installed & Installed & Installed & \\
\hline $1-59$ & Carbon Tape & - & Installed & Installed & Installed & Installed & \\
\hline $1-60$ & Carbon Tape & - & Installed & Installed & Installed & Installed & \\
\hline
\end{tabular}




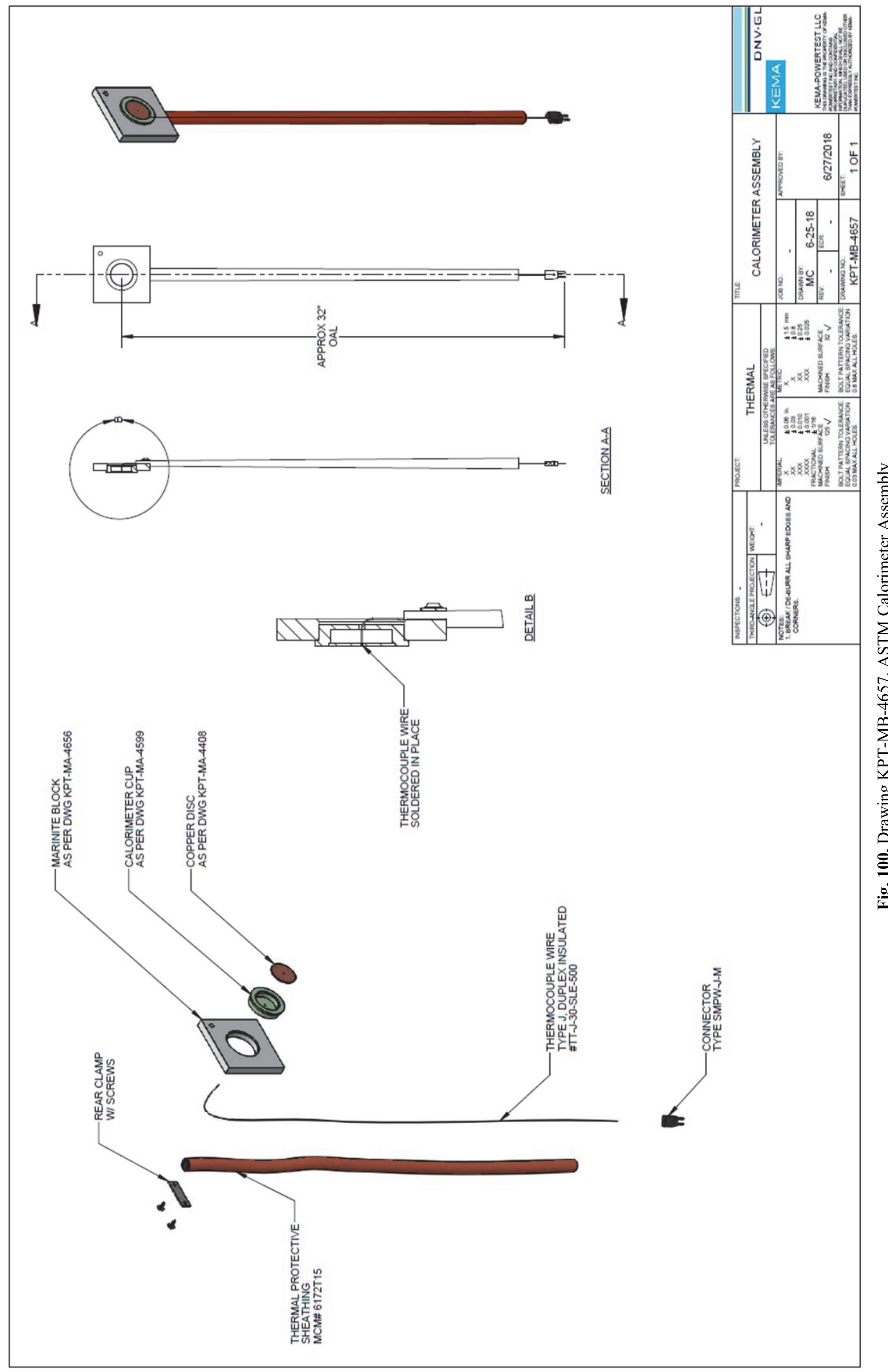




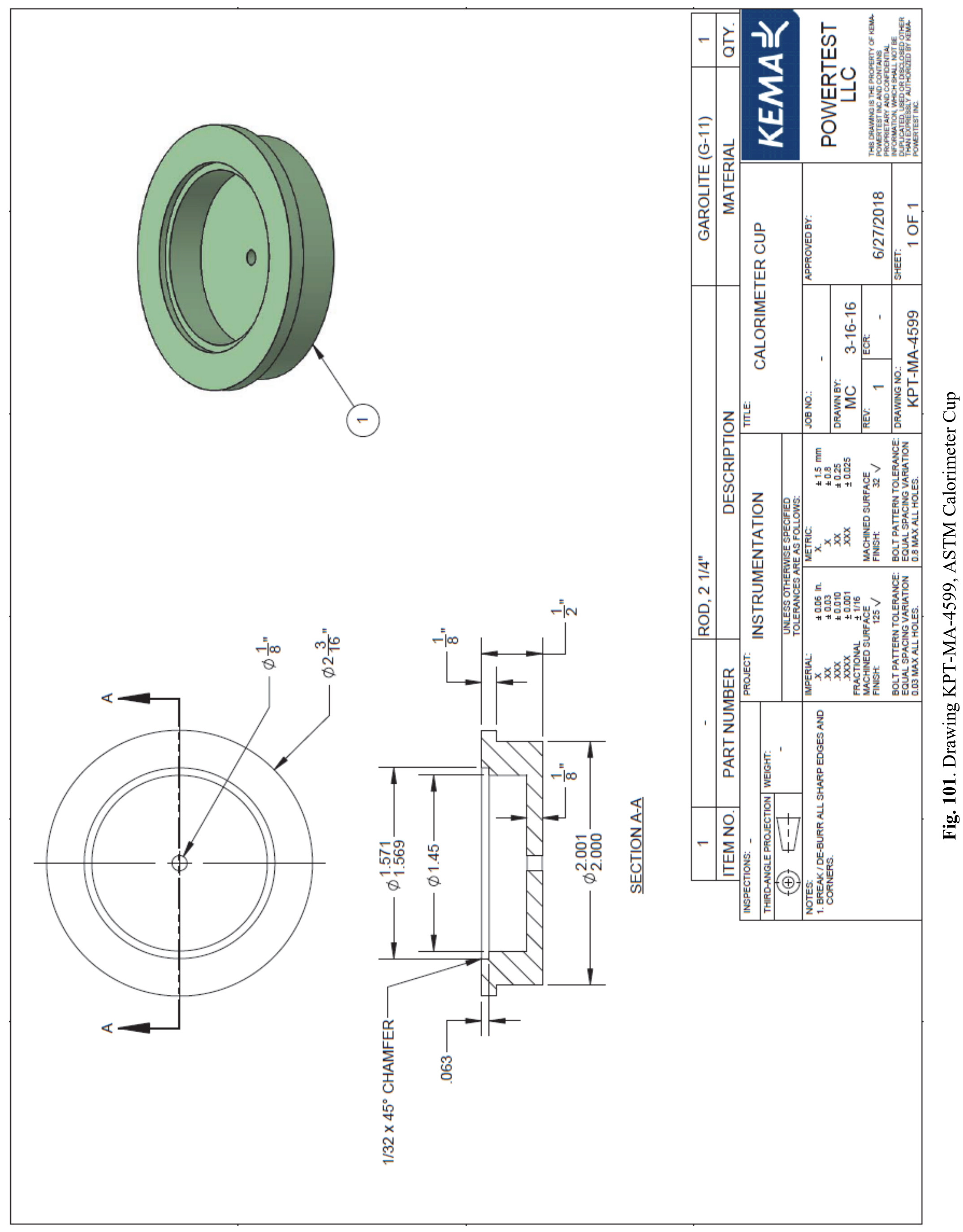




\section{Appendix C: Weights and Measurements}

Provides mass and dimension measurements of test object components.

\section{C.1 Electrical Enclosure and Conductors}

Prior to performing high energy arcing fault experiments on the test devices, the electrical contractor removed the metal cladding, and with the support from NIST staff, each removed panel was weighed using calibrated mass balances. The initial and final measurements for the metal cladding are presented below for each test device. The figures that follow (Fig. 87 through Fig. 92) have been annotated to identify the panels that were weighted. The figures include panel dimensions which are reported in inches. The bus conductors in the primary cable connection compartment were removed and weighed before and after each experiment. Those measurements are also reported in this appendix.

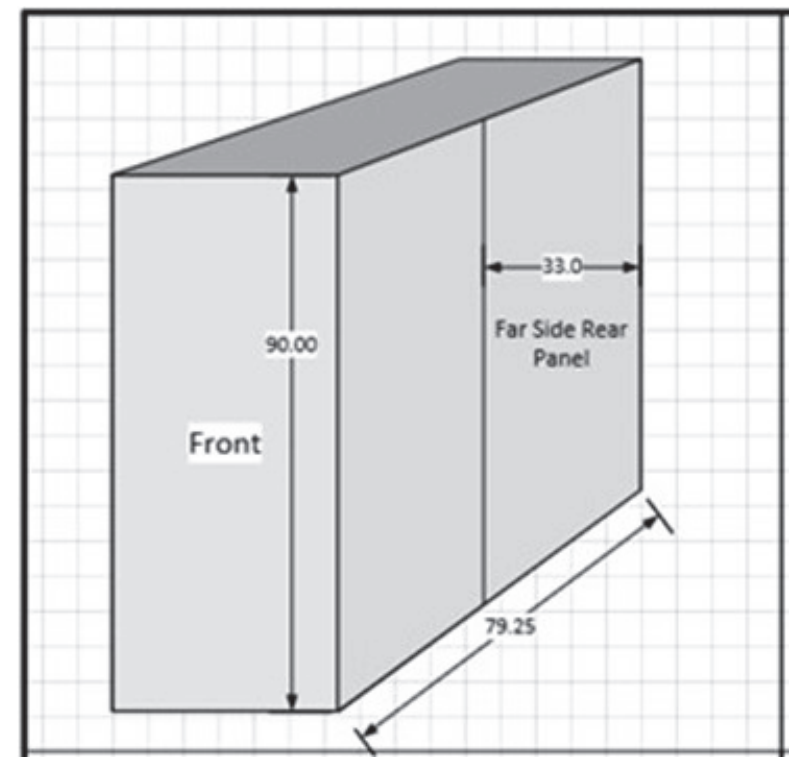

Fig. 102. Exterior Isometric. Dimensions in inches \pm 0.25 inches. 


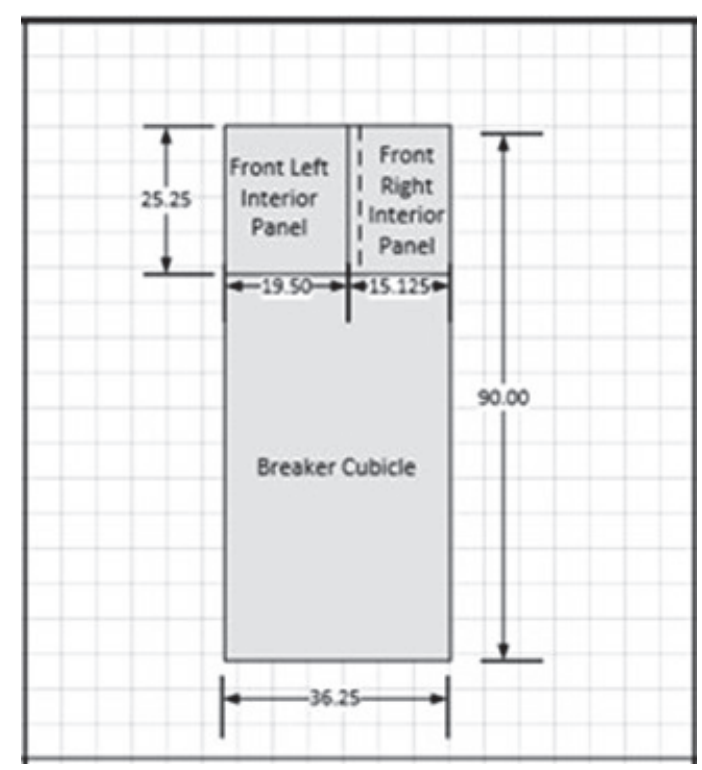

Fig. 103. Interior Front. Dimensions in inches \pm 0.25 inches.

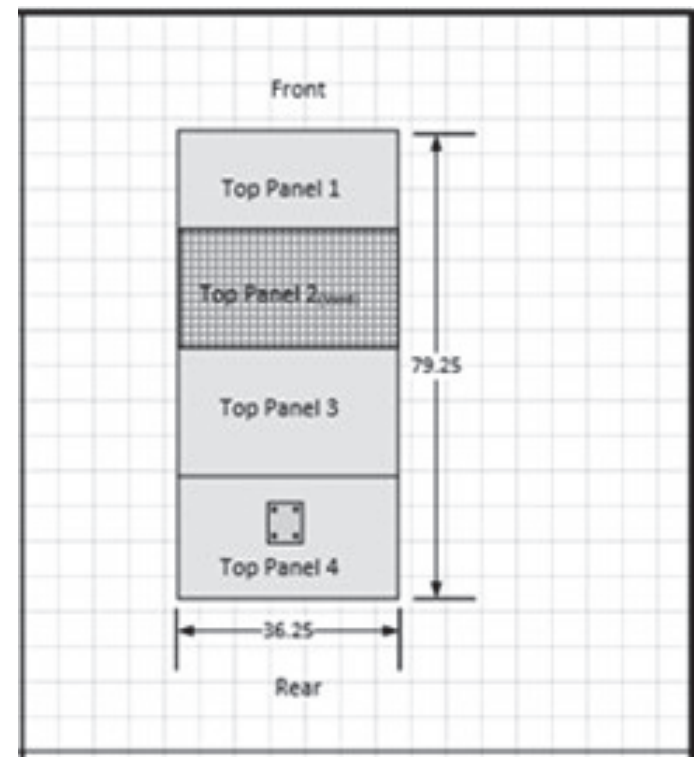

Fig. 104. Exterior Top. Dimensions in inches \pm 0.25 inches. 


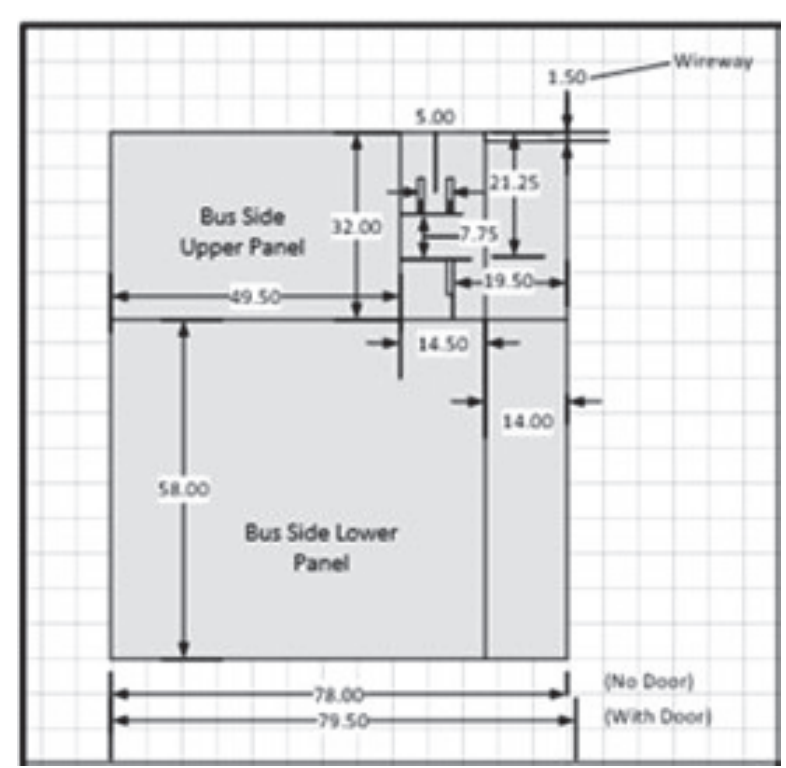

Fig. 105. Side Left. Dimensions in inches. Overall dimensions \pm 0.25 inches, interior dimensions \pm 0.13 inches.

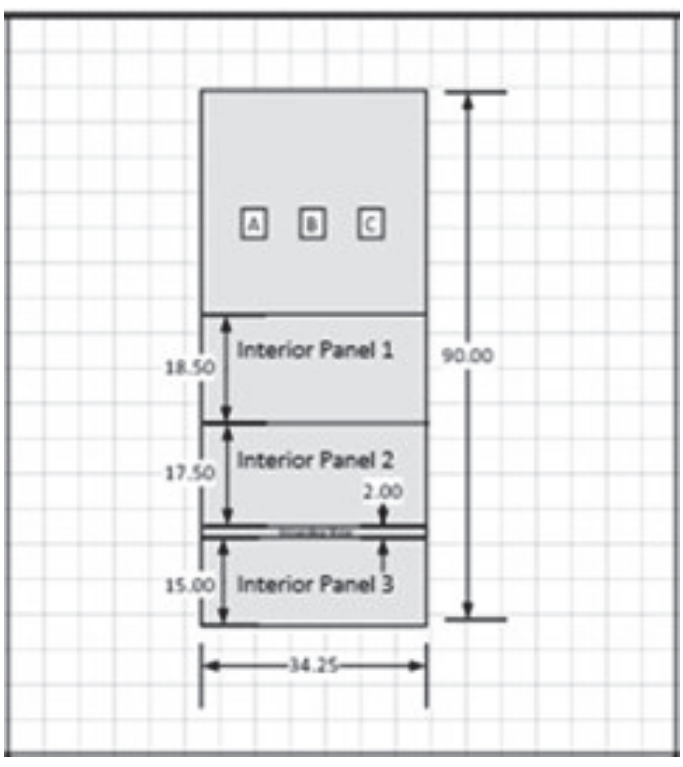

Fig. 106. Interior Rear. Dimensions in inches \pm 0.25 inches. 


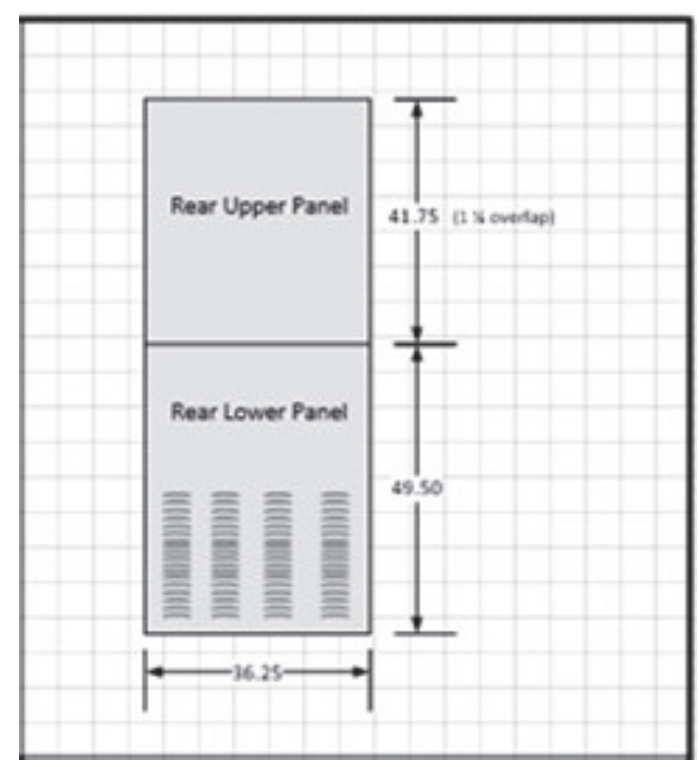

Fig. 107. Exterior Rear. Dimensions in inches \pm 0.25 inches. 


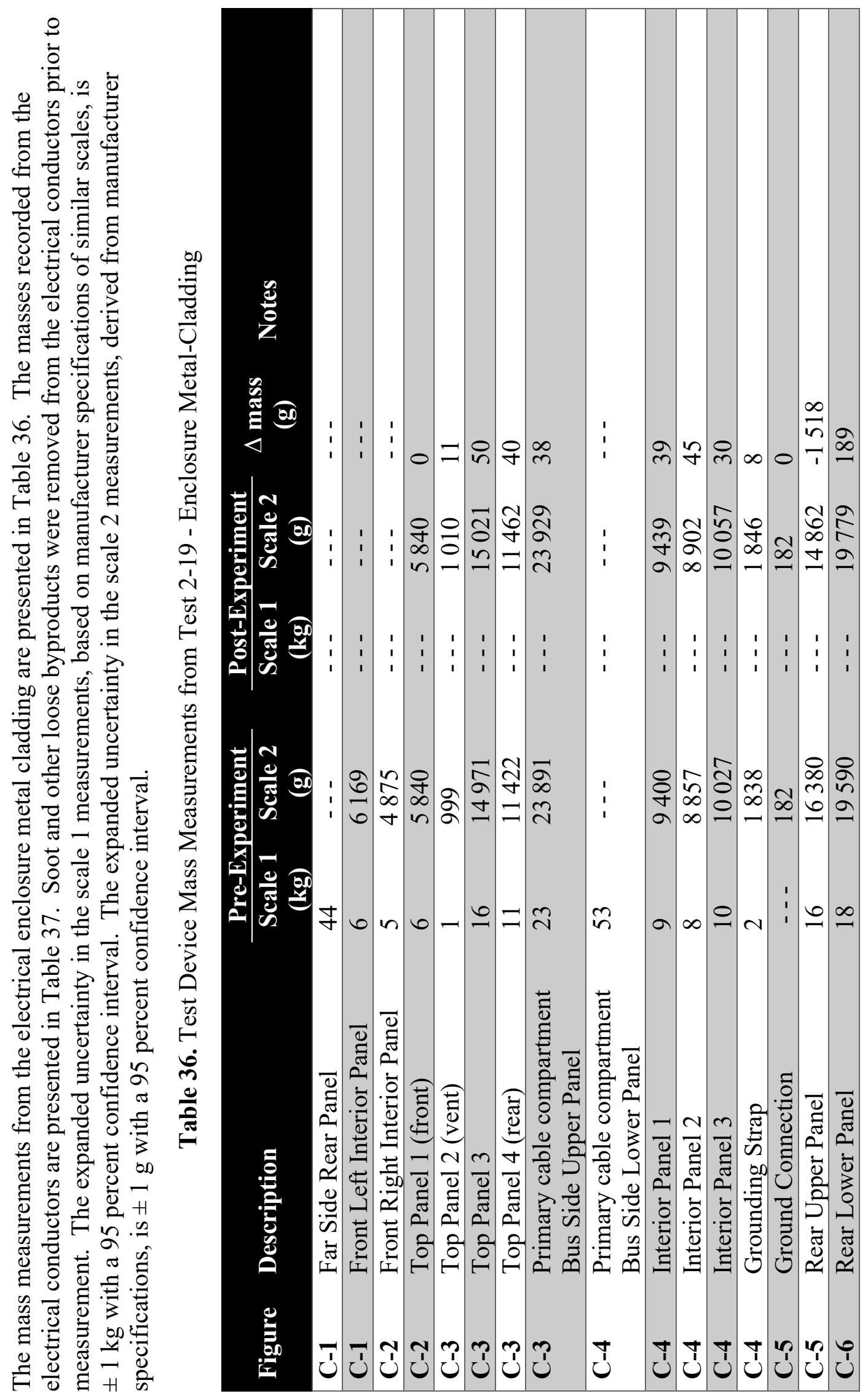




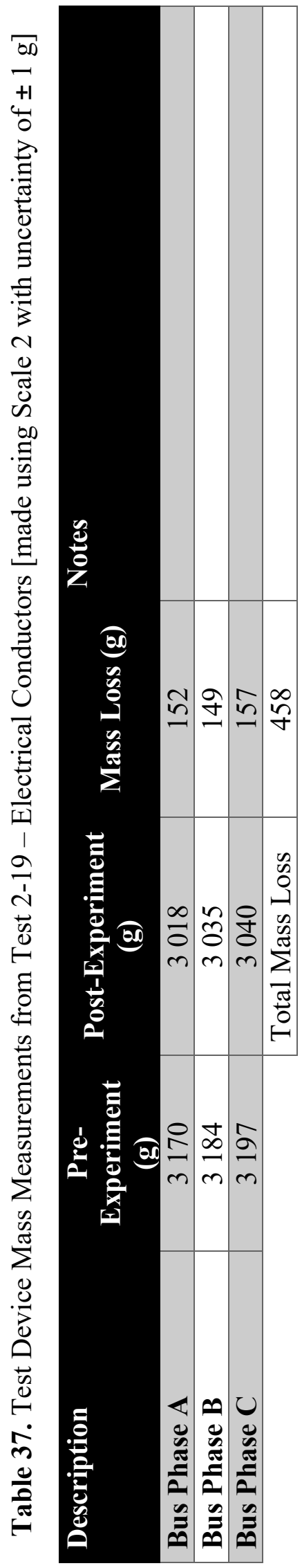

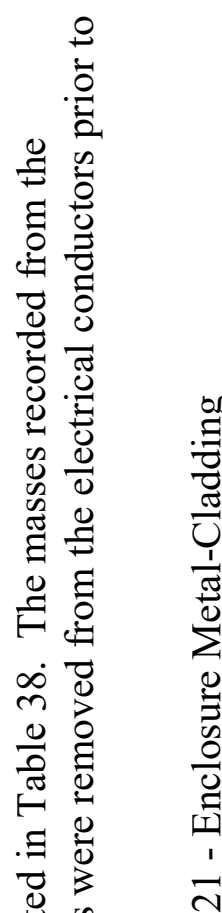

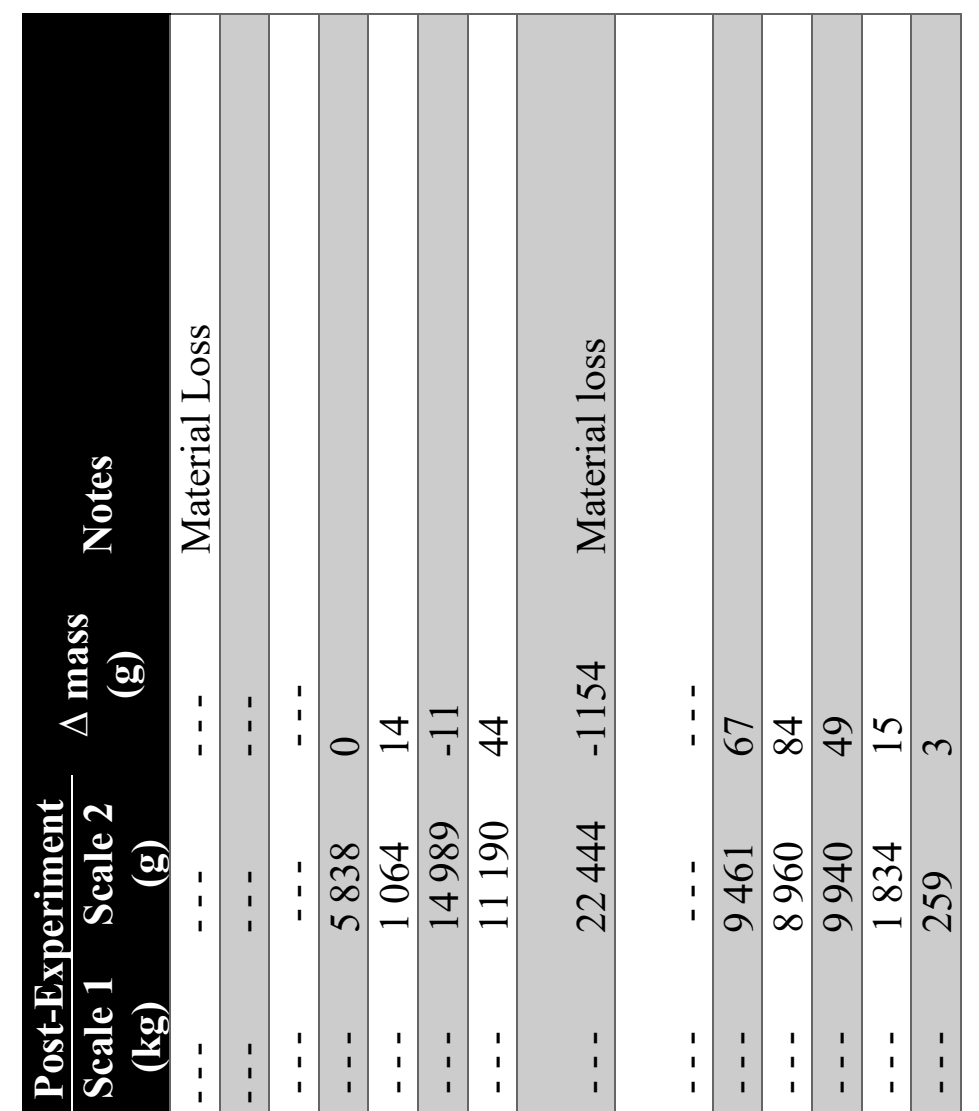

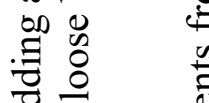

它

त

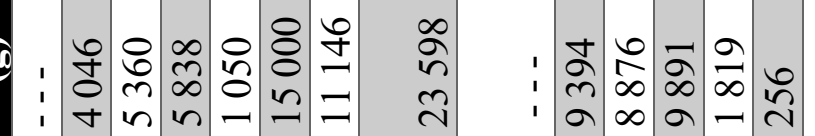

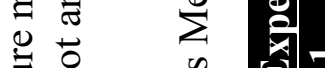

可

वे

苞 $\frac{0}{\pi} \quad \frac{0}{0}$

E

过

$\stackrel{\overbrace{}}{\stackrel{0}{0}}$

हี

荎

ฮี

글

귱

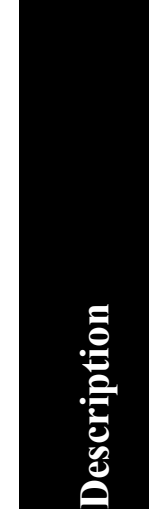

小

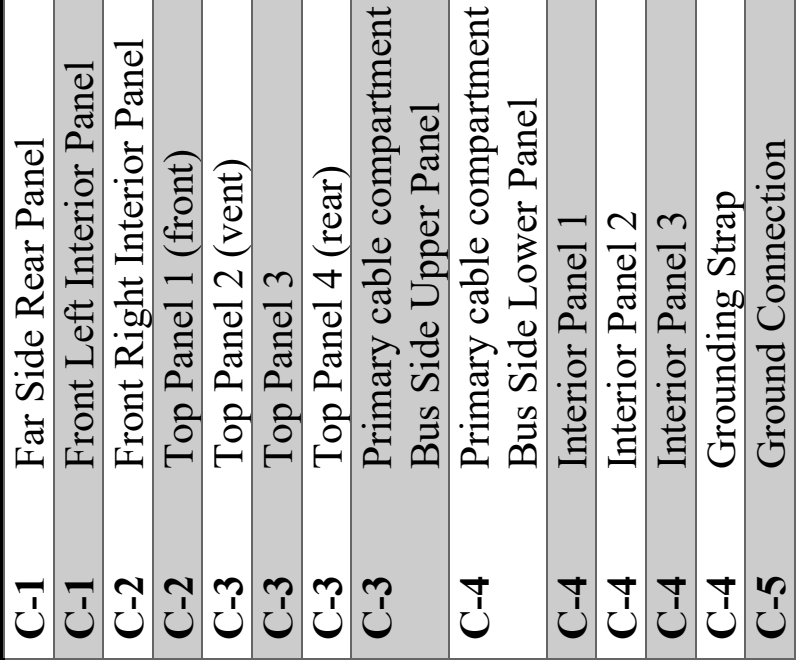




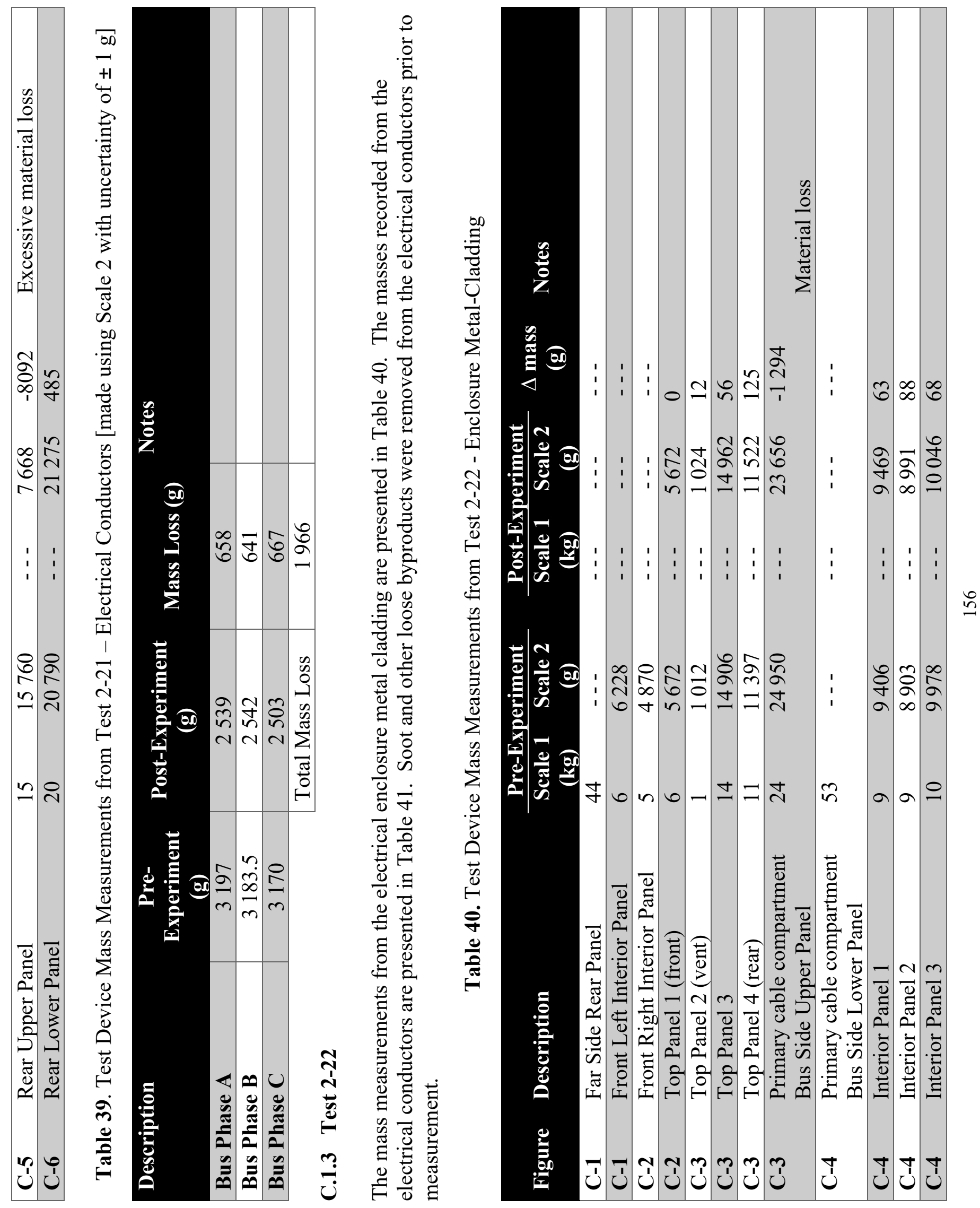




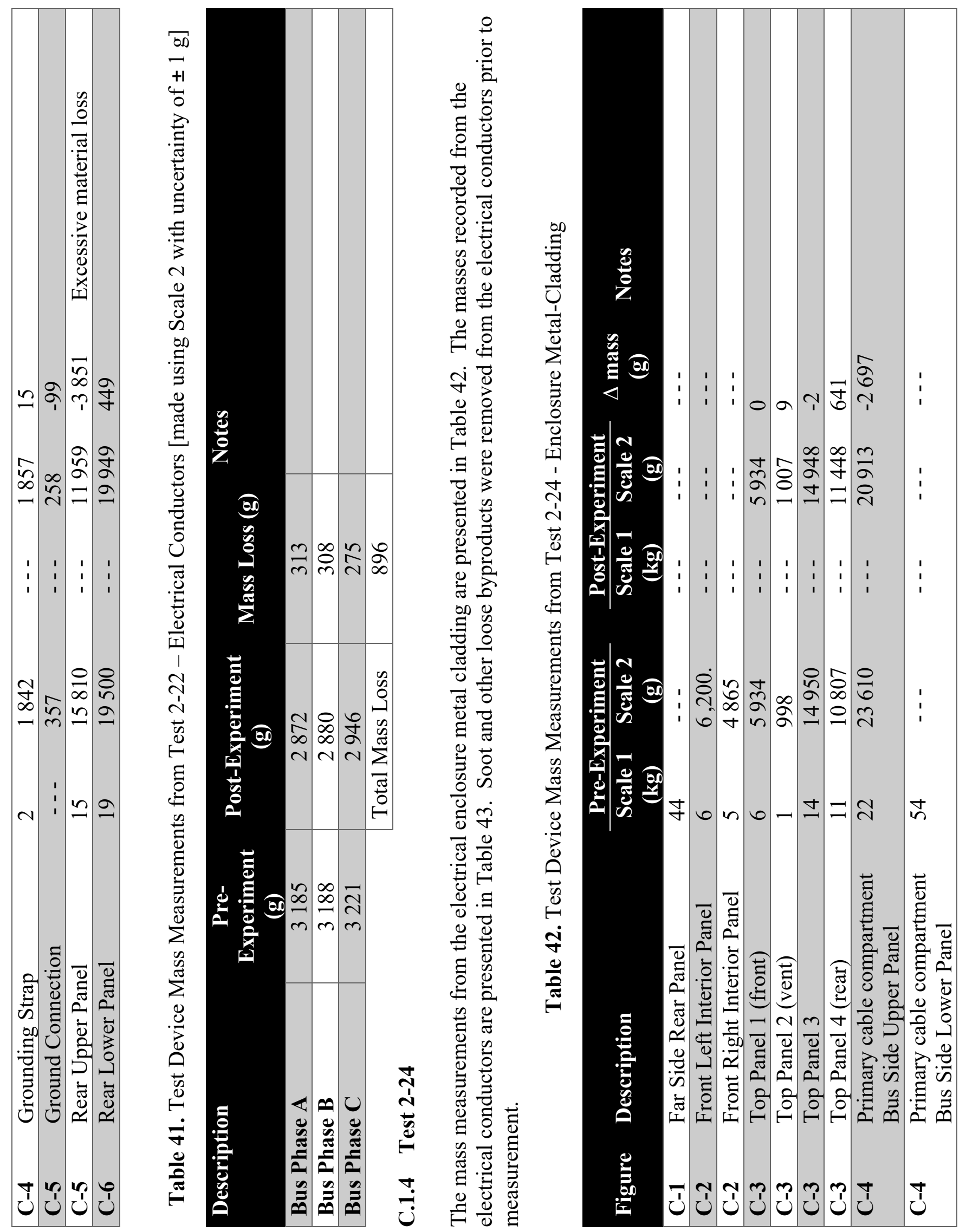




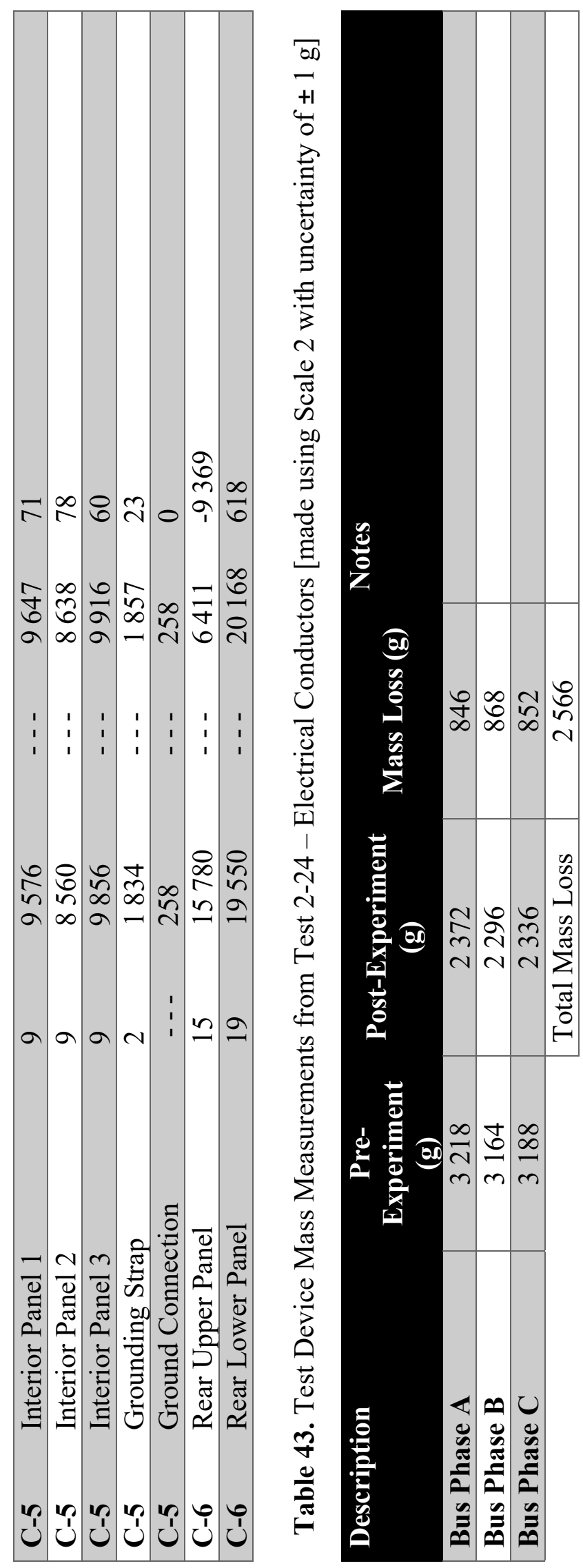




\section{Appendix D: Photographs}

This appendix provides photographic images of various experimental components. Cable samples (coupons) were provided in every experiment as a passive indication of thermal damage. The inclusion of cable samples was highly recommended by stakeholders during the April 2018 public workshop [D1].

The cable coupons were constructed using six or eight segments of cable, approximately $100 \mathrm{~mm}$ (4 in) long. The cables were affixed to a square piece of fiberglass reinforced cement board ("Durock"), measuring approximately $100 \mathrm{~mm}$ (4 in) square and nominally $13 \mathrm{~mm}(0.5 \mathrm{in})$ thick, using steel wire protected with a glass braid sheath. The wire was also used to connect the cable coupon to the horizontal steel DIN rail. Descriptions and specifications of the cables are listed in Table 44 and Table 45. Face and side views of a typical cable coupons are presented in Fig. 108 through Fig. 111. Photographs of the cable coupons were taken before and after every experiment and are shown below.

Table 44. Manufacturers' Descriptions of cables included in experiments

\begin{tabular}{|l|l|l|l|l|}
\hline $\begin{array}{c}\text { Cable } \\
\text { No. }\end{array}$ & Source & Manufacturer & Date & \multicolumn{1}{c|}{ Cable Markings } \\
\hline 900 & Purchased & Lake Cable & 2015 & $\begin{array}{l}\text { \#2582 FT. TPT127 LAKE CABLE 12AWG 7C } \\
\text { PE/PVC2010 CONTROL CABLE 600V 75 C 2015 } \\
\text { "ROHS 11" REACH MADE IN USA 280547 }\end{array}$ \\
\hline 902 & TVA & $\begin{array}{l}\text { Cyprus Wire \& } \\
\text { Cable }\end{array}$ & 1975 & $\begin{array}{l}\text { 3460 FEET CYPRUS WIRE \& CABLE 75K/-8615U- } \\
\text { 1 PJJ-600 3/C \#14 1975 }\end{array}$ \\
\hline
\end{tabular}

*Note that the CAROLFIRE \# refers to the number assigned to that particular cable during the CAROLFIRE program [36]

Table 45. Nominal Cable Properties

\begin{tabular}{|c|c|c|c|c|c|c|c|c|c|c|c|c|}
\hline $\begin{array}{l}\dot{0} \\
\frac{0}{0} \\
\frac{0}{\tilde{U}}\end{array}$ & 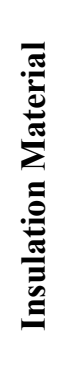 & 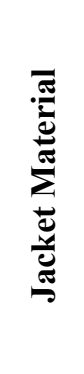 & $\begin{array}{l}\dot{\dot{\omega}} \\
\stackrel{\tilde{U}}{U}\end{array}$ & 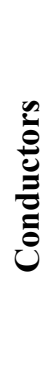 & 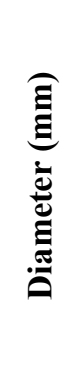 & 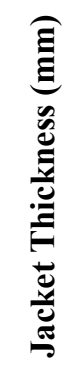 & 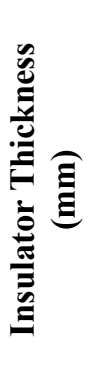 & 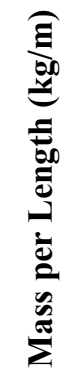 & 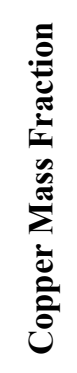 & 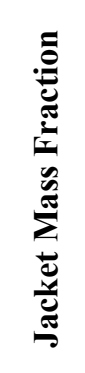 & 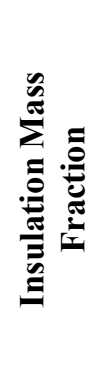 & 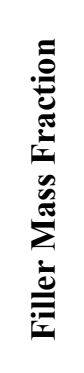 \\
\hline 900 & $\mathrm{PE}$ & PVC & TP & 7 & 15.9 & 1.85 & 1.07 & 0.38 & 0.55 & 0.27 & 0.10 & 0.08 \\
\hline 902 & $\mathrm{PE}$ & PVC & $\mathrm{TP}$ & 3 & 10.0 & 1.32 & 1.09 & 0.13 & 0.42 & 0.36 & 0.10 & 0.12 \\
\hline
\end{tabular}




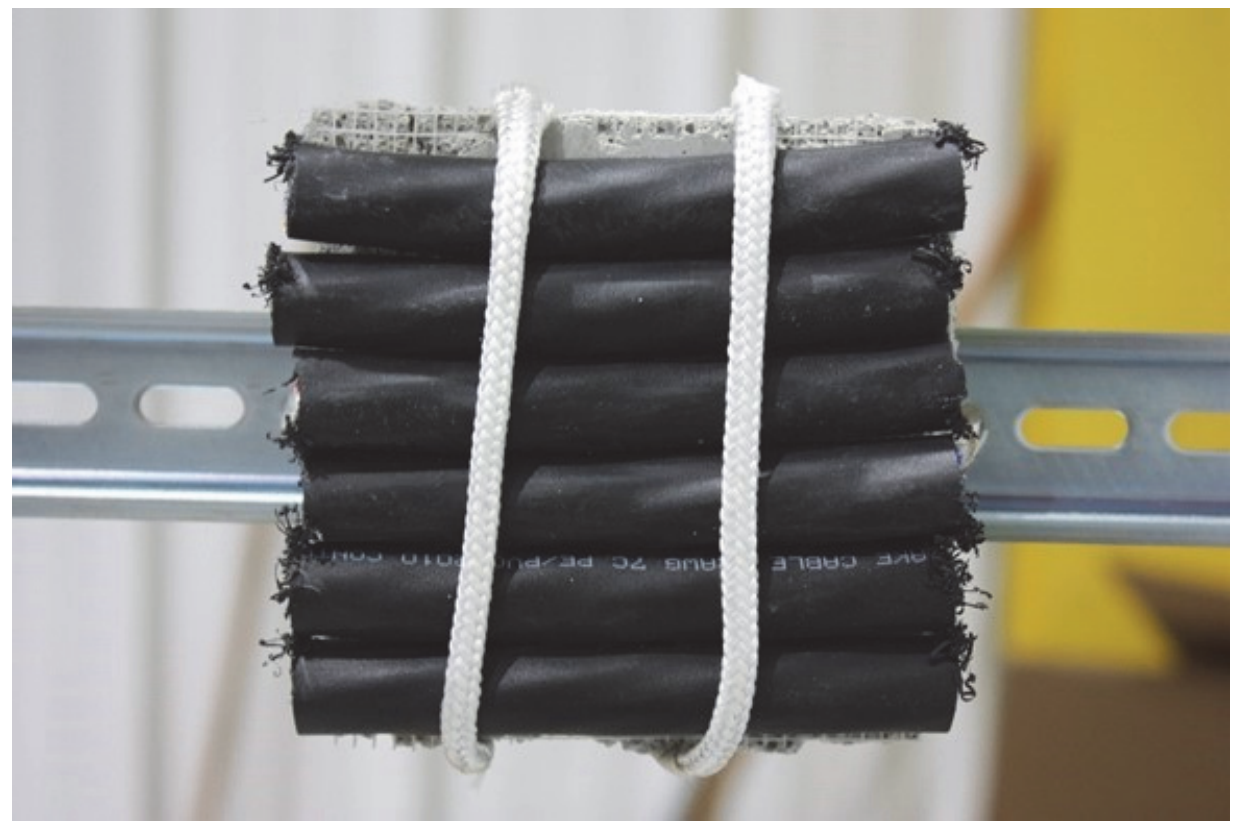

Fig. 108. Cable coupon constructed of seven conductor PE / PVC control cable (Cable 900). Front view.

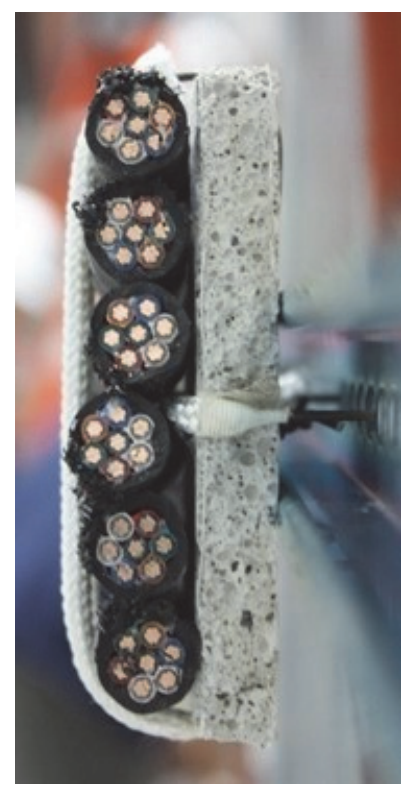

Fig. 109. Cable coupon constructed of seven conductor PE / PVC control cable (Cable 900). Side view. 


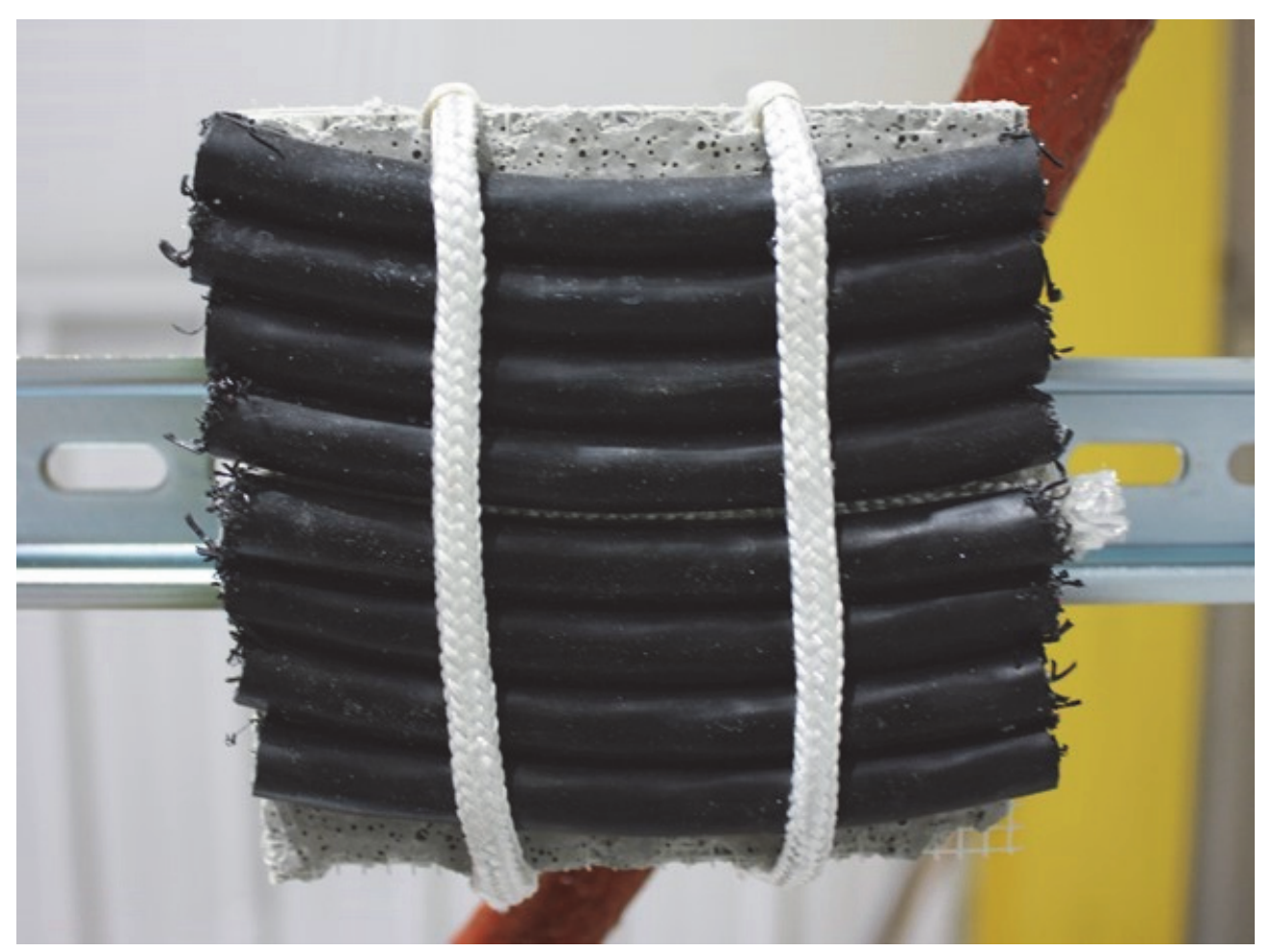

Fig. 110 Cable coupon constructed of three conductor PE / PVC control cable (Cable 902). Front view. 


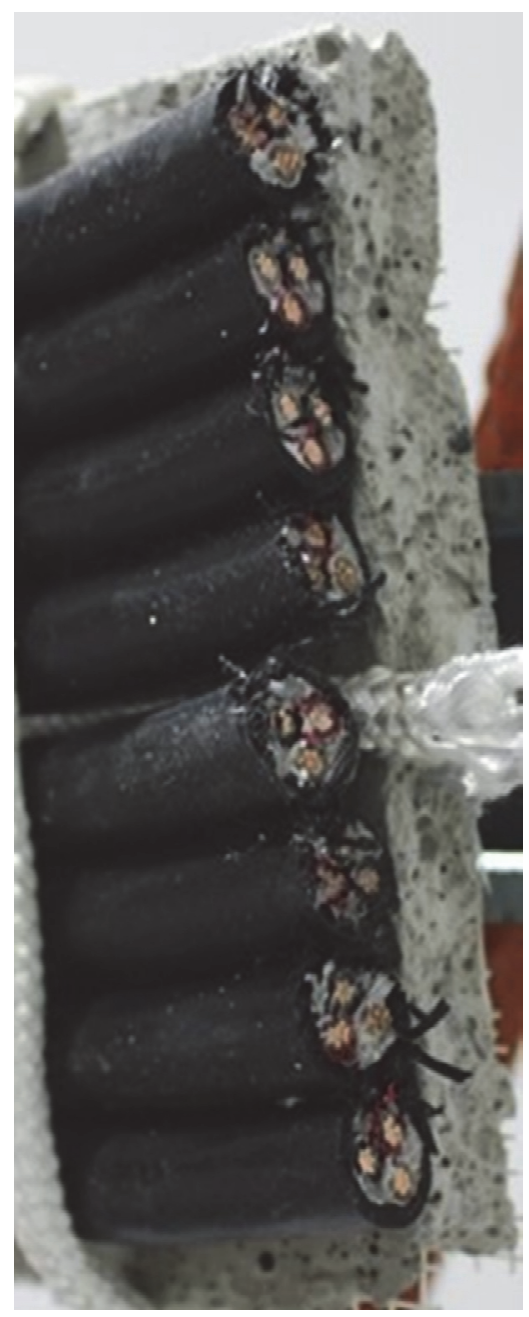

Fig. 111. Cable coupon constructed of three conductor PE / PVC control cable (Cable 902). Side view.

\section{E.1 Test 2-19 Rack Photographs}

Post-Test 2-19 photographs of the cable and instrument racks are shown in Fig. 112 through Fig. 116. See the body of the report, Section 2.4, for detailed rack drawings and dimensions. 


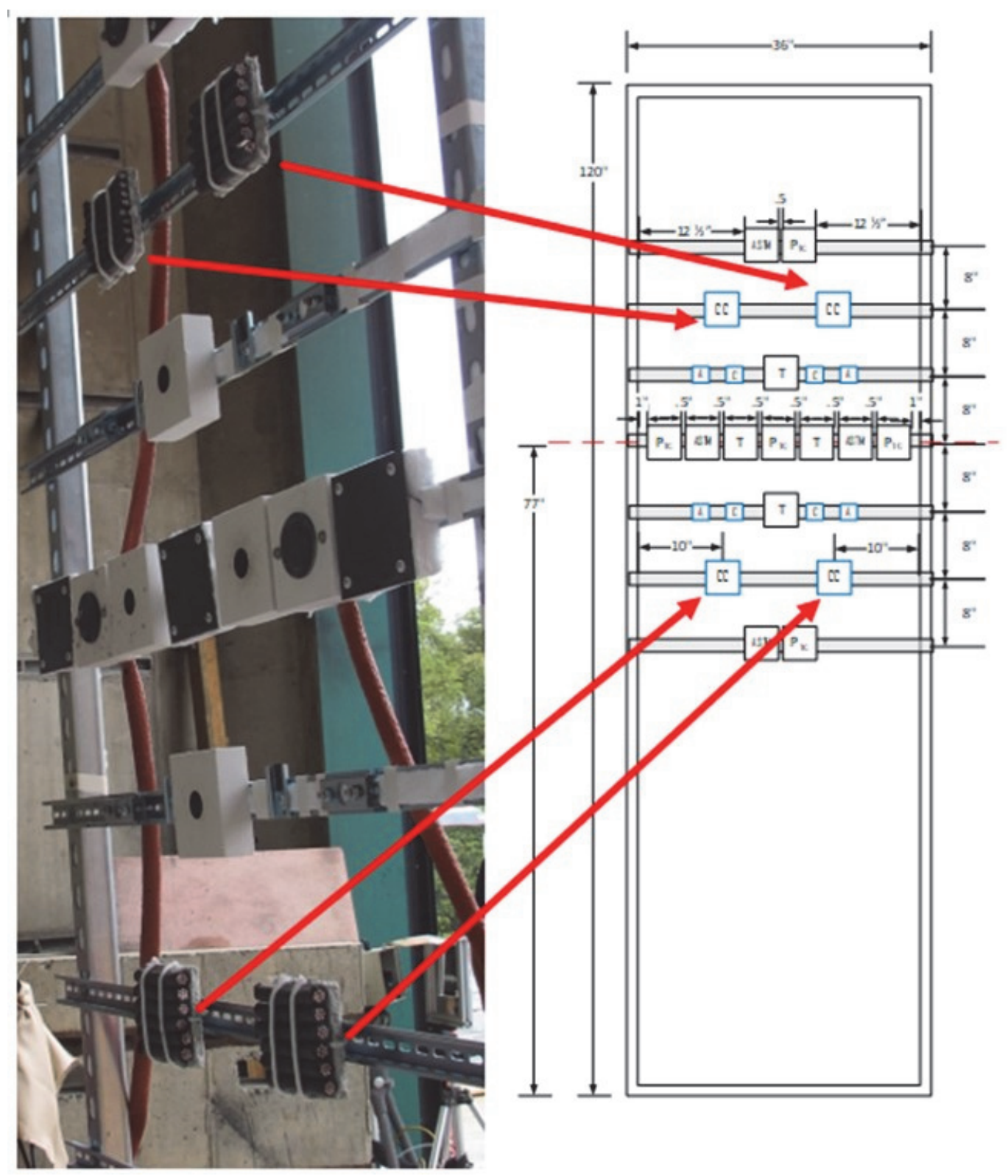

Fig. 112. Test 2-19, Rack \#1 

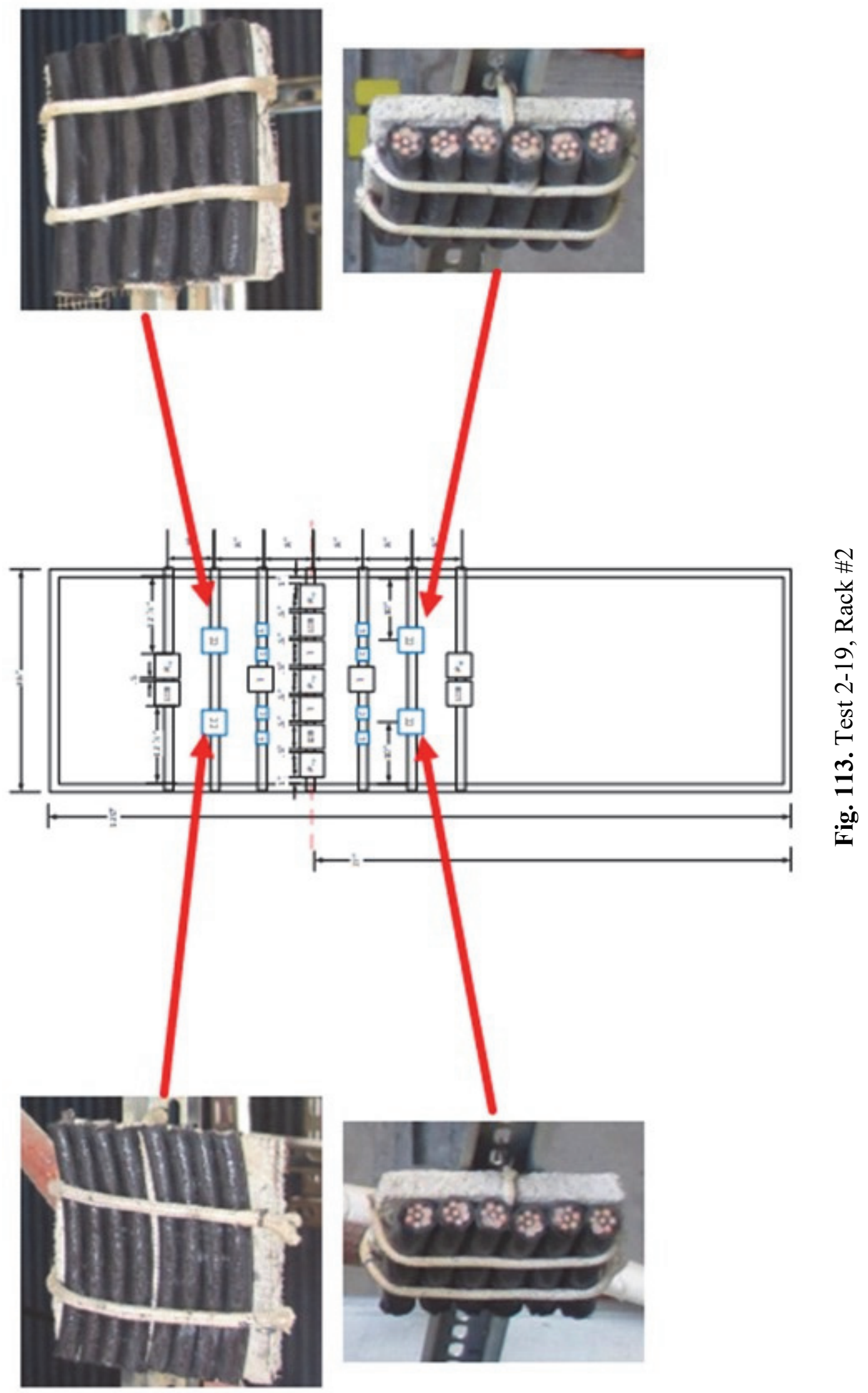


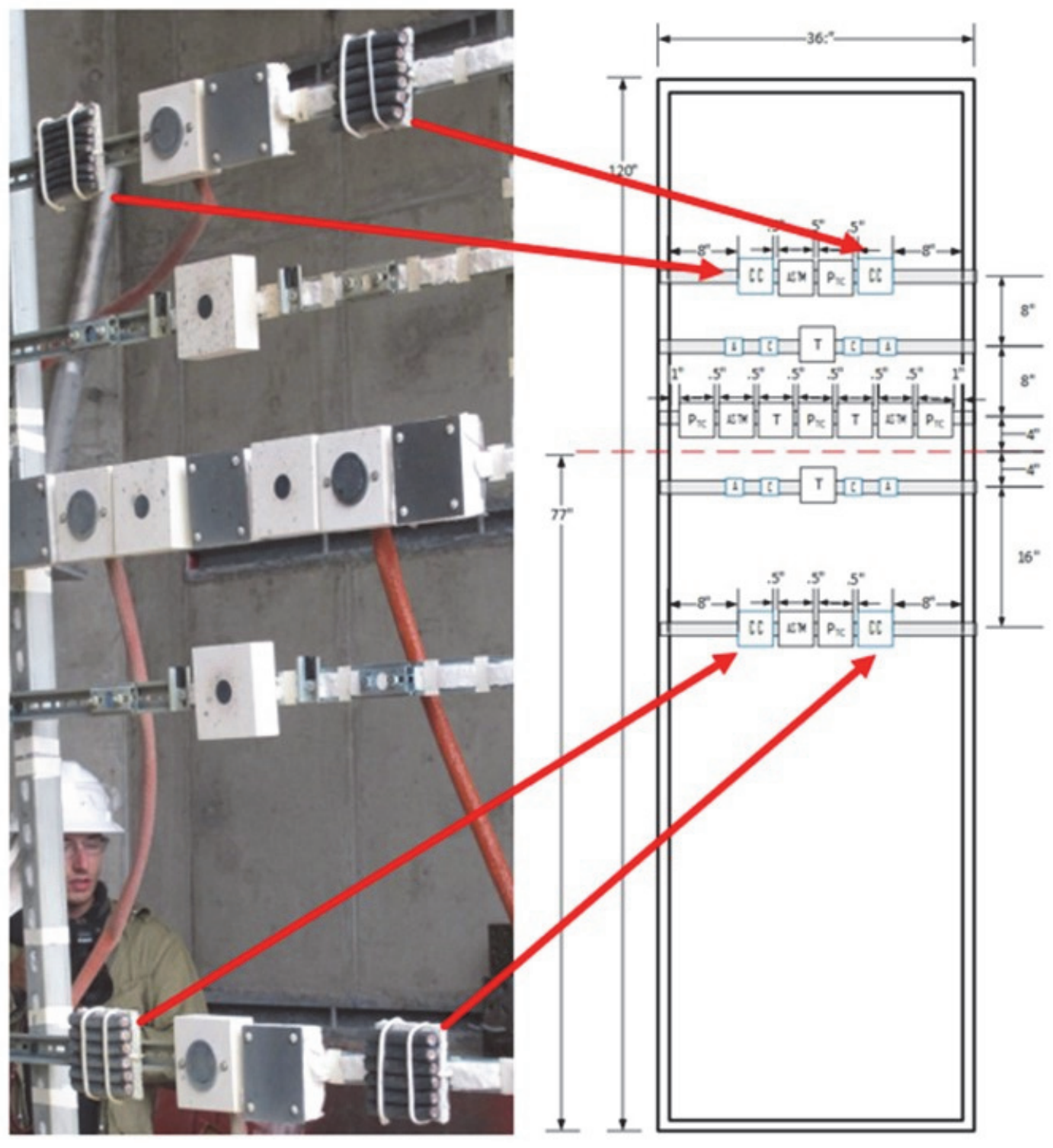

Fig. 114. Test 2-19, Rack \#3 


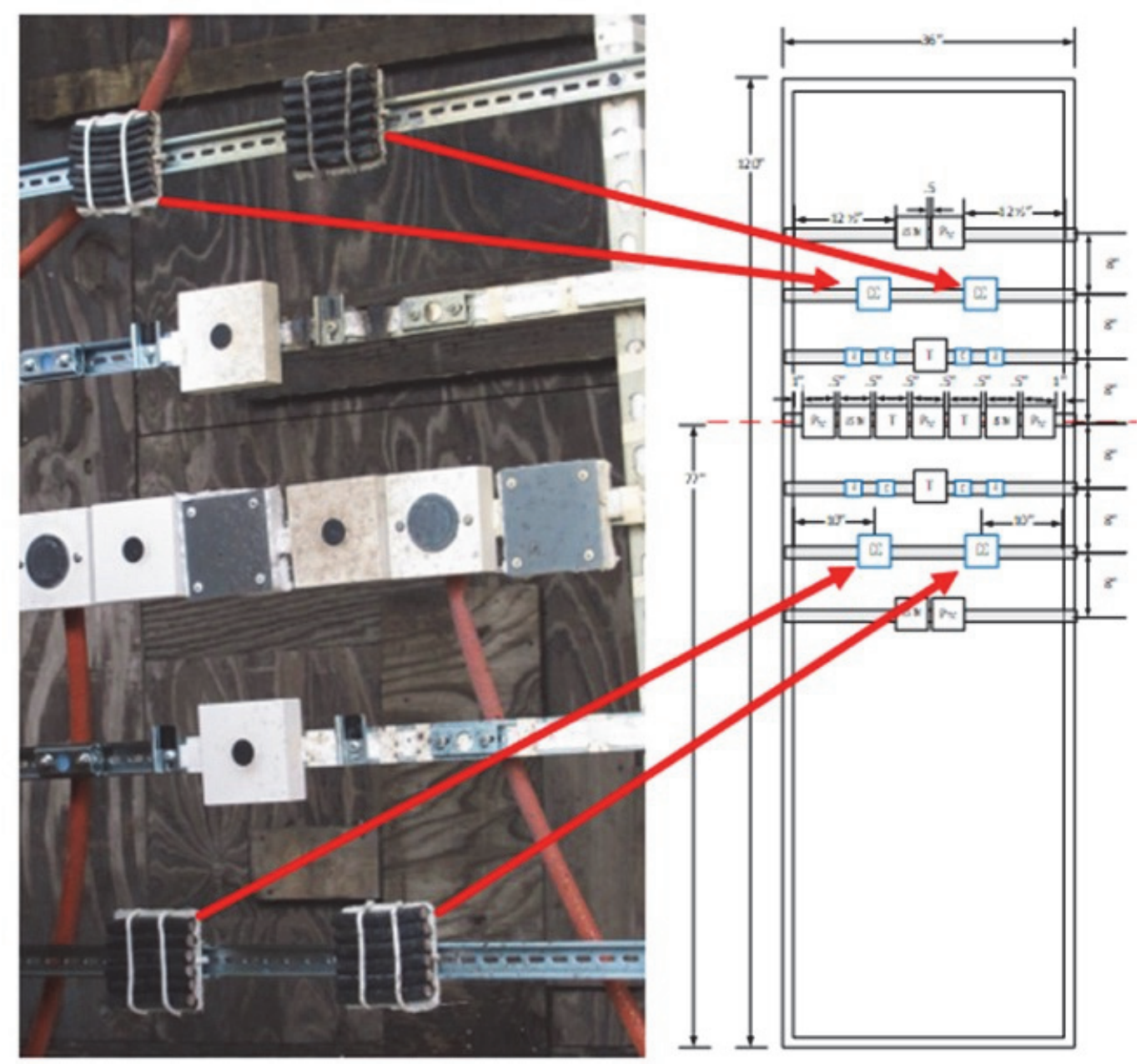

Fig. 115. Test 2-19, Rack \#4 


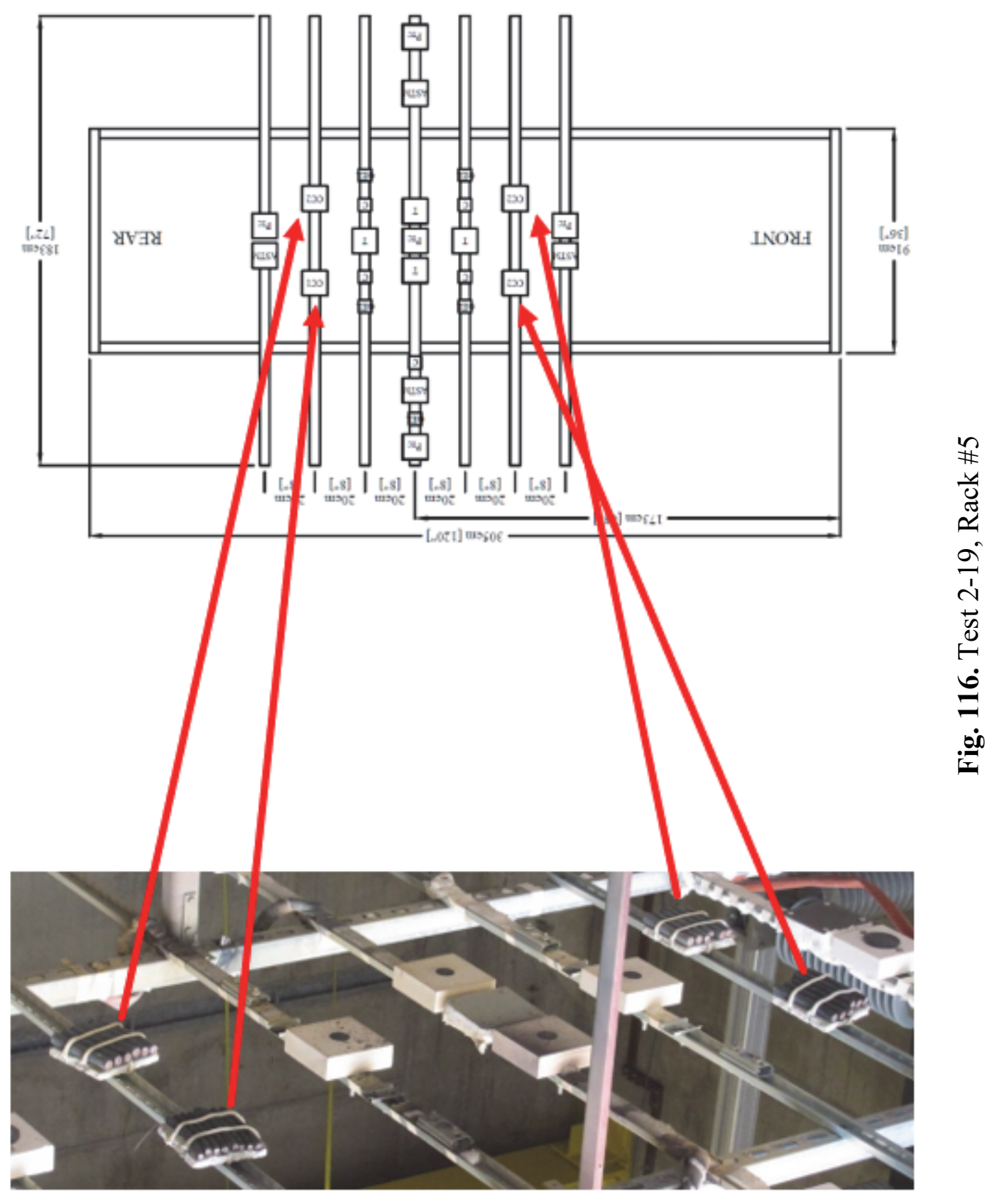

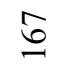




\section{E.2 Test 2-21 Rack Photographs}

Post-Test 2-21 photographs of the cable and instrument racks are shown in Fig. 112 through

Fig. 116. See the body of the report, Section 2.4, for detailed rack drawings and dimensions. 


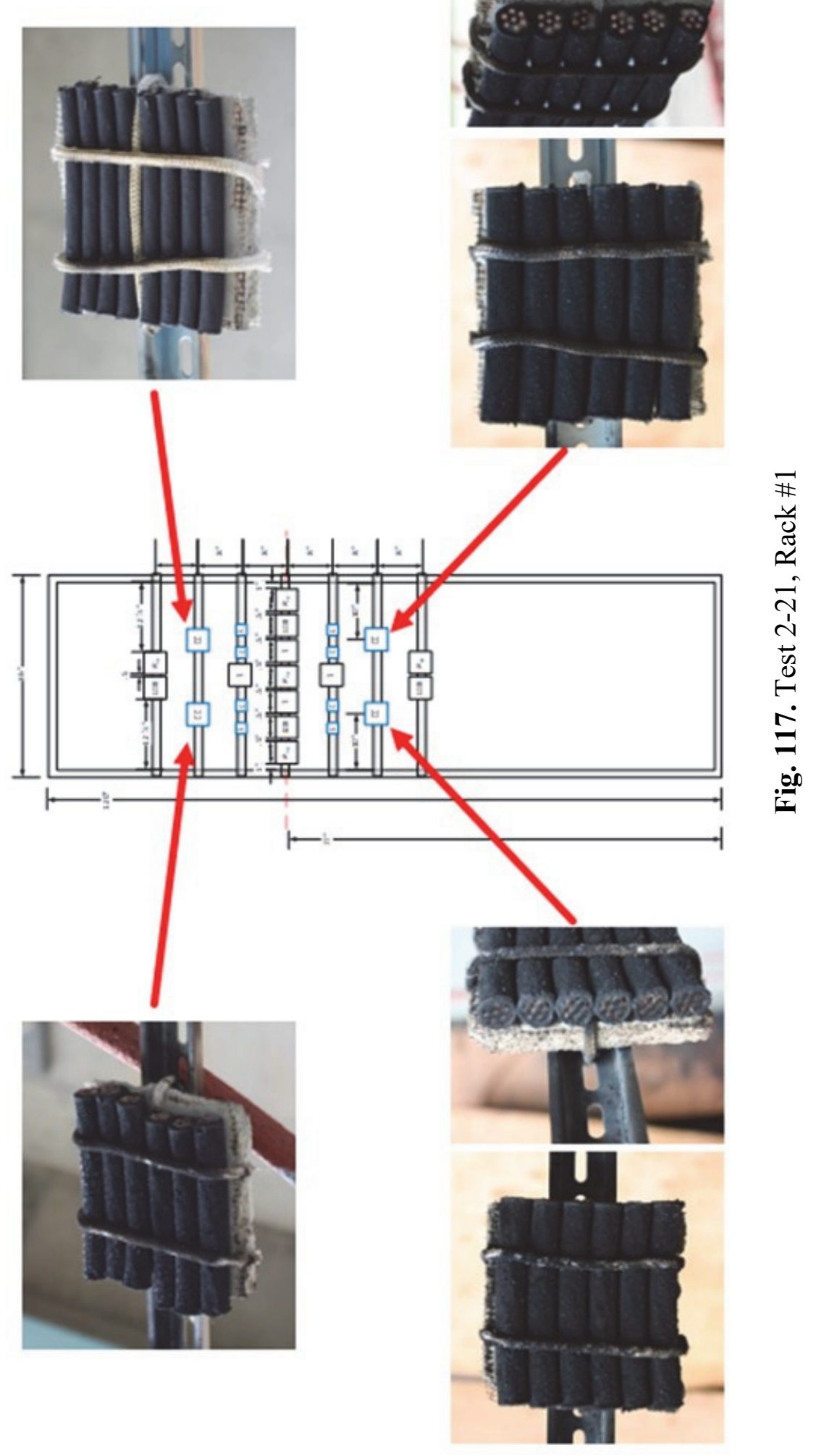




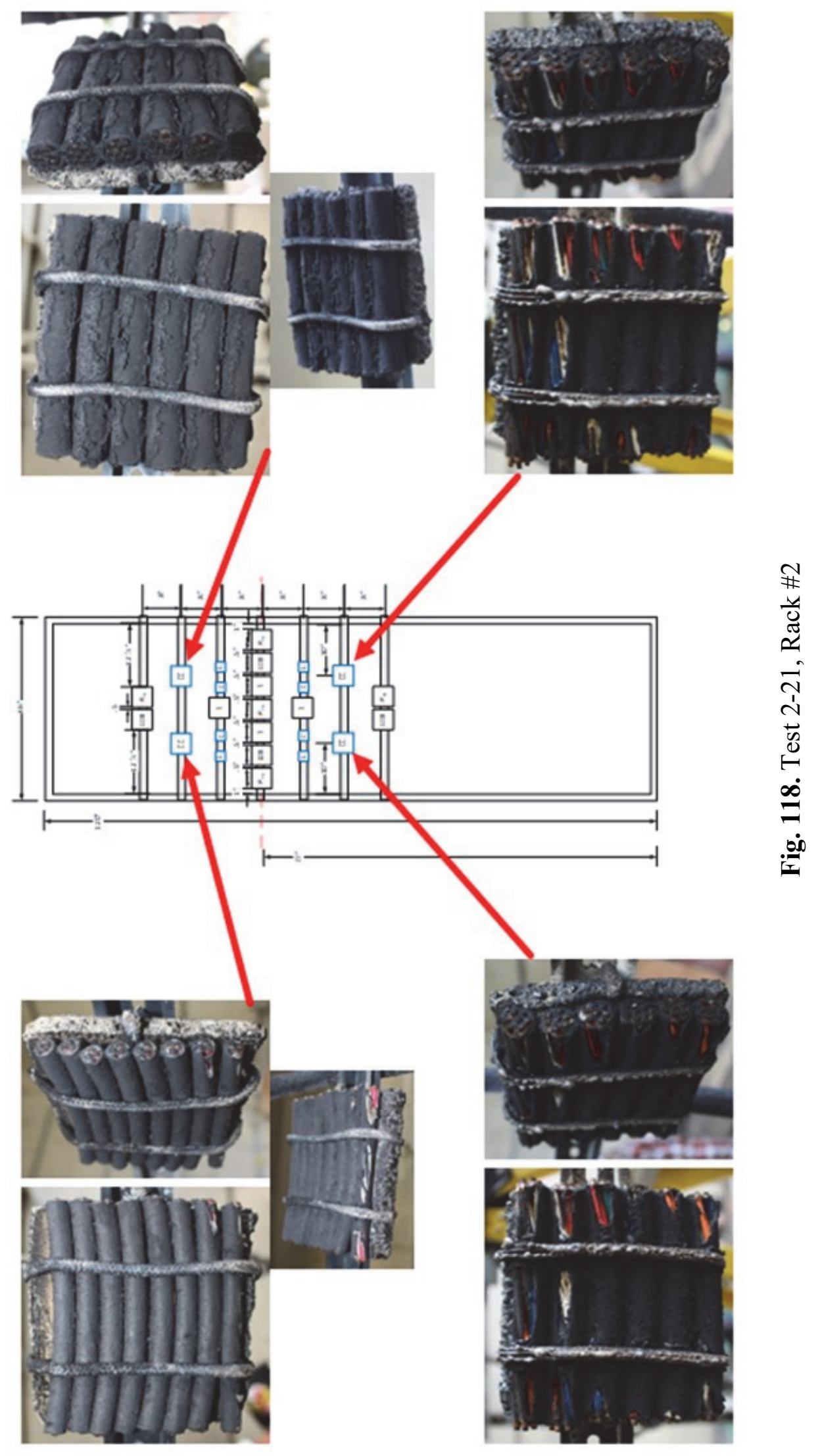




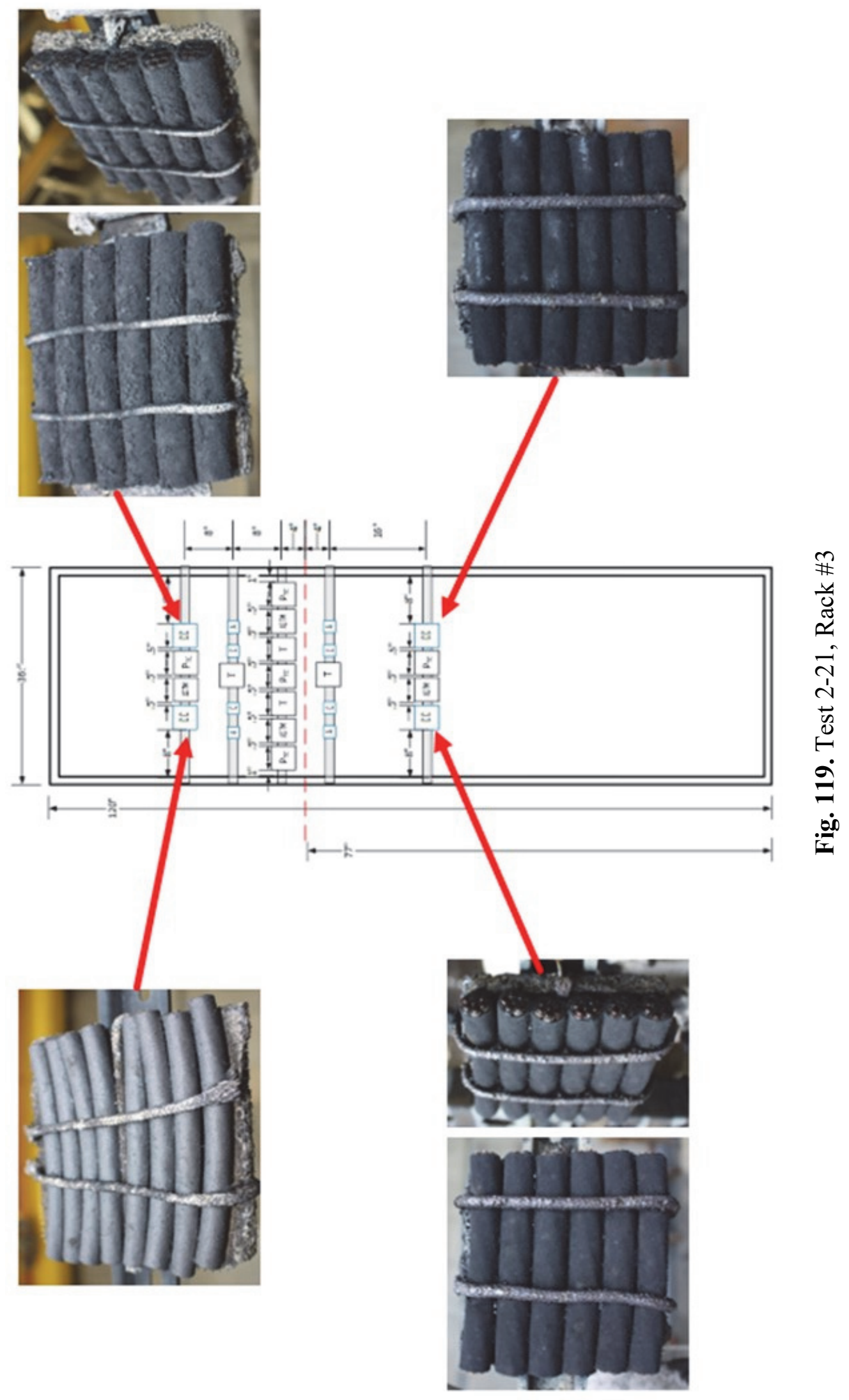




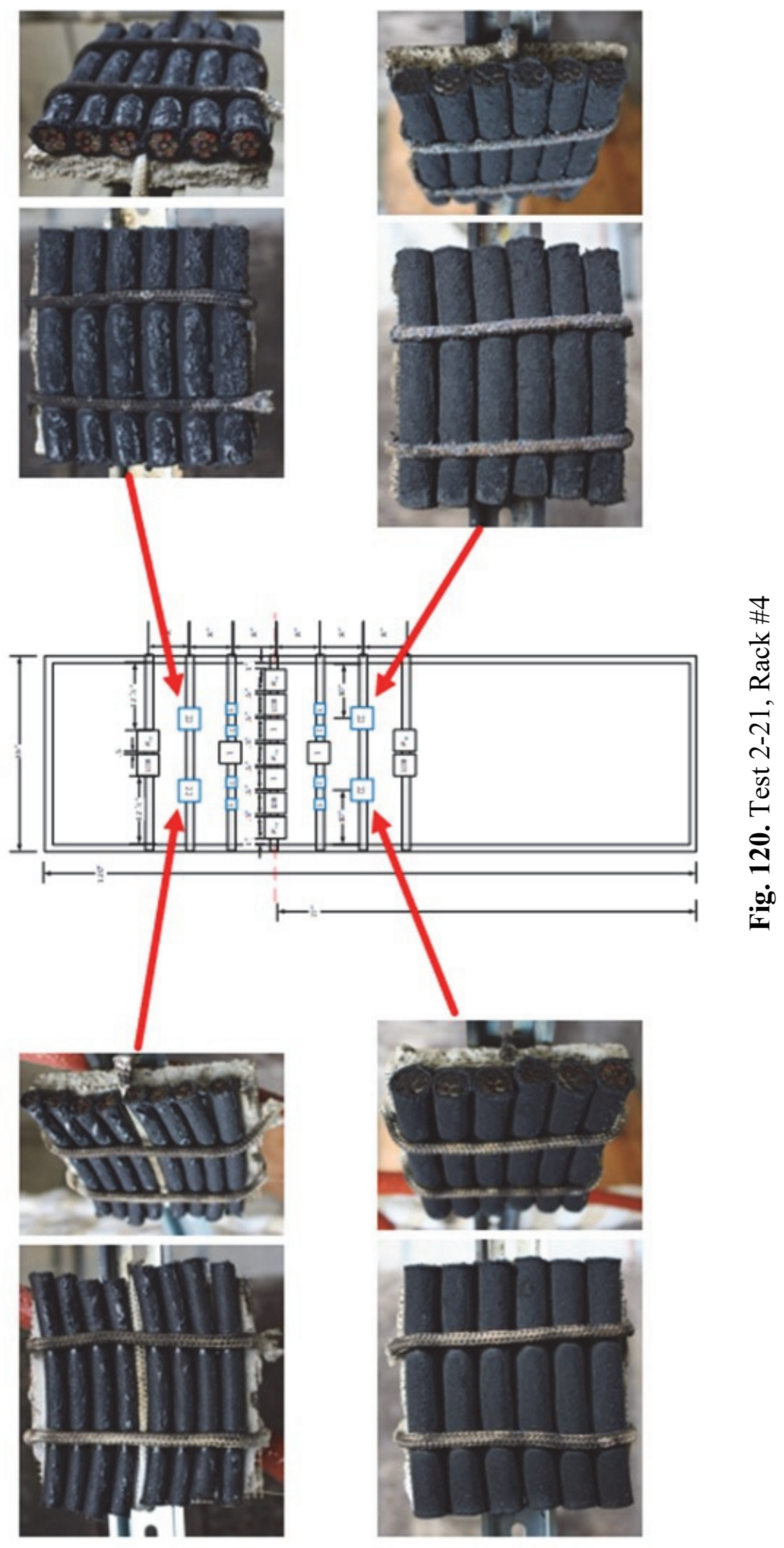



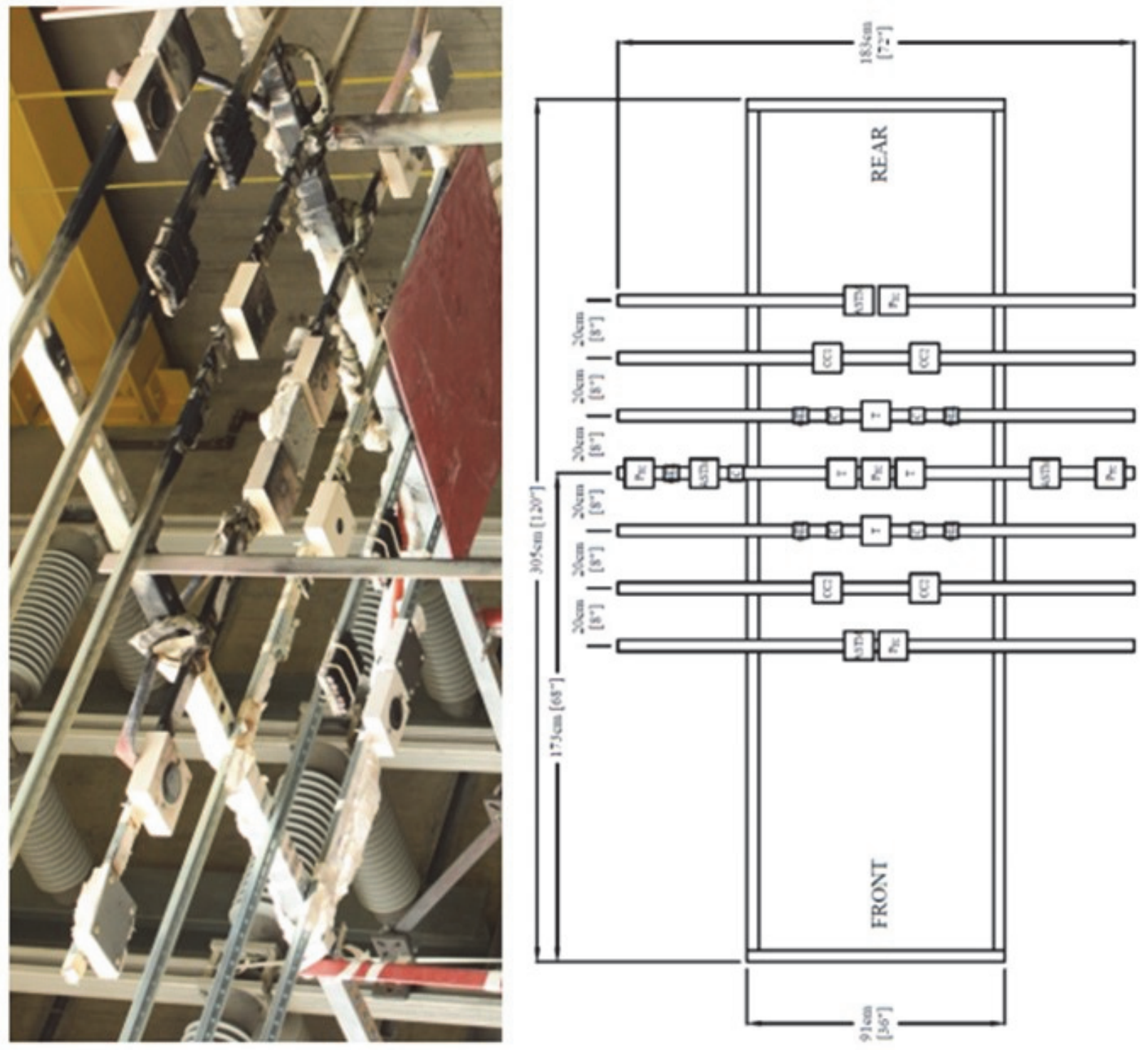

Fig. 121. Test 2-21, Rack \#5 


\section{E.3 Test 2-22 Rack Photographs}

Post-Test 2-22 photographs of the cable and instrument racks are shown in Fig. 122 through

Fig. 126. See the body of the report, Section 2.4 , for detailed rack drawings and dimensions. 


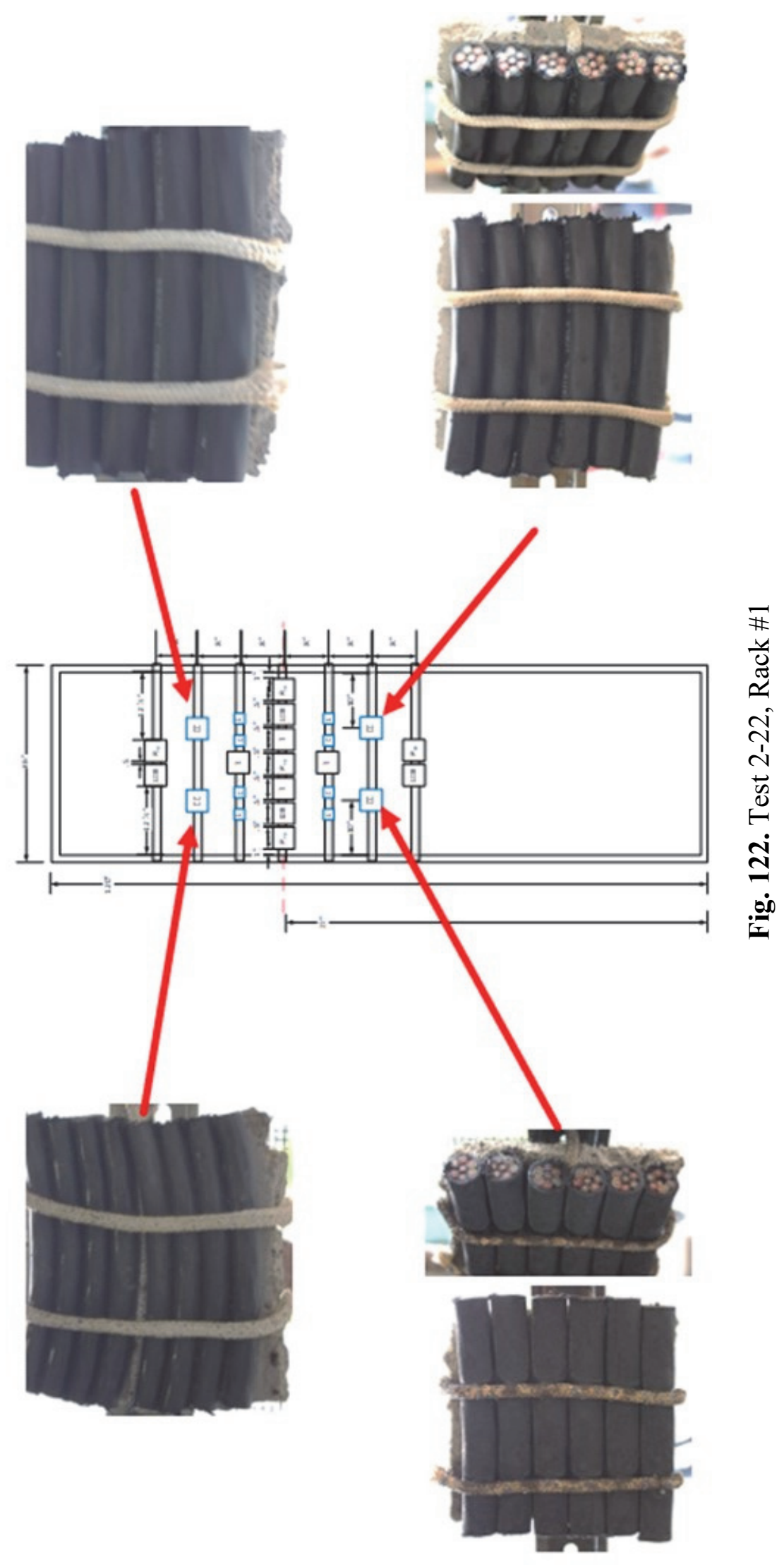




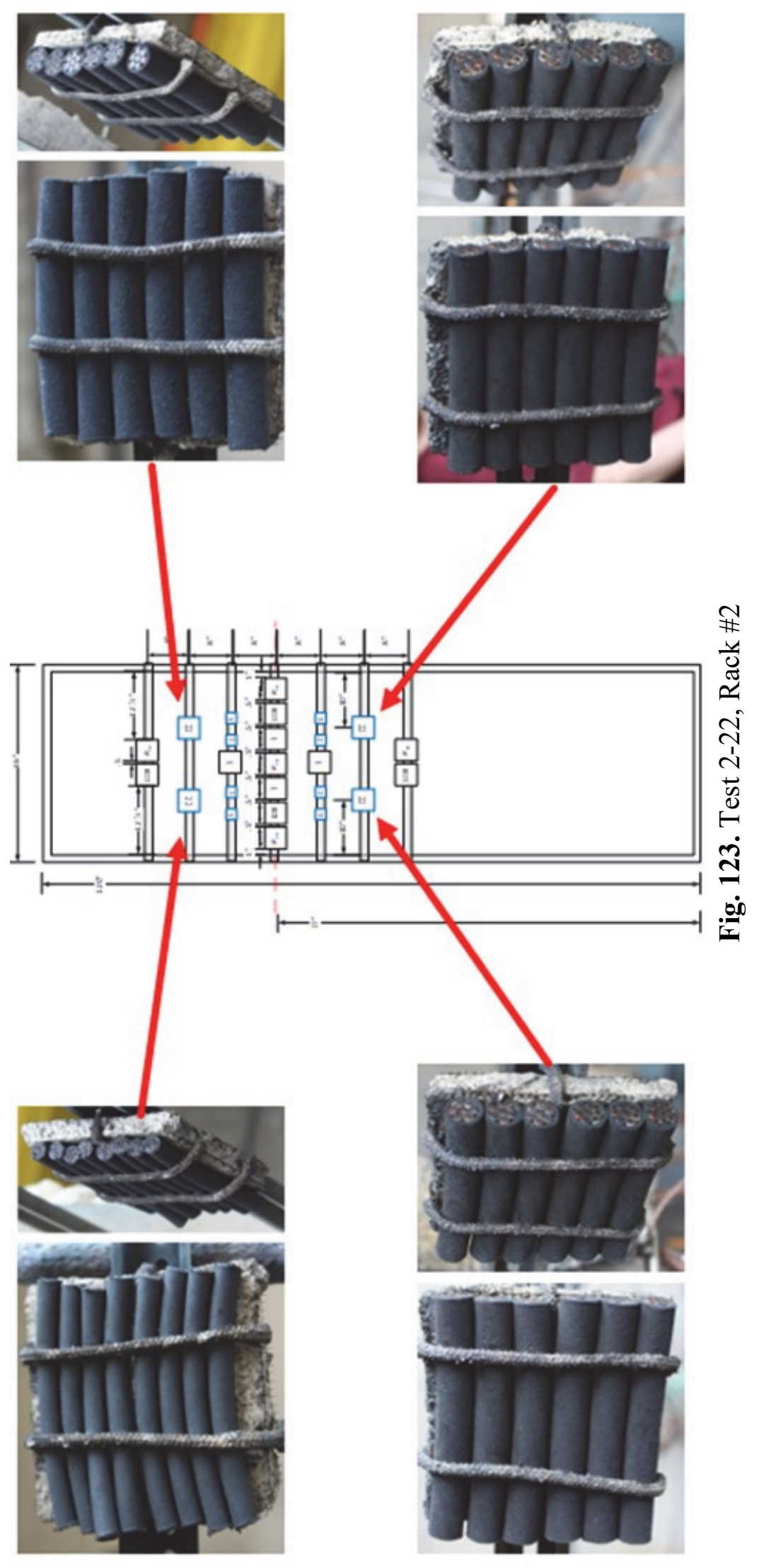



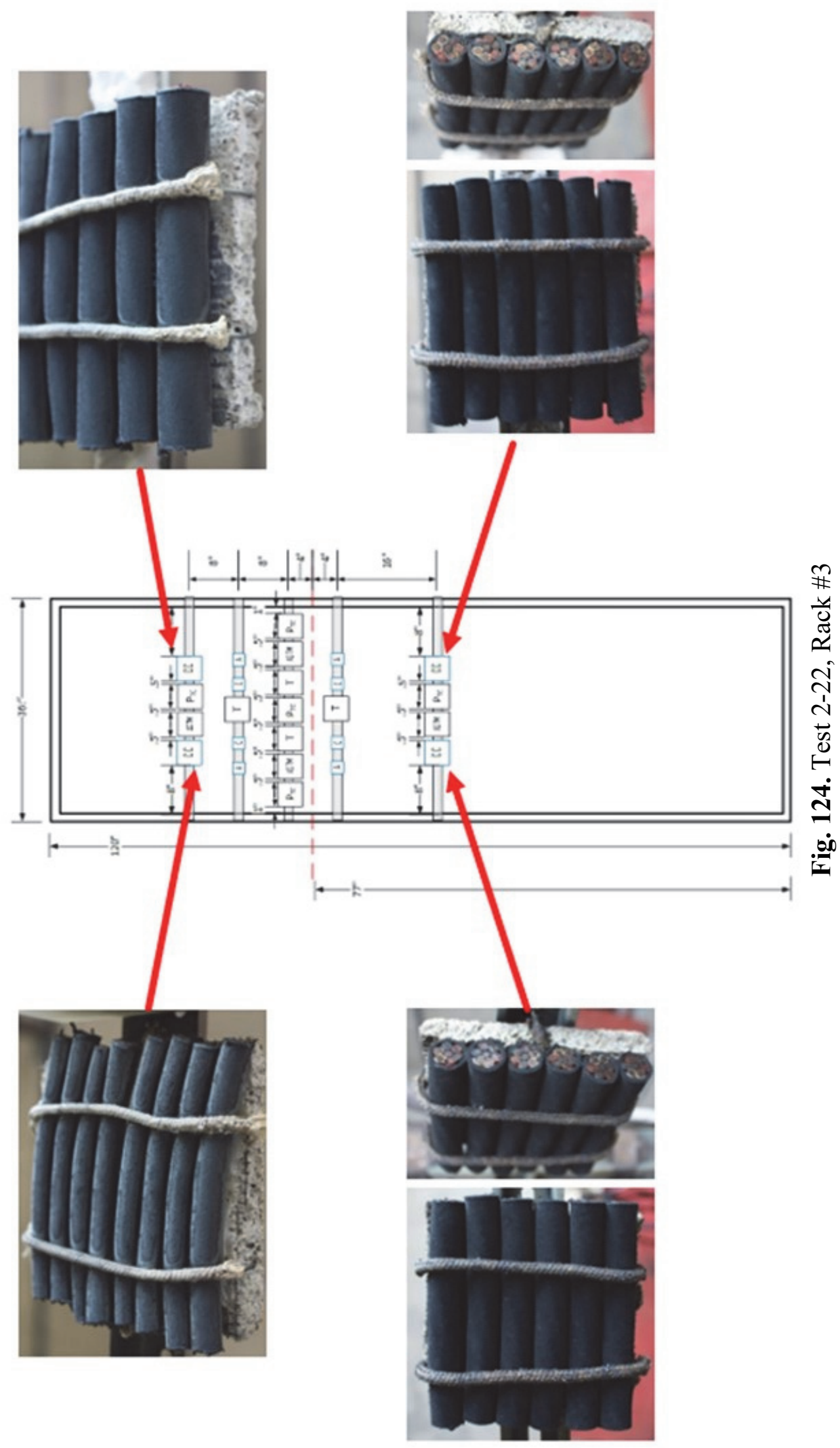


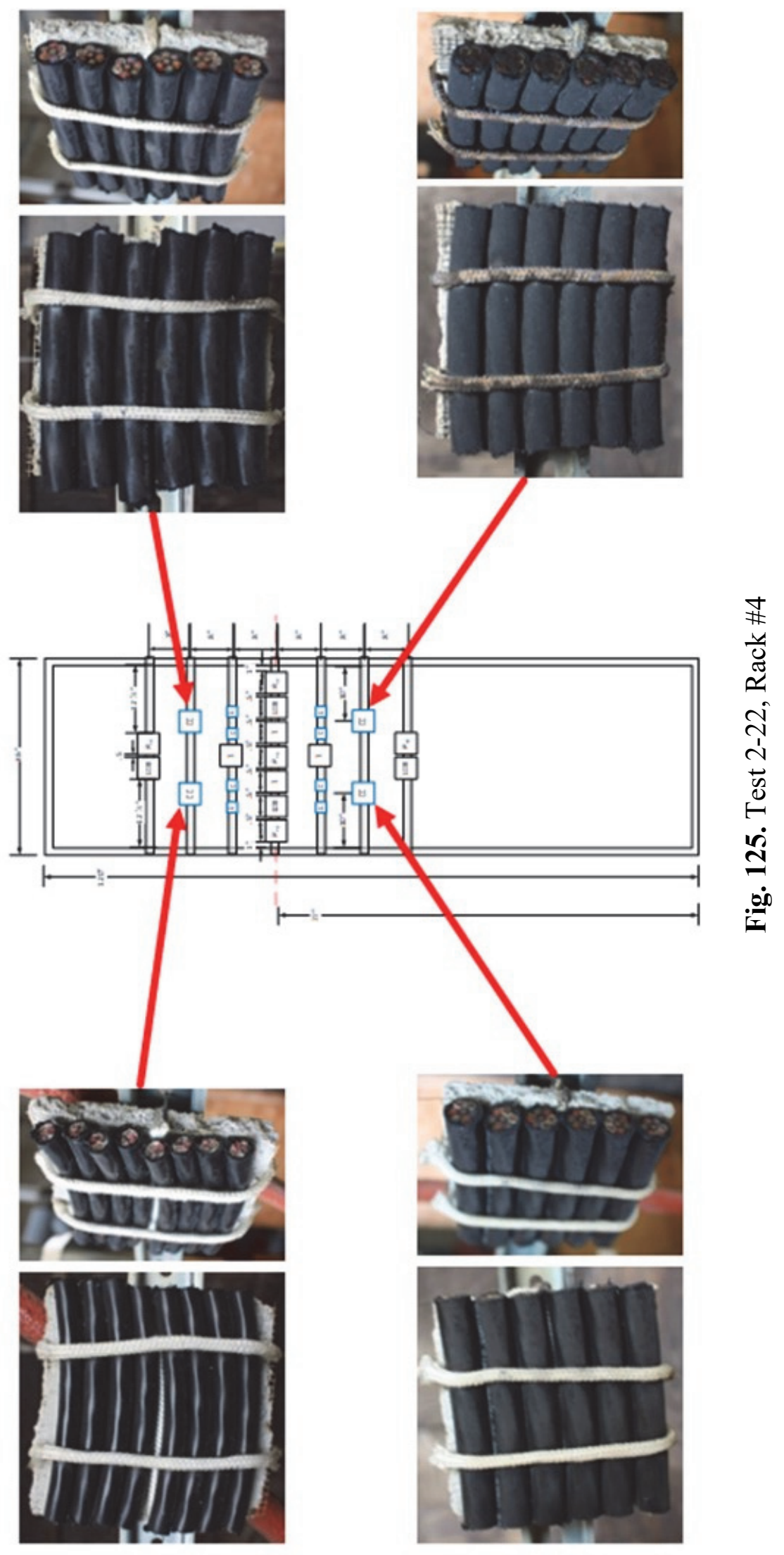




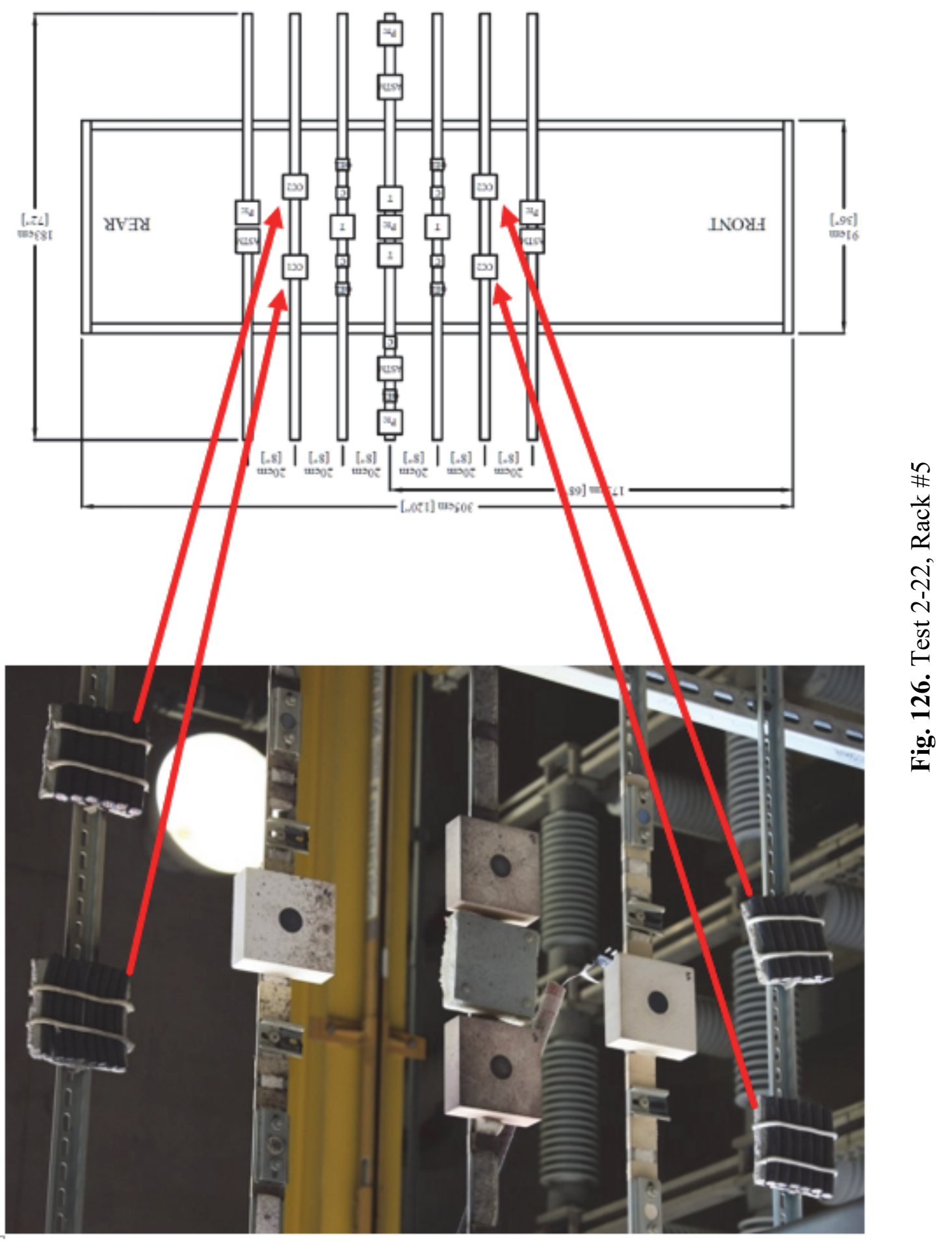

$\stackrel{2}{ }$ 


\section{E.4 Test 2-24 Rack Photographs}

Post-Test 2-24 photographs of the cable and instrument racks are shown in Fig. 127 through

Fig. 131. See the body of the report, Section 2.4, for detailed rack drawings and dimensions. 


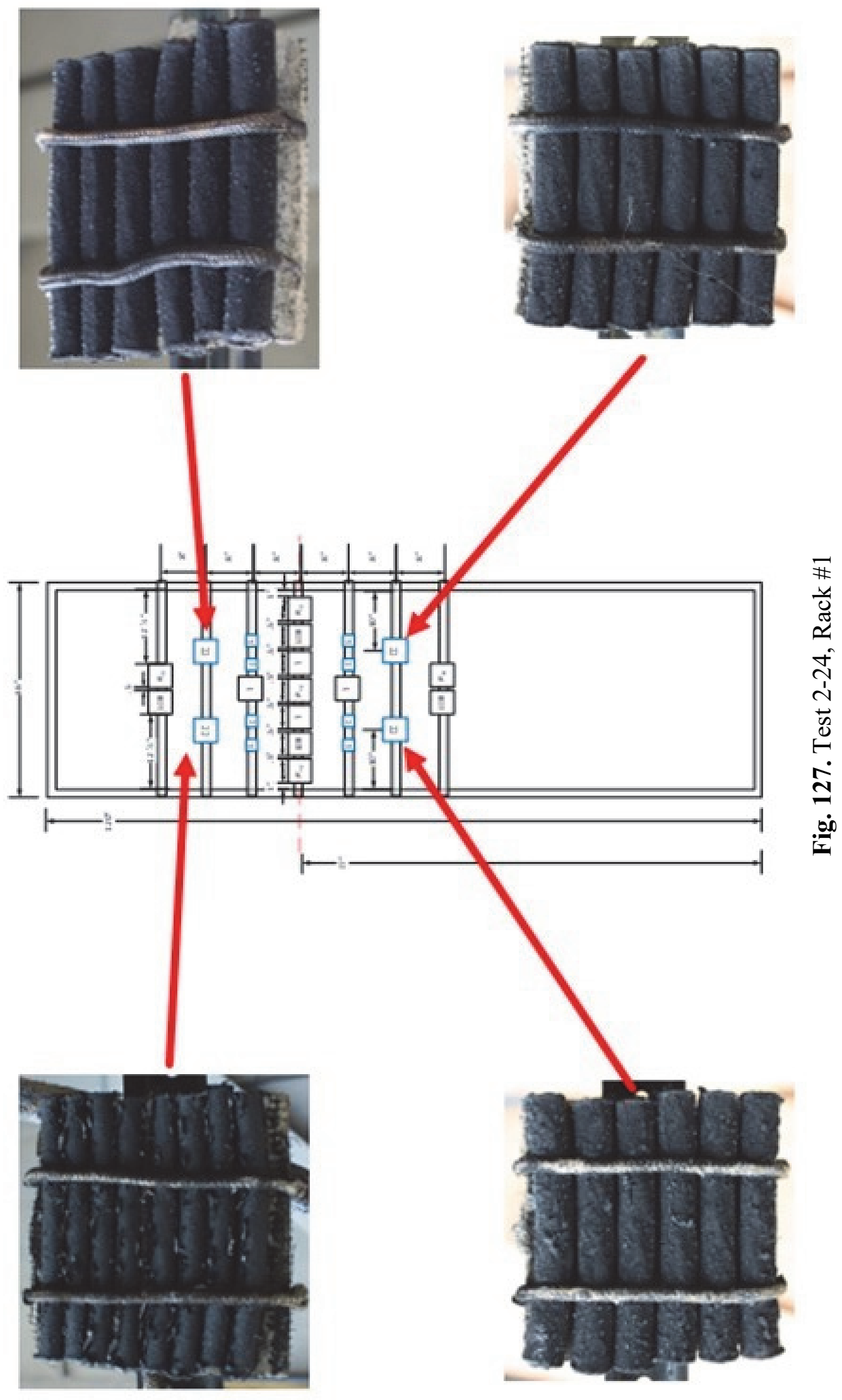




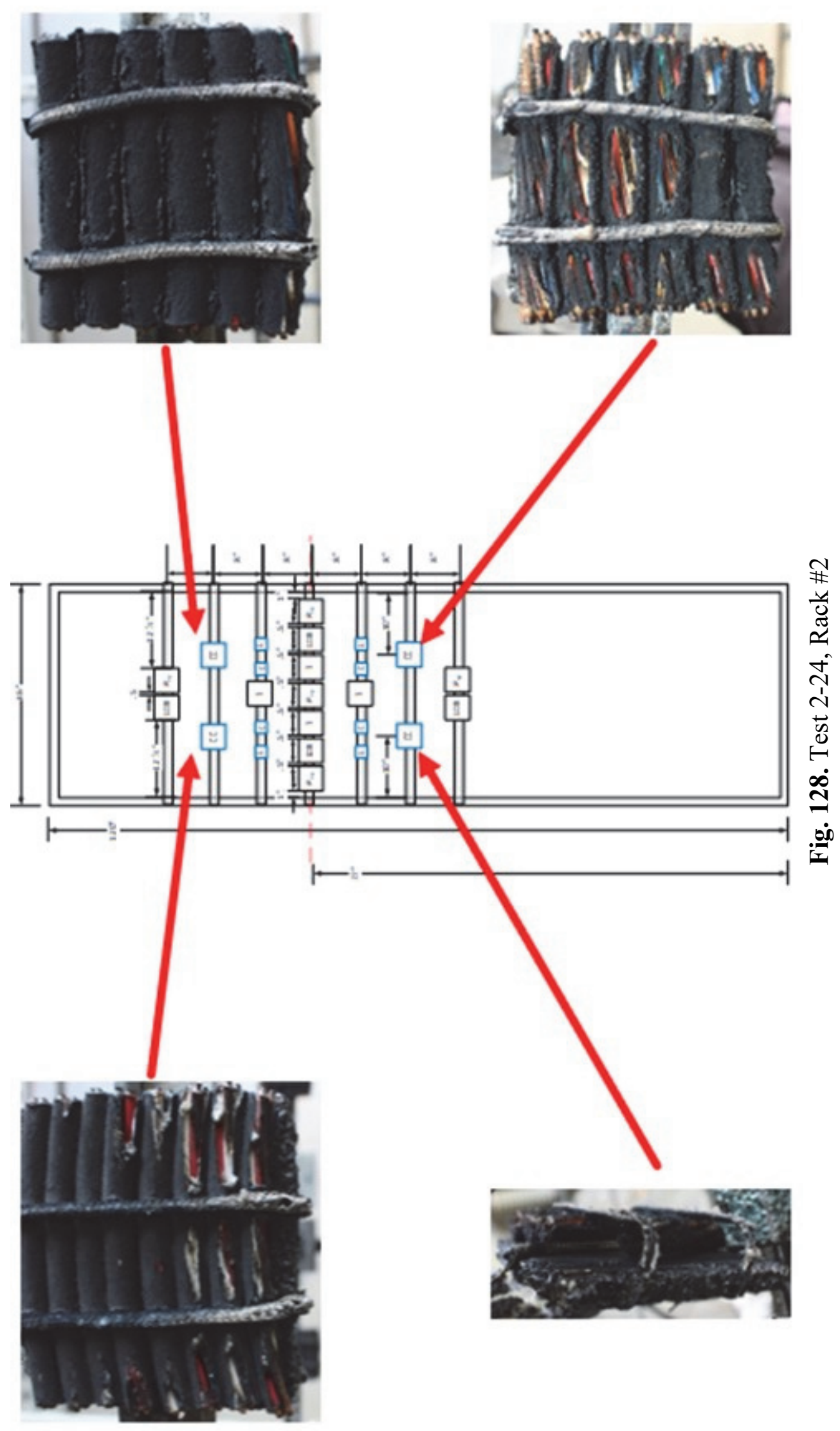




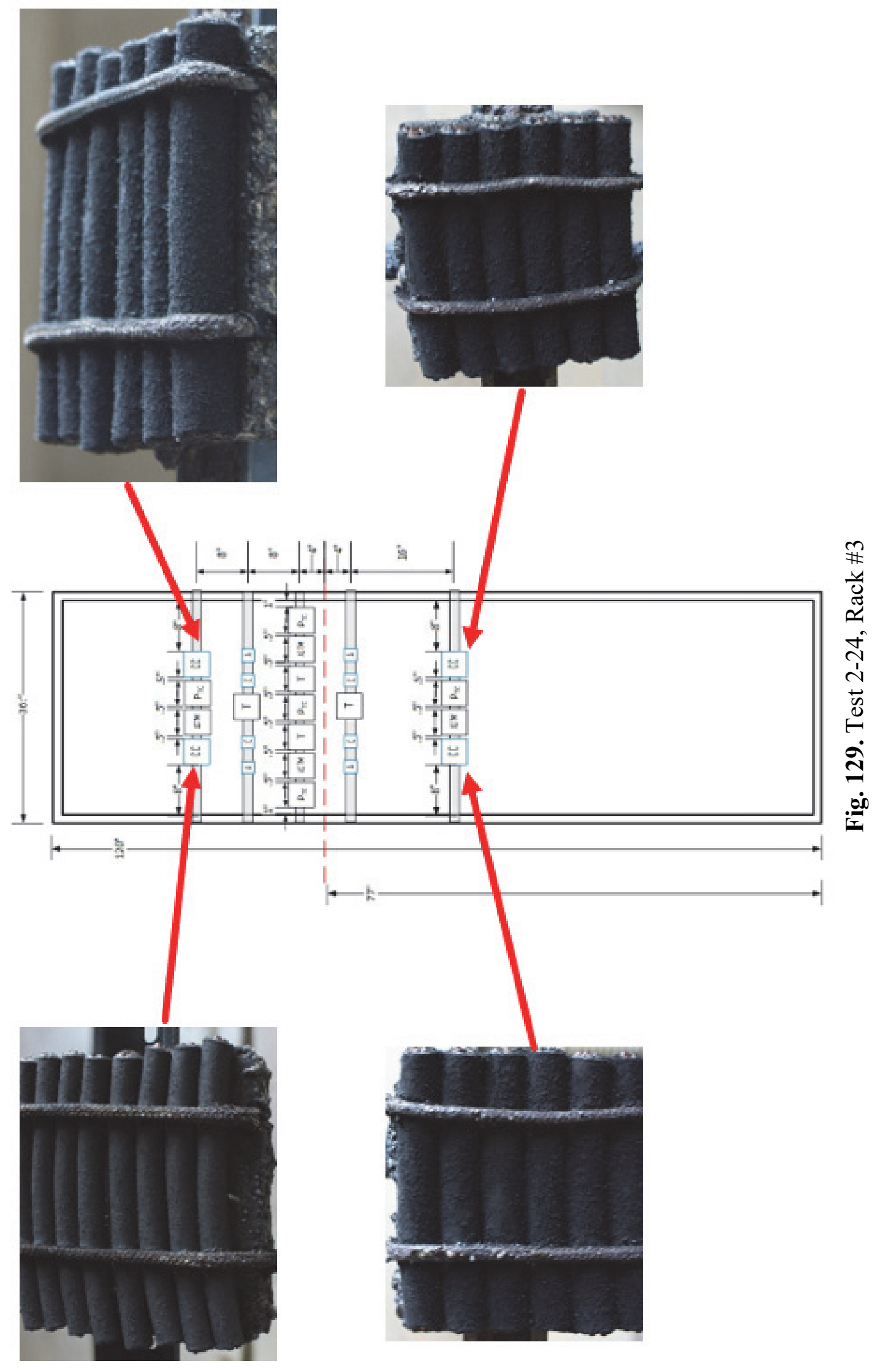




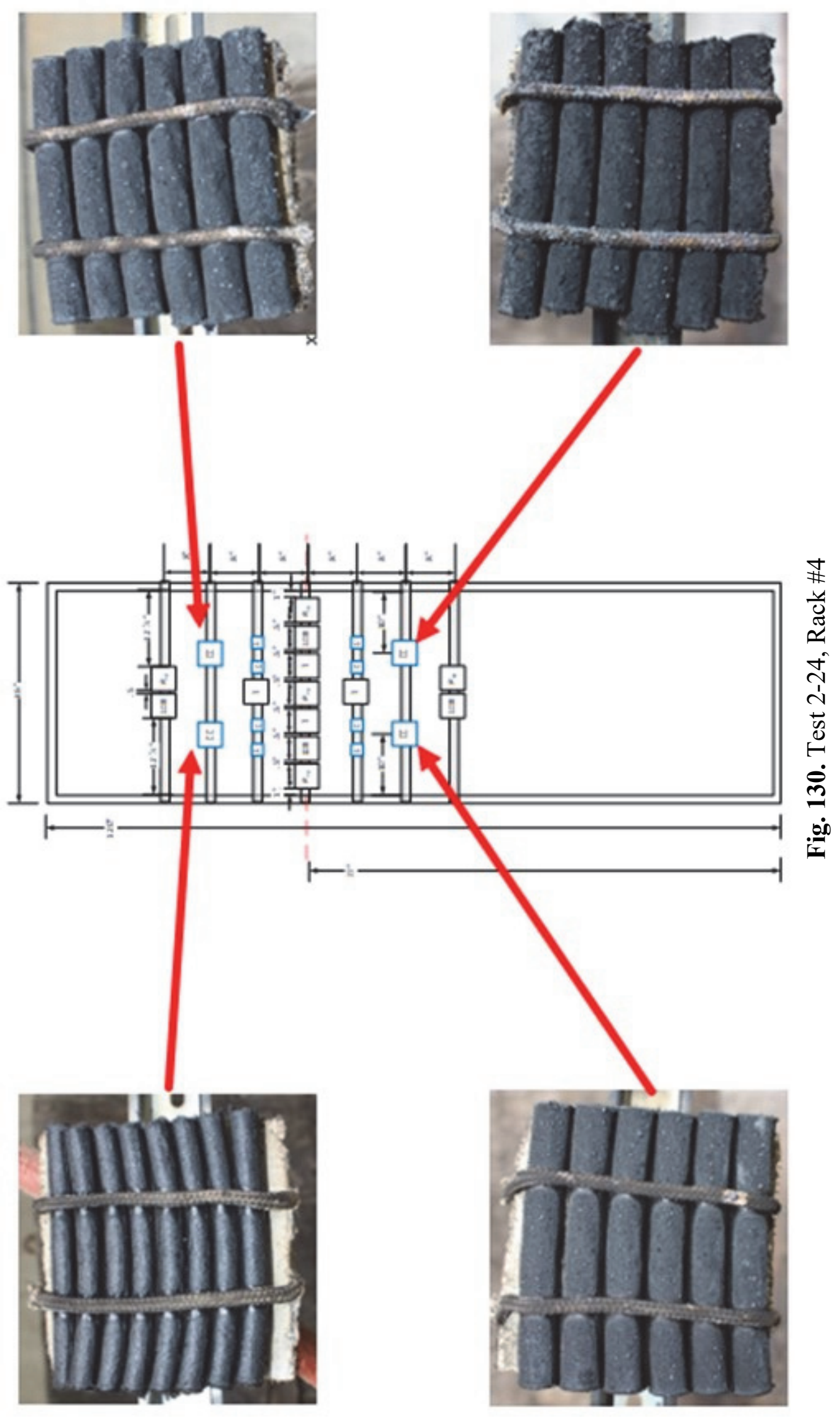




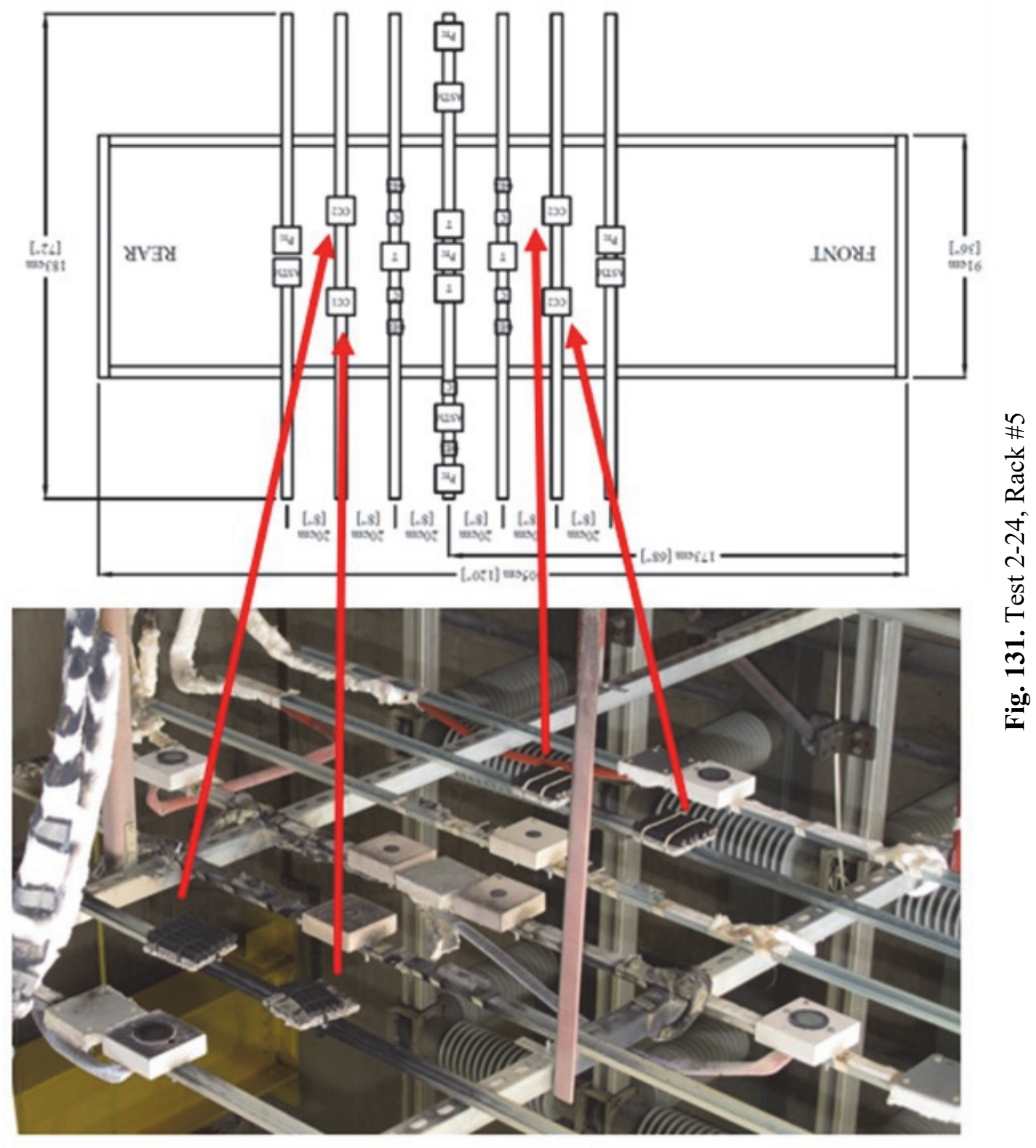




\section{References}

[D1] Taylor, G., et. al., NUREG/CP-0311, Proceedings of the Information Sharing Workshop on High Energy Arcing Fault (HEAF), U.S. Nuclear Regulatory Commission, Rockville, MD, July 2019. 


\section{Appendix E: Data Pre-Processing}

\section{Removal of outliners and data cleaning:}

As shown in Fig. 132 (black line), the temperature data obtained using thermocouples can be influenced due to electro-magnetic interference (EMI) from arcing and high current flow. To reduce the unphysical oscillations, two data pre-processing techniques (Hampel identifier [E1] and 1-D median filter [E2]) are utilized. In general, the Hampel identifier ${ }^{6}$ helps to remove outliers and the 1-D median filter ${ }^{7}$ helps suppressing noise or provides smoothing for the signal. As seen in Fig. 132 (red dashed line), the "outliners" (i.e., the two peaks) are first being replaced. The green dashed line is the final temperature data that will be used for data analysis. It should be noted that the use of only the 1-D median filter cannot effectively reduce unphysical large amplitude oscillations.

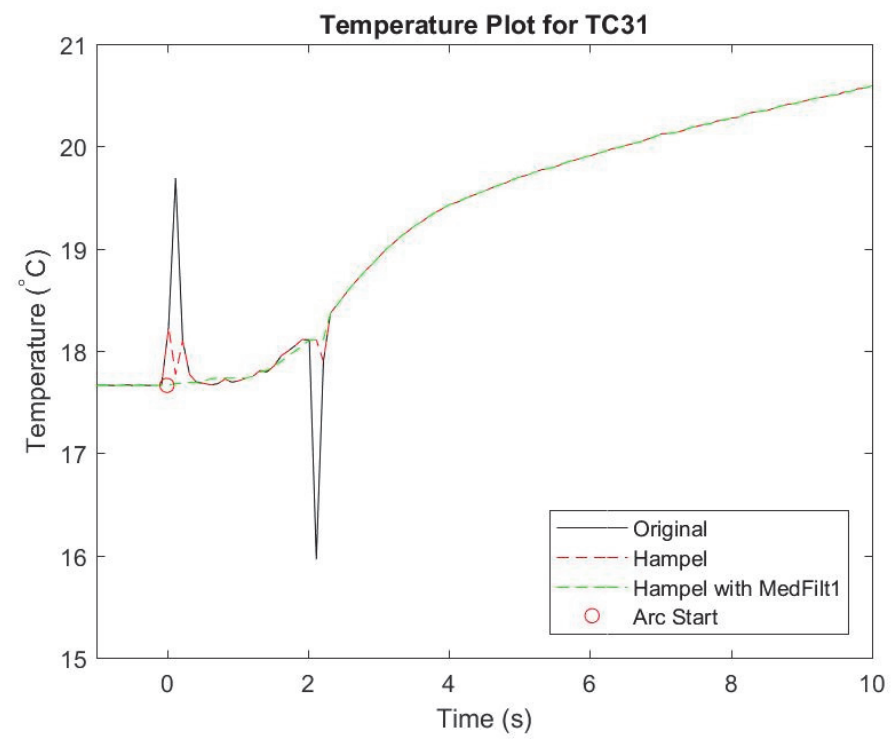

Fig. 132. Raw and filtered temperature data for Tcap 31 for Test 2-19.

\section{Determination of time for triggering, arc start, arc end, and delay:}

KEMA laboratories provided a TTL triggering signal for synchronizing the KEMA Laboratories control and data acquisition system with the NIST data acquisition system. The triggering signal channel went from low to high on the order of milliseconds (ms) prior to the KEMA breaker closing in the test cell, thereby allowing the flow of current to the electrical enclosure where the arc is initiated. The triggering time of an arc is obtained by examining the synchronization channel voltage difference associated with time $t_{i}$ and $t_{i-1}$ where $i$ is the

\footnotetext{
${ }^{6}$ Given a vector of temperature with $N$ samples of $x$, the function computes the median of a window composed of the sample and its 6 surrounding samples, 3 per side. It also estimates the standard deviation of each sample about its window median using the median absolute deviation. If a sample differs from the median by more than three standard deviations, it is replaced with the median. It should be noted that this arrangement is identical for all test cases.

${ }^{7}$ The function applies an nth-order one-dimensional median filter to $x$. In all of the test cases, a $15^{\text {th }}$ order of the one-dimensional median filter is used. For that, a median at time stamp $k, y(k)$, is obtained from $x(k-(n-1) / 2: k+(n-1) / 2)$. With the current arrangement, when $n=15$, then $y(k)$ is the median of $x(k-7: k+7)$.
} 
time index ranging from 1 to $N$ with $N$ being the maximum number of data points for an experiment. If the voltage difference is larger than $0.1 \mathrm{~V}$, an arc is determined to be triggered. It should be noted that the trigger threshold (i.e., $0.1 \mathrm{~V}$ ) is being carefully selected. In general, when an arc does not exist, the average reading from the voltage channel is about 3.47E-4 V with a standard derivation of about 2E-5 V. Fig. 133 shows the voltage plot against time from Test 2-19. The circled value is identified as triggering time.

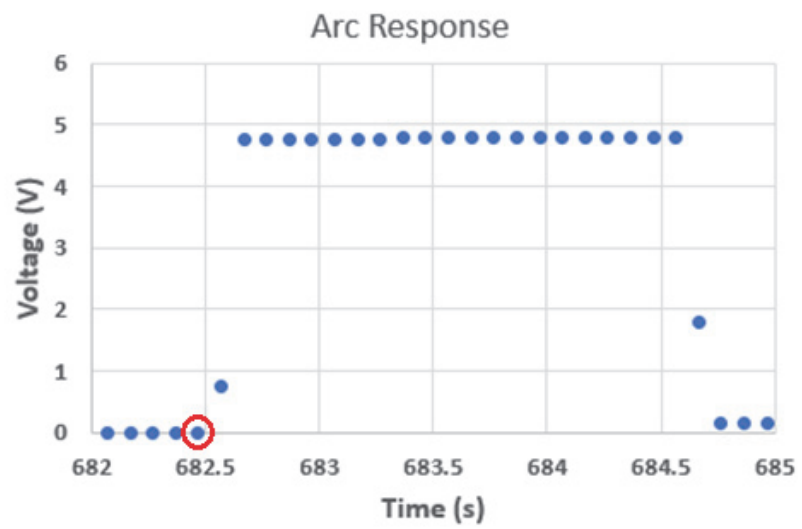

Fig. 133. Voltage vs time plot for Test 2-19.

Although fiber optic cables are used, the synchronization signal always proceeds the breaker closing by a short delay of $\mathrm{ms}$ in order to prevent EMI from obscuring the signal. The short delay is denoted as dt_trigger. Therefore, the actual arc start time will be the triggering time plus the short delay. Mathematically, it is expressed as:

$$
\text { arc start time }=\text { triggering time }+d t_{-} \text {trigger }
$$

Given an arc duration, the arc end time is then given as:

$$
\text { arc end time }=\text { arc start time }+ \text { arc duration }
$$

Similarly, the delay end time is:

$$
\text { delay end time }=\text { arc end time }+ \text { delay time }
$$

Although the determination of time associated with arc start, arc end, and delay end is trivial, the determination of the corresponding temperatures requires additional effort. This is simply due to the fact that the sampling time is not infinitesimally small (i.e., $<<1$ ). In fact, the sampling frequency is about $10 \mathrm{~Hz}$.

\section{Offset:}

For better visualization, the plots are offset relative to the arc start time. The offset time is taken to be the arc start time. 


\section{Temperature determination for triggering, arc start, arc end, and delay:}

Fig. E3 shows a table consisting of time and temperature from different channels. If any of the arc start times, arc end times, and delay end times lie between two time indices, the early time index is used as the referenced time index $\left(t_{\text {index }, i}\right)$. The corresponding temperature is then determined based on linear interpolation. An example is shown in the green box. If the arc start time is $682.80 \mathrm{~s}$, the reference time index will be selected for time at $682.7688 \mathrm{~s}$ and the interpolation time will be approximately $17.6827^{\circ} \mathrm{C}$.

\begin{tabular}{|r|r|r|r|r|r|r|r|}
\hline Test Time 0: T1 $\left({ }^{\circ} \mathrm{C}\right)$ & $1: \mathrm{T} 2\left({ }^{\circ} \mathrm{C}\right)$ & $2: \mathrm{T} 3\left({ }^{\circ} \mathrm{C}\right)$ & $3: \mathrm{T} 4\left({ }^{\circ} \mathrm{C}\right)$ & $4: \mathrm{T}\left({ }^{\circ} \mathrm{C}\right)$ & $5: \mathrm{T} 6\left({ }^{\circ} \mathrm{C}\right)$ & $6: \mathrm{T7}\left({ }^{\circ} \mathrm{C}\right)$ \\
\hline 682.669 & 17.42679 & 18.02104 & 16.95807 & 16.95699 & 17.94859 & 17.68516 & 17.84472 \\
\hline 682.7688 & 17.66423 & 18.22996 & 17.22339 & 18.03925 & 17.91451 & 17.7649 & 18.09103 \\
\hline 682.8686 & 17.72353 & 18.14528 & 17.32008 & 17.92595 & 17.977 & 17.72677 & 18.04 \\
\hline 682.9684 & 17.93206 & 18.13818 & 17.43018 & 17.96917 & 17.9833 & 17.71292 & 18.07201 \\
\hline 683.0683 & 18.11113 & 18.13446 & 17.55298 & 17.96549 & 17.99604 & 17.70887 & 18.10287 \\
\hline 683.1681 & 18.35041 & 18.13996 & 17.68795 & 17.96652 & 17.98114 & 17.71893 & 18.18558 \\
\hline 683.2679 & 18.73181 & 18.14184 & 17.91243 & 17.98207 & 17.98286 & 17.71573 & 18.32765 \\
\hline 683.3677 & 19.24259 & 18.15876 & 18.29752 & 17.98824 & 17.98092 & 17.72982 & 18.58741 \\
\hline 683.4675 & 20.01742 & 18.17694 & 19.08836 & 18.01257 & 17.98983 & 17.73775 & 18.94316 \\
\hline 683.5674 & 21.11658 & 18.1913 & 20.4048 & 17.9985 & 18.00052 & 17.75168 & 19.48025 \\
\hline
\end{tabular}

Fig. E3. Screenshot of data for raw data associated with Test 2-19.

\section{Determination of maximum temperature and its time index:}

The maximum temperature is determined based on the following relationship:

$$
\text { maximum temperature }=\max \left(T_{i}\right) \text { for } i=1 \text { to } N
$$

where $T_{i}$ is the temperature at time index $i$ and $N$ is the maximum number of data points for each experiment. Similarly, the time index $i$ that corresponds to the maximum temperature is donated as $i_{\max }$ which is the time index for maximum temperature.

\section{Background temperature:}

Background temperature is the corresponding temperature for the triggering time. Even though data pre-processing techniques are applied to help reduce unphysical oscillation, small fluctuation due to noise still exist. In order to eliminate biases associated with the fluctuations, a mean temperature is obtained based on a window of temperature points. The window size is selected to be 20 which is equivalent to be about 2 seconds worth of data. The original temperature for the triggering time and all temperature points prior to the triggering time are replaced with the background temperature. Note that no analysis is carried out for any of the background temperatures.

\section{Remarks}

It should be noted that all the above data pre-processing steps are applied and are identical to data associated with both HEAF devices [E3, E4]: Tcap slug and plate thermometer. 


\section{References}

E1. Liu, Hancong, Sirish Shah, and Wei Jiang. "On-line outlier detection and data cleaning." Computers and Chemical Engineering. Vol. 28, March 2004, pp. 1635-1647.

E2. Pratt, William K. Digital Image Processing. 4th Ed. Hoboken, NJ: John Wiley \& Sons, 2007

E3. NEA/CSNI/R(2017)7, "Report on the Testing Phase (2014-2016) of the High Energy Arcing Fault Events (HEAF) Project - Experimental Results from the International Energy Arcing Fault Research Programme," Nuclear Energy Agency, 2017.

E4. Putorti, Anthony, Nicholas B. Melly, Scott Bareham, and Joseph Praydis Jr. "Characterizing the Thermal Effects of High Energy Arc Faults." In 23rd International Conference on Structural Mechanics in Reactor Technology (SMiRT 23)-14th International Post Conference Seminar on Fire Safety in Nuclear Power Plants and Installations. 2015. 


\section{Appendix F: Tcap Heat Transfer Analysis}

Fig. 134 shows the plot of heat transfer rate for Tcap 20 in Test 2-19. The plot consists of a number of outputs: 1) the maximum heat transfer rate (HTR), 2) the rate of change of temperature, 3) the maximum incident flux, 4) the average incident flux, and 5) the average incident energy. Details for the determination of each parameter are given below.

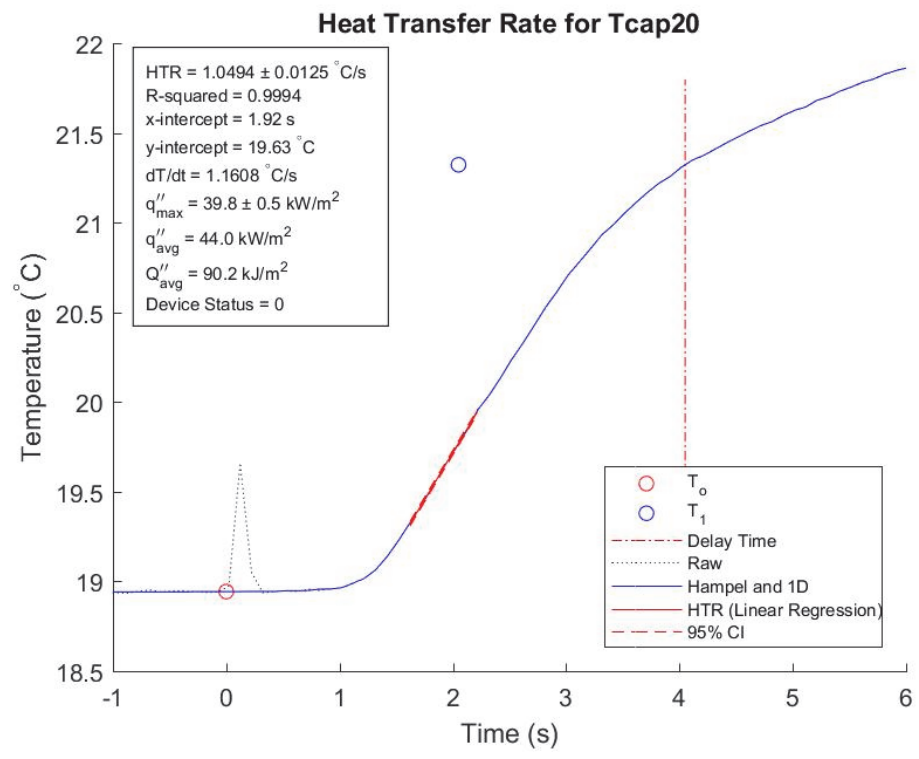

Fig. 134. Plot for outputs associated with TC 20 for Test 2-19.

\section{Incident heat flux and energy flux:}

Incident heat flux onto the slug surface can be determined at each time step using the initial temperature, $T_{0}$, the final temperature, $T_{1}$, and the average heat capacity, $\bar{C}_{p}$, by using the following relationship [F1]:

$$
q^{\prime \prime}=\frac{m \bar{C}_{p}}{A} \frac{\left(T_{1}-T_{0}\right)}{\left(t_{1}-t_{0}\right)}
$$

where $m$ is the mass of the material, $A$ is the cross-sectional area of the slug, and $t$ is the time. The average heat capacity is evaluated as:

$$
\bar{C}_{p}=\frac{C_{p}\left(T_{1}\right)-C_{p}\left(T_{0}\right)}{2}
$$

The heat capacity of a material, such as tungsten, as a function of time can be obtained in [F2, F3]. Introducing the heat transfer rate, HTR, Eqn. F1 can be simplified as:

$$
q^{\prime \prime}=\frac{m \bar{C}_{p}}{A} H T R
$$


for

$$
H T R=\frac{\left(T_{1}-T_{0}\right)}{\left(t_{1}-t_{0}\right)}
$$

In practical scenarios, the incident heat flux can be better interpreted using the density and the thickness of the material. Rewriting the above expression with density and thickness, the expression yields:

$$
q^{\prime \prime}=\rho \bar{C}_{p} \delta H T R
$$

where $\delta$ is the thickness of the material. Similarly, the energy flux, $Q$ ”, is:

$$
Q^{\prime \prime}=\rho \bar{C}_{p} \delta H T R\left(t_{1}-t_{0}\right)
$$

\section{Maximum HTR:}

The HTR can be understood as the rate of change of temperature with respect to time (slope in two temperature points). In various engineering applications, the maximum HTR, HTR max $_{\text {, }}$ is the parameter of interest. In our analysis, the $H T R_{\max }$ is obtained as:

$$
H T R_{\max }=\max \left(H T R_{i}\right)
$$

where the $H T R_{i}$ as each time step is first determined:

$$
H T R_{i}=\frac{\left(T_{i+w}-T_{i}\right)}{\left(t_{i+w}-t_{i}\right)} \quad \text { for } \quad w=1,2, \ldots, N-w
$$

where $w$ is the number of time indices in between the two time steps and it is typically selected depending on the data behavior.

Theoretically, when temperature measurements are smooth, Eqn. (F7) and (F8) will yield the maximum HTR. However, measurements often have fluctuations of different magnitudes. Fig. 135 show the zoom-in temperature profiles for two different example cases in which there is noise in the temperature measurement near arc-end. As shown in Fig. 135 the noise in the temperature data is relatively small whereas the noise in the temperature data in Fig. 135 is larger. In order to account for the contribution of each data point within the time window (i.e., $2 * w+1$ ) for the determination of $H T R_{i}$, a fitting procedure is carried out. Specifically, a linear regression is utilized to determine the $H T R_{i}$. A commonly used MATLAB ${ }^{8}$ function, $1^{\text {st }}$ order polyfit, is applied to the data. It should be noted that the window size, $w$, is being carefully selected such that the HTR best captures the localized heat transfer effect without being greatly affected by the data fluctuations from electromagnetic

${ }^{8}$ Certain commercial products are identified in this paper in order to specify adequately the equipment used. Such identification does not imply recommendation by the National Institute of Standards and Technology, nor does it imply that this equipment is the best available for the purpose. 
interference. For all experiments in this current study, the window size is determined to be 3 data points and the time window is 7 data points.
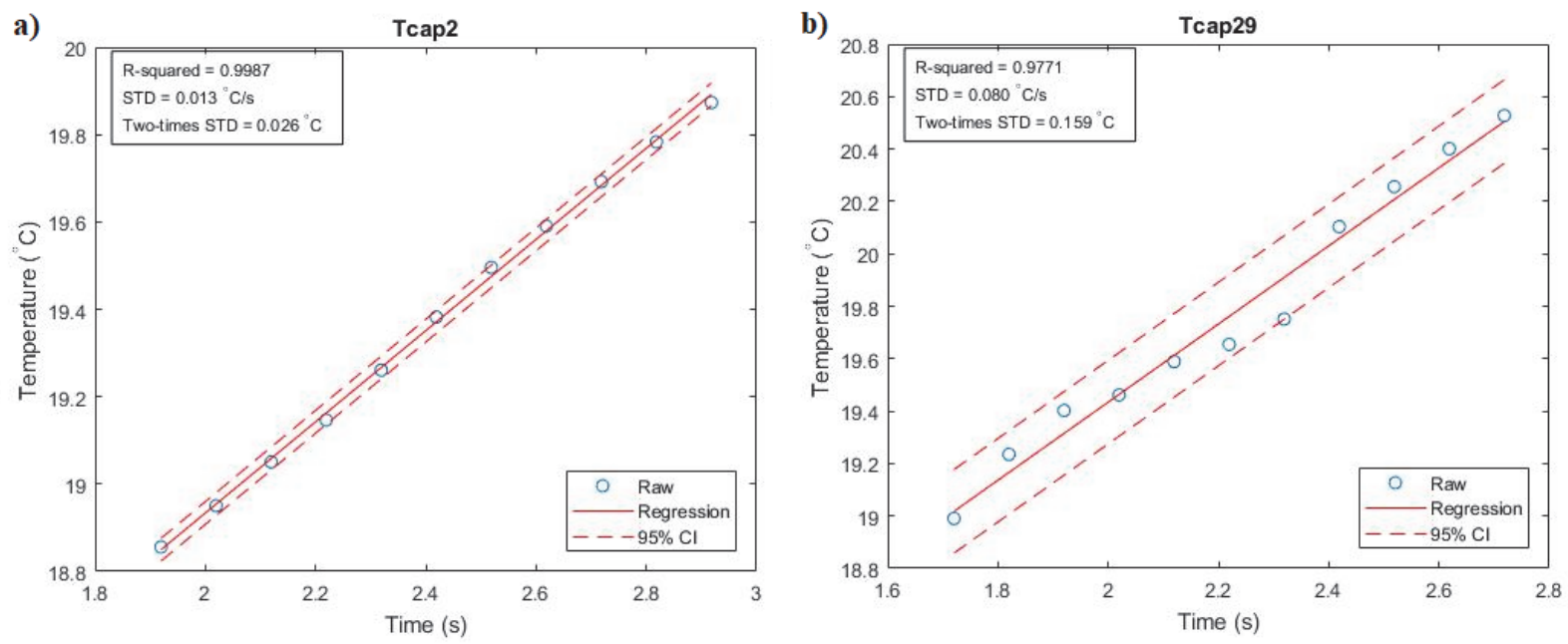

Fig. 135. Raw data, linear regression, and 95\% confidence interval for a) Tcap 2 and b) Tcap 29 for Test 2-19.

\section{Goodness-of fit measure (R-squared) [F4]:}

In the current study, R-squared is the percentage of dependent variable variation that a linear model explains and it is given as:

$$
R^{2}=1-\frac{\sum_{i}\left(y_{i}-y_{f, i}\right)^{2}}{\sum_{i}\left(y_{i}-\bar{y}\right)^{2}}
$$

where $y_{i}$ is the measurement, $y_{f, i}$ is the predicted value from the fitted model, and $\bar{y}$ is the mean value of $y_{i}$.

\section{Uncertainty to maximum HTR [F4]:}

Given the raw data and the linear regression provided in Fig. 135, the uncertainty associated with the linear model is taken to be the standard derivation or the square root of the variance, $s$, and it is defined as:

$$
s^{2}=\left(\frac{1}{n-2}\right) \sum_{i=1}^{n}\left(y_{i}-y_{f, i}\right)^{2}
$$

where $\mathrm{n}$ is the complete time window (i.e., $\mathrm{n}=7$ ). The $95 \%$ confidence interval $(\mathrm{CI})$ on the linear model is:

$$
95 \% C I \cong H T R_{\max } \pm 2 s
$$




\section{Maximum incident heat flux:}

The maximum incident heat flux, $q^{\prime \prime}$ max , is evaluated as:

$$
q^{\prime \prime m a x}=\rho \bar{C}_{p} \delta H T R_{\max }
$$

\section{Average incident heat flux over arc:}

The average incident heat flux over the arc, $q^{\prime \prime}{ }_{\text {over_arc }}$, is obtained to evaluate the average heat transfer from the arc start time to the delay end time. Instead of using the temperature at the arc end time, the temperature at the delay end time is utilized to account for the thermal penetration of a material with a finite thickness (instrument response time). Therefore, the average incident heat flux is expressed as:

$$
q_{\text {over_arc }}^{\prime \prime}=\rho \delta \frac{C_{p}\left(T_{\text {delay }}\right)-C_{p}\left(T_{\text {arc_start }}\right)}{2} \frac{\left(T_{\text {delay_end }}-T_{\text {arc_start }}\right)}{\left(t_{\text {arc_end }}-t_{\text {arc_start }}\right)}
$$

Similarly, the average energy flux is:

$$
Q{ }_{\text {over_arc }}=\rho \delta \frac{C_{p}\left(T_{\text {delay }}\right)-C_{p}\left(T_{\text {arc_start }}\right)}{2}\left(T_{\text {delay_end }}-T_{\text {arc_start }}\right)
$$

\section{Energy flux over experiment (total incident energy):}

This quantity captures the heat transfer effect between the maximum temperature of the experiment and the arc start temperature:

$$
Q{ }_{\text {over_test }}=\rho \delta \frac{C_{p}\left(T_{\max }\right)-C_{p}\left(T_{\text {arc_start }}\right)}{2}\left(T_{\max }-T_{\text {arc_start }}\right)
$$

The 'energy flux over the experiment' is reported as 'total incident energy' in this report. This is done to be consistent with the customary reporting of results of the calorimeter devices described in ASTM F1959 for rating arc flash protective clothing [F5].

\section{Unit Conversion:}

A unit conversion is applied to convert SI units $\left(\mathrm{W} / \mathrm{m}^{2}\right)$ to British units $\left(\mathrm{cal} /\left[\mathrm{s} \cdot \mathrm{cm}^{2}\right]\right)$ and the conversion factor is:

$$
1 \mathrm{cal} /\left[\mathrm{s} \cdot \mathrm{cm}^{2}\right]=41870.0 \mathrm{~W} / \mathrm{m}^{2}
$$




\section{Properties for Tungsten [F2, F3]:}

\begin{tabular}{|c|c|c|c|}
\hline Density & Thickness & $\begin{array}{c}\text { Cross-sectional } \\
\text { Area }\end{array}$ & Conductivity \\
\hline $\mathrm{kg} / \mathrm{m}^{3}$ & $\mathrm{~m}$ & $\mathrm{~m}^{2}$ & $\mathrm{~W} /[\mathrm{m} \cdot \mathrm{K}]$ \\
\hline 19250 & 0.015 & $5.07 \mathrm{E}-04$ & 170 \\
\hline
\end{tabular}

\begin{tabular}{|c|c|c|c|c|c|c|c|c|c|c|c|}
\hline Temperature & $\mathrm{C}$ & -72 & 27 & 127 & 327 & 527 & 727 & 927 & 1227 & 1727 & 2227 \\
\hline $\begin{array}{c}\text { Heat } \\
\text { Capacitance }\end{array}$ & $\mathrm{J} / \mathrm{(kg} \cdot \mathrm{K})$ & 122 & 132 & 137 & 142 & 145 & 148 & 152 & 157 & 167 & 176 \\
\hline
\end{tabular}

\section{References}

F1. ASTM E457-08(15) Standard Test Method for Measuring Heat-Transfer Rate Using a Thermal Capacitance (Slug) Calorimeter, ASTM International, West Conshohocken, PA, 2015, www.astm.org

F2. JANAF Thermochemical Tables, https://janaf.nist.gov/tables/W-001.html, accessed February 17, 2021.

F3. Basic Atomic Spectroscopic Data, https://www.physics.nist.gov/PhysRefData/Handbook/tables/tungstentable1.htm, accessed February 17, 2021.

F4. Morrison, F.A., 2014. Obtaining uncertainty measures on slope and intercept of a least squares fit with Excel's LINEST. Houghton, MI: Department of Chemical Engineering, Michigan Technological University. Retrieved August 6 2020, p.2015.

F5. ASTM Standard F1959 / F1959M-14, 2014, "Standard Test Method for Determining the Arc Rating of Materials for Clothing," ASTM International, West Conshohocken, PA, 2014. 


\section{Appendix G: Plate Thermometer Heat Transfer Analysis}

Fig. 136 shows the instantaneous gauge heat flux onto the plate thermometer (PT) 21 for Test 2-19.

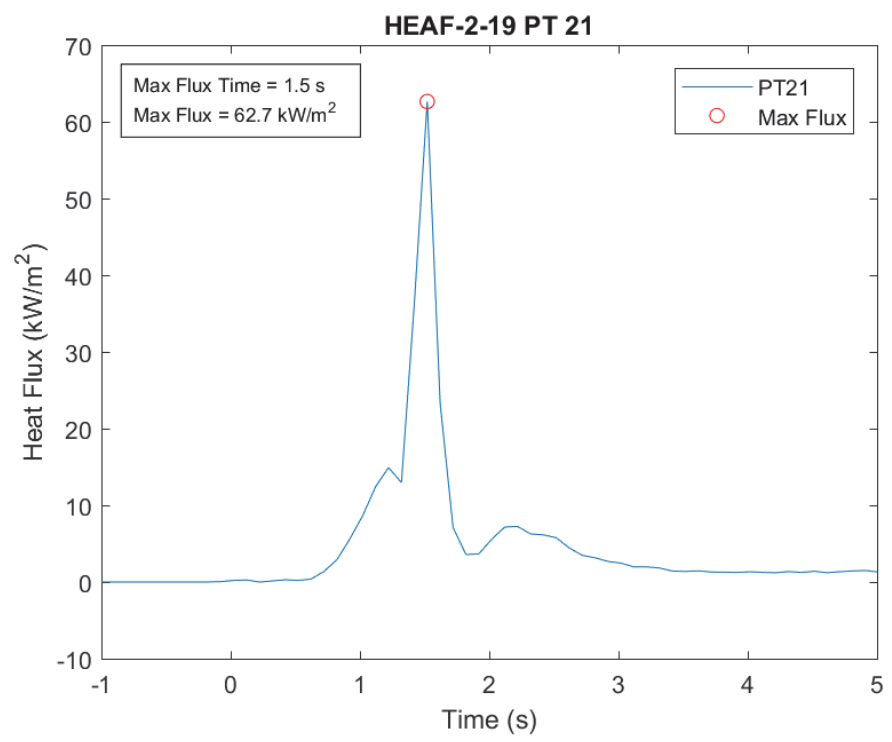

Fig. 136. Instantaneous gauge heat flux for PT 21 for Test 2-19

\section{Incident heat flux:}

Based on Ingason and Wickstrom [G1], the heat flux, $\dot{q}_{1}{ }^{\prime \prime}$, is given as:

$$
\begin{aligned}
\dot{q}_{1}{ }^{\prime}=\sigma T_{P T, i}^{4}+ & \frac{1}{\varepsilon_{P T}} h_{P T}\left(T_{P T, i}-T_{\infty}\right)+\frac{1}{\varepsilon_{P T}} K_{P T}\left(T_{P T, i}-T_{\infty}\right) \\
& +\frac{\rho_{P T} \delta C_{P T}}{\varepsilon_{P T}}\left(\frac{T_{P T, i}-T_{P T, i-1}}{t_{i}-t_{i-1}}\right)
\end{aligned}
$$

where $\sigma$ is the Stefan-Boltzmann Constant, $T_{P T}$ is the temperature of the plate, $h_{P T}$ is the convective heat transfer coefficient, $K_{P T}$ is the conduction correction factor, $T_{\infty}$ is the ambient temperature, $\varepsilon P T$ is the plate emissivity, $\rho_{P T}$ is the plate density, $C_{P T}$, is the plate heat capacity, $\delta$ is the plate thickness, and $t_{i}$ is the time at $i$ time index. It should be noted that the conduction correction factor and convection heat transfer coefficient are experimentally determined. The summary of the properties are provided in the table below. 


\section{Instantaneous gauge heat flux:}

The instantaneous gauge heat flux as shown in Fig. 136 is given as:

$$
\begin{aligned}
\dot{q}_{2} "=\sigma T_{P T, i}^{4}+ & \frac{1}{\varepsilon_{P T}} h_{P T}\left(T_{P T, i}-T_{\infty}\right)+\frac{1}{\varepsilon_{P T}} K_{P T}\left(T_{P T, i}-T_{\infty}\right) \\
& +\frac{\rho_{P T} \delta C_{P T}}{\varepsilon_{P T}}\left(\frac{T_{P T, i}-T_{P T, i-1}}{t_{i}-t_{i-1}}\right)-\sigma T_{\text {gauge }}^{4}
\end{aligned}
$$

\section{Average gauge heat flux during arcing phase (in Excel):}

The average gauge heat flux, $q^{\prime \prime}{ }_{2, a v g}$, is obtained to evaluate the average effect of heat transfer in between arc start time and delay end time. For that, the average gauge heat flux is expressed as:

$$
\begin{aligned}
q_{2, \text { avg,arc }}^{\prime \prime}= & \sigma T_{P T, \text { delay_end }}^{4}+\frac{1}{\varepsilon_{P T}} h_{P T}\left(T_{P T, \text { delay_end }}-T_{\infty}\right) \\
& +\frac{1}{\varepsilon_{P T}} K_{P T}\left(T_{P T, \text { delay_end }}-T_{\infty}\right) \\
& +\frac{\rho_{P T} \delta C_{P T}}{\varepsilon_{P T}}\left(\frac{T_{P T, \text { delay_end }}-T_{P T, \text { arc_start }}}{t_{\text {arc_end }}-t_{\text {arc_start }}}\right)-\sigma T_{\text {gauge }}^{4}
\end{aligned}
$$

It should be noted that the determination of arc start time, arc delay time and their corresponding temperature is identical to that shown in Appendix E.

\section{Average gauge heat flux over experiment (in Excel):}

The average gauge heat flux, $q^{\prime \prime}{ }_{2, a v g}$, is obtained to evaluate the average effect of heat transfer from the arc start time to the time associated with maximum temperature. Therefore, the average gauge heat flux is expressed as:

$$
\begin{aligned}
q_{2, \text { avg,test }}= & \sigma T_{P T, \max }^{4}+\frac{1}{\varepsilon_{P T}} h_{P T}\left(T_{P T, \max }-T_{\infty}\right)+\frac{1}{\varepsilon_{P T}} K_{P T}\left(T_{P T, \max }-T_{\infty}\right) \\
& +\frac{\rho_{P T} \delta C_{P T}}{\varepsilon_{P T}}\left(\frac{T_{P T, \max }-T_{P T, \text { arc_start }}}{t_{\text {max }}-t_{\text {arc_start }}}\right)-\sigma T_{\text {gauge }}^{4}
\end{aligned}
$$

It should be noted that the determination of maximum temperature and its time index is identical to that shown in Appendix E.

Properties for Inconel 600 [G2, G3]:

\begin{tabular}{|c|c|c|c|c|c|c|}
\hline Density & Thickness & $\begin{array}{c}\text { Cross- } \\
\text { sectional } \\
\text { Area }\end{array}$ & $\begin{array}{c}\text { Heat } \\
\text { Capacitance }\end{array}$ & $\begin{array}{c}\text { Conduction } \\
\text { Correction } \\
\text { Factor }\end{array}$ & $\begin{array}{c}\text { Convection } \\
\text { Coefficient }\end{array}$ & $\begin{array}{c}\text { Surface } \\
\text { Emissivity }\end{array}$ \\
\hline $\mathrm{kg} / \mathrm{m}^{3}$ & $\mathrm{~m}$ & $\mathrm{~m}^{2}$ & $\mathrm{~J} /(\mathrm{kg} \cdot \mathrm{K})$ & $\mathrm{W} /(\mathrm{m} \cdot \mathrm{K})$ & $\mathrm{W} /\left(\mathrm{m}^{2} \mathrm{~K}\right)$ & $(-)$ \\
\hline 7470 & $7.90 \mathrm{E}-04$ & $1.0323 \mathrm{E}-02$ & $5.0200 \mathrm{E}+02$ & 4 & 10 & 0.85 \\
\hline
\end{tabular}




\section{Reference}

G1. Ingason, H. and Wickström, U., 2007. Measuring incident radiant heat flux using the plate thermometer, Fire Safety Journal, Vol. 42, No. 2, pp. 161-166.

G2. NEA/CSNI/R(2017)7, "Report on the Testing Phase (2014-2016) of the High Energy Arcing Fault Events (HEAF) Project - Experimental Results from the International Energy Arcing Fault Research Programme,” Nuclear Energy Agency, 2017.

G3. Putorti, Anthony, Nicholas B. Melly, Scott Bareham, and Joseph Praydis Jr. "Characterizing the Thermal Effects of High Energy Arc Faults." In 23rd International Conference on Structural Mechanics in Reactor Technology (SMiRT 23)-14th International Post Conference Seminar on Fire Safety in Nuclear Power Plants and Installations. 2015. 


\section{Appendix H: KEMA Test Report}

This appendix provides a copy of KEMA test report. 


\section{KEMA TEST REPORT}

\section{4-B}

Object

Type

Client

Manufacturer

Tested by

Date of tests

Test specification The tests have been carried out in accordance with client's instructions.
Medium Voltage Switchgear

Medium Voltage Switchgear

$6.9 \mathrm{kV}-25 / 32 \mathrm{kA}-60 \mathrm{~Hz}$

U.S. Nuclear Regulatory Commission

Washington, DC, USA

U.S. Nuclear Regulatory Commission Washington, DC, USA *)

KEMA-Powertest LLC, 4379 County Line Road Chalfont, PA 18914, USA

10, 11, 12 and 13 September 2018
Serial No. Various 


\section{NFORMATI ON SHEET}

\section{$1 \quad$ KEMA Type Test Certificate}

A KEMA Type Test Certificate contains a record of a series of (type) tests carried out in accordance with a recognized standard. The object tested has fulfilled the requirements of this standard and the relevant ratings assigned by the manufacturer are endorsed by DNV GL. In addition, the object's technical drawings have been verified and the condition of the object after the tests is assessed and recorded. The Certificate contains the essential drawings and a description of the object tested. A KEMA Type Test Certificate signifies that the object meets all the requirements of the named subclauses of the standard. It can be identified by gold-embossed lettering on the cover and a gold seal on its front sheet.

The Certificate is applicable to the object tested only. DNV GL is responsible for the validity and the contents of the Certificate. The responsibility for conformity of any object having the same type references as the one tested rests with the manufacturer.

Detailed rules on types of certification are given in DNV GL's Certification procedure applicable to KEMA Laboratories.

\section{KEMA Report of Performance}

A KEMA Report of Performance is issued when an object has successfully completed and passed a subset (but not all) of test programmes in accordance with a recognized standard. In addition, the object's technical drawings have been verified and the condition of the object after the tests is assessed and recorded. The report is applicable to the object tested only. A KEMA Report of Performance signifies that the object meets the requirements of the named subclauses of the standard. It can be identified by silver-embossed lettering on the cover and a silver seal on its front sheet.

The sentence on the front sheet of a KEMA Report of Performance will state that the tests have been carried out in accordance with ...... The object has complied with the relevant requirements.

\section{$3 \quad$ KEMA Test Report}

A KEMA Test Report is issued in all other cases. Reasons for issuing a KEMA Test Report could be:

- $\quad$ Tests were performed according to the client's instructions.

- $\quad$ Tests were performed only partially according to the standard.

- No technical drawings were submitted for verification and/or no assessment of the condition of the object after the tests was performed.

The object failed one or more of the performed tests.

The KEMA Test Report can be identified by the grey-embossed lettering on the cover and grey seal on its front sheet.

In case the number of tests, the test procedure and the test parameters are based on a recognized standard and related to the ratings assigned by the manufacturer, the following sentence will appear on the front sheet. The tests have been carried out in accordance with the client's instructions. Test procedure and test parameters were based on ..... If the object does not pass the tests such behaviour will be mentioned on the front sheet. Verification of the drawings (if submitted) and assessment of the condition after the tests is only done on client's request.

When the tests, test procedure and/or test parameters are not in accordance with a recognized standard, the front sheet will state the tests have been carried out in accordance with client's instructions.

\section{4}

Official and uncontrolled test documents

The official test documents of DNV GL are issued in bound form. Uncontrolled copies may be provided as a digital file for convenience of reproduction by the client. The copyright has to be respected at all times.

\section{5}

\section{Accreditation of KEMA Laboratories}

The KEMA Laboratories of DNV GL are accredited in accordance with ISO/IEC 17025 by the respective national accreditation bodies. KEMA Laboratories Arnhem, the Netherlands, is accredited by RvA under nos. L020, L218, K006 and K009. KEMA Laboratories Chalfont, United States, is accredited by A2LA under no. 0553.01. KEMA Laboratories Prague, the Czech Republic, is accredited by CAI as testing laboratory no. 1035. 


\section{TABLE OF CONTENTS}

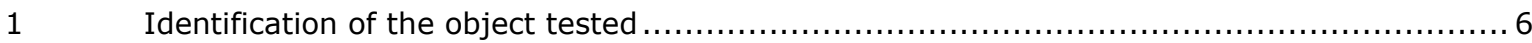

1.1 Ratings/characteristics of the object tested 6

1.2 Description of the object tested 6

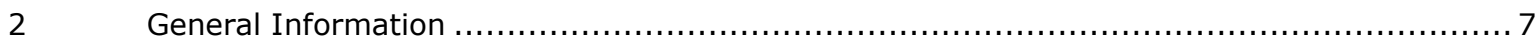

2.1 The tests were witnessed by 7

2.2 The tests were carried out under responsibility of 7

2.3 Accuracy of measurement 7

$\begin{array}{lll}2.4 & \text { Notes } & 7\end{array}$

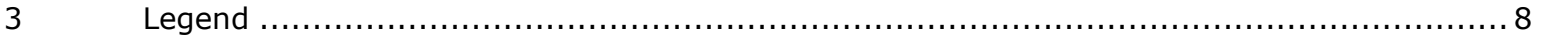

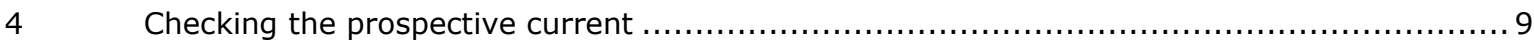

4.1 Condition before test 9

$\begin{array}{lll}4.2 & \text { Test results and oscillograms } & 10\end{array}$

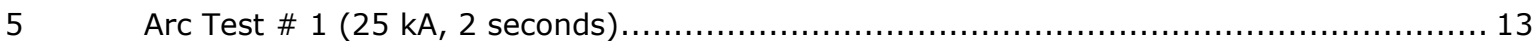

5.1 Condition before test 13

$\begin{array}{lll}5.2 & \text { Test circuit S01 } & 14\end{array}$

5.3 Test results and oscillograms $\quad 15$

$\begin{array}{lll}5.4 & \text { Condition / inspection after test } & 17\end{array}$

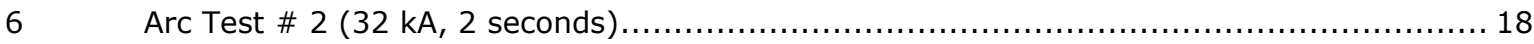

6.1 Condition before test 18

$\begin{array}{lll}6.2 & \text { Test circuit S02 } & 19\end{array}$

6.3 Test results and oscillograms 20

6.4 Condition / inspection after test 22

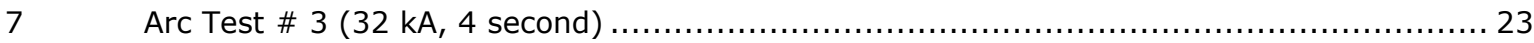

$7.1 \quad$ Condition before test 23

$\begin{array}{lll}7.2 & \text { Test circuit S02 } & 24\end{array}$

7.3 Test results and oscillograms 25

$\begin{array}{lll}7.4 & \text { Condition / inspection after test }\end{array}$

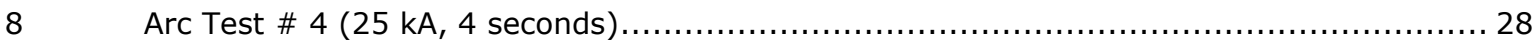

$8.1 \quad$ Condition before test 28

$\begin{array}{lll}8.2 & \text { Test circuit S01 } & 29\end{array}$

8.3 Test results and oscillograms 30

8.4 Condition / inspection after test 32 
9 ATTACHMENTS

Calorimeter Data [3 PAGES]

Instrumentation Test Stand Drawings [4 PAGES]

Instrumentation Information Sheet [1 PAGE]

Photographs (48) [24 PAGES]

END OF DOCUMENT PAGE [1 PAGE] 


\section{I DENTI FI CATI ON OF THE OBJ ECT TESTED}

\subsection{Ratings/ characteristics of the object tested}

Voltage

Short-circuit current

Number of phases

Frequency
$6.9 \mathrm{kV}$

25/32 kA

3

$60 \mathrm{~Hz}$

\subsection{Description of the object tested}

Four (4) General Electric Type M-36 metal-clad medium voltage switchgear units 


\section{GENERAL I NFORMATI ON}

\subsection{The tests were witnessed by}

\section{Name}

Gabriel Taylor

Kenneth Hamburger

Mike Franovich

Mike Cheok

Nick Melly

Kenn Miller

Thin Dihn

Mark Henry Salley

Francesco Pellizzari

Ken Fleischer

Drew Mantey

Scott Bareham

Chris Brown

Anthony Putorti

Eric Link

Phil Deardorff

Anthony Tanbakuchi

Chris Lafluer

Byron Demosthenous

Paul Clem

\section{Company}

U.S. Nuclear Regulatory Commission

Washington, DC, USA

Electric Power Research Institute

National Institute of Standards and Technology

Gaithersburg, MD, USA

Sandia National Laboratories

\subsection{The tests were carried out under responsibility of}

Name

Joe Duffy

\section{Company}

KEMA Powertest LLC, Chalfont, PA, USA

\subsection{Accuracy of measurement}

The guaranteed uncertainty in the figures mentioned, taking into account the total measuring system, is less than $3 \%$, unless mentioned otherwise. Measurement uncertainty can be verified by reviewing the instrument calibration records. The instruments used are calibrated on a regular basis and are traceable to the National Institute of Standards and Technology.

\subsection{Notes}

The calorimeter data for the arc test conducted on September 12 (NRC test 2-24) was not captured. The recording was started and stopped prior to the arc event due to human error. 


\section{LEGEND}

\section{Phase indications}

If more than one phase is recorded on oscillogram, the phases are indicated by the digits 1,2 and 3 . These phases 1, 2 and 3 correspond to the phase values in the columns of the accompanying table, respectively from left to right.

\section{Explanation of the letter symbols and abbreviations on the oscillograms}

pu Per unit (the reference length of one unit is represented by the black bar on the oscillogram)

G2 A-N G2 A-N Voltage

G2 B-N G2 B-N Voltage

G2 C-N G2 C-N Voltage

I1TO Current through test object

I2TO Current through test object

I3TO Current through test object

PT\#1 Pressure transducer \# 1

PT\#2 Pressure transducer \# 2

PT\#3 Pressure transducer \# 3

PT\#4 Pressure transducer \# 4

TRIG Trigger signal transient recorder 
KEMA Laboratories

$-9-$

18174-B

\section{CHECKI NG THE PROSPECTI VE CURRENT}

Standard and date

Standard Client's instructions

Test date $\quad 10$ September 2018

\subsection{Condition before test}

Shorting bar connected at station terminals. 


\subsection{Test results and oscillograms}

\section{Overview of test numbers}

180910-9003, 9004

\section{Remarks}

Full-level circuit checks performed at $6900 \mathrm{~V}$. Client accepted the following circuit parameters: $6900 \mathrm{~V}, 25.6 \mathrm{kA}$ symmetrical, $70.2 \mathrm{kA}$ peak. $7000 \mathrm{~V}, 32.0 \mathrm{kA}$ symmetrical, 86.4 kA peak. 
Checking the prospective current

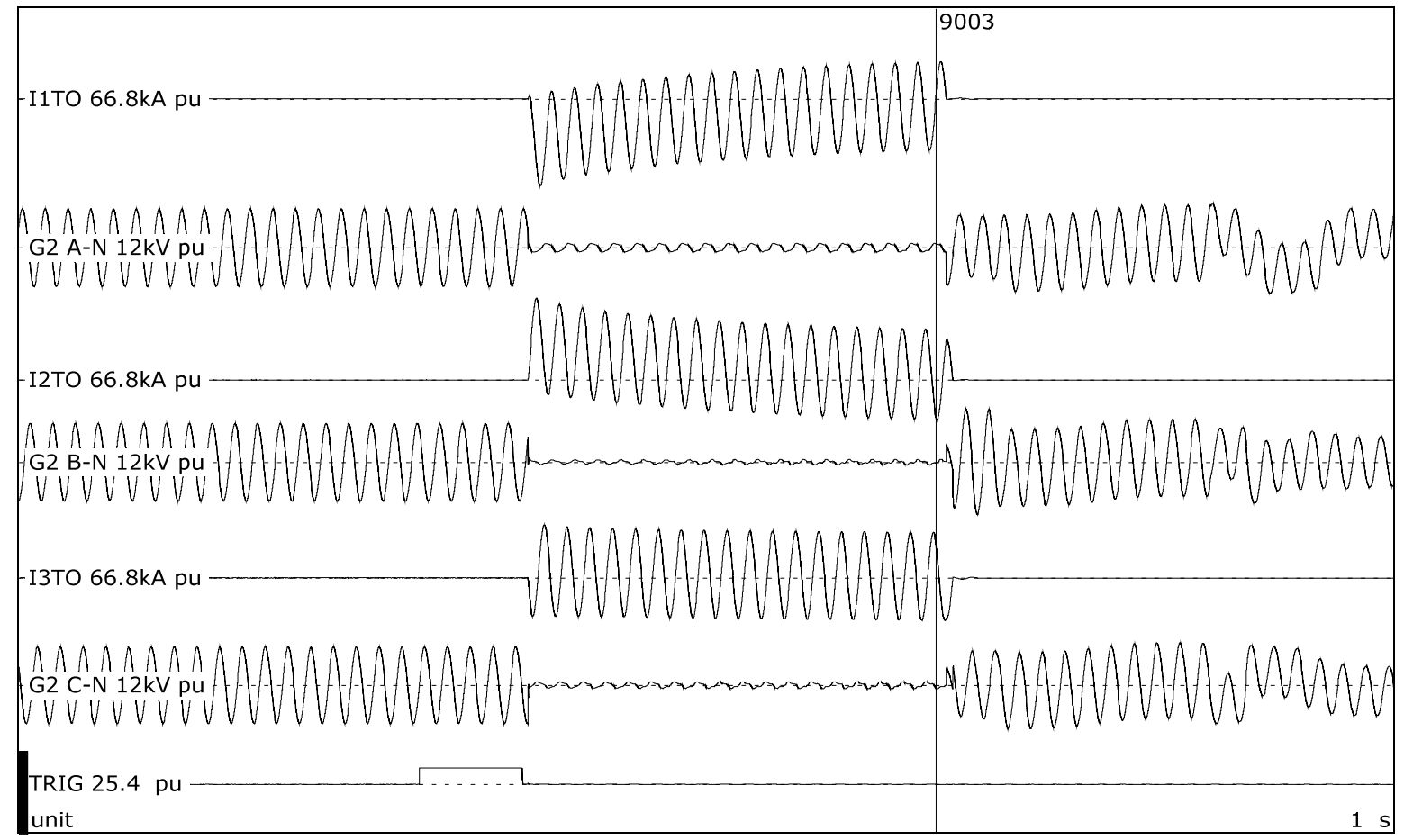

Test number: $\quad 180910-9003$

\begin{tabular}{|c|c|c|c|c|}
\hline \multicolumn{2}{|l|}{ Phase } & A & B & C \\
\hline Applied voltage, phase-to-ground & $\mathrm{kV}_{\mathrm{RMS}}$ & 4.00 & 4.02 & 3.96 \\
\hline Applied voltage, phase-to-phase & $k V_{\text {RMS }}$ & \multicolumn{3}{|c|}{6.91} \\
\hline Making current & $\mathrm{kA}_{\text {peak }}$ & $-70,2$ & 65,9 & 42,9 \\
\hline Current, a.c. component, beginning & kARMS & 26,2 & 26,8 & 26,2 \\
\hline Current, a.c. component, middle & $\mathrm{k} A_{\text {RMS }}$ & 25,2 & 25,8 & 25,2 \\
\hline Current, a.c. component, end & kARMS & 25,3 & 25,8 & 25,2 \\
\hline Current, a.c. component, average & $\mathrm{k} \mathrm{A}_{\mathrm{RMS}}$ & 25,4 & 26,0 & 25,4 \\
\hline $\begin{array}{l}\text { Current, a.c. component, three-phase } \\
\text { average }\end{array}$ & kARMS & \multicolumn{3}{|c|}{25,6} \\
\hline Duration & $\mathrm{s}$ & 0,297 & 0,297 & 0,297 \\
\hline
\end{tabular}

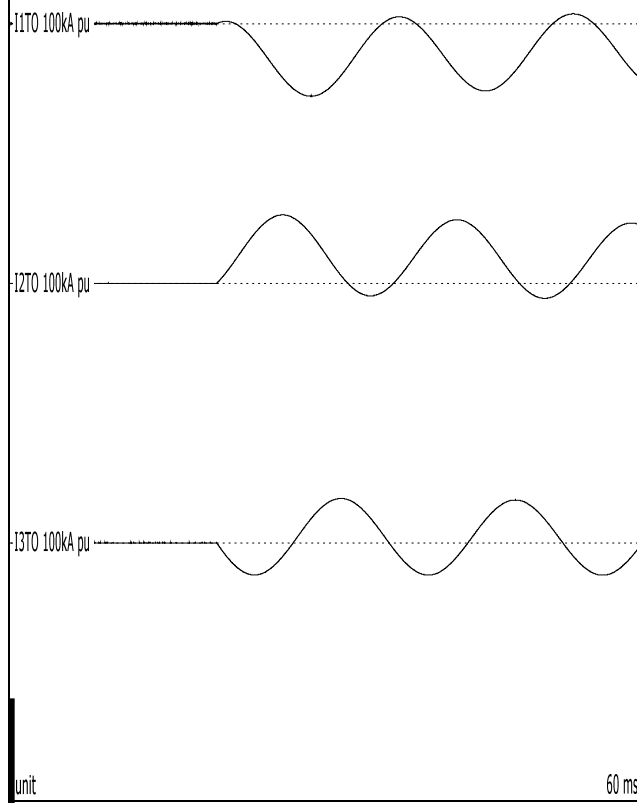

Observations: Checking the prospective current. 
Checking the prospective current

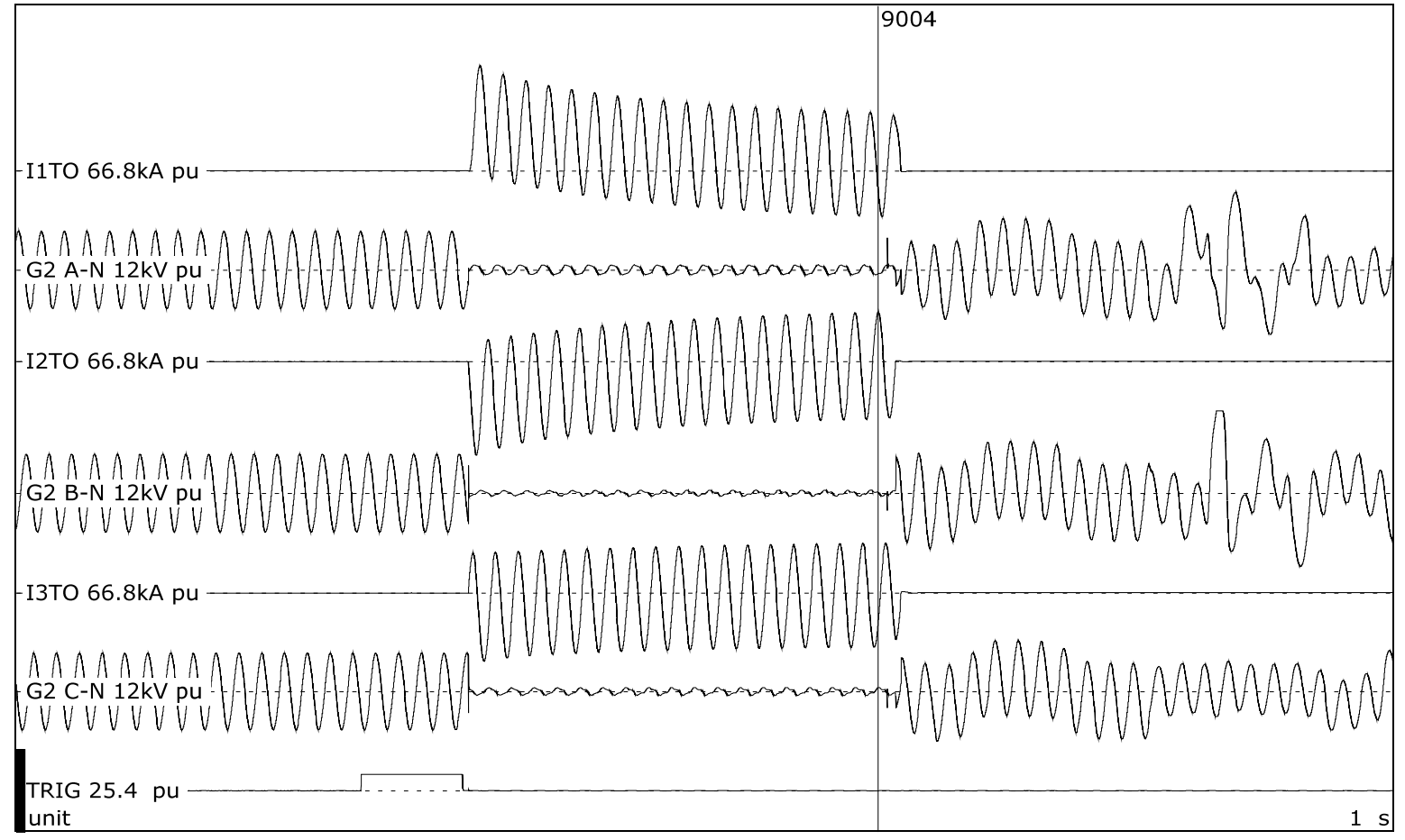

Test number: $\quad 180910-9004$

\begin{tabular}{|c|c|c|c|c|}
\hline \multicolumn{2}{|l|}{ Phase } & A & B & C \\
\hline Applied voltage, phase-to-ground & $\mathrm{kV}_{\mathrm{RMS}}$ & 4.00 & 4.02 & 3.96 \\
\hline Applied voltage, phase-to-phase & $k V_{\text {RMS }}$ & \multicolumn{3}{|c|}{6.91} \\
\hline Making current & kA peak & 85,2 & $-76,0$ & $-55,5$ \\
\hline Current, a.c. component, beginning & kARMS & 31,2 & 32,1 & 31,2 \\
\hline Current, a.c. component, middle & KARMS & 29,6 & 30,5 & 29,7 \\
\hline Current, a.c. component, end & kARMS & 29,7 & 30,6 & 29,7 \\
\hline Current, a.c. component, average & $\mathrm{K} A_{\mathrm{RMS}}$ & 30,0 & 30,9 & 30,0 \\
\hline $\begin{array}{l}\text { Current, a.c. component, three-phase } \\
\text { average }\end{array}$ & kARMS & \multicolumn{3}{|c|}{30,3} \\
\hline Duration & $\mathrm{s}$ & 0,297 & 0,298 & 0,298 \\
\hline
\end{tabular}

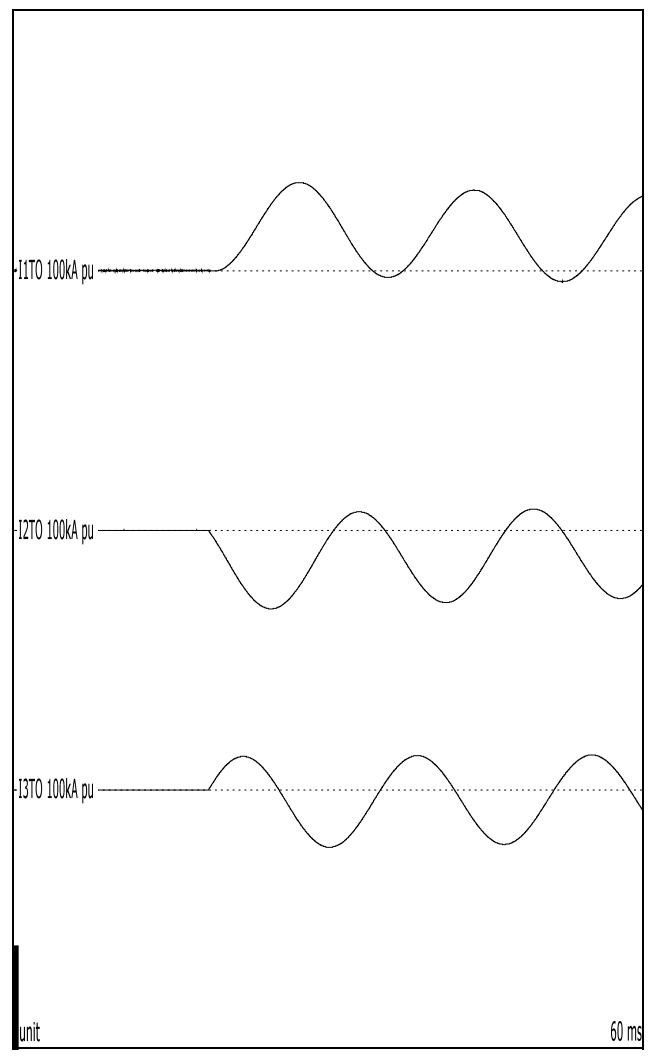

Observations: Checking the prospective current. 


\section{ARC TEST \# 1 (25 KA, 2 SECONDS)}

\section{Standard and date}

Standard Client's instructions

Test date $\quad 10$ September 2018

\subsection{Condition before test}

Used and refurbished General Electric Type M-36 switchgear in good serviceable condition, procured from an ISO 9001 certified low and medium voltage circuit breaker and electrical power distribution supplier.

Pressure transducers \# 1 \& \#2 located in secondary enclosure (instrumentation compartment). Pressure transducers \#3 \& \#4 located in primary enclosure (bus compartment). 


\subsection{Test circuit S01}

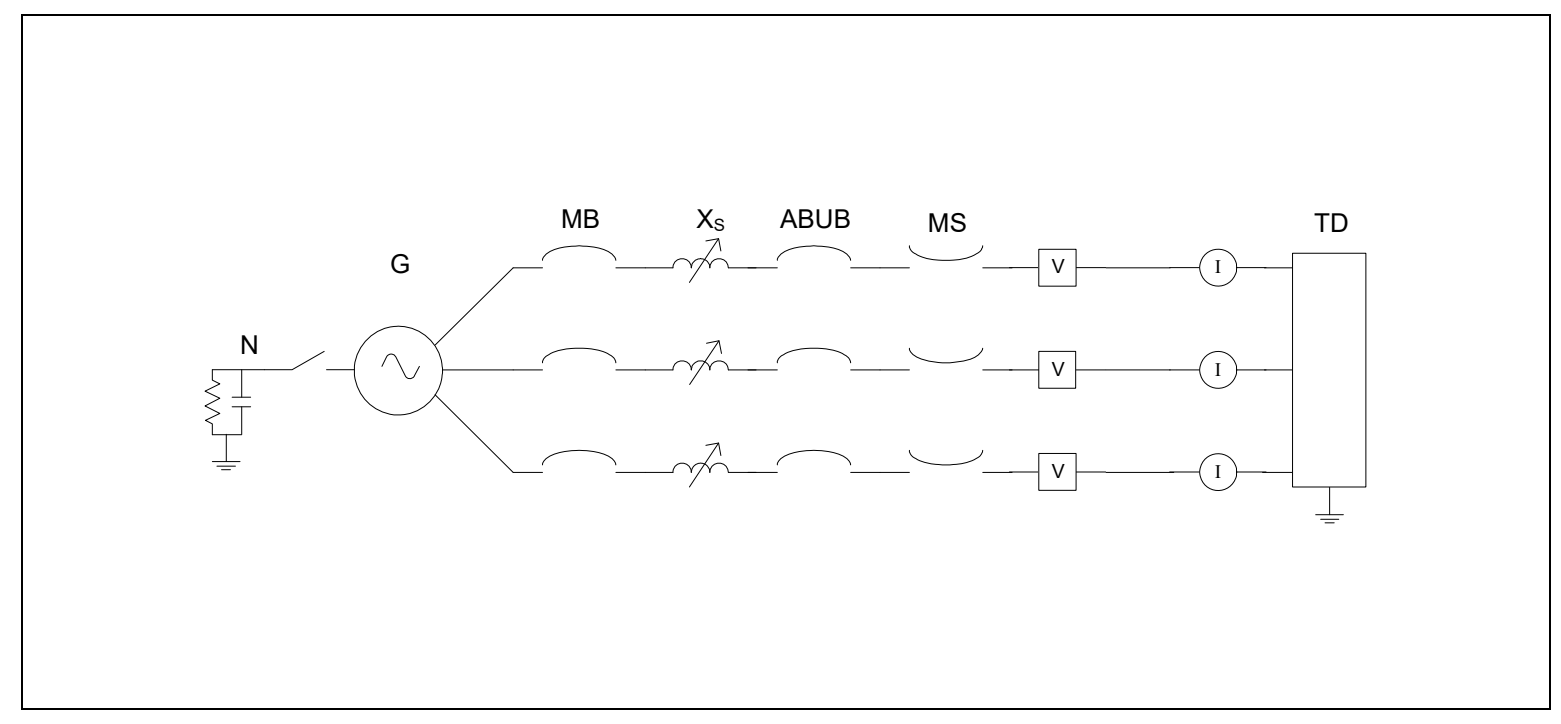

\begin{tabular}{|c|c|c|c|c|c|}
\hline G & $=$ Generator & $A B \cup B$ & $=$ Aux. Breaker & $\mathrm{R}$ & $=$ Resistance \\
\hline $\mathrm{N}$ & $=$ Neutral & XFMR & $=$ Transformer & C & = Capacitance \\
\hline MB & $=$ Main Breaker & TD & $=$ Test Device & 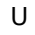 & $=$ Voltage Measurement \\
\hline MS & $=$ Make Switch & $x$ & $=$ Inductance & I & $=$ Current Measurement \\
\hline
\end{tabular}

\begin{tabular}{|lr|c|}
\hline Supply & \multicolumn{2}{l|}{} \\
\hline Power & MVA & 306 \\
\hline Frequency & $\mathrm{Hz}$ & 60 \\
\hline Phase(s) & & 3 \\
\hline Voltage & $\mathrm{kV}$ & 6.9 \\
\hline Current & $\mathrm{kA}$ & 25.6 \\
\hline Impedance & $\Omega$ & 0.1556 \\
\hline Peak current & $\mathrm{kA}$ & 70.2 \\
\hline Neutral & & not earthed \\
\hline
\end{tabular}


KEMA Laboratories

\subsection{Test results and oscillograms}

Overview of test numbers

180910-9005

Remarks

NRC Test 2-19 
Arc Test \# 1 ( 25 kA, 2 seconds)

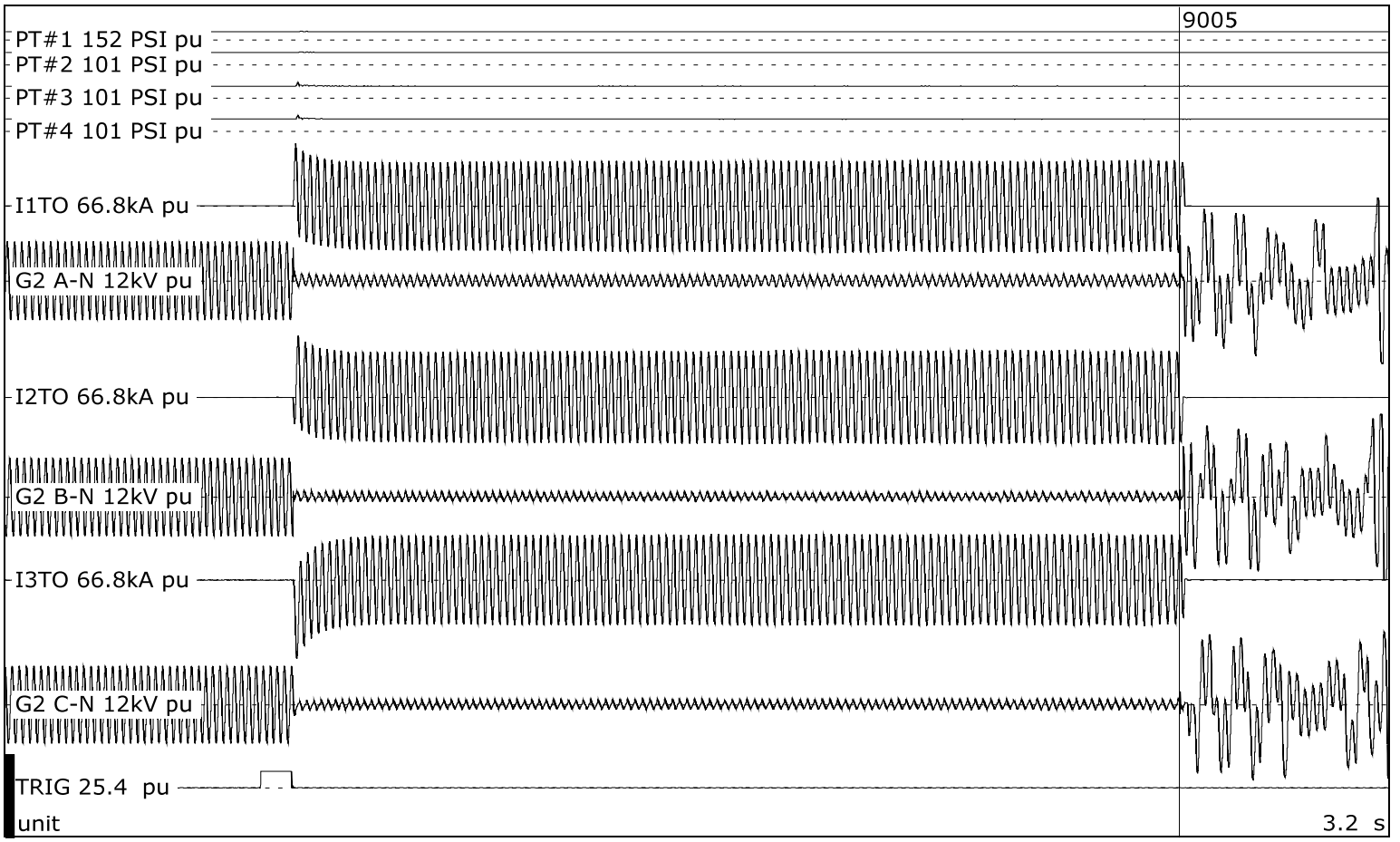

Test number: $\quad 180910-9005$

\begin{tabular}{|c|c|c|c|c|c|}
\hline \multicolumn{2}{|l|}{ Phase } & \multirow{2}{*}{$\frac{\text { A }}{4,00}$} & \multirow{2}{*}{$\frac{\text { B }}{4,02}$} & \multirow{2}{*}{$\frac{\text { C }}{3,97}$} & \\
\hline Applied voltage, phase-to-ground & $\mathrm{kV}_{\mathrm{RMS}}$ & & & & \\
\hline Applied voltage, phase-to-phase & $\mathrm{kV}_{\mathrm{RMS}}$ & \multicolumn{3}{|c|}{6,92} & \multirow{4}{*}{ PFA3 12 PSI pu. } \\
\hline Making current & $\mathrm{kA} A_{\text {peak }}$ & 50,2 & 49,3 & $-63,0$ & \\
\hline Current, a.c. component, beginning & KARMS & 25,5 & 25,9 & 25,8 & \\
\hline Current, a.c. component, middle & $\mathrm{kA}$ RMS & 25,8 & 26,5 & 25,7 & \\
\hline Current, a.c. component, end & KARMS & 25,8 & 26,6 & 25,5 & \multirow{5}{*}{ PT\#4 20 PSI pu -..... } \\
\hline Current, a.c. component, average & KARMS & 25,6 & 26,1 & 25,6 & \\
\hline \begin{tabular}{|l|} 
Current, a.c. component, three-phase \\
average
\end{tabular} & kARMS & \multicolumn{3}{|c|}{25,8} & \\
\hline Duration & $\mathrm{s}$ & 2,05 & 2,05 & 2,05 & \\
\hline Arc energy & MJ & \multicolumn{3}{|c|}{21,0} & \\
\hline
\end{tabular}

Observations: Emission of flames and gas observed. 


\subsection{Condition / inspection after test}

PT \# 1 peak pressure: 0.59 PSI above atmospheric PT \#2 peak pressure: 0.66 PSI above atmospheric PT \#3 peak pressure: 4.02 PSI above atmospheric PT \#4 peak pressure: 4.01 PSI above atmospheric 


\section{ARC TEST \# 2 (32 KA, 2 SECONDS)}

\section{Standard and date}

Standard

Client's instructions

Test date

11 September 2018

\subsection{Condition before test}

Used and refurbished General Electric Type M-36 switchgear in good serviceable condition, procured from an ISO 9001 certified low and medium voltage circuit breaker and electrical power distribution supplier.

Pressure transducers \# 1 \& \#2 located in secondary enclosure (instrumentation compartment). Pressure transducers \#3 \& \#4 located in primary enclosure (bus compartment). 


\subsection{Test circuit S02}

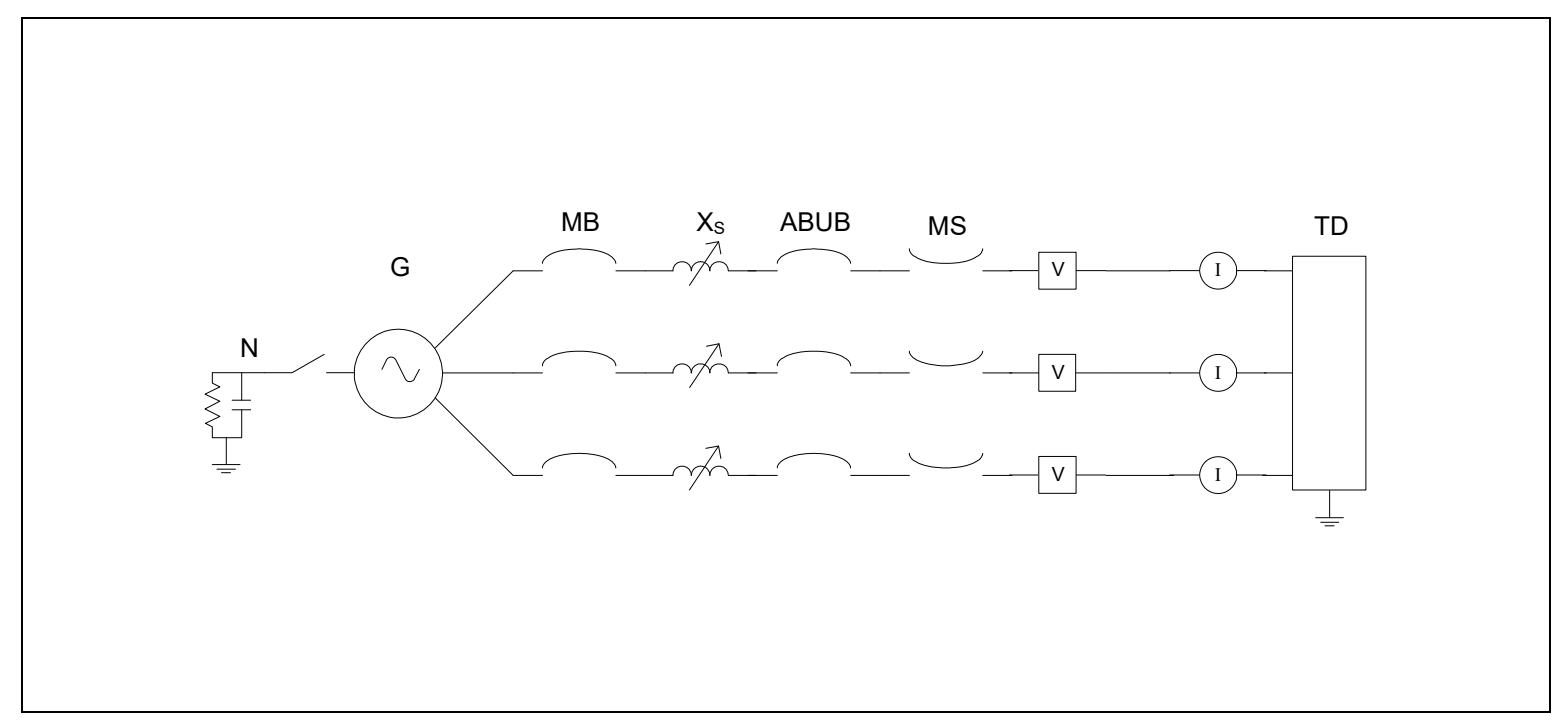

\begin{tabular}{|c|c|c|c|c|c|}
\hline G & $=$ Generator & $A B \cup B$ & $=$ Aux. Breaker & $\mathrm{R}$ & $=$ Resistance \\
\hline $\mathrm{N}$ & $=$ Neutral & XFMR & $=$ Transformer & C & = Capacitance \\
\hline MB & $=$ Main Breaker & TD & $=$ Test Device & 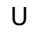 & $=$ Voltage Measurement \\
\hline MS & $=$ Make Switch & $x$ & $=$ Inductance & I & $=$ Current Measurement \\
\hline
\end{tabular}

\begin{tabular}{|lr|c|}
\hline Supply & \multicolumn{2}{l|}{} \\
\hline Power & MVA & 388 \\
\hline Frequency & $\mathrm{Hz}$ & 60 \\
\hline Phase(s) & & 3 \\
\hline Voltage & $\mathrm{kV}$ & 7.0 \\
\hline Current & $\mathrm{kA}$ & 32.0 \\
\hline Impedance & $\Omega$ & 0.1263 \\
\hline Peak current & $\mathrm{kA}$ & 86.4 \\
\hline Neutral & & not earthed \\
\hline
\end{tabular}


KEMA Laboratories

\subsection{Test results and oscillograms}

Overview of test numbers

180911-9001

Remarks

NRC Test 2-22 
Arc Test \# 2 ( 32 kA, 2 seconds)

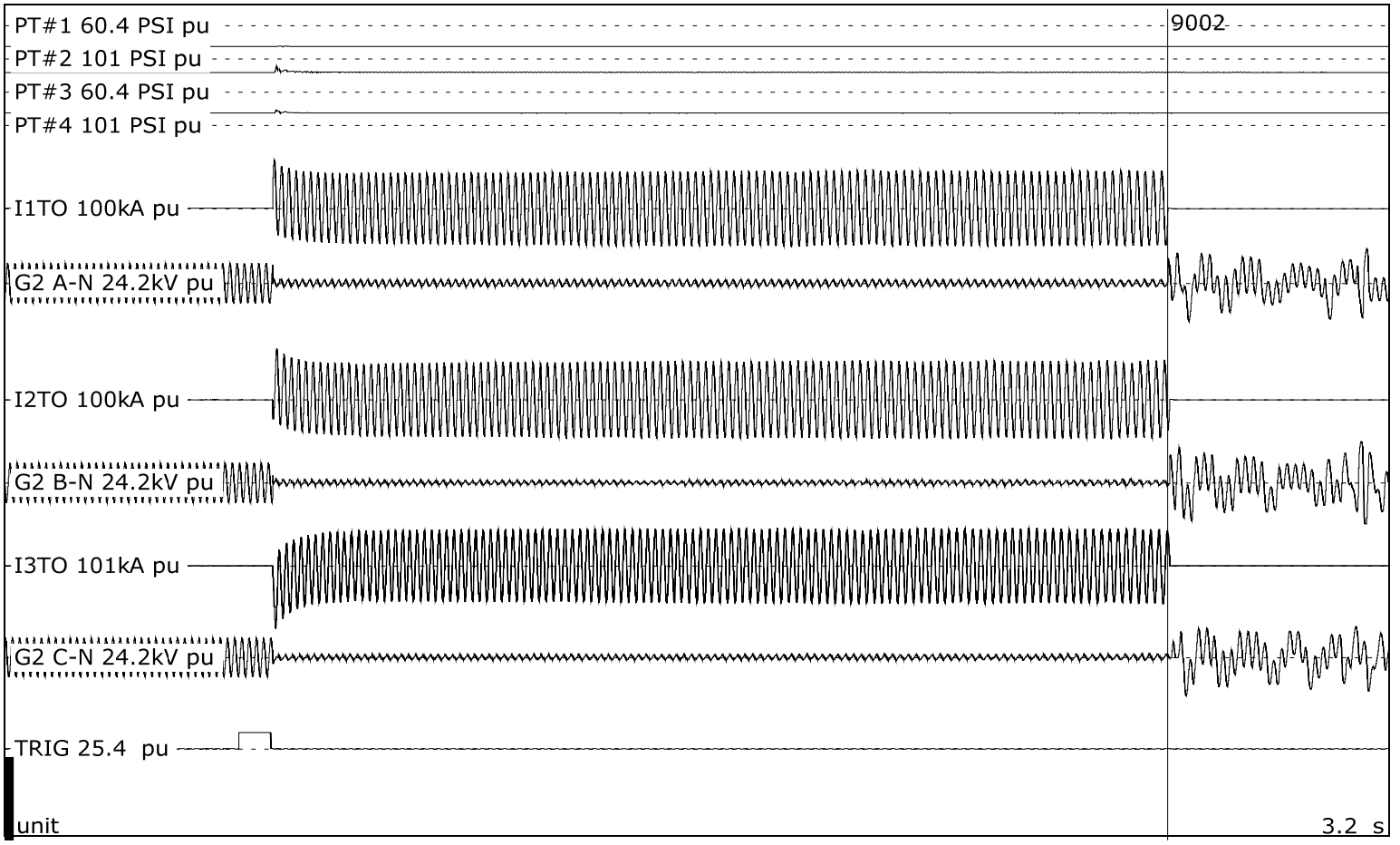

Test number: $\quad$ 180911-9001

\begin{tabular}{|c|c|c|c|c|c|}
\hline \multicolumn{2}{|l|}{ Phase } & \multirow{2}{*}{$\frac{\text { A }}{4,06}$} & \multirow{2}{*}{$\frac{\text { B }}{4,09}$} & \multirow{2}{*}{$\frac{\text { C }}{4,03}$} & \\
\hline Applied voltage, phase-to-ground & $\mathrm{kV}_{\mathrm{RMS}}$ & & & & \\
\hline Applied voltage, phase-to-phase & $\mathrm{kV}_{\mathrm{RMS}}$ & \multicolumn{3}{|c|}{7,03} & \multirow{4}{*}{ PPA3 12 PSI pu. } \\
\hline Making current & $\mathrm{kA} A_{\text {peak }}$ & 58,9 & 61,6 & $-75,9$ & \\
\hline Current, a.c. component, beginning & kARMS & 31,0 & 31,5 & 31,4 & \\
\hline Current, a.c. component, middle & kARMS & 32,0 & 32,6 & 31,8 & \\
\hline Current, a.c. component, end & kARMS & 31,9 & 33,4 & 31,3 & \multirow{4}{*}{ PT \#4 2O PSI pu ... } \\
\hline Current, a.c. component, average & KA RMS & 31,4 & 32,2 & 30,6 & \\
\hline $\begin{array}{l}\text { Current, a.c. component, three-phase } \\
\text { average }\end{array}$ & kARMS & \multicolumn{3}{|c|}{-} & \\
\hline Duration & s & 2,07 & 2,07 & 2.07 & \\
\hline Arc energy & MJ & \multicolumn{3}{|c|}{21.1} & \\
\hline
\end{tabular}

Observations: Emission of flames and gas observed. For this test, C-phase current (I3TO) was patched to data system improperly. C-phase current trace was artificially created for this report by taking the negative sum of $\mathrm{A}$ and B-phase currents. This is due to the fact that currents in the three phases must always sum to 0 Amperes. The data in the table for C-phase was calculated from the generated signal. 


\subsection{Condition / inspection after test}

PT \# 1 peak pressure: 0.78 PSI above atmospheric PT \#2 peak pressure: 0.77 PSI above atmospheric PT \#3 peak pressure: 4.17 PSI above atmospheric PT \#4 peak pressure: 4.08 PSI above atmospheric 


\section{ARC TEST \# 3 ( 32 KA, 4 SECOND)}

\section{Standard and date}

Standard Client's instructions

Test date $\quad 12$ September 2018

\subsection{Condition before test}

Used and refurbished General Electric Type M-36 switchgear in good serviceable condition, procured from an ISO 9001 certified low and medium voltage circuit breaker and electrical power distribution supplier.

Pressure transducers \# 1 \& \#2 located in secondary enclosure (instrumentation compartment). Pressure transducers \#3 \& \#4 located in primary enclosure (bus compartment). 


\subsection{Test circuit S02}

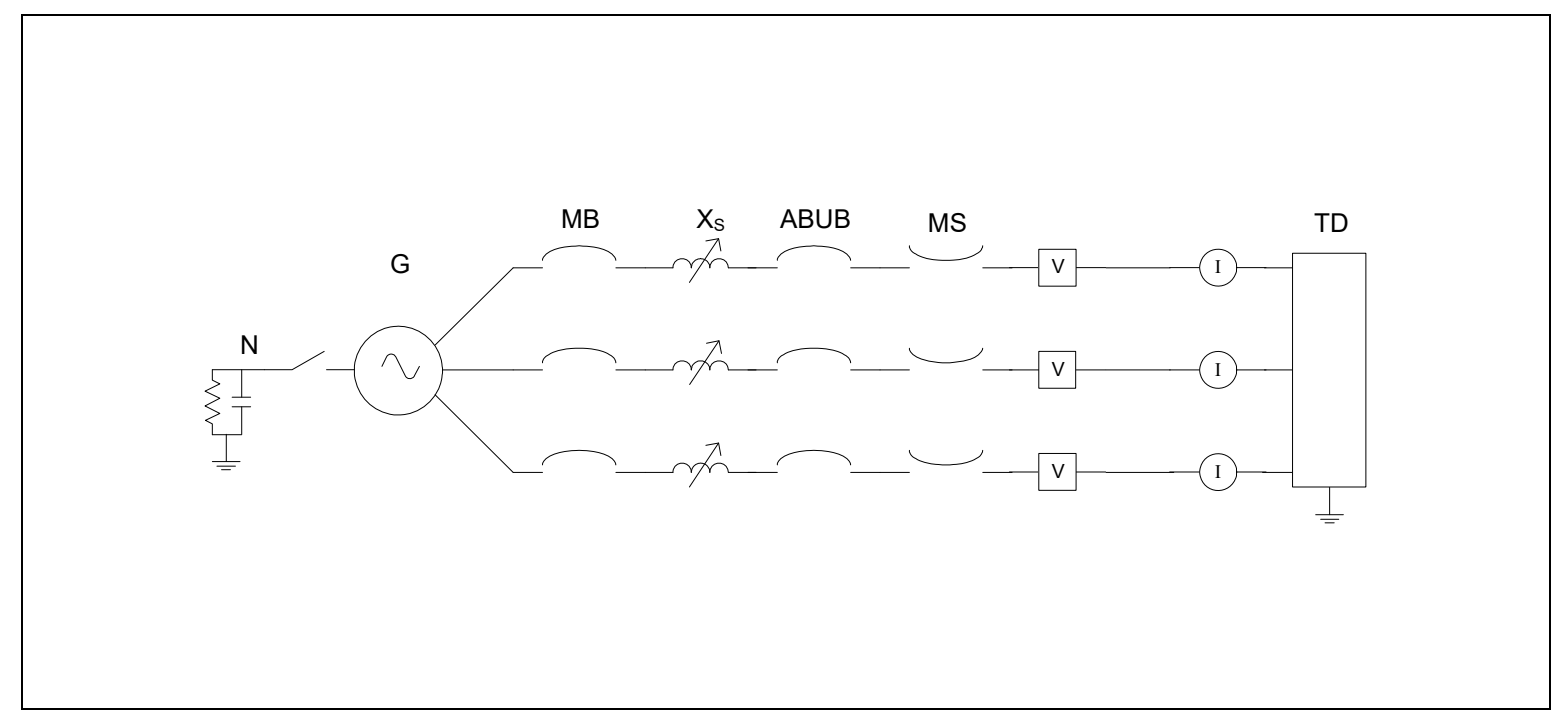

\begin{tabular}{|c|c|c|c|c|c|}
\hline G & $=$ Generator & ABUB & $=$ Aux. Breaker & $\mathrm{R}$ & $=$ Resistance \\
\hline $\mathrm{N}$ & $=$ Neutral & XFMR & $=$ Transformer & $\mathrm{C}$ & = Capacitance \\
\hline MB & $=$ Main Breaker & TD & $=$ Test Device & $U$ & $=$ Voltage Measurement \\
\hline MS & $=$ Make Switch & $\mathrm{x}$ & $=$ Inductance & I & $=$ Current Measurement \\
\hline
\end{tabular}

\begin{tabular}{|lr|c|}
\hline Supply & \multicolumn{2}{l|}{} \\
\hline Power & MVA & 388 \\
\hline Frequency & $\mathrm{Hz}$ & 60 \\
\hline Phase(s) & & 3 \\
\hline Voltage & $\mathrm{kV}$ & 7.0 \\
\hline Current & $\mathrm{kA}$ & 32.0 \\
\hline Impedance & $\Omega$ & 0.1263 \\
\hline Peak current & $\mathrm{kA}$ & 86.4 \\
\hline Neutral & & not earthed \\
\hline
\end{tabular}




\subsection{Test results and oscillograms}

Overview of test numbers

180912-9001

Remarks

NRC Test 2-24 
Arc Test \# 3 ( 32 kA, 4 second)

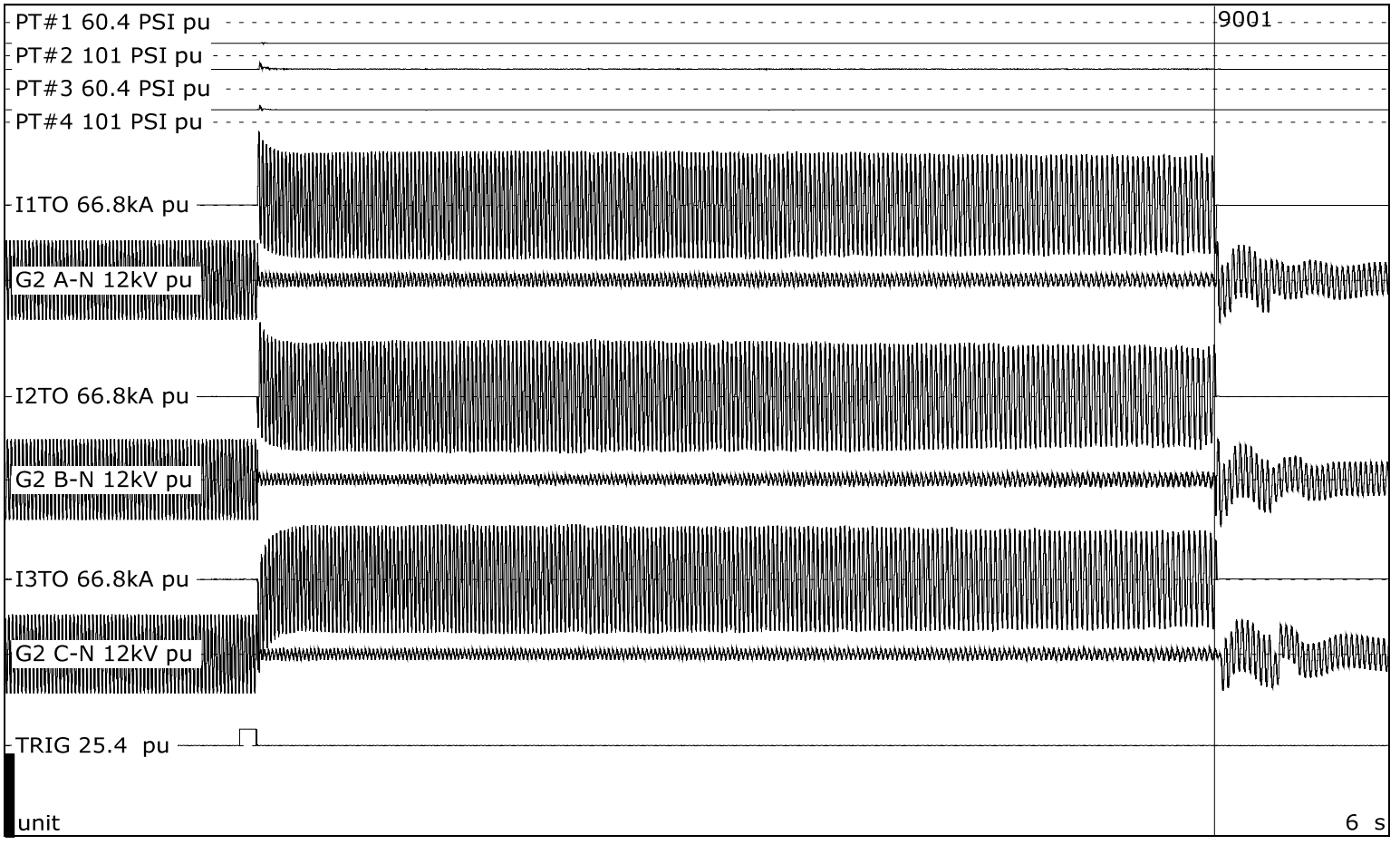

Test number: $\quad$ 180912-9001

\begin{tabular}{|c|c|c|c|c|c|}
\hline \multicolumn{2}{|l|}{ Phase } & \multirow{2}{*}{$\frac{\text { A }}{4,07}$} & \multirow{2}{*}{$\frac{\text { B }}{4,10}$} & \multirow{2}{*}{$\frac{\text { C }}{4,04}$} & \\
\hline Applied voltage, phase-to-ground & $\mathrm{kV}_{\mathrm{RMS}}$ & & & & \\
\hline Applied voltage, phase-to-phase & $\mathrm{kV}_{\mathrm{RMS}}$ & \multicolumn{3}{|c|}{7,05} & \multirow{4}{*}{ PPA3 12 PSI pu. } \\
\hline Making current & $k A_{\text {peak }}$ & 59,4 & 59,3 & $-75,0$ & \\
\hline Current, a.c. component, beginning & kARMS & 30,6 & 31,3 & 31,4 & \\
\hline Current, a.c. component, middle & kARMS & 30,1 & 31,0 & 30,0 & \\
\hline Current, a.c. component, end & kARMS & 27,6 & 27,7 & 27,1 & \multirow{4}{*}{ PT $\$ 420$ PSI pu - } \\
\hline Current, a.c. component, average & KA RMS & 29,8 & 30,8 & 30,0 & \\
\hline $\begin{array}{l}\text { Current, a.c. component, three-phase } \\
\text { average }\end{array}$ & kARMS & \multicolumn{3}{|c|}{30,2} & \\
\hline Duration & s & 4,15 & 4,15 & 4,15 & \\
\hline Arc energy & MJ & \multicolumn{3}{|c|}{49.38} & \\
\hline
\end{tabular}

Observations: Emission of flames and gas observed. 


\subsection{Condition / inspection after test}

PT \# 1 peak pressure: 0.82 PSI above atmospheric PT \#2 peak pressure: 0.81 PSI above atmospheric PT \#3 peak pressure: 4.41 PSI above atmospheric PT \#4 peak pressure: 4.27 PSI above atmospheric 


\section{ARC TEST \# 4 (25 KA, 4 SECONDS)}

\section{Standard and date}

Standard

Client's instructions

Test date 13 September 2018

\subsection{Condition before test}

Used and refurbished General Electric Type M-36 switchgear in good serviceable condition, procured from an ISO 9001 certified low and medium voltage circuit breaker and electrical power distribution supplier.

Pressure transducers \# 1 \& \#2 located in secondary enclosure (instrumentation compartment). Pressure transducers \#3 \& \#4 located in primary enclosure (bus compartment). 


\subsection{Test circuit S01}

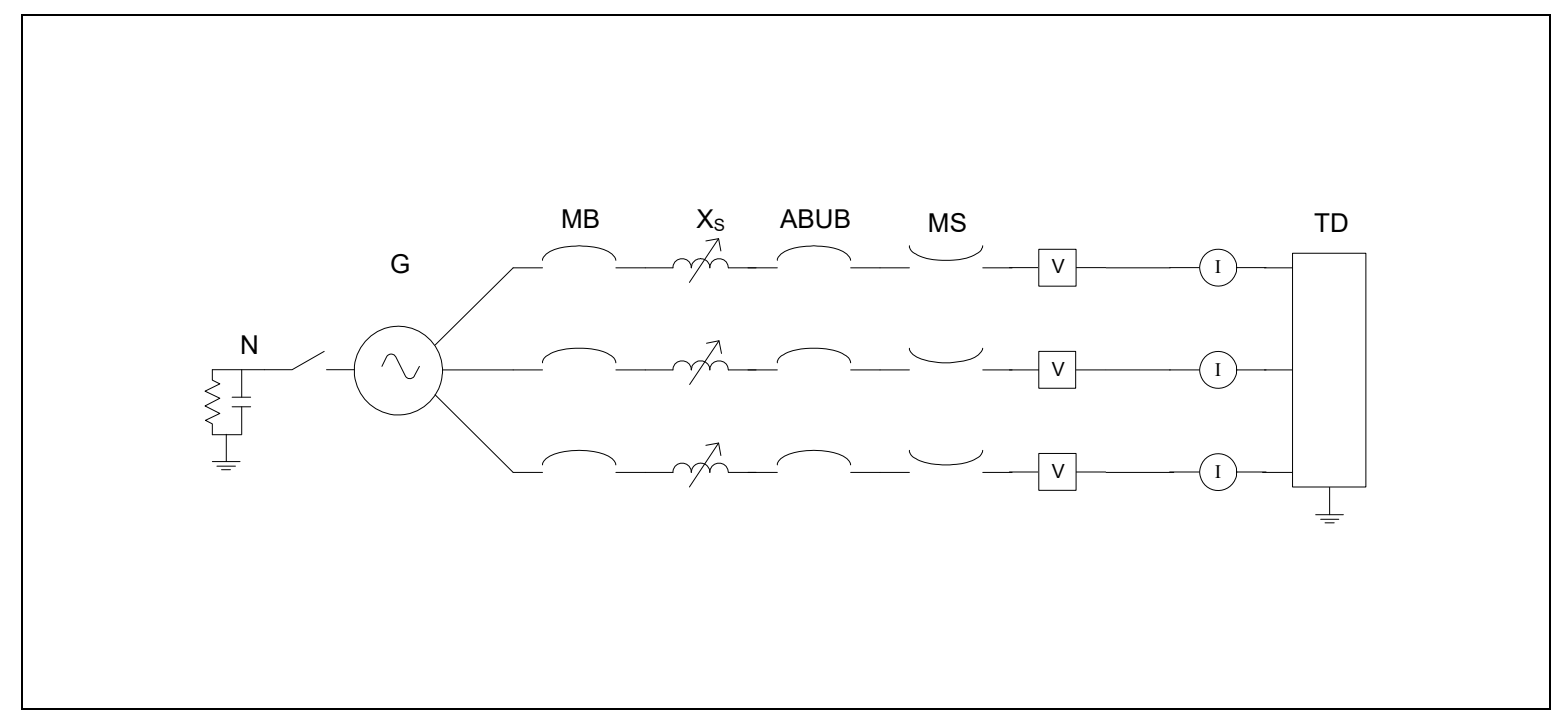

\begin{tabular}{|c|c|c|c|c|c|}
\hline G & $=$ Generator & $A B \cup B$ & $=$ Aux. Breaker & $\mathrm{R}$ & $=$ Resistance \\
\hline $\mathrm{N}$ & $=$ Neutral & XFMR & $=$ Transformer & C & = Capacitance \\
\hline MB & $=$ Main Breaker & TD & $=$ Test Device & 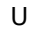 & $=$ Voltage Measurement \\
\hline MS & $=$ Make Switch & $x$ & $=$ Inductance & I & $=$ Current Measurement \\
\hline
\end{tabular}

\begin{tabular}{|lr|c|}
\hline Supply & \multicolumn{2}{l|}{} \\
\hline Power & MVA & 306 \\
\hline Frequency & $\mathrm{Hz}$ & 60 \\
\hline Phase(s) & & 3 \\
\hline Voltage & $\mathrm{kV}$ & 6.9 \\
\hline Current & $\mathrm{kA}$ & 25.6 \\
\hline Impedance & $\Omega$ & 0.1556 \\
\hline Peak current & $\mathrm{kA}$ & 70.2 \\
\hline Neutral & & not earthed \\
\hline
\end{tabular}




\subsection{Test results and oscillograms}

Overview of test numbers

180913-9003

Remarks

NRC Test 2-21 
Arc Test \# 4 ( 25 kA, 4 seconds)
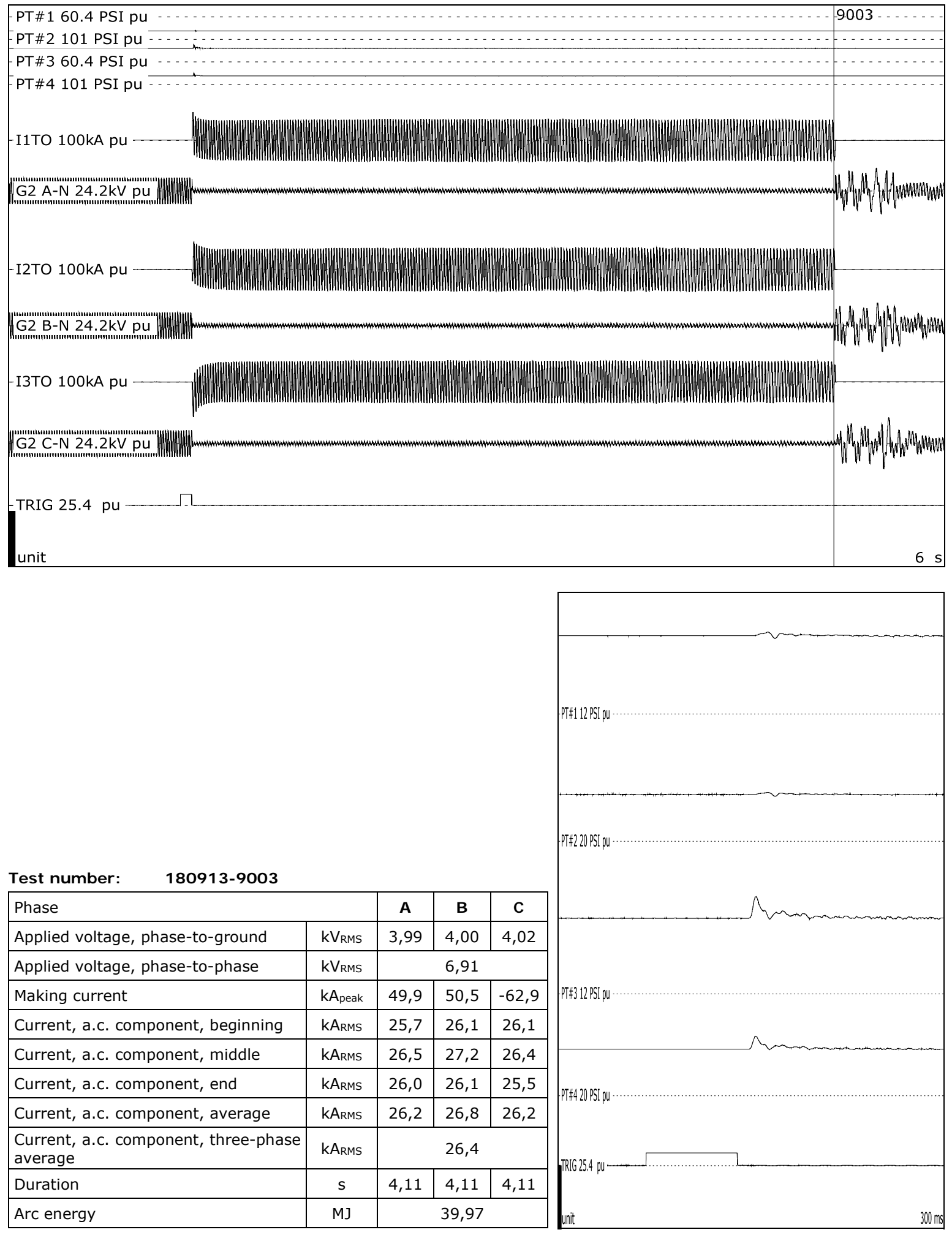

Observations: Emission of flames and gas observed. 


\subsection{Condition / inspection after test}

PT \# 1 peak pressure: 0.70 PSI above atmospheric PT \#2 peak pressure: 0.73 PSI above atmospheric PT \#3 peak pressure: 4.07 PSI above atmospheric PT \#4 peak pressure: 4.16 PSI above atmospheric 


\section{ATTACHMENTS}


Test Number:

Trial Number:

DAS Operator:
18174-B Date and Time:

180910-9001 (NRC 2-19)

Joe Duffy
9/10/2018

1:33:00 PM

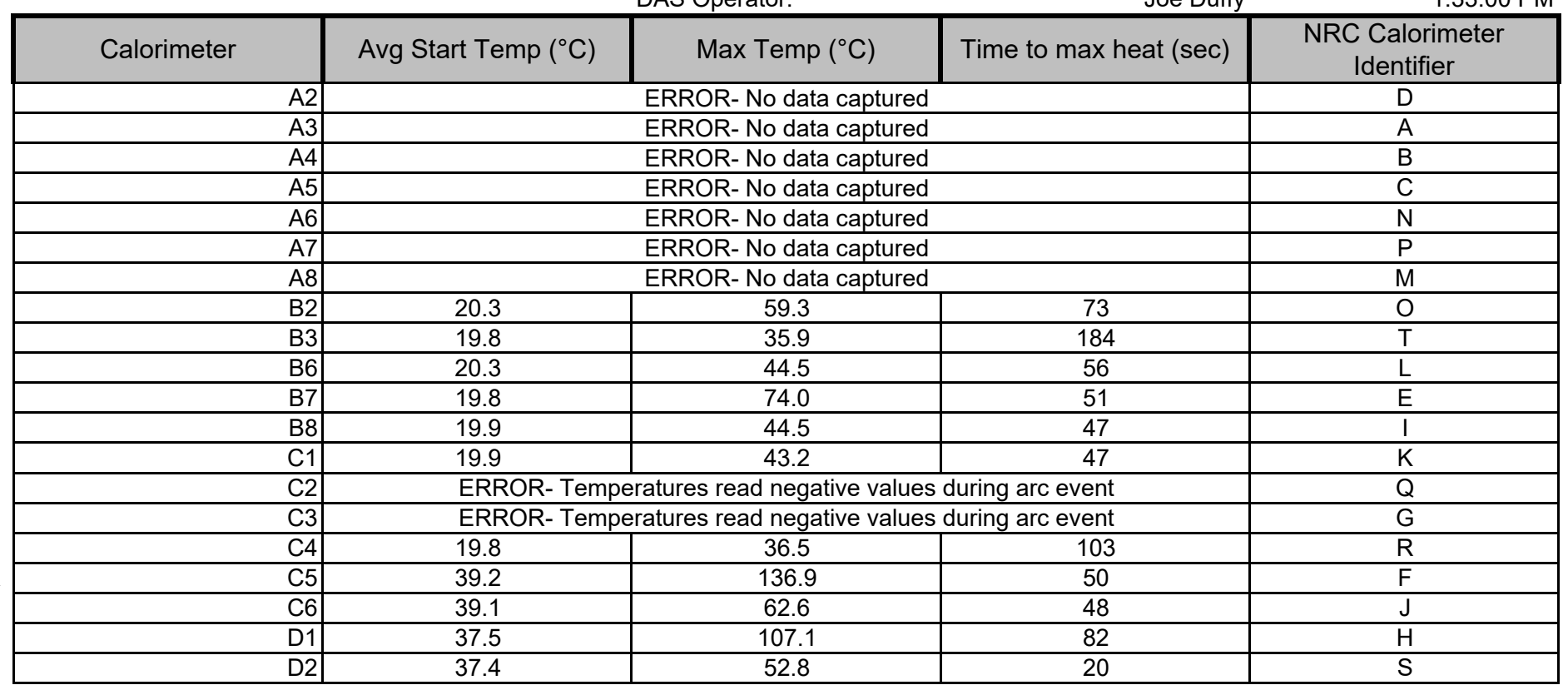

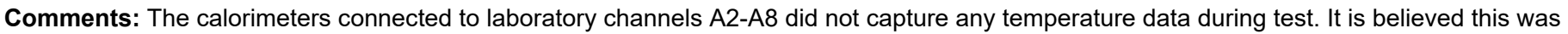
due to system error. The software shows an error message in the log stating that a connection error occurred between the beginning of the

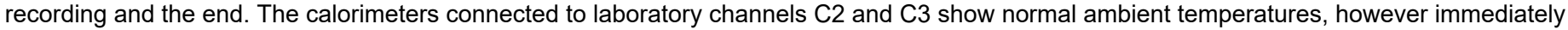
after the arc begins, the temperature readings go negative. The ambient temperatures on laboratory channels C5, C6, D1, and D2 are higher than other temperatures, the reason for this is unknown. 
Test Number:

Trial Number:

DAS Operator:
18174-B Date and Time:

180911-9001 (NRC 2-22)

Joe Duffy

\begin{tabular}{|c|c|c|c|c|}
\hline Calorimeter & Avg Start Temp $\left({ }^{\circ} \mathrm{C}\right)$ & Max Temp $\left({ }^{\circ} \mathrm{C}\right)$ & Time to max heat (sec) & $\begin{array}{l}\text { NRC Calorimeter } \\
\text { Identifier }\end{array}$ \\
\hline A2 & 19.7 & 71.1 & 12 & $\mathrm{D}$ \\
\hline A3 & 22.0 & 55.6 & 2 & $A$ \\
\hline A4 & 22.1 & 76.2 & 25 & $\mathrm{~B}$ \\
\hline A5 & 22.1 & 57.7 & 79 & $\mathrm{C}$ \\
\hline $\mathrm{A} 6$ & 21.7 & 62.6 & 80 & $\mathrm{~N}$ \\
\hline A7 & 21.6 & 73.2 & 68 & $P$ \\
\hline A8 & 21.8 & 52.0 & 30 & $\mathrm{M}$ \\
\hline B2 & 22.0 & 83.4 & 18 & $\mathrm{O}$ \\
\hline B3 & 21.7 & 40.2 & 137 & $\mathrm{~T}$ \\
\hline B6 & 21.8 & 109.4 & 2 & $\mathrm{~L}$ \\
\hline B7 & 21.7 & 110.3 & 8 & $E$ \\
\hline B8 & 21.9 & 72.3 & 7 & $\mathrm{I}$ \\
\hline C1 & 21.8 & 87.5 & 6 & $\mathrm{~K}$ \\
\hline $\mathrm{C} 2$ & 23.2 & 71.2 & 13 & Q \\
\hline C3 & 21.7 & 190.0 & 18 & $G$ \\
\hline C4 & 22.7 & 49.0 & 2 & $\mathrm{R}$ \\
\hline C5 & 41.0 & 230.7 & 6 & $\mathrm{~F}$ \\
\hline C6 & 40.5 & 112.5 & 1 & $\mathrm{~J}$ \\
\hline D1 & 38.0 & 174.2 & 23 & $\mathrm{H}$ \\
\hline D2 & 38.0 & 65.9 & 7 & $\mathrm{~S}$ \\
\hline
\end{tabular}

Comments: The ambient temperatures on laboratory channels C5, C6, D1, and D2 are higher than other temperatures, the reason for this is unknown. 
Report Number:

Trial Number:

Test Engineer:
18174-B Date and Time:

180913-9003 (NRC 2-21)

Joe Duffy
9/13/2018

2:16:00 PM

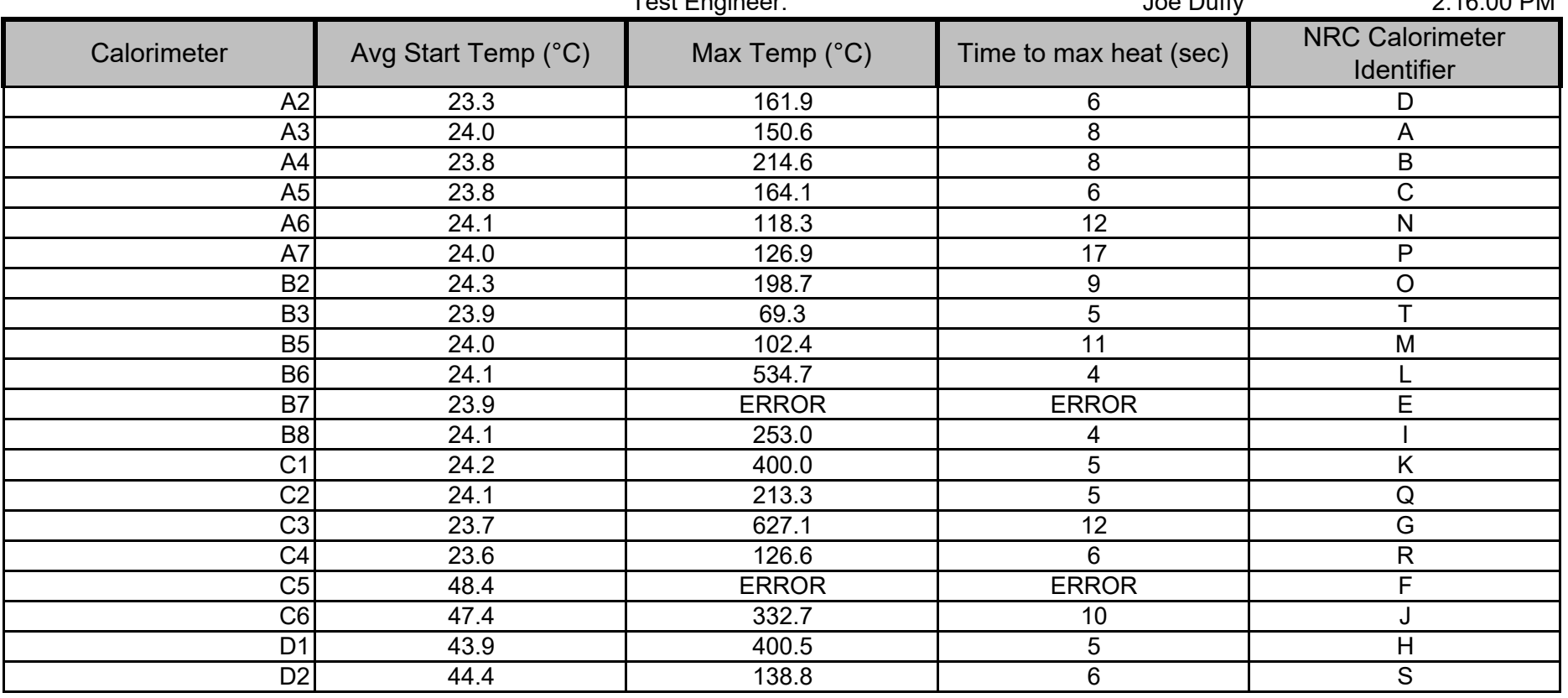

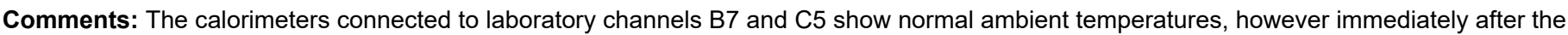

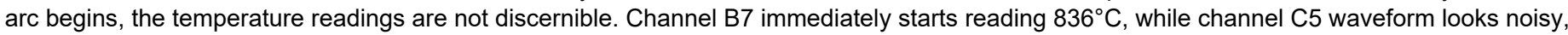
rather than the temperature curve that should be seen. The ambient temperatures on laboratory channels C5, C6, D1, and D2 are higher than other temperatures, the reason for this is unknown. 


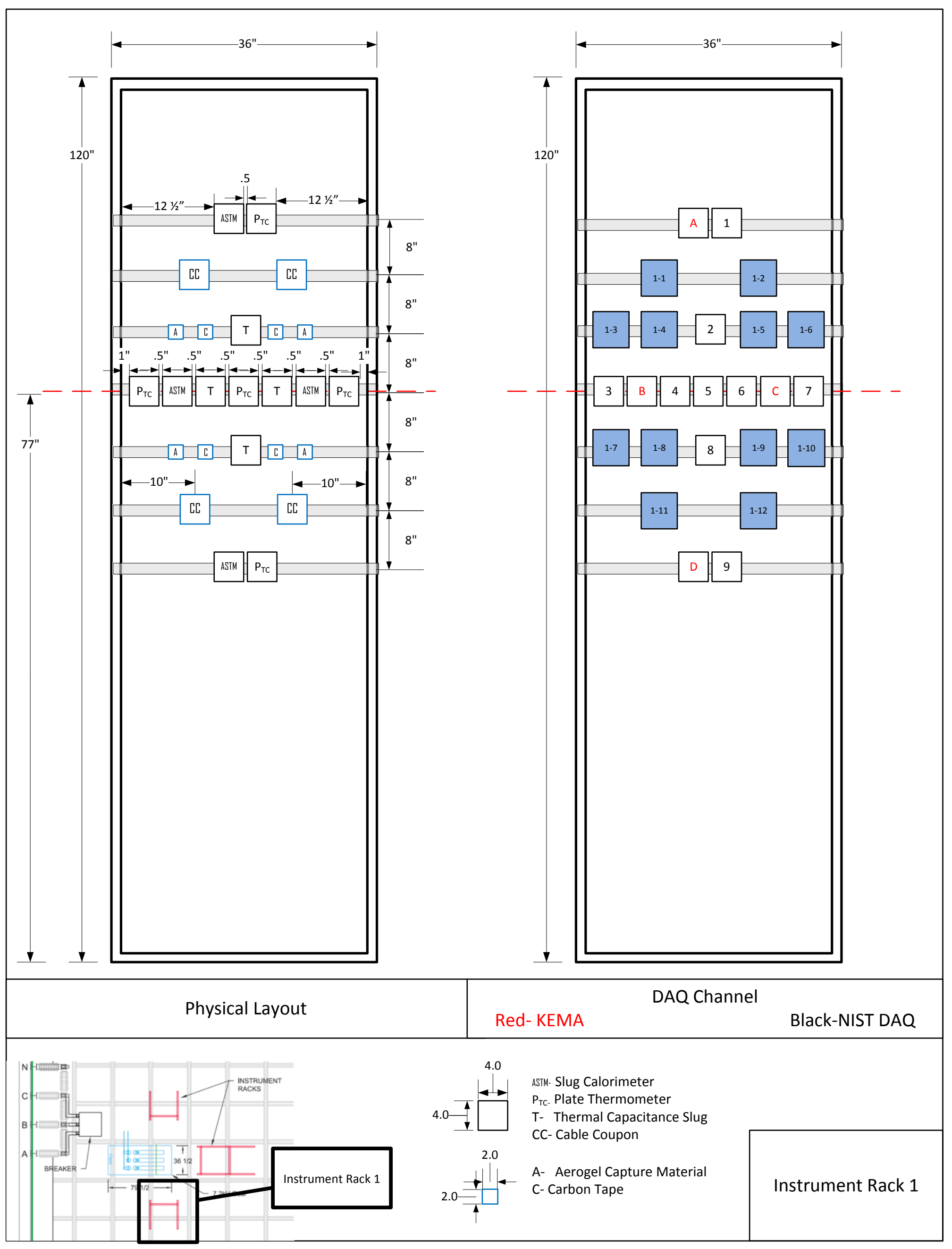




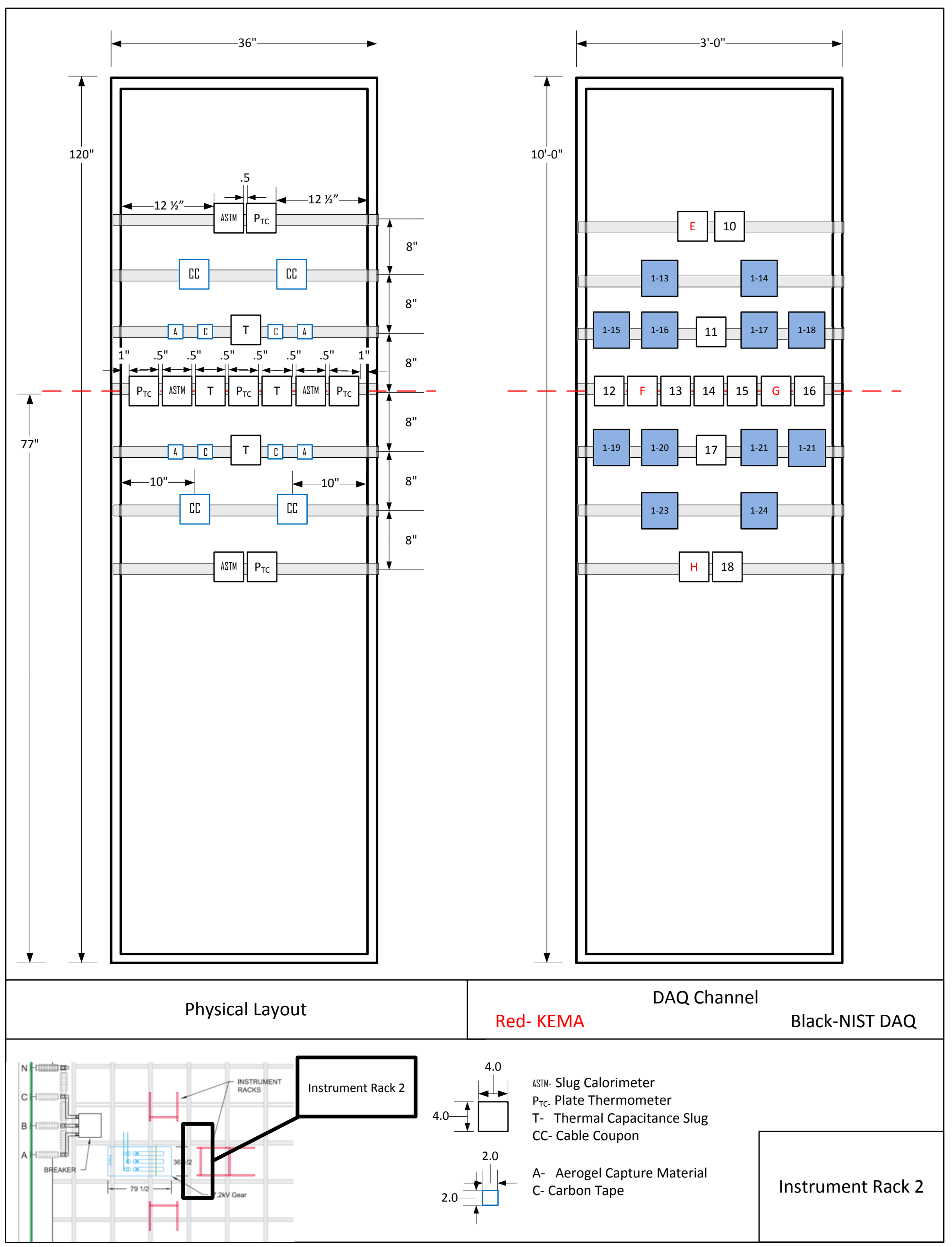




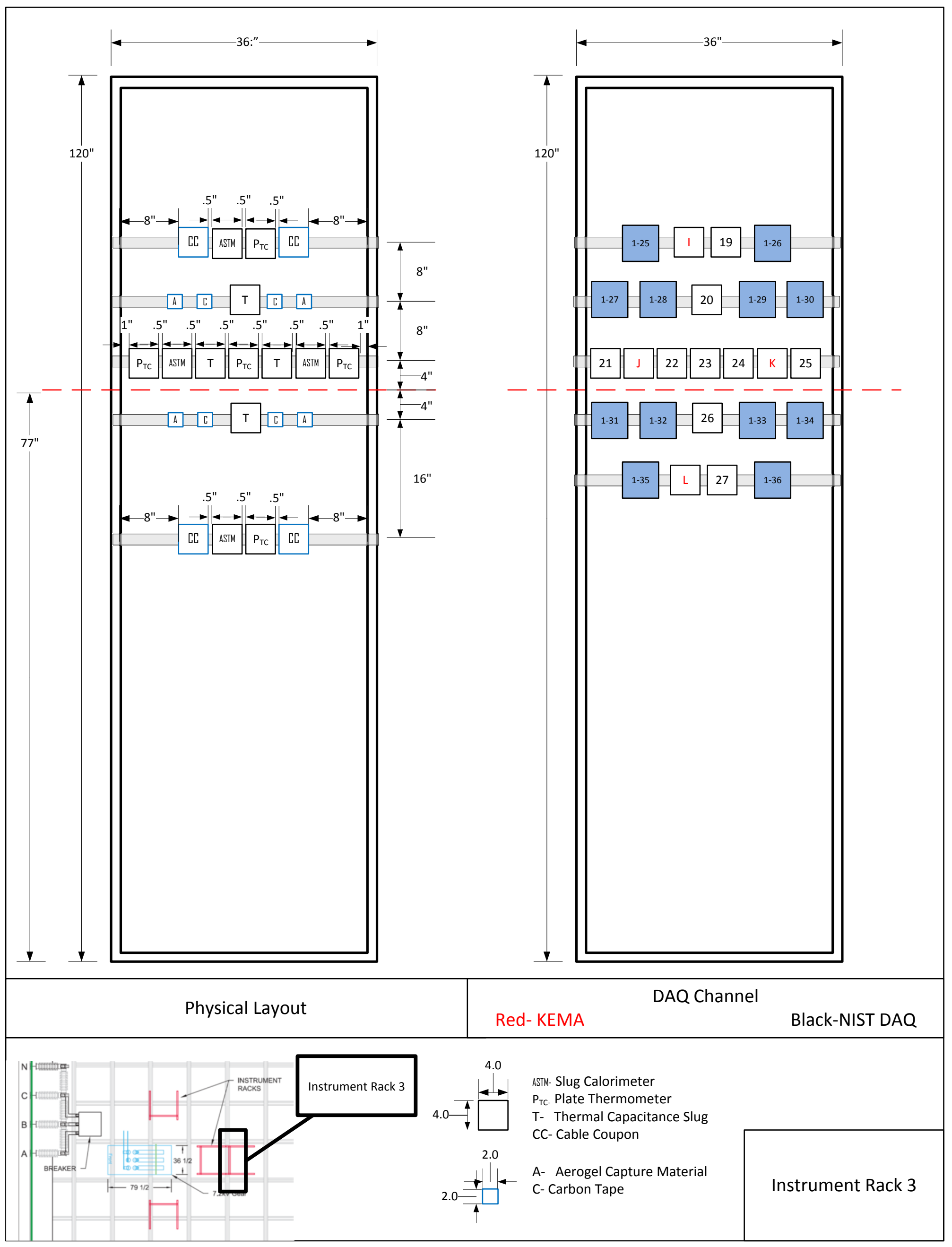




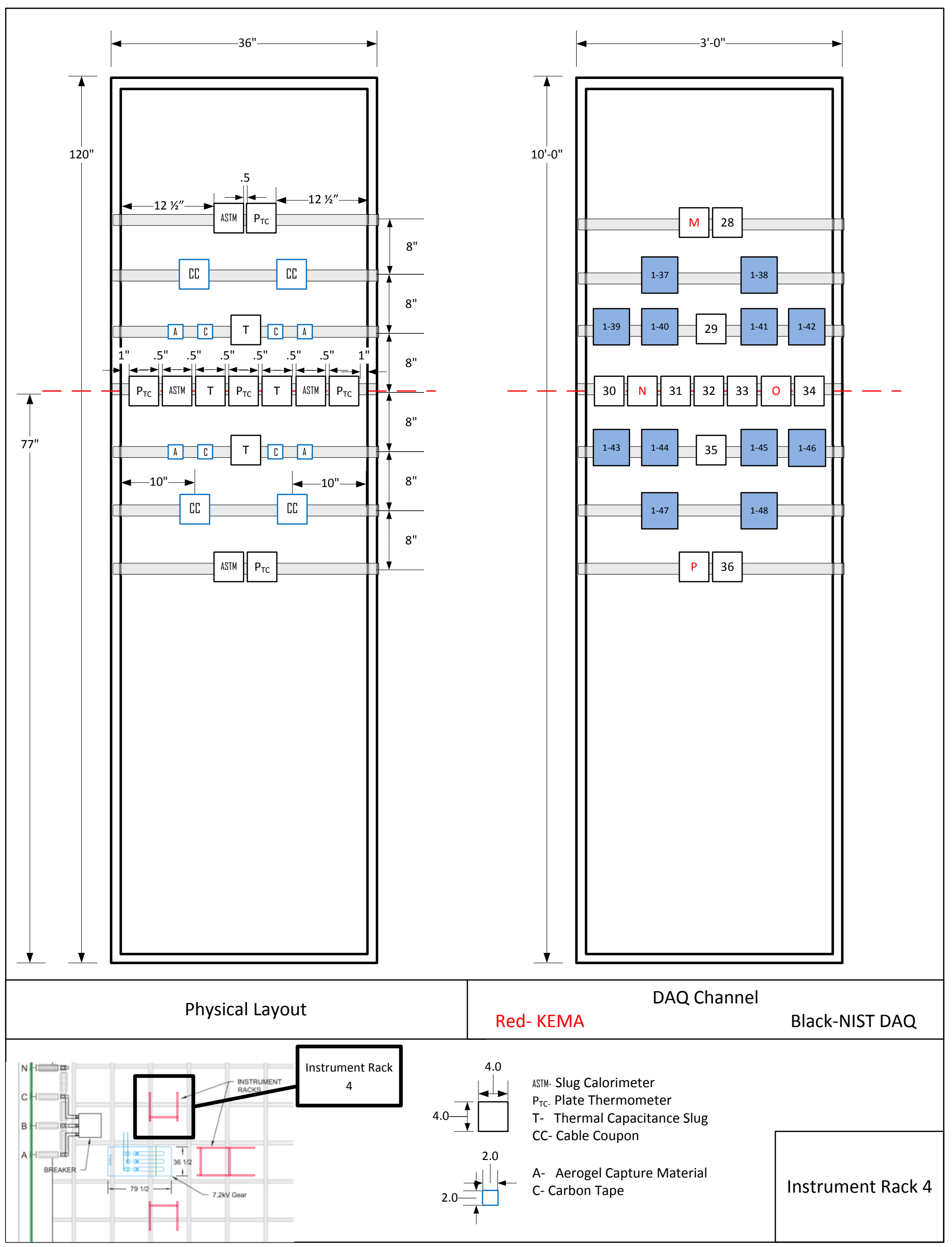




\section{KEMA-Powertest, Inc. Instrumentation Information Sheet}

TEST NO: $18174-B$

DATE: 09/14/2018

TEST DEVICE: MV Switchgear

TESTED BY: J. Duffy

\begin{tabular}{|c|c|c|c|c|c|c|}
\hline \multirow[b]{2}{*}{ CODE\# } & \multirow[b]{2}{*}{ TYPE } & \multirow[b]{2}{*}{ MANUFACTURER } & \multirow[b]{2}{*}{ MODEL\# } & \multirow[b]{2}{*}{ SERIAL\# } & \multicolumn{2}{|c|}{ CALIBRATION } \\
\hline & & & & & LAST & DUE \\
\hline DAS17 & DAS & NI/DEWETRON & DEWE-30-16 & 0195ВВ69 & $8 / 27 / 2018$ & $3 / 15 / 2019$ \\
\hline PAV37 & PNL.VOLTMTR & SIMPSON & F45-1-34 & N/A & $11 / 29 / 2018$ & $6 / 17 / 2019$ \\
\hline TEM90 & TEMP.LOGGER & DEWESoft & KRYPTONi & D05980d382 & $10 / 19 / 2018$ & $5 / 7 / 2019$ \\
\hline TEM91 & TEMP.LOGGER & DEWESoft & KRYPTONi & D05980F2EA & $10 / 19 / 2018$ & $5 / 7 / 2019$ \\
\hline TEM92 & TEMP.LOGGER & DEWESoft & KRYPTONi & D05980F2EB & 10/19/2018 & $5 / 7 / 2019$ \\
\hline ISO108 & ISO AMP & DEWETRON & HIS-LV & 437702 & $8 / 27 / 2018$ & $3 / 15 / 2019$ \\
\hline ISO109 & ISO AMP & DEWETRON & HIS-LV & 437703 & $8 / 27 / 2018$ & $3 / 15 / 2019$ \\
\hline ISO110 & ISO AMP & DEWETRON & HIS-LV & 437704 & $8 / 27 / 2018$ & $3 / 15 / 2019$ \\
\hline ISO111 & ISO AMP & DEWETRON & HIS-LV & 437705 & $8 / 27 / 2018$ & $3 / 15 / 2019$ \\
\hline ISO132 & ISO AMP & DEWETRON & HIS-LV & 437726 & $8 / 27 / 2018$ & $3 / 15 / 2019$ \\
\hline ISO117 & ISO AMP & DEWETRON & HIS-LV & 437711 & 8/1/9874 & $3 / 15 / 2019$ \\
\hline ISO118 & ISO AMP & DEWETRON & HIS-LV & 437712 & $8 / 27 / 2018$ & $3 / 15 / 2019$ \\
\hline ISO128 & ISO AMP & DEWETRON & HIS-LV & 437722 & $8 / 27 / 2018$ & $3 / 15 / 2019$ \\
\hline ISO129 & ISO AMP & DEWETRON & HIS-LV & 437723 & $8 / 27 / 2018$ & $3 / 15 / 2019$ \\
\hline ISO130 & ISO AMP & DEWETRON & HIS-LV & 437724 & $8 / 27 / 2018$ & $3 / 15 / 2019$ \\
\hline KPT102 & PRESS.TRANS & OMEGA & PX329 & $030318 I 131$ & $8 / 1 / 2018$ & $2 / 17 / 2019$ \\
\hline КРT94 & PRES.TRANS. & OMEGA & PX329 & $082514 I 109$ & $5 / 18 / 2018$ & $12 / 4 / 2018$ \\
\hline КРТ101 & PRESS.TRANS & OMEGA & PX329 & $030318 I 148$ & $8 / 1 / 2018$ & 2/17/2019 \\
\hline КРT93 & PRESS.TRANS & OMEGA & PX329 & $071114 \mid 056$ & $5 / 18 / 2018$ & $12 / 24 / 2018$ \\
\hline AMP41 & FO ISO AMP & AAA LAB SYST & AFL-300 & 1 & $6 / 25 / 2018$ & $1 / 11 / 2019$ \\
\hline AMP42 & FO ISO AMP & AAA LAB SYST & AFL-300 & 2 & $6 / 25 / 2018$ & $1 / 11 / 2019$ \\
\hline AMP43 & FO ISO AMP & AAA LAB SYST & AFL-300 & 3 & $6 / 25 / 2018$ & $1 / 11 / 2019$ \\
\hline AMP44 & FO ISO AMP & AAA LAB SYST & AFL-300 & 4 & $6 / 25 / 2018$ & $1 / 11 / 2019$ \\
\hline CTX172 & ROGOWSKI CT & PEM & SDS0680 & $0002-0100 A$ & $9 / 7 / 2018$ & $3 / 26 / 2019$ \\
\hline CTX173 & ROGOWSKI CT & PEM & SDS0680 & 0002-0100B & 9/7/2018 & $3 / 26 / 2019$ \\
\hline CTX174 & ROGOWSKI CT & PEM & SDS0680 & $0002-0100 C$ & 9/7/2018 & $3 / 26 / 2019$ \\
\hline PTX06 & P.T. & GE & JVM5 & 3737435 & $10 / 3 / 2018$ & $10 / 3 / 2020$ \\
\hline PTX07 & P.T. & GE & JVM5 & 3737433 & $10 / 3 / 2018$ & $10 / 3 / 2020$ \\
\hline PTX08 & P.T. & GE & JVM5 & 3737432 & $10 / 3 / 2018$ & $10 / 3 / 2020$ \\
\hline VTD10 & VOLT.TRANSD & LEM & CVS-200 & 11411940445 & $412 / 4 / 2018$ & $6 / 22 / 2019$ \\
\hline VTD11 & VOLT.TRANSD & LEM & CVS-200 & 11411940445 & ๓2/4/2018 & $6 / 22 / 2019$ \\
\hline VTD12 & VOLT.TRANSD & LEM & CVS-200 & 11411940445 & $512 / 4 / 2018$ & 6/22/2019 \\
\hline
\end{tabular}



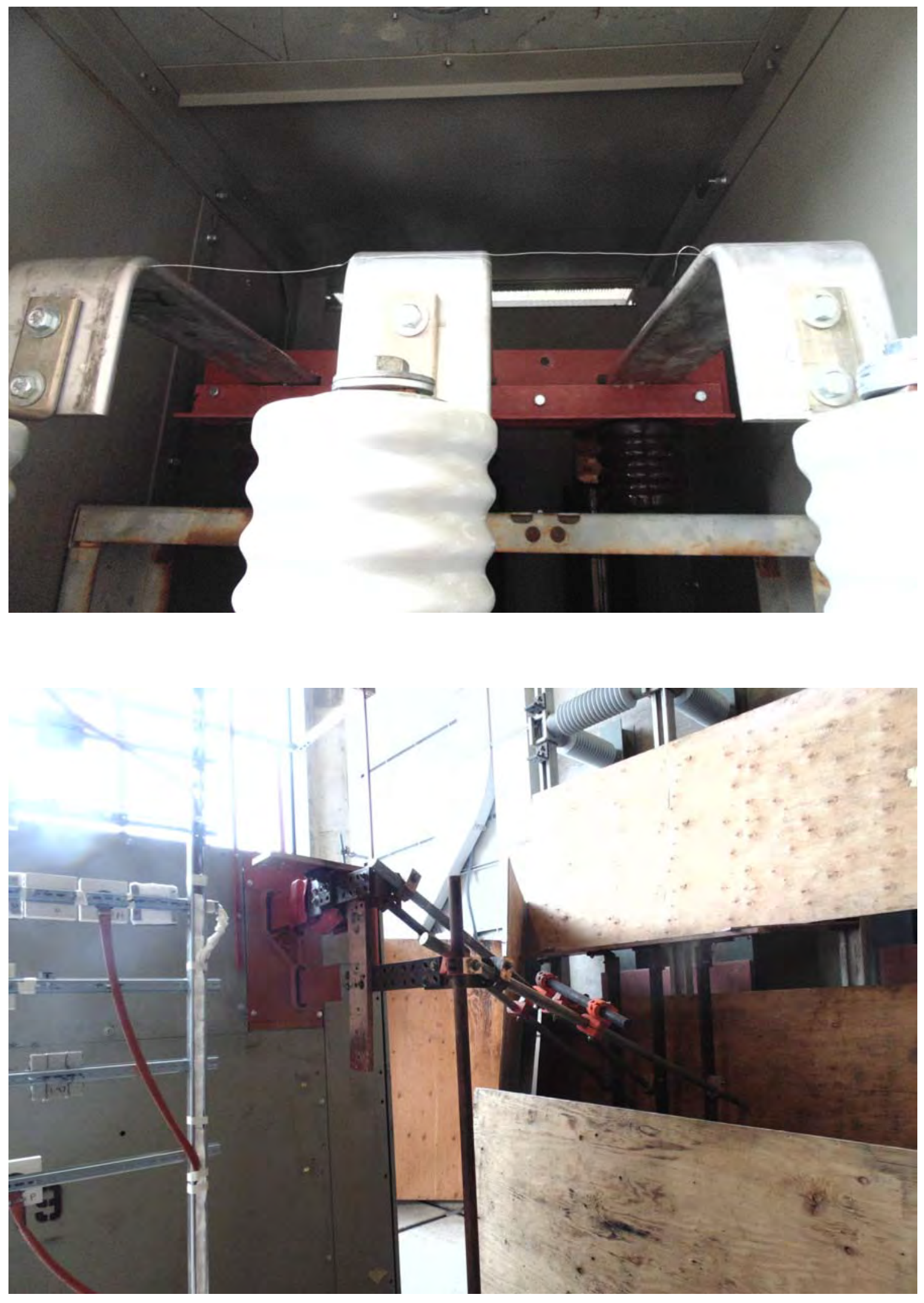

REPORT \# 18174-B 

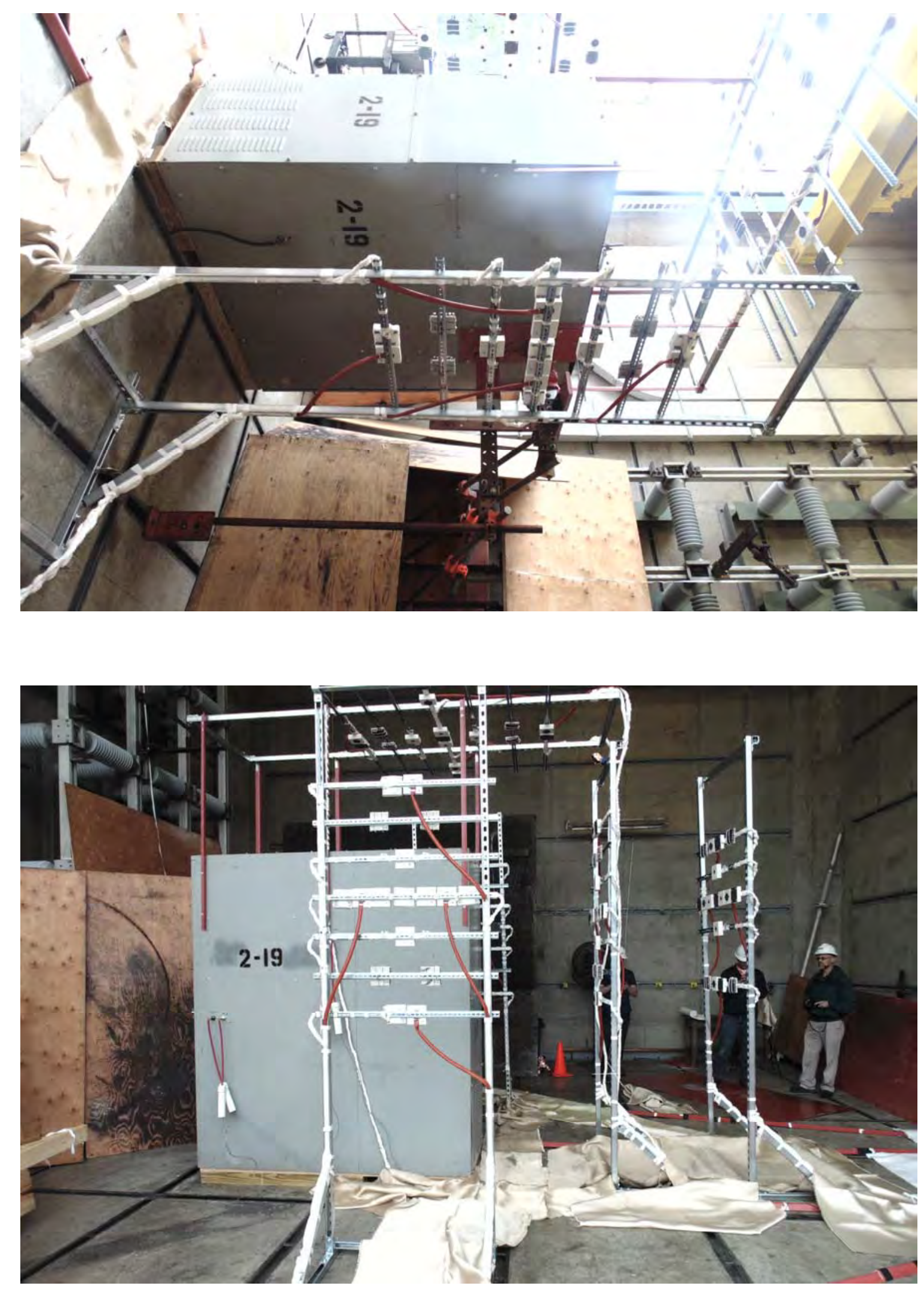

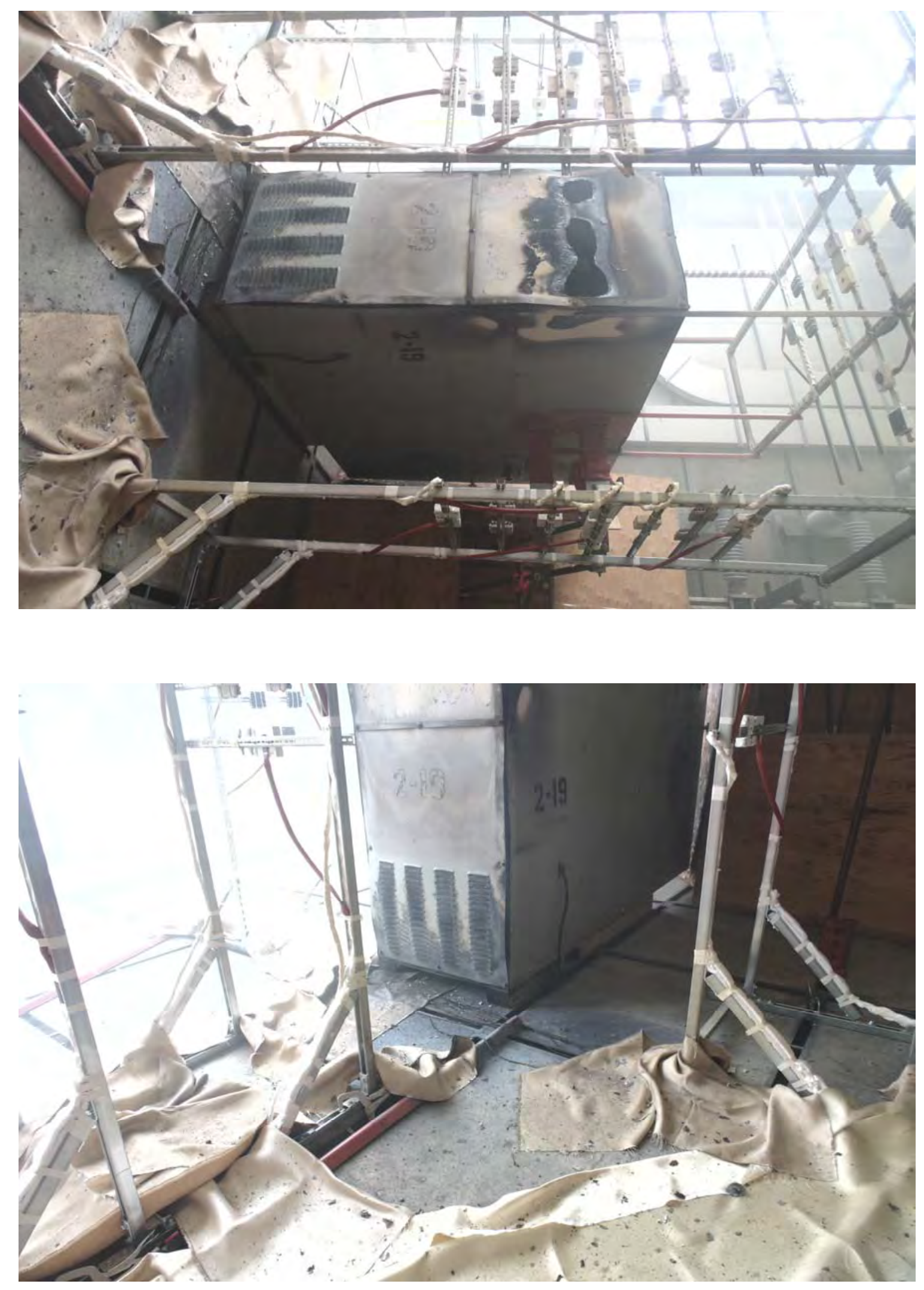

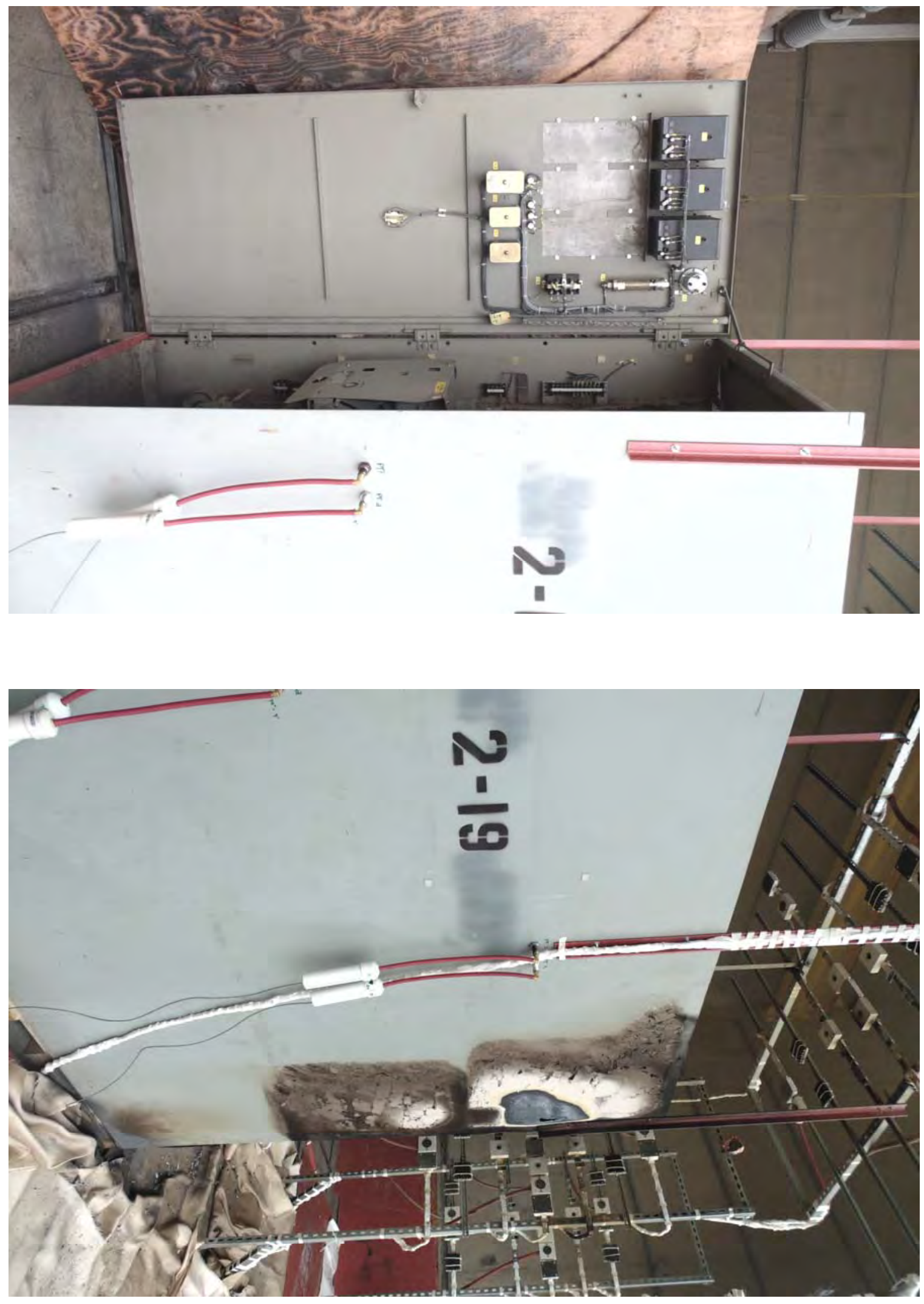

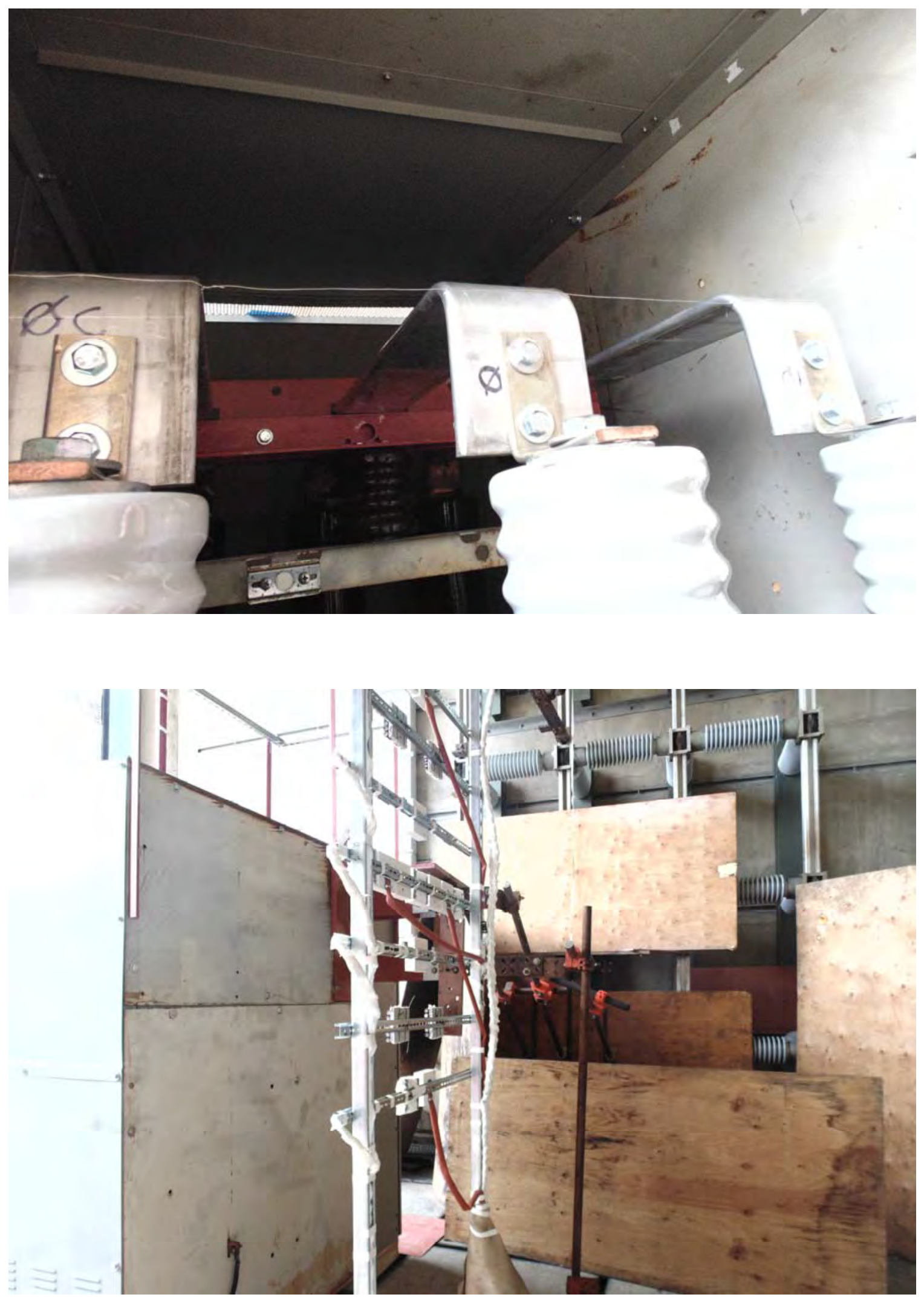

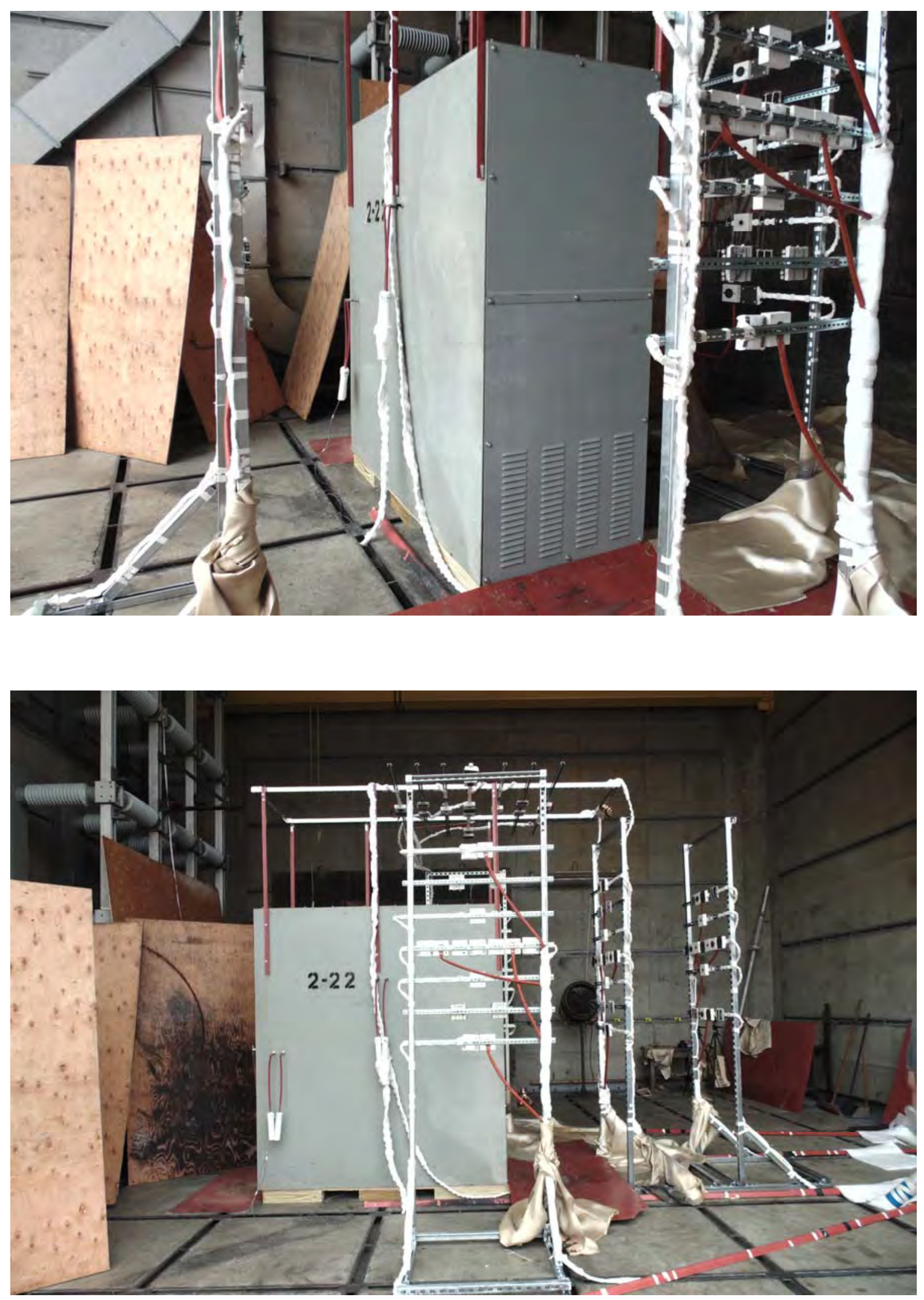

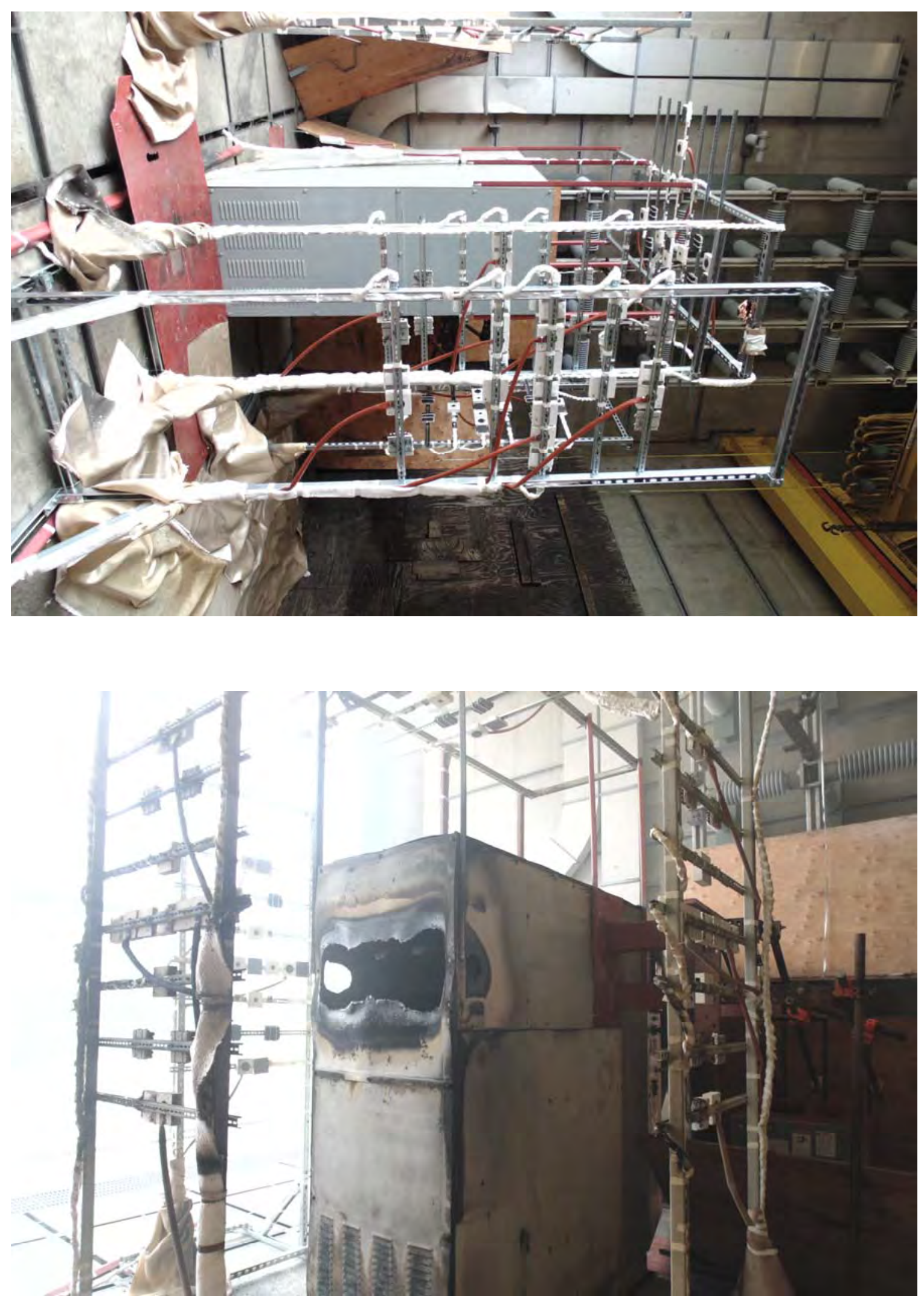

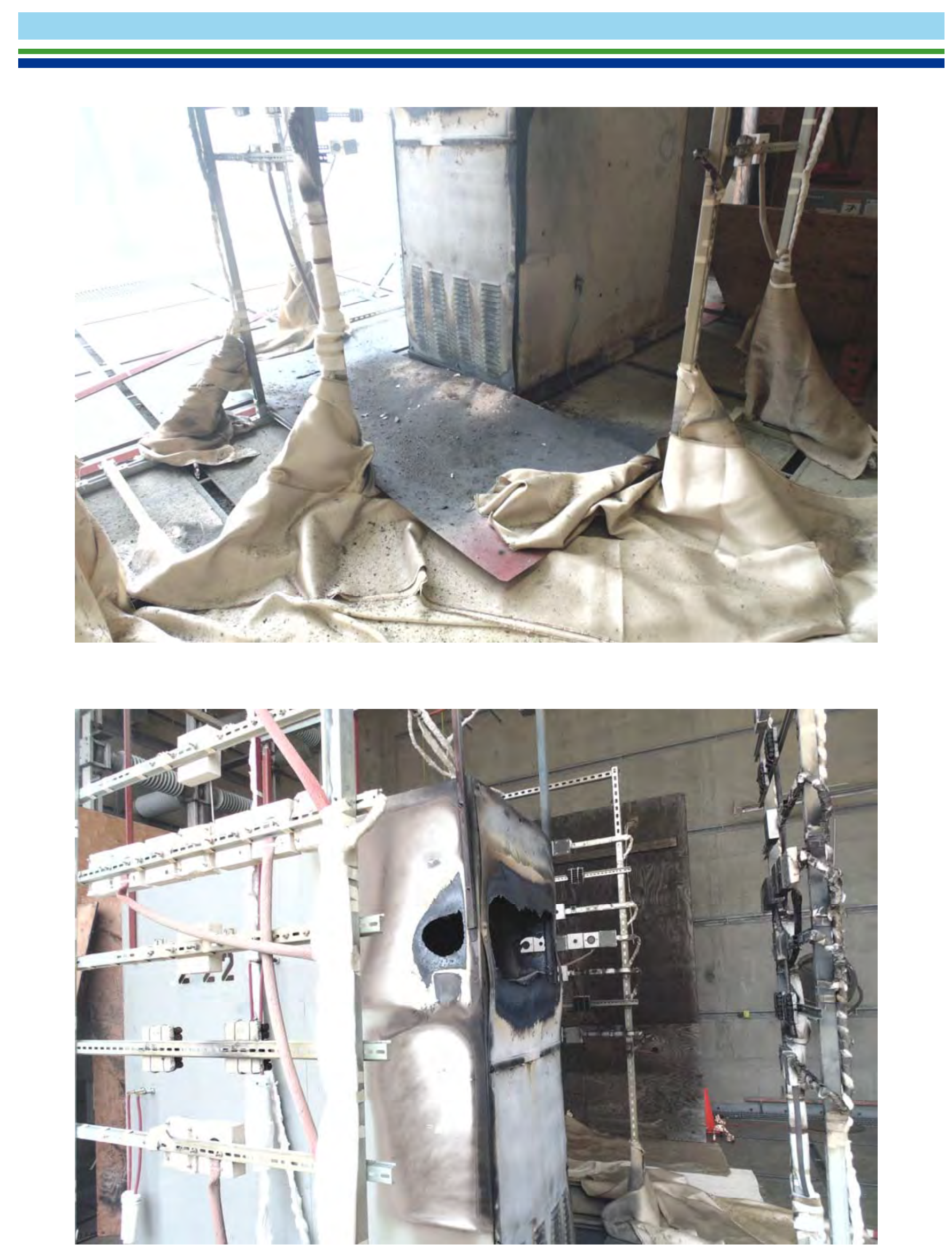

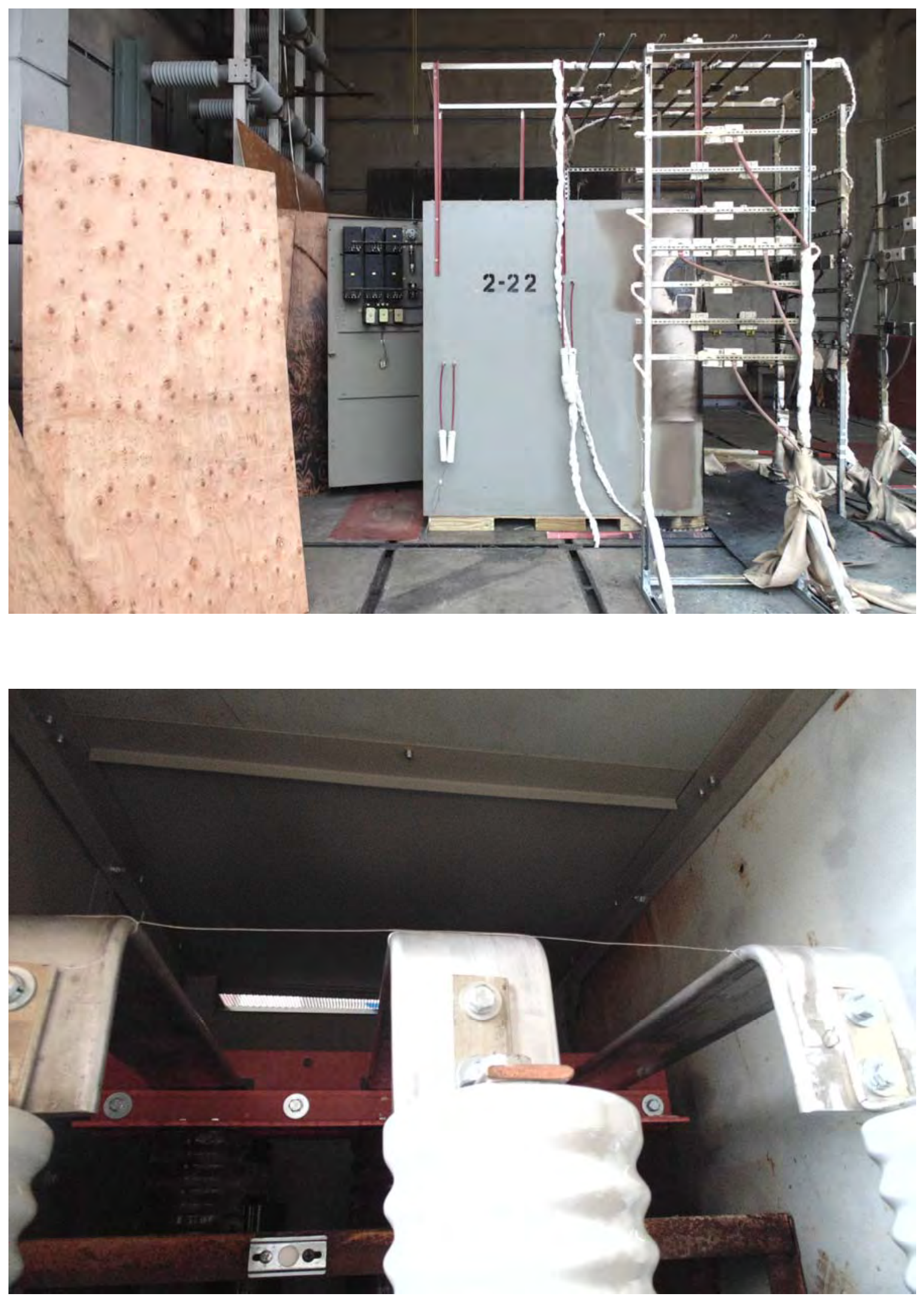

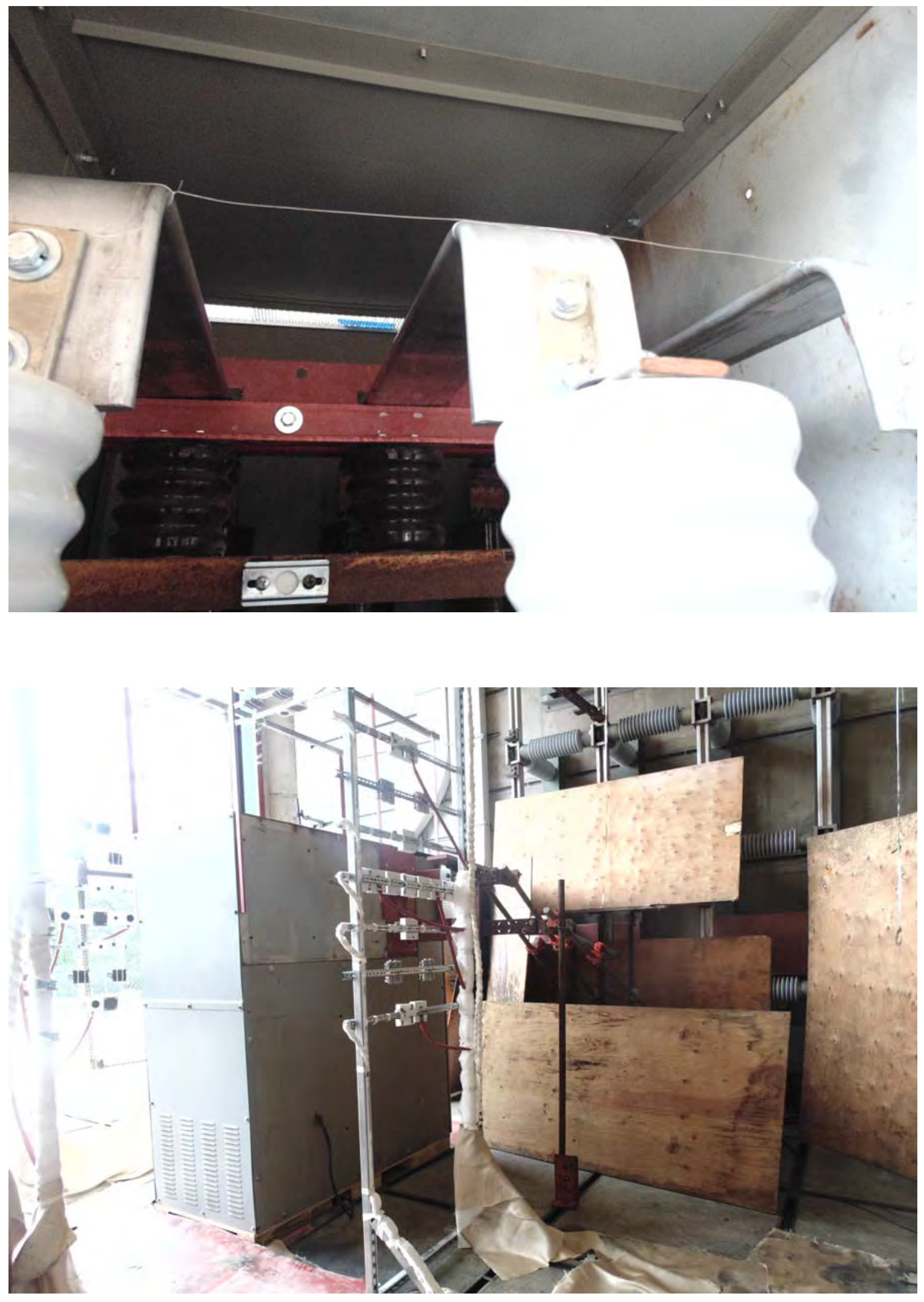

REPORT \# 18174-B 

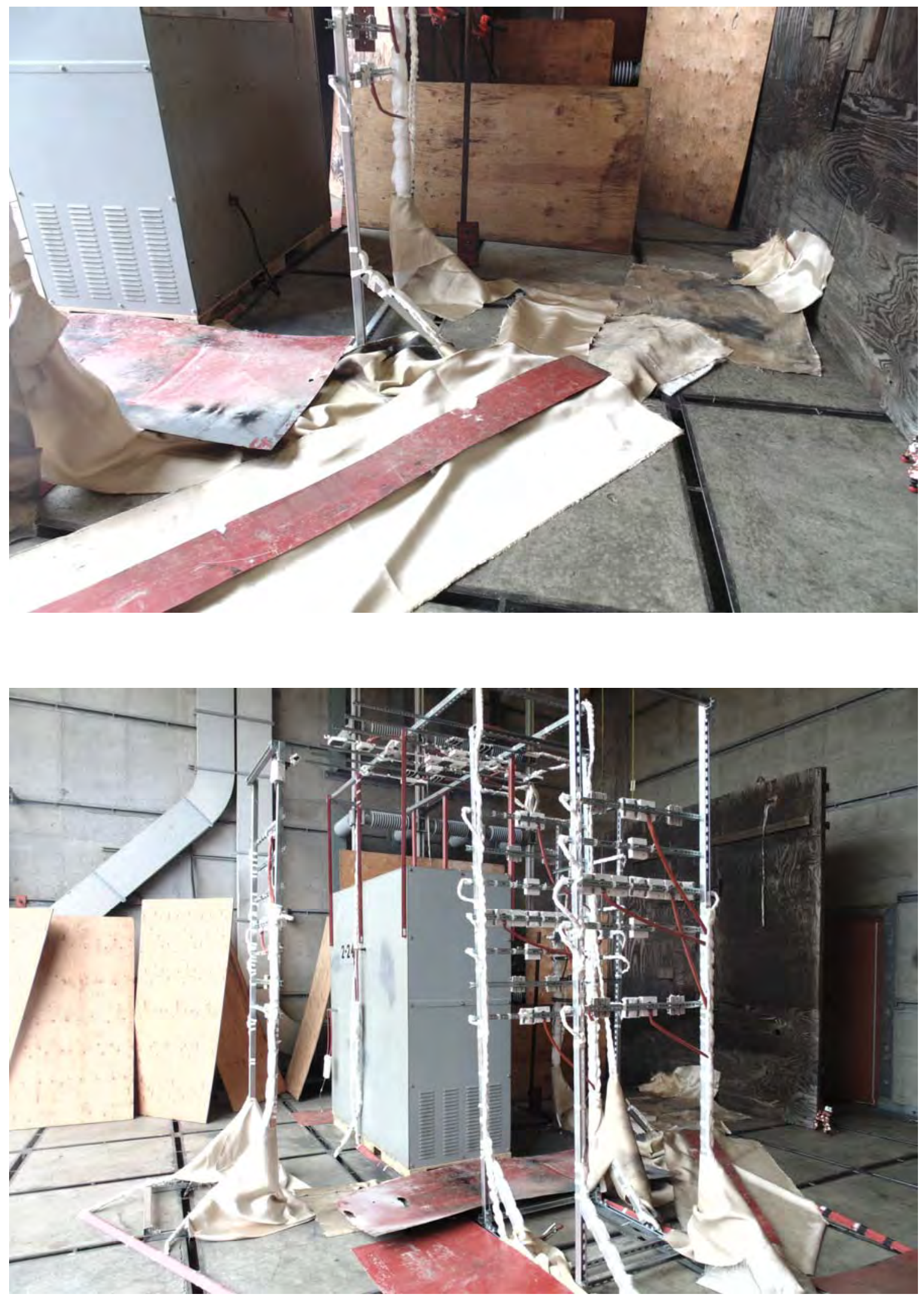

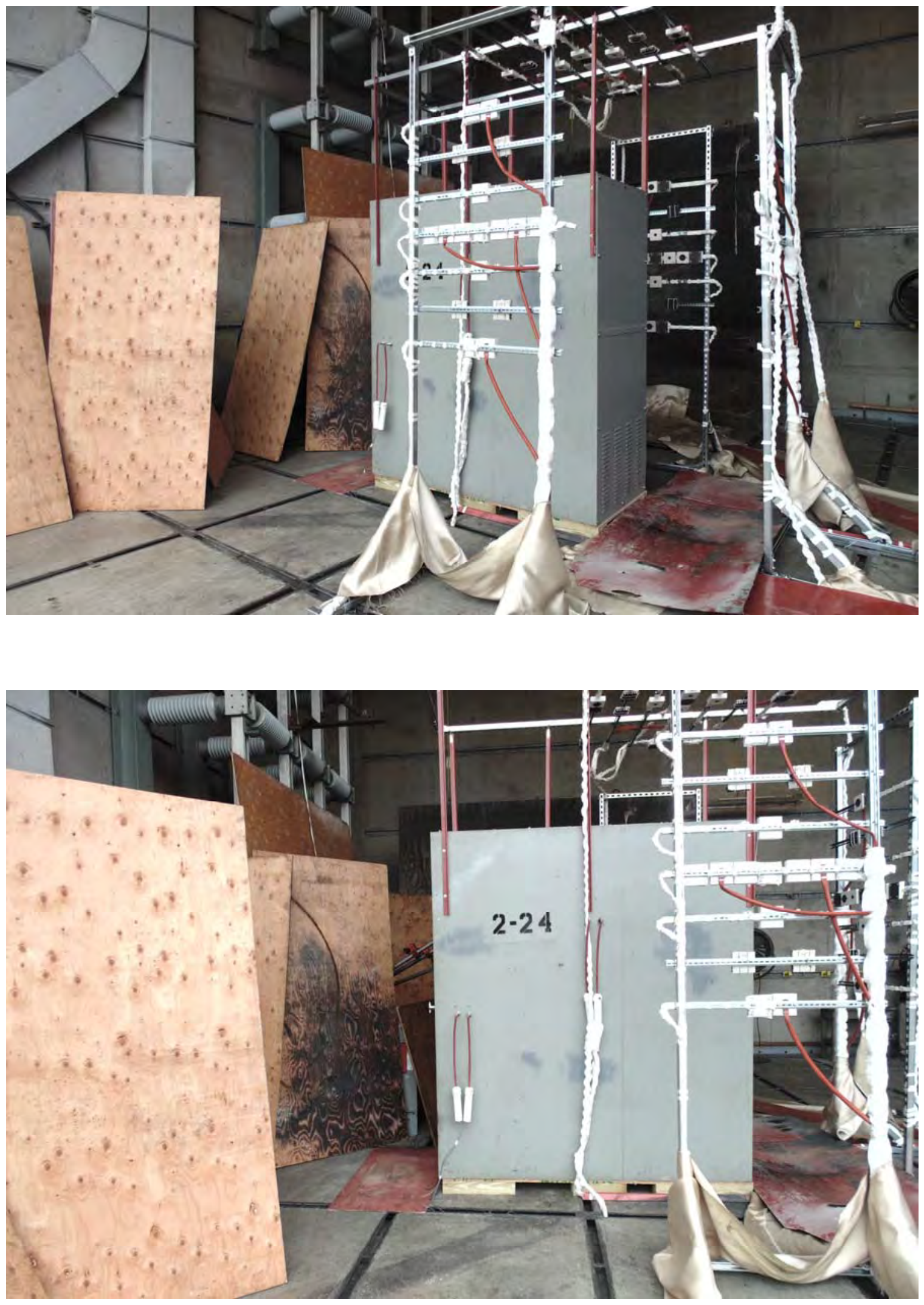

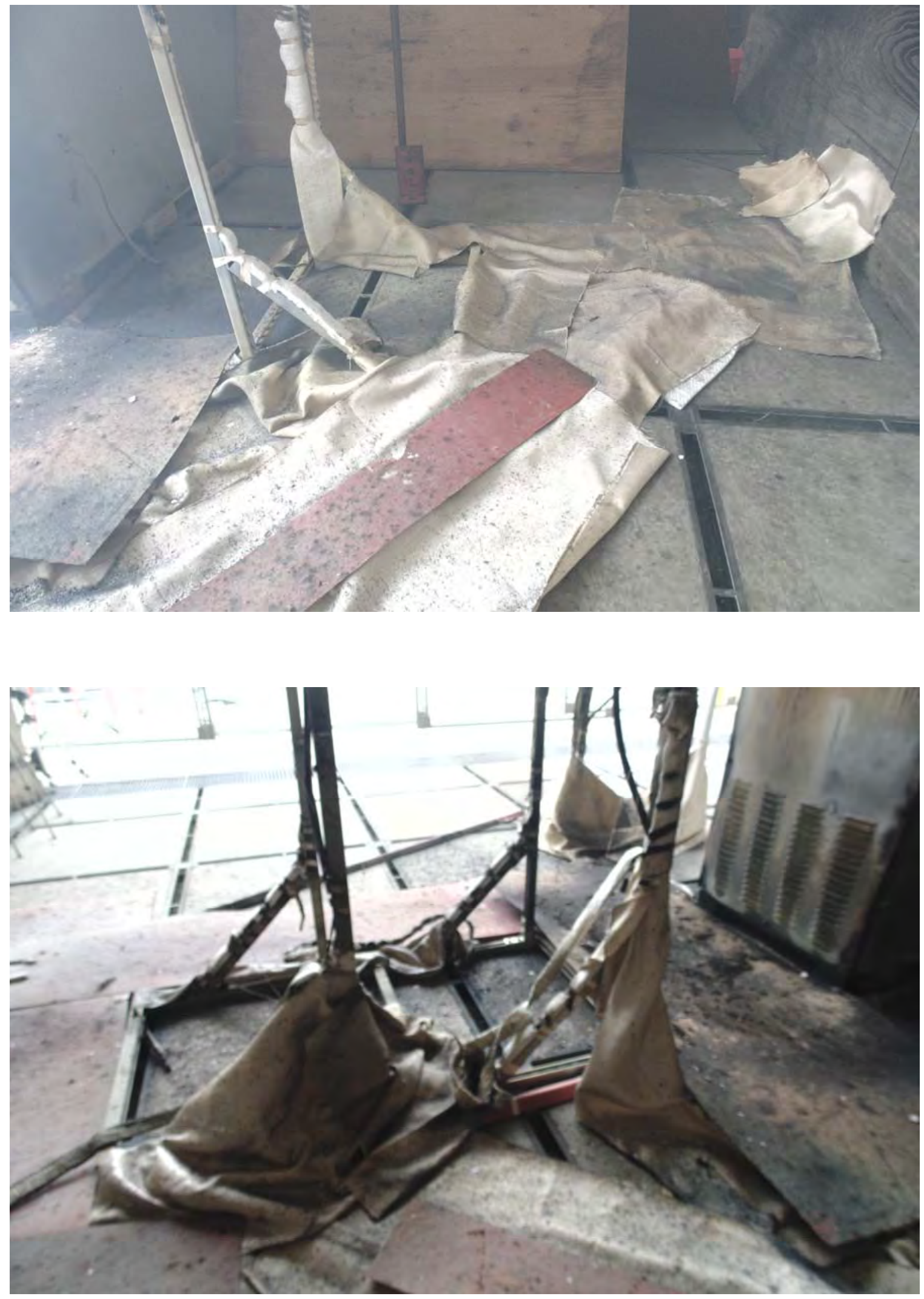

REPORT \# 18174-B 

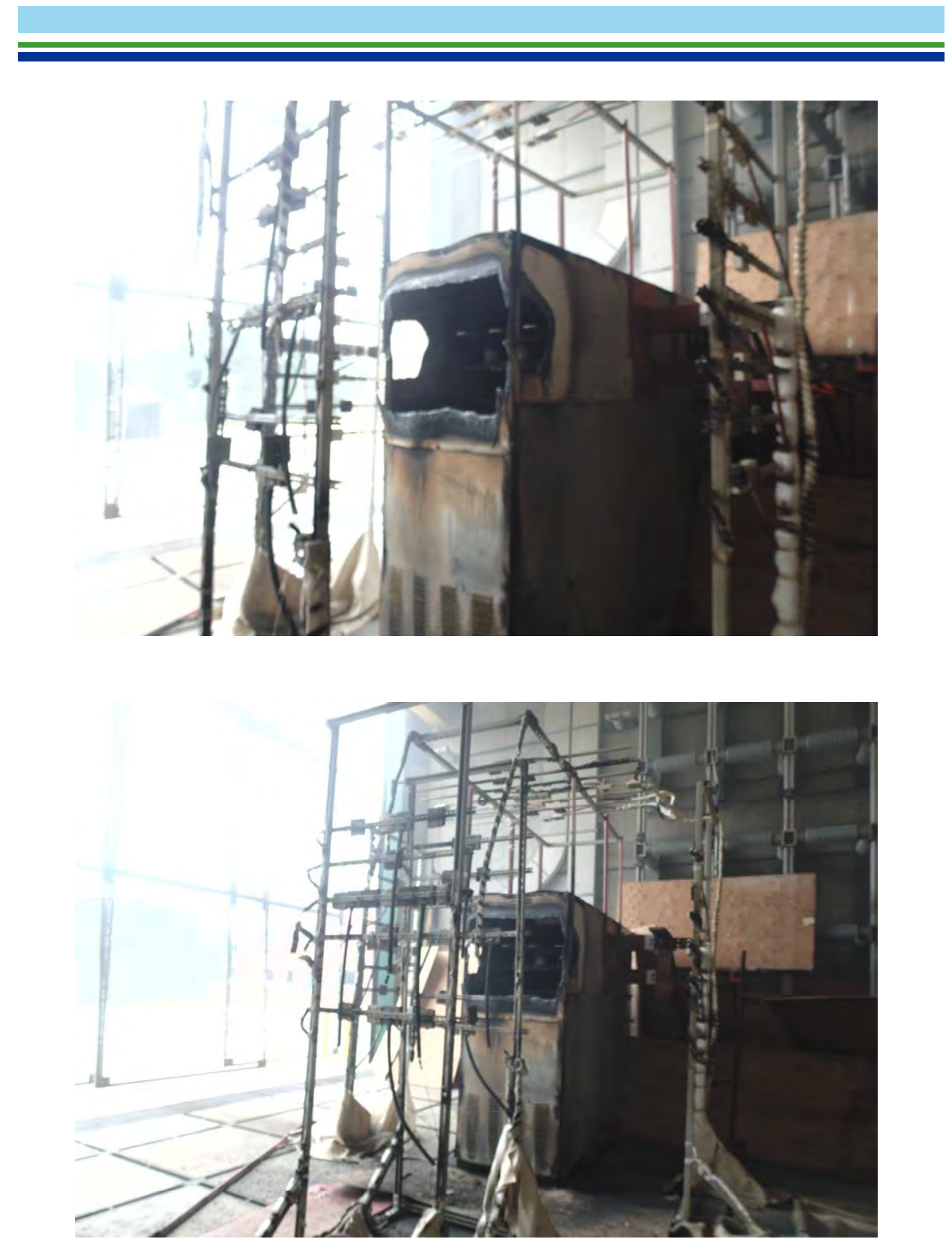

REPORT \# 18174-B 

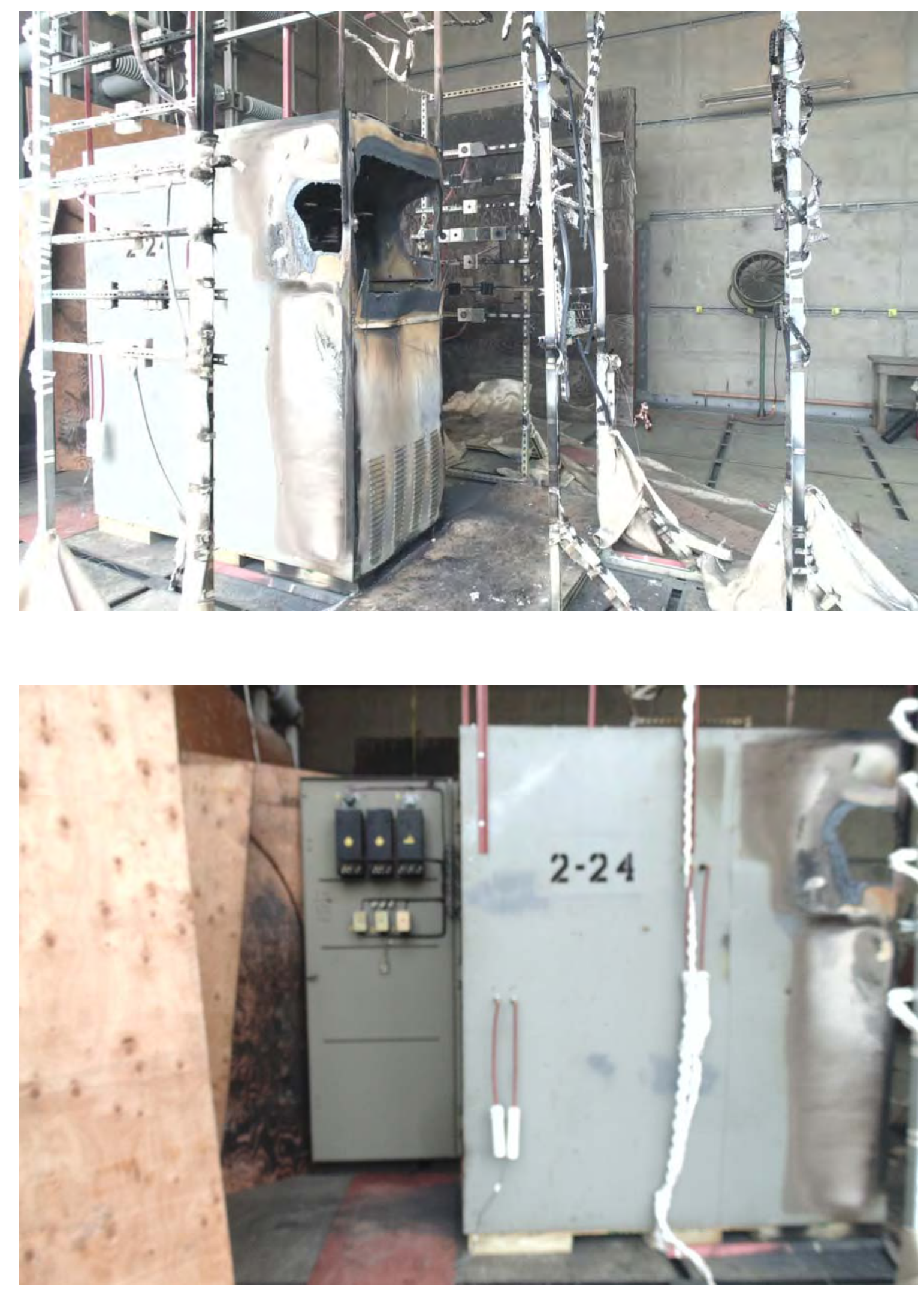

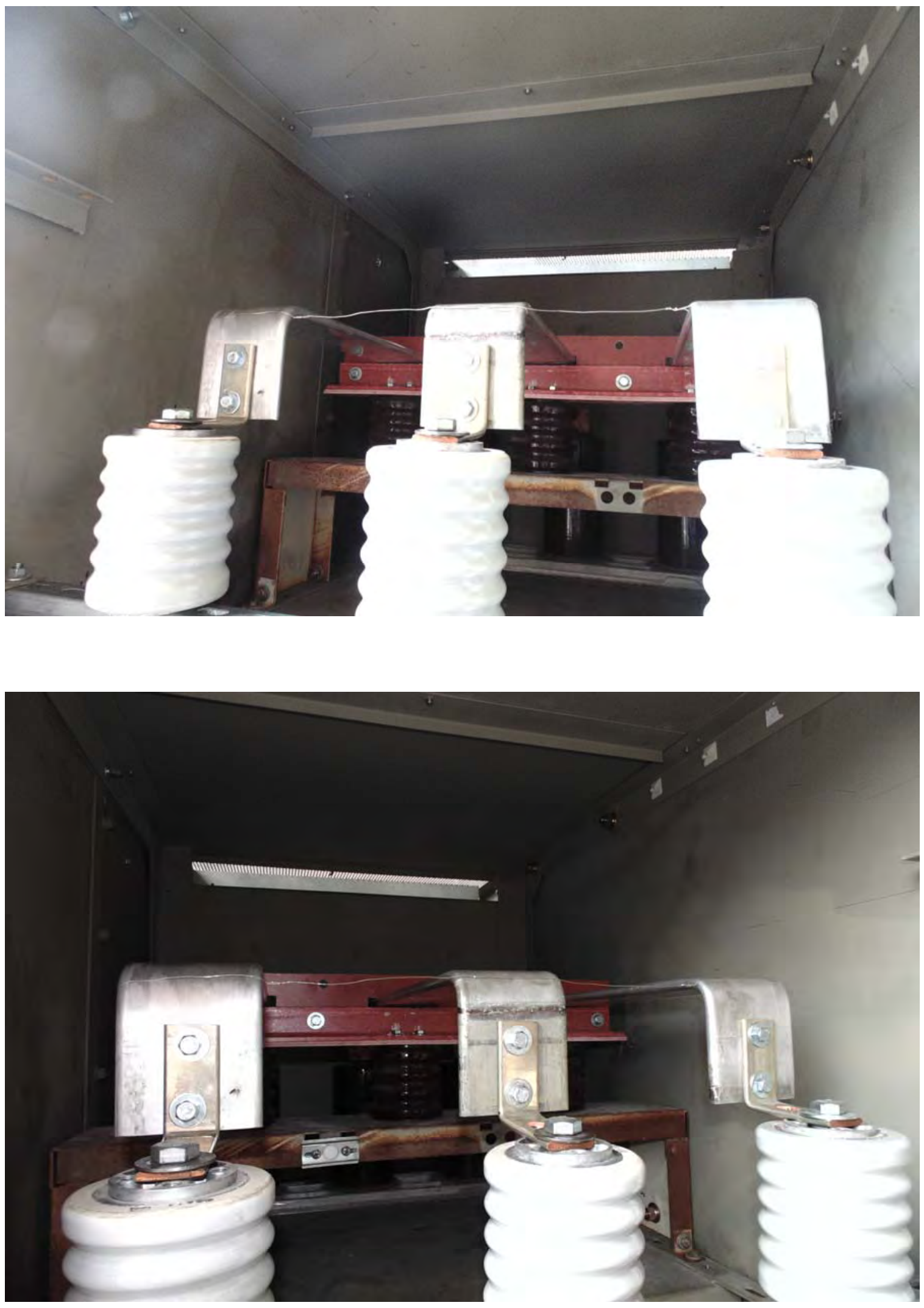

REPORT \# 18174-B 

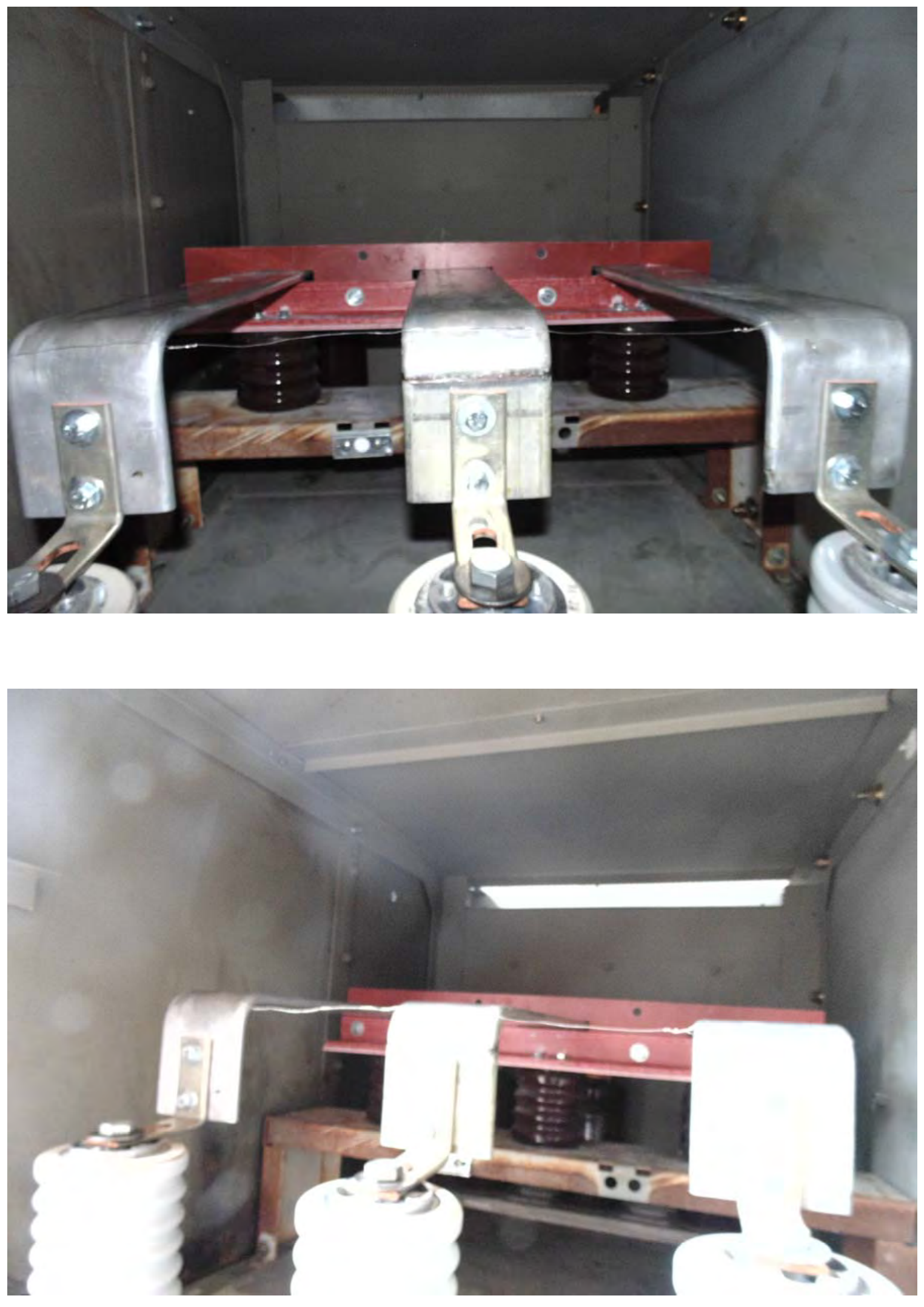

REPORT \# 18174-B 

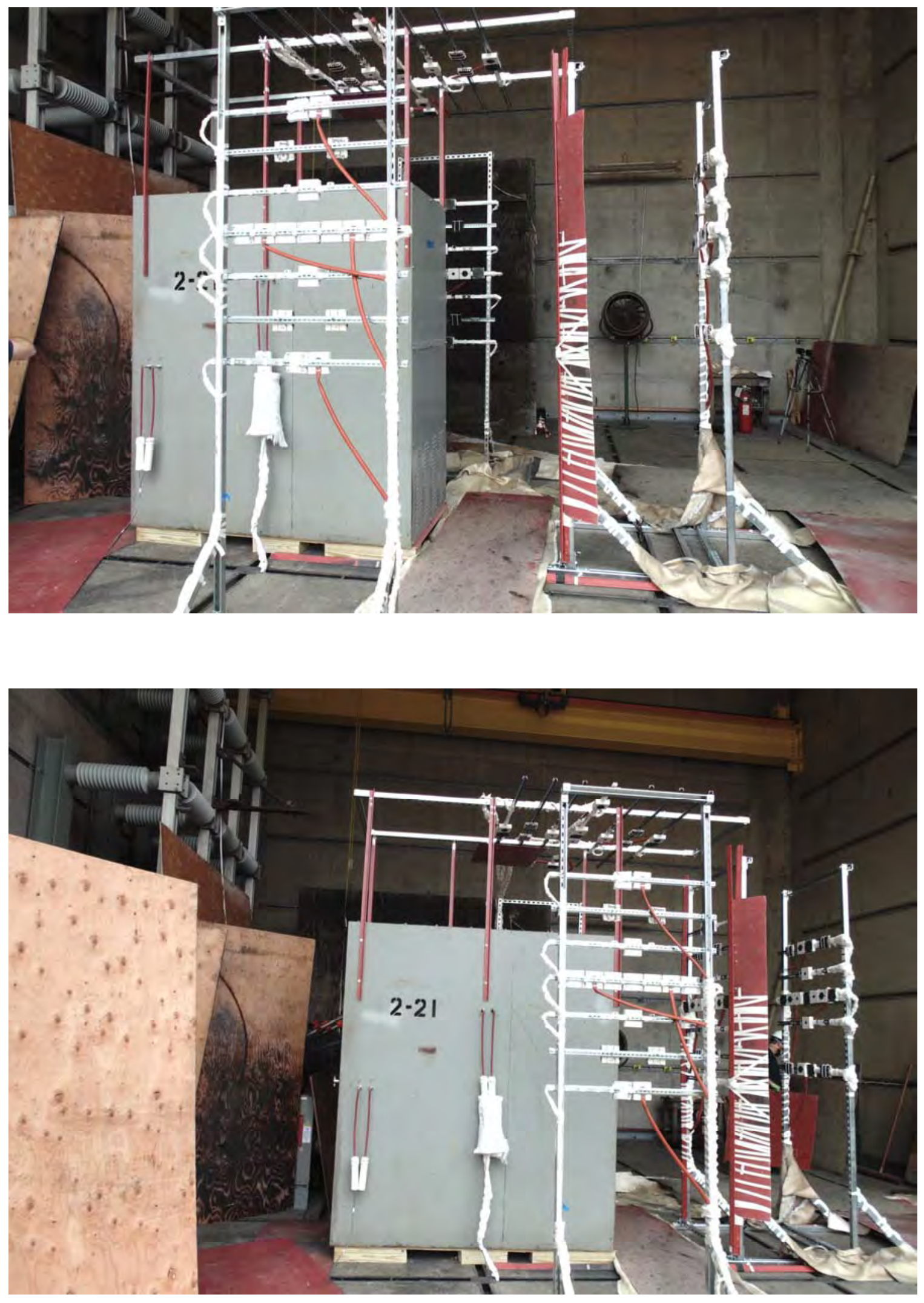

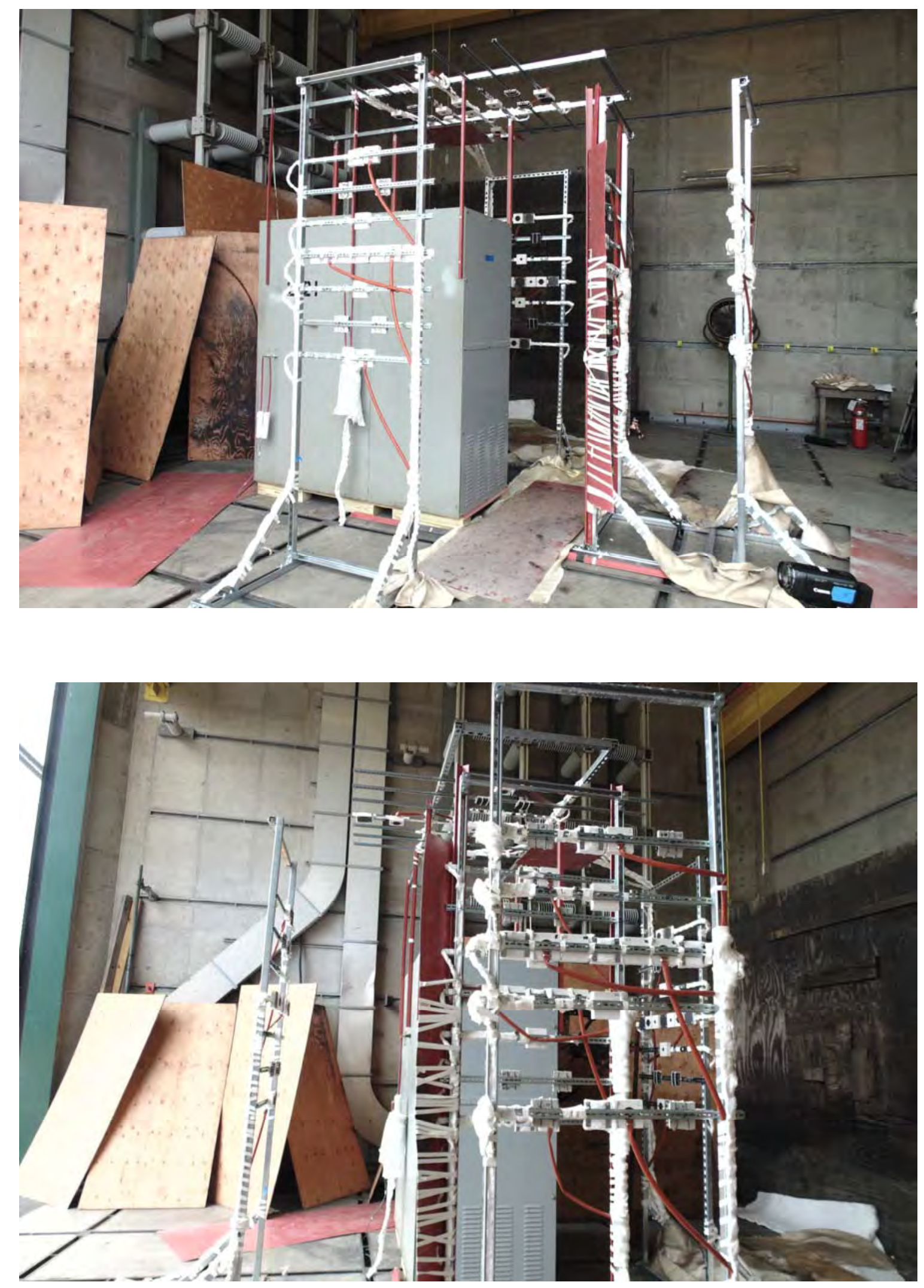

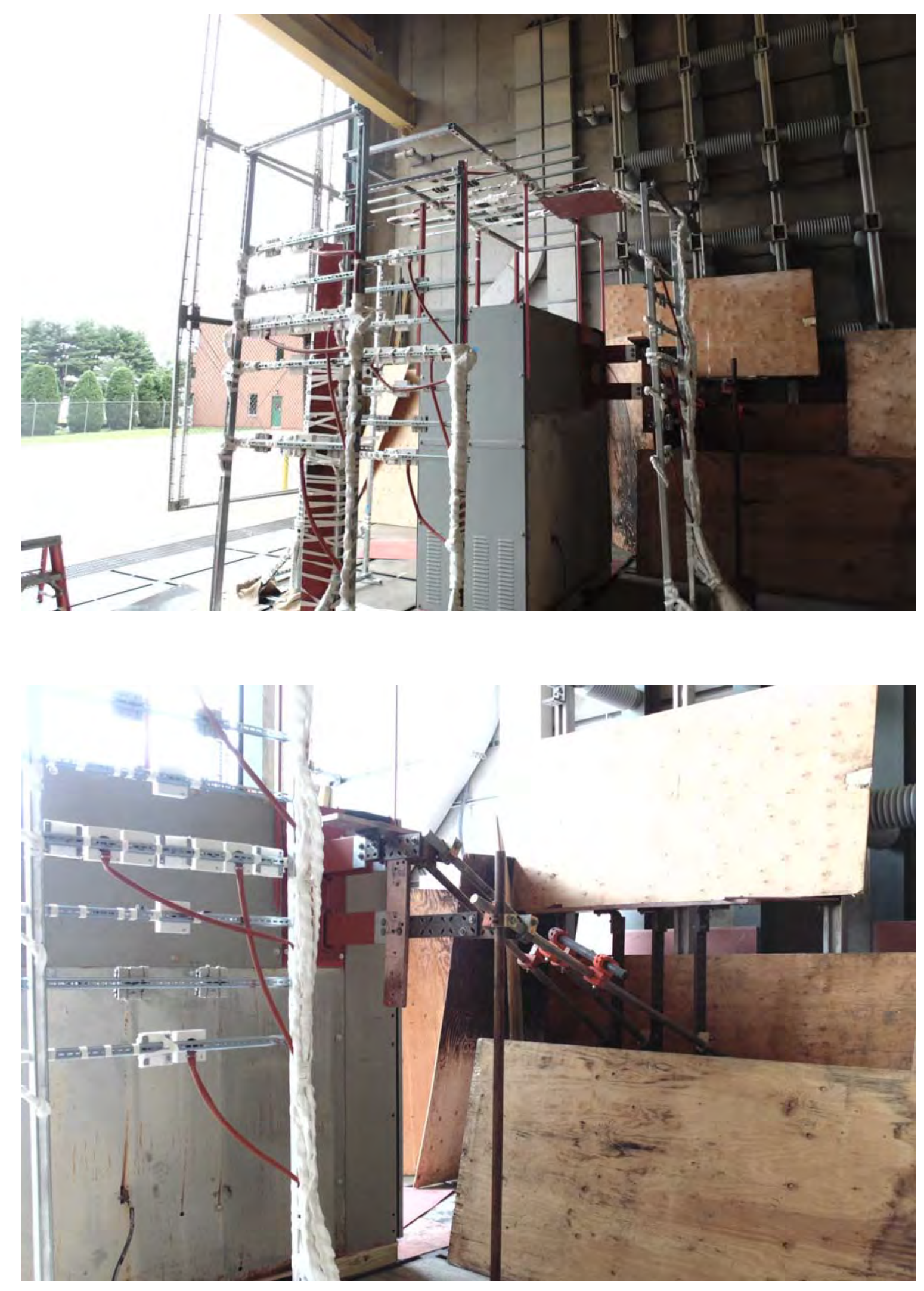

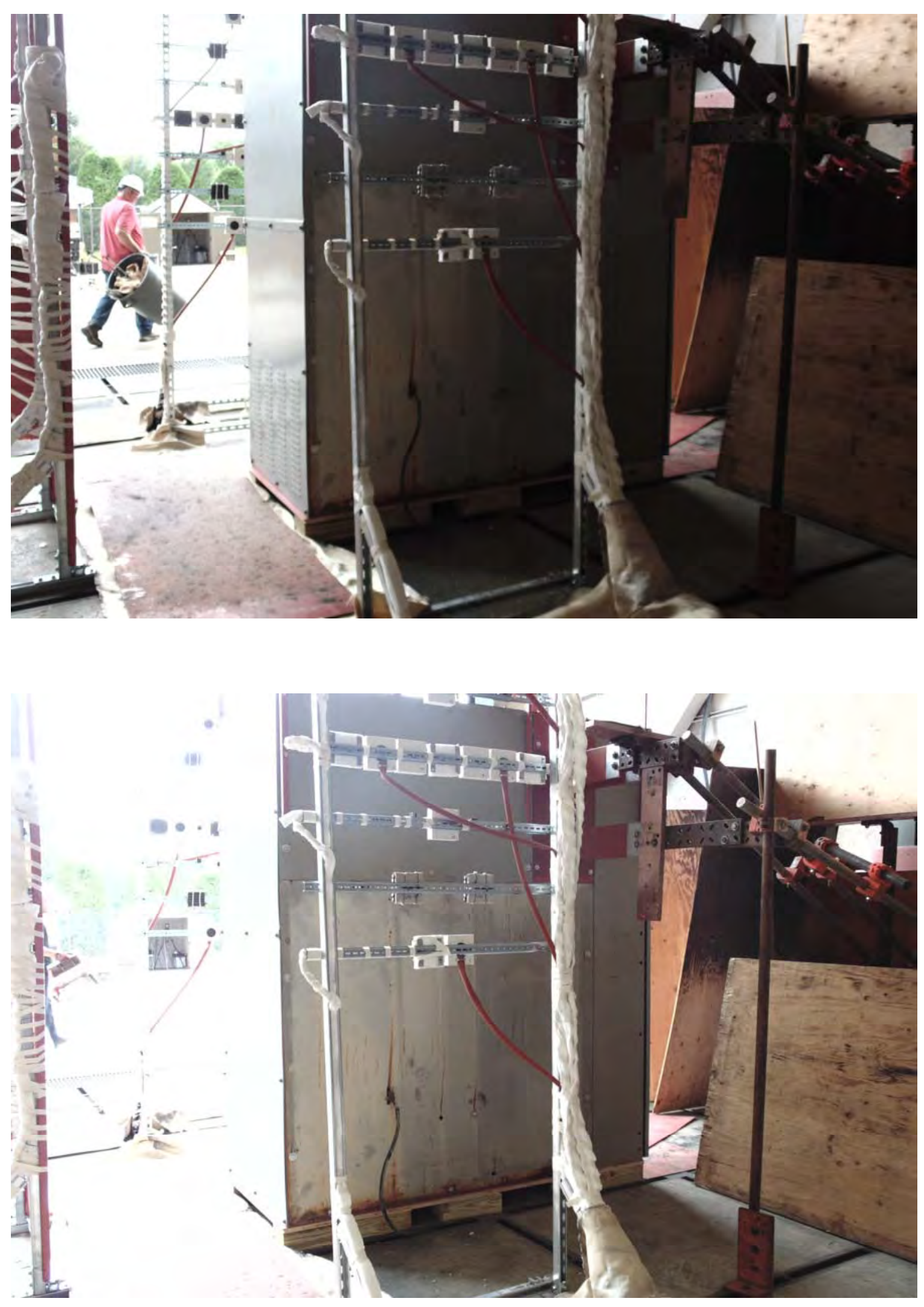

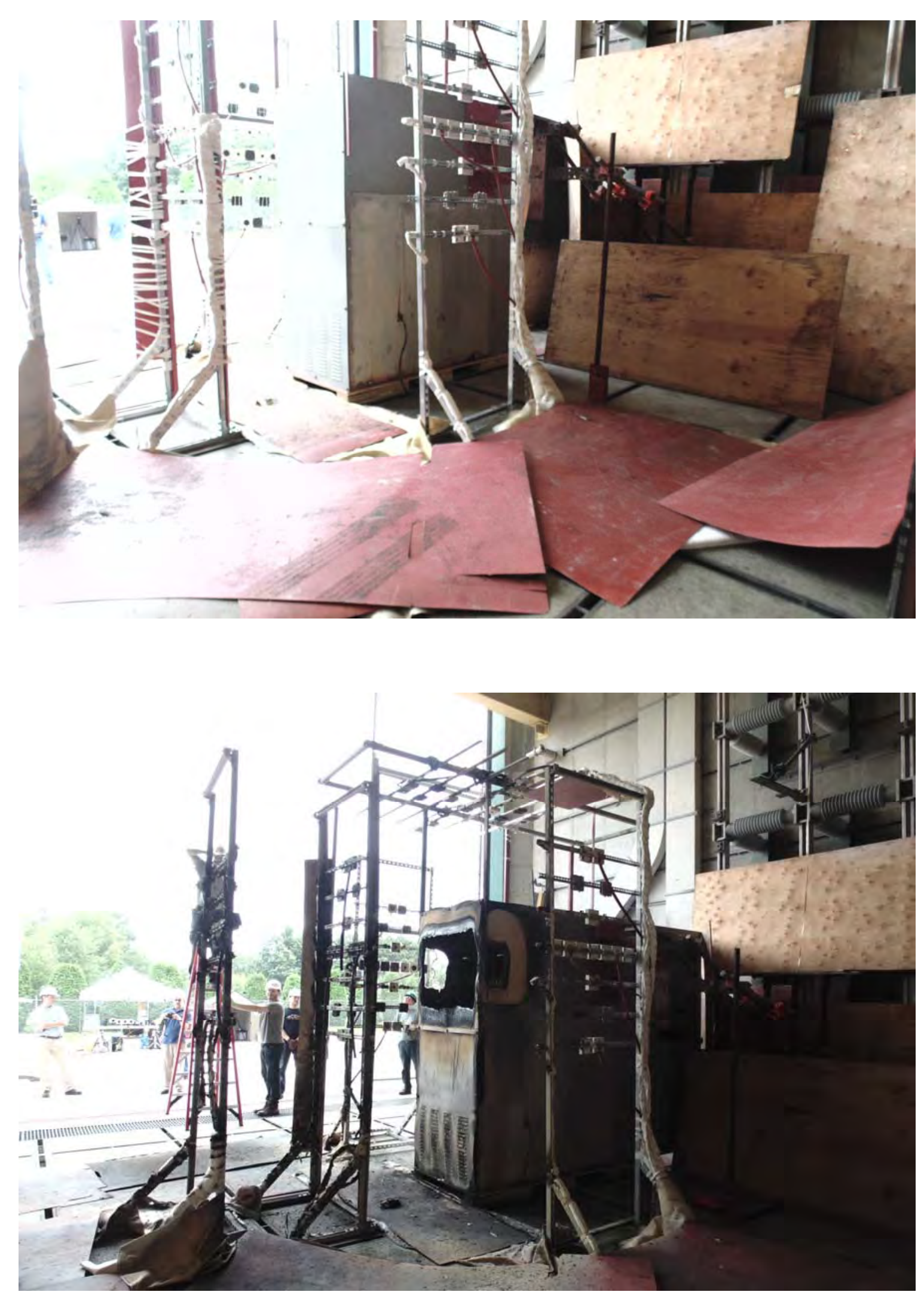

REPORT \# 18174-B 

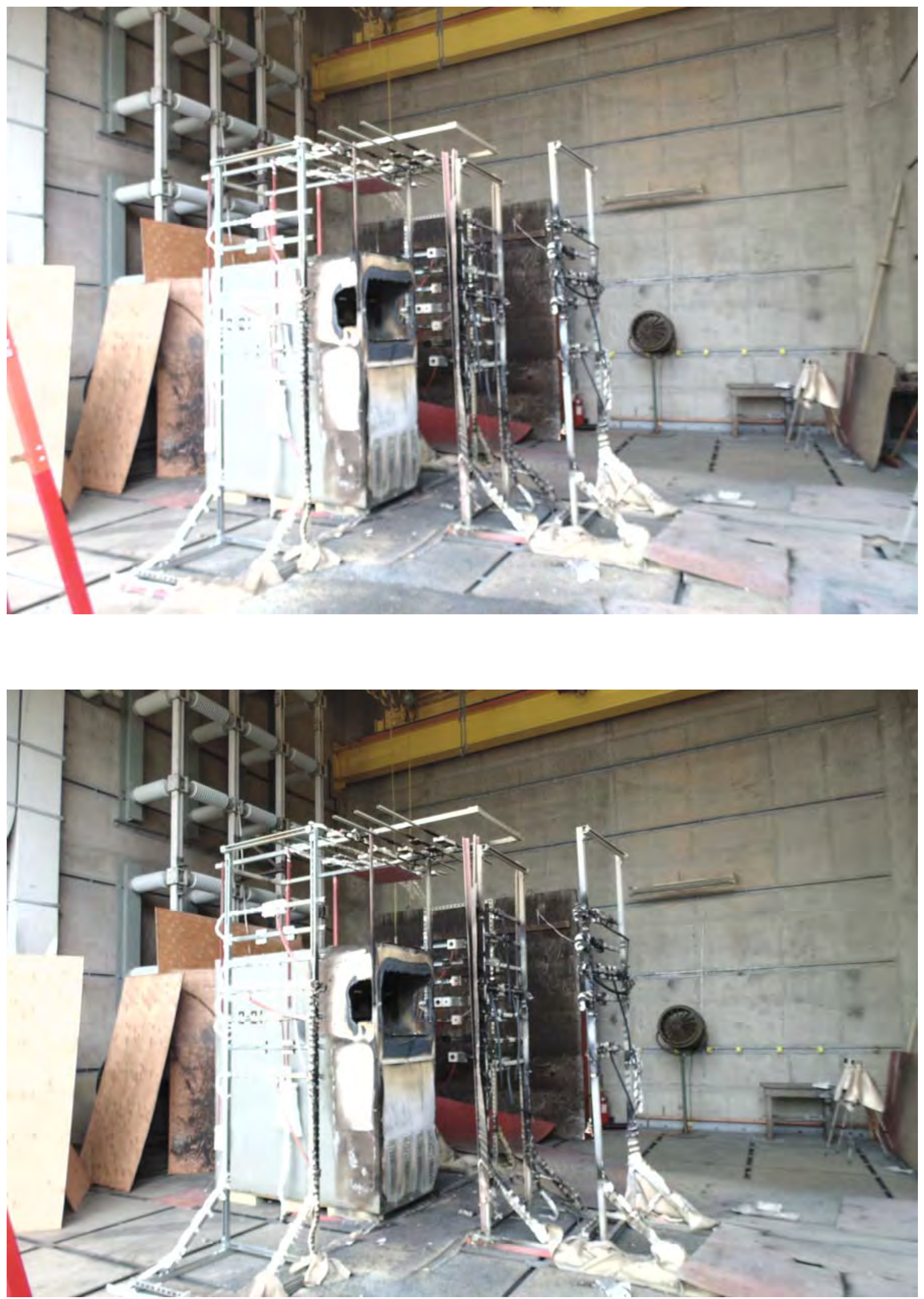

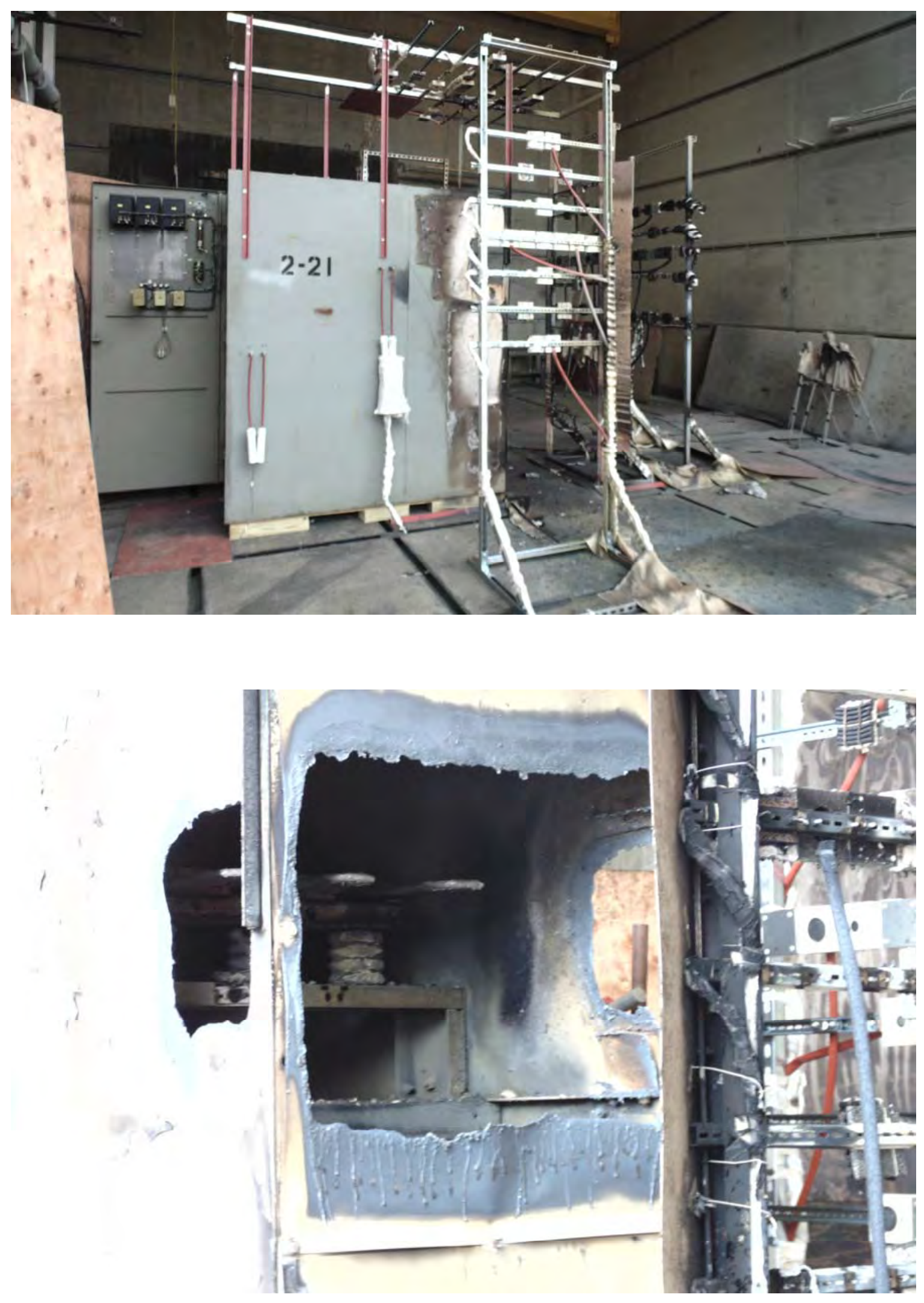
